
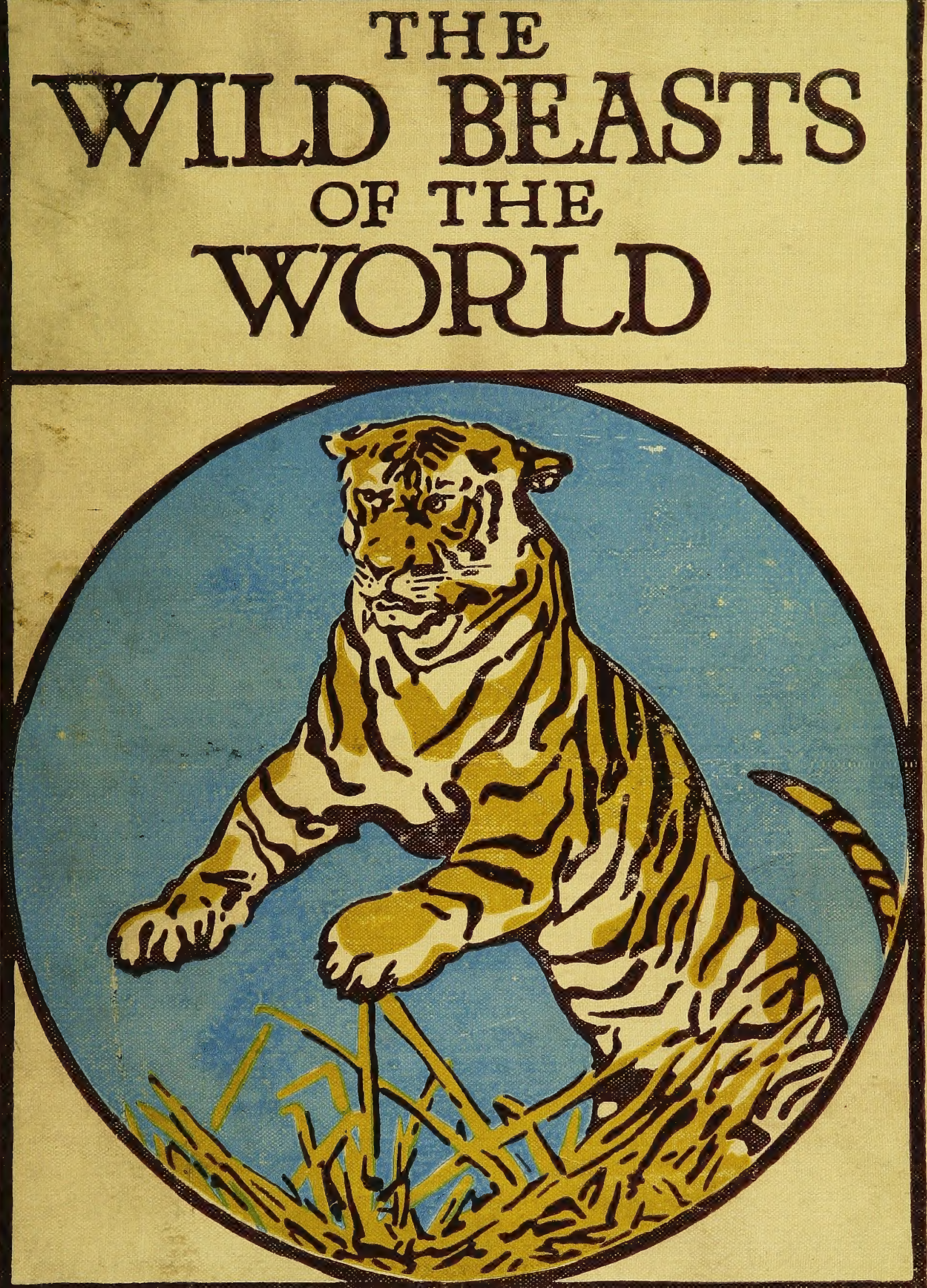

BY FRANK FINN $\mathrm{F} \cdot \mathrm{Z} \cdot \mathrm{s}$. $10 O$ PLATES IN COLOUR BY LOUIS SARGENT C CUTHBERT E.SWAN \& W WINIFRED AUSTIN 


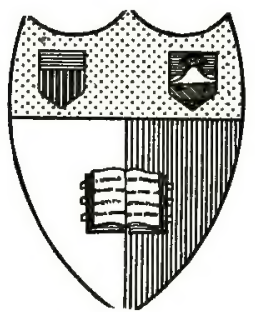

Garnell \#ntuersity Wilhrary

Jthrara, Nem Wark

BOUGHT WITH THE INCOME OF THE

SAGE ENDOWMENT FUND

THE GIFT OF

f HENRY W. SAGE

1891 
QL 50.F51 Cornell University Library

Wild beasts of the world;

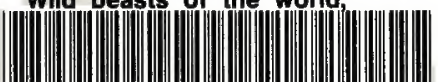

$\begin{array}{lllllll}3 & 1924 & 024 & 761 & 284\end{array}$ 


\section{Cornell University Library}

The original of this book is in the Cornell University Library.

There are no known copyright restrictions in the United States on the use of the text.

http://www.archive.org/details/cu31924024761284 
THE WILD BEASTS OF THE WORLD 




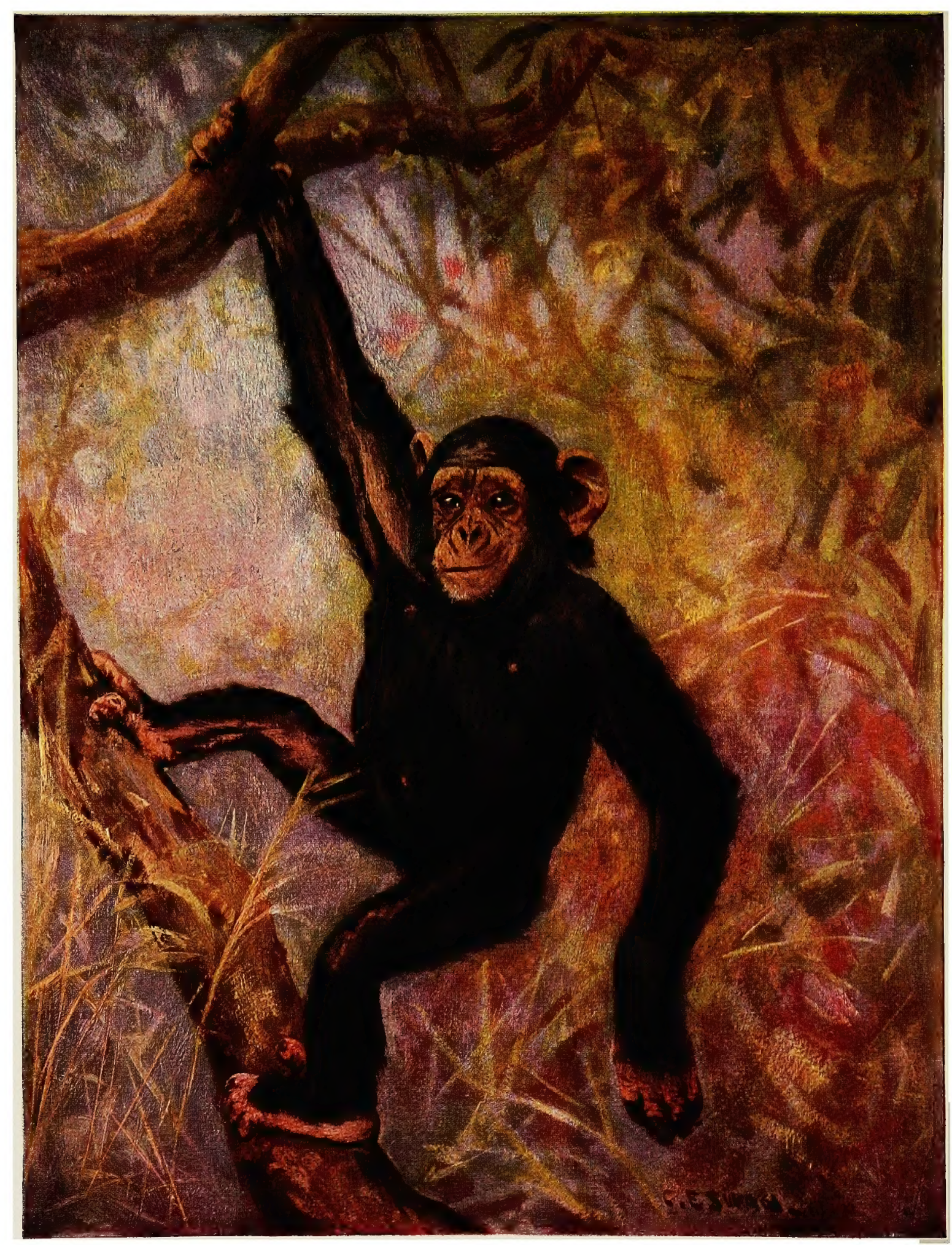

CHIMPANZEE

By C. E. Swan 


\section{THE WILD BEASTS OF \\ THE WORLD}

$\mathbf{B Y}$

FRANK FINN, B.A., F.Z.S.

AUTHOR OF "BIRDS OF THE COUNTRYSIDE," "PETS, AND hOW TO KEEP THEM," IETC.

ILLUSTRATED WITH 100 REPRODUCTIONS IN FULL COLOURS

FROM DRAWINGS BY LOUIS SARGENT, CUTHBERT

E. SWAN, AND WINIFRED AUSTIN

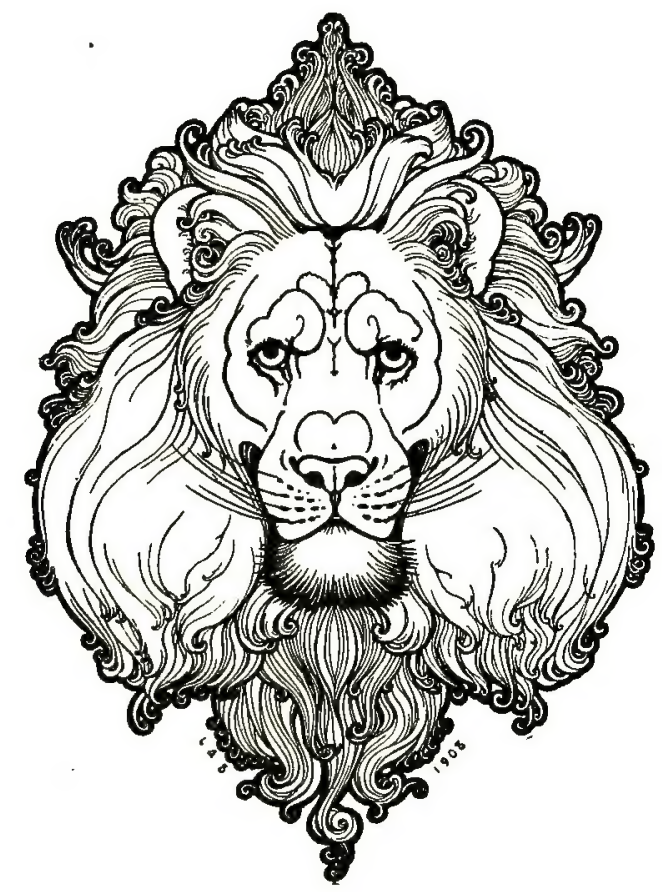

LONDON : T. C. छ E. C. JACK

I6 HENRIETTA STREET, W.C., AND EDINBURGH 



\section{CONTENTS}

The Chimpanzee (Anthropopithecus troglodytes)

The Gorilla (Anthropopithecus gorilla) . The Orang-Utan (Simia satyrus) . . 9

THE Hoolock (Hylobates hoolock) . . I 3

THE LUNGOOR (Semnopithecus entellus) I 7

The Guereza (Colobus guereza) . . 2 I

The Bunder (Macacus rhesus) . . 25

The Diana Monkey (Cercopithecus diana) 29

The Mangabeys . . . . . 32

The Mandrill (Cynocephalus mormon) . 33

The Red-faced Spider Monkey (Ateles paniscus)

"The Barrigudos . . . . . 39

The Brown Capuchin (Cebus fatuellus) . $4 \mathrm{I}$

The Red Howler (Mycetes seniculus) • 45

The Ouakaris . . . . . . 47

ThE SAKIS . . . . . . 47

The Squirrel Monkeys . . . 48

The Teetees . . . . . 48

The Douroucoulis . . . . . 48

The Lion Marmoset (Midas rosalia) • 49

The Ruffed Lemur (Lemur varius) . 53

The Sifakas . . . . . 55

The Mouse Lemurs . . . . 55

The Galagos . . . . . 55

The Slow Lemurs . . . 56

The TARSIER . . . . . 56

The Aye-Aye . . . . 56

The Lion (Felis leo) . . . . 57

The Tiger (Felis tigris). . . . 6 I

The LeOpard (Felis pardus). . 65

The Puma (Felis concclor) . . . . 69

The Ounce (Felis uncia) . . . . 73

The Jaguar (Felis onca) . . . 74

The Clouded Leopard (Felis nebulosa) . 77

The Ocelot (Felis pardalis) . . . 78

The Serval (Felis serval) . . 79

The Wild Cat (Felis catus) . . . 79

THE LyNX (Felis lynx) . . . 8 I

The Caracal (Felis caracal) . . 83

The Cheetah (Cyncelurus jubatus) . 85

The Crvet (Viverra civetia) . . . 89

The Genets. . . . . . 90
THE TREE-CIVETS PAGE

$\cdot 9^{\mathrm{I}}$

The Binturong (Arctictis binturong) . 92

The Water-Crvet (Cynogale bennettii) . 92

The Fossa (Cryptoprocta ferox) . . 92

The Grey Indian Mongoose (Herpestes

griseus) . . . . . 93

The Egyptian Mongoose (Herpestes ichneumon) . . . . . 95

The Meerkat (Suricata tetradactyla) . 96

The Striped Hyena (Hyoena striata) . 97

The Brown Hyena (Hyona brunnea) . 98

The Spotted Hyena (Hyana crocuta) . 99

The AARD-Wolf (Proteles cristatus) , I00

THE WOLF (Canis lupus) . . . roI

The Coyote (Canis latrans) . . . . I04

The Black-backed Jackal (Canis mesomelas) . . . . . 105

The Indian Jackal (Canis aureus) . 106

The Dingo (Canis dingo) . . . 107

The Maned Wolf (Canis jubatus). . I08

THE Fox (Canis vulpes). . . . 109

The ARctic Fox (Canis lagopus). . I II

The Fennec (Canis cerdo) . . I I 2

The DHole (Cyon dukhtmensis) . . I I3

The Hunting-Dog (Lycaon pictus) . I I 5

The Raccoon-Dog (Canis procyonoides) , I I 6

The SAble (Mustela zibellina) . . I I 7

The Mink . . . . II

The Polecat (Mustela putorius) . . I I 9

The Stoat or Ermine (Mustela erminea) i 20

The Weasel (Mustela vulgaris) . . I 20

The Glutton (Gulo luscus) . . . I 2 I

The TaYra (Galictis barbara). . . 123

The Grison (Galictis vittata). . . 123

The Badger (Meles taxus) . . . I 25

The American Badger (Taxidea americana) . . . . . $\mathrm{I} 27$

The Hog-Badger (Arctonyx collaris) . I 27

The Ratels . . . I 28

The Skunk (Mephitis mephitica) . . I 29

The Southern Skunk (Conepatus mapurito) . . . . $\cdot \mathbf{I}_{3} \mathbf{I}$

The Small Skunk (Spilogale putorius) . I 3 I

ThE ZORILlaS . . . . $13^{2}$ 
The Teledu (Mydaus meliceps) . $\quad{ }^{\text {PAGE }}{ }^{I^{2}}$

The OTter (Lutra vulgaris) . . . 133

The Sea-Otter (Latax lutris) . . ${ }^{3} 6$

The White-Nosed Coati (Nasua narica) I 37

The Raccoon (Procyon lotor) . . . I 38

The Kinkajou (Cercoleptes caudivolvulus) I 39

The Cacomistle (Bassaris astuta) . . 140

The Panda (AElurus fulgens) . . . I 40

The Polar Bear (Ursus maritimus) . I4I

The Pied Bear (AEluropus melanoleucus) 144

The Blue Bear (Ursus pruinosus) . . I 44

The Brown Bear (Ursus arctos) . . 145

The Grizzly Bear (Ursus horribilis) . I 48

The Sloth Bear (Melursus ursinus) . I 49

The Himalayan Bear (Ursus tibetanus) I 5 I

The Japanese Bear (Ursus japonicus). I 5 I

The- American Black Bear (Ursus americanus) . . . . . ${ }^{5}$

The Malayan Bear (Ursus malayanus). I 52

The Spectacled Bear (Ursus ornatus) . I 52

The Californian Sea-Lion (Otaria californiana.

Tu Watrus (Trichechus rosmarns) 153

The WalRus (Trichechus rosmarus) - I57

The Common Seal (Phoca vitulina) . I6 I

The Grey Seal (Halichorus grypus) • ${ }^{1} 63$

The Ringed Seal (Phoca hispida) . . 163

The Harp Seal (Phoca groenlandica) . ${ }^{6} 63$

The Bladdernose (Cystophora cristata) . 164

The Sea-Elephant (Macrorhinus leoninus) ${ }^{6} 64$

The HEDGeHog (Erinaceus europaeus) . ${ }^{2} 65$

The Mole (Talpa europaca) . . . I67

The Star-nosed Mole (Condylura cristata) I68

The Desman (Myogale moschata) . . I68

The Golden - tailed Tupaia (Tupaia chrysura).

THE SHREWS

The Common Shrew (Sorex araneus)

The Pigmy Shrew (Sorex minutus)

The Water Shrew (Neomys fodiens).

The Musk Shrew (Crocidura coerulescens)

The Elephant Shrews

The OtTer Shrew (Potamogale velox).

The Tenrec (Centetes ecaudatus) . . 172

The Almiqui (Solenodon cubanus) . . I 72

The Golden Moles . . . . $\mathrm{I}_{72}$

The Cobego (Galeopithecus volans) . . I 73

The Indian Flying - Fox (Pteropus medius) .

Tue Vame I7

The Indian VAmpire (Megaderma lyra) . 183
The FISHING Bat (Noctilio leporinus) PAGE

The Rat-TAILed Bat (Rhinopoma microphyllum). . . . . . 183

The Pipistrelle (Vesperugo pipistrellus) $\mathbf{1} 84$

The Noctule (Vesperugo noctula) • . I84

The Long-Eared Bat (Plecotus auritus) . $\quad$ r 84

The Beaver (Castor fiber) . . . 185

The Indian Striped Squirrei (Sciurus

palmarum) . . . . . ${ }_{1} 89$

The Common Squirrel (Sciurus vulgaris) I 90

The Flying-Squirrels . . . I9I

THE GROUND-SQUIRRELS . . . I I I

The Marmots . . . . . I 92

The Scaly-tailed SQuirrels . . 192

The Musquash (Fiber zibethicus) . . 193

The Lemming (Myodes lemmus) • . 194

The Arctic Lemming (Cuniculus torquatus) . . . . . . 195

The Field-Vole (Arvicola agrestis) • 196

The WATER-Vole (Arvicola amphibius) . I96-

THE Hamster (Cricetus frumentarius) - 197

The House-Mouse (Mus musculus) . 199

The Wood - Mouse OR LONG-TaIled

Field-Mouse (Mus sylvaticus) . . 199

The Harvest-Mouse (Mus minutus) . 199

The House-Rat (Mus rattus) . . 200

The Sewer-Rat (Mus decumanus) . . 200

The Spring-HaAs (Pedetes caffer) . . $20 \mathrm{I}$

The Jerboas . . . . 202

The Gophers . . . . . 202

The Kangaroo-Rats . . . . 203

The Mole-Rats . . . . . 203

The Dormice $. \quad . \quad . \quad . \quad .204$

The Coypu (Myopotamus coypus) . . 204

The Common Porcupine (Hystrix cristata) 205

The Brush-talled Porcupines . . 206

The Canadian Porcupine (Erethizon dorsatus)

The Courendou (Symetheres prehensibs)

THE Vizcacha (Lagostomus trichodactylus) 209

The Chinchilla (Chinchilla lanigera) . 2 I I

The Long-tailed Chinchilla (Lagidium cuvieri) . . . . . . $2 \mathrm{r} 2$

The Capybara (Hydrochcorus capybara) . 213

The Patagonian Cavy (Dolichotis patachonica). . . . . 2 I4

The Guinea-Pig (Cavia porcellus) . . 2 I4

The Agoutis . . . . . 2 I 5

The Paca (Coclogenvs paca) . . . 215

The Talled PaCa (Dinomys branicki) . $2 \times 6$ 
The Common Hare (Lepus europous) page

The Mountain Hare (Lepus,variabilis) . 2 I

The RabBit (Lepus cuniculus) . . . 2I9

The Pikas (Lagomyida) . . . . 220

The Dassie (Hyrax capensis) . . . 221

Tree Dassies . . . . . 223

The Indian Elephant (Elephas indicus). 225

The African Elephant (Elephas africanus) $\quad 228$

The Indian Rhinoceros (Rhinoceros indicus).

The SondaIC Rhinoceros (Rhinoceros sondaicus)

The Asiatic Two-horned Rhinoceros (Rhinoceros sumatrensis) . . . $23 \mathrm{I}$

The Common African Rhinoceros (Rhinoceros bicornis) . . . .

The Great African Rhinoceros (Rhinoceros simus).

The AMERICAN TAPIR (Tapimus americanus)

BaIRD's TAPIR (Tapirus bairdi) . . 234

The Pinchaque Tapir (Tapirus roulini) . 235

The Malayan Tapir (Tapirus indicus) . 235

Burchell's ZEBRA (Equus burchelli). - 237

The Mountain Zebra (Equus zebra) . 238

Grévy's Zebrá (Equus grevyi) • • . 239

The Ass (Equus asinus) . . . . 239

The Kiang (Equus hemionus) . . . 240

TheWILd Horse(Equuscaballusprezevalskii) 240

The American Bison (Bison americanus). $24 \mathrm{I}$

The European Bison (Bison bonasus) . 243

ThE YAK (Poephagus grunniens) . . 243

The Gaur (Bibos gaurus). • . . 243

The Banteng (Bibos sondaicus) • . 244

The Wild Ox (Bos taurus) . . . 244

The Indian Buffalo (Bos bubalus). . 245

The African Buffalo (Bubalus caffer) . 247

The Tamarao (Bubalus mindorensis) . 248

The Anoa (Anoa depressicornis) . $\quad 248$

The Black - TAILed GNu (Connochates taurinus) . . . . . . 249

The White-tailed GNu (Connochates gnu) 250

The Hartebeests . . . . . $25 \mathrm{I}$

The Sassaby (Damaliscus lunatus) . . 252

The Blesbok and Bontebok (Damaliscus albifrons and D. pygargus) . . . 252

The Springbox (Gazella euchore) . . 253

The Dibatag (Ammodorcas clarkei) . . 254

The Gerenook (Lithocranius walleri) 255

The Beira (Dorcotragus megalotis) - . 255

The Chiru (Pantholops hodgsoni) • . 255

The Saiga (Saiga tatarica) • • . 255
The Pallah (Aipyceros melampus) Page

The Blackbuck (Antilope cervicapra)

The BeISA Oryx (Oryx beisa)

The Tufted Oryx (Oryx callotis) . $\quad 258$

The Gemsbok (Oryx gazella) . . . 259

The Beatrix (Oryx beatrix) . . . 259

The Leucoryx (Oryx leucoryx) . . 260

The Addax (Addax naso-maculatus). . 260

The SABle ANTelope (Hippotragus niger) 26I

The RoAN ANtelope (Hippotragus equinus) $\quad 262$

The Kob ANtelopes (Kobus) . . . ${ }_{26} 63$

The Waterbuck (Cobus Mipsiprymnus) . 263

The Lechwe (Cobus lechi) . . . 264

The Eland (Oreas canna) . . . 265

The Derbian Eland (Oreas derbianus) • 268

The Koodoo (Strepsiceros kudu) . . 269

The Lesser Koodoo (Strepsiceros imberbis) 270

The Bongo (Boocercus euryceros) . . 270

The Inyala (Tragelaphus angasi) . . 27 I

The Bushbucks . . . . . 27 I

The Sitātungas . . . . . 272

The Nilghai (Boselaphus tragocamelus) • 273

The Four-HoRned ANTELOPE (Tetraceros quadricornis) . . . . . 274

THE Duikers . . . . . . 274

The KLIPSPRinger (Oreotragus saltalor) • 276

The Royal ANTelope (Nanotragus pygmaus) . . . . . . 276

The Dikdiks . . . . . . 276

The Chamois (Rupicapra tragus) . . 277

The Goral (Nemorhadus goral) . . 278

The Serows . . . . . $\quad 279$

The Rocky-Mountain Goat (Haploceros montanus) . . . . . . 279

The Takin (Budorcas taxicolor) . . 280

The Musk-Ox (Ovibos moschatus) . . 280

The Markhor (Caprafalconeri) - . 281

The Wild Goat (Capra hircus) • 282

The Ibexes . . . . . . 283

The TURS . . . . . . 284

The TAHr (Hemitragus jemlaicus) . $\quad 284$

Marco Polo's Sheep (Ovis poli) . $\quad 285$

The Mouflon (Ovis musimon) . . . 287

The URIal (Ovis vignei) . . . . 287

The Burrhel (Ovis nahura) . . . 288

The Aoudad (Ovis tragelaphus) . $\quad{ }_{288}$

The Giraffe (Camelopardalis giraffa) 289

The OKaPI (Okapia johnstoni) . . . 293

The Prong-Buck (Antilocapra americana) 295

The Musk-Deer (Moschus moschiferus) . 297

TyPical DeER 
The Muntjac (Cervulus muntjac) ..

The Red-Deer (Cervus elaphus) . . 301

The Sambur (Cervus unicolor) . • . 303

The Spotted Deer (Cervus axis) . $\quad 303$

ThE FALLOW-DeER (Dama vulgaris) • 304

ThE ELK OR Moose (Alces machlis) • 305

The Milou Deer (Cervus davidianus) • 308

The Virginian Deer (Cariacus virginianus) 309

The Mule-Deer (Cariacus macrotis) • 310

The Pampas Deer (Cariacus campestris) . 3 II

The Huemul (Xenelaphus bisulcus) • • 3 II

The Brockets. . . . . . 3II

The Pudus . . . . . . 3II

The Roe (Capreolus caprea) . . . $3^{12}$

The Water-Deer (Hydrelaphus inermis) . $3^{12}$

The ReIndeEr or Caribou (Rangifer tarandus) . . . . . . . $3^{\mathrm{I}} 3$

The Indian Mouse-Deer (Tragulus meminna) .

THE Kanchll (Tragulus javanicus) .

The NAPU (Tragulus napu) . . .

The Water Chevrotain (Hyomoschus aquaticus)

The Camel (Camelus dromedarius).

The Bactrian Camel (Camelus bactrianus)

The Guanaco or Wild Llama (Auchenia huanacus) . . . . . . 325

The Vrcugna (Auchenia vicuna) . $\quad .328$

The Hippopotamus (Hippopotamis amphibius) .

The Pigmy Hippopotamus (Hippopotamus liberiensis).

The Indian Wild Boar (Sus cristatus)

The European Wild Boar (Sus scrofa) 335

The Pigmy Hog (Sus salvanius) • . 336

The Red River-Hog (Sus porcus) . • 336

The Babirusa (Babirusa alfurus) • • 337

The Wart-Hog (Phacochaerus cethiopicus) 339

THE Forest-HoG (Hylocharus meinerzhageni) 340

The Collared Peccary (Dicotyles tajagu) 34I

The White-lipped Peccary (Dicotyles labiatus)

The Sperm-Whale (Physeter macrocephalus)

The Pigmy Sperm-Whale (Cogia breviceps)

The Beaked Whales

THE PORPOISE (Phoccena communis) • • 349

The Common Dolphin (Delphinus delphis)

The Grampus (Orca gladiator).

Risso's Dolphin (Grampus griseus).

The Blackfish (Globicephalus melas)

The Beluga (Delphinapterus leucas).
THE NARHWaL (Monodon momoceros) - PAGE

THE NARHWAL (Monodon monoceros). $\quad 357$

The Whalebone Whales . • . 358

The Right Whales . . . 359

The Rorquals. • • . . . 359

The Humpback (Megaptera longimana) - 360

The Californian Grey Whale (Rhachianectes glaucus) . . . . . $3^{60}$

The Manatee (Manatus americanus) $\quad 3^{61}$

The Dugongs . . . . . . $\quad 3^{63}$

The Two-tond Sloth (Cholopus didactylus) 365

'The Three-toed Sloths • • . $\quad 3^{67}$

The Great Ant-Eater (Myrmecophaga jubata) . . . . . . 369

The Tamandua Ant-Eater (Tamandua tetradactyla) . . . . . $37 \mathrm{I}$

The Little Ant-Eater (Cycloturus didactylus). . . . . . . 371

The Pangolins . . . . $\quad$. 372

The Hairy ARmadillo (Dasypus villosus) 373

The Giant Armadillo (Priodon gigas) . 375

The Ball Armadillos . . . . 375

The Pichiciago (Chlamydophorus truncatus) 375

The Aard-VARKs . . . . . 376

The Red Kangaroo (Macropus rufus) , 377

The Tree Kangaroos . . . . 380

The Rat Kangaroos . . . . 380

T'He Musk Kangaroo (Hypsiprymnodon moschatus) . . . . . . 380

The Vulpine Phalanger (Trichosurus vulpecula) . . . . . . $38 \mathrm{r}$

The Cuscuses . $\cdot$ • $\quad \cdot \quad \cdot \quad \cdot 3^{82}$

The Flying Phalangers - • 382

The Koala (Phascolomys ursinus) • $\quad 3^{8} 3$

The Noolbenger (Tarsipes rostratus) $\quad 3^{8} 4$

The Wombats . . . . . . 384

The Tasmanian Devil (Sarcophilus ursinus) 385

The Thylacine (Thylacinus cynocephalus). 386

The Typical Dasyures . • • . 386

The TAPoA-TAFA (Phascologale penicillata) $\quad \mathbf{3}^{87}$

The Banded ANT-Eater (Myrmecobius fasciatus) . . . . . $\quad 387$

The Bandicoots . . . . . $\quad . \quad 388$

The Common American Opossum (Didelphys virginianus).

The Water-Opossum (Chironectes yapock)

The Marsupial Mole (Notoryctes typhlops)

The Raton Runcho (Canolestes obscurus)

The Echidna (Echidna hystrix)

The Three-toed Echidna (Proechidna bruijni)

The Platypus (Ornithorlynchus anatinus)
389

391

391

392

393

396

397 


\section{LIST OF ILLUSTRATIONS}

\begin{tabular}{|c|c|c|c|c|c|c|c|}
\hline \multirow{2}{*}{\multicolumn{2}{|c|}{$\begin{array}{l}\text { CHIMPANZEe (Anthropopithecus troglodytes) } \\
\text { MALE GoRILLA (Anthropopithecus gorilla) }\end{array}$}} & $\cdot$ & • & - & \multicolumn{3}{|c|}{ Frontispiece } \\
\hline & & . & . & . & To fac & page & 4 \\
\hline ORANG-UTANS (Simia satyrus) & . & $\cdot$ & - & . & $"$ & $"$ & \\
\hline HooLocks (Hylobates hoolock) & . & . & $\cdot$ & $\cdot$ & $"$ & $"$ & I 2 \\
\hline LUNGOORS (Semnopithecus entellus) & $\cdot$ & $\cdot$ & $\cdot$ & $\cdot$ & $"$ & $"$ & 16 \\
\hline BRUSh-TAILED GUEREZA (Colobus guerez & & . & - & - & $"$ &, & 20 \\
\hline BUNDERS (Macacus rhesus) & . & · & $\cdot$ & $\cdot$ & $"$ & $"$ & 24 \\
\hline Diana Monkeys (Cercopithecus diana) & . & . & $\cdot$ & $\cdot$ & $"$ & $"$ & 28 \\
\hline MANDRILLS (Cynocephalus mormon) & $\cdot$ & $\cdot$ & · & $\cdot$ & $"$ & $"$ & $3^{2}$ \\
\hline Red-Faced Spider Monkeys (Ateles po & aniscus) & . & $\cdot$ & $\cdot$ & " & $"$ & 36 \\
\hline Brown CaPuchins (Cebus fatuellus) & $\cdot$ & . & . & . & $"$ & $"$ & 40 \\
\hline RED How LERS (Mycetes seniculus) & . & $\cdot$ & - & $\cdot$ & $"$ & $"$ & 44 \\
\hline LION MaRmoset (Midas rosalia) & . & $\cdot$ & · & $\cdot$ & $"$ & $"$ & 48 \\
\hline RUFFED LEMUR (Lemur varius) & . & $\cdot$ & $\cdot$ & . & $"$ & $"$ & $5^{2}$ \\
\hline LiON AND Lioness (Felis leo) & . & · & . & • & $"$ & $"$ & $5^{6}$ \\
\hline TIGER (Felis tigris) & . & & $\cdot$ & . & $"$ & $"$ & 60 \\
\hline LEOPARDS (Felis pardus) AND SPOTTED & DEER & (Cervus & axis) & · & $"$ & ", & 64 \\
\hline Puma (Felis concolor) & · & $\cdot$ & $\cdot$ & · & " & ", & 68 \\
\hline OUnce (Felis uncia) & · & · & . & · & $"$ & " & 72 \\
\hline Clouded Leopari (Felis nebulosa) & . & $\cdot$ & $\cdot$ & $\cdot$ & $"$ & $"$ & 76 \\
\hline Lynxes (Felis $(y n x) \quad$. & $\cdot$ & · & . & . & , & , & 80 \\
\hline СHeEtaH (Cynoelurus jubatus) & . & $\cdot$ & · & $\cdot$ & $"$ & $"$ & 84 \\
\hline AFRICAN CIVET (Viverra civetta) & $\cdot$ & $\cdot$ & . & · & $"$ & ", & 88 \\
\hline Indian GREY Mongoose (Herpestes gri. & iseus) & $\cdot$ & · & . & $"$ & $"$ & 92 \\
\hline STRIPED HyæNA (Hyoena striata) & · & . & $\cdot$ & . & $"$ & $"$ & 96 \\
\hline Wolves (Canis lupus) & $\cdot$ & . & $\cdot$ & $\cdot$ & $"$ & $"$ & 100 \\
\hline BLACK-BACKED JACKALS (Canis mesomel & las) & · & $\cdot$ & $\cdot$ & $"$ & $"$ & I०4 \\
\hline VIXEN AND CUBS (Canis vulpes) & . & · & $\cdot$ & $\cdot$ & $"$ & $"$ & 108 \\
\hline Dholes (Cyon dukhunensis) & $\cdot$ & $\cdot$ & $\cdot$ & $\cdot$ & $"$ & $"$ & I I 2 \\
\hline SABLES (Mustella zibellina) & $\cdot$ & $\cdot$ & $\cdot$ & $\cdot$ & $"$ & $"$ & I 6 \\
\hline Glutton (Gulo luscus) . & $\cdot$ & • & $\cdot$ & $\cdot$ & $"$ & $"$ & 120 \\
\hline BADGER (Meles taxus) & $\cdot$ & $\cdot$ & $\cdot$ & $\cdot$ & $"$ & $"$ & I 24 \\
\hline SKUnKS (Mephitis mephitica) & . & - & $\cdot$ & $\cdot$ & $"$ & $"$ & 128 \\
\hline OTTER (Lutra vulgaris) . & $\cdot$ & - & $\cdot$ & $\cdot$ & $"$ & $"$ & 132 \\
\hline WhITE-NOSED COATIMONDIS (Nasua nar & ${ }_{\mathrm{ix}}$ & $\cdot$ & $\cdot$ & $\cdot$ & $"$ & $b "$ & 136 \\
\hline
\end{tabular}


Polar Bear and Cubs (Ursus maritimus)

To face page $14^{\circ}$

Brown BEAR (Ursus arctos)

SLOTh BeAR (Melursus ursinus).

Californian Sea-Lion (Otaria californiana)

WALRUS (Trichechus rosmarus) .

SEAL (Common) (Phoca vitulina)

HEDGEHOG (Erinaceus europaus)

Tupaia (Tupaia chrysura)

COBEGo (Galeopithecus volans)

Flying-Fox (Pteropus medius) .

VAMPIRE (Desmodus rufus)

BeAver (Castor fiber)

INDIAN STRIPED SQUIRREL (Sciurus palmarum)

Musquash (Fiber zibethicus)

Hamster (Cricetus frumentarius)

Spring-HaAs (Pedetes caffer)

Porcupine (Hystrix cristata)

VizCacha (Lagostomus trichodactylus)

Capybara (Hydrochoerus capybara)

HARE (Lepus europaeus)

Dassies (Hyrax capensis)

Indian ELephant (Elephas indicus)

INDIAN ONE-HORNED RHINOCEROS (Rhinoceros indicus)

AMERICAN TAPIRS (Tapirus americanus).

Burchell's Zebras (Equus burchelli)

American Bison (Bison americanus)

Indian Buffaloes (Bos bubalus)

BLACK-TAILED GnUs (Connochoetes taurinus)

SPRINGBOKS (Gazella euchore)

ELAND (Oreas canna)

SABLE ANtelope (Hippotragus niger)

BeISA ORYX (Oryx beisa)

Koodoo (Strepsiceros imberbis)

Nilghai (Boselaphus tragocamelus)

Chamors (Rupicapra tragus)

MARKhor (Capra falconeri)

Marco Polo's Sheep (Ovis poli)

GIRAFFES (Camelopardalis giraffa)

OKaPIS (Okapia johnstoni)

Musk-Deer (Moschus moschiferus)

RED-DeER (Ceraus elaphus)

ELK (Alces machlis) 
Virginian Deer (Cariacus virginianus)

To face page 308

ReINDEer oR Caribou (Rangifer tarandus)

312

Mouse-Deer (Tragulus meminna)

Camel (One-humped) (Camelus dromedarius)

Guanaco (Auchenia huanacus).

Hippopotamus (Hippopotamus amphibius)

WILD BOAR (Sus cristatus)

Babirusa (Babirusa alfurus)

Peccary (Collared) (Dicotyles tajaçu) .

SPERM-WhaLe (Physeter macrocephalus) .

PORPOISE (Phocona communis).

Grampus (Orca gladiator)

NARHWAL (Monodon monoceras)

Manatee (Manatus americanus).

Two-toed Sloth (Cholopus didactylus) .

Great ANT-EATer (Myrmecophaga jubata)

Hairy Armadillo (Dasypus villosius)

RED KangaRoo (Macropus rufus)

Vulpine Phalanger (Trichosurus vulpecula)

Tasmanian Devil (Sarcophilus ursinus)

VIRGINIAN Opossum (Didelphys virginiana)

ECHIDNa (Echidna hystrix)

Platypus oR DUCKBILl (Ornithorhynchus anatinus)

" $\quad 316$

" $\quad 320$

" $\quad 324$

" $\quad 328$

" " 332

" $\quad 33^{6}$

" 340

" $\quad 344$

" $\quad 348$

9 $135^{2}$

" $" 356$

$" \quad 360$

" " 364

" " 368

" $\quad 372$

" $\quad 376$

$" \quad 380$

$" \quad$ " 384

" $\quad 388$

"

" $\quad 396$ 



\section{WILD BEASTS OF THE WORLD}

\section{THE CHIMPANZEE}

\section{(Anthropopithecus troglodytes)}

TAKING it all round, from youth to old age, in appearance and behaviour, the Chimpanzee is the most nearly human of all beasts, and, as it is the hardiest of all man-like apes, and therefore the most familiar in captivity, it is the best known of all of them by sight, though hardly rivalling its formidable relative, the Gorilla, in reputation in the popular mind.

It will be noticed in the illustration that the arms of the creature, as in all apes, are very long, reaching, indeed, below the knee when it stands erect; but they are shorter, and therefore more human, than in any other ape; while the legs, though shorter proportionately than in Man and the Gorilla, are longer than in the Orang. The big ears of the Chimpanzee contrast with the small, refined-looking ones of the latter apes; but as the size of the ears varies much in Man, this is not a very important point. The sex difference in the face of the Chimpanzee is not notable, nor is there much difference in size between the sexes, although the male is the larger, attaining a height of more than four feet. He also has more powerful teeth.

There is, however, much diversity in Chimpanzees, both individual and racial; each seems to have a different face, though all preserve the same general "caricature Irishman" type, and the complexion may vary from dirty flesh-colour to black, many having mottled faces. The coat, though always long and generally black, also shows much diversity, some individuals being nearly as shaggy as bears, while others are scantily clad, especially on the head. The celebrated "Sally," formerly at the London Zoological Gardens, belonged to a black-faced, 
bald-headed variety, which has generally been ranked as a distinct species, the Bald Chimpanzee (Anthropopithecus calvus).

Local racial distinctions do undoubtedly exist, but, in view of the great amount of variation, it seems best to regard all Chimpanzees as forming members of one species; none of them, at all events, could be mistaken for any other ape.

The home of this animal is the forest region of Tropical Central Africa from Uganda westwards; most of the specimens seen in Europe, however, have come from Loango and the Gaboon. Here the Chimpanzees live in small bands of from five to ten, and spend much of their time on the ground, though often ascending trees to gather wild frưit; on which, with other vegetable produce, they subsist: As some specimens show a liking for animal food-Sally, for instance, would even kill and eat pigeons and rats-they no doubt, like most of the monkey tribe, are not by any means strict vegetarians.

The gait of these apes, although fairly rapid, is awkward-looking; they go on all fours, doubling under the first two joints of the fingers of the hand, so that in front they rest upon their knuckles. They can stand and walk erect; but do not do so much as a rule, although a little female, Daisy, formerly in the Zoo; was much in the habit of acting the biped, clasping a duster over her stomach with her hands meanwhile.

Being powerful animals-even the female being a match for a strong man-they probably have hardly any enemies to flee from, with the exception of the Leopard ; and even he might think twice before attacking an adult, let alone a party of them.

The young Chimpanzee at birth clings closely to its mother, and is thus carried about, after the fashion of monkeys generally. At night its mother takes it to bed in a tree, where a nest or platform of twigs, \&c., has been built; for the construction of this a low elevation is preferred, no doubt for the sake of shelter from the wind.

Occasionally they are said to associate in large bands, and to indulge in a sort of concert, accompanying their howls and yells by drumming with sticks on hollow logs: this is very probably correct, as many animals take a pleasure in making noises by any means in their power. 
The Chimpanzees exhibited in zoological collections have almost always been brought over as quite young animals; they are undeniably delicate, but far less so than the other great apes, and I have recently heard of a case in which one has been successfully kept all through the winter in an outdoor house without artificial heat.

-What they undoubtedly require, when small at all events, is plenty of petting and attention; and they prove decidedly more "reasonable," if the expression may be used, than Orangs or Gorillas, not even objecting to correction when they have deserved it-which is pretty often the case, as they are, as one might expect, full of mischief and often very spiteful. When angry they strike with their hands and bite severely. They have a great variety of notes and calls, one very usually heard being a sort of repeated hoot uttered with protruding lips, and accompanied by frenzied dancing or jumping. In the wild state the uproar they create is most annoying at times.

Of course individuals vary a great deal in disposition and intelligence; Sally was a good example of a clever specimen, while Mickey, an apparently dwarfed male, who is the senior Chimpanzee at the Zoo at the time of writing; having been there for ten years, is a kind, affectionate creature, good to smaller Chimpanzees, and tractable with his keeper, besides having a fair share of brains.

The most remarkable Chimpanzee I have seen, however, is one which was recently for some months in the possession of the wellknown animal dealer, Mr. J. D. Hamlyn, who has made a specialty of anthropoid apes. This animal, Peter by name, was kept tied up in a living-room, but was often let out, and regularly had his meals with the family; and I have often had the pleasure of sitting at table with him. His behaviour was exactly that of a rather naughty child; his owners assured me that he understood all that was said to him, and certainly his behaviour went far to bear out this statement. I have seen him, on being told to do so, fetch whisky and soda and pour out a "peg," bring his master's slippers and put them on, set up a chair he had pulled over, and so forth, besides coming at call and kissing. 
He had, moreover, ideas of his own; when given a note-book and a pencil, he would scribble on one page after another just as a child does, and he would steal any key he could get hold of and try to unlock the padlock of his chain with it. Another original idea of his was to get hold of a whip or a strap, and therewith thrash another Chimpanzee, Pat, of his own size, who, being spiteful, was always tied up. Peter tyrannised over Pat very much, tried to shut him in his box, and always kept him under whenever possible; yet on occasion he would side with him.

Peter had previously been in a private owner's house for some months before he came into Mr. Hamlyn's possession; but a previous specimen Mr. Hamlyn had, Pansy, was trained on his premises throughout, and was as civilised in his behaviour as Peter, though not so widely accomplished. He met his death by taking a fatal chill, owing to a practice he had of taking a sponge and washing the stairs -a proceeding in which, needless to say, he received no encouragement.

From instances like these, and other similar ones which have been recorded, it would seem that Chimpanzees when young could be well dealt with in much the same way as children, though their capricious disposition, and strength and ferocity when roused, always make restraint desirable, and it would be absolutely necessary when the animals became fully adult. 


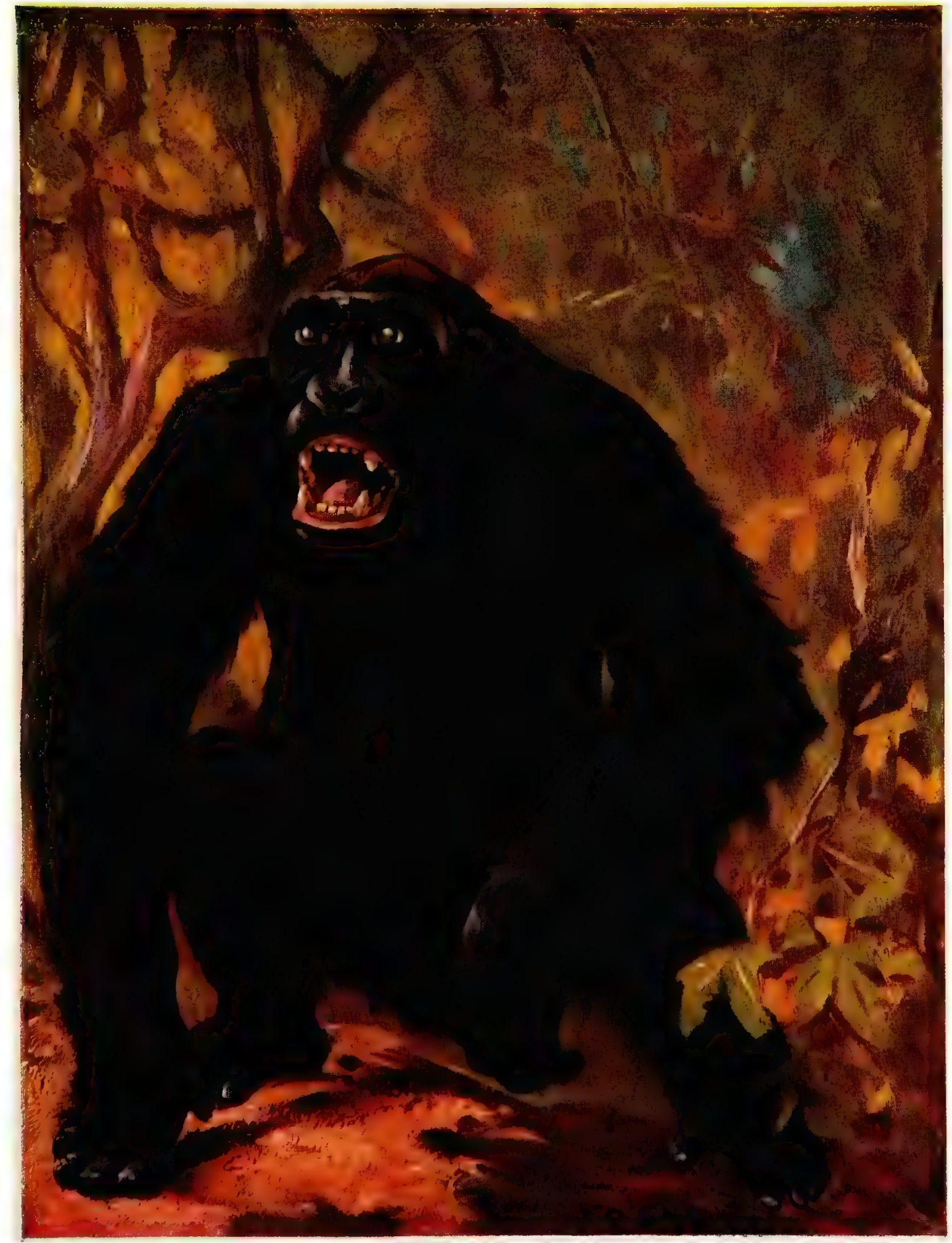

MALE GORILLA

By C. E. Swan 



\section{THE GORILLA}

(Anthropopithecus gorilla)

WERE it not for our own existence on the earth, the Gorilla could claim to be the head of the animal kingdom, for he is by very far the most powerful of all apes, and we do not know that his intelligence is at all inferior to that of the Chimpanzee.

In general form he has much resemblance to that animal, but is more heavily built, with longer arms and legs; the fingers and toes are, on the other hand, much shorter and thicker than the Chimpanzee's, the latter webbed at the base, while the whole hand and foot are broader. The eyebrow-ridges are very prominent in the Gorilla, especially in the male, whose skull also bears great central and lateral crests for the attachment of muscles.

The Gorilla has the face and skin all over the body black; the coat, which is shorter, closer, and of a more woolly nature than the Chimpanzee's, is also black, but with a strong tendency to grey on the back, especially in advancing age, when it also is inclined to disappear on the chest and about the hips altogether. The crown of the head is commonly, but not always, covered with chestnut-red hair.

The female Gorilla attains about the same size as the male Chimpanzee, although stouter and more powerful, and chiefly differs in her prominent eyebrows and the other points above described; but the adult male, as the illustration shows, has a very different and much more animal cast of face, the jaws becoming greatly developed; in size also this sex far surpasses any other ape, male Gorillas of six feet in height being on record, while in breadth they much surpass a man of the same stature. The teeth, especially the canines, are very powerful. The young Gorilla, however, is more human-looking than the Chimpanzee, distinctly recalling a badly-developed negro child in appearance, the resemblance being increased by the fact that the Gorilla more readily stands up and 
walks on its hind legs, though its normal gait, like that of the other, is on all fours, with the ends of the fingers similarly bent under. The habit of beating the breast, so characteristic of the Gorilla, is already found in young animals, as is so commonly the case with animal peculiarities of behaviour-thus, the young peacock. spreads his little tail when he is only of the size of a partridge.

As in the case of the Chimpanzee, there is much local variation in Gorillas, and several races and sub-species have been named and described, though it is very doubtful if any of these possess full specific value.

The Gorilla inhabits part of the same region as the Chimpanzee, the great forest region of West Equatorial Africa; but its range is not nearly so extensive, being confined to the district between the Cameroons and the Congo, and it is very rarely found near the coast.

It is a thoroughly forest-haunting animal, but, although a good climber, lives a good deal on the ground, and often makes its bed there, by breaking down and piling up stalks of plants into a mass about a foot thick. Its food is mainly vegetable, but it is said to be more carnivorous in its tastes than the Chimpanzee. Like that animal, it will raid the cultivated patches of the natives. Gorillas also live in smaller troops than Chimpanzees-a male, female, and one or two young animals being all that are usually found together. The head of the family is said to sleep at the foot of a tree, while the weaker members of it sleep in a nest made in the branches; for this species also builds nests in trees.

The old male Gorilla is, of course, a match for practically any animal, on account of his gigantic strength and huge teeth; but he appears to avoid an encounter with man, although a terrible adversary when wounded. Old accounts, indeed, say otherwise, and it is quite possible that solitary males, such as are found among most animals, may become fierce and dangerous; for it is a well-known fact that the monkey tribe in general become morose and spiteful with advancing years, as indeed do a great number of animals, especially of the male sex, from grouse to men! 
The Gorilla does not usually frequent the same parts of the forest as its smaller relative, and it is much rarer; indeed, it has hardly ever been seen wild by Europeans. It also appears not to be very noisy, although the male roars as well as beats his breast when enraged. Alliances between the two great apes are said to occur at times, and it has been suggested that one or two doubtful specimens, notably one "Mafuka," a female exhibited in the Dresden Zoological Gardens in 1875, were hybrids between the Gorilla and Chimpanzee; and, considering that the lower monkeys frequently produce hybrids in captivity, it would seem that this is quite possible.

The Gorilla is not only the most striking in appearance of all apes, but it has been known longer than any other; that is, if the "Gorillas" described by Hanno the Carthaginian; in his voyage of discovery made in 470 B.C., really were animals of this species. What he says is, that in a bay called "The Horn of the South," on the West African Coast, he found an island containing a lake, in which was yet another island full of "hairy men and women," which his interpreters called Gorillas. These creatures were very active, and defended themselves by throwing stones; three females were, however, captured, and, as they "refused to go quietly," were killed, and their skins brought to Carthage, where they were to be seen for centuries afterwards, for Pliny records that Roman invaders saw two of them at Carthage in the temple of Astarte, in $\mathrm{I} 46$ B.c. Doubt has been thrown on this account, and it has been suggested that the animals in question were Baboons, who are well known to defend themselves by stone-throwing.

But, as a matter of fact, any of the more intelligent monkeys will use missiles. Chimpanzees : certainly do so in captivity; and the ancients, who knew the tailless monkey of North Africa, the so-called "Barbary Ape," quite well, were not likely to mistake the far less human-looking Baboons for hairy people; while this is jușt the sort of mistake which is actually made by young children and primitive people about anthropoid apes to-day. At the same time, it must be admitted that Chimpanzees may be meant.

The next recorder of the Gorilla was an English sailor, Andrew 
Battel, whose adventures in West Africa were given in "Purchas his Pilgrims," published in 1625 ; here are described two "monsters" found in the West African forests, as the "Pongo" and "Enjocko." His "Pongo" was evidently the Gorilla, the other ape being the Chimpanzee, still called "'Ntschego" by the natives, while the Gorilla is known as M'pungu.

The Gorilla is still a very little-known animal, however, and its delicacy has so far prevented us from gaining much knowledge of its habits even in captivity, for it is difficult to keep alive even in its own country, and the few individuals, all young, which have been exhibited in Europe have seldom lived even for a year. Several have been exhibited in our own Zoological Gardens, but the first one brought to England was one for some time exhibited in a travelling menagerie as a Chimpanzee! The Gorilla which so far has done best in captivity is one which lived in the Berlin Aquarium, and had been carefully looked after in West Africa for some time before he reached that institution. He was allowed a good deal of liberty, had his meals at table and behaved well, and showed much affection for his human friends, though rather mischievous. In fact, his manners appear to have been much the same as those of the Chimpanzees treated in the same way, which I have been able, as previously remarked, to observe.

The Gorilla is, however, undoubtedly not only more delicate than the Chimpanzee, but is generally, at any rate, quite different in temperament, being fiercer, and at the same time more nervous and sensitive, so that it is always likely to require greater care in its management. I was particularly struck by the human way in which a female imported by $\mathrm{Mr}$. Hamlyn - the largest which has reached England alive so far-covered her face with handfuls of hay held up to it when looked at in her travelling cage, and then struck the bars furiously if the inspection were persevered in. Such an animal as this needs very considerate handling, but the obstacles to its successful treatment ought not to be insuperable. 


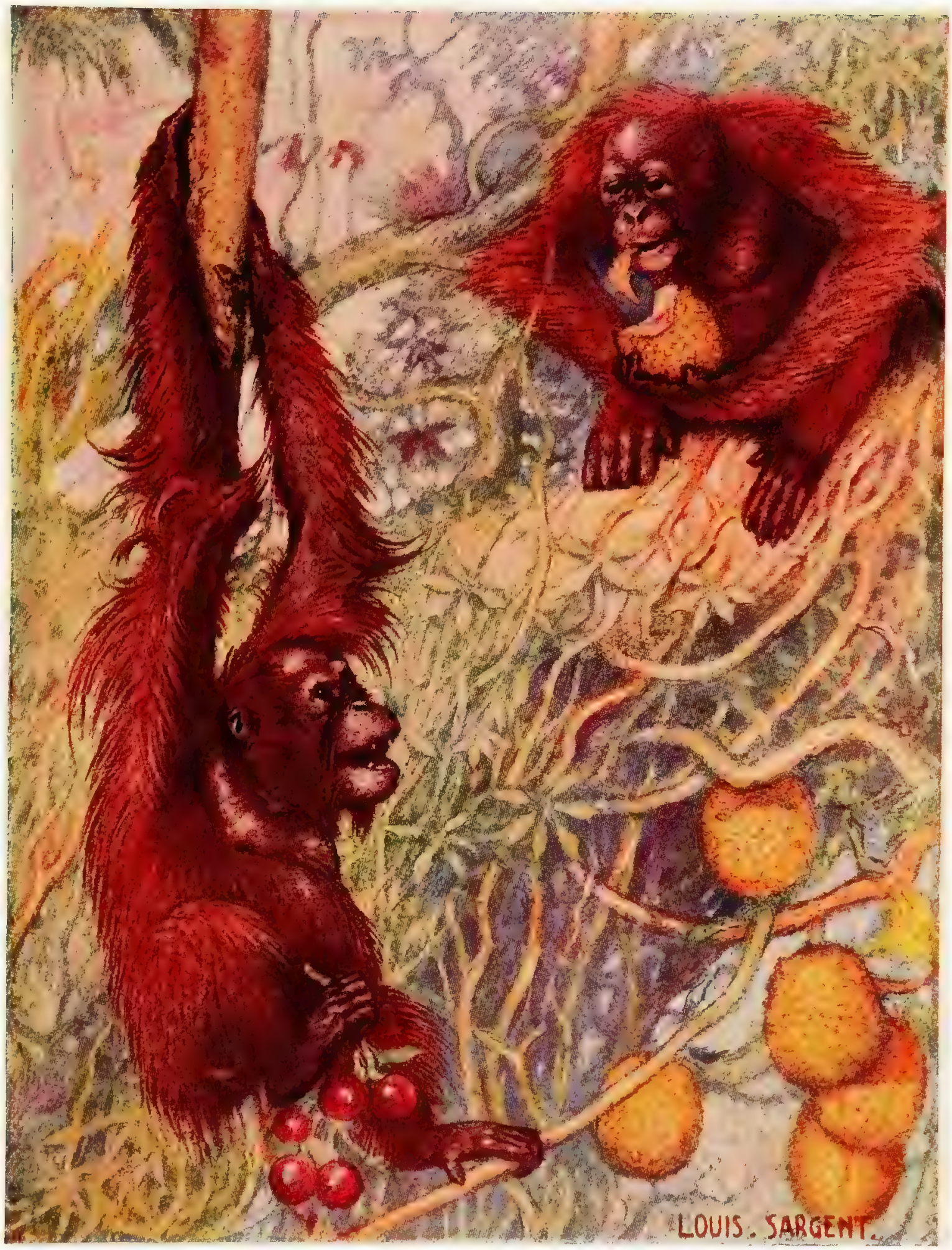

ORANG-UTANS

By Louis A. Sargent 



\section{THE ORANG-UTAN}

(Simia satyrus)

THIs, the third and last of the great man-like apes, is found far away from the African home of the Gorilla and Chimpanzee-in Borneo and Sumatra; where, by the way, there occur other animals with near African relatives. It differs from the other two not only in the red colour of its hair, but equally remarkably in its shape, which departs much further from the human form; the arms in the Orang being so long as to reach the ground when the creature stands erect, and the legs being very short, while the body is also very short and round. The fingers and toes are very long ${ }_{n}$ with the exception of the thumb and great toe, which are very small indeed, and often minus the last joint. The colour of the coat, the hair of which is particularly long and lank, varies from almost chocolate to a bright auburn, and, as in the Chimpanzee, there is a great amount of variation in its abundance and in the colour of the skin, many Orangs being but scantily furnished with hair, and dark in the face and skin, while in the ordinary type the face is mostly dirty flesh-colour, and the hair abundant.

There is as great a difference in the sexes as in the case of the Gorilla, the male, which is much the larger, having particularly big canine teeth, and, in many instances, developing a fatty expansion of the cheeks which makes the face peculiarly broad. Such individuals, however, occur side by side with those of the ordinary type. The goitred appearance of the neck is due to a large vocal sac. The ears of the Orang are small and delicate, and its general expression much more pleasing and refined-if one can apply the term to any of these creatures-than in the other two. In height the male reaches four or five feet, when erect, but this animal very seldom stands upright on the ground, and indeed seldom comes there at all; when it does, it walks, like the others, on the knuckles and feet. It is, however, essenti- 
ally a tree animal; and, although very slow in its movements compared. to the Chimpanzee, and not given to jumping, gets along at such a pace by swinging itself with its long powerful arms, that it is often all a man can do to follow it on the ground. Like the Chimpanzee, it builds a platform nest of boughs to rest and sleep in, constructing a fresh one every two or three nights.

Its food consists of wild fruits, leaves, and so forth, and it is especially fond of the large spiny fruit of the Durian (Durio zibethinus), that East Indian fruit which has long been celebrated for the unequalled delightfulness of its flavour and the singular and penetrating vileness of its smell. In search of this it will at times approach human habitations, but usually lives far away from these, and often in flooded forests, which is the more remarkable, as it is quite unable to swim-at least this was the case with a specimen observed by Mr. W. Hornaday.

In its native haunts it has but few enemies; it is said to be occasionally attacked by the Crocodile or the Python; but to be able to give a good account of itself with either of them, jumping on the back of the former and wrenching its jaws asunder, and disabling the great snake with its powerful bite.

Against man it also makes a vigorous defence, seizing its adversary and biting him severely; cases have been known in which the victim has escaped with the loss of the ends of his fingers, which were bitten off by the infuriated ape. In this manner also they attack each other, and specimens with mutilated fingers are frequently met.with.

The Orang, although not a ferocious animal, is less sociable than the Gorilla and Chimpanzee, being usually found alone in the case of the male, though a female is commonly found accompanied by her young - a baby in arms, and an elder one which is more or less independent. The infant Orang clings tightly to its mother's long hair, as usual in creatures of this kind. I have more than once seen quite small specimens which had been imported to Calcutta, and these little things clung gladly to one; it was pitiful to hear them cry when they were taken away.

In the ordinary way the Orang is a rather silent animal, its whole 


\section{THE ORANG-UTAN}

character being quiet and self-contained compared with that of the Chimpanzee; the adult, however, has a grunting note. It has long been known in captivity, and in my time was often brought to Calcutta, as it had been long previously, being a great object of interest to the natives of Bengal, who call it "Bun manus"-jungle man, almost the same name as the Malay "Orang-utan"-wild man. I have, indeed, been asked by a native woman at the Calcutta Zoo whether an Orang she and her husband were looking at was not a man, just as I have heard a little child hail Mickey, the Chimpanzee at the London Zoo, as "boy." The Dyak name of the animal is "Mias."

Even in the East, the Orang is a delicate animal in confinement, and it is, now at all events, less often to be met with in captivity than the Chimpanzee in Europe. It is a much less energetic and lively creature than that species, and this is, no doubt, one reason why it is not so easy to keep. It is also more sensitive; when disappointed in anything - as when food is offered and not given, or when its keeper leaves it, or it is put back into a cage after being out-it will often roll about on the floor and scream with passion. There is, however, something very attractive about this animal, with its quiet, gentle ways, and humorous intellectual expression; and it is undoubtedly capable of great attachment to its own kind, as was shown many years ago in the case of three specimens, a male, a female, and a young one, which were allowed liberty in India.

After some time the female fell ill and died, and her two companions showed the most touching grief; the young one wished to follow the body as it was carried away, and when prevented showed its vexation in the manner described above. The sorrow of the male, although they had never been very intimate, was deeper: he mounted to the top of their house, and remained for days gazing fixedly in the direction in which he had seen the corpse of his companion taken away. Ultimately he came down dizzy and staggering with sunstroke, and before long he died also.

A good-sized female in the Calcutta $Z o o$ in my time was very friendly with me, and would affectionately put her arm round my neck 
through the cage bars, paying no attention to food offered her at the time by other visitors; yet she took a malicious pleasure in grabbing little boys by the leg as they passed, and moped when part of the cage was wired up to prevent this amusement. I have seen her tear off about half of a native woman's linen shawl, and promptly cover her own head with it, to the great edification of its former owner, who laughed till she had to lean against a lady friend for support. This specimen did not live very long, and was found on her death to be grossly fat, but after this an outdoor extension was made to the Orang cage in this house, and when I left Calcutta a young pair had been thriving in it for some time. The male of these was decidedly inclined to be mischievous, and when exhibited in a climate like that of Calcutta, where temperature allows fresh air to be given, the Orang is certainly. more cheerful and energetic than it appears over here, though, as above remarked, it cannot be called hardy even in the East.

The instinct of covering its head is very marked, and in the wild state the animal is said to cover itself over with large leaves when sleeping in its nest, should the weather be wet or chilly; it is not an early riser, and goes to bed betimes, in conformity with its generally sluggish nature. 


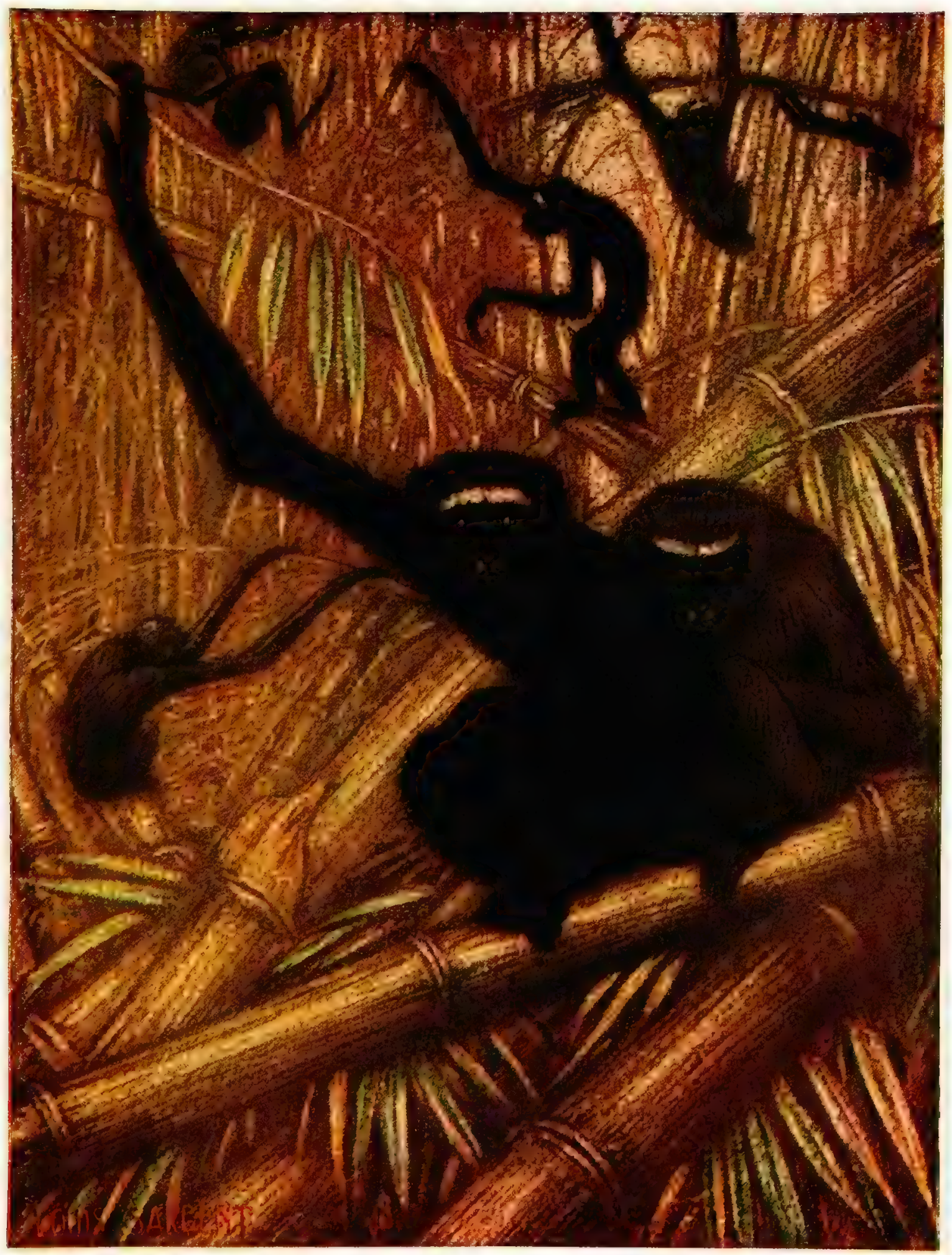

HOOLOCKS

By Louis A. Sargent 



\section{THE HOOLOCK}

(Hylobates hoolock)

THE Hoolock is the best known of the group of small long-armed apes, known as Gibbons, which range through the hilly forest regions of Eastern Asia from Bhutan to Hainan and Java; the present species, which is the most westerly in its range, extending east to Arracan.

The form of this creature is slender and graceful; the bodily shape generally much resembles that of man, except for the great length of the arms, which allow the finger-tips to touch the ground when the animal stands erect; the thumb and great toe are much larger than in the other apes. The Hoolock, however, approaches the lower monkeys in several anatomical characters, and in having, though only to a small extent, the bare callous patches on the seat so commonly found in them, but absent. in the great anthropoid apes before dealt with. The canine teeth are long and slender in both sexes.

The coat is also composed of fur like a monkey's, rather than what we more usually distinguish as hair. It varies very remarkably in colour, the normal hue being black with a white band across the brow; females, however, are usually brownish-black, and often not black at all, but pale straw colour, or pale above and brown below. The face, palms, and soles, however, are always black. In size the creature is small, only reaching. a little over two feet in height.

The Hoolock resembles man very markedly in one particular, in that it is a true biped, running and walking on the hinder limbs alone, just like a human being; the long arms are often stated to be held up or forward when walking, but as I have seen the animal, it has done just as a man would do if his arms were of such great length-slightly bent them so as to keep the hands clear of the ground. Although the gait is flat-footed and awkward, the creature is nimble enough, and gets along nearly as fast as a human being equally small could do. 
In its natural state, however, the Gibbon can seldom come to the ground, as it is a thoroughly arboreal animal, travelling among the trees and bamboos by swinging itself along with its great arms. The beauty of its movements must be seen to be realised; it is the champion gymnast of the animal kingdom, and one never tires of admiring the grace of its swinging leaps and the sureness of its hold, even in the confined limits of a menagerie. "Taking off" from one hand, it will throw itself halfa-dozen yards-merely touch, as it seems, with the other hand, swing off again, and so on for an hour at a time. Its powers are seen at their best when a troop is descending a hill-side clothed with bamboos, and it flings itself from one bending stem to another lower down, thus getting down-hill at a marvellous pace. They also ascend very rapidly, and from the hilly nature of their haunts have to go up and down a great deal, especially as, in many cases, they retire to the low warm valleys to sleep, and come uphill in the morning to feed. They do not build nests like the great apes, simply roosting on the boughs like ordinary monkeys none of which have any notion of nest-building.

Their food consists not only of leaves, shoots, wild fruit, and so forth, but also to a great extent of insects, spiders, the eggs of small birds, and even the birds themselves. These may be even captured on the wing at times, for a specimen of the allied Silvery Gibbon (Hylobates leuciscus) in captivity has been seen to take a flying bird with one hand as she swung from one perch to another, her landing not being in the least disturbed by the feat performed en route.

Water is drunk by the Hoolock in rather a peculiar way; it dips its hand in, and licks off the drops, often sliding down a bough to do this. This way of drinking is characteristic of Gibbons generally; but the animal also drinks by putting down its mouth in the ordinary way. An early observer records, by the way, that he has seen the female of some Gibbon take her young one to the water and wash its face, in spite of its fractious objections to the process. The young are habitually carried clinging to the parent, maintaining their hold securely during all its gymnastic performances.

The Hoolock appears to be quite unable to swim; when in deep 


\section{THE HOOLOCK}

water it throws its arms up and struggles helplessly, just like a human being who has no knowledge of swimming. As the Orang is also no swimmer, it is possible that the inability to swim applies to all these man-like apes. It may have something to do with the biped attitude, for many of the lower monkeys swim instinctively like other quadrupeds, using the "dog-stroke" like them.

One of the most notable peculiarities of the Hoolock is its call, which is a fine loud, clear, two-syllabled whoop, like "Whooko, Whooko," frequently repeated. It is generally ready to respond to an imitation of this note in captivity, and one we had in the Calcutta Zoo used to practise duets with a cock Argus pheasant (Argusianus argus), whose call is very similar in character. Hoolocks are very fond of the sound of their own voices, and the noise a troop can make has been described as "a storm of sound." They are particularly noisy in the morning and evening, when, as has been humorously remarked, they perform "regular oratorios"; thus their calls are some of the characteristic sounds of jungle life wherever they are found.

They are delicate creatures, having been found suffering from chest complaints even in the wild state, and they are hard to keep in captivity even in India, although a specimen once survived nine years in the Calcutta Zoo. Animals with such active habits need a great deal of space for exercise; and it seems to me also that a more varied diet, and one consisting more of substances they would be likely to obtain in a wild state, would be better for them than what is usually given to monkeys. Delicate animals can generally be kept if due attention is given to this point of dietary, which is usually the main difficulty.

When Hoolocks are allowed to go at large and find much of their own food, they do well; and they are so tameable that this liberty can be permitted them in about a month after they are acquired. We had a male loose in the Calcutta $Z_{0 o}$ in my time, and they are often so kept by planters in Assam. When thus living near the native haunts of his species, it has been observed that the tame Hoolock cannot obtain admission to their society, and the like has been noticed with a Javanese Gibbon which was released after being kept confined for a time. 
Hoolocks are thoroughly nice animals, quite different from ordinary monkeys, and most people like them in consequence; they become very affectionate, and are little inclined to mischief; they may, however, ultimately become spiteful, especially to human beings of their own sex; and for this reason those allowed liberty in Calcutta had to be shut up in the end.

The proper way to treat them would be to give them a large warm indoor house, with a structure like a big aviary outside, in which they could pass their time in fine weather.

There are several other species of Gibbons, but all have a very close resemblance to the Hoolock in appearance and general habits, with the exception of the Siamang of Sumatra (Hylobates syndactylus), which is more distinct. The colour variation seen in the Hoolock is repeated in other species; and an example of the Hainan Gibbon (Hylobates hainamus) in the London Zoological Gardens actually changed from sooty to straw colour. This creature had a stiff arm, but one had to look closely to notice this, as it swung itself about so freely with the sound limb that the defect was not at all obvious.

The Siamang is the largest of the Gibbons, reaching three feet in height, and the most stoutly built; it is always black all over, and has an enlargement of the throat, formed by the presence of a vocal sac; its note is loud and powerful, and must be very different from the whoop of the Hoolock, as it is described as a loud barking howl.

The Siamang is rare in captivity, and has been credited with a morose disposition by several observers; but this was not the case with a young specimen possessed by Dr. H. O. Forbes when in Sumatra, whose character was the height of amiability. It even bore him no grudge for pain inflicted on it in lancing boils and extracting teeth while it was teething, and it much appreciated the use of an umbrella as a sunshade, crying for this to be given it if there was any sign of its being forgotten. Such intelligence shows that the creature has a reasonable idea of what is for its welfare, and ranks the Siamang high among the lower animals in mental power. 


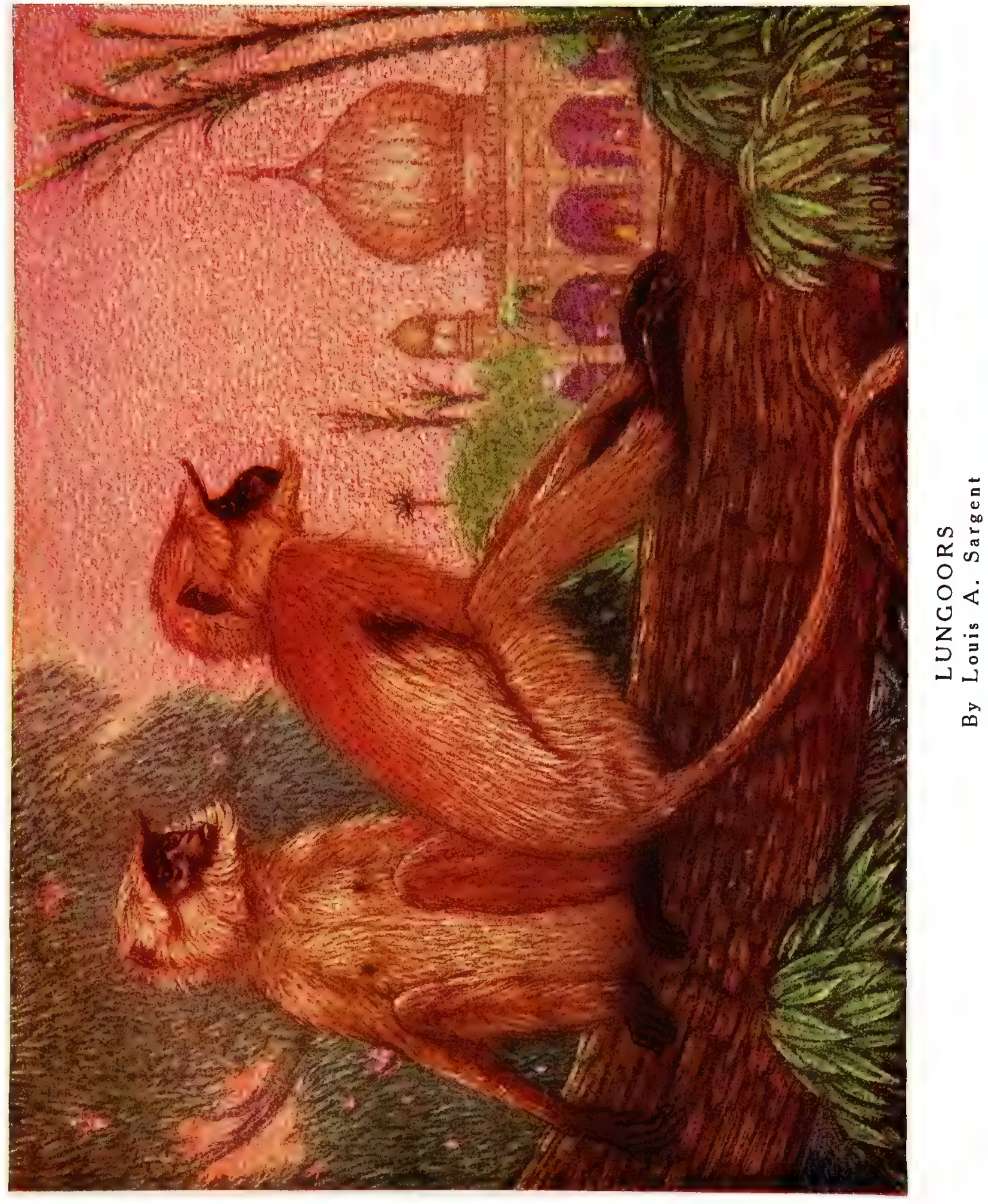





\section{THE LUNGOOR}

\section{(Semnopithecus entellus)}

THE Lungoor is one of the most familiar and striking animals of India, being very abundant and widely spread, and enjoying particular immunity from molestation as the incarnation of the monkeygod Hanuman, by whose name, indeed, the species is sometimes known.

It is a large monkey, about equalling a greyhound in size, and somewhat resembling one in form, owing to its light and long-limbed build; the tail is very long, more than equalling the head and body in length. The colour is very constant, being alike in both sexes, while the young are very similar to the adult animals. Males, however, are larger than females, and have more powerful canines, as is usual with monkeys.

The Lungoor is essentially a tree-monkey, being an active and powerful climber, and a remarkable leaper. On the ground it is also an agile animal, its bounding gallop being remarkable for grace, while a touch of grotesqueness is given by the curving of the long tail over the back. The monkey, however, cannot long hold his own against a horse; when the experiment was tried the poor beast was soon run to a standstill, and could only lie and gaze imploringly at his pursuer, who of course spared him.

The creature, however, has not much occasion to come to the ground except when travelling over a treeless space, for its ordinary food consists of the leaves of trees; of these it devours a great variety, and probably eats some poisonous kinds, for it is found to be able to take with impunity doses of strychnine which prove fatal to the common brown monkey or Bunder (Macacus rhesus).

Fruit and grain also form part of this animal's food, and it makes no. scruple of levying tithes upon its worshippers' property, not only in 
the orchards and the corn-fields, but from the shops in the bazaar, for where it is under Hindu protection it comes about human dwellings, perching on the roofs, and making itself generally as great a nuisance as a monkey living in the odour of sanctity might be expected to become.

It is a highly social animal, living in troops of several dozen individuals, including both sexes; the leading male of the troop, however, is credited with exercising despotic authority, and is also said, when becoming enfeebled with age, to be hunted to death if possible by his rivals. This is probable enough; and at any rate old solitary males-no doubt deposed monarchs-may be met with at times.

Although Lungoors are more grave and composed in demeanour than the common monkeys, they will fight most desperately at times, and a quite Homeric combat was once witnessed by Mr. T. Hughes, formerly of the Geological Survey of India. In this case, two troops, a small and a large one, looked on while the leader of the formeran unusually large specimen-heroically engaged two males from the latter. He had mortally wounded one by ripping open his throat, when two females of the opposing party attacked and injured him so terribly that he shortly died, whereupon his followers were cruelly persecuted by the winning side, who even shook down from a tree one of his females carrying her young, so that she died also. It has been noticed as a curious fact, that even in the remotest jungles these creatures appear instinctively to recognise man as an ally against the Tiger, whom they follow about in the trees overhead, abusing him lustily. The Leopard, however, is a far worse enemy to them, and they also fall victims to Pythons, which will attack even large male specimens.

Lungoors possess a considerable variety of notes, the harsh guttural alarm-note being strongly contrasted with the loud musical whoop or call given as they bound from tree to tree. This note is seldom heard in captivity, and the species does not do very well in that condition even in India, though it has not unfrequently reproduced when caged. It needs a good supply of its natural diet of leaves, its stomach being 
especially adapted for the digestion of such food, being large and divided into compartments.

The active habits of this monkey also render a larger cage than is needed for other species of the same size a matter of necessity. A good many, however, are captured and exported, so that this is the most familiar of its group in captivity in Europe, and has often been exhibited in the London Zoological Gardens.

The range of the Lungoor is wide, from the Deccan to the southern bank of the Ganges; it is a denizen of the hot plains, being represented in the northern hills by a nearly allied species or local race, the Himalayan Lungoor (Semnopithecus schistaceus), a larger animal, with a longer coat and smaller ears. This animal, although in the ordinary way moving up and down the mountains according to the temperature, may sometimes be seen sporting in the trees among the snow, as high up as I I,000 feet, in the neighbourhood of Simla.

Common as is the ordinary Lungoor, its range has not yet been completely mapped out to the north-west, west and south, but a different species, the Madras Lungoor (Semnopithecus priamus) occupies the Coromandel Coast and the north of Ceylon, and another, the Malabar Lungoor (Semnopithecus hypolencus) lives on the Malabar side. In the Nilgiri Hills is found a very handsome species (Semnopithecus johni), with long glossy-black hair and a light-brown head, while in south and west Ceylon there is a species peculiar to the island, the true Wanderoo (Semnopithecus cephalopterus), a brown animal with a ruff of white whiskers; this is remarkable for producing a completely white variety, in which, however, the face and eyes remain dark. Altogether there are about thirty species of these leaf-eating monkeys or Lungoors, extending east to Java in one direction and Tibet in the other. They resemble the subject of this article in general form and habits, but often have markedly different colours. None are common in captivity.

Two species, however, are so remarkable as to deserve speçial mention. The Proboscis Monkey (Nasalis larvatus) of Borneo, a chestnut and buff animal of large size, in which the old male has a huge long, flattened, drooping nose-an absurd caricature of our 
prominent feature. The local natives know it by the-to Europeansuncomplimentary title of "White Man." In the female the nose is less well developed, and in the young it is short and turned up. This is a very delicate animal, but has been kept in captivity both in Calcutta and London. It has been observed in its wild state to keep among boughs overhanging the water.

The other kind, the Snub-nosed Monkey (Rhinopithecus roxellana). of Moupin in North-eastern China, which extends to Kokonoor, is equally extraordinary in its way. It is also a large animal, and powerfully built, with an absurd-looking small turned-up nose, set in a green face. Its fur is thick and very gaily coloured, chiefly grey above and yellow below, becoming bright orange on the fur around the bare face and on the neck and chest. This monkey is a true cold-climate species, living permanently in mountain forests where snow lies more than half the year-a very strange contrast to the tropical haunts of most of this group. Such a hardy and quaint-looking animal would be a great acquisition to any European Zoological Garden; but, so far as I am aware, no such institution has ever exhibited it. 


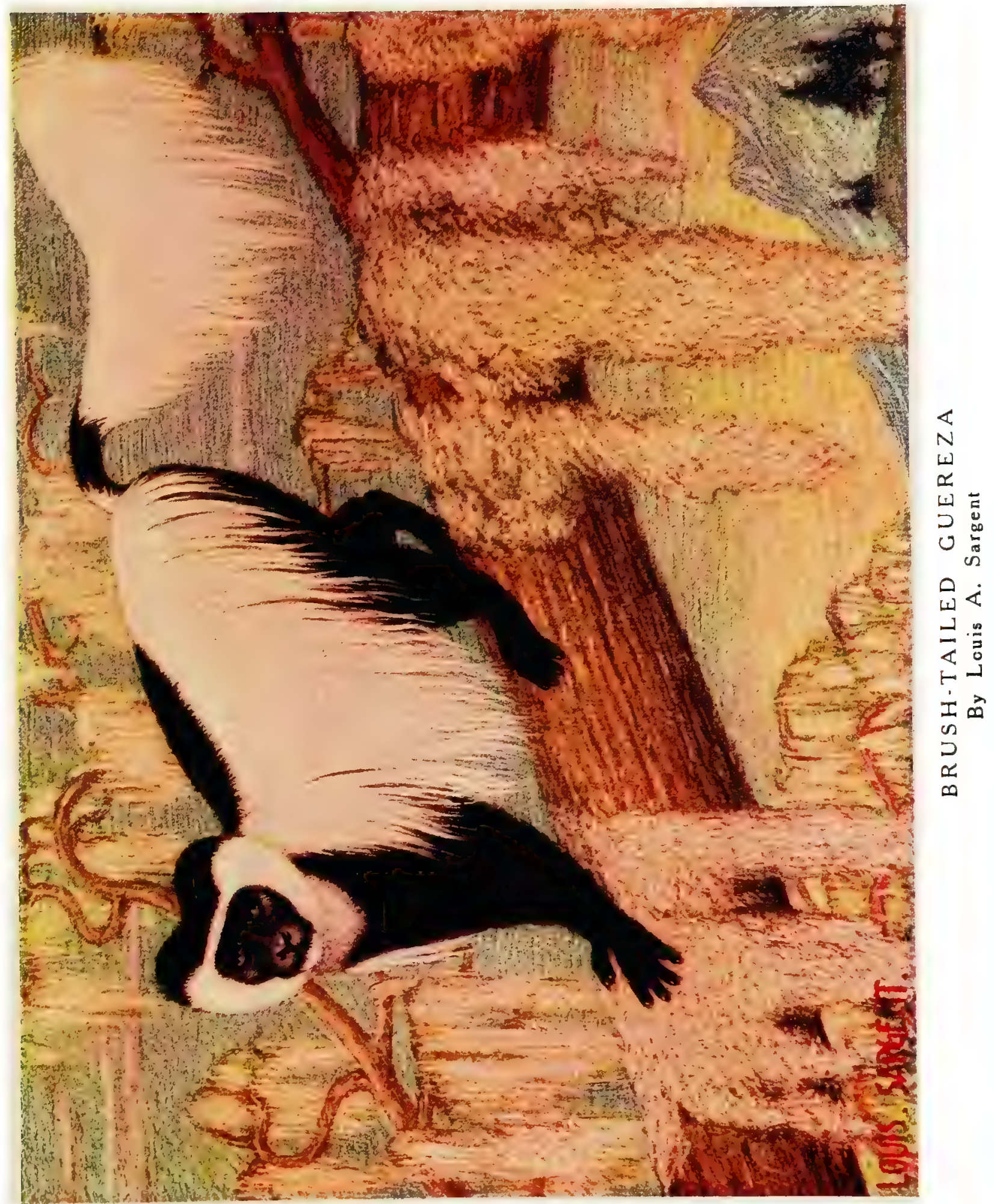





\section{THE GUEREZA}

(Colobus guereza).

THE Lungoors are an exclusively Asiatic group of monkeys, but they have allies in Africa in the shape of the Colobus Monkeys, of which the Abyssinian species, or typical Guereza, may be considered a characteristic sample.

It is a slender, long-limbed, long-tailed monkey, though not so long and slim as a Lungoor; and while it agrees with that group in only having small seat-pads, it differs in possessing cheek-pouches, though these are but small. A marked point of difference is the absence of a thumb in the hand, though the great toe of the foot is sufficiently well developed.

These monkeys are, like the Lungoors, essentially tree-animals and leaf-feeders; they seldom come to the ground, and have the large, partitioned stomach characteristic of a leaf-eating monkey. They also eat insects, and, of course, they partake of fruit as well, but they appear not to rob gardens; at any rate $\mathrm{Sir}$ H. H. Johnston speaks of the Guereza as avoiding human cultivations. They go in small companies, and do not appear to be noisy animals.

Both sexes of the animal have the beautiful black-and-white coat, with snowy side-flounces and brush-tip to the tail ; the size about equals that of a terrier. In Abyssinia and East Africa this monkey has only the tip of the tail white; but on the slopes of Kilimanjaro it is replaced by a very beautiful long-haired race (Colobus guereza caudatus), in which the side-fringes hang down as far as the middle of the legs, and the tail is clothed from the tip to nearly the root with long drooping hairs, forming a beautiful brush like that of a collie. This handsome creature, perhaps the most beautiful of all monkeys, is also found on Mount Kenia, where it ranges to a great height. One would expect such a strikingly 
coloured animal to be very conspicuous in the forest trees; but this is said not to be the case, as the long white hair is deceptively like the tresses of grey lichen which clothe the boughs. This, however, does not apply to the lowland form with shorter hair, which I have seen myself in trees at Wasin on the East. African Coast, and noticed it was as conspicuous as a black-and-white cat would have been in a similar situation.

The fact is, that after studying the colouration of monkeys in general, and the African ones in particular, one is inclined to suppose that it does not much matter what colour these active tree-haunting creatures wear, and it is probable that the long coat of the mountain Guereza is destined as a protection from the cold rather than for concealment from possible enemies.

The Guereza is described as a gentle, harmless creature, and this character was well borne out by specimens recently exhibited in the London Zoological Gardens, though it must be admitted that both of these were young.

One was confined along with a specimen of the Angolan Guereza (Colobus angolensis), which is not unlike the typical Guereza in general colour, but has very long drooping white whiskers, and the white hair of the body forming a mantle on the shoulders. These inhabited one of the side cages in the monkey-house, and on one occasion I saw one of them, after playing for some time with the tail of his companion as it hung down through the barred floor of their sleeping box, actually go up to the bedroom, and, holding up the brush of his tail to the other, offer it to him, as if to say, "One good turn deserves another."

Another specimen of the common Guereza arrived along with a White-tailed Mongoose (Herpestes albicauda), with which it had been living previously; the two incongruous associates were the most devoted of friends, and always close together. The Mongoose, like the monkey, was a young animal, but was the bigger of the two-the White-tailed species being one of the largest of the Mongooses-and could easily have disposed of his companion had he wished. He treated him, how- 
ever, with the greatest consideration, and would even allow him to take away food. The monkey, for his part, would often sit beside the Mongoose with his arm round it, in which position they reminded one most comically of those pictures of a little child and a big dog which are so popular.

Unfortunately, although the Mongoose, now full-grown, survives at the time of writing, the monkey is now dead. The Guerezas, like the Lungoors, are delicate animals in captivity, and, as in their case, special arrangements will have to be made if they are ever to be kept successfully. The beautiful brush-tailed Alpine variety, although not so far imported alive, would probably be the best for European menageries, as it ought to be suitable for out-door treatment.

All the Guerezas are rare in captivity, and the Abyssinian and Angolan species, mentioned above, have only been exhibited in the Zoological Gardens quite lately. There are about a dozen species altogether in this group, and of these half are either black-and-white or all black. The beautiful silky fur of these creatures is in great request for ornament, not only among African savages, who delight in making war head-dresses of it, but also among civilised people, who ought to know better, for these monkeys are not in any way noxious or objectionable animals, and deserve protection rather than persecution at the hands of humanity.

The largest kind, and one of the best known, is the black Guereza (Colobus satanas) of the West Coast of Africa, which measures more than a yard long in the body, and has a tail also of great length. As its name implies, it is black all over, both in fur and face.

Kirk's Guereza (Colobus kirki), of the island of Zanzibar, which exhibits brown as well as black-and-white in its colouration, has a peculiar and melancholy interest as the only monkey which has become extinct by human agency. It was confined to the island, and Sir John Kirk, its discoverer, finding that in 1884 it had nearly disappeared owing to the destruction of the forest, sent his native hunters to a wood where it was believed to linger, to report upon it. The wretched negroes discovered a dozen specimens, and killed them all! 
Of course, the proper thing to have done would have been to have transported two or three pairs to some suitable island unoccupied by other monkeys, where the species might have had a new lease of life if properly protected, while any undue increase could be restricted by the occasional sacrifice of a few specimens for museum purposes, or their capture for Zoological Gardens. 


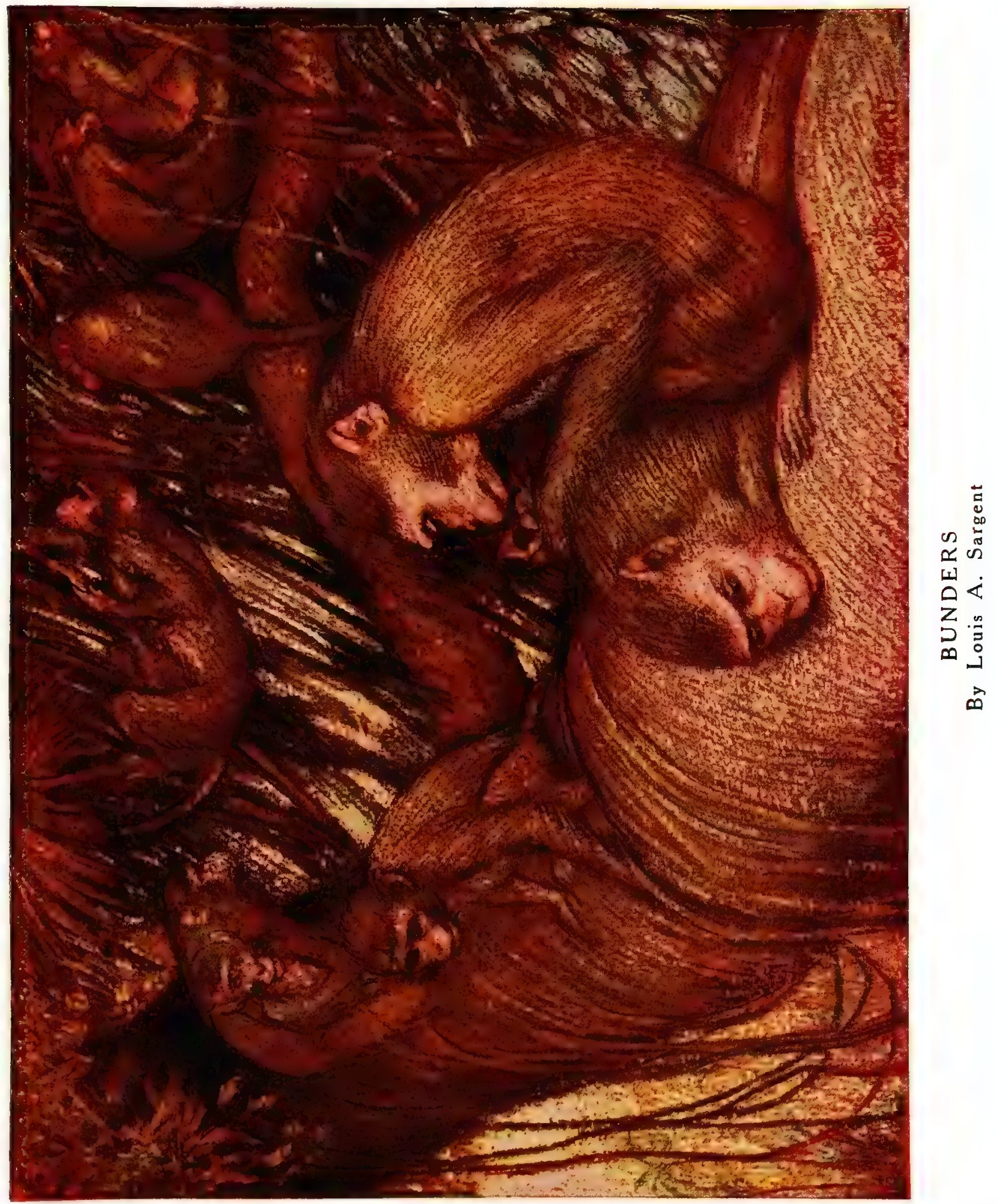





\section{THE BUNDER}

\section{(Macacus rhesus)}

The common Brown Monkey of India is one of the most abundant of its tribe, ranging in the wild state from Chitral to China, and being an abundant species all over Northern India, though below Bombay and the Godavery River it is replaced by the allied Bonnet Monkey (Macacus sinicus), a long-tailed species with the hair of the crown radiating, not regularly inclined backwards.

The common Rhesus varies a good deal in length of tail, which is, however, never much more than half as long as the rest of the animal; there is also some variation in form, certain individuals being stouter built than others, while the brown fur may be more or less richly tinted; in any case it is generally inclined to tawny in the hindquarters. Some individuals are very red about the face and hinderparts, which have a considerable naked area around the callosities on which the animal sits. The cheek-pouches are also large, these points being characteristic of the Macaque group as a whole.

- In size the Bunder, when adult, about equals a big terrier, the males being stouter and more powerful than their mates, and with a bolder and more virile type of feature. Young ones are coloured much like their parents, but have the most comical little wizened faces; they cling to the fur of the parent's chest for about a fortnight, but then begin to venture abroad under her supervision, which is certainly needed, as in India at all events it would be difficult to find a spot on which some bird of prey or other had not fixed its eye, to say nothing of enemies without wings, in the shape of Leopards, wild Cats, Snakes, and so forth. Possibly Crocodiles account for some of them, as these monkeys are rather fond of water, and some young individuals allowed to go free in the Calcutta Zoo have been observed 
to jump into it off boughs purely for the fun of the thing, just like a party of schoolboys bathing.

Although very active, these monkeys cannot compare with the Lungoor in gymnastic feats, and they are more inclined to come to the ground, as they are most omnivorous feeders, eating not only leaves, fruit, and grain, but also insects, lizards, and so forth. Like their sacred relative, they come about cultivation and houses, and commit various depredations; for the respect in which the Lungoor is held appears to be: extended to his lay relatives to some extent, and in any case the Indian native is very tolerant of animals even when noxious - a characteristic which, although it occasionally allows of a good deal of annoyance from the creatures, makes India perhaps the best country in the world for the naturalist, wild animals being so astonishingly confiding there.

The Bunder is not only widely distributed in the plains, but ascends the hills in places, as in Kashmir and about Simla, where a colony inhabits Jacko Hill. Its existence in Chitral, in a decidedly cold climate, has only been recently ascertained by Captain Macmahon, and a specimen received from him is, at the time of writing, in our Zoological Gardens; it has a thick silky coat, somewhat like that of the Tcheli Monkey (Macacus tcheliensis) of North China, which is itself doubtfully distinct from the present species.

These monkeys are sociable animals, like most of their kind, but they are continually quarrelling amongst themselves, teasing each other and striking; when enraged their faces become quite red, as Darwin pointed out long ago. Although they have no call, unlike Lungoors or Hoolocks, their vocabulary is fairly extensive, but the expressions are not musical by any means. Even the mother will snatch food from her young one when it is weaned and begins to feed itself, and, of course, there is always unpleasantness between the leading male and his would-be rivals.

Bunders are captured in large numbers for export, and in England, at all events, this is far the commonest monkey kept in captivity nowadays; it is the usual companion of the organ-grinder. Most of those seen for sale are quite young, and I was told in India that they were 
caught by the simple device of 'placing food under a basket propped up by a stick with a string attached-much like the familiar sieve-trap for sparrows.

The species, being a hardy and omnivorous one, bears captivity well, and will winter out-of-doors in England; it has also bred here as well as in captivity in its own country. Old females often get very obese, and they seem long-lived; I have known cases of specimens over fifteen years old in India, and they seemed still healthy. One of these was a very fine male of the yellow variety; for now and then individuals of this species are found of a golden-buff tint, with very fair skin on the face and paws-monkey blondes in fact. It would be interesting to isolate pairs of these, and see if the colour proved to be hereditary.

The group of Macaque Monkeys, of which this animal is a good typical example, is purely Asiatic, except for the tailless Barbary Ape (Macacus inuus), which is found in North Africa; to this species the well-known monkeys on Gibraltar belong. It was by dissecting this monkey that the ancient Greek doctors acquired the knowledge of anatomy which they applied to the human subject.

There are nearly a score of these Macaque Monkeys, as far as is known very similar in voice and habits, and not showing much difference in size, though they vary most remarkably in the matter of tail. They all seem also to bear captivity well, and hence the common ones are very familiar, not only the Bunder, but the above-mentioned Bonnet Monkey and the Crab-eating Macaque (Macacus cynomolgus) being freely imported.

This last is a short-limbed and long-tailed species, typically much darker in colour than the Bunder, with the ears and paws black. Its swollen muzzle gives it a decidedly brutal appearance, and it is a coarse, hardy animal, with a decided appetite for animal food. Ranging from Burma through the East Indies even to Timor, it frequents estuarine forests and mangrove swamps, coming down into the tidal mud to catch shrimps and crabs. The ways of the old females with their young are said to be very amusing, the vagrant propensities of the youthful 
monkey being restrained by a jerk of the tail and a cuff on the head, followed by maternal cuddling to appease his fractious shrieks.

In the case of a little Japanese monkey recently reared at the Zoo, one could often see him hauled away from the public or the interested occupants of the next cage in this way, but his mother never seemed to think it necessary to correct him. This species (Macacus speciosus) is, by the way, interesting as the most northerly in its range of all monkeys. It has a stump tail and thick greyish fur, set off by a brilliantly red face, brightest in the female.

The most remarkable-looking of the Macaques is the so-called Wanderoo-this name really belonging to a Ceylonese Lungoor-or Lion-tailed Monkey (Macacus silenus). This animal, which comes from Southern India, is black all over, with a rather short tail tufted at the end, and a full ruff of grey hair round its black face. The young one has no ruff, and its face is like fair human skin, so that the contrast between the infant; so like a tiny wizened child, and its black-faced whiskered mother is more than ordinarily comic. It is not a common species, but one that always attracts attention by its appearance, and so has long been well known in captivity. 


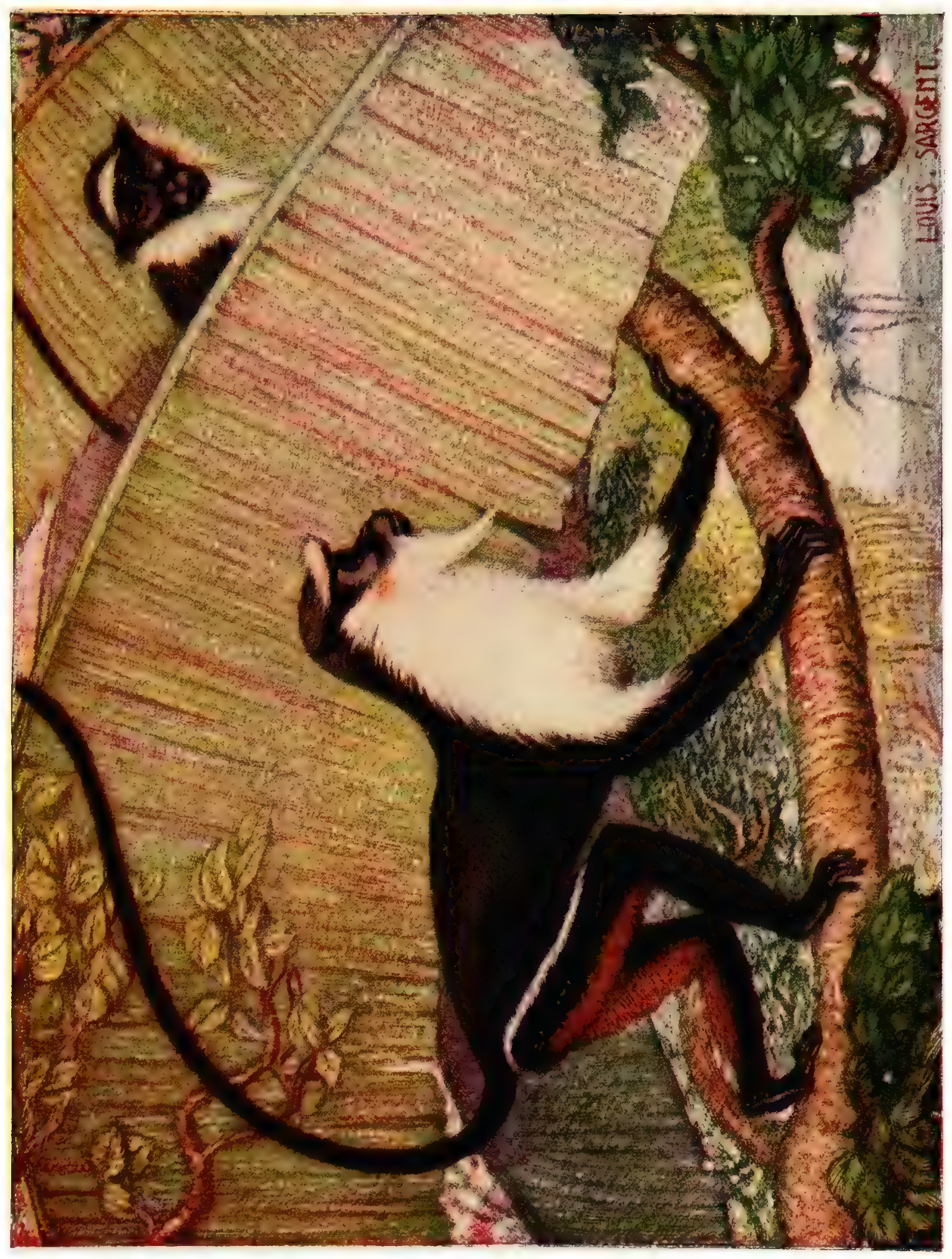





\section{THE DIANA MONKEY}

(Cercopithecus diana)

The Diana Monkey is one of the most notable species in the world, and always attracts attention in menageries, from its showy pied colouration and quaint "goatee" beard. The sexes are alike, and the young animal much resembles the older ones, being already bearded even when quite small.

There is, however, a certain amount of individual difference, the bright colour at the region of the thighs varying from light yellowish buff to bright bay. This monkey would appear to be very proud of its beard, as it is said to carefully hold it out of the way with its hand when drinking. According to some recent authorities, the monkey here called the Diana, which has for a long time borne that name, is not the true Diana of Linnæus originally described, but the Roloway (Cercopithecus roloway). The real animal is very similar, but has a quite short beard, partly black in colour, and the abdomen black. Until, however, some book on Mammals similar to the British Museum Catalogues of Birds and Reptiles is published, it does not seem advisable to alter a generally accepted name, and, in any case, popular names cannot be changed like scientific ones, once they have found general acceptance.

The Diana is not only a pretty and graceful monkey, but a very lively and playful one; as it grows old, however, it loses this amiability and becomes more reserved and disagreeable. It is chiefly known from menagerie specimens, for, as with most of these African monkeys, there is little on record about its wild life; it comes from the West Coast, and is well known in Liberia.

The group of Guenons, to which it belongs, are the common and characteristic monkeys of Africa, and as they do fairly well in captivity, and some are especially hardy, they are the best known monkeys in captivity here also, with the exception of two or three of the com- 
monest Asiatic Macaques. These Guenons, of which there are at least forty species, making the group the most numerous among the monkeys, are very easily recognised, in spite of the great variation in colour between different species. They are all long-tailed monkeys, and of very much the same shape, well-proportioned and long-tailed, with short faces; their cheek-pouches are large, but the seat-pads small. Their fur is thick and short, and, whatever its colour, is of a grizzled or pepper-and-salt type over much of the body, the individual hairs being marked with light and dark rings.

In the Diana these rings are white and black, producing an iron-grey effect, and this colour is found in a few others; but the commonest tint is olive-green-a very curious hue for a furred quadruped-produced by rings of black and yellow on the hairs. Only two, the Patas and the Nisnas (Cercopithecus patas and C. pyrrhonotus) are chiefly red in colour, and these have peculiarly long limbs, and appear to live more on the ground than the others.

As a rule, the Guenons are essentially tree-monkeys, and most of them come from the great forest regions of West and Central Africa. They are extremely active among the boughs, and feed on fruit and leaves, with the addition of insects and birds' eggs, \&c. ; in fact, they are, like the Macaques, omnivorous. They live in troops, under the direction of a leading male, who acts as sentinel or commander-in-chief, having different notes or expressions which he uses in giving his orders. The Guenons, however, do not appear to be very noisy monkeys. Of course, there is much quarrelling among them; but they will, like the tribe in general, unite against a common enemy, and carefully attend to each other's fur, cleaning it and freeing it from thorns, burrs, and parasites.

Monkeys, by the way, are popularly supposed to be always fleahunting; but, as a matter of fact, parasites have little chance of existence on a monkey, unless it is kept alone with no friends to look after its coat; the constant picking and scratching that goes on is really more a sort of curry-combing, and is the means by which the fur is kept neat and in good order. What monkeys find and eat on each other are little lumps of secretion from the skin. The young of these monkeys are carried at first clinging below the body, but afterwards mount on to their mother's back. 
The Guenons are well known to the natives of Africa as very destructive animals; they constantly raid cultivated plots, and not only destroy more than they eat, but carry off all they possibly can in their cheek-pouches and their hands; a monkey has been seen to go off with five ears of maize at once. In their turn they are used for food by men, and sometimes their skins are made into furs; while among other enemies they have to dread Leopards, large Snakes, and Eagles.

Although the Diana has been selected for illustration on account of its beauty and conspicuous appearance, and is a well-known animal in captivity, it is not by any means the best known of the group, that distinction belonging to the Green Monkey (Cercopithecus callitrichus), also West African. This species is olive-green, with a black face and yellow whiskers; it is a hardy animal, will live outdoors in England with proper shelter, and has produced young in captivity. In spite of its scientific name, it appears not to be the Callithrix (beautifulfurred) of the ancients; which was more probably the splendid Guereza Monkey: The Green Monkey is said to present the curious peculiarity of having no voice. This monkey has been introduced into St. Kitts and Barbadoes in the West Indies.

In South and East Africa a very common species is the Vervet: (Cercopithecus pygerythrus), which is very much like the Green Monkey, but has the whiskers white instead of yellow, is greyer in tinge of coat, and has black hands and feet instead of grey, and the tip of the tail black instead of yellow, while it also has a reddish patch just under the tail instead of a yellow one. Sir H. H. Johnston observed that the monkey frequented native gardens on Kilimanjaro, at a height of 5000 feet; he also says that he ate it frequently, and found it went very well in a stew. In the case of a specimen born in the London Zoological Gardens in 1893, it was noticed that the young animal had a curious habit of sucking both its mother's nipples at once.

Most of the monkeys of this group are about the size of a light terrier, but one of them, the Talapoin (Cercopithecus talapoin) is only about as large as a cat, and is thus the smallest monkey in the Old World, though quite a giant compared to some of those in the New. The Talapoin is a very quaint-looking little monkey, with a round head and large eyes surrounded by yellow rings, a black nose and 
large black ears, and yellow whiskers. The general colour of the coat is olive-green above and white below. This pretty little animal is unfortunately scarce, though a fair number have been imported of late; it comes from West Africa.

\section{THE MANGABEYS}

THE Mangabeys (Cercocebus) are a small group of monkeys which are considered to be intermediate between the Guenons and the Macaques. They are large monkeys of slender form, with long tails, and darkcoloured fur as a rule, which is not grizzled. Their faces have a very pleasing expression as a rule; the skin is light-coloured, and their upper eyelids are conspicuously white.

They all inhabit Africa, and seem to have much the same habits as the Guenons; in captivity they live well, and are very active and good-natured. Those most frequently seen are the Sooty Mangabey (Cercocebus fuliginosus), which is dull black shading into slaty below, which is said to keep much on the ground in the wild state; and the White-collared Mangabey ( $C$. collaris), which is slate-coloured above and has a white collar and under-parts, with the crown of the head bright red-brown, whence the name of "Cherry-crown" Monkey given it by animal dealers. Both of these species are West African. There are less than a dozen species of Mangabeys altogether, but these two are among the best known of imported monkeys. There is at the time of writing a very curious white Mangabey at the Zoo, which has been described as a new species under the name of Jamrach's Mangabey (C. jamrachi); it is not a complete albino, as its eyes are brown, though its face and hands are flesh-colour; but it will very possibly turn out to be only a variety after all, since albino varieties do not necessarily always show complete albinism by having pink eyes, as we see with white dogs and cats, and with the White Lungoor of Ceylon above mentioned. 


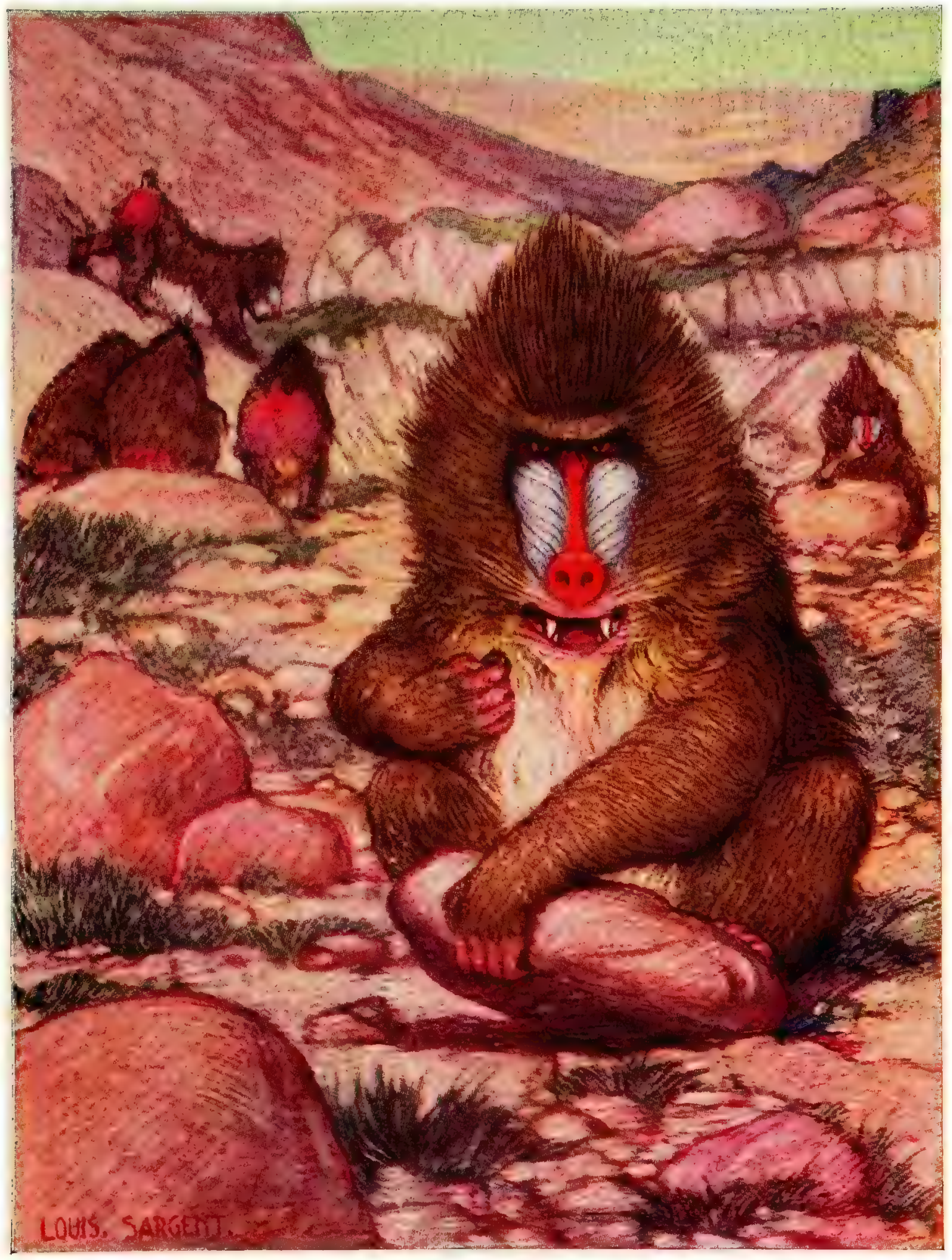

MANDRILLS

By Louis A. Sargent 



\section{THE MANDRILL}

\section{(Cynocephalus mormon)}

Bотн in strength and in the attention it attracts the Mandrill comes next to the great man-like apes, and, indeed, its very name would seem really to belong to the Chimpanzee, for an old Dictionary of I68I says that "Drill" means a "large overgrown ape or baboon, so-called," while an early woodcut of the "Mandrill," in William Smith's "Voyage to Guinea" (I744), is certainly intended for the superior animal; to say nothing of the accompanying description, which is that of an undoubted Chimpanzee.

Anything in the shape of a monkey less man-like than the old male Mandrill can scarcely be imagined, and, indeed, the Baboons, of which he is the chief, depart further from human form and feature than any other monkeys. In the Mandrill the difference is accentuated by the great size of the head, with its long, swollen, ridged muzzle, so brilliantly decorated with blue and scarlet. Like all the typical monkeys the Mandrill is a true quadruped, habitually going on all fours, the hind-feet being flat on the ground, and the fore-feet only touching it by the under surface of the fingers. The body is remarkably short and stout, and the limbs also short and robust; the hands and feet are small and neat-looking for so huge and burly an animal, and the former look particularly human. The tail is a ridiculous two-inch stump, carried erect and set on very high; the hind-quarters are very thinly haired, the skin here being really beautifully coloured with scarlet, azure, lilac, and pink. The coat generally is thick and rather long, of an olive colour, the hairs being ringed with yellow and black much as in the Guenons.

The male reaches the size of a very large dog when adult, and stands five feet high when on his hind-legs; he does not attain his full face-colour till he cuts his great canines-which are as big and formidable as a Leopard's-at nine years old. Till then his face lacks the red tints, as the female's always does. 
She has also a much smaller head and less swollen muzzle, and is much smaller altogether; the immature male resembles her. The infant Mandrill, of about the size of a cat, is a most comical little being, large-eyed and short-faced, though already showing the furrowed cheeks and yellow beard, and is absurdly playful, the very antithesis of his beetle-browed, glowering, sullen-looking father. The old Mandrill is credited with great ferocity, and with about every other bad quality an animal can possess; and in its wild state, in West Africa, little else is known about it except that the natives hold it in great dread. It is omnivorous and sociable, and frequents rocks and trees indifferently.

As a menagerie inmate, it has long been well known and borne a very bad character. Dangerous it is no doubt, its savage temper and great strength rendering it as terrible an antagonist as a Leopard would be; but after being acquainted with several adult male specimens, I must say that they seemed to me rather reserved and dignified animals, and certainly no worse-behaved than any other Baboons. They have a very curious habit of turning round so as to show their bright-hued hind-quarters; but this is well meant, the animal instinctively displaying his decorations behind as well as before. The beautiful colours of the face have been observed to fade when the animal is unwell, much as may be seen with the comb of the cock under similar circumstances. The Mandrill is not a noisy animal, though it occasionally gives vent to a grunt.

The Mandrill in captivity not only relishes animal food, which is natural and desirable for all omnivorous monkeys, but has a strong taste for alcohol; the late Mr. W. Rutledge, in his day the leading animal dealer in Calcutta, always maintained that a daily drink of beer or whisky-and-water was good for Mandrills, and certainly I never saw specimens in finer condition than those he had bought young and cared for well for years-for Mandrills seem always to be exported young. One of his specimens had the interesting trick of refusing to drink from a bottle of beer unless, he saw the label; this animal I never saw, and the story would be incredible, only that Rutledge explained to me that, though the appreciation of the beer was instinctive, the scrutiny of the label was an acquired detail; no doubt the animal had been trained to it by giving him water in an unlabelled bottle. 
A Mandrill which was in the old Surrey Zoological Gardens a century ago has become quite historical ; his name was "Happy Jerry," and he not only drank grog, but smoked a pipe with apparent enjoyment. This "was the animal which was once invited to dine with George IV. at Windsor, and apparently behaved quite respectably-for that occasion, at all events.

The name Drill is still used in its original signification, being applied to the only other baboon closely resembling the Mandrill, and also coming from West Africa, and better known in menageries than at large. This species (Cynocephalus leucophaus) is slightly smaller and less powerfully built than the Mandrill, and has a more soberly coloured coat, and a black face, only the lips being red. The cheeks are less swollen than in the other species, and have only two furrows, but the hind-quarters are nearly as brilliant. The female and young differ from the old male much as in the Mandrill.

Both these species are hardy in captivity, and will live in outdoor dens in England; the fine male Drill in the Belle Vue Gardens at Manchester has, at the time of writing, been there for twelve years.

The same hardiness characterises the Baboons generally; indeed, except for their very short tails, heavier build, and conspicuous sexual colouration, the Drill and Mandrill fairly typify the group. Most Baboons, however, have a tail of fair length, which is carried in a peculiar way, rising an inch or two from the root, and then hanging straight down. They are all found in Africa or Arabia, and generally prefer rocks to trees. They are highly gregarious, and feed much on insects and lizards, and do not fear to devour scorpions, first seizing them by the tail and pinching off the sting from it. Such prey they hunt by turning over stones. Several will unite to do this if the stone is too big for one, and in general they show a strong idea of cooperation-so much so, that on account of the great size and powerful canine teeth of the males, they are much feared by other animals. Even the Leopard only attacks stragglers, and they will show a bold front, or even assume the aggressive, to man himself. They have a particularly disagreeable habit of rolling stones down on their enemies.

Indeed, in spite of the brutish look produced by their long dog-like muzzles and active quadruped gait on the ground, these large ugly 
monkeys undoubtedly come nearer to humanity in their mental faculties than any other creatures but the great man-like apes. Their usual note is a kind of bark, and they have a curious habit of gibbering silently with the lips when they mean to be pleasant.

There are about a dozen species of the typical Baboons, of which the best-known are the Sacred Baboon (Cynocephalus hamadryas) of Arabia and Abyssinia and the Chacma ( $C$. porcarivis) of South Africa. The former is a grizzly-grey animal with a tufted tail; the male is adorned with a cloak of long hair, and is a statuesque and majestic animal when seen seated; the ancient Egyptians worshipped it as the incarnation of the god Thoth, and trained it to work for them.

The Chacma (Cynocephalus porcarius), which is as big, though not as heavily built, as the Mandrill, is an olive-coloured animal, with a black face. It is a great deal too well known at the Cape, committing depredations not only on crops, but on sheep, for it tears open young lambs, drinking the milk in their stomachs, and eating the flesh.

It is a terrible antagonist to dogs, very hard to shoot, and will take doses of poison which will kill anything else-is, in fact, a serious allround pest. Yet it can be trained to be most useful ; the most remarkable case of this is one which was authentically reported and became widely known, some years back; a signalman at the Cape, who had lost his legs, taught one of these Baboons to work the points for him, and it also propelled his trolley, and indeed was an indispensable assistant. in his employment.

The Gelada Baboons (Theropithecus), of which there are two species, both large, maned, and dark-coloured, connect the Baboons with the Macaques to some. extent, having the nostrils not at the end of the snout, as in Baboons generally, but some distance back. A further link is found in the Black Baboon of Celebes (Cynopithecus niger). This animal, found at the extreme limit of the range of monkeys in the East Indies, is, like the Macaques, of moderate size, about equalling a spaniel, and has a face intermediate in length, and the position of the nostrils, between Baboons and ordinary monkeys. It is black all over, both in hair and skin, and is practically tailless, the tail being only a rudiment about an inch long. Although not a common monkey, it has often been exhibited at the Zoological Gardens. 


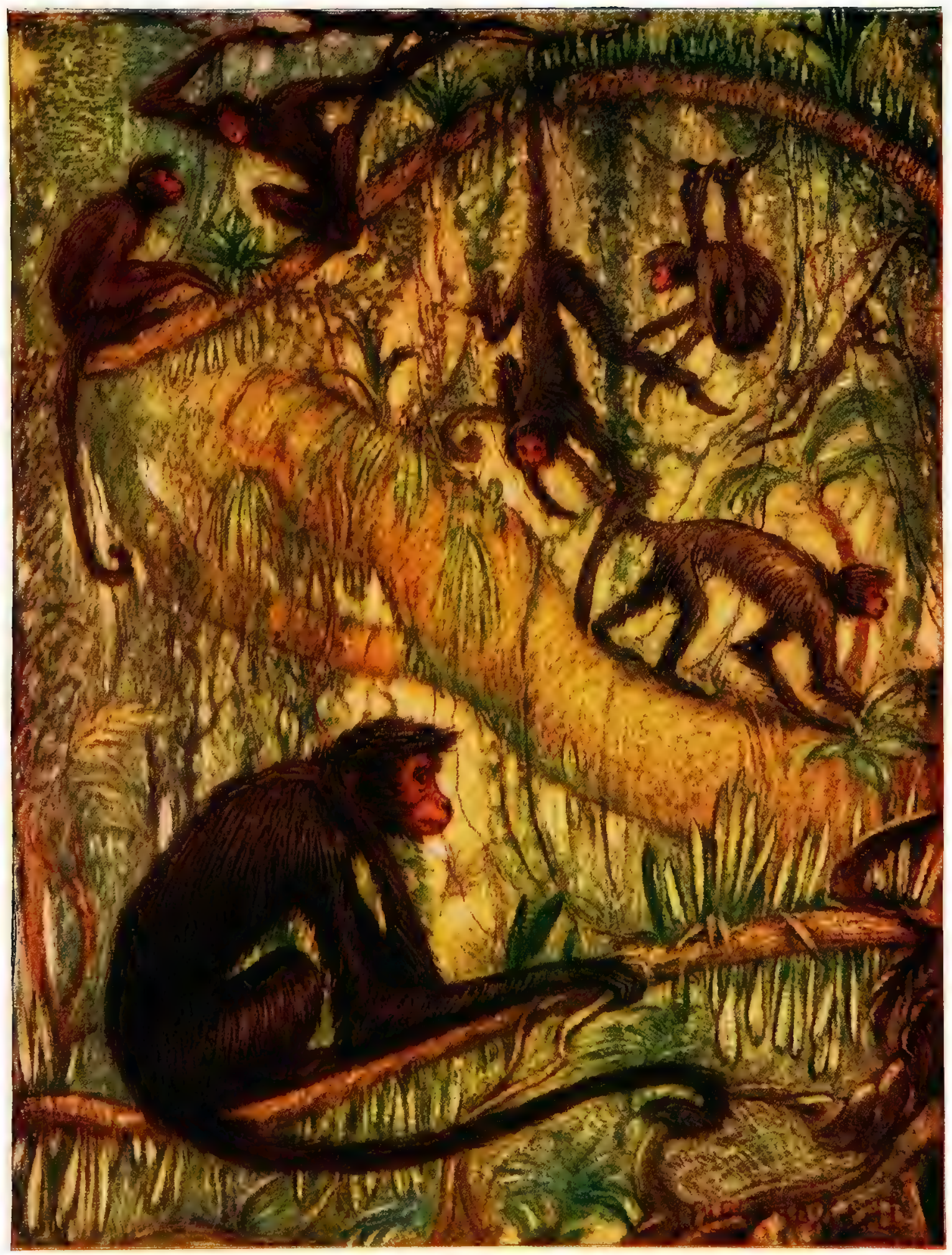

RED-FACED SPIDER-MONKEYS

By Louis A. Sargent 



\section{THE RED-FACED SPIDER MONKEY}

(Ateles paniscus)

IN this animal and its allies we find the highest type of the New World monkeys, which are readily distinguished from those of the Old World by the broad partition between the nostrils, which open sideways, those of the Old World apes and monkeys being separated by a narrow partition as in man, and looking forwards. The New World monkeys never have seat-pads or cheek-pouches, but it is only among some of them that one finds the prehensile tail, which attains its greatest perfection in the Spider Monkeys.

It is bare for a considerable distance on the under-surface at the end, and is very sensitive, and amusingly independent in its action, often being raised in front of the monkey's head, and taking hold before the hands, in a way which irresistibly reminds one of the proverbial tail which tried to wag the dog. It seems, indeed, that one of these monkeys whose tail is injured loses its nerve to a great extent, thus showing the great dependence it places on its "fifth hand," which is not only useful to swing by, but will grasp and bring to hand objects a little distance off. The actual hands of the monkey are somewhat imperfect, as the thumb is wanting, as in the Guerezas of the Old World; the great toe, however, is well developed, but not opposable to the other toes as in Old World monkeys, a peculiarity which runs through the family. All the typical New World monkeys also have four more teeth than the Old World ones, there being an extra pre-molar on each side of both jaws.

The Spider Monkey, like all American monkeys, is a forest animal ; it frequents the tops of high trees, where it moves about in an erect position, in this, as in its slender form, recalling the Gibbons of the Old World. Its food consists chiefly of fruit, and it does not appear 
to display the strong appetite for animal food which is so characteristic of the small American monkeys.

It is a sociable creature, and usually found in large troops, sometimes numbering as many as a hundred. This is about the largest of the American monkeys as far as dimensions go, being two feet long in the body, with the tail six inches more, though some other species considerably exceed it in weight. The black coat is common to both sexes, and is constant in colour, but there is a certain amount of variation in the hands, which sometimes have a tiny rudimentary thumb; this may be present on one of them and not the other.

Like other Spider Monkeys this species is esteemed as human food, being eaten not only by the Indians, but also by Europeans, though naturally, in the case of the latter, with reluctance, owing to the human aspect of the animal. The meat itself would appear to be good enough, as Bates says of an allied species, the White-whiskered Spider Monkey (Ateles marginatus), that it was the best-flavoured he ever tasted, being like beef, but with a richer and sweeter taste. It is very lean and dry, and will keep well for a long time if smoke-dried. This Spider Monkey probably often finds an enemy also in the great Harpy Eagle (Thrasaëtus harpyia), which is known to prey on monkeys of this kind.

Many of these Red-faced Spider Monkeys are captured as pets, in which capacity none of their kind are superior. The creature's face is a singularly pleasing one for a monkey's, being very human and pathetic in expression, and its disposition is remarkably gentle and affectionate, so that it readily learns to accompany its owner.

Bates gives an amusing account of an old female, which was very sensitive to language; its owner, a Portuguese, would sometimes roundly abuse the poor monkey, which would thereupon exhibit all the symptoms of extreme sorrow, rocking itself to and fro and wailing pitifully, while it rubbed its long arms backwards and forwards over its head. When, however, its owner changed his abusive expressions for terms of endearment, its grief was soon appeased, and it came and sat beside him.

Although not a common monkey in Europe, the species is still no 
rarity, and has often been exhibited in our Zoological Gardens. Its range extends from Northern Brazil to Eastern Peru; but it does not range to the south beyond the limits of the great Amazonian plains, its place there being taken by the White-whiskered Spider Monkey above mentioned. This is slightly smaller, and grey in colour below, with the face mostly black, but diversified by white on the surrounding fur.

Altogether there are about a dozen species of these typical Spider Monkeys, with long straight fur and slender bodies; they range from Peru northwards to Mexico, the species found there (Ateles vellevosus) being remarkable for its long coat, which is variable in colour, but usually black or brown above and cream-colour below. In South America these monkeys are known as Coaitas.

In South-western Brazil is found a monkey of a peculiar type which connects the Spider Monkeys with the Woolly Monkeys or Barrigudos, next to be noticed. This Woolly Spider Monkey resembles the typical kind in its long limbs and tail, but has a stouter and heavier body, clothed with short dense woolly fur of a brown colour. There appears to be but the one species (Brachyteles arachnoides), but this is so variable in the development of the thumbs that two or three forms have been described; sometimes it may have a small nailed thumb on both hands, sometimes only a wart, and sometimes this on one hand and the little thumb on the other; or, as is usually the case, no thumb at all. This monkey is smaller than the typical Spider Monkeys, but seems to resemble them in general habits; it is, however, a rare animal, and not much is known about it.

\section{THE BARRIGUDOS}

THE true Barrigudos or Woolly Monkeys (Lagothrix) are very peculiarlooking animals. Their limbs are of moderate length, with welldeveloped thumbs, and their tails fully prehensile; their heads are round, and their bodies heavy and bulky, showing a "corporation" which fully accounts for their Portuguese nickname of "Barrigudo" 
- paunchy or big-bellied. Their fur is short, but very thick and close and of a woolly texture. Their range extends from Ecuador to Venezuela, but there are only two species, of which Humboldt's Barrigudo, or the Negro Monkey (Lagothrix humboldti), is the best known. This is a large animal, much heavier than the Red-faced Spider-Monkey, and clothed in iron-grey fur, with the head and extremities black. It is not a very active animal, and lives on fruit, which it devours in great quantities, as might be expected from its corpulent appearance. Its portly carcase is in great request for food among the natives, by whom it is greatly persecuted in consequence. It is also frequently kept as a pet, in which condition it is found to be gentle and affectionate, while its very quaint appearance-its face being absurdly like that of a negro -is an additional recommendation. It has frequently been exhibited in our Zoological Gardens. 


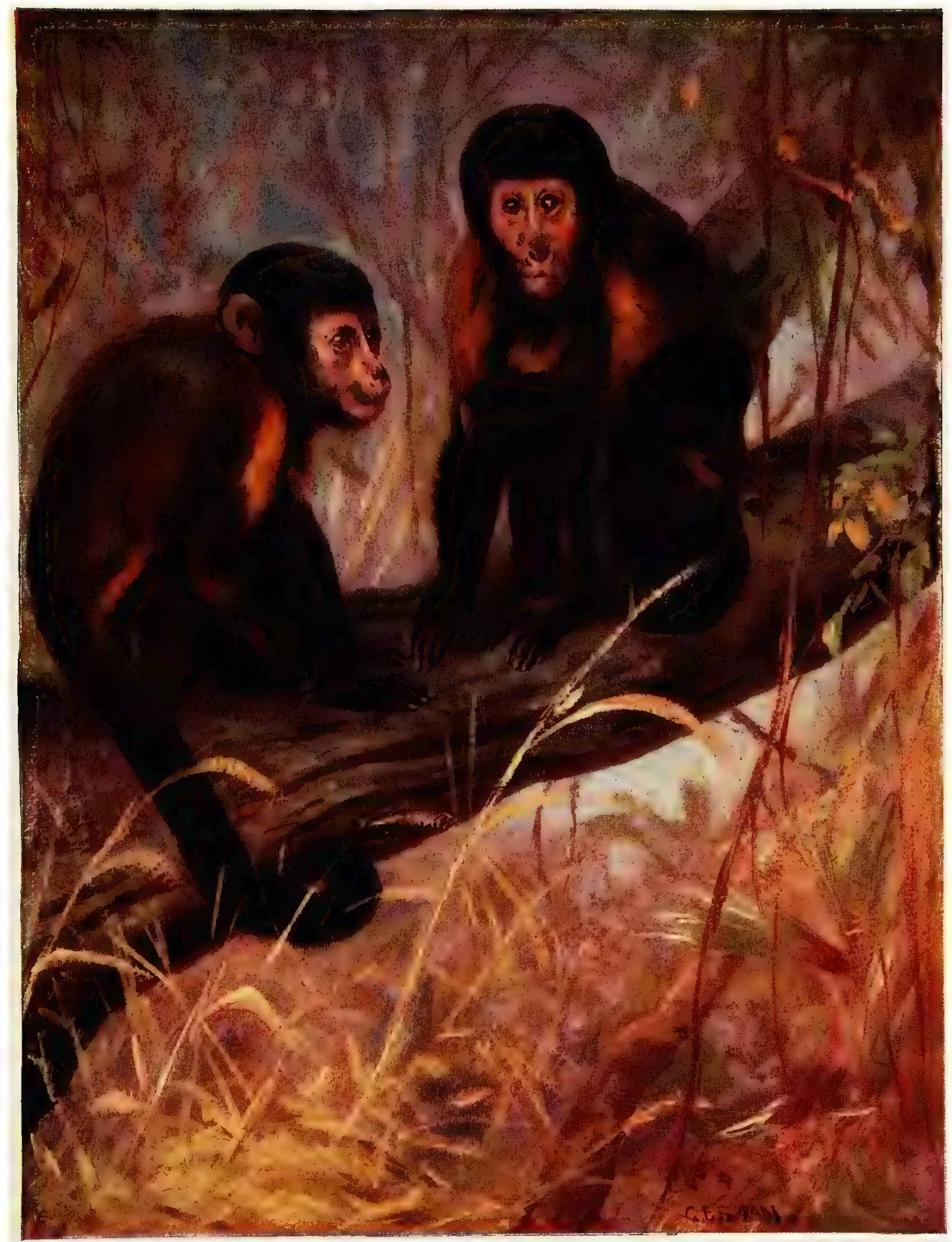

BROWN CAPUCHINS

By C. E. Swan 



\section{THE BROWN CAPUCHIN}

(Cebus fatuellus)

The Brown Capuchin, being the species most commonly brought to Europe, is much the most familiar of the South American Monkeys, of which it may be said to exemplify the typical or average type. In size about as large as a cat, it is a well-proportioned animal, with limbs of moderate length and well-developed thumbs and great-toes, which cannot, however, be opposed to the other fingers, so that the hands, both fore and hind, are so far less perfect than those of the Old World Monkeys.

The tail is prehensile, but has not the extreme sensitiveness and independence of action found in the Spider Monkey's, and, in conformity with this less degree of delicacy, it is hairy all over, and shows no bald surface below at the tip.

The coat, which is short, thick, and glossy, shows no sex difference in colour, but it is extremely variable in shade, some specimens being much lighter in colour than the typical hue shown in the picture, even ranging to a pale yellow.

There is much variability, too, in the hair of the crown, some writers considering the so-called Horned Capuchin (Cebus apella), which has it rather long and parted in the centre so as to form two horn-like crests, as only a variety of this species, while the Smooth-headed Capuchin (C. monachus) is also very like the present species.

In fact, although about sixteen kinds of Capuchins, ranging from Costa Rica in Central America southwards down to Paraguay, have been described, it is doubtful how many are really distinct, as they are so similar in general appearance and so variable in detail.

One, however, which is that most frequently seen in captivity after the Brown Capuchin, appears to be really distinct, and certainly looks very different. This is the White-throated Capuchin (Cebus hypoleucus), which is a smaller, slighter, and more delicately-formed animal, especi- 
ally about the head. Its face is very naked, and of a flesh-colour just like human skin; its neck and shoulders are straw-colour, contrasting with the dark hue of the rest of its body; and on the crown is a patch of very short black fur, like a little cap. It is more gentle and delicate than the Brown species.

The Capuchins are to America what the Guenons are to Africa, the common and characteristic monkeys of the country, found all over the forest regions, and often approaching and pilfering from the cultivations of men. They live in troops, which travel from tree to tree under the direction of leaders, springing from bough to bough and swinging themselves by their tails, the young being of course carried clinging to their mothers according to the usual monkey custom. They seldom come to the ground, and when there do not move so actively as the common monkeys of the Old World. In walking they place the flat of the whole hand on the ground, and do not support themselves on the fingers only. Some will make great leaps in the air, from one tree to another fifty feet below, their tails being of course of great assistance in righting themselves after such a leap.

Their food, as with other monkeys, consists partly of fruit, and when they visit a plantation to steal, they will carry away all they can; but they have a very strong propensity for animal food, devouring all sorts of insects, even the largest beetles, and harrying the nests of birds. Indeed, as in captivity they have been known to kill such large and powerful species as Macaws and Toucans, few of their feathered neighbours can be safe from their attacks.

They have a great variety of notes, though not given to uttering loud cries, and their common expression is a kind of tittering or twittering sound; when pleased they smile in a very human manner. The intelligence of these monkeys is undoubtedly very great, as shown by their actions in captivity, and they need all of it to escape such foes as Jaguars, Eagles, and Boas, which they are liable to fall victims to in the forests. In many works will be found the statement that the Capuchins are the monkeys most commonly seen in captivity ; but, whatever may have been the case some decades back, it is not so now, and 


\section{THE BROWN CAPUCHIN}

even the Brown species is a scarce animal compared with the ordinary Asiatic Macaques and African Guenons. It is also more delicate, though this may be partly due to the fact that people into whose hands it falls do not allow for its carnivorous propensities, so that it is kept on too low a diet.

With a great deal of the ordinary monkey malice and mischief, the Capuchin displays a great capacity for affection to people to whom it takes a fancy, and its great intelligence makes it about the most attractive of all pets for people who like an interesting animal. A very excellent account of the ways of a tame Brown Capuchin is given by Romanes in his book "Animal Intelligence," he having borrowed a male of this species from the Zoological Gardens for the express purpose of study. A diary of the monkey's proceedings was kept by the late professor's sister, who had the chief charge of the creature, which, nevertheless, did not show any fondness for her, much preferring the lady's mother, an invalid. His tenderness with her was touching to witness; he was always happy when on her bed, and would let her take anything away from him, though in such a case he would often vent his dissatisfaction on any one else, especially if he were laughed at. If unable to bite people through being chained up, he would throw anything at them which he could manipulate, and, when he found that throwing things at their feet did not annoy them particularly, would climb up wherever he could and launch his missiles at their heads. He had a great idea of the use of tools, used a hammer quite naturally for breaking his nuts, and often tried to open the trunk in which they were kept with a key, while he would use a cane to drive away the dog with. When confined away from his chief friend, he was more amiable to his younger protectress, and would put pieces of his food into her hand, and submit to be robbed of his treasures. Towards Professor Romanes himself he exhibited the very greatest affection, rather unaccountably, as that gentleman had very little to do with him.

This account of the intelligence of the Brown Capuchin is paralleled by Belt's remarks on the Nicaraguan kind which he kept tied up in his verandah. This monkey would bring otherwise inaccessible articles 
within his reach by launching a swing, which hung near, in their direction; and when there were young ducklings about he would lure them to their destruction by holding out a piece of bread to them with one hand, while keeping ready to seize them with the other. His notes were extremely varied, and one could tell, his master found, by the noise he was making, whether he was hungry or in the enjoyment of food, angry or frightened; so that he could be said to have a language. On one occasion he was seen to be making off with a milk-jug, walking on his hind-legs; and when he saw he was found out in the theft, he put it down without spilling any, uttering an apologetic note which he always used on such occasions.

From these accounts it would seem that the intelligence of the Capuchins cannot be much below that of the Chimpanzee and other higher apes; a sufficiently remarkable fact, as the American monkeys are always considered to be on a lower grade than those of the Old World. 


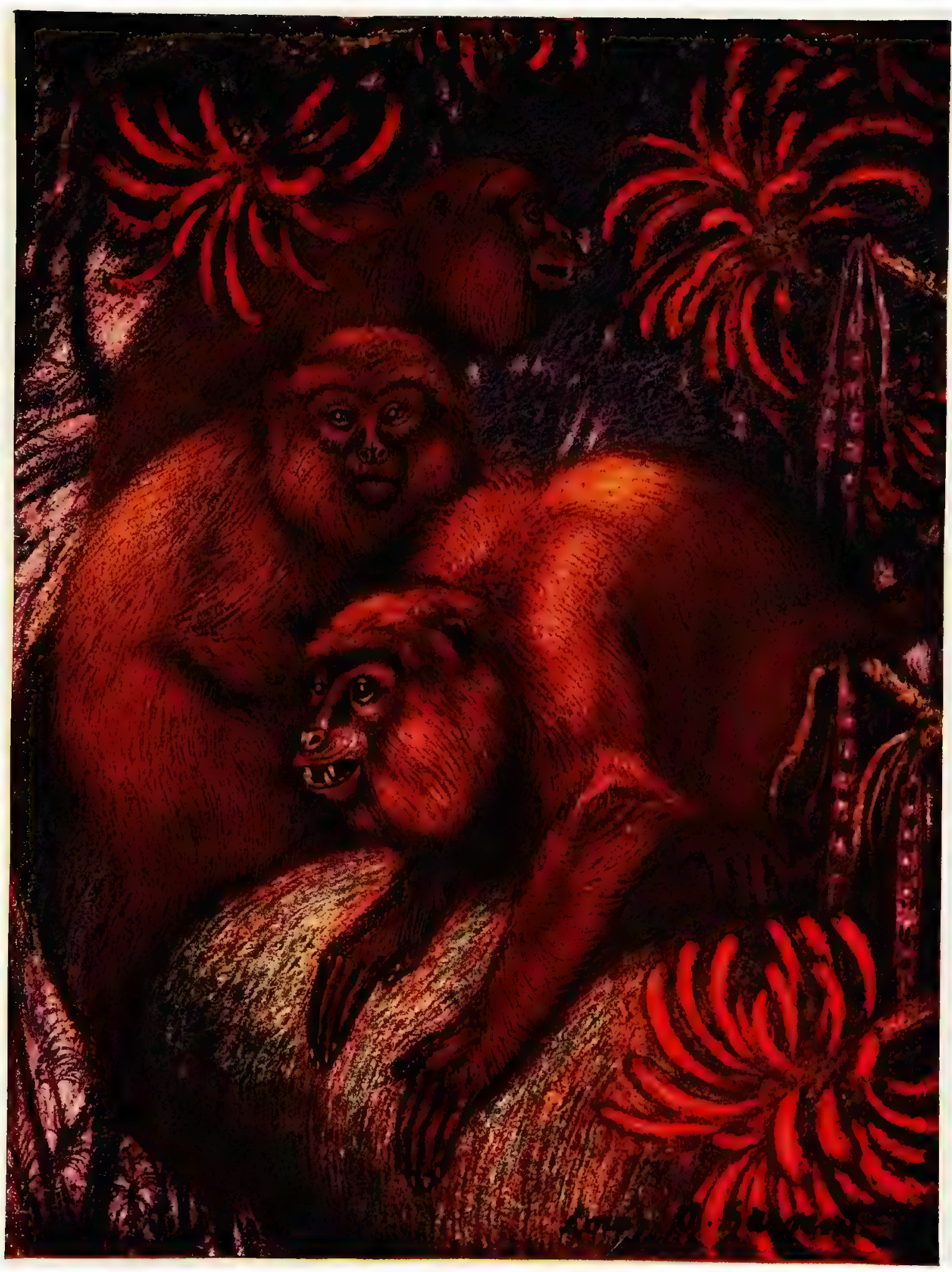

RED HOWLERS

By Louis A. Sargent 



\section{THE RED HOWLER}

\section{(Mycetes seniculus)}

Alrhough not so familiar in its habits as the Capuchins, and but rarely seen in captivity, the Red Howler is perhaps the most generally familiar of the American monkeys, owing to its qualifications and propensity for making a noise in the world, and the consequent importance it has always assumed in the narratives of travellers, who sometimes allude to it, very incorrectly, as a "baboon." Although a large animal for one of the New World species, it does not equal the Spider Monkey in size, being more shortly and stoutly built. Its tail is thoroughly prehensile, being bald at the tip beneath, and it has normal thumbs on the hands. The face has a brutish expression, owing to the large development of the jaws at the expense of the brain-case, and the throat is swollen by the presence of a curious bony drum caused by an enlargement of the larynx, a structure which assists in the production of the remarkable voice of the monkey. To accommodate this organ the sides of the lower jaw are greatly expanded in depth, so that a Howler's skull is easily known from that of any other monkey.

The red colour of the coat is common to both sexes, but there is a certain amount of individual variation in the extent of the yellow tinge.

The Red Howler is widely spread over the northern portions of South America, living in large bands in the tops of the forest trees, under the leadership of a male, whose movements are followed by the rest of the troop with remarkable uniformity, "taking off" with a swing from their tails from the same branch as he has last vacated. The females carry their young on their backs, and the Indians accuse them of sometimes throwing their young down to facilitate their own escape when threatened by the hunters. Humboldt suggests that this is merely 
accidental, and that the Indians, who do not admire the Howler's looks, and likewise object to its dismal vocalisations, carry their dislike so far as to cast aspersions on its character, just as, one may remark, Europeans revile the donkey because its figure and voice do not appeal to them in comparison with those of the horse.

At the same time, it may be remarked that native accounts of the habits of animals have a way of turning out to be correct, and it is possible that the Howler, whose character is morose and stupid, has really less affection for its young than monkeys generally.

The voice of the Howler is extraordinarily powerful for the size of the animal, and its roars are so modulated that one would think that a number of animals were engaged, and that a terrible fight was being carried through from start to finish. Nevertheless, it would appear to be the case that the whole of the apparent concert can be the result of the efforts of one animal, generally an adult male. The howling is mostly to be heard before dawn and after sunset, and the creatures are also especially noisy before rain, like so many other animals.

Whatever objections the Indians may have to the Howler in life, they keenly appreciate its flesh as food, and it is one of the most valued items on their game list. If killed, however, it does not come to hand at once, but hangs on to the tree even in death, and not till the muscles of the feet and tail relax does it drop from its perch aloft.

As a pet the Howler is not in any estimation, being surly and showing no particular intelligence; neither does it usually live very long in captivity. Specimens of it have, however, occasionally been on view at our Zoological Gardens, as well as of the Brown Howler (Mycetes fuscus), which is black when young, and of the Black Howler ( $M$. caraya). In the last species the adult males only are black, the females and young being straw-coloured. This is the most southerly in its range of the Howlers, being found as far south as Paraguay. The most northern species is the Guatemalan Howler ( $M$. villosus), which is black at all ages in both sexes. This species is only found in small bands of about half-a-dozen, and is one of the very few American 


\section{RED HOWLER-OUAKARIS-SAKIS}

monkeys found in a cool climate, as it lives in the mountains of Chilasco at an elevation of 6000 feet, where the climate is cold and damp. There are only half-a-dozen species of Howlers altogether. Most of the other South American monkeys are little known, with the exception of the distinct family of the Marmosets, next to be noticed, but it is convenient here to pass them in review.

\section{THE OUAKARIS}

THE monkeys of this genus (Brachyurus) are of moderate size, but larger than the Capuchins, and they are remarkable among New World monkeys for their short tails, which are non-prehensile, and not half as long as the body. Unlike the short-tailed monkeys of the Old World, however, they display no tendency to come to the ground. They are fruit-eaters, gentle in disposition, and tender in constitution; but all the three kinds have been exhibited in the Zoological Gardens. These are the Red Ouakari (Brachyurus rubicundus), which has a coat much like the Orang's and a bright red face; the Bald Ouakari (B. calvus), which has also a red face, but a white coat; and the Black-headed Ouakari ( $B$. melanocephalus), which is black in the face and on most of its fur. They are all South American, and each inhabits a separate small area.

\section{THE SAKIS}

THE Sakis (Pithecia) are closely allied to the Ouakaris, but have long tails, which are very bushy and not prehensile. Their whole coat is long and thick, and mainly black in colour; and they are well bearded, the most conspicuous in this respect being the Red-backed Saki (Pithecia chiropotes), at any rate in the male sex, the female having no beard. The male is said to drink from its hands, for fear of wetting this appendage. It is a fierce, unsocial animal, and hard to tame, but has been exhibited at the Zoological Gardens, as have all the other Sakis, four in number. The Hairy Saki ( $P$. monachus) is said by Bates to be, although not a lively animal, remarkable for its affectionate disposition when tamed, at any rate to its owner. It is, however, very delicate; and none of the Sakis are common in captivity. All are found in South America only. 


\section{THE SQUIRREL MONKEYS}

THE common Squirrel Monkey (Chrysothrix sciurea) is frequently brought to Europe, and so is a quite familiar species. It is of a very different type from any of those previously mentioned, being a very small animal, not much larger than a squirrel, with a greyish-yellow coat of short close fur, and a black patch on its flesh-coloured face. The back part of the skull is much enlarged, as in man, and, indeed, the brain of this little monkey is larger in proportion than our own. The long tail is not prehensile. This monkey is highly insectivorous in its habits, and makes a most charming pet. It is widely spread in northern South America; other species are found there, and some range to Central America, but there are only four or five in all.

\section{THE TEETEES}

ThE Teetees or Whaiapu-Sais (Callithrix) are, like the Squirrel Monkeys, softfurred animals, with non-prehensile tails; but they are not quite so small, and less remarkable in the shape of their heads, which are small and rounded. They have a wide range over South America, and, being noisy and sociable, are conspicuous in their own country; but they are very uncommon in captivity here, although feeding in much the same way as the Squirrel Monkeys and Capuchins. There are about a dozen species, but not more than half the number have been exhibited at the Zoological Gardens.

\section{THE DOUROUCOULIS}

THESE small monkeys (Nyctipithecus) bear a general resemblance to the last two groups, and are similarly not prehensile-tailed. They differ much, however, from all other monkeys, in their very large eyes and short inconspicuous ears, and in being nocturnal in habits. Their fur is grey and tan, and their faces curiously streaked with black and white. By day they sleep in little companies in hollow trees, and at night come out to feed on insects, small birds, and fruit; at this time they also indulge in howls and caterwaulings. They are found in both Central and South America, but there are only five species, and none are common in captivity; but three of them have been exhibited by the Zoological Society, and the first live specimen of the group I ever saw I met with in Calcutta, a curious place in which to find a rare animal from South America. 


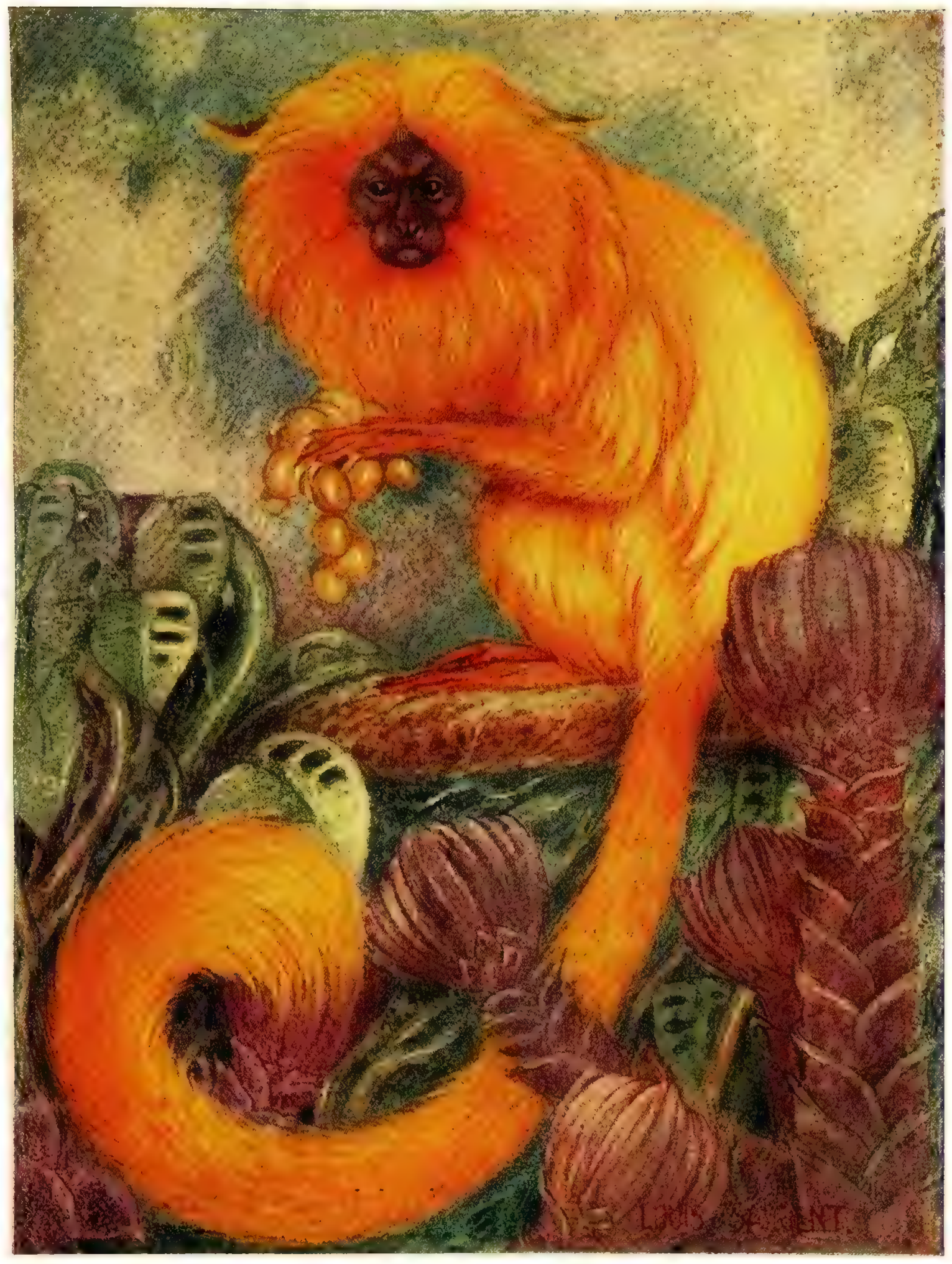

LION MARMOSET

By Louis Sargent 



\section{THE LION MARMOSET}

(Midas rosalia)

THIS little Monkey, whose extreme beauty attracts the admiration of every one, whether in the ordinary way they like Monkeys or not, is not very much larger than an English Squirrel, and resembles that animal in having the feet in the form of "paws," furnished with sharp curved claws, and with the thumb and great toe not opposable, so that they do not in the least resemble the hands-fore and hind-of ordinary monkeys, except with regard to the great toe-really small in this animal-which has the nail usual in monkeys. There are no seat-pads or cheek-pouches, and the teeth are only thirty-two in number. This is the same as that found in the Old World monkeys, but the arrangement is not quite identical, these animals having two pre-molars and three molars on each side of each jaw, whereas in the Marmosets the reverse is the case. The tail in the Lion Marmoset is long and inclined to be bushy, but is not prehensile. The ordinary name of the animal is derived from the long mane which surrounds its quaint little face, but it is also known as the Silky Tamarin, owing to the glossy texture of its fur.

The beautiful colour of the coat is common to both sexes, but varies a good deal individually, some being much more brilliant than others. I have seen one specimen which was quite orange all over, though as a rule the darker shade is confined to the under-parts.

The present species is one of the most widely-ranging of the Marmosets, being found from the Isthmus of Panama to South-eastern Brazil and New Granada. It is a forest animal, and keeps to the tops of the highest trees, where it lives in small troops. Its food consists of fruit, insects, and such small birds as it can capture. As, in captivity, it likes to have a box to retire into; it presumably sleeps 
in hollows in trees. Its cry is a rather bird-like twitter. It is not very commonly seen in confinement, but it makes a most charming pet, its chief drawback being that it is so very shy and difficult to tame, although it is said to be very intelligent.

As a general rule it has been the custom to treat these as animals requiring much warmth, but lately that well-known amateur, Mrs. Johnstone, who has been particularly successful with rare and remarkable birds, such as Birds of Paradise, has recorded that she keeps these little Monkeys with great success in a place like an aviary, with a warmed indoor compartment, and a netted outdoor one, to which they have access at will during the day. The animals here are in beautiful condition and full coat, but their home is situated in the south of England and has a southerly exposure.

Wherever such creatures are kept, it is important to bear in mind that they are to a great extent animal feeders, and to treat them accordingly. The Lion Marmoset has bred in captivity, but I do not know of any case in which the young have been reared successfully as yet. They are two in number, this being the rule among Marmosets, and forming one of the distinctions between them and the higher Monkeys.

The present species is about the largest of the Marmoset group, which, as a rule, do not exceed our Squirrel in size, and are sometimes even smaller, as in the case of the Pigmy Marmoset (Hapale pygmaa), which is not so big as a Rat, and is thus the smallest monkey known. It has also the widest range of all the American monkeys, ranging from Brazil up into Mexico, whereas most of the Marmosets, about a score in number, are found in Central and Southern America. The Pigmy is a soberly-coloured little creature, being simply light-brown, with the tail ringed with black - the latter a common marking among Marmosets, though never found in any other Monkeys.

In general form, appearance, and habits, the Marmosets are very similar, being all small animals with squirrel-like paws, and often very squirrel-like actions, for in most cases they prefer to run along and round the large branches and trunks instead of climbing about in the 
ordinary monkey fashion. Those of them which are known as Marmosets proper (Hapale), as opposed to Tamarins (Midas), are characterised by their long and protruding incisor teeth, and by the lower canines not being longer than the incisors, but the distinction is not of much importance, and some Tamarins are commonly called Marmosets. The Lion "Marmoset," for instance, is a "Tamarin."

The commonest of them in captivity are the Brazilian White-eared and Black-eared Marmosets (Hapale jacchus and $H$. penicillata), which are of a sort of tabby-grey colour, with long tufts in front of the ears, white in the former and black in the latter species. There is also a white spot on the forehead.

These miniature Monkeys are very freely imported, but it is to be feared that their lives in captivity are too often shortened by their being treated too exclusively as fruit-eaters, whereas, as above remarked, they need plenty of animal food, and no doubt if this were duly supplied, they would not be found to be so delicate as is commonly supposed: Young of the common Marmoset have been successfully reared, and it has been noticed that the male takes his turn at carrying them as well as the female. Indeed, the gentle, affectionate nature of these little things is one of their greatest charms, and they do not display the ill-conditioned spitefulness of ordinary Monkeys, though they will bite sharply enough on occasion.

The Pinché (Midas oedipus) is a fairly common Marmoset, remarkable for its crest of long snow-white hair; the under-parts are also white, and the upper surface brown.

The Red-handed Tamarin (Midas rufimanus) is black, with tancoloured paws; and the Black Tamarin (M. ursulus), has black paws. All these three are fairly familiar in captivity, though, like the Lion Marmoset, very scarce indeed compared to the ordinary grey kinds.

Several rarer ones have, however, been exhibited at the Zoological Gardens, including the Pigmy Marmoset above mentioned. The rest are the Golden-headed Marmoset (Midas chrysomelas), which is very like the Lion Marmoset, only black instead of golden-yellow, except on the head and paws. Very possibly this was the original form, and the 
yellow animal is a variety which has become a permanent race, beginning as a sport, like the yellow variety of the common Rhesus Monkey. Geoffroy's Marmoset (Midas geoffroyi) of Panama is somewhat like the Pinché, but has merely a white spot on top of the head, not a long bushy crest; and the Moustached Tamarin (M. mystax) is much like the Black Tamarin, but has white fur on the lips. Then there are two beautiful white species, the Silky and the Black-tailed Marmosets (Hapale chrysoleucus and $H$. melanura), the latter with a black tail, and the former with a brown one; these beautiful little things almost rival the Lion Marmoset in beauty, but have not its ornamental mane.

The most remarkable of all the Marmosets has, however, never been exhibited here, and has, indeed, only been described in 1907. This is the Emperor Marmoset (Midas imperator), in which the male is decorated with a long white moustache, fiercely' curled at the ends, which gives him a most absurd appearance, especially as the Marmosets are, except for their pretty little faces, much less human in appearance than any other of the Monkey tribe. 


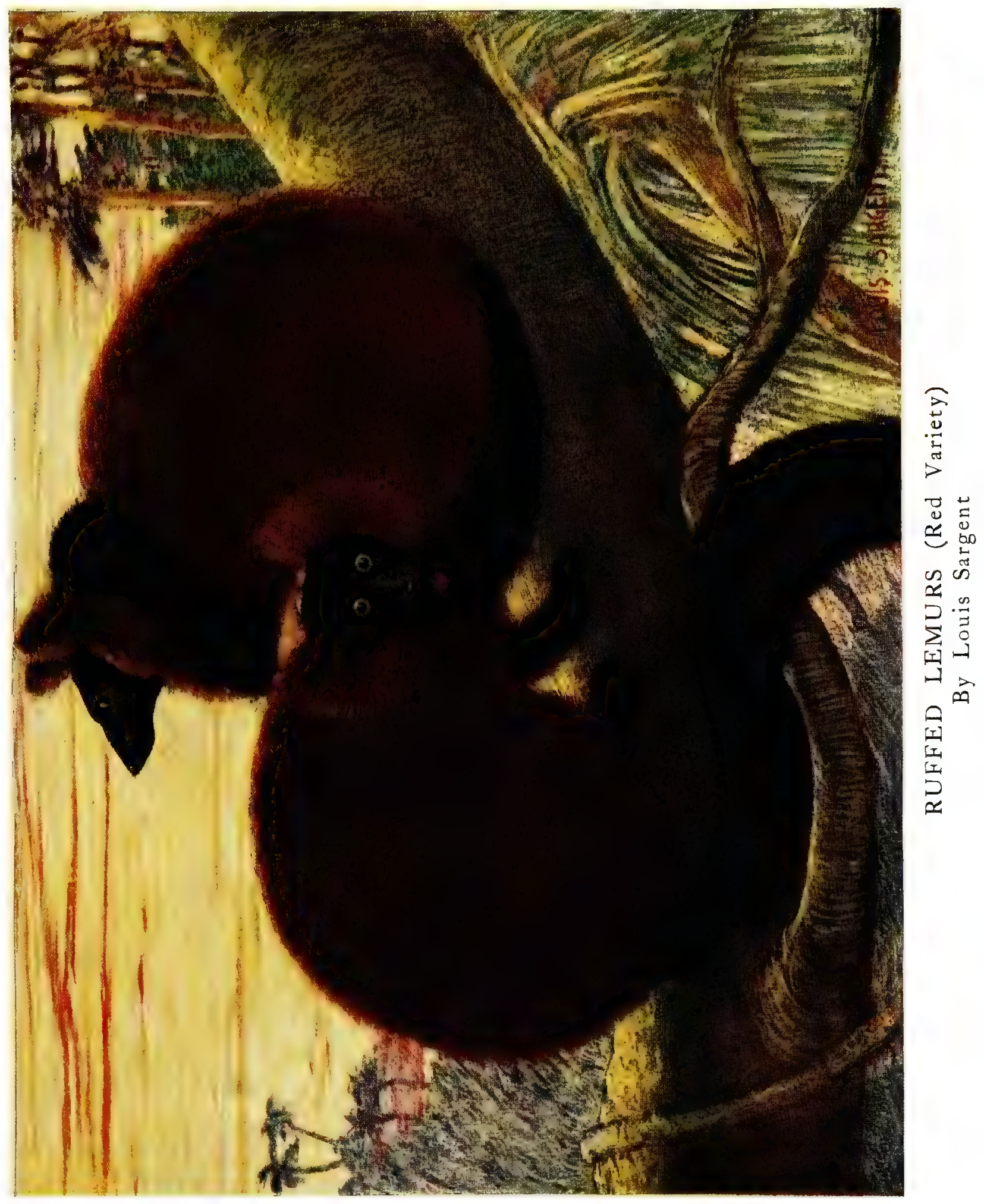





\section{THE RUFFED LEMUR}

\section{(Lemur varius)}

This beautiful animal is the largest of the typical Lemurs, and is exceeded in size by but few species in the family to which it belongs; it about equals a terrier in dimensions. In the face it presents no human semblance whatsoever, the long muzzle being much like that of a fox; and the play of feature, so usual in monkeys, being quite absent.

The teeth are remarkable for the forward projection and narrowness of the incisors of the lower jaw, and for the fact that the canines are very similar and lie on each side of them, though there is an erect tusk-like tooth in this jaw, in the form of the first grinder, which is sharp and pointed. In the upper jaw the canines have the usual tusklike form and downward direction.

The paws, however, are more like human hands than those of many monkeys, the thumb being large and well developed; the feet are similar in structure, with a large opposable great toe; all the fingers and toes have flat nails, except the second toe, which has a sharp curved claw, with which the animal scratches itself.

The limbs are also particularly human in that the fore are distinctly shorter than the hind; this renders the Lemur's gait on all fours less agile than a monkey's, especially as it places the whole palm on the ground as well as the sole; on the trees; however, it bounds about with great agility. The tail is often carried raised and curved, so as to look like a note of interrogation; when the beast is at rest it wraps its tail round its body.

The habits of the typical Lemurs are very similar; they are nearly all tree-animals, and they live upon much the same food as most monkeys-leaves, fruit, and any small creatures they can capture. They are sociable in habits, and are said to be very noisy, the Ruffed species in particular giving vent to harsh roars, chiefly in the morning and evening; they are not, however, nocturnal, unlike most of the Lemur tribe. 
The young Lemur or Lemurs-for there are often twins-are carried by the mother for some time, like a young monkey, but not quite in the same way. The little monkey clings lengthways to its mother's chest, while the infant Lemur lies across her stomach, passing its long tail round her waist behind and wrapping the end round its own neck, thus fairly tying itself to her. When older it often rides on her back, as monkeys do under similar circumstances.

The Ruffed Lemur is remarkable among its relatives not only for its size, but for the length of its fur, and its remarkable variety of colouring, in which it is not exceeded by any animal, and equalled only by few. The types usually seen are the black-and-white and the red; the latter, however, always has some black on the face and limbs and some white on the back of the neck. Intermediate specimens between these types also occur.

This species is found in the north-east of Madagascar; it is not so common in captivity as some of the smaller kinds, and in confinement does not seem so lively, nor does it breed in that condition. Its relations are more readily reconciled to captive life, and some of them breed more freely than any of the monkeys, especially the Black Lemurs (Lemur macaco). In this the male only is black, the female being brown with white whiskers; and he is black from birth, unlike many animals in which this colour is confined to the male sex. The note of this animal is a grunt.

A very commonly imported Lemur is the Ring-tailed species (Lemur catta). This is very distinct in appearance and habits. In size it is about equal to a Cat, and its fur is short and close, and very constant in colour, which is the same in both sexes. The general hue is silver-grey, with the face and feet white and a black patch round: each eye; the tail is white, with numerous rings of black. This very beautiful animal comes from the Betsileo district of Madagascar, and, unlike all other Lemurine animals, is usually found away from trees, frequenting rocks, which it traverses with great agility. All the typical Lemurs are confined to Madagascar and the Comoro Islands. 


\section{THE SIFAKAS}

The Sifakas (Propithecus), of which there are three species, all very variable in colour, and all confined to Madagascar, resemble the true Lemurs in general form and size, but have shorter muzzles, more like a Cat's than a Fox's. They are tree animals for the most part, but when they come to the ground do not go on all fours, but jump along on their hind feet. They are more purely vegetarian than any others of the Lemur family, and are very delicate in captivity. Only one kind, the Diademed Sifaka ( $P$. diadema) has been exhibited at Regent's Park, and this quite recently; it only lived a few days. The Avahi (Avahis laniger), a closely allied animal of small size and brown colour, has, however, been several times in that collection. Another relative of the Sifakas is the Endrina or Babakoto (Indris brevicaudatus), the largest of all Lemurs, and remarkable in having but a rudimentary stump of a tail. It is pied like the Ruffed Lemur, but is also a very variable animal. It is well known in Madagascar from the dismal howls it constantly utters, and is reverenced by the natives, but seems never to have been brought to Europe alive.

\section{THE MOUSE LEMURS}

The Mouse Lemurs (Chirogale), Dwarf Lemurs (Microcebus), and Fat-tailed Lemurs (Opolemur) are all Madagascar animals of small size and nocturnal habits. Several sleep during the dry season, having previously got very fat, especially about the root of the tail. They are usually about as big as Rats, and are inhabitants of the tree-tops, where they build nests and feed on fruit and insects ; they are marvellously active, jumping about as quickly as birds. In colour they are brown or grey.

\section{THE GALAGOS}

THE Galagos (Galago) are the only large group of Lemurs found outside Madagascar; they are confined to Africa, but widely spread there. They vary in siza from that of a Cat to that of a Rat, and have soft grey or brown fur, long bushy tails, and large eyes. Their ears, however, are their most remarkable peculiarity, being capable of folding up till they are hardly noticeable, although usually large and conspicuous; in this point the Galagos are unique among beasts. They are nocturnal and extremely active, bounding for yards on their hind feet. They have a strong appetite for animal food, and do well in captivity, so that some are generally on view in Zoological collections. 


\section{THE SLOW LEMURS}

$\mathrm{T}_{\mathrm{HE}}$ few species of this group are also found outside Madagascar; the Potto and Awantibo (Perodicticus potto and $P$. calabarensis) in West Africa, and the Slow Loris (Nycticebus tardigradus) in Eastern Asia. They are slow-moving, omnivorous, nocturnal animals, about as big as Guinea-pigs, and much like miniature Bears in shape; the Slow Loris has no tail, and the other two very short ones. In these African forms, too, the forefinger is reduced to a mere stump. The Slender Loris (Loris gracilis) of South India and Ceylon, is a little tailless creature about as big as a Rat, with huge eyes and peculiarly slender limbs, painfully like those of a human being when wasted by disease or privation. All have been frequently kept in captivity.

Two Lemur-like animals, the Tarsier and the Aye-aye, are so distinct from all the rest, that each is put in a family of its own.

\section{THE TARSIER}

THIS extraordinary little animal (Tarsius spectrum) is found in the East Indies from Sumatra to the Philippines, and is nocturnal and insectivorous. It is barely as big as a Rat, with large eyes and ears and a small pointed snout. Its tail is long and bare, though tufted at the end, and its body-fur thick. The feet are peculiarly long from hock to toes, and the tips of these and the fingers are expanded as in Tree-frogs; like these creatures, also, the Tarsier hops about the trees by means of its powerful hind-legs. It seems never to have been brought to Europe alive.

\section{THE AYE-AYE}

THE Aye-aye (Chiromys madagascariensis) is the most remarkable in appearance of all its tribe, and would certainly not be taken for a Lemur at first sight. It is as big as a Cat, dark-brown in colour, with a long bushy tail, and all its fingers and toes are clawed, except the great toe," which has a nail. The middle finger of the hand is as thin as a wire, and the creature uses this to clean itself with, ard also for a pick and probe in seeking wood-boring grubs. It gnaws down to the tunnels of these with its powerful teeth, which are just like those of rodents, the incisors being only two in each jaw, enamel-faced and continually growing, while, as in rodents, there are no canines. The first set of teeth, however, are more like those of other Lemurs. Besides insects, the Aye-aye feeds on fruit. It is a nocturnal animal, regarded with superstitious fear by the inhabitants of Madagascar, where alone it is found; but nevertheless a good many specimens have reached Europe, especially of late years, and several have been exhibited in the London, Zoological Gardens, where the habits of this strange creature were carefully studied by the late Mr. A. Bartlett. 


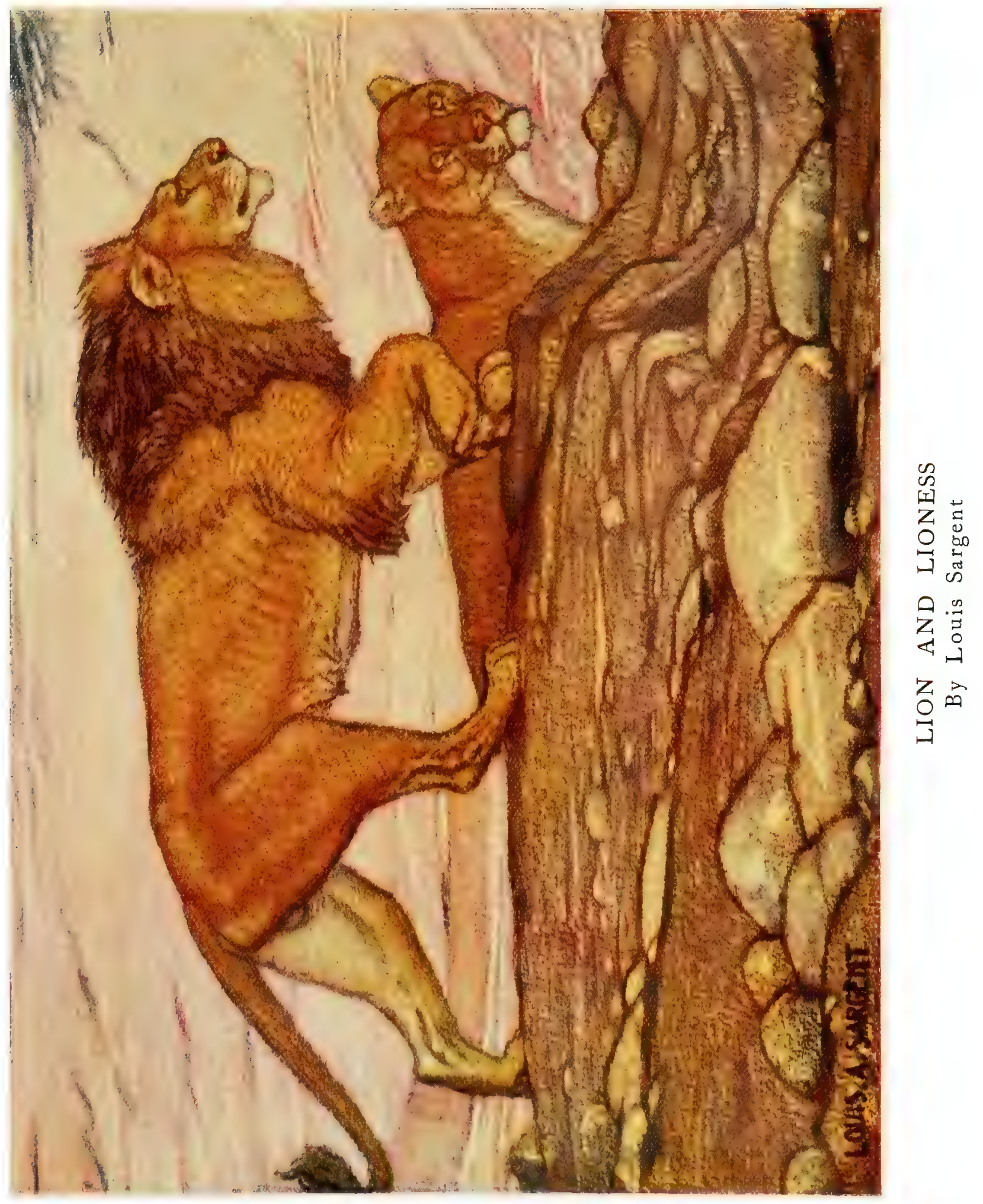





\section{THE LION}

(Felis leo)

THE Lion is the acknowledged king, not only of the Cat family and the order of carnivora, but of the beasts at large, and it cannot be denied that he deserves his position on account of his imposing presence and the thunderous majesty of his voice.

The mane, the special insignia of the feline monarch, is, however, as every one knows, absent in his consort, and is not developed in the young male before his third year; while it varies much in colour and development, like the beard in man, being mostly black in some specimens and all yellow in others, while it may be absent altogether. The variation is purely individual, for a lion with a fine long black mane may be own brother to an animal with a scanty yellow one.

The colour of the coat is also rather variable, some specimens having more of the reddish or yellowish tinge; and others being rather greyer; but extreme variations, like black and white, seem to be unknown in the Lion.

The form and expression of the face are also noticeably different in different specimens, some having a much nobler aspect than others. The black tuft at the end of the tail is a most constant point; it often conceals a short claw-like horny appendage, which used in ancient times to be considered the instrument by which the animal goaded himself into frenzy when enraged. As a matter of fact, it is too small to be of any importance, and a similar tail-claw is found in such mild creatures as some of the smaller Kangaroos or Wallabies.

Lion cubs, which are born, unlike kittens, with their eyes open, are closely but indistinctly spotted, and traces of this marking often last throughout life on the legs and under-parts of some specimens, especially Lionesses. The pupil of the eye in the Lion, as in all the great Cats, is always circular, not contracting slit-wise as in the common Cat. In 
all essential details of structure, however, the King of Beasts agrees with this familiar creature, as he does also in most of his habits and attitudes. In connection with this, it may be mentioned that while the Lion often, like the Cat, tucks in his fore-paws when lying down, he often also extends them in front like a Dog, and thus any adverse criticism of sculptured lions represented in this, undoubtedly the most majestic, position, is quite misplaced. The Lion differs from most Cats in not climbing trees, though it is possible that young and light individuals might not find this feat impracticable.

Although characteristically an African animal, the Lion also ranges through Western Asia into North-west India, where a few specimens linger in the Gir Forest in Kattywar. The idea that the Indian Lion is maneless is, by the way, quite an erroneous one. The range of the Lion has been contracting during all the time which the animal has been under human observation - and few wild creatures can have been observed more thoroughly. In Herodotus' time, between 400 and 500 B.C., Lions inhabited Europe, being found in Thrace, but by the beginning of the Christian era they had disappeared. There is evidence that they once ranged into Central India, and in Africa, their main home, they have now become much reduced in numbers both in the north and south of the continent.

They are naturally absent from the damp dark forests of the equatorial region, for the Lion is generally an animal of open dry country, although he likes cover, such as reeds, bushes, or long grass. Like most Cats, he is nocturnal, and is bold and dangerous by night, though little to be feared by day. He captures his prey by surprise, and, seizing it with his powerful claws, kills it by a bite or two on the neck or head. Sometimes the death-stroke may, indeed, be dealt with the paw, as there is a case on record of a man having been killed inside a tent by a lion which thrust in its fore-leg for the purpose, and then noiselessly hooked out his victim. Human beings, however, are not the normal prey of the Lion, which generally feeds on large wild animals, such as the larger Antelopes and Zebras, or on domestic cattle. When the animal does take to man-eating, he is a terrible scourge, and is apparently 
worse than the Tiger, displaying greater boldness. The case of the two man-eaters of Tsavo, in East Africa, who devoured more than a score of human beings before being themselves accounted for, is fresh in the memory, and has been the subject of a most interesting work.

It is therefore obvious that the terrors of the Lion have not been exaggerated by early writers, but that where he has come into contact. with well-armed and resolute natives or with Europeans, his courage has naturally suffered by the elimination of the fiercer individuals, a result certain to occur with all such dangerous animals.

The Lion, in spite of the ancient ideas about his magnanimity, is. quite willing to sink his dignity and eat dead and even putrid meat, if he finds a convenient carcase; the Zebra is said to be his favourite food. His own kill he often conceals, and watches it to keep off carrion-animals. In feeding, he begins by disembowelling the prey and burying its entrails; he then eats the internal organs and the flesh from the hind-quarters. He hunts for his Lioness, to whom he is much attached, when they have a family, and indeed is a remarkably sociable animal, unlike most wild animals of this family; troops of as many as a dozen or even a score of Lions have been seen. When these roar in concert, the effect is indescribably grand, if rather terrifying; and when an animal is attacked by several Lions at once, its end is very painful, as all fall upon it without system, and mangle it terribly.

The male animals naturally often fight for a mate, and in such a. case the Lioness, as appears usually to happen with her sex amonganimals, calmly awaits the victory of the strongest. She has usually two or three cubs at a birth, and goes with young only four months. Many cubs appear to die during the period of teething, the males. especially. Otherwise there are few causes for Lion mortality; some, however, must perish from conflicts with each other, and others meet death on the horns of some of their more formidable prey, such as the Oryx Antelopes, while they are said to fear the Spotted Hunting$\operatorname{dog}$ (Lycaon pictus) so much that an imitation of its cry will keep. them at a distance. Old Lions have been found living on Mice and 
Rats, and even devouring grass to stay their hunger, so that the end of the King of Beasts, if it comes naturally, must be a sad one.

In captivity the Lion thrives well, and breeds freely; in fact, if the beast were sufficiently in demand, it would have been domesticated by this time, and as it is, many of the finest specimens shown in menageries have been tame-bred. Such an one was Hannibal II. of the Clifton Zoological Gardens, a magnificent black-maned animal, and certainly the finest Lion I ever saw. Captive Lions in Europe, at any rate, grow finer manes than wild ones, and also assume a fringe of long hair along the under-parts, whereas the wild animal has only a bunch behind the arm-pit.

Many accounts show that the Lion in captivity is susceptible of much attachment, and has a better disposition than most of the Cats, though of course it is unwise to rely too much on such an animal; and the sad fate which overtakes so many of the "tamers" is notorious, though the nature of their exhibitions is certainly such as to afford some excuse for the unfortunate animals compelled to take part in them. 


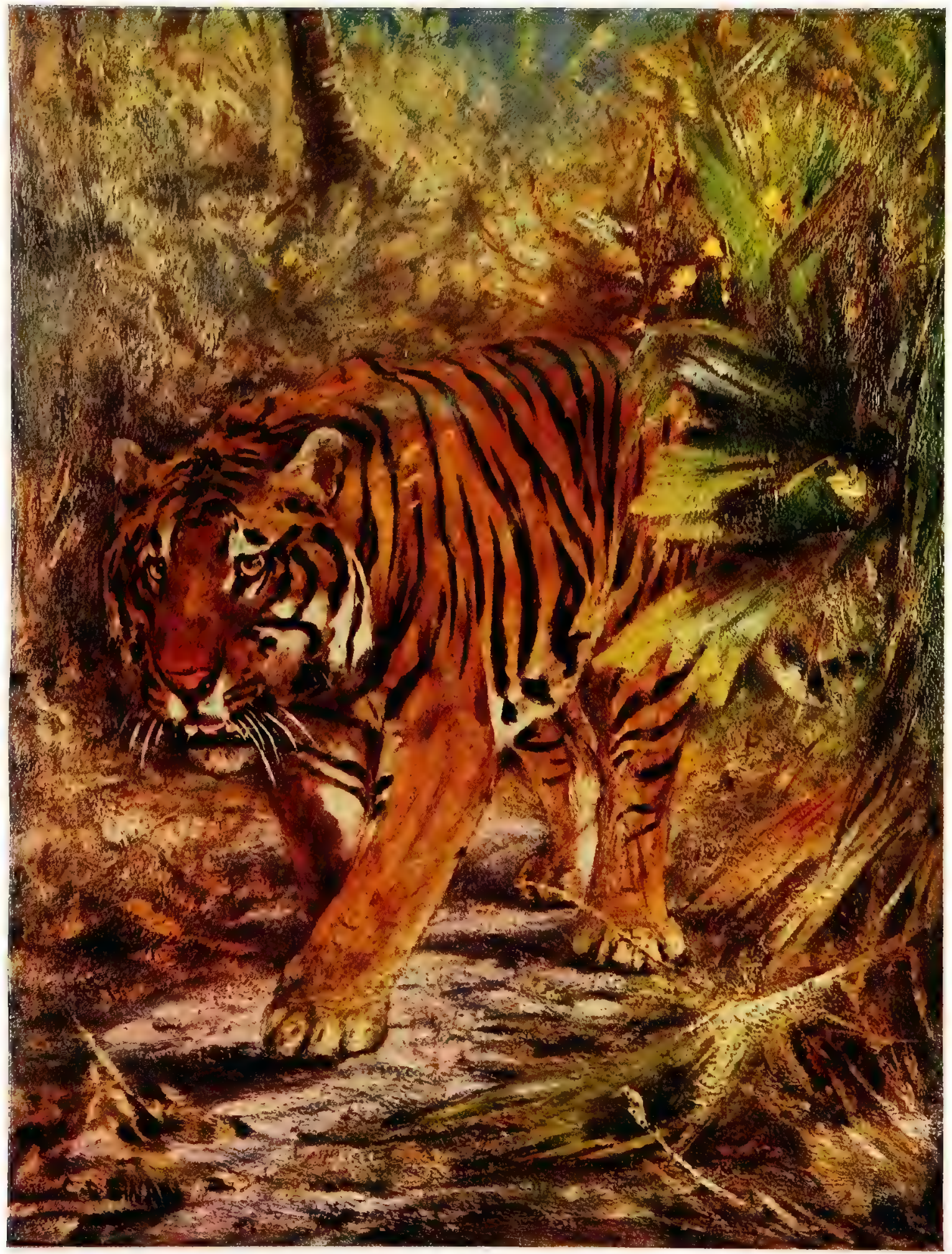

TIGER

By C. E. Swan 



\section{THE TIGER}

(Felis tigris)

THE Tiger is not only the most brilliantly coloured of the Cats, but the largest and most powerful; for he is more evenly developed than the Lion, whose hind-quarters are less massive than his fore-parts, and he also attains to a larger size and greater weight. A fine Tiger measures about ten feet in total length, and few exceed this measurement.

The Tigress is very similar to her mate in general appearance, but is rather smaller and less stoutly built, especially about the head, and she lacks the long hair which forms the whiskers at the side of the face in the old male.

Young cubs are striped just like their parents, so that stripes form the characteristic livery of the beast under all circumstances.

There is, however, much individual variation in the development of these markings; it would hardly be an exaggeration to say that the fine animal in the illustration-the best Indian male in the London Zoological Gardens at the time-has twice as many stripes as either of two Nepal specimens also in the collection. In some Tigers, too, the individual stripes are to a great extent double, and the variation in details of pattern is almost endless.

Extreme varieties, however, are rare in the Tiger; a black one has once been seen, but though it was found dead its skin was not preserved. White specimens sometimes occur, and I have myself seen two skins of such; one, which was exhibited some years ago at a scientific meeting of our Zoological Society, showed the characteristic stripes in a pale fawn tint, while the other, which was fished, for my inspection, out of the pickling-tub in which it was being cured, in Calcutta, appeared to have no stripes at all on the hair, though they were to be seen on the underlying skin; much like the dark spots so common on the under-parts of white Dogs. 
Tigers inhabiting climates with a cold winter assume a thick long coat at that time of year; this fur is, however, less brilliant in colour, and naturally does not show the stripes so well. In summer, judging from the Zoological Society's pair, the Siberian Tiger is indistinguishable from the Indian animal.

The fact that Tigers inhabit Siberia at all comes as a surprise to most people; but as a matter of fact the Tiger is essentially Asiatic, not merely Indian. $\mathrm{He}$ is found in the West on the southern shores of the Caspian, the ancient Hyrcania, and he extends through Persia and Central Asia, India and Burma, up to Saghalien in one direction and Java in the other, so that he must be able to bear great extremes of climate. In India his distribution is curious; he has never reached Ceylon, and he does not range high up in the Himalayas, in spite of his power of enduring cold. He has no aversion to wet lowlying localities, and, indeed, is never found far away from any water. He wallows in hot weather, and will swim long distances.

As ancient classical literature chiefly knows the Tiger as a Hyrcanian animal, and in consideration of the evidence afforded by the beast's distribution to-day, it would seem that he is a comparatively recent immigrant into India, or at any rate that he was formerly far less common there. The recession of the Lion in that country may have. been caused by the invasion of this rival, for the two animals would certainly not live in peace side by side.

One often reads of "Tigers" in Africa and America; but in this: case the name is wrongly applied. In South Africa the Leopard is commonly called Tiger, while the Tiger of America is really the Jaguar.

The Tiger is, though it hardly ever climbs trees, a forest animal, and, like most Cats, nocturnal in habit and generally solitary, though a pair may be found together, or a Tigress with cubs. His food, like: that of the Lion, consists of large animals as a rule, but in case of need he will devour almost anything living, down to frogs and locusts, and has no aversion to making a meal of carrion.

Like the Lion, he attacks the neck of his prey, and begins his meal on the carcase at the hind-quarters. In the ordinary way he does not: 


\section{THE TIGER}

attack man, and is not feared by the forest-living primitive tribes of India; but, as is well known, Tigers often take to man-eating, and such an animal becomes a terrible scourge.

The ordinary game-killing Tiger is not only harmless, but a beneficial animal, as the Deer, wild Pigs, Nilghai, \&c., on which he preys, are very destructive to the crops of the native farmers. But when he takes to feeding on cattle he becomes a great nuisance himself, and is always liable to end as a man-eater, owing to the likelihood of collisions with the aggrieved owners of his prey. There is, however, a case, recorded by Sanderson, of a notorious cattle-killer which haunted a district for twenty years, and during that time only killed one man; this unfortunate individual had got in the tiger's way during a beat, and it was generally felt that his death was due to misadventure rather than malignity on the part of the animal.

The amount which such an animal may cost a district may, however, be estimated when one considers that a Tiger will kill two Bullocks a week, and naturally does not choose the worst. Exceptionally, a young Elephant may fall a prey to the tiger, and there is even a case known in which an adult was killed by the great Cat, though it did not die at the time, but some days afterwards, having been terribly lacerated along the back-bone. One original Tiger has even been known to specialise as a Bear-eater, and cases of Tiger cannibalism have occurred; indeed, the Tiger is not a "family man," like the Lion, and cannot be trusted with his own cubs. He is not only much less sociable than the Lion, but also much less noisy, though his roar, when heard, can hardly be distinguished from that of his rival.

The Tiger is a very esteemed sporting animal in India, and, except in the case of a man-eater, any unsportsmanlike method of destroying it is indignantly scouted by Europeans. It has, indeed, been suggested that the rewards now paid by the Government for the destruction of Tigers should be done away with, except, of course, for man-eaters. Tigers are seldom pursued on foot, as Lions are in Africa; the sportsman more usually rides on an Elephant, or sits upon a platform or "machan" constructed in a tree near the animal's 
last victim, or a live bait-usually a Bullock or young Buffalo-tied up to entice it, and waits for a chance of a shot.

The skin, as every one knows, is a valued fur for rugs, but is not nearly so expensive as the Lion's, except in the case of the heavilyfurred Siberian skins.

The Tiger has long been a familiar exhibit in menageries, but is scarcer and more expensive than the Lion. In my time, a good adult Tiger was worth between $£ 30$ and $£ 40$ even in Calcutta.

This is due to the fact that the Tiger does not breed at all freely in captivity, even in its own country, so that the supply has to be obtained by capturing the wild animals, preferably when young.

The Tiger has, however, on more than one occasion produced hybrids with the Lion in menageries; these animals are large and fine, but inferior in beauty to the parent species, the males having but a short mane, and the coat being but scantily striped. The captive Tiger, though to some extent amenable to kindness, is less reliable than the Lion in its temper, though not so treacherous as the Leopard. 


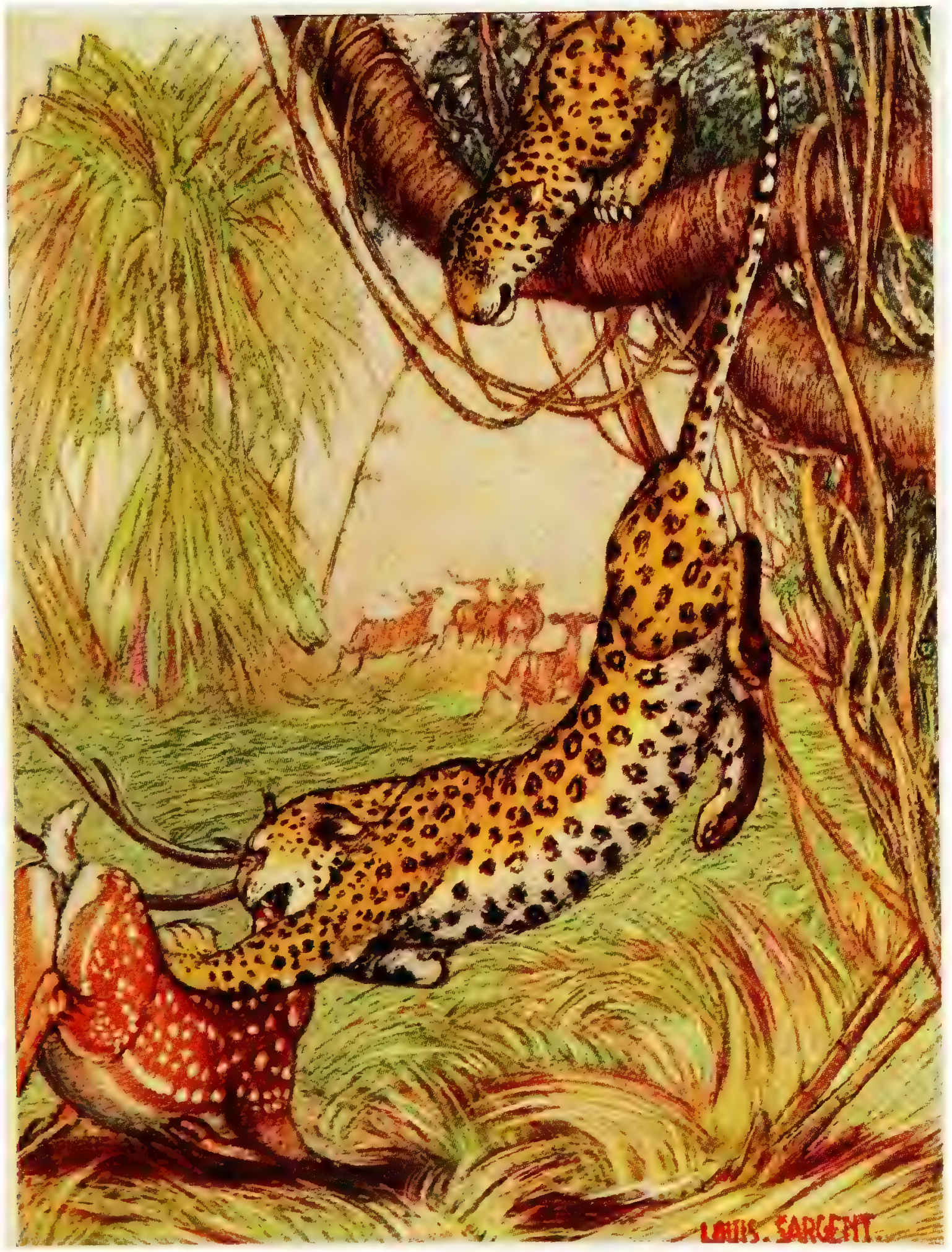

LEOPARDS AND SPOTTED DEER

By Louis Sargent 



\section{THE LEOPARD}

(Felis pardus)

THE Leopard is the third largest of the Old World Cats, but it is a remarkably variable animal, so that it was long believed, and probably is still by many people, that the big spotted Cats, at any rate in India, belonged to two species, the Leopard and the Panther.

It is now pretty well established, however, that "Panther" is only a courtesy title applied to a big finely-developed Leopard, approaching a Tigress in build, and nearly equalling a small one in size, such animals being naturally more inclined to attack large prey than the smaller and more cat-like individuals which are the typical Leopards. A big "Panther" will measure eight feet from nose to tail-tip, whereas a small "Leopard" may be as much as a yard less in length.

In addition to showing such great differences in size, Leopards show much variety in colour, though their proverbial inability to change their spots still holds good as a rule. Thus, I have seen a skin in which the black colour of the spots was replaced by fawn, and the well-known Black Leopards owe their colour to a darkening of the ground-tint, on which the spots can still be seen in certain lights. These Black Leopards are not uncommon in certain localities, especially in the Malay Peninsula; they are mere "freaks," as one may occur in the same litter as a spotted one, but a pair of Black Leopards in captivity will produce black cubs.

The Leopard has much the widest range of any Old World Cat, being found over Africa generally, including the heavy forests of the west, where the Lion does not venture, and over a large part of Asia also, from Manchuria to Ceylon (where it is called the Cheetah), and from Asia Minor to Sumatra. It ascends the Himalayas to a much greater height than the Tiger. Leopards from colder climates, at any 
rate the West Asiatic race, have paler colouring and thicker fur than the tropical type, thus somewhat approaching the Ounce; and African Leopards have smaller and closer spots than Asiatic ones, many more of the spots being solid instead of rosette-like. Black Leopards are very rare in Africa, and when they occur seem to owe their hue to the confluence of the spots rather than the darkening of the groundcolour.

The wide distribution of the Leopard can easily be explained by his great adàptability; for he can exist and pick up a living where a Lion or Tiger would starve, and can and does live alongside these beasts. He frequents either rocks or forest, and is a fine climber, like an ordinary Cat; his variegated coat is well adapted for concealment in the woods, and at a distance, when seen in the open, is not more conspicuous than the Lion's is, as it then appears uniform; he is indifferent to water, and can do without it for days. As to food, no creature, from small birds to Bullocks, is safe from him; he is a deadly enemy of the monkey tribe, and has a peculiar fancy for the flesh of Dogs, which he will venture to steal even from a verandah, for he is a much bolder animal than the Tiger. This attribute makes him far more terrible when he takes to killing human beings, which occasionally happens; indeed, almost the worst man-eater on record was the celebrated Leopard of Seeonee in India, which killed a couple of hundred people before it was brought to book itself.

It may be mentioned here that the name "Panther," which is of genuine classical Greek derivation, means "the hunter of everything," and shows that the ancients were well acquainted with this audacious plunderer. Being much commoner than the Tiger, and, owing to his cunning and versatility, remarkably difficult to circumvent by sportsmen, the Leopard; in India at all events, is regarded more as vermin than as a game animal. He is generally solitary in habits, and has a most peculiar call, very like the sound produced by cutting wood with a coarse saw.

In eating his prey, it is observed that a Leopard begins, unlike the Lion and Tiger, at the fore instead of the hind quarter, and by this 
his "kill" may be easily identified. He often prudently takes the remains of a partly eaten carcase up a tree, and thus is less likely to be robbed of food than are the Lion and Tiger.

Leopard cubs are not so distinctly spotted as the old animals; they are often taken and reared, but as pets they are very objectionable, being peculiarly treacherous and dangerous as a rule. The animal is, of course, a well-known exhibit in Zoological Gardens; it breeds fairly well in captivity, and is so easily procured in India that in my time an adult specimen was not worth more than three or four pounds in Calcutta. The Black variety is, of course, always comparatively scarce and expensive, and it is a curious fact that individuals of this colour almost invariably show a more savage temper than the spotted ones. Of several specimens I have seen, all bore out this commonly received opinion except perhaps one; but this I only saw once.

That different colours accompany differences of disposition and constitution is well known to every one who has to do with Horses, and it would be interesting if this correlation were to be worked out in connection with all animals which present well-marked colour variations.

The greater ferocity of the Black Leopard may account for its comparative scarcity, since an undue degree of this quality in any animal is liable to lead it into conflicts which may prove fatal, even in the case of such a powerful and active creature as is the Leopard. An interesting exception to the general untrustworthiness of the captive Leopard's disposition was furnished by a West African individual kept many years ago at Coomassie, which was allowed to go about loose, and even to associate with children, along with whom he would stand looking out of a window. It is even recorded that on one occasion his playfellows pulled him down by the tail, as he was in their way, so that he must have been as gentle as large dogs so often are in juvenile company. This very amiable animal, however, did not long survive after arrival in England, and it is possible that his disposition might have become less pleasant when he grew older. 
A reward is paid by the Indian Government for the destruction of Leopards, and as the skin is also in demand for rugs, \&c., there is considerable inducement for the destruction of the animal on the part of native huntsmen, who kill more of these animals than are brought to book by. Europeans. 


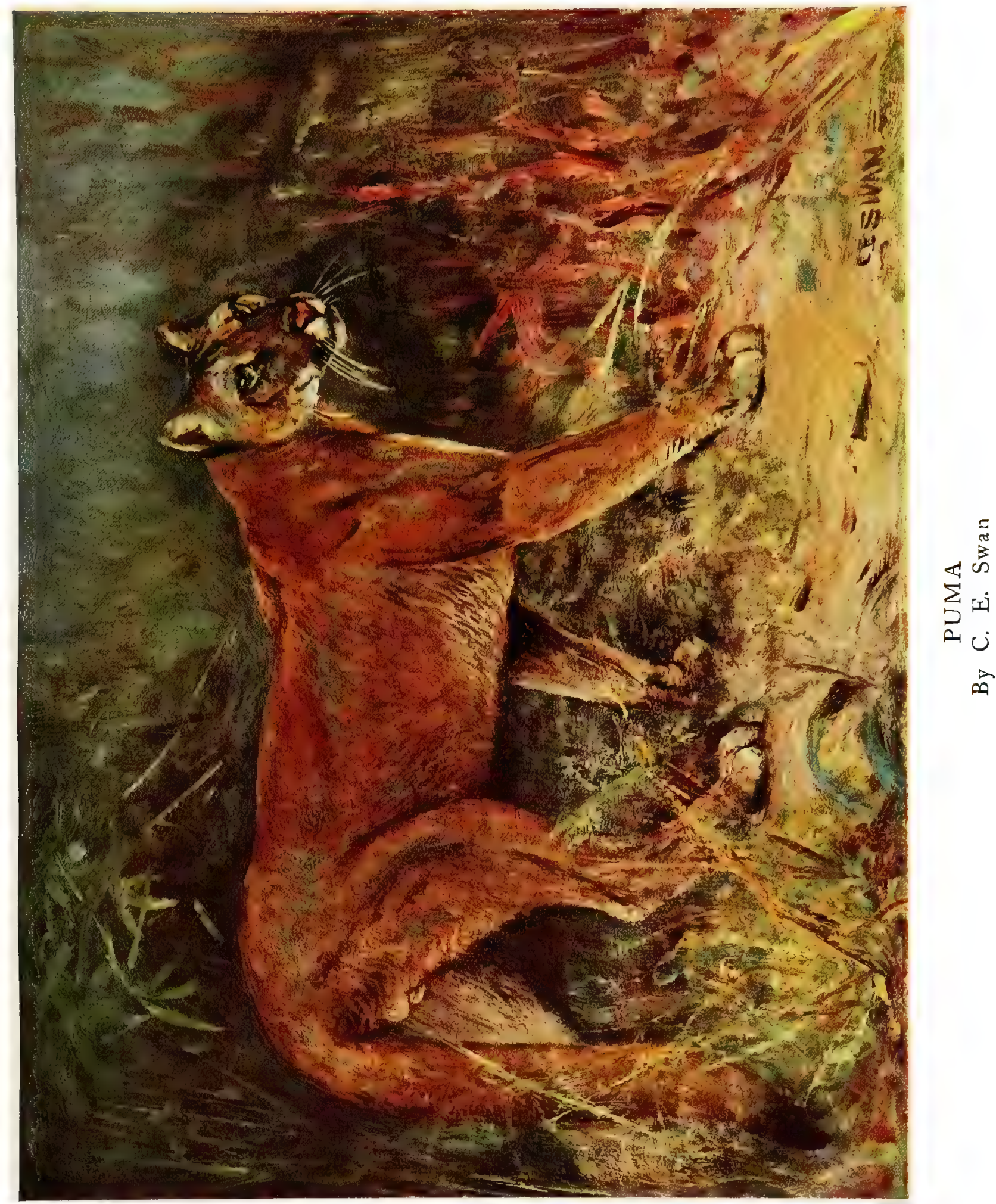





\section{THE PUMA}

\section{(Felis concolor)}

The Puma, the only other large self-coloured Cat besides the Lion, usurps the name of that animal in many parts of America, to which continent, like the Jaguar, it is restricted. It is an animal of many aliases, being sometimes known-in North America at any rate-as the Cougar, and more frequently as the "Painter," a corruption of "Panther." Although, of course, quite a distinct animal from the Panther or Leopard, it is better compared with that animal than with the Lion, which it only resembles in colour, whereas in size, form, and general habits its resemblance to the Leopard is very great.

The average length of the Puma is that of an ordinary-sized Leopard, but there appears to be at least one individual on record as big as a Lioness. On the whole, however, Pumas do not vary in size so much as Leopards do, nor are they so diversified in colour. Their range of colour-variation is much like that of the Lion, some individuals being redder and others greyer, while absolutely black and white varieties seem to be unknown. In Patagonia the Pumas are particularly grey, though a reddish variety, with a shorter tail, is also found there. There is no sex-difference in Pumas, but the young cubs are very unlike the old animals, being strongly spotted with black, and having black rings on the tail-which seems to point to the fact that the Puma was once a spotted animal in a previous stage of its evolution.

The Puma has such a wide range in the New. World that it may well be considered the characteristic beast of that continent, for it ranges from Canada in the north right down to the extremity of South America. It is not at all particular about climate or situation, living on mountaintops near the snow-line, in forests, or on open plains; it is an active climber among either trees or rocks, and will make its lair in a cave or a swamp, or under the giant grasses of the Pampas. On the whole, 
though a much more widely-ranging animal than the Jaguar, it is perhaps less attached to forests and water-side haunts than that animal.

It preys on a great variety of creatures, attacking, like the Leopard, anything it is quick enough to capture and powerful enough to kill, and even adult Horses do not always escape it, though it is more particularly destructive to colts, as well as to calves. It is a deadly foe of the Rhea, or American "Ostrich," and of the Guanaco or wild Llama, while that curious social burrowing rodent, the Vizcacha, is keenly hunted by it. When attacking domestic animals, it gives the preference to. Horses, at any rate when young, but in default of horseflesh, it can very well. put up. with mutton. To. the unfortunate Sheep it is a most deadly foe, for it is a bloodthirsty creature, and; if it can get access to a fold, will think nothing of killing half-a-hundred sheep in a night. $\therefore$ In North America it is a merciless enemy. of the Deer, and even its own relative, the Lynx, falls a victim to it at times. It is also reported to be on bad terms with the Jaguar, which is sometimes found in the same localities, and, what is much more remark: able, to get the better of that animal, in the fights which naturally ensue. It is true that the Jaguar is much stronger and heavier, but: the Puma has the advantage in lightness and agility, and by virtue: of these qualities it is said also to grievously annoy the huge Grizzly Bear in the northern parts of its home.

With all these awe-inspiring attributes, it is curious that the Puma. should be a kittenish and playful creature, always ready for a game, and that it is hardly to be regarded as a serious foe to man. A regular man-eater seems to be an unknown creature among Pumas, nor are they nearly so dangerous when brought to bay as Leopards are; though there are not wanting instances of men being injured by them with or without provocation. They will also follow people in a way which is, to say the least of it, uncomfortable, though Mr. W: H. Hudson regards this interest as merely friendly curiosity, and states that the Gauchos consider the Puma as man's only friend among the wild animals. He even cites instances in which a Puma has not only. refrained from attacking human beings, whom circumstances had placed 
in its power, but even defended them against other wild animals. The fact that the Puma in captivity is undoubtedly less dangerous and more tractable than almost any other large Cat, goes a good way towards substantiating these ideas as to its natural disposition towards humanity, with whom it may have some instinctive inclination to friendship, such as; in the Dog, has made the latter animal domesticable. A similar case would be the natural attachment which that curious little animal, the South African Meerkat.(Suricata tetradactyla) shows, when tamed, to the Dog itself.

In spite of this amiability-or at any rate comparative inoffensiveness -towards man's person, the Puma is, by its inroads on his live-stock, one of the most noxious animals he has to deal with, and is consequently persecuted by him wherever it is found. In consequence of this, it has been exterminated in all anciently settled districts, and is now rare over most of the United States, for instance.

In compensation it supplies a useful skin, which is employed by the Patagonian Indians for their mantles and boots, though for the latter the hind-leg of a large specimen only will serve. These people also eat and appreciate the flesh of the Puma, which is generally pretty fat even in spring, when Guanacos and Rheas are lean. Captain Musters, living with the Indians and faring as they did, as described in his very interesting book "At Home in Patagonia," says that Puma "goes better" boiled than roasted, and that it tastes like pork.

Compared with the Lion and Leopard, the Puma, like the Tiger, is a remarkably silent animal; in the breeding season, however, it expresses its feelings in a kind of magnified caterwauling, and tame well-disposed specimens in captivity purr like cats. The Puma does well in this condition, and sometimes breeds, having one or two cubs in a litter, though in a wild state twice as many are produced. It is not, however, so commonly kept as the Leopard, being a less attractive exhibit; indeed, our leading dealer in India, the late W. Rutledge, once told me that the native rajahs-formerly great amateurs of animalsdid not care about it, regarding it as "only a Cat." As might be expected, it stands the climate of Bengal as well as that of England. 
Its remarkable inoffensiveness, compared with that of most other large Cats, has been alluded to, and is especially shown by the fact that specimens have been allowed to go about outdoors among people; but the Puma does not hold with the proverb "Love me, love my dog," and is generally roused to fury at the sight of this hated animal. That caged Pumas should not always be amiable is not surprising, seeing that Dogs: themselves notoriously become surly if tied up too much, so that there seems good: reason for regarding the Puma as being as much unlike the Leopard in nature as it is in colour of coat. 


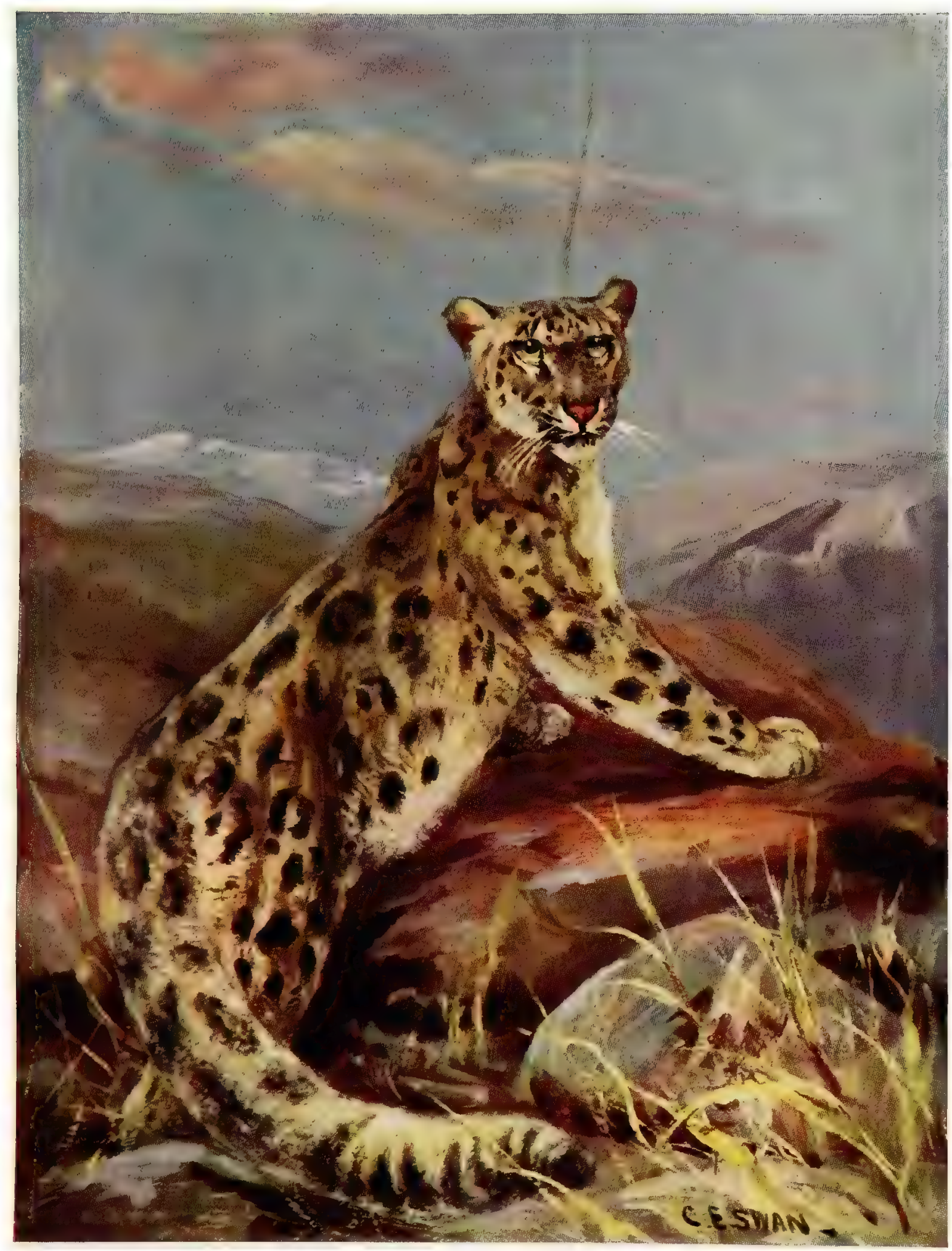

OUNCE

By C. E. Swan 



\section{THE OUNCE}

(Felis uncia)

THE Snow-Leopard, as the Ounce is often called, is noteworthy as being the only one of the "Great Cats" which is confined to temperate and cold climates. It is only found in the heights of the Himalayas and the Central Asiatic ranges, and is seldom seen below eight thousand feet. Its range, however, is a wide one, as it is found from Turkestan. to China. In accordance with the bleak nature of its haunts, its fur is peculiarly thick and full, especially on the tail, which member is very long. In size the Ounce about equals an ordinary specimen of the Leopard, the pale mountain form of which, as above remarked, somewhat approaches it. The true Snow-Leopard, however, has hardly any yellow tinge at all in its fur, and the rings of spots are much larger and wider than those of the Leopard proper; the face in the present animal, also, is much shorter, and has more of the mild character of that of the domestic Cat.

In disposition, indeed, the Snow-Leopard appears harmless enough from our point of view, as it has never been known to attack human beings, but with regard to other animals it appears to be as fierce and indiscriminate a foe as is the ordinary Leopard; its ordinary prey are the wild Goats and Sheep found in its haunts, especially the Burrhel or Blue Sheep (Ovis nahura); indeed, in consequence of this it is known in the Simla district as Bharal-hay (Burrhel-tiger) according to Mr. Lydekker. It is also a destructive foe to tame Goats and Sheep, and even Ponies fall victims to it; probably, also, it preys on the mountainhaunting Game-birds, such as the great Partridges known as Ramchukors or Snow-Cocks (Tetraogallus), which also frequent high elevations in the mountains of Asia. Being a little-known animal even in the wild state, it is not surprising that the Ounce is seldom to be found in captivity; indeed, till the year $189{ }_{73}$ it had not been exhibited at our 
Zoological Gardens, nor have any of the few specimens which have lived there survived very long.

It may be thought that the foggy atmosphere of London, so different from the pure clear mountain air of the Ounce's natural haunts, may be accountable for this, but in that case it is curious that the animal's frequent prey, the Burrhel, stands the same conditions so well, for this Sheep thrives and breeds well in the Regent's Park Gardens.

The Ounce appears to be fairly tameable, and Captain Baldwin, in his work "The Large and Small Game of Bengal and the North-Western Provinces of India," gives an interesting account of a young one which came into his possession when he was in Tibet, in a rather curious way. He found that one of the local Tibetans had killed a female Ounce by rolling a big stone down on the unfortunate beast as she lay asleep in the sun outside her den, and some days later came across one of her cubs, being led to the discovery by a pair of large birds which were mobbing it. The poor creature was nearly starved, being evidently unable to provide for itself, although about as big as a Lynx, and was not captured without some difficulty, and at the cost of a good many scratches. However, in ten days, although much stronger, it had become accustomed to sleeping on the bed of its owner, who considered that it would have in time become quite tame; but unfortunately it died quite suddenly, and was suspected to have been poisoned by his native servants to avoid the trouble it gave them.

\section{THE JAGUAR}

(Felis onca)

Although living at the other side of the world, and not next door to the Leopard, as it were, as the Ounce does, this great American Cat is so like the former animal that at the first glance it is likely to be passed over as the same species. Closer comparison, however, shows that the Jaguar's rosettes of spots have for the most part an extra dot in the centre, which is wanting in those of the Leopard; the American animal 
is also more heavily built, especially about the head and paws, and it is, indeed, the most strongly framed of all the Cats. In size it equals the largest Leopards, and indeed often exceeds them, being the third most powerful of its family. In some cases it is said almost to rival the Tiger in size, and, as remarked above, usurps the name of that animal in South America. Black Jaguars occur, just as black Leopards do, as casual sports, and they are similarly credited with being especially ferocious in disposition.

The Jaguar is chiefly confined to the forest regions of America, and to warm climates, not ranging farther north than Mexico; it used, however, to inhabit the Pampas of Argentina, though never so numerous there as the Puma, and now almost extinct. Although such a heavy animal, it is a skilful climber, and is sometimes found in such impenetrable parts of the Amazonian forests that it has perforce to hunt monkeys and such-like prey in the trees, being unable to get about on the ground. It has a strong liking for the vicinity of water, and not only takes to that element quite readily, but preys on aquatic animals more than any other large Cat, lying in wait for large fish, fresh-water Porpoises, and Otters, and being a deadly foe of the great fresh-water Tortoise (Podocnemis expansa), whose meat it skilfully scrapes out of the shell with its paw. One of its most common victims is the Capybara (Hydrochoerus capybara), but even the American Tapir does not escape it, and it will overcome full-grown cattle and horses also. Besides this, it attacks birds, and is altogether even more versatile in its hunting than the Leopard in the Old World. Sometimes man falls a victim to it, and the anecdote related by Darwin, of the Jaguar which found its way, being driven from its haunts by a flood, into a church at Santa Fé in Paraguay, and killed two of the officiating priests one after another, is well known.

The note of the Jaguar is unlike that of the Leopard, being a sort of repeated short grunting roar, much like the concluding short notes of the roar of the Lion; it is most frequently to be heard in the breeding season. As in the case of the Leopard, the cubs have rougher fur with less well-defined markings than the adults; they seem to be 
precocious, following their mother when only a fortnight old and not: larger than Cats.

The Jaguar, although not a positively rare animal in captivity, is: not nearly so common in menageries even as the Tiger, and very much rarer than its own compatriot and reputed rival and enemy, the Puma. It lives well, however, in the captive condition, and has not only reproduced its. own species in confinement; but has produced a hybrid with the Leopard. 


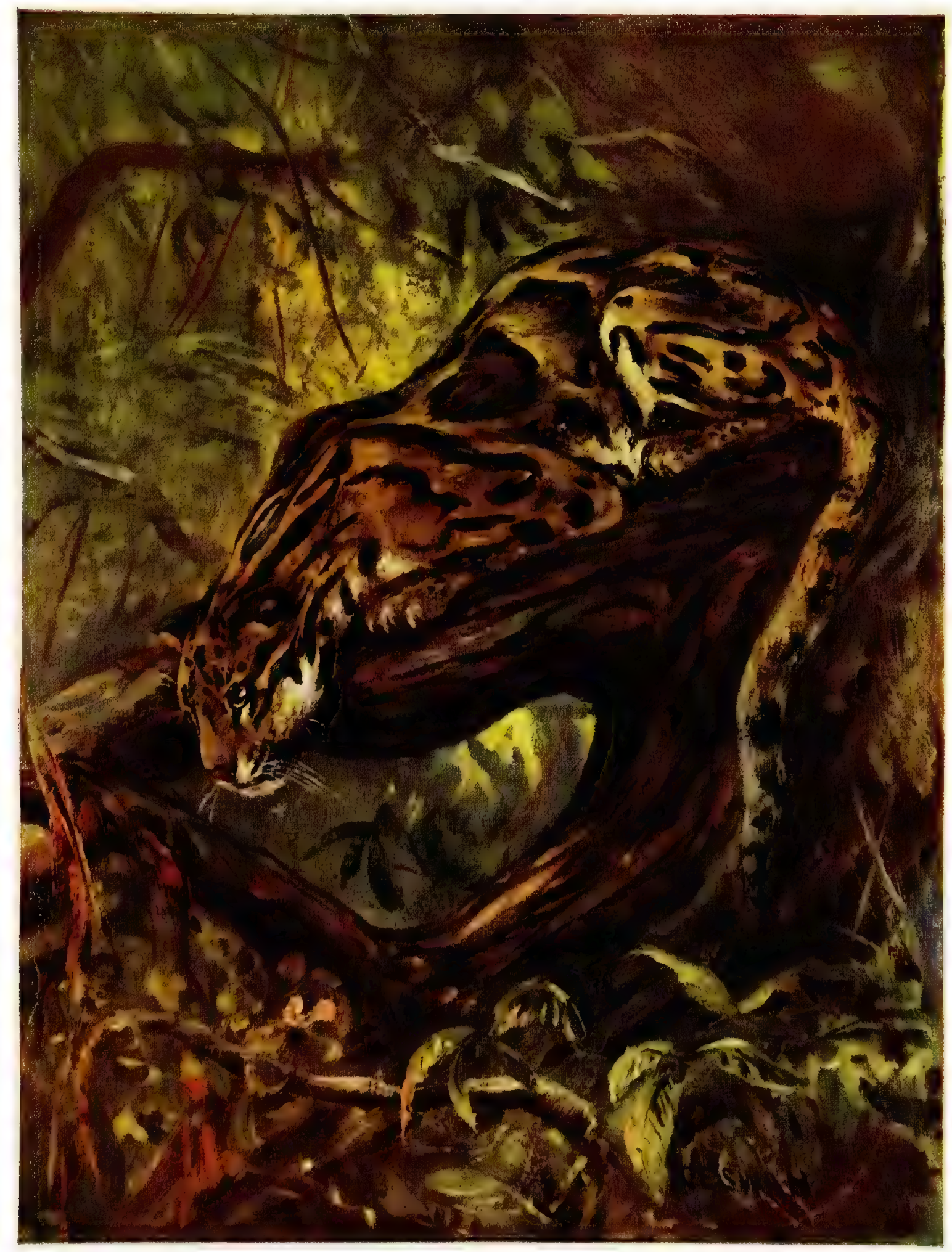

CLOUDED LEOPARD

By C. E. Swan 



\section{THE CLOUDED LEOPARD}

(Felis nebulosa)

IT is a pity that this remarkable animal has not a special name of its own, for its alternative title of Clouded Tiger is as unfortunate as that given above, the beast being neither Leopard nor Tiger, but as distinct from both of these as are the Ounce, Jaguar, or Puma. Indeed it differs markedly from all the other great Cats in its shape, which is long and low, the legs being unusually short for the size of the animal. The tail is usually very long, and the head is also of an elongated. shape, while; owing to the eyes being dark brown, the expression contrasts strikingly with the pale-eyed savagery of the ordinary Leopard. Yet the creature is remarkably well armed, its canine teeth being longer in proportion than those of any other living Cat. The closeness of the coat, and the distribution of the markings in great patches bordered with a darker tint, make the general effect of the colour much like that of the great Pythons found in the same countries, and this pattern no doubt. in both cases tends to conceal the creatures by breaking up the outline.

The colour-variation is simply in tone, some specimens being redder and others greyer; but there is a good deal of difference in size. The first specimen I ever saw, a splendid male acquired years ago by the Calcutta Zoological Garden, was quite as big as any ordinary Leopard, but generally this Cat is only the size of a small-sized individual of that species, and so is the smallest of the six species distinguished as "Great Cats."

It inhabits South-Eastern Asia, ranging from Assam down the Malay Peninsula and islands into Sumatra, and in another direction to Formosa, in which island it does not possess so long a tail as it does elsewhere. It is always a forest animal, being a remarkably good. climber, and spending much of its time in the trees, where it is wont. to rest lying in the boughs, whence its Malay name of A rimau-dahan 
(Tiger of the branches). Its ordinary food consists of birds and the smaller beasts, and although from its lithe activity and long fangs it would be a deadly foe to man if so disposed, it appears never to attack him, and is not considered in any way an objectionable animal except for its attacks on poultry.

Very little, however, is known of the creature's habits, and it is not at all common in captivity, although occasional specimens have reached Europe during many years past, and several have been exhibited at our Zoological Gardens. The last shown there was a female, and was a charmingly tame animal, as affectionate with her keeper as the most confidential ordinary Cat. This amiable disposition has been repeatedly noticed in these animals, and, in some cases at all events, they have proved friendly even with children, which is not by any means always the case with wild beasts, even when they are safe with adults.

In captivity heavy meat like beef and horse-flesh is unsuitable to this creature, and it is always best to give it goat's flesh or mutton, or preferably rabbits, pigeons, and such-like light and tender articles of food. It also needs a large cage fitted up with branches for climbing, so as to be able to exercise its remarkable agility, which is almost equal to that of a Squirrel.

\section{THE OCELOT}

(Felis pardalis)

IN the marbled character of its coat, and in having dark eyes and a pink nose, the Ocelot of South America somewhat resembles the Clouded Leopard, but it is a very differently-built animal, having much the proportions of an ordinary Cat, though it is particularly stout and heavy in build. Although considerably smaller than any of the big Cats, it is a good-sized animal, about equalling a medium-sized Dog. Its colour and pattern are astonishingly variable, some specimens being brown and others grey, while the precise size and pattern of the colour-markings vary enormously, this being the most variable in colour of coat of all the Cats, as far as details of marking are concerned, though extremes like black and white do not occur. In general, however, the markings take the form 


\section{THE SERVAL-THE WILD CAT}

of rather large elongated patches, enclosed in black borders, of a colour darker than the general ground-tint, while the head and limbs have small solid black spots. The bodily size of the animal also varies a good deal, from about a yard in total length to nearly a foot longer.

In one or other of its numerous varieties the Ocelot has a wide range, reaching Arkansas in North America, and ranging south to Patagonia; but wherever it is found it is an inhabitant of wooded country. Like the smaller Cats generally, it preys on small beasts and on birds, and is credited with being very fierce. It is, however, not uncommon in captivity, and appears to be fairly easy to tame, though its temper is not by any means to be implicitly trusted.

\section{THE SERVAL}

\section{(Felis serval)}

THE Serval, which is found all over Africa, is another Cat of medium size, measuring about four feet in length. It is peculiarly built, very slender, standing high on its legs, with a rather short tail and decidedly large ears, the more noticeable on account of the small size of the head. The coat is close and of a tawny colour, marked with bold solid black spots.

A form in which the spots are very numerous and small is distinguished as the Servaline Cat ( $F$. servalina), but there seems to be no difference between this and the type except these markings. The Serval frequents bushy country, and feeds on game-birds and Antelope fawns; it is a good runner, and seems to approximate to the Cheetah-presently to be noticed-to some extent in its hunting-habits, as it certainly does, very markedly, in colour and length of limb.

It is not rare in captivity, and may become very tame; in East Africa, in 1892, I got a kitten of this species which bade fair to make a very nice pet, but unfortunately it died on the voyage home. One peculiar thing about it was that it showed no desire to attack some guinea-fowls I also had on board, though these form part of the natural prey of the species. It has been observed that an otherwise tame Serval is roused to ferocity by the sight of a negro, just as the really formidable Lion, Tiger, and Leopard sometimes are.

\section{THE WILD CAT}

(Felis catus)

IT is, of course, out of the question here to go into the subject of all the various species of small felines known as "Wild Cats," found almost all over the world where Cats are found at all-i.e., except in Madagascar and the Australian region. 
But the Wild Cat of Europe and Western Asia, although now nearly extinct in these islands, and only lingering in the Western Highlands, deserves notice. It is rather larger and more powerful than any tame Cat, and has thick close fur, the length of which makes the tail appear blunt and round at the tip instead of pointed. The colour is just like that of some tame Cats, a rusty grey with dark streaks down the sides and face, and a ringed tail; in fact, it is a poorly-marked, unattractive, striped tabby. Its expression is surly and ferocious, and its disposition corresponding; it is a deadly enemy to all furred and feathered game, and will attack poultry and lambs, while when cornered it is a dangerous antagonist even to man. It usually frequents mountain forests, where it makes night hideous at times with its dreary caterwaulings. None of the Cats are so untameable as this apparently, even the Tiger being docile and contented in comparison, judging from those usually on view at the Zoo. It is therefore not surprising to find that our tame Cats appear to be the descendant of another species, although a closely allied one, the Wild Cat of Africa (Felis maniculata). This animal, although generally less fully striped than English 'Cats, is practically indistinguishable from the more uniform-coloured specimens one often sees in India, and would not be noticed as anything peculiar if seen roaming about our streets.

It was apparently domesticated first by the ancient Egyptians, and seems not to have reached Europe till only a few centuries before the Christian era, as the Greeks employed the Beech-Marten (Mustela foina) as the domestic mouser. The Tame Cat was evidently, judging from the laws for its protection, a scarce and valued animal in Britain at the time of the Conquest, when the Wild Cat was still common in the South. There has probably been some crossing between the two, and a kitten bred in the Zoological Gardens between a male Wild Cat from Scotland and an African female, was well striped and just like an ordinary tame kitten, thourh showing a ferocious temper; this, however, my pet Serval did at first. There seems to be no reason to suppose that 'the variously coloured coat or long fur of some domestic Cats are due to anything else than ordinary variation, and, indeed, the $C$ at has varied less than most animals which have been as long under human protection-no doubt because, until of late years, it has not been selectively bred. 


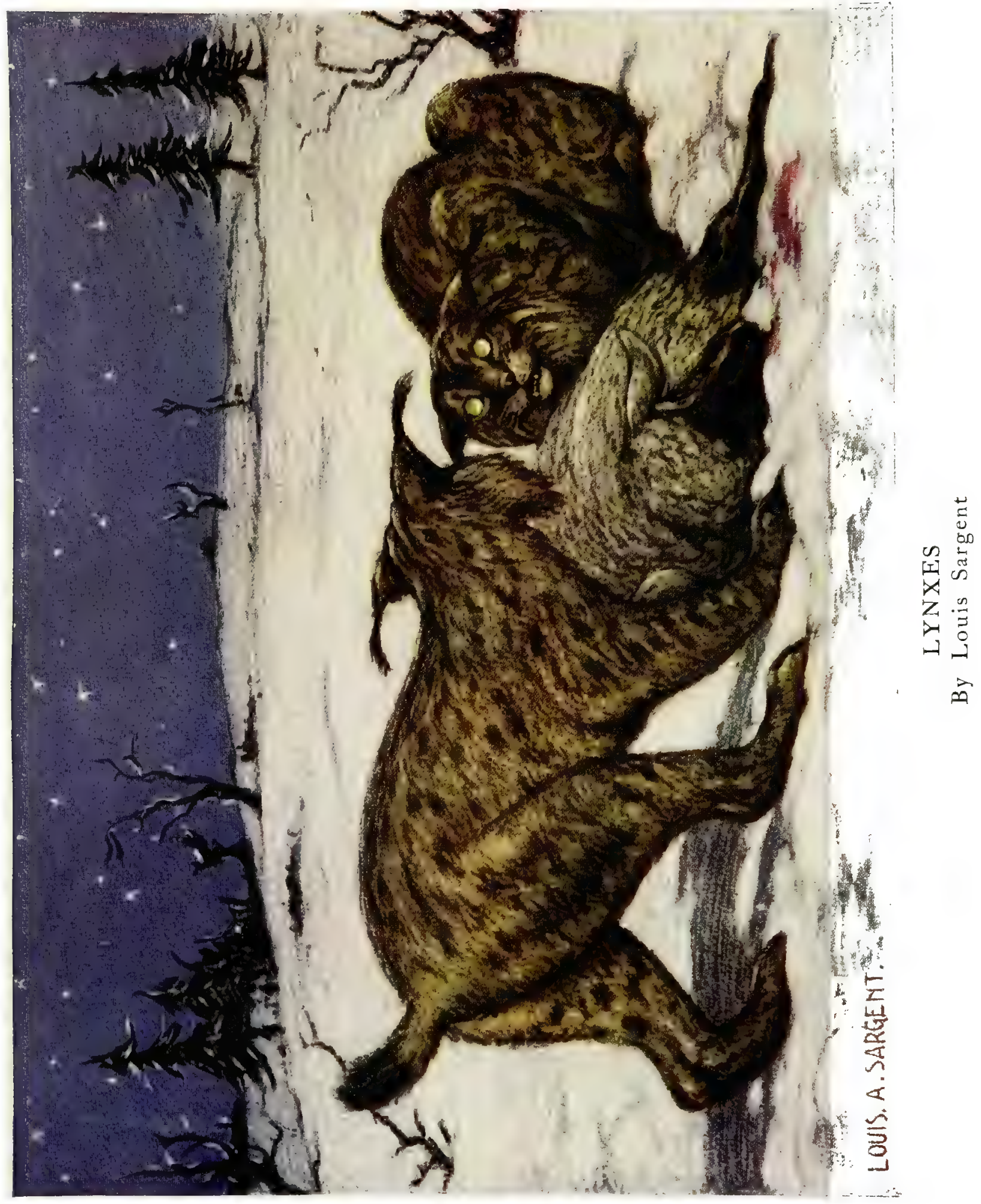





\section{THE LYNX}

(Felis lynx)

THE Lynx, the only large feline animal now found wild in Europe, is an imposing-looking beast, though it does not grow large enough to rank as one of the great Cats-not exceeding a moderate-sized Dog.

Its characteristic points are its remarkably short tail and the long tufts of hair at the ends of its ears; it is also a short-bodied, leggy animal compared with most of the Cats. The eyes have a circular pupil, and are light in colour. The coat of the Northern Lynx is heavy and thick, especially in winter, when it is less spotted and greyer in colour than in summer, but Lynxes vary a good deal both in tint and spotting, both individually and locally; the Himalayan Lynx; for instance, is almost without spots at all in winter.

As there seems good reason to consider the unspotted Canadian Lynx or "Lucivee" as a mere local race of the Northern Lynx of Europe and Asia, this Cat may be said to range all round the world, a distinction unique in the family. Indeed, it would not be straining matters much to include the Spotted Lynx (Felis pardina) of Southern Europe and the Bay Lynx (Felis rufa) of the United States as local races also; they chiefly differ from the Northern Lynx, as might be expected in more southern races, in being shorter-coated and having: redder fur with more distinct spots. The former is the animal which the ancients regarded as sacred to Bacchus, and the latter is the "bobcat" or "wild cat" of American writers.

The Lynx inhabits forests or mountainous districts; it is an animal of considerable all-round abilities-in spite of its leggy build, it is a good climber, and often lies in wait for its prey in a tree, springing on it from some distance with great rapidity, so that it can capture even birds so active as Pigeons, while the clumsier Game-birds, such as Grouse, naturally fall an easy prey. It travels fast and far on the 
ground, and swims powerfully in case of need, while its strength is such that, though it preys usually on the larger birds and smaller beasts such as Hares and fawns, it will on occasion attack Deer and even cattle -a case has even been recorded in which a Lynx, in Scandinavia, killed a Horse. To Goats and Sheep it is a deadly enemy; wild, it has been found killing the Burrhel or Blue Sheep in Tibet, and its ravages on tame creatures are very severe, so that it has been exterminated over a large part of Europe, and is now chiefly to be found in Northern Scandinavia, Russia, and eastwards through Northern Asia; a few, however, still inhabit the mountains of Central Europe.

The Lynx, although it is a really formidable beast, has apparently never been known to attack man unprovoked; and, when taken young, it can be easily tamed. This is the more remarkable, as it is a very bloodthirsty animal, killing for killing's sake, so that if it gets access to a sheepfold it destroys a large number of the inmates. It dislikes tame Cats, and they reciprocate the feeling; while, in America, it sometimes, as remarked in dealing with the Puma, falls a victim to a larger feline relative. So it does, at times, to the Wolf; but it will itself kill the Fox, and, in America, the Raccoon.

The female Lynx conceals her young in a cave or hollow of a tree, or some such sheltered hiding-place; she usually produces two or three kittens. This animal is of course often hunted, both on account of its valuable fur and to keep it down; it fights bravely against Dogs, uttering loud yells of defiance. One of the uses to which the fur is put is the manufacture of the well-known "busbies" worn by our Hussar officers. For these the skin is dyed, a "black Lynx" having so far only occurred in the poet Browning's imagination, apparently.

The flesh of the Lynx has often been used as food, and is said to be white and palatable, not unlike that of the Rabbit.

Lynxes are fairly common in captivity, but not nearly so well known in that condition as the more "sensational " Cats. It is of interest here to note that a specimen of the Tibetan variety was once kept for two years in good health in so unnatural a climate as that of Calcutta; but it was treated with great care, being always tied up in the shade, and 
bathed with soap and cold water every morning, being afterwards rubbed dry with a towel: This gives a good idea of the tameness to which the creature will sometimes attain; as a contrast, may be mentioned an individual from the Caucasus at present in the London Zoological Gardens, which is so shy that it is difficult to get even a sight of it.

\section{THE CARACAL}

(Felis caracal)

THis handsome Cat, though undoubtedly a near relative of the Lynxes, is very distinct from any form of these. Its general shape is similar, but it is more slenderly built; and has a much longer tail, though this is still shorter than that of Cats generally, only reaching down to the hocks. The long ear-tufts so characteristic of Lynxes, however, are particularly well developed in this species, whereas in the Bay Lynx they are hardly noticeable.

The coat of the Caracal is very close, and it has not the neck-ruff of the Lynx; the beast is self-coloured, being of some shade of reddishbrown, from chocolate to fawn. The ears are either jet-black, or grizzled black and white. In size the Caracal is not equal to the largest Lynxes, but exceeds most of the other minor Cats.

The Caracal is found both in Africa, where it ranges all over the continent, and through Western Asia into India, where it is found chiefly in the west. It is an animal of open, dry country, keeping to bush- and grass-jungle, and feeding on small Antelopes, Hares, and birds, especially large species, such as Bustards, Cranes, and Peafowl. It has a great advantage over such quarry as these big birds, which "get under way" heavily and comparatively slowly, as it will make bounds of a couple of yards into the air to bring down its victim, when it is literally " all over it" in an instant.

Its speed of foot is also very great, for it is said to be even swifter for its size than the Cheetah, and apparently runs down much of its prey in the same way. In South Africa, where it is known as the 
"Rooi-Kat" (Red Cat), it has been found a dangerous antagonist when robbed of its cubs, and in India a famished specimen has been known to make an unprovoked attack on a native. It is, in fact, a thoroughly savage animal, and in menageries its continual grin and snarl are a strange contrast to the usual amiability of the Lynx; but some Caracals can be made tame enough, and there is one such in the London Zoological Gardens at the time of writing. Here, also, the young have recently been born for the first time in that institution; the kittens were two in number, and already brown, with black ears like their parents.

In former times, at all events, the Caracal used to be captured and employed in hunting like the Cheetah; and a cruel amusement was, and very likely still is, derived from letting a couple loose among a flock of tame Pigeons feeding on the ground, in order to see which could kill the most before they got away. It is said that the almost incredible number of a dozen might be cut down before the flock got clear.

One curious use of the animal is worth mention: the fur is in any case a handsome one, and the Boers in South Africa are firmly convinced that a rug of Caracal skins is a preventive of rheumatism, and Messrs. Nicholls and Eglington, who mention this, state that the fur even of the dead animal is highly electrical, as that of the living tame Cat is so well known to be. 


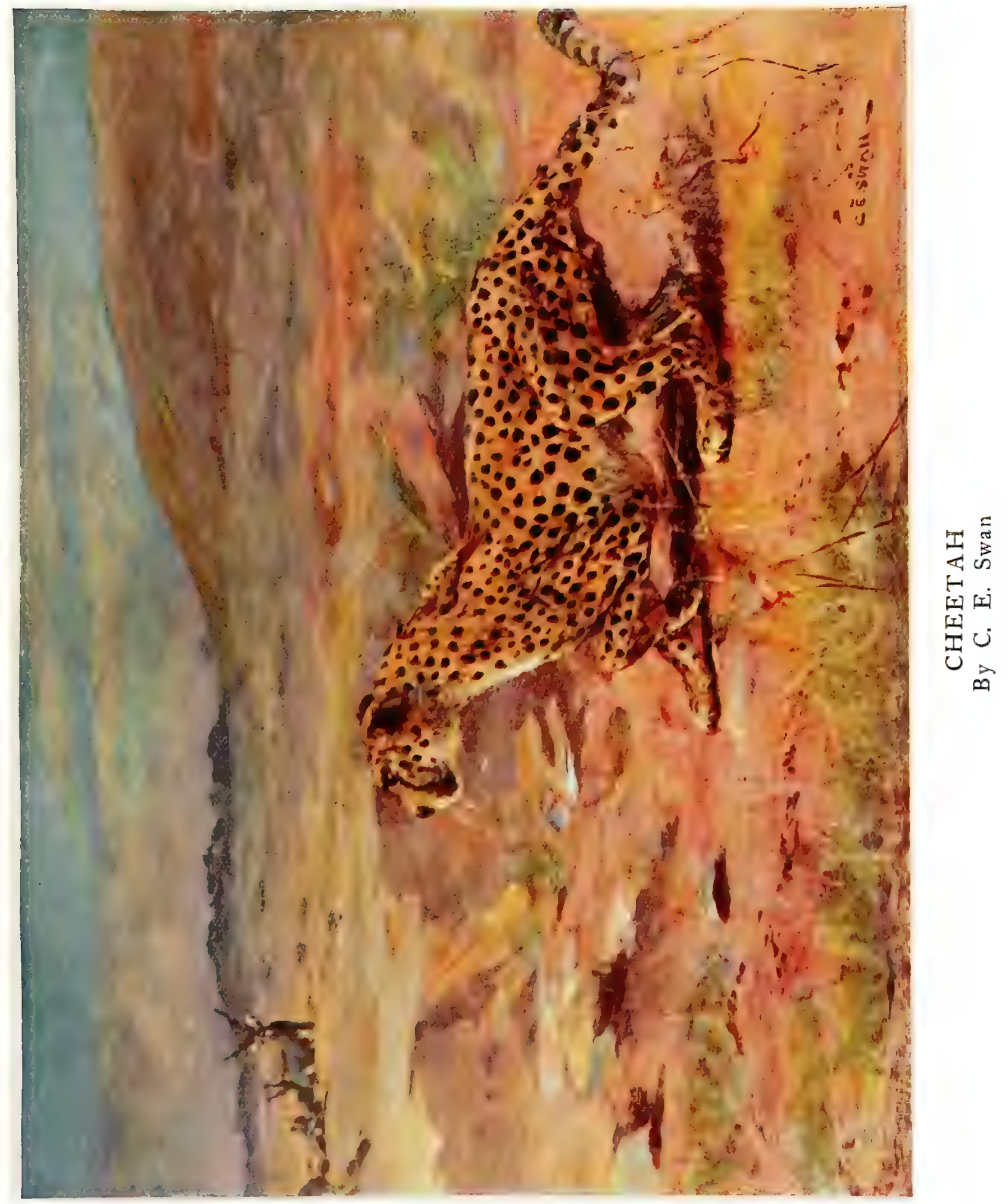





\section{THE CHEETAH}

\section{(Cyncelurus jubatus)}

Although the term "Cheetah" is simply the Indian word "chita" written according to pronunciation, and is applied in India to the Leopard as well as the present animal, in accordance with its signification of "spotted," it is a better name than "Hunting Leopard," as well as a more familiar one. For the Cheetah stands apart, not only from the true Leopard, but from all other Cats, in certain points of structure which are correlated with a somewhat different way of getting a living.

Of these the most important is the fact that the claws are only slightly retractile, and are thus always visible, and get worn at the tips as in the case of a Dog, whereas in all the other Cats, as every one may see for himself in the case of our domestic animal, the claws when not in use are completely drawn back and invisible, and always retain their sharpness.

In size the Cheetah about equals the ordinary Leopard, but is different in form, being much higher on the legs and slenderer in the body-it is, in fact, the Greyhound idea carried out in a Cat. The coat is comparatively coarse, and varies but little in colour, though a woolly-furred variety, with pale brown instead of black spots, was once procured from the Cape, and at first ranked as a distinct species, under the name of Felis lanea. The cubs have particularly long fur, which is grey in colour and unspotted, but, curiously enough, if this coat be clipped the spots can be seen underneath. It will be noted in the illustration that the spots are solid and single, not arranged in rosettes like those of the Leopard.

The Cheetah is an animal with a very wide range, being one of the few wild beasts common to Africa and Asia; in the latter country it is

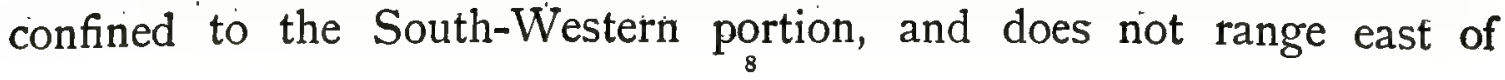


India. Neither is it found in the Malabar Coast of that country, or in Ceylon-the "Cheetah" of that island being the true Leopard.

It is not found in heavy forest, although it is able, in spite of its blunt claws, to climb trees on occasion; for its method of hunting is such as can only be practised successfully in the open, and accordingly it lives in districts where bush and rocks are the only cover; it is especially characteristic of dry districts, and does not ascend high mountains.

Its food is such animals as it may come across in the districts it inhabits-chiefly the smaller kinds, such as Hares, Gazelles, and large ground-birds. It seldom attacks tame animals, and has never been known to make an assault on man; but that it can master animals of considerable size and strength is shown by its preying on the Nilgai in India, though its more common quarry is the Blackbuck; in Africa also a pair have been seen to pull down so large and powerful a beast as the bull Koodoo.

The Cheetah's methods are a modification of those of the ordinary Cats-it begins by stalking its intended victim, but is not dependent on a mere short rush when it gets within its range, but pursues its prey for some distance and captures it by sheer speed, the chase sometimes lasting for nearly a quarter of 'a mile. The animal's fleetness is agreed by all observers to be something astonishing, and far superior to that of the Greyhound, for the Dog cannot fairly pull down the female Blackbuck, for instance, at all, whereas the Cheetah will often run up to her in a couple of hundred yards, though she may have a start for that distance; for the swift Cat, though he employs the tactics of his tribe at the commencement, is enabled by his speed to make his attack openly at the finish. When he overhauls his prey, he knocks its feet from under it with a blow of his paw, and then pins it by the throat. Often, of course, he is unsuccessful, and then gives up the chase; no doubt often through discouragement, but also because, like all Cats, he is really short-winded, being unable to keep up his marvellous speed for a really long run, unlike the Dog tribe. Thus, it has been repeatedly proved in India, that a horseman can ride down and spear a Cheetah after a 
short run, while a Wolf can usually gallop straight away from his pursuer.

When thus overtaken, the Cheetah makes but little resistance, but is said to be apt to spring on the Horse from behind if chance gives the opportunity of so doing.

That the whole nature of the animal is not very savage or dangerous, as far as man is concerned, is proved by the facility with which it is tamed, and, indeed, it is much better known as a tame than a wild animal, for, though so widely spread, it is uncommon, and sportsmen seldom come across it. The popularity it used, at any rate, to enjoy among the Indian princes and other well-to-do natives has, however, resulted in its being largely captured and kept for hunting purposes, and it is owing to this that so much is known of its habits and powers.

The men who capture Cheetahs are in the habit of marking certain trees to which these animals resort to scratch the bark with their claws -a habit well known in all Cats-and also to play about together. Here they set nooses of dried antelope sinews, and when a Cheetah is captured, manage to muffle its head in a blanket, and secure it with ropes, and so drag it home.

After this the beast is kept sleepless and hungry for days, constantly scared by flapping cloths in its face, and roundly abused by the women, until it submits from exhaustion. Once tamed, the Cheetah is friendly with its keeper, and, the animal being commonly kept tethered to one of the light wooden bedsteads known as "charpoys," man and beast often share the same couch, as depicted in Mr. L. Kipling's "Beast and Man in India." A tame friendly Cheetah purrs like a Cat.

When taken out to hunt, the Cheetah is placed on a bullock-cart, with its keeper, and the cart is driven as near as possible to the Blackbuck herd destined for attack before unhooding their enemy. Should an Antelope be captured, the keeper runs up and cuts its throat, catching some of the blood in a bowl, and offering it to the Cheetah, which is meanwhile hooded. A good animal will run down three or four Blackbucks in a morning, but, of course, there is much variation in powers among them. Only adult-caught animals are of any use, it being 
considered that they can only be taught their trade by their parents. Probably, also, they would never attain such vigour and high condition when reared in captivity; besides which it must be remembered that any animal caught leading an independent wild life has proved its fitness for this, whereas a creature which one rears by hand may have some defect in bodily or mental powers which would have soon proved fatal to it under the more rigorous conditions of nature, though not prejudicial in domestication.

The Cheetah, kept in the ordinary way in a Zoological Garden, is not a very hardy animal, and cannot be called at all common in captivity. Probably, if kept tame enough for handling, and often taken out for a run, under due restraint, it would thrive much better. 


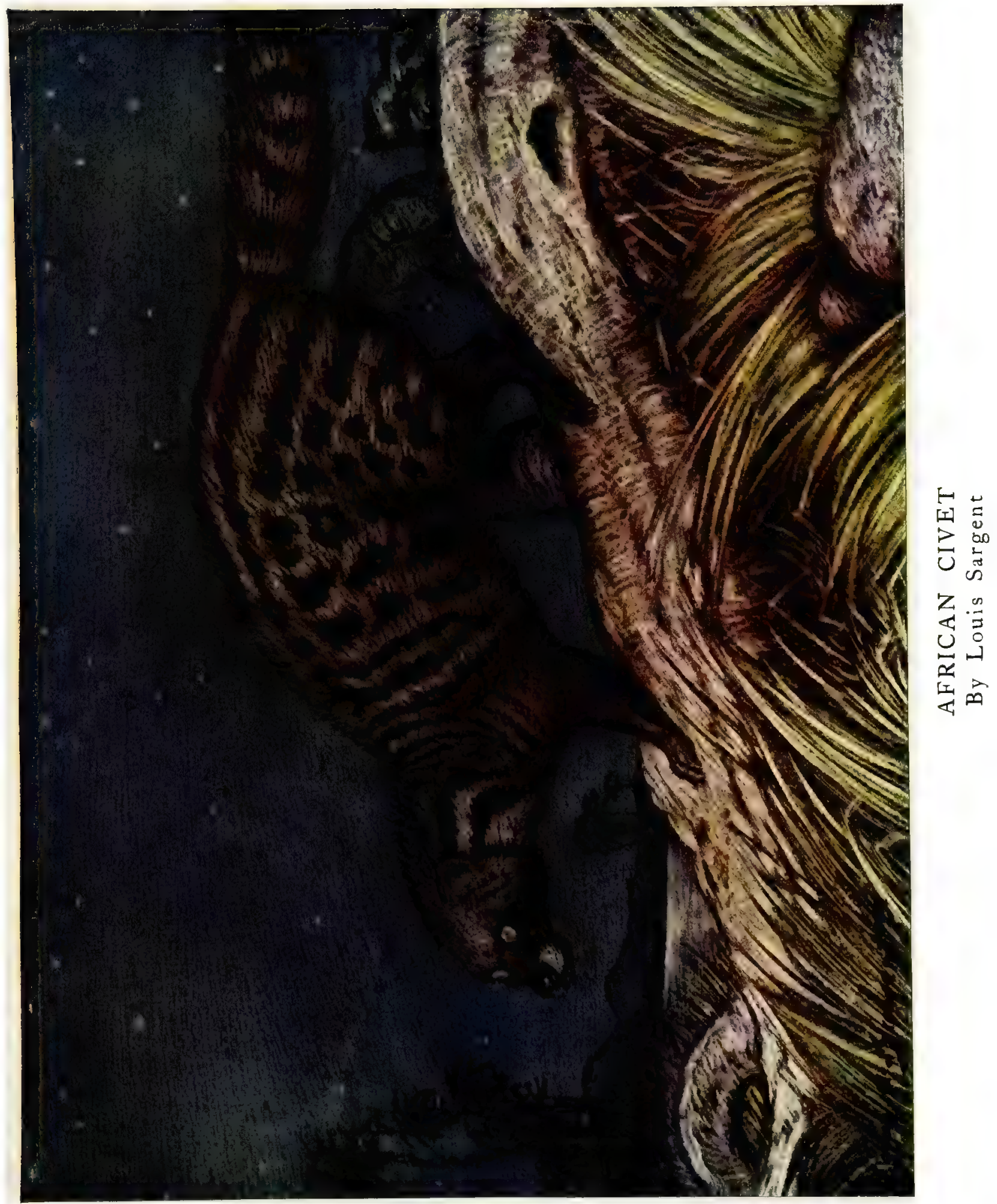





\section{THE CIVET}

(Viverra civetia)

OwING to its former repute as a producer of perfume, the Common Civet is one of the best known of its family (Viverrida), a very varied assemblage of creatures restricted to the Old World, many of which, like the present, are often credited with being "Cats." Cats, however, they are not, although resembling those animals closely in many ways, and undoubtedly nearly allied; and it will be particularly noticed that the long foxy nose and comparatively small eyes are very different from the characteristic Cat countenance. The grinding teeth of the Civet are more numerous than those of the Cats, and it has five toes on the hind- as well as the fore-foot, armed with claws which are only partially retractible. This Civet is a large animal for its family, although not much bigger than a Fox.

The long hair along the ridge of the back can be bristled up when the animal is enraged, at which time it growls and snarls like a Dog, though usually silent.

The perfumed substance which it secretes is to be found in a pouch situated below the tail, and this pouch and its secretion is present in both sexes; the substance is greasy and pasty in consistence, and very strong in odour. When the creature feels itself overcharged, it squeezes out some of the secretion on any hard object, such as a log or stone. Other glands situated in the same region secrete a horribly offensive fluid.

This Civet is confined to Tropical Africa ; it lives in wooded country, and has much the same habits as the Fox, hunting about on the ground at night for any small animals it can overpower, and being a great enemy to poultry. Besides animal food, it will eat fruit and roots.

It is easily kept in captivity, being omnivorous, and thriving well in even a small space, and is still kept to a great extent for its perfume, though this is no longer in such vogue among us Europeans as it was, judging 
from his repeated allusions, in Shakespeare's time. It is, indeed, too strong and rank for our modern tastes; but it is still of some use in compounding other perfumes, though even for this, musk has largely taken its place. In the East, however, where taste is still in many matters remarkably like what it was among us three centuries ago, Civet is still much esteemed. To obtain it, the pouch is everted with the fingers, or the secretion scooped out with a wooden spatula. The operation can be performed twice a week, but as the Civet does not, at first at any rate, at all approve of it, and is not the sweetest-tempered of animals at the best of times, it is put into a cage in which it cannot turn round.

In addition to the African Civet, several Asiatic species closely related to it contribute their perfume in captivity, and have very similar wild habits. The Large Indian Civet (Viverra zibetha) is well known in Bengal as Bagdas, and often hunted by "bobbery packs." This has plain grey sides instead of the black-spotted flanks of the African animal, and ranges east to China and the Malay Peninsula. The Tangalung ( $V$. tangalunga) inhabits the East Indies from Java to the Philippines, and, like the Burmese Civet ( $V$. megaspila), is more spotted than the Indian kind, but not so large.

The Small Indian Civet, or Rasse (Viverricula indica) is also kept as a civet-producer, but this is a rather different animal from the typical Civets, being smaller, with no mane along the back, and with shorter claws; in accordance with this structure, it is more of a climber. Its coat is grey spotted with black. It is not only found in India, where it ranges all over the country, and eastwards as far as does the Large species, but also in Madagascar, where, however, it may very likely have been introduced.

\section{THE GENETS}

The Genets and Linsangs (Genetta, Prionodon, Poiana) are very beautiful animals, of small size, with very short legs and long bodies, necks, and tails. In their sleek spotted coats and retractile claws, they much resemble the true Cats, but 
have the characteristic foxy head of the Civets. They are good climbers, and feed on birds and the like. They are found in the warmer parts of the world, the Linsangs, with the exception of one African species, being Asiatic, while the Genets are chiefly African. The Common Genet (Genetta vulgaris) is grey with black spots, and rather smaller than a Cat. It is found not only over Africa from north to south, but in South-western Asia, and also, unlike most of the Civet family, in Europe, where it inhabits Spain and even Southern France. It is sometimes tamed, and kept to destroy Rats and Mice, but, though it has no scent-pouch and does not smell unpleasant, exhales sufficient odour to make it rather a highly-flavoured house-pet. It is usually on view in our Zoological Gardens.

\section{THE TREE-CIVETS}

ThE Tree-Civets, like the Genets, are long-bodied, short-legged animals, with foxy heads and retractile claws; but they are heavier-bodied and larger than the Genets, equalling or exceeding a Cat in size, and their long tails are slightly prehensile. Their coat is often self-coloured or nearly so; they are essentially climbing animals, spending most of their time in trees, and feed a great deal on fruit as well as on small animals. The common Tree-Civet or Toddy-Cat. (Paradoxurus niger), which is grey variegated with black, is a very well known animal in India; though, owing to its nocturnal habits, it is seldom seen. The stuffy musky smell it diffuses, however, often betrays it; and I have sometimes. seen it in the evening or at night quite among the houses in Calcutta-indeed, I caught two individuals in a big box-trap in my own pantry, which they had been attempting to raid, producing a terrible din by trying to get the bread out of a tin box. So skilful a climber is this creature, that I have seen it swarm up. a water-pipe in the angle of a wall-a climb which I fancy an ordinary Cat. would have had some difficulty in negotiating. The Paradoxures found in Bengal are often intermediate between this species and the Malayan one ( $P$. hermaphroditus), which is usually greyer and more spotted. The Toddy-Catso called from its habit of drinking the toddy or juice of the palm from the vessels hung to collect it-is constantly on view at the London Zoological Gardens, and at the time of writing there is a curious pied specimen there. The Tree-Civets are an Asiatic group, except the West African Nandinia. binotata. 


\title{
THE BINTURONG
}

\author{
(Arctictis binturong)
}

Thrs curious animal is sometimes called the Bear-Cat, a peculiarly unhappy. name for a creature which is neither Cat nor Bear, though with its short, free, lynx-like tufted ears, and long, coarse, grizzly black coat, it does suggest a combination of Bear and Cat. It is, however, practically a large Paradoxure; in size it may equal a large Terrier, and it is remarkable for having a very long tail which is truly prehensile, being the only non-marsupial animal in the Old World endowed with this means of suspending itself. It is an omnivorous, nocturnal, forest animal, found from Assam to Java, and is not unfamiliar in captivity, though it cannot be called common.

\section{THE WATER-CIVET}

\section{(Cynogale bennettii)}

Although one or two of the Mongooses-the group next to be noticed-are more or less aquatic, the present animal is the only member of the Civet family specially adapted for an aquatic life. This otter-like Civet is about as big as a large Cat, short-tailed, short-eared, and broad-muzzled, with abundant whiskers. It is web-footed and a good swimmer, but also able to climb. In colour this animal is a grizzly brown; it is very omnivorous, devouring anything, from fish to fruit. The Water-Civet ranges from Borneo to Sumatra; it is a rare animal, and I have only once heard of it being kept in a Zoological Garden. In this case the specimen was exhibited in that of Calcutta, where I had a chance of studying it myself.

\section{THE FOSSA}

\section{(Cryptoprocta ferox)}

THE Fossa of Madagascar is a very curious creature, forming a connecting link between the Civets and Cats, though ranged by most naturalists with the former. It is nearly as big as a small Leopard, long in body and tail, with retractile claws and the brown fur of a Puma, and the teeth of a true Cat in a Civet's long muzzle. It is a great climber, very savage and extremely active, and credited with being dangerous to men, while it at any rate attacks Goats. It has once been exhibited at the Zoological Gardens in London, but is a rare animal, and little known even in its own country. 


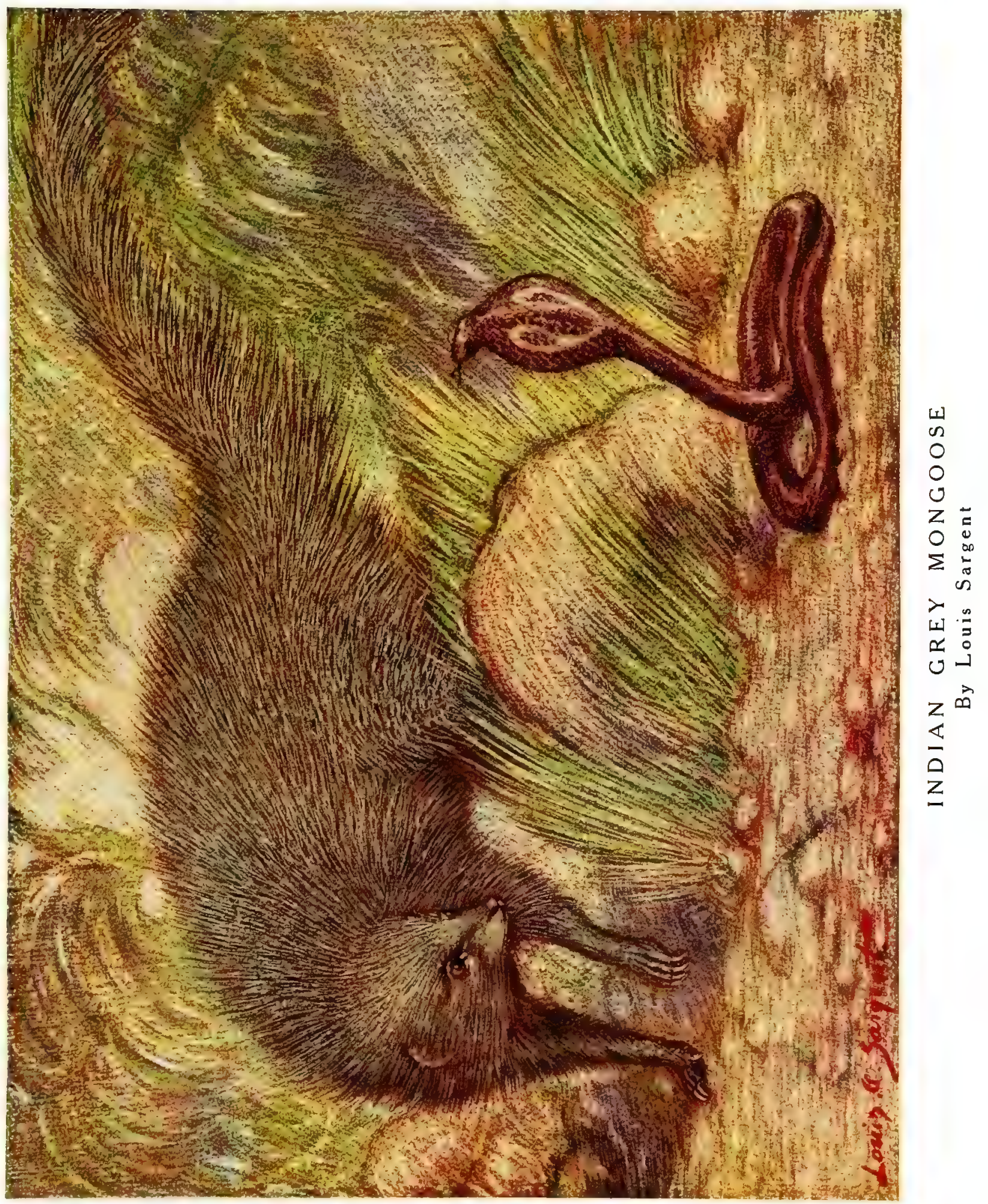





\section{THE GREY INDIAN MONGOOSE}

(Herpestes griseus)

THIs, the commonest in captivity of the little animals known as Mongooses or Ichneumons, is a very fair type of the group, which forms a well-defined section of the Civet family. It is not a large animal, being about half the size of a Cat, and its grizzly-grey fur is loose and coarse in texture. There are five toes on each foot, and these are armed with strong claws suited for digging, and not at all like the more or less cat-like claws of some of the Civets. The coat varies somewhat in colour locally, specimens from the district of Sind being rusty-red in colour instead of grey.

This is a very widely spread animal in India, and is confined, in the natural state, to that country and Ceylon, though it has been introduced far and wide abroad owing to its reputation as a vermin-killer, and has thus gained a footing in the Malay Peninsula, the West Indiesespecially Jamaica-and Hawaii.

Unlike so many small animals, and carnivora especially, the Mongoose hunts by day, and so is often seen and very well known; it does not at all shun human habitations, and comes into suburban gardens and even about houses, which it has been known to enter voluntarily and, on encouragement, to make itself at home. It is generally a ground animal, sheltering in holes, but can climb on occasion. In its diet it is particularly omnivorous, feeding on almost any animal which its great courage and activity enable it to master, and also eating various kinds of fruit. Birds, beasts, reptiles, and insects contribute to its fare, and it is doubtful whether it does more good by destroying. Rats, Snakes, and such-like vermin, or harm by its raids on poultry and its destruction of birds and eggs generally, and harmless and useful reptiles such as lizards. It is well known to be able to kill and devour even large poisonous snakes, such as the Cobra, though it probably does not risk 
an encounter with such dangerous quarry if easier game is available. In its fights with such foes, it relies on its extreme activity to escape their fangs, and, as it bristles up its long wiry coat when attacking, and has a tough thick skin, they have the less chance of making an impression on it.

If fairly bitten, however, the Mongoose succumbs ultimately just as any other animal would do, though it seems to have some power of resistance to the poison. The idea that it seeks an antidote in some (unknown) herb is of course erroneous.

The voice of the Mongoose is a sharp yapping bark or yelp, but when irritated, as when disturbed while feeding, it utters a growl remarkably loud for so small an animal. The young of the Mongoose are produced three or four at a time, and lodged in a burrow, which may be dug by the animal itself.

This animal is readily tamed when taken young, and becomes a very affectionate as well as interesting and intelligent pet, though it is of course a dangerous companion for other animals. One specimen kept by Sterndale, which was devoted to its master and would perform many amusing tricks, killed a tame cock Bustard (Eupodotis edwardsi), a bird as large as a big Turkey-cock, and even attacked a Greyhound.

The results of the introduction abroad of this animal is often cited as an example of the harm done by upsetting the balance of naturethough it must be remembered that this may be done in other ways than by introducing a new wild creature into a country, the mere settlement of any region by man producing a greater disturbance of conditions than anything else could effect. The Mongoose was introduced into Jamaica to kill down the sugar-cane Rats, and did so to such purpose that in only ten years from the original introduction of nine specimens, it was estimated to be saving the colony $£ 100,000$ to Er 50,000 annually.

After this, however, it became too numerous, finding, probably, too. few natural enemies; for in its native country, what with Pythons, the great Monitor Lizards, the numerous birds of prey, Wild Cats, Jackals, and other carnivorous creatures stronger than itself, there are plenty 
of destructive agencies. This being so, the Mongoose was found to be destroying not only the Rats, but all the ground-birds, the local harmless snakes, and the lizards, while it extended its depredations from poultry even to kids and calves, and showed its vegetarian tastes by devouring fruit and even the sugar-cane it had been introduced to guard. The havoc wrought upon the birds and lizards resulted in a great multiplication of the ticks, which had been kept down by these creatures, and in the end the Mongoose was voted a worse evil than the Rats had been. After this, however, the Mongoose itself began to decline in numbers, one cause suggested for this being that it was much worried by the ticks it had contributed to encourage, and its great influence for good or ill is now considered to be over, the balance of nature having become readjusted. The state of affairs in Hawaii seems to have been somewhat similar.

It is easy to see that the unfortunate result could have been avoided if the Mongooses had been thinned down as soon as they were seen to be exceeding their instructions, so to speak; but the lesson has produced a deep effect, and the neighbouring American Government has taken it so much to heart that it does not allow living Mongooses to be landed at any port under its control. The fact is that, if an alien pest-exterminator is needed, birds are far better than beasts, as, if they get too numerous, they are much more easily kept under control, as every gamekeeper knows.

\section{THE EGYPTIAN MONGOOSE}

(Herpestes ichneumon)

THIS is the celebrated Ichneumon of the ancients; it is very similar to the Indian species, but twice as large, and distinguished by having a tassel or bunch of black hairs at the end of the tail. This animal is the only Mongoose found in Europe, where it inhabits the south of Spain; it is spread over North Africa generally, and is replaced in the south by a very similar species $(H$. caffer). In general habits it 
resembles the Indian Mongoose, and was the species which gained so much reputation by destroying the eggs of the Crocodile, as well as by its combats with snakes.

The typical Mongooses number about a score of species, found in various parts of Africa and Asia, and there are a number of little animals more or less closely allied to them, which cannot be particularised here, with one exception.

\section{THE MEERKAT}

(Suricata tetradactyla).

THE Meerkat is sometimes known as the Suricate, but the above is its name in its own country, South Africa, where it is a very familiar animal. In size, it resembles a half-grown kitten; its coat is close, and banded with black and brown, and its tail covered with particularly short hair, chestnut at the root and black at the tip, so that it is very different from the brush of the Mongoose. The eyes also differ much, being large and dark, while the ears are very short and the head round, with a pointed snout. There are only four toes on each foot.

The Meerkat is a burrowing animal, living in colonies, and in many ways resembles the Prairie Marmot (Cynomys ludovicianus) of North America, which is interesting, seeing that the latter is a rodent and the former a carnivore. The Meerkat, however, is far less carnivorous than the Mongooses, feeding largely on bulbous roots, which it scratches up, and, though readily feeding on little animals, not attacking large prey. It is thus a more convenient pet, and is often kept in that capacity, both in Africa and here; it has produced young in captivity.

This animal is remarkably fond of the sun, and basks in a peculiar manner, sitting up like a Dog begging. It also frequently stands quite up on its toes, being much more inclined to assume an erect position than most quadrupeds, though the Mongoose does this also to a small extent. 


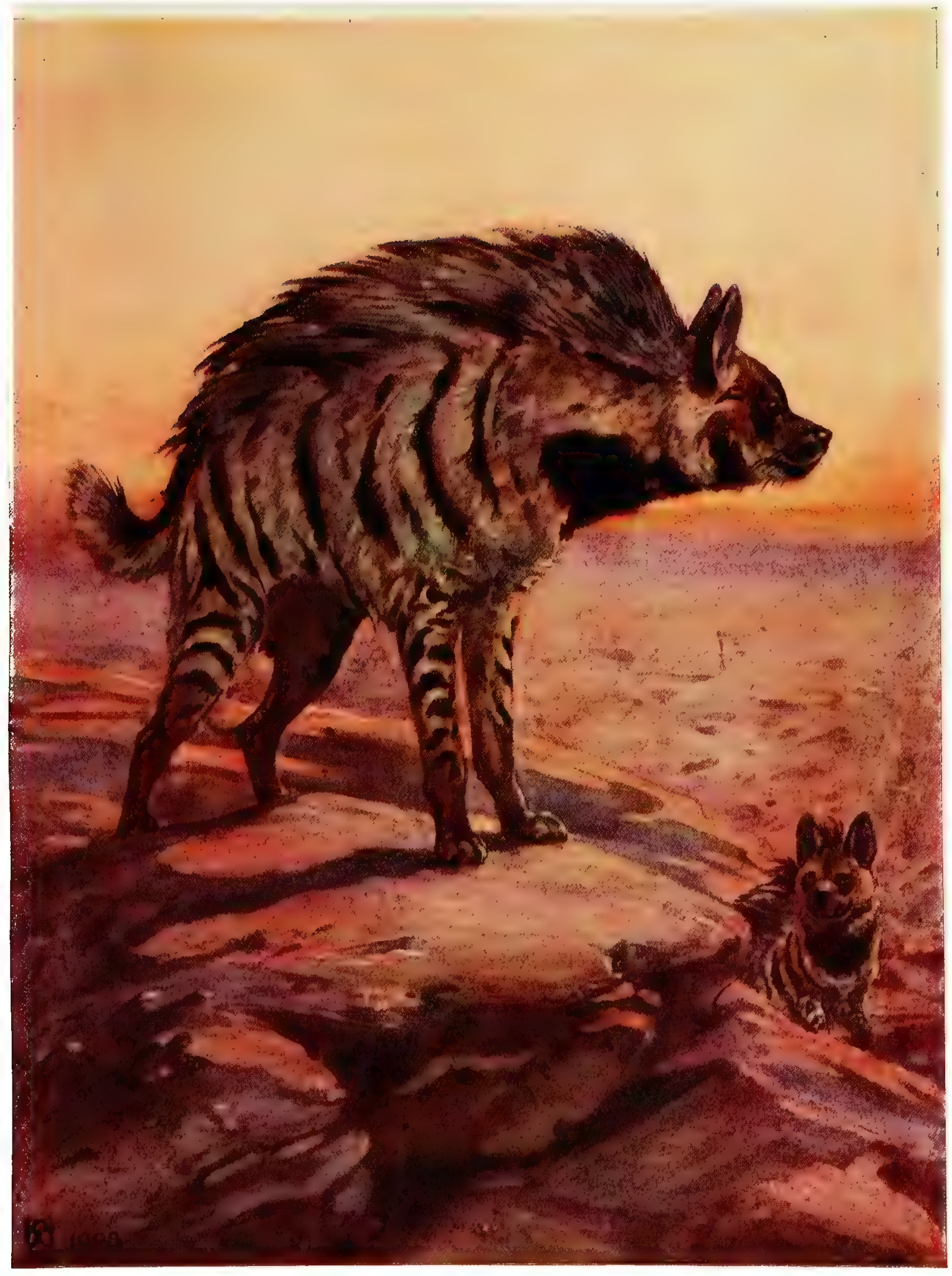

STRIPED HY ÆNA

By Winifred Austen 



\section{THE STRIPED HYÆNA}

\section{(Hycena striata)}

BeING a widely diffused animal, ranging throughout North Africa and east through India, the Striped Hyæna is the most generally known of the small family of carnivores which it represents. There are only three kinds of Hyænas, all confined to the Old World, and there is a strong family resemblance between them.

Our illustration well shows the somewhat dog-like form-with, however, a strong slope in the back not seen in any Dog; but Hyænas differ from all Dogs in having only four toes on all the feet, whereas in Dogs there are always five on the fore-foot, except in the curious Hunting-Dog of Africa. This, however, although somewhat Hyænalike in other respects also, is not to be mistaken for any Hyæna.

Hyænas do not differ much in size, the present species being about as large as a Mastiff. Their teeth are extraordinarily powerful; it is stated that they can snap the shin-bone of a Horse or Bullock in a single effort.

Indeed, they feed largely on bones, coming to a carcase after more powerful creatures have left it. The Striped Hyæna is, in fact, a pitiably cowardly creature, and seldom attacks living prey if it can get carrion, though it will occasionally carry off Goats and Dogs. It is nocturnal in its habits, retreating to some cave or other similar hiding-place during the day.

Sportsmen generally look upon this animal as mere vermin, and do not molest it unless it makes a nuisance of itself by petty larceny about a camp; but it is occasionally, in India, ridden at and speared, as is done with more worthy quarry. When thus pursued, it is apt to give a long run, for, although not a very fast animal, it jinks or dodges to avoid the spear very adroitly.

It has long been contended by hunting men that Horses like the 
sport, and a good proof of this was once furnished by an old Arab Horse, who happened to lose his rider during a chase after a Hyæna. He took up the pursuit on his own account, and got near enough to attempt to bite the beast and strike it with his forefoot, the miserable Hyæna only responding by tucking his tail between his legs.

The cry of this Hyæna is loud and peculiar, and native tradition asserts that it beguiles Dogs away by its vocalisations in order tó devour them.

The cubs are said to be three or four in number, but little is known about the breeding habits of this otherwise familiar beast.

In captivity the Striped Hyæna, like all Hyænas, does well; it is the commonest kind seen in menageries, but does not often breed there -at any rate it has seldom done so in the London Zoological Gardens. The idea that these animals are untameable is a mistake; they do not appear to be worse to manage than any other carnivora.

\section{THE BROWN HYÆNA}

(Hyana brunnea)

In the Striped Hyæna a noteworthy point is the mane of long dark hair running down the back; in the present species this long hair is continued over the sides, and the body of the animal is self-coloured. In other respects, however, the Brown Hyæna is very much like the Striped species, and its legs are short-haired and marked with stripes in a similar manner.

The Brown Hyæna was the characteristic species of South AfricaI say "was," for it is now a very scarce animal, and is believed to be approaching extinction. It was known to the early settlers as a seashore beast, whence it received the name of Strandwolf. True Wolves, by the way, are not found south of the Sahara, and any references to them in South Africa really concern Hyænas. Later on it was found that the Strandwolf also occurred inland, and in the early days of South African colonisation it seems to have been a ferocious and dangerous 
animal, attacking even man at times. The beast concerned in the oftentold story of the drunken trumpeter, who was effectually sobered by finding himself being carried off by a Hyæna, was one of the present species.

The Brown Hyæna is naturally much less commonly seen in captivity than the other kinds; but it has several times been exhibited in our Gardens, and there is a specimen there at the time of writing.

\section{THE SPOTTED HYANA}

(Hyana crocuta)

THIS is the typical Hyæna of Africa generally, though not occurring north of the Sahara; where the Striped species is the only one found; in Somaliland, however, they meet. The Spotted Hyæna is decidedly larger and more powerful than either of the others; it may reach a length of over six feet from the nose to the tip of the tail.

Its coat is short and close, and there is no mane on the back; the colour is clear, marked with large black spots.

The traditional laugh of the Hyæna is one of the characteristic notes of this species, which has a rather extended vocabulary; but the horrid cackle of "laughter" is commonly heard about a carcase, and seems to be the expression of annoyance in the animal. Ancient tradition credited the Hyæna with laughing to beguile its victims, and, although on the whole a cowardly brute, there is no doubt that this species is the most ferocious and dangerous of the three, nowadays at all events.

Although its usual food is carrion, it frequently attacks domestic animals, and even sleeping or wounded people, having a horrid custom of snatching a mouthful from some convenient part of its victim, and then making off. Thus, the tails of domestic animals and the udders of cows are torn away by it, and human beings have to dread having the cheeks torn out, or a similar attack, made on other fleshy parts of the body.

In the ordinary way the beast is nocturnal, but it must sometimes 
hunt for food by day, as it is recorded to be in the habit of discovering carrion by watching and following the flight of its fellow scavengers the Vultures, which are strictly diurnal birds. It shamelessly poaches on the "kill" of the Lion, and sometimes pays with its life for its audacity, if the outraged monarch takes it by surprise.

When I was in East Africa in 1892, the laugh of the beast might then be heard quite close to bungalows on the little island of Mombasa, then mostly covered with bush, and even harbouring Lions occasionally.

In captivity this Hyæna seems rather more tameable than the striped species; owing to its laughing note it is a popular exhibit, and it has bred both on the Continent and in our Zoological Gardens.

\section{THE AARD-WOLF}

(Proteles cristatus)

THE curious South-African animal known by this name and sometimes as "Maanhaar Jackal" (Maned Jackal) is a near ally of the Hyænas, though usually placed in a separate family (Proteleida). In general appearance it is like an under-sized striped Hyæna, but is bigger than a Fox, and has a narrow muzzle and a rather long bushy tail. Its grinding teeth are very unlike the great bone-crushers of the Hyænas, being remarkably small, weak, and set far apart. Its food is chiefly insects and carrion, but of late years it has developed the habit of attacking lambs, and is hence in great disfavour with Cape farmers. Like Hyænas, it lives in burrows or dens underground. One very curious point it has in common with the Hyænas is its habit of going down on its fore-knees when fighting, Hyænas doing this with a view to saving their paws from the terrible teeth of their assailant.

In internal characters the Aard-Wolf somewhat approaches the Civets, and forms a link between them and the Hyænas proper; it is interesting to note that some of the oldest naturalists described the common scent-producing Civet as the "Odoriferous Hyæna." The Aard-Wolf bears captivity well, and, although not common in that condition, has several times been exhibited at our Zoological Gardens. 


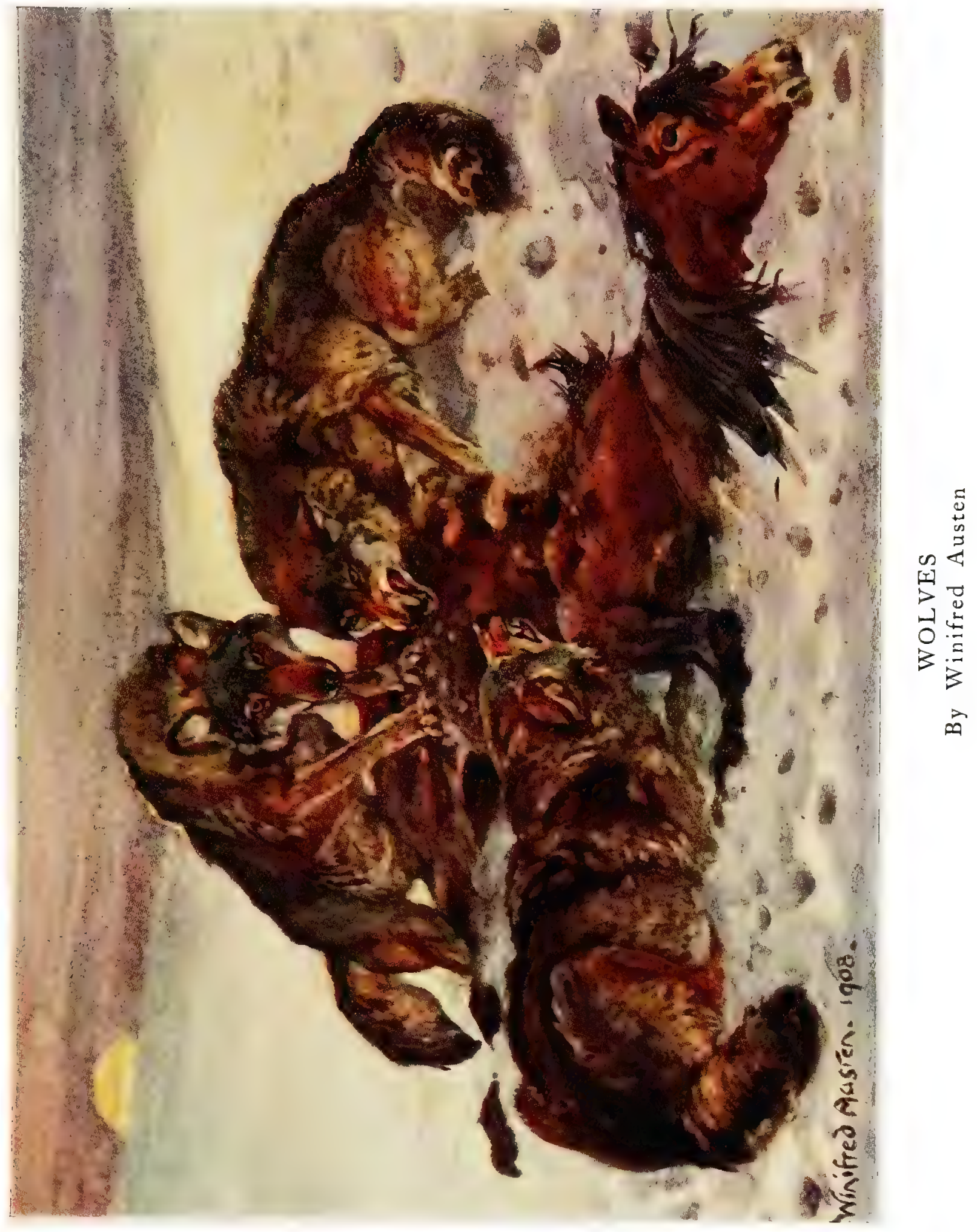





\section{THE WOLF}

\section{(Canis lupus)}

This typical member of the Dog tribe-so nearly related to our tame Dogs that some naturalists consider it their ancestor, is a very widely ranging beast, being found all round the Northern Hemisphere, though it presents a great deal of local as well as individual variation in size, coat, and strength of teeth.

The Wolves in the illustration, sketched from a very fine Siberian animal in the London Zoological Gardens at the time, are redder in tint than many specimens, the more ordinary hue of a Wolf being a sort of washed-out dun or yellowish-grey. Some black "ticking" on the upper parts is always present, and entirely black Wolves occur in widely separated localities. White ones may also be found, and the Wolf of the high Arctic regions forms a white race.

As with so many other widely ranging animals, the Wolf attains a finer development in cold than in hot climates; it is natural that he should wear a thicker coat in the former, but his actual size is also greater. The largest Wolves seem to be those of Alaska; a huge black specimen exhibited in the British Museum is bigger than any Dog.

In the plains of India, on the other hand, the Wolf is a poor weedy degenerate brute, about six inches shorter in length than the typical Wolf, and with a close coat devoid of the usual woolly under-fur found in Wolves. It is, indeed, usually ranked as a distinct species (Canis pallipes), but all its peculiarities seem obviously due to what may be called tropical degeneration.

The ordinary length of a dog Wolf is about three and a half feet from muzzle to root of tail, the bitch being somewhat smaller. The Wolf is thus larger than most of our tame Dogs, and he is, indeed, the largest of the members of the Dog family found wild.

As he has been for ages the traditional enemy of man and his domestic 
animals, the habits of the Wolf are well known. He is generally a nocturnal animal, frequenting forests and overgrown localities generally, wherever such exists, and usually hunts singly or in pairs, except when, under stress of necessity, several, or even a large number, unite to overcome a powerful victim.

Essentially a cowardly animal, the beast usually prefers to attack prey which is easily overcome, but he is well armed for combat, inflicting a terrible snatching bite, while his speed and endurance in pursuit of prey or escape from enemies are well known. It is very rare, indeed, for a Wolf to be fairlÿ ridden down.

The Wolf will readily feed on carrion when he finds it conveniently accessible, and he preys not only on Hares, Deer, and such like wild creatures, and on domestic cattle and poultry, but on his fellow-carnivores. The Fox is a frequent victim, and the tame Dog, in spite of such nearness of relationship that the two species sometimes voluntarily cross, is greedily sought for as prey. Indeed, the Wolf is not at all averse to cannibalism when pinched by hunger, as many stories of wolf-hunted sledge-parties testify-the devouring by their companions of Wolves that have been shot being a common incident.

In spite of his cowardice, the Wolf appears to be a more inveterate man-eater than any other animal; for ages he has been celebrated as the worst foe of children, and many are destroyed by him even at the present day in India, while, when pressed by the rage of hunger in winter, packs will, as is well known, attack adults. Never a severe winter passes without lamentable reports in our newspapers of the death of human beings on the Continent at the jaws of these brutes, which in such seasons press westward from their fastnesses in the forests of Eastern Europe, especially Russia. They linger, however, almost all over the Continent, and were not completely exterminated in Britain till a comparatively recent date. In England, it is true, it is supposed to have become extinct in the reign of Henry VII. ; but in Scotland they amounted to a serious plague in the time of the unhappy Queen Mary, and did not become extinct till the end of the seventeenth century at all events. In Ireland they appear to have lingered till perhaps a century later, but in all these cases the exact 
date of their final extinction is unknown. The lateness of this, however, even in an insular area like ours, gives an idea of the difficulty of keeping down the pest on the Continent; yet, in North America, the Wolf disappears before civilisation far more quickly. It is curious, also, that he is not nearly so dangerous to man as in the Old World, though equal to his relatives there in size and power. In America, by the way, this species is generally distinguished as the "Timber" Wolf, to distinguish it from the "Prairie Wolf" or Coyote, to be noticed later.

The she-wolf brings forth in spring, and deposits her litter in a thicket, or an earth dug out by herself or appropriated from some other animal; the whelps number usually about half-a-dozen, and are suckled about six weeks. After this the female gives them meat disgorged from her stomach, and brings them some unfortunate little creature to kill. Her mate takes no interest in the litter, except that he will devour them if he has the chance. Although adult at the age of a year, a Wolf does not attain its full development till twice that age, and lives to about fifteen.

The note of the Wolf is the well-known howl; in the wild state it does not bark, but may learn to do so in captivity, from hearing tame Dogs. It lives well in confinement, and breeds freely; it will also in this condition-and even when wild, as noted above-cross with Dogs. Wolves brought up from early youth have been known to display all the affection and fidelity of Dogs; but they have serious faults from the point of view of a lover of pets. They are very nervous animals, and are seldom to be trusted with children.

Considering the close relationship of the Wolf with the Dog; it is curious that their normal attitude to each other is one of ferocious animosity; but very probably this is due to the proverbial aversion often existing between relations. Domestic Dogs, at any rate, hate as well as fear the Wolf, and Wolf-hounds are among the best agents to use in exterminating it. They are, however, usually afraid of the quarry, for a Wolf is almost invariably more than a match for a Dog of the same size, owing to his tougher skin and more powerful teeth, as well as to his better training. 
It is thus a good deal easier to run a Wolf with swift hounds till he turns to bay, than to get the hounds to tackle and worry him. Strychnine has been found an excellent means of exterminating Wolves, but the use of poison has the objection that Dogs as well are likely to suffer. The only use of the Wolf when taken is to provide a very warm and serviceable fur for rugs, coats, \&c.

The Wolf is subject to hydrophobia, and much dreadful havoc has been, and still is, occasionally wrought by rabid Wolves.

\section{THE COYOTE}

(Canis latrans)

THE Coyote is a purely American animal, haunting the prairie districts of the north of that continent. In colour it is quite similar to many Wolves, being reddish grey with black ticking, but it is a smaller beast than a true Wolf, with a narrower muzzle and fuller brush, thus showing a distinct approach to the Fox type. The coat generally is very full.

The Coyote is a timid, skulking creature, full of cunning, and a dire foe not only to small and weak wild animals, but to sheep, poultry, and the like, but it does not attack man. It is, indeed, inclined to hang about his vicinity in the hope of what it can find or steal. It barks a great deal, and in nocturnal howling it is particularly proficient, like the Jackals of the East, which it much resembles in ways and character; and, like the Jackal of India, it can put up with fruit as food when its more natural animal diet is not conveniently available. It does well in captivity, but is not nearly so common in menageries as the Wolf. 


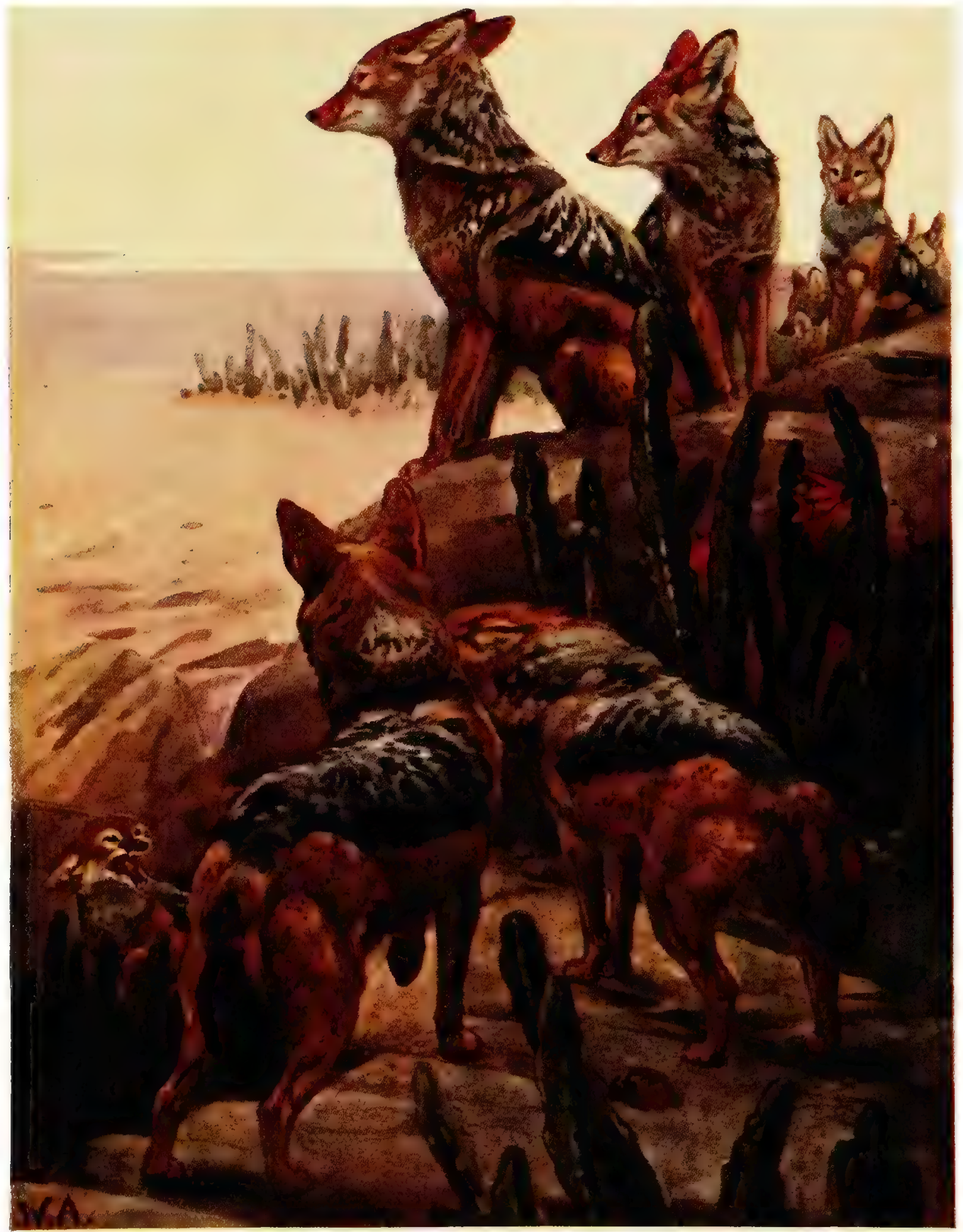

BLACK-BACKED JACKALS

By Winifred Austen 



\section{THE BLACK-BACKED JACKAL}

(Canis mesomelas)

THE beautiful Black-backed Jackal of South Africa is the handsomest and most distinct of the group of wild canines known as Jackals, which, although presenting some points of resemblance to Foxes, come closer to the Wolves. Indeed, as far as size goes, there is little to choose between the large dull-coloured Jackal of Egypt (Canis anthus) and the under-sized Wolf of the Indian Peninsula.

The Black-backed Jackal is rather larger than the average Fox, which size is characteristic of Jackals in general. Its tail is, however, longer than those of Jackals usually are, but it does not form as full a brush as Foxes' tails do. By the name of "Fox" it is commonly known near Cape-Town, where it has been regularly hunted for many years, in the orthodox way-with Fox-hounds. It has also been so hunted in Bechuanaland, but for the most part it is simply regarded as vermin, and has a reward of $7 \mathrm{~s}$. $6 \mathrm{~d}$. set on its tail, for it is a serious pest to the flocks of the Cape farmers. Like Jackals generally, however, it is a terrible coward, and seldom summons up enough pluck to tackle a fullsized Sheep. It feeds readily on carrion, and also kills Hares, while, as might be expected, it is destructive to poultry. Nothing, indeed, comes amiss to it in the way of meat; even a Water-tortoise has been found in the stomach of one.

At times several may be seen together in the evening as depicted in the illustration; but as a general rule the animal cannot be called social, even the parents not living in the earth along with their cubs, but lying out in any adjacent cover. They are, however, attentive to their young, the male as well as the female helping to provide for the family, which. usually numbers about half-a-dozen. It has been noticed that the burrow, which the animals prefer to find ready-made, has almost always a "back-door" to allow the young to escape in case of need. 
The note of this Jackal is a wailing laugh "Wa-ah wah, wah, wah"; it also utters a cackling sound when attacked. Besides being the familiar species in South Africa, it ranges north up to Abyssinia. It is not uncommon in captivity; many specimens have been exhibited in the London Zoological Gardens, where some have been bred. A number are at the time of writing thriving in a small outdoor enclosure with an earth-covered mound provided with burrows, and bear the cold as well as the common Foxes similarly housed alongside.

\section{THE INDIAN JACKAL}

(Canis az:reus)

ThIs is the best known of the Jackals, but it is a far less handsome creature than the Black-backed, being less slender and elegant in form, with a much shorter brush. Its colour also is simply brown, grizzled with black above.

In India this is a most familiar creature, hanging about the habitations of man, in hope of picking up any garbage it can find, or making prey of some kid or fowl left unsecured in the evening. It is found even in populous towns, taking refuge during the day in the drains; I have had one bolted from such a retreat under my front doorway in Calcutta. At night it goes forth on its rounds, emitting at times an abominable howl, which is calculated to rouse one from the soundest sleep. The cry is commonly rendered as "Dead Hindoo I where, where? where, where?" and I can vouch for the accuracy of the last syllables, at all events; the first crash of discord is what wakes one up!

It is said that not only dead Hindoos, but their live babies, may fall victims to this stealthy cowardly brute: and he is a real danger owing to the fact that he contracts, and of course communicates, hydrophobia. His chief use is to provide sport for the Anglo-Indian hunting community, the "Jack" taking the same place among them as the Fox does in England. A tame Jackal I saw in India had all the 


\section{THE DINGO}

actions of a Dog, and some would claim that our Dogs are descended from Jackals. How this may have come about was shown me by an anecdote told me by the late Mr. W. Rutledge, our leading animal-dealer in Calcutta and a keen practical naturalist. He had discovered the presence of a miserable mangy Jackal in a drain about his house, and kindly threw it some food at times. The creature's health improved with better meals, and it took to entering the verandah, and would at last lie down on a couch there, and, when approached, look up and wag its tail as if asking not to be disturbed-in fact, it fairly domesticated itself.

\section{THE DINGO}

(Canis dingo)

Whatever the Dog may have started from, however, there is no doubt that the Dingo of Australia is a Dog at present; it closely resembles the pariah or street dogs of the East, and I have seen, in Calcutta, a cross between one of these and a Chinese "Chow" Dog, which any naturalist would have called a Dingo at once.

The Dingo is a medium-sized animal, about as big as a Fox-hound, but lower on the legs; it has prick ears and a narrow muzzle, and the tail is bushy. There is, however, a less foxy appearance about it than is noticeable in the Wolf or in a large Jackal. The coat is tan, with more or less black ticking on the back; but there is much variety in colour, especially nowadays, when Dingos so often cross with strayed tame Dogs.

Dingos usually hunt in pairs; they are very cunning, and exceedingly destructive to sheep, calves, and poultry. Their natural wild prey is Kangaroos, when they can get them, and ordinarily Rats and such small fry.

They are often domesticated by the Australian blacks, but are not very docile, and often leave their masters, although kindly treated. As most of the Australian beasts are, as is well known, of the marsupial or pouched order, zoologists find a difficulty in believing that the Dingo 
got there naturally, and not by the aid of man. Be that as it may, his fossil remains are found in Australia along with those of extinct animals, so that if he were artificially introduced, it must have been by some very ancient race. As I have elsewhere suggested, it is quite possible that away from Australia the true Dog does not occur wild at all, but is represented by the pariahs of the towns, which have domesticated themselves to a certain extent of their own free will, the case being similar to that of the common Mouse-and, it may be added, to that of the Sparrow. This hypothesis would not, of course, exclude a descent in some cases from the Wolf, or one or more of the Jackals, and probably there has been much crossing. In any case, the original Dog was a poor, skulking brute, and owes all his fine qualities to our selection of the best individuals from our point of view; the Dingo is an unmitigated pest, and is kept down in Australia by all possible means.

\section{THE MANED WOLF (Canis jubatus)}

THE Dog family is widely distributed over the world, but, with the exception of the Wolf, the species of America are different from those of the Old World. Of the South American kinds the most remarkable is the Maned Wolf or Aguara-guazu, the latter name meaning "large fox."

This beast almost equals the true Wolf in size, but is otherwise very different; in form it is light and high on the legs, and is a far less powerful animal. Its colour is bright chestnut, with some black on the muzzle and front of the legs, and the inside of the ears white. This coloration is, by the way, repeated in a South American Deer (Cariacus paludosus), which would, by some naturalists, be supposed to have acquired its hue by natural selection in mimicry of the canine. The Aguará-guazu is a solitary nocturnal animal, and a good runner and swimmer. It seems not to attack large prey, though domestic animals are sometimes frightened by its mournful cry of "Goo-ah." It is rare in captivity, but has been exhibited at the London Zoological Gardens. 


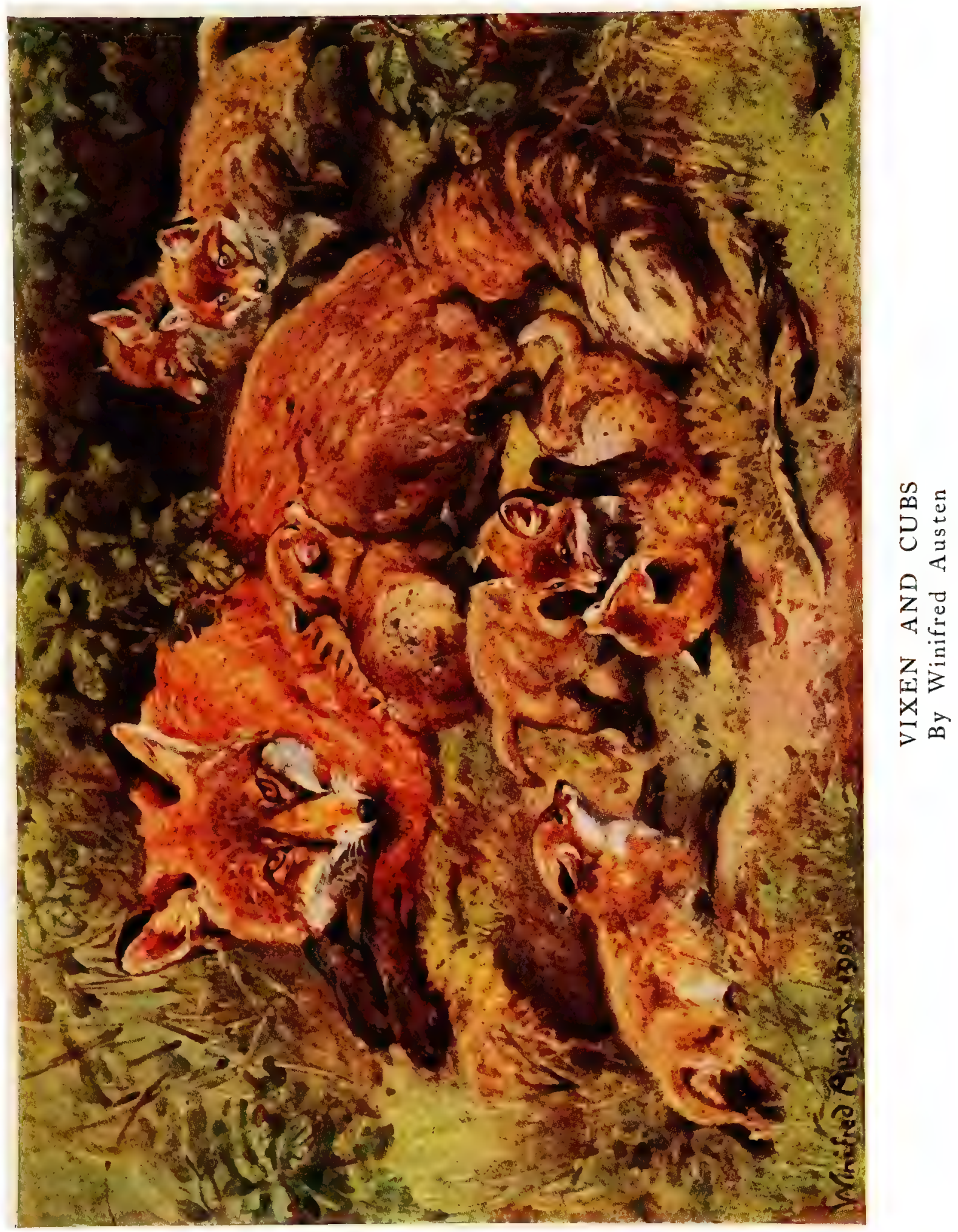





\section{THE FOX}

\section{(Canis vulpes)}

OUR familiar beast of chase can boast of a very extended range over the world, for he is found not only throughout Europe, but all along Northern Asia, including the Himalayas, while the Red Fox of North America (Canis vulpes fulvus) is simply a local race. Foxes vary a great deal in colour, both locally and individually, the typical red not being always equally intense, and sometimes absent. Our Highland Foxes are greyer, besides being larger, than the Lowland Fox, and in the Himalayas the Fox's colour is a sort of mixture of grey and yellow. In Southern Europe is found a variety of the Fox in which the under-parts are sooty-black instead of white, and the white "tag" at the end of the brush is often absent here.

What are called "Cross Foxes" in America have a dark shading along the back and a dark bar crossing this over the shoulders; while the much-prized "Silver Fox" is a black variety ticked with white hairs. The great value of this skin is due to this casual occurrence of the colour, and any one who could catch alive Silver Foxes, isolate them, and raise a. breed, would make his fortune.

Both black and white Foxes have occurred in England, and in one locality there is a superstition that if one of the former colour is run by the hounds there will be some accident during that run to one of the followers of the hunt. As the Fox has been so much and so long hunted, his life-history is a matter of common knowledge with many people. $\mathrm{He}$ preys, as all know, on any small creature he can overpower, and is the traditional foe of poultry; he is adroit enough to make the Hedgehog unroll and yield himself a victim, and is really very useful by the number of Rats and Field-Mice which he destroys. Rabbits form a large and important part of his food, and he also feeds upon Hares when he can catch them. His usual method is to stalk his prey, but he has many ruses, and has been seen to capture so wary and quick a bird as the Wood- 
pigeon by walking right among the flock with an elaborate affectation of indifference.

Lambs sometimes fall victims to the Fox in our mountain districts; and in such places, where he cannot be hunted in the orthodox way, he is shot down like any other destructive animal in consequence. Carrion is always acceptable to Reynard, and, though he is not known to eat fruit in England, he does so on the Continent, and after revelling for some time on the traditional grapes and other soft fruit, he becomes fat and loses his rank smell to some extent.

Whatever is left from his meals the Fox carefully hides, like the Dog tribe generally; this is some excuse for the apparently wanton destruction he wreaks in a hen-house, in which he will kill all the inmates. No doubt he intends in such a case to take away all the fowls and bury them, in order to live in luxurious idleness for some time.

Although he will often "lie out," especially in hot weather, the Fox's proper home is in his earth, which he does not dig for himself if he can possibly appropriate another animal's home. The Rabbit's, of course, needs enlarging, but the Badger's suits him exactly, and is often used. In the earth the vixen has her cubs, which are at first very different from old Foxes, being of a sooty colour throughout. They are playful and amusing little things, and make interesting pets, though naturally it is difficult to get them to let poultry alone. The vixen is a very fond mother, and spares no trouble in feeding and educating them. Except during their family life, Foxes are solitary animals, and usually quiet; their note is a yapping bark.

One of the most interesting habits of the Fox is his custom of sparing Rabbits or fowls which live near his den. In the case of poultry it is easy enough to see that it is obviously to his interest to do this, if he wishes to live in peace with his human neighbours; but it is noticed that his family, when they begin to forage for themselves, are not so forbearing, and the habit may have reference to the obvious need of having a confiding population of fur and feather for the cubs to practise hunting upon.

The Fox is, of course, not a popular individual with other animals- 


\section{THE ARCTIC FOX}

birds espesially; the Magpie, who has a very similar character himself, takes particular pleasure in mobbing him and betraying his movements. Among serious foes he has, out of Britain, to reckon the Wolf and the Lynx, while he may occasionally fall a prey to the Eagle, which grips him by the haunches with one foot, while muzzling him with the other. Man, except in England, is his most deadly foe, but the little beast's cunning and resource render him a difficult animal to exterminate, and he survives long even in cultivated and civilised countries.

\section{THE ARCTIC FOX}

(Canis lagopus)

Foxes as a group are very widely distributed and numerous in species, but of the foreign ones the Arctic animal is the best known and one of the most remarkable in several ways. It is smaller than our Fox, with. shorter muzzle and ears, and altogether less elegant form. Its coat is either dark-coloured-greyish or brownish slaty-or white, often varying according to season. Not all individuals, however, are dark in summer and white in winter, even in the same localities; some are always dark, and some always white. Of two individuals in the London Zoological Gardens at the time of writing, one is merely brownish in summer and bluish-slate in winter, while the other is dark with white under-parts and extremities in summer, and all white in the winter. The grey winter skins are the valuable Blue Fox fur, and in the Prybiloff Islands, where the Fur-seals breed, American enterprise is attempting to fix this blue strain. Not only are the Foxes fed in winter with sealmeat, but they are selected when captured for fur. Some of the best blues are set free again, while all white ones are killed off.

Inhabiting as it does the high northern regions of the world, this Fox has for long been a puzzle to naturalists, who could not understand how it lived in winter. It has been found, however, that it practises "cold-storage" in the short summer season of plenty, hiding away the eggs of sea-fowl and doubtless the birds themselves, as well 
as quantities of the queer little short-tailed mice called Lemmings, which are preserved by the frozen subsoil. The Fox also follows the Polar Bear in the hope of dining off his leavings, and now and then gets a welcome windfall in the shape of unfortunate Razor-bills (Alca torda). These diving-birds, wintering in the high north, often fall exhausted on the ice when they cannot discover open water after long flights, and the Fox naturally does not waste such an opportunity of adding to the larder.

$\mathrm{He}$ himself is regarded as a welcome addition to the commissariat of our Arctic explorers, and is eaten with relish whenever he can be obtained.

\section{THE FENNEC}

(Canis cerdo)

This is a beautiful little Fox inhabiting the deserts of North Africa. It is very small, only about as large as a Cat, and thus the smallest of the Dog family. The ears are, however, very large, being big enough for an ordinary Fox. The coat is of a pale sandy, almost cream colour, and the eyes dark. The Fennec feeds mostly on small creatures like the Jerboas, which share its dry and lonely home, and, like them, hides in burrows during the day. It is also very fond of fruit.

As might be expected, this pretty miniature Fox makes a charming pet, but unfortunately it is not very common in captivity. 


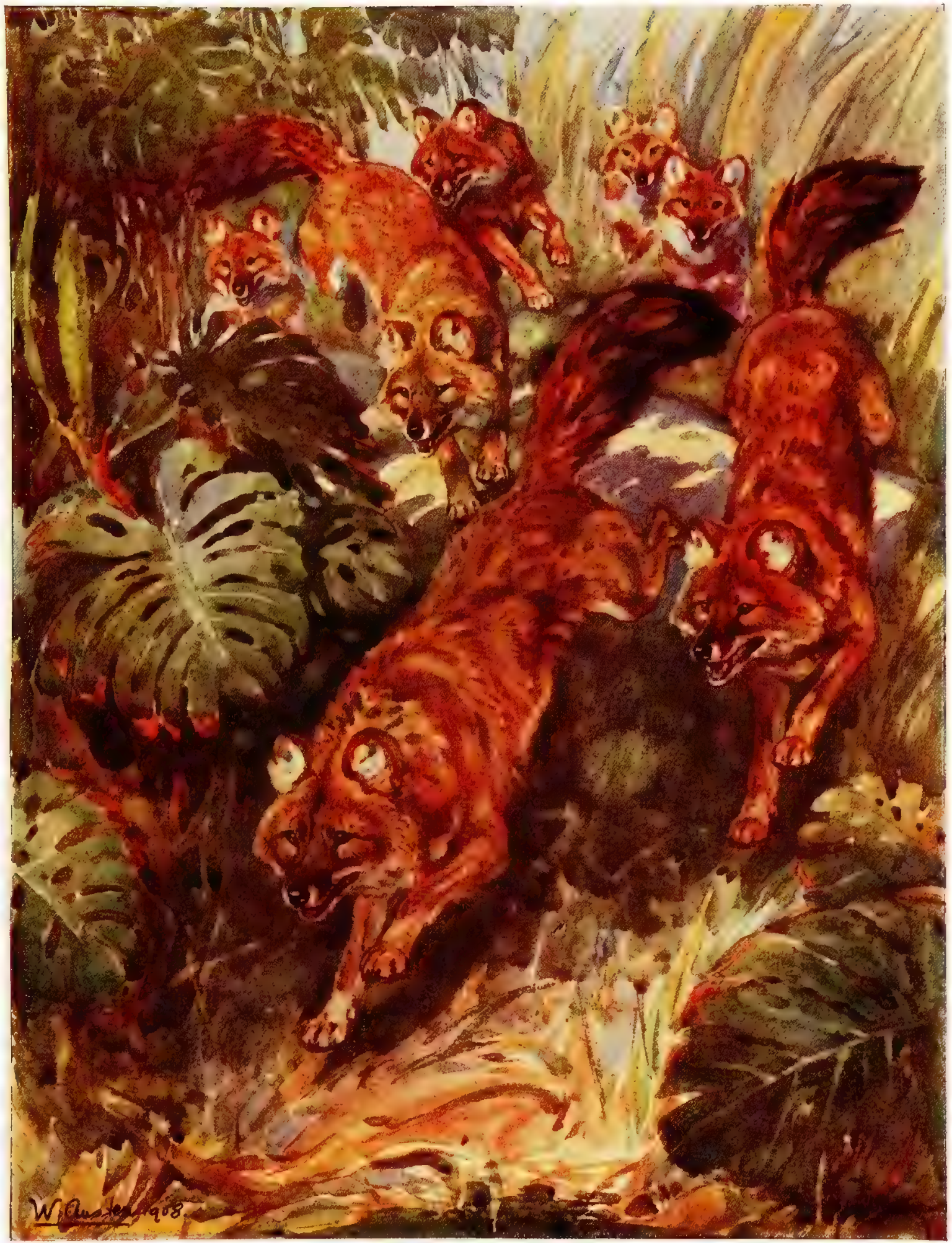

DHOLES

By Winifred Austen 



\section{THE DHOLE}

(Cyon dukhunensis)

The Dhole, or Red Wild Dog, of India, was not a very familiar animal by reputation until the publication of Mr. Kipling's "Jungle-Book," and, although sportsmen in India knew of it as one of the worst enemies of game, it is not-abundant even there. Yet it has a wide range, from Eastern Tibet almost all over India, usually in forest country. East of India it is replaced by the allied race-it is hardly a speciesthe Malay Dhole (C. rutilans).

In Siberia there is another Dhole, the only other species known (C. alpinus), which chiefly differs from the Indian animal in its much lighter colour and fuller coat, the latter being particularly noticeable on the tail, which is in winter a splendid brush.

Dholes differ from Dogs, Wolves, and Foxes in having fewer teeth, two molars in the lower jaw being missing; the teats of the female are also more numerous, and there is long hair between the foot-pads. This disposes of any possibility of tame dogs : being descended from them, and so the term "Dhole" is preferable to that of "Wild Dog."

Wild enough they are in one sense; the Indian Dhole, whose habits are the best known, is a wandering creature, travelling in packs of a dozen or less, which soon clear out the game in a jungle by the terror they inspire, and so constantly have to shift their own quarters. Their quarry is usually Deer, Nilghai, and so forth ; but almost any animal may fall a prey to them, for, although they are not bigger than Collies, and not very fast, they have a deadly persistence in following a trail, and their courage is indomitable when they have run down their prey, which they will bait until it or they perish in the fight. Even that magnificent wild Ox, the Gaur (Bos gaurus), which even the Tiger generally lets alone, has fallen a victim to them, and they have been 
seen slowly worrying to death a Himalayan Bear (Ursus torquatus), though poor Bruin, with desperate courage, was defending himself as well as he could, and had killed more than one of them. Even the Tiger himself is believed occasionally to be killed by the red pack, and in any case their operations so terrify his prey that he may be forced to leave the depleted district.

When attacking, it is the custom of the Dholes to snap at the belly and hind-quarters of the victim, and thus disembowel it, some of the pack, when necessary, making feints at it in front to distract its attention. The terrible force of their bite may be judged from a case comparatively recently reported; in which a Sambur stag (Cerous unicolor) had been attacked by them when drinking. Taking him at a disadvantage, they had wasted no time in finesșe, but had flown at his throat forthwith, and nine inches of his windpipe had been snatched out! Although awkwardly-made animals compared with the Wolf or Fox, or even the Dingo, they spring with great energy and even in confinement no other canines give such an impression of sheer ravenousnèss as these do.

They have but little fear of man, but have only once as yet been known to attack him in India. The Siberian Dhole, however, is said to be dreaded by hunters, and if the Indian species also becomes thus dangerous it will be an infinitely worse enemy to the poor natives than the Wolf or even than a man-eating Tiger. There is thus every reason to put a price on the head of the Dhole, a measure which has long been urged by sportsmen, who are naturally disgusted by its depredations on game animals.

Unlike most of the Dog family, Dholes do not appear to eat carrion ; but from the behaviour of a captive specimen in India; it has been thought that they eat some vegetable food, as this individual devoured leaves and grass with evident relish, not medicinally, as Dogs do.

Dholes breed in earths which they dig out, and in some cases at all events they form quite a colony. The pups are sooty brown, not red, when very young, like very young Foxes. They are not so tameable as Wolves and Jackals, and are very seldom seen in captivity even in 


\section{THE HUNTING-DOG}

the East; but at the time of writing this there were some fine specimens in the London Zoological Gardens, though they have since died.

\section{THE HUNTING-DOG}

\section{(Lycaon pictus)}

THIs African animal is one of the most remarkable of the Dog family, resembling as it does the Hyænas in having four toes on all feetother dogs having five on the fore-foot-and also in the form and colour of the face and ears. It is, however, a true Dog in all essential points. In size it about equals a Hound, but is remarkably thin and leggy; its coat is close on the body, and the brush short and meagre. The colour is most remarkable, being a sort of mottled tortoiseshell, disposed irregularly in a manner quite unique among wild animals, the two sides, even, of the same animal not matching. There is a little white intermixed, and the end of the brush is. always of this colour, while the mask is black. In addition to individual variation in the colours and their arrangement, there is some difference between local races in this respect, but the animal is in any case quite unlike any other beast.

It is widely spread over Africa in open dry country - in the main haunts of game, in fact-and is as deadly a foe to the Antelopes as the Dhole is to Deer in . India. It has also the same method of attack, and the same fearlessness of man, which is curious, as it is not more nearly related to the Dhole than to any other canine. The HuntingDog, however, runs in much larger packs than Dholes do, and is a remarkably. swift animal, rapidly overhauling even large Antelopes by sheer speed. It frequently attacks cattle and sheep, and commits terrible havoc amongst them.

Unlike the Dhole, it is rather given to using its voice; it has a bark of defiance, and a rallying-note, described as beautifully melodious.

Even the Lion is said to fear this animal, and to be scared by an imitation of its cry $-\mathrm{a}$ curious parallel to the relations of the Dhole with the Tiger. That it does not spare its fellow-carnivores is shown 
by an anecdote recently told by Mr. F. C. Selous, to the effect that a friend of his had known a pack of these brutes to bait a Spotted Hyæna all night-a fact he adduces as showing that Hyænas are not always the cowards they are supposed to be, since this specimen had kept them at bay, and ultimately succeeded in getting off with his life.

Hunting-Dogs breed in colonies, and display much skill in driving their game towards the home of the nursing bitches, so as to kill it conveniently near to them. In short, they seem to know all about hunting that an animal could learn, their tactics being nearly perfect.

They are not common in captivity, but have several times been exhibited in the London Zoological Gardens, and have bred in the Dublin institution.

\section{THE RACCOON-DOG}

(Canis procyonoides)

As a general rule, the Dog family have a great general resemblance to each other, not presenting so much variation in type even as the Cats, as our illustrations plainly show; but, in addition to the HyænaDog, there is another species which might be mistaken for an animal outside the canine family, although typical in the number of its toes and teeth.

This is the curious little animal known as the Raccoon-Dog, an inhabitant of Amoorland, China, and Japan. It is considerably smaller than the common Fox, and has shorter limbs and tail; its coat is very full, and varies much in colour, being usually a grizzled mixture of black and brown. The eyes are surrounded by a black patch, and this, with the general build and coat of the animal and its habit of humping its back as it walks, gives it a quite remarkable likeness to the American Raccoon (Procyon lotor). Like the Raccoon, also, it feeds much on vegetable food.

It is not a swift animal, and does not destroy poultry, the animal part of its diet being the flesh of small animals only, such as Rats and Mice. 


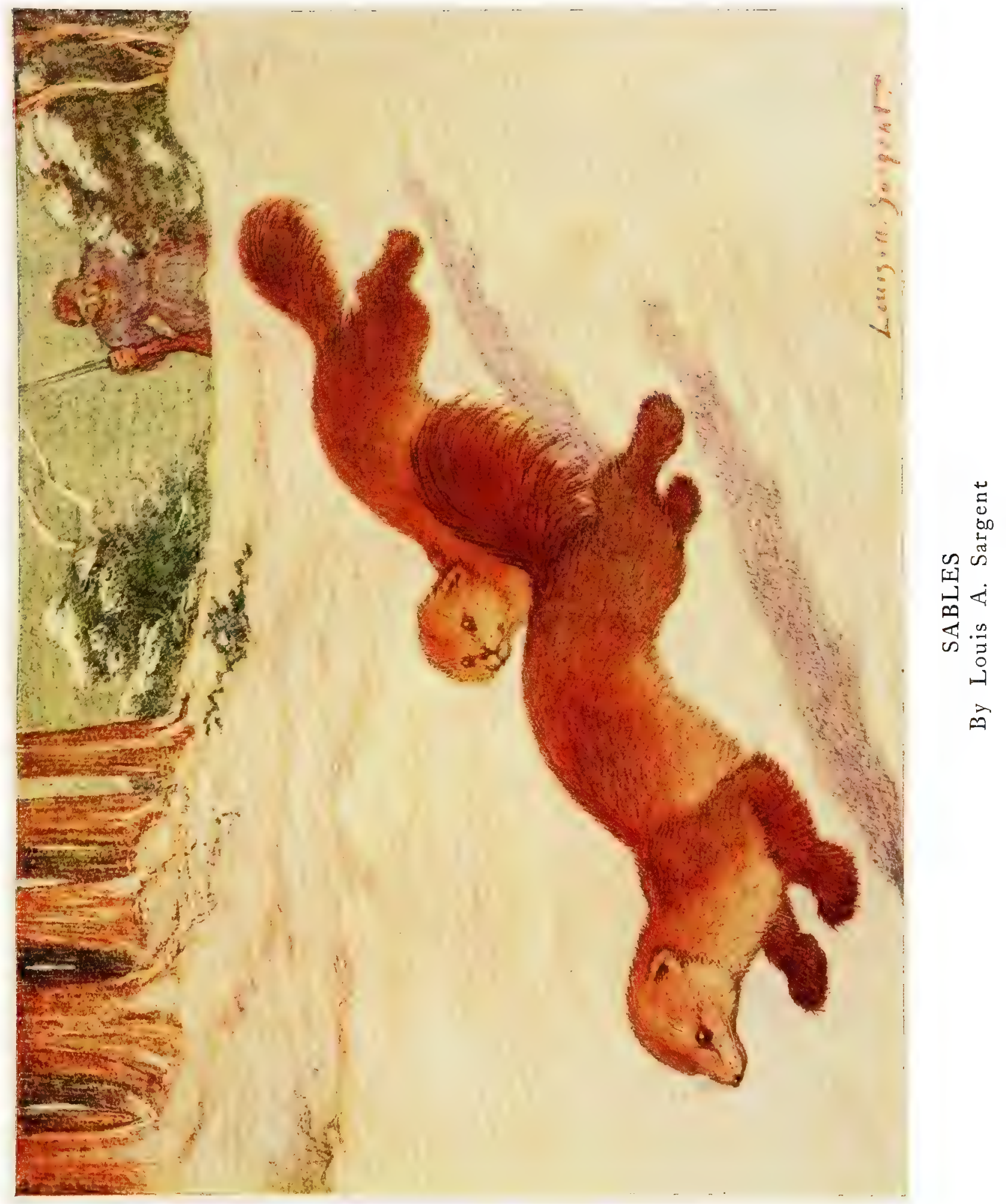





\section{THE SABLE \\ (Mustela zibellina)}

Owing to the extravagant value set on its fur, the Sable is the most celebrated of the Weasel tribe-with the exception of the Erminebut it is very unfamiliar as a living animal. It is not a large beast, measuring about a couple of feet from nose to tail-tip, and with the slim-bodied, short-legged build of Weasels and Martens generally.

Its colour is very variable, and in general the blackest skins are considered the best; a peculiarly rich effect is given by the contrast of the glossy longer hairs with the soft reddish under-fur. Except for the length and quality of the coat, there is little difference between the Sable and the Pine Marten (Mustela martes), which ranges over much of Northern Europe and Asia, and even lingers in our islands in the remote mountainous districts of all three kingdoms. Scarcely separable also is the American Sable or Marten (M. americana), one of the most valuable fur-animals of North America.

The true Sable's especial home is Eastern Siberia; formerly, at all events, it extended west to the Urals, but relentless persecution has reduced and is still reducing its numbers. The hunt for Sable pelts is full of hardships for the hunters themselves, for the creatures have to be pursued in winter, when the fur is best and thickest, and the cold is of course terrible in the Siberian forests at that season.

The Sable is a great climber, like other Martens, and when pursued by the hunter's Dogs, runs up a tree, whence it is, if possible, shaken or knocked into a net spread round the trunk, the great idea being to capture it with as little injury to the skin as may be. The creature's activity in climbing stands it in good stead in procuring its food, which consists of Squirrels, birds, and such-like defenceless creatures; it will, indeed, prey upon anything it can overcome, and is of a very bloodthirsty disposition. Occasionally, in Kamtschatka at 
all events, where the rivers so swarm with fish that fish-dinners are the order of the day with carnivora of all sorts, it will partake of this kind of food; and, in spite of its appetite for blood, it does not disdain vegetable diet, but feeds readily on berries when they are in season.

The Sable makes its den in a hole in a tree, and here is sometimes scented "out by the dogs of the hunters; in such a retreat, also, the female deposits her young, which are generally born in April, and number four or five.

The Màrtens generally display very similar habits to those described, but the Pine Marten in our country has been forced through longcontinued persecution to leave its woodland haunts and live chiefly in barren stony placès, a habit more natural for the Beech or Stone Marten $(M$ : foina $)$, which is a common animal on the Continent:

The Stone Marten has a white breast, whereas in the Pine Marten this is yellow-at any rate, in youth. It has a more southern range than the Pine Marten, but nevertheless ranges into Turkestan, where it shows a much finer coat, approaching the Sable type.

Especial interest attaches to the Stone Marten, on account of its having been domesticated by the ancient Greeks, and kept in the houses to fulfil the duties of our Cats; indeed, the word (gale) often translated "Cat," really: means this animal; although Herodotus made acquaintance with the real Cat (ailouros) in Egypt.

This Marten indeed is inclined to cultivate the society of man; from motives of its own; to inconvenient extent, for it is commonly found near human habitations on the Continent; and is an all-round pest, not only destroying poultry and stealing eggs wholesale, but devouring fruit in the orchards. It is even yet not difficult to tame, and makes a pretty and amusing pet, like other Martens. The Martens generally are northern animals, though one, the Indian Marten ( $M$. flavigula); a short-coated but most elegant and richly-coloured animal; is found even as far south as Sumatra; while it ranges in the west to Kashmir;

The most distinct of them, as well as the largest; is the Pekan or Fisher (M. pennanti), which is about as big as a Cat, and nearly all 
black in colour; from this, and from being shorter in the body and longer in the leg than other Martens, it is often called "Black Cat," or even "Black Fox." It doës riot really èatch fish, though glad to eat them if it finds any lying about.

\section{THE MINK}

THERE are, however, real fishing Weasels in the Minks, of which there are two species, the European (Mustela lutreola) and the American (M. vison), but they are so closely allied that they may be reckoned as one. They are brown in colour, with thick fur and very short ears. The American Mink is the best known, its fur being exported in large quantities, while it is a standing nuisance to poultry-owners, for Minks prey on fish, flesh, and fowl, pursuing their aquatic prey in the water almost as nimbly as the Otter. In America some successful attempts have been made to domesticate Minks, both for their fur and to use them as Ferrets are used. The Mink is about two feet long.

\section{THE POLECAT}

\section{(Mustela putorius)}

THE Polecat is the best known of the Weasels in the living state, when we conșider that our tame Ferrets are its descendants, the brown PolecatFerret showing the wild colour, while the white ones are albinos. Wild Polecats are, however, very rarely seen in Britain nowadays, for the creature is so abominably destructive to game, rabbits, and poultry that it has been killed out wherever possible. It is found, however, all across the Continent and Siberia. It is a ground-animal, and not nearly so active as the Martens or typical Weasels. Like Weasels and Stoats; Polecats have been introduced into New Zealand to keep down the imported Rabbits, but unfortunately they have not confined their destructive energies to those rodents, but do much harm otherwise. 


\section{THE STOAT OR ERMINE \\ (Mustela erminea)}

OUR common gamekeeper's pest, the Stoat, is identical with the famous Ermine whose fur trims the robe of royalty, for in cold climates it changes its coat of chestnut above and white below for a pure white all over except for the black tuft at the end of the tail, which is the same all the year round. This change seldom occurs in the south of England, but becomes common as one goes north, till in the north of Scotland it is nearly universal among these animals. Most Ermine fur, however, comes from Siberia, but some from America, for the Stoat is one of the few beasts which range all round the world. In Great Britain it is still common and well known, in spite of the persecution meted out to it by gamekeepers. It is seldom kept in captivity, but has hybridised in that state with the female Ferret, and the hybrids have bred together for two generations.

\section{THE WEASEL}

(Mustela vulgaris)

This tiny, active, long-bodied little creature, the smallest of the carnivora, has, like the Stoat, a wide range all round the world. Like that animal, too, it turns white in winter, but not so readily; thus, this change rarely occurs in our British Weasels. The Weasel is much smaller than the Stoat, though, as the sexes in both species differ much in size, there may not be much to choose between a small female Stoat and a large male Weasel. A safer distinction, therefore-the colours of the two animals being much the same- is the tail, which in the Weasel never has a black tip.

Some confusion may be caused by the fact that what are called Weasels in Ireland are not really of this species at all, but a small local race of the Stoat (Mustela erminea hibernica), for neither the real Weasel nor the Polecat are natives of that country. The true Weasel is generally a comparatively harmless animal, its depredations being chiefly on Mice and small birds; indeed, many people reckon it as highly useful. 


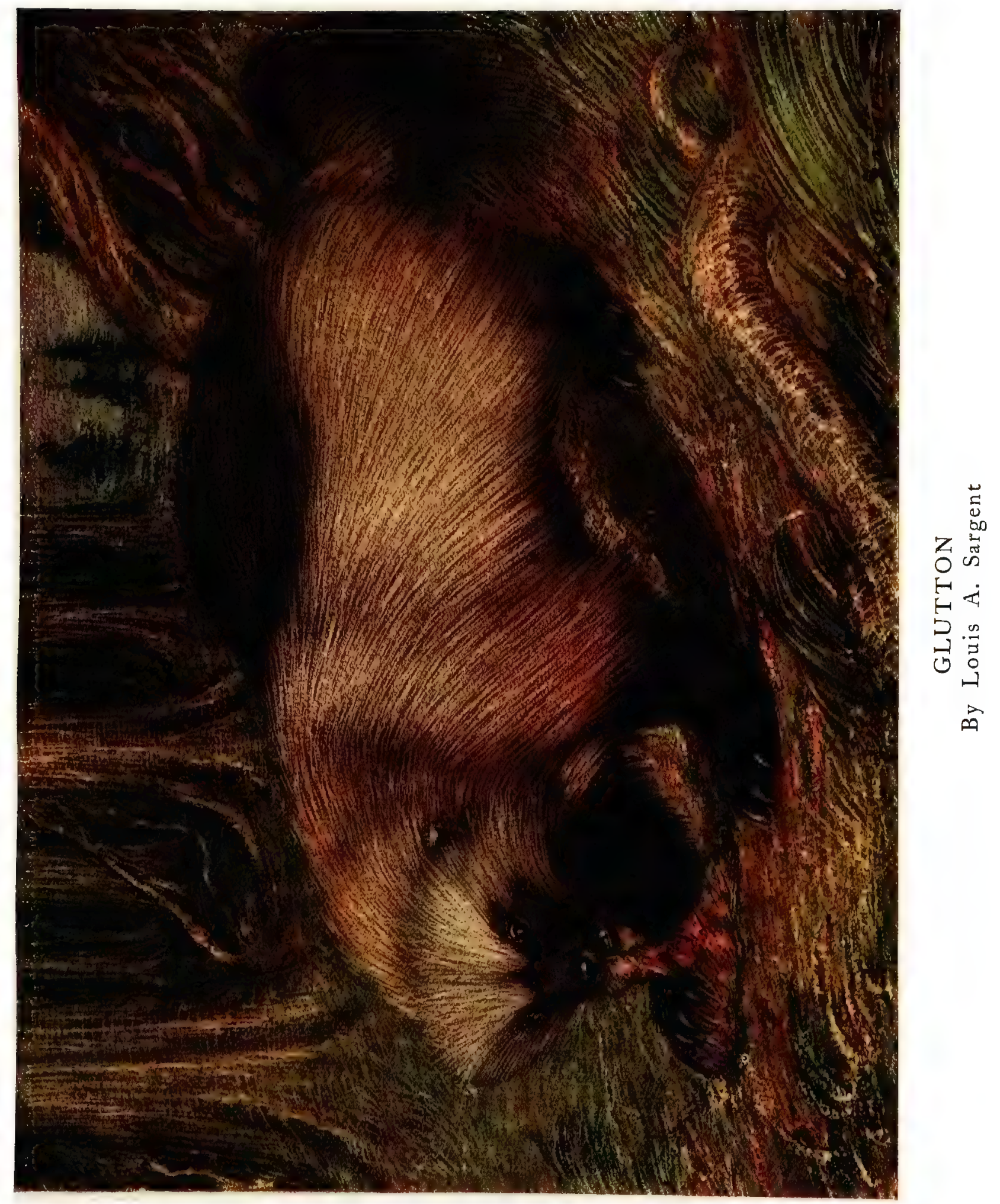





\title{
THE GLUTTON
}

\author{
(Gulo luscus)
}

THE Glutton is an animal of very wide distribution, being found all round the world in the northern forests, and it enjoys quite a number of aliases, of which "Wolverine" and "Carcajou" are the best known.

Although allied to the Weasels, it is, as the illustration shows, much more like a Bear in form, although provided with a fair-sized bushy tail. The claws are very strong and powerful, and the teeth also; the latter bear a strong likeness to the Hyæna's. The coat varies much in colour, some individuals being much darker than that represented; it is long and thick, and well adapted to resist the cold of the sub-arctic regions where the animal lives.

The Glutton is not a very active animal, but his indomitable courage and energy make up for this; he will plod for miles through the frozen forests, and, as he is a climber, sometimes lies in wait for his prey in a tree. He spares no creature that he can overpower, and his strength is such that even such large animals as the Reindeer fall victims to him; on this creature he is said to pounce from above.

His appetite is large, though he is somewhat belied by the extravagant fables which used to be told about his capacities for gormandising; and it is fortunate for him that, in addition to great strength, he is endowed with unusual cunning.

Indeed, this seems to be his great characteristic, and renders him the determined enemy of other animals, and even indirectly of man himself. $\mathrm{He}$ has a keen nose for other creatures' goods, and many a poor beast which has carefully hidden the remains of its last meal finds, when it comes back to eat these, that the Glutton has been beforehand and consumed its little store. The robber takes good care not to be retaliated upon, by indulging in its filthy practice of defiling what it cannot eat at 


\section{WILD BEASTS OF THE WORLD}

the time, thus insuring that no one else can enjoy it; for it is said that no other creature but the Glutton itself, however famished, can eat food that has been thus tainted.

The Glutton will treat in this way a cache made by the trappers, into which it has failed to make an entrance; and if it does get in, it creates lamentable havoc, for it destroys everything which is not edible, or carries the objects away, if small enough, and hides them, out of pure mischief, apparently. In a similar spirit it hunts up the traps set for the fur-bearing animals, such as Martens, eats the bait, and springs the trap, taking good care not to get caught itself. The Martens themselves it does not usually care to eat; but, in pursuance of its usual policy, it mauls and spoils them, and hides them in the snow or up in a tree.

It is not surprising that an animal with these characteristics is cordially detested by trappers ; indeed, "Indian Devil " is one of the names commonly applied to it in the fur-countries of North America, where the animal is best known, and where the above characteristics have been especially noted. When it comes to trapping the Glutton itself, the task is one of the greatest difficulty; the beast is so cunning that it has been known, when a spring-gun was set for it, to gnaw through the cord communicating with the trigger, and so appropriate the bait in safety. Like so many other cunning people, however, the Glutton sometimes over-reaches himself, and accordingly it is found that the best plan for catching him is to bury the trap, bait and all, as if one did not wish him to find it, in which case there is a considerable chance of his wariness being discounted by his desire to unravel the mystery. When captured, the animal is of some use as furnishing a valuable fur, but not very many skins come into the trade. The female Glutton deposits her young in a burrow; they are born about midsummer, and number four or five. At first they are very much lighter than the adult, being only cream-colour, and the mother displays the most desperate courage in defence of them; indeed, the Indians say they would rather meet a she-bear. with her young than a Glutton.

The Glutton can be kept in captivity, and is generally on view at the London Zoological Gardens. When taken old, however, it is usually 
almost impossible to tame, and, though the cubs are tameable and playful enough, they become more and more surly as they advance in years.

\section{THE TAYRA}

(Galictis barbara)

THE Tayra is, though a powerfully-built animal, distinctly of the usual Weasel type and form-long-bodied and low on the legs. The tail is long, and the coat short and close, of a deep-brown colour relieved by a yellow patch at the throat. The beast is of a good size, rather exceeding that of a Cat.

It is a South American animal, and widely distributed, ranging from Demerara to Paraguay. It keeps to cover, haunting either high grass or forest, and making its home in a hollow tree or the burrow of an Armadillo. A pair live togetber, and they hunt in the morning up till noon, and again in the evening. Their food consists of birds and small beasts, and they readily climb trees in order to rob nests or obtain the honey of wild Bees. As they readily approach human habitations, and commit great ravages among the poultry, they are regarded as pests; in fact, their whole habits, like their appearance, are similar to those of the Martens.

Like Martens, also, they are easily tameable, will eat almost anything, and can be allowed to run about a house like a Cat, proving more useful than that animal in destroying Rats and Mice; but it is impossible to cure them of their propensity for attacking poultry.

\section{THE GRISON}

(Galictis vittata)

The Grison, another South American animal with much the same range as the Tayra, and closely related to it, is, however, much smallerbeing hardly larger than our Polecat, if shorter on the legs. In colour 
also it differs considerably, being mostly black, with the crown and more or less of the back grey. Its expression is peculiarly villainous, and rendered more impressive by the way in which the beast will sit up and look at one. The Huron, as this animal is often called, has a habit of hunting in packs, but, except for this, its manners are much like those of the Tayra, and it is also a well-known farmyard pest. It can also make itself nearly as disagreeable as the Skunk when annoyed, it being possible to smell the scent it emits at least fifty yards off.

Notwithstanding this, it is sometimes tamed, and specimens are on view at the London Zoological Gardens at the time of writing. 


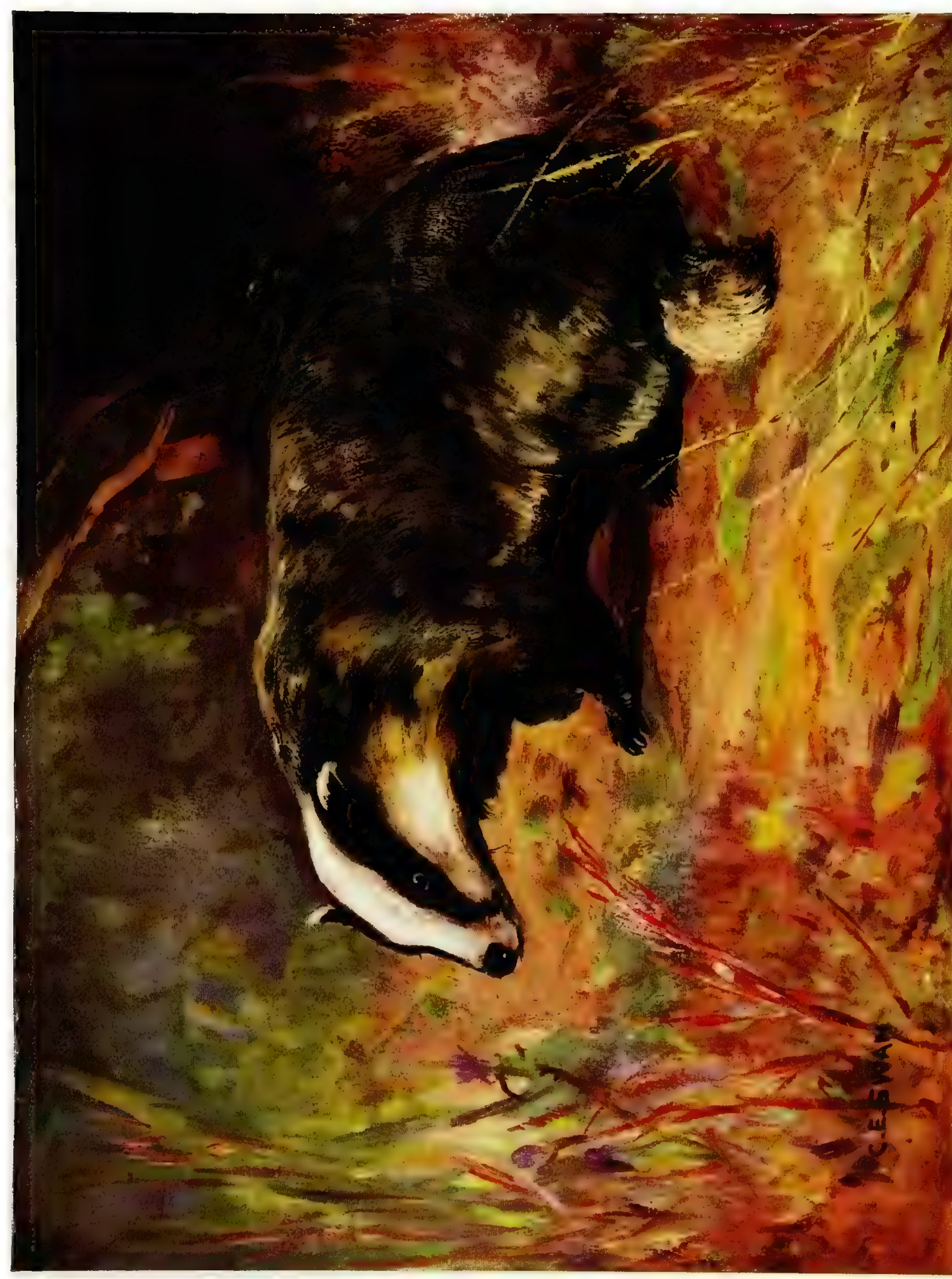

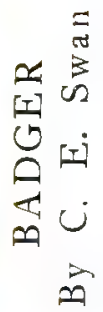





\section{THE BADGER}

(Meles taxus)

THE Badger was evidently once a very familiar animal; such expressions as "badgering," proverbs like "grey as a badger," and the number of place-names beginning with "Brock"-a local name of the beast-bear witness to his former abundance in our islands; he is also a widely-spread animal abroad, extending, all through Europe and Northern Asia.

Nowadays, the Badger cannot be called a common animal in Britain, but is still to be found almost everywhere in small numbers, and would probably be quite well known if he were not such a recluse. $\mathrm{He}$ is generally a woodland animal, but sometimes frequents rocks, and is very strictly nocturnal, for he does not come out before nightfall, and takes good care to be back home and in bed an hour before sunrise. When on the move, he travels at a fairly good pace, though with the flat-footed gait of a Bear, an animal which he much resembles in many ways, though really a member of the Weasel family. His fore-claws are very large and powerful, and he is a great burrower, his earth being large and commodious, and having several chambers. and entrances. Not being very active, he has to rely on his powers. of 'self-defence when abroad; he is extraordinarily tough in the skin, and can give a most powerful bite, so that he is a match for anything of his own weight. His great biting-power may be partly explained by the peculiar articulation of the jaw; in most animals this falls away from the skull when the bones are cleaned, but the knuckle-ends of the 'Badger's jaw are so firmly gripped in bony sockets that it cannot be separated from the skull without breakage of the bone.

The Badger is a fair-sized animal, some heavy old males reaching the weight of forty pounds, though this is exceptional. His colour is well shown in the illustration, but it is worth mentioning that the species 
is rather subject to albinistic variation, white Badgers turning up more frequently than might be expected. At the present time, also, there are at the London Zoological Gardens a pair of cinnamon Badgers, in which the black and grey tints are replaced by chocolate and sandycolour.

The Badger is essentially "a good easy" beast; he loves a good meal and a soft bed; the latter he takes care to provide by carrying into his earth quantities of well-dried fern or grass, which he hugs in armfuls and then backs into his den with it. He is very cleanly, and suffers a good deal by the Fox's intrusion into his well-kept house. Not that he seems to object to Reynard's company, and of course he is not afraid of him; but the Fox, for all his trim and smart appearance, is a dirty beast, and the way in which he leaves decomposing fragments of his meals about, and otherwise makes his surroundings unpleasant, is too much for the cleanly Badger, who often leaves his den in consequence.

The Badger's love of good living is easily gratified, as he is one of the most omnivorous of all beasts. He relishes a nice young Rabbit dug out of the nest, and no eggs that he can find come amiss, while beetles, worms, slugs, and in fact any small creature he can catch, suit his palate well. He is fond of wasp-grubs, and makes no difficulty of the stings of the old Wasps. Nor does he despise vegetable food, eating roots and fruit readily: in fact, people who feel, as many do, a fondness for this quaint and harmless beast, find one of the best ways of conciliating him is to strew dates and raisins at the entrance of the earth. By such kind treatment it is possible to get some insight into Badger life, which seems a pleasant and sociable existence. The male and female live together all the year round, and the cubs.remain with their mother quite a long time. She is as careful of their toilet as a Monkey; and carefully examines them every evening for parasites. In winter the Badger comes abroad very little, and in severe weather may almost be said to hibernate.

It is not an easy matter to trap a Badger, as it needs a strong trap to hold the beast, and he is so cunning that he will deliberately spring again by turning a somersault on it, the jaws getting no grip on his broad 


\section{THE AMERICAN BADGER-THE HOG-BADGER}

back. The best way to take him is to place a sack in the entrance of his earth when he is out foraging, and then hunt him back home with Dogs, when he will bag himself in his hurry.

As is well known, Badgers used to be largely captured for the brutal sport of "Badger-drawing," the beast being given a barrel to retire into, whence the Dogs were expected to pull him, if they could, for to do so severely taxed their pluck and strength. The chief motive: for the capture of Badgers nowadays is the use made of their hair, which is worked up into all sorts of small brushes, especially shavingbrushes. The flesh also is esteemed in some places, the hind-quarters in particular being reputed to make good hams.

Badgers do well in captivity, and often breed in that condition, while, if taken young, they can be made so tame as to run at large.

\section{THE AMERICAN BADGER}

\section{(Taxidea americana)}

IT often happens that the North American representative of an OldWorld species differs little, if at all, from it; but the American Badger is very noticeably different from ours, although the relationship of the two beasts is obvious enough. The general colour is very similar, but the American animal has a much narrower stripe of white down the face, which is continued down the back, and the head is somewhat differently formed. The body is also peculiarly broad and flat-looking.

The American Badger is a beast of the plains, where it lives in burrows, relying on this and on its great strength for safety against the Wolves. It is mainly carnivorous, living on small beasts like Mice, "Gophers" and Ground-squirrels, which it digs out of their holes.

\section{THE HOG-BADGER}

(Arctonyx collaris)

OuR Badger is in many ways reminiscent of the Bear and the Pig, but this Indian animal is at once more bearish and more piggy, so to 
speak, as it is higher on the legs than the true Badger, and also has a very pig-like snout. The native name for the animal, Bhaloo-soor (Bear-pig) recognises this, as well as the English title. The Hog-badger is said to be able to stand on its hind-legs as readily as a Bear; in its general habits it is not unlike the common Badger, being omnivorous and dwelling in rock-crevices or burrows.

\section{THE RATELS}

THE Ratels (Mellivora) are more bear-like in general form than the other Badgers, and are remarkable for having no external ears and for their very short and scanty coat. Two species have long been distinguished, the African (Mellivora capensis) and the Indian (M. indica), but they are so closely allied that they might fairly be reckoned as local races of one. Both are black below and on the muzzle, and grey above, the African species having the grey upper parts bordered with white. Recently an entirely black species $(M$. cottoni) has been described from the Ituri forest in Central Africa.

Like Badgers generally, Ratels live on the ground and in holes, but climb trees occasionally. They seem to be more carnivorous than the ordinary Badger, and the Indian species is said to dig up graves in order to devour corpses, which, after all, is a feat any carnivorous animal which is a good burrower might be expected sometimes to perform.

The African Ratel is very fond of honey, and is said to be guided to it by those wonderful little birds the Honey-guides (Indicator), so well known for their habit of taking men into partnership in honey-getting. In captivity Ratels live remarkably well, and are most amusing animals; whatever their habits may be in the wild state, they are active enough by day in captivity, and show themselves remarkably good climbers. They also so frequently show the habit of turning somersaults, that it would seem likely that this is one of their actions in a wild state, whatever the purpose of it may be under those circumstances. 


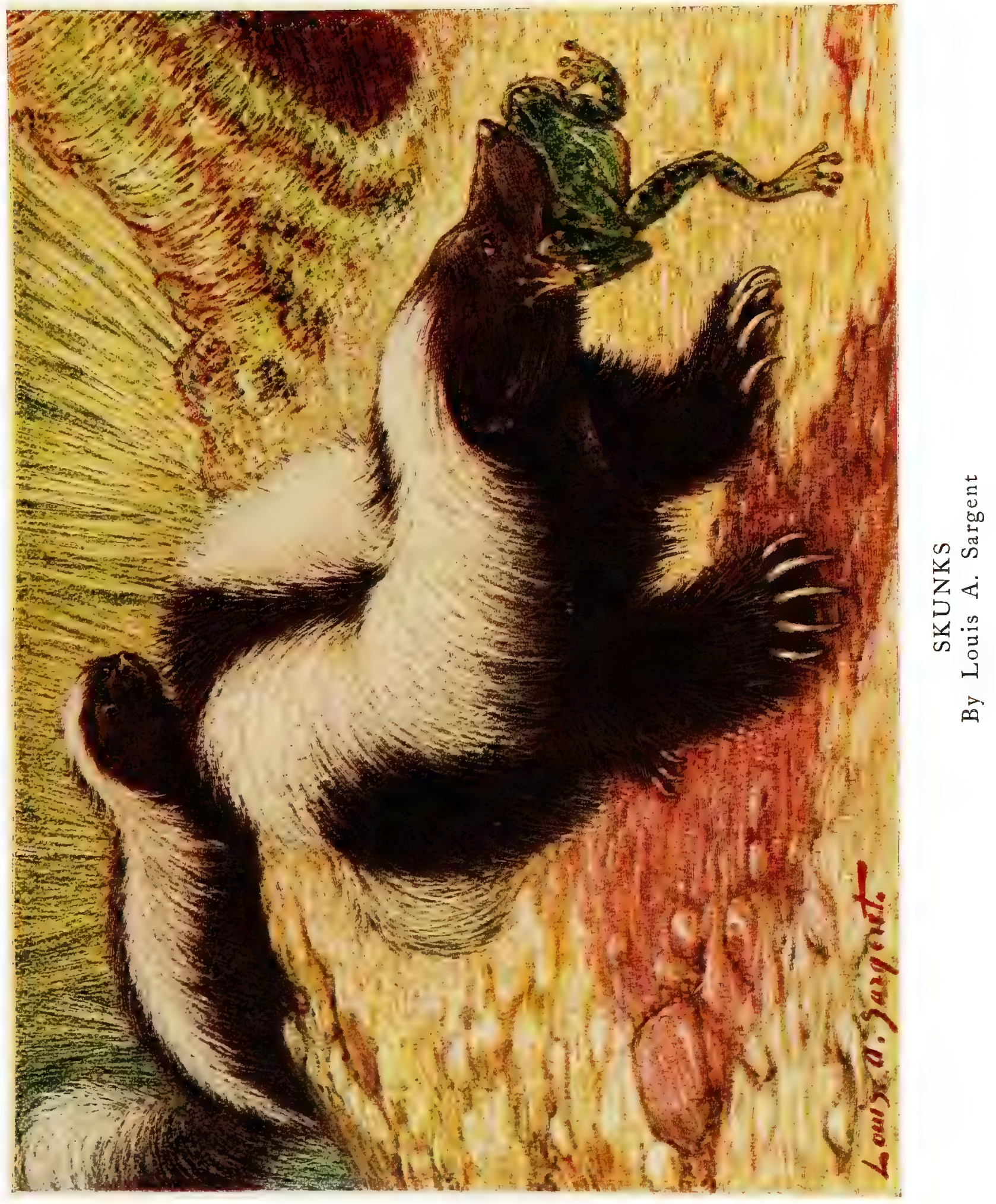





\section{THE SKUNK}

(Mephitis mephitica)

EVER since the pioneers of civilisation in America made his acquaintance, the Skunk has enjoyed a reputation a good deal wider than it was high, on account of his remarkable power for making himself objectionable when interfered with.

He is a member of the Weasel family, but is a clumsy, slow, heavilybuilt animal compared to the typical Weasels, nor has he their strength and ferocity, though his comparative immunity from molestation by other animals gives him impudence.

The illustration well shows the colour of his pied coat, but the amount of black and white on it varies a great deal ; the latter colour is always, however, on the upper surface. The tail in some varieties forms a beautiful white brush, which the beast holds aloft as a kind of dangerflag in his nightly walks abroad.

Secure in his defensive artillery, he does not hurry himself, and shows hardly any fear of man; indeed, such is the respect in which he is held that no one will venture to drive over him, and if he comes into camp and starts rifling one's provision basket, he cannot be summarily ejected for fear of consequences, for any article tainted with his odoriferous secretion is useless ever afterwards.

This powerful fluid is of a yellow colour, and clear; it is contained in two sacs situated under the tail, and can be ejected to a distance of three or four yards. Its offensiveness consists not only in its vile smell, but in its appalling pungency ; it painfully affects even a Dog-an animal which has a decided taste for some smells which are highly objectionable to us -and if it reaches the eye gives rise to much pain and serious inflammation. If the animal is killed instantaneously, as by a shot through the head, it has no chance to avenge its death, but of course this is not always practicable, so that the Skunk is habitually treated with a deference as great as it is begrudged. 
Another odious attribute of the beast is its habit of approaching sleeping people and biting them-not from spite, apparently, but from a wish to eat them, just as Rats sometimes do; but the Skunk's bite is said to produce hydrophobia, and in any case it is greatly dreaded even by such hardy and courageous men as the Western cowboys.

Enough has been said to show that the Skunk's ill name has certainly sufficient justification; but, except for its stench and its bite, it is really an excellent little animal. Although of fair size for a Weasel, being about as big as a small Cat, it is less bloodthirsty than most of its tribe, though occasionally guilty of raids on the hen-roost. Its ordinary prey consists of mice, frogs, insects, and so forth, and it really does a great deal of good in the destruction of vermin.

It is a ground-animal and a burrower, having large powerful claws on the fore-feet; in its burrow its young are deposited. They keep with the parent for some time after they can go about, and when quite small will erect their tails, stamp, and make ready for action with as much energy as the old ones. Skunks become very fat in autumn, and hibernate in the northern parts of their range, for the species is a wide-ranging one, being a familiar animal from Canada to Guatemala. It shows, however, much local variation, and several races are distinguished.

The flesh of the Skunk is quite good to eat, being white and tender, and is appreciated by the Indians, while the fur is well known to ladies. The animal is also devoured by some predatory creatures, in spite of its smell, which, of course, may not necessarily offend the nostrils of all creatures.

Skunks can be tamed if taken young enough, and make very nice pets; but I fancy few people would care to keep them unless the scentglands had been removed, an operation which can be successfully performed. Thus the animal has been exhibited at our Zoological Gardens, and a female and her young, which were quite small when the family was imported, are there at present. These animals when annoyed show unmistakable signs of what they would do if they could, so that a specimen in full possession of its powers would demand more consideration than could be conveniently given in a menagerie or even a private household. 


\section{THE SOUTHERN SKUNK-THE SMALL SKUNK 131}

\section{THE SOUTHERN SKUNK}

\section{(Conepatus mapurito)}

THE Skunk of South America, which ranges north into the territory of the other, in Texás, and extends south to Patagonia, although similar in general appearance to the northern species, is a very distinct animal, larger, heavier in build, and with a much more pig-like snout. Its general colouration is similar, and is also very variable, but it is apt to show more white, some specimens being of this colour all along the upper parts, which gives them a very handsome appearance.

As a scent-producer the South American Skunk is quite equal to its northern relative, and the same sort of stories are told about it. It is, however, also not always immune from the attacks of beasts and birds of prey; though on one occasion a Caracara or Carrion-hawk (Polyborus brasiliensis) was seen to be woefully discomfited by getting the discharge of his intended victim full in his face. This, however, was the bird's own fault; with the cowardice of his kind, he had been making a half-hearted attack on foot from behind; the crushing pounce and grip of a nobler bird of prey would have had a very different result.

The South American Skunk is said to be unable to discharge its fluid if boldly seized by the tail, though it is only fair to say that there is a difference of opinion on the matter! No doubt there is a right and a wrong way of "tailing" a Skunk, and so good an observer as Mr. O. V. Aplin has actually seen it done successfully. As in the case of the proverbial nettle, half-hearted measures in grasping the offence, such as the unfortunate Hawk tried, are of no use:

\section{THE SMALL SKUNK}

(Spilogale putorius)

IN the more central parts of America, from Guatemala north to the Southern United States, is found a little Skunk not larger than a 
Ferret, and more delicately shaped than the other species. Its colouration also differs in detail, the white markings being more numerous, but, like Skunks generally, it shows much local variation.

\section{THE ZORILLAS}

THERE are no true Skunks in the Old. World, but some very colourable imitations of them exist, which after all are very nearly allied, being themselves members of the Weasel family. The African Zorillas (Ictonyx) connect the Skunks with the typical Weasels, in size and form resembling Polecats, while they have the black-and-white colour of Skunks. As in the small Skunk, the most Polecat-like of the Skunk groups, the stripes in the Zorillas are more numerous than in the large Skunks. Zorillas not only look like Skunks, but are said to smell nearly as bad; notwithstanding this, however; they are often tamed, and many specimens have been exhibited at the London Zoological Gardens.

\section{THE TELEDU}

(Mydaus meliceps)

IF on the one hand the Skunks approach the Weasels, they are on the other even nearer the Badgers, the Teledu, which ranks as a Badger, being in several respects very like a Skunk. This animal, found in the mountains of Java and Sumatra, is a small beast; hardly as big as a Cat, with a badger-like general shape, long pig-like nose, and very short stump-tail well tufted with hair. In colour it is dark brown, with white along the back, and, in addition to this Skunk-colouration, it is able to produce an odour which fairly rivals that of the real Skunks. For the rest, it is a burrowing animal, and feeds much on earthworms. Though said to be easily tamed, it seems rare in captivity-it would certainly not be an inviting pet, as it is not even good-looking-and I have never heard of its being brought to Europe alive. 


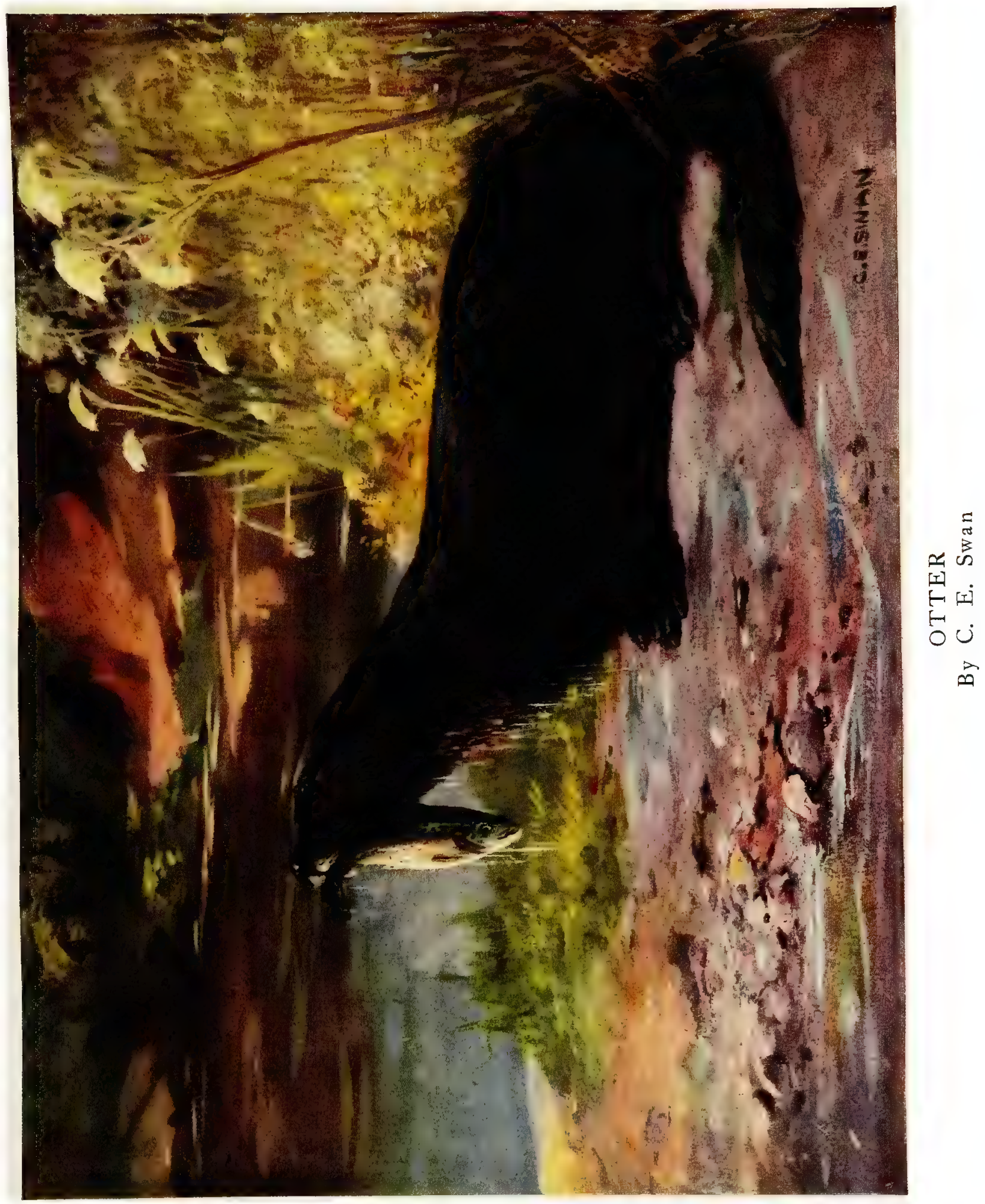





\section{THE OTTER}

\section{(Lutra vulgaris).}

Although very seldom seen, owing to its caution and nocturnal habits, the Otter is the most widely diffused of our larger animals, and there are few streams which it does not occasionally visit, while on the Highland coast it frequents the sea-coasts. In size the Otter may be compared to a medium-sized Dog, although very low on the legs, which are furnished with webbed five-toed paws. The general structure of the beast is that of a large Weasel, and the existence of the Mink shows how the Otters may have exolved from a land-animal of the Weasel kind. The coat of the Otter is composed of two sorts of hair, long piles which form the external surface, and a short thick fur which is not seen till the long hairs are removed. There is little variation in colour, but albinos have been recorded. The male Otter is rather more than a yard long, and weighs about twenty pounds, the female averaging about five pounds less; but much heavier individuals occur, dog-Otters of over thirty pounds being on record, and one, taken more than a century ago, weighed over forty.

The Otter is beautifully adapted for an aquatic life, and spends a great deal of its time in the water in pursuit of the fish on which it preys to a great extent; its motions are beautifully easy and rapid, and it readily captures small fish, though it is not a match in speed for those approaching its own size. Among fish, eels are its favourite food, and it is by no means especially destructive to game fish such as trout and salmon. Like most of the Weakel family, however, it is apt to be wantonly destructive; and when food is abundant is very dainty, often only eating a small piece from the back of the neck of a big fish, and then catching another. Indeed, St. John tells a story of an old Highland woman who, living near a salmon river, looked on the neighbouring Otters as very useful providers, since on most days 
they left her a fine fish which she thought "was none the worse for the bit the poor beasts had taken for themselves." In spite of its special adaptation for an aquatic life, the Otter does not confine itself to a fish diet; it also feeds on Frogs and on waterfowl, especially Moorhens and Dabchicks, while its character is not above suspicion in the matter of poultry and Rabbits.

Either in search of such prey, or in shifting its quarters, the Otter travels about a good deal on land, where it moves actively in a sort of jumping gallop; it is a great wanderer, seldom staying long in one locality, and thus it is that it is sometimes found in most unlikely places. Sometimes, too, it lies up in a hedge or other covert away from the water, but more often its den or "holt" is in some hole quite close to the water-side.

Here the female deposits her cubs, which may be born at any time of the year, and may number as many as six. She is a fond mother, and takes great care of her young; their first education seems to be in catching Frogs in the meadows, for they do not take to the water at once. Otters are playful creatures, and spend much time in aquatic gymnastics, even when adult. Their note is a sort of whistle, but they also utter a harsh yelping mew.

Otter-hunting, as it is carried on in summer, and on foot, has attractions of its own, and the practice undoubtedly makes for the preservation of this interesting creature, though, even if the pursuit of the Otter were not followed, it does not do enough harm to justify very rigorous measures against it. The fur it furnishes is a good one, and the flesh has been used for food; it is said to be permitted to be eaten as fish by the Roman Church.

The hound proper for the chase of the Otter is rather smaller than the Fox-hound, and rough-coated; it is very mellow-voiced, but savage in temper. Fox-hounds will also hunt the Otter well, and are often used for the purpose. The barbarous custom of spearing the poor brute when hunted down has now long been obsolete, fortunately, and the only interference permitted is the "tailing" of the Otter under certain circumstances, or the lifting of it with the leaping-pole carried 
by the followers of the hunt, and this only in exceptional cases. Any one "tailing" an Otter, by the way, has to be careful, or he is likely to find out that the quarry can inflict a very severe bite.

Young Otters brought up by hand make very interesting pets, and can be taught to catch fish for their masters; in captivity they have been observed to eat horse-chestnuts, which looks as if the wild animal may sometimes vary its carnivorous diet.

The Common Otter has a wide range, all across Europe and Northern Asia, while it is also found in India.

In that country, however, another Otter is common, the Small-clawed species (Lutra leptonyx); this is only about as large as a Cat, and, as the name implies, has very small claws. In general appearance it is much like our species, and indeed all Otters look much alike but for size. They are found everywhere except in the Australian region.

In Africa two Otters are well known, the Spotted-necked (Lutra maculicollis) which is very similar to our Otter but with brown spots on the neck, and a much larger kind, the Clawless Otter (Aonyx inunguis), which has no claws at all, and the feet only half-webbed; this species seems to be less thoroughly aquatic in its habits. The North American Otter (Lutra canadensis) is much like our own, and supplies most of the Otter skins which come into the fur trade.

In South America there occurs the giant of the group, the great Brazilian Otter (Lutra brasiliensis), which is twice as large as oursnearly as big as a small Leopard, in fact. These great Otters are often seen in small parties in the rivers, and they show little fear of man; in fact, in some places the natives seem to be rather afraid of them.

It is suggested that the mysterious "Water-tiger" of Patagonia, a river-haunting carnivore which is dreaded by the Indians-by no means a timid set of savages-and leaves tracks as big as a Puma's, is a large race of this beast, or some nearly-allied species; but so far no European has got even a sight of it, though more than one traveller has been convinced of its existence. 


\section{THE SEA-OTTER}

(Latax lutris)

THE Sea-Otter is very distinct from all the other species, and in some respects, both in appearance and habits, approaches the Seals. It is rather short and bulky in form, with the tail comparatively short and bushy, not sleek and tapering as in ordinary Otters. The toes of the fore-feet are remarkably short and stumpy, while those of the hind are very long, increasing in length from the inside outwards, and, as they are fully webbed, the whole foot distinctly recalls a Seal's flipper.

The animal is much bigger than the Common Otter, and of a darkbrown colour, silvered by lighter hairs. It is only found on the North Pacific coasts, and chiefly about the islands of the Aleutian coast, and is now rare even there, being so much persecuted for its skin, which is one of the most valuable of furs.

It spends almost all its time in the water, and is slow and awkward on land; indeed, it is said that its single cub is often brought forth on the floating beds of kelp-weed. Its mother often nurses it while lying on her back in the sea, this position being a favourite one with the animal.

The Sea-Otter does not feed much on fish proper, but on clams, mussels, sea-urchins, and such-like "shell-fish"; it is also stated to eat sea-weed. In accordance with this diet; its grinding-teeth are much broader in the crowns than those of the typical Otters, being adapted for crushing rather than cutting. It is said not to be possible to keep this animal in captivity, but all such statements should be received with caution; probably the right method has not been tried in this, as in so many other cases of the kind.

Sea-Otters are now usually procured with the gun, and are very timid and wary; it is greatly to be wished that the pursuit of them could be regulated or even put a stop to for a time, as it would be a great pity if so valuable and interesting an animal were allowed to become extinct. 


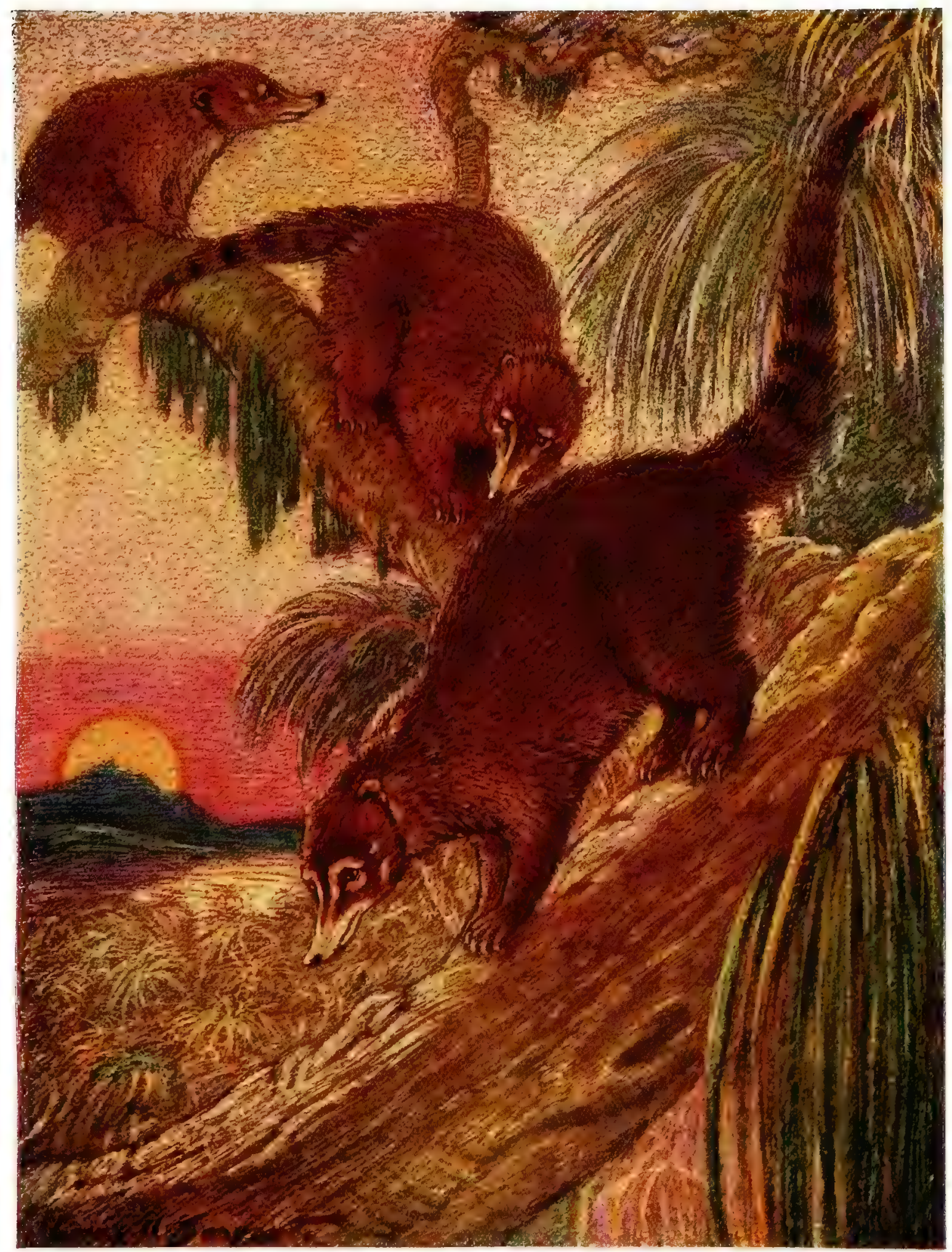

WHITE-NOSED COATIMONDIS

By Louis A. Sargent 



\section{THE WHITE-NOSED COATI}

\section{(Nasua narica)}

THE Coatimondis are the quaintest-looking members of the small family of carnivores known as Procyonida, and chiefly inhabiting America. The absurd-looking long nose, which is remarkably flexible, is confined to the Coatis, but the long tail and short legs, with five strongly-clawed toes on each foot, are family characteristics, as is the climbing habit. The canine teeth are remarkably strong, and flattened sideways like knife-blades. In size the Coatis are about equal to a Scotch terrier; there are two species, the White-nosed one represented, which is Central American, and the Ringtailed Coati (Nasua rufa) of South America. Both species vary very much in colour, but the more distinctly ringed tail of the Southern species is a fairly good distinction as a rule, and it has longer ears and a coarser coat. Its general hue is foxy-red, but it is sometimes iron-grey.

Coatimondis are forest animals, and wander about either singly or in troops, in search of prey. The White-nosed species, called Pisoti in Nicaragua, was watched by Belt in that country hunting the great Iguana Lizards : a single individual seemed to have but poor luck, for so soon as he got near his apparently unconscious victim, the Lizard would, according to its habit when alarmed, drop down to the ground, so that nothing was left for his pursuer but to follow suit and try again. The more usual method of the Coati, however, was to hunt in packs, some climbing the trees to rouse the game, while others ran below, so that any unfortunate creature hoping to escape from the scaling party by a jump would simply fall in to the arms of those underneath.

In addition to reptiles, birds, and other animals, the Coatimondis feed on fruit and other vegetable substances, being, like all the Procyonid family, omnivorous to a greater or less extent. They show great dexterity in manipulating their food, using the fore-paws more or less like hands, while the snout is used both as a feeler and for ploughing up the ground, in search of insect-grubs and worms. 
Coatimondis of both species are frequently kept in captivity, and are commonly on view in our Zoological Gardens. They are, in spite of the warm countries they inhabit, quite hardy, and winter well in covered dens outdoors, while their quaint appearance and ways make them amusing pets. They are, however, very vicious to each other, so that it is not an easy matter to get even a pair to live together. Both species, however, have bred in captivity.

\section{THE RACCOON}

(Procyon lotor)

As in the case of the Coatis, there are two species of Raccoons, but these very closely allied, the Crab-eating Raccoon of South America ( $P$. cancrivorus) differing chiefly from the Northern species in its short coat. The long handsome grizzled fur of the common Northern Raccoon is a familiar constituent of rugs, and appended to these are seen the pretty black-andyellow-ringed tails of the animals. In size and general form the Raccoon is not unlike a Fox, especially about the face, which is black about the eyes, forming a sort of mask. The tail is, however, much shorter and less bushy than a Fox's, and the peculiar humping of the back as the animal walks, the fact that it goes on the soles of its feet and not on the toes, together with the full development of all the five toes, and their almost finger-like freedom of action, marks out the creature as something quite different from the Dog tribe.

Being common over North America generally, the 'Coon, to use the familiar abbreviation of its name, is a very well-known animal, although, from its very nocturnal habits, one that is not frequently seen unless hunted for. It passes the day in a hole or fork in some large tree, rolled up with its head between its fore-paws, and at night prowls about in search of food, which consists practically of anything it can get, vegetable or animal. It is a great robber of hen-roosts, and also has some idea of fishing, adroitly hooking out the unfortunate fish with one of its nimble paws, which are almost as hand-like as a Monkey's. It is very destructive to maize-crops before the grain has hardened. 
In cold winter weather it hibernates, a whole family often occupying the same den. The young are born in the spring, and number up to six ; they stay with the parents for one season at least, being sociable creatures.

The use of the Raccoon's fur has been previously alluded to, and it may be mentioned that its flesh is sometimes eaten. For this reason, and on account of its occasional misdeeds, it is hunted a good deal, but nevertheless holds its own, and is apparently even spreading, life in a settled country suiting it.

Raccoons do well in captivity; the Northern species at any rate has bred in the Zoo, and the Southern one, curiously enough, stands outdoor life quite as well. They show themselves very cunning and intelligent, and have the remarkable habit of washing their food in water before eating it : this has very long been known, the scientific name "lotor" meaning "a washer."

\section{THE KINKAJOU}

(Cercoleptes caudivolvulus)

THE pretty animal known by this name was originally classed as a Lemur, and indeed it is somewhat like one in general appearance, while, although its paws are furnished with claws instead of nails, they are so hand-like in use that the beast can hold a bit of food in one and break pieces off it with the other. The tail is long and strongly prehensile, this being the only carnivore but the Binturong which possesses a tail of this type. In size the Kinkajou about equals a Cat; its coat is short and thick, and of a peculiar sooty yellow in colour. It is a South American forest animal, nocturnal, and an active climber, and lives chiefly on fruit. Its tongue is long and very extensible, and it is fond of honey. In captivity it makes a nice pet, and is often kept. Very similar to the Kinkajou is the Bassaricyon (Bassaricyon alleni), also a South American animal of this family. This, however, is a rare beast ; it has not the long tongue of the Kinkajou, and is ill-tempered-at least, the specimen shown at the Zoo was soso that any one who gets hold of a short-tongued and short-tempered Kinkajou has got a bargain from the scientific point of view. 


\section{THE CACOMISTLE}

\section{(Bassaris astuta)}

THIs pretty little animal, about the size of a small Cat, is remarkable for its long thickly-furred tail, ringed with black and white. Its coat is grey, and its face rather fox-like; the claws are somewhat retractile. It is found in Mexico and Central America, and is an omnivorous nocturnal tree-climber. It is often tamed, and makes a charming pet, but only one has ever found its way to our Zoo. There is another species (Bassaris sumichrasti), which much resembles the common one.

\section{THE PANDA}

(Alurus fulgens)

The Panda is the only member of the 'Coon and Coati family which is found out of America, being a native of the Himalayas. It is a thick-set animal about as big as a small Fox, with a short face like a Cat; the eyes, however, are small, not large and full like a Cat's eyes. The tail is long and bushy, and all the fur very full, even on the feet. The colour of the coat is very beautiful, a rich maroon-red, shading into black below, and with white on the face; the tail is ringed with light and dark red.

The Panda is, like all this family, a climber, but it appears to be particularly vegetarian, feeding mostly on fruit and leaves, especially bamboo-shoots. In accordance with this habit, its teeth are more adapted for grinding vegetable food than those of other carnivores, and its canines are small; it is also very slow and harmless for a beast of the carnivorous order.

Being uncommon, and very intolerant of heat, so that it can only be brought down to the Indian sea-coast during the winter season, it is seldom seen in captivity even in India; but I once saw a beautiful specimen in Calcutta, and one or two have reached the London Zoological Gardens. 


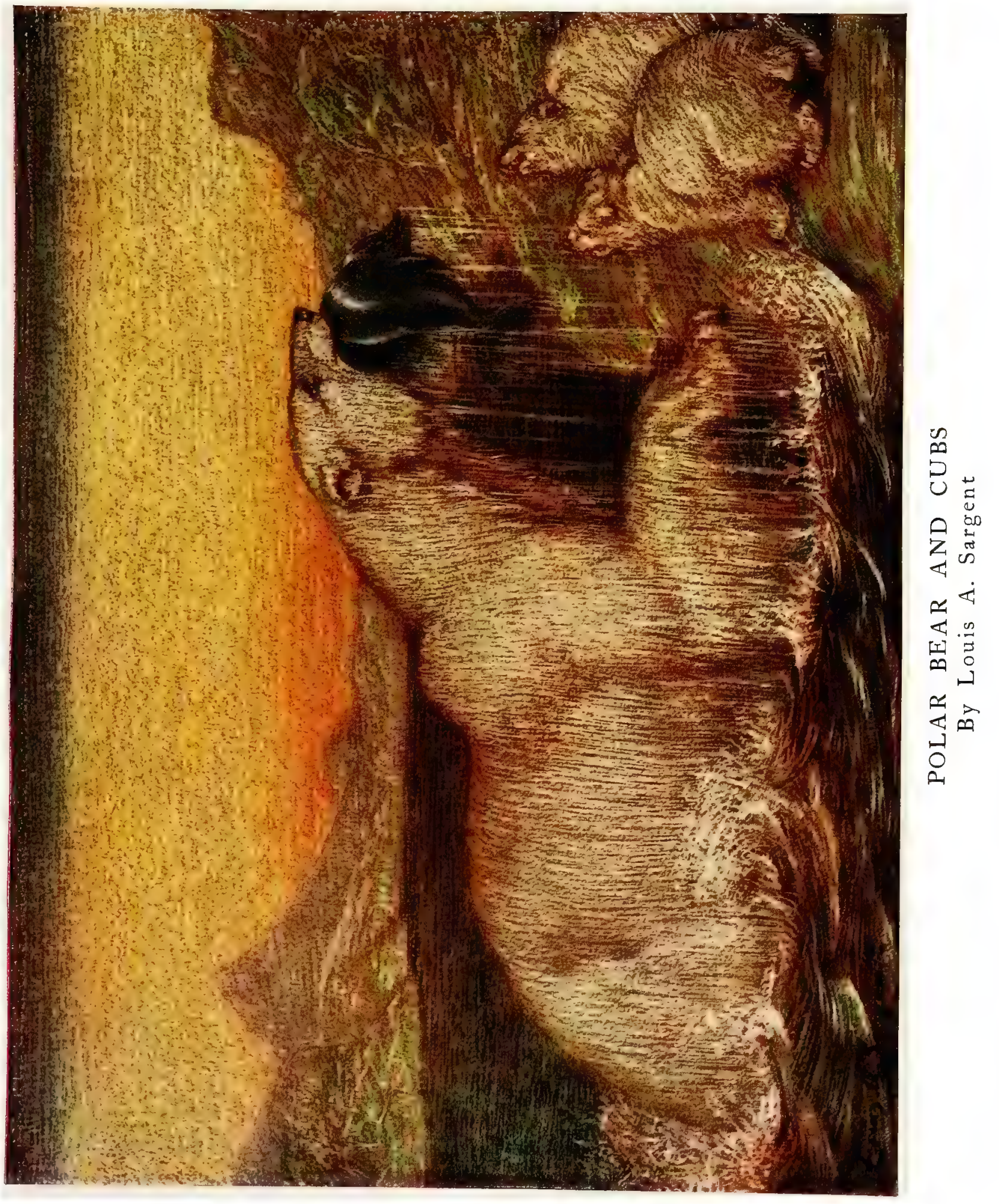





\section{THE POLAR BEAR}

\section{(Ursus maritimus)}

A BEAR is usually taken as the type of everything that is uncouth and grotesque, but the splendid White Bear of the north, "the whale's bane, the seal's dread, the rider of the iceberg, the sailor of the floe," as Kingsley calls him in that most living of historical novels, "Hereward the Wake," is a creature fit to rank in beauty alongside the great animal nobles of the Cat family. In size he surpasses all other Bears except the Alaskan race of the Brown Bear, reaching nearly nine feet in length, and his proportions incline to elegance, his neck being longer and his head smaller than in other Bears, while the aristocratic straightness of his profile is another distinctive mark, though this occurs also in the Grizzly Bear. The soles of his feet are largely covered with hair, to secure his footing on the ice; what naked skin is visible there is black, like the muzzle, lips, and even the inside of the mouth, contrasting beautifully with the white fur. The fur, by the way, is not always pure white, generally having a creamy tinge; it is whiter in young animals than in adults, and it is noted that the large white specimens whose colour is particularly pure are those which carry the most fat. The male is larger than his mate, but otherwise they are much alike.

The Polar Bear is noticeable as being one of the very few beasts which are white all the year round, the only others being three very different ones, the Rocky Mountain Goat (Haploceros montanus), the South American White Bat (Diclidurus albus), and the Beluga or White Whale (Delphınapterus leucas), also an Arctic animal. Every one knows, of course, that the Polar Bear is peculiar to the Arctic regions; and, like so many Arctic animals, it is found all round the world. It is much more aquatic in habits than any other Bear, taking to the water readily, and diving and swimming with great power; it is also very active in its movements on land, and, although it has no trees to exercise its climbing powers upon, no doubt finds 
sufficient scope for them among the rocks and icebergs of its native home, for it is certainly very sure-footed. Its food is chiefly animal, and consists of whatever it can find or catch; one day it may have a bountiful feast off the carcase of a stranded Whale, on another it will make a lighter repast off the eggs or young of the numerous Arctic seafowl.

The various Seals, however, are its most especial prey, and it displays great cunning in stalking them at the breathing-holes they make in the ice in winter. It is said, at such times, when making its stealthy approaches, to cover its black nose with its paws, lest this little spot of colour should betray it to its victim, and, from what I shall have to relate further on of its intelligence in captivity, the story does not seem impossible. In spite of the carnivorous habit it usually displays, however, it has the usual liking of its family for vegetable food, and feeds on the scanty Arctic herbage when summer makes this available. When, also, it comes across and breaks into a cache made by European visitants to the Arctic regions, almost everything is sampled, down to coffee and canvas. Indeed, from its great strength, it is a serious nuisance in this way, and stores need to be well secured from its powerful paws. Nowadays it seems not to make attacks on man himself, but the earlier explorers found it a serious foe, which approached them fearlessly and ferociously, and several cases of man-eating are put on record in the relations of the old voyagers.

Polar Bears usually prowl about singly, but several may at times be seen in company; the female is long accompanied by her two cubs, for which she shows a most touching affection, carefully providing them with food, and readily dying in their defence. They are born in the winter time, the female making her lair under a rock and letting herself be snowed in. Here she remains till spring almost in a state of hibernation, but continuously suckling her cubs, which are born very small, only about the size of Rabbits. Males also hibernate if they are fat enough in autumn, but otherwise they prowl about all the winter.

So powerful a creature as the Polar Bear has naturally few enemies. It may, however, now and then get the worst of it in an attack on the Walrus, or have the misfortune to be drifted out to sea on the ice. In this way individuals may be stranded as far off as Iceland, but no doubt they often perish at sea, in spite of their swimming powers. Man, 
however, is this beast's most dangerous active enemy, and finds the flesh excellent as food, though the liver, curiously enough, appears to be a dangerous article for human consumption, and is hence given by the Eskimos to their Dogs. The skin, of course, has considerable value as a fur. Although so large and active a beast, the Polar Bear does not seem to be very dangerous; it is observed to be particularly given to biting, rather than to using its fore-paws in attack like Bears in general.

A good many specimens are captured for menageries, for the Polar Bear has been valued as a curiosity ever since the days of the Vikings.

It bears the climate of Europe well if supplied with a good bath, not seeming more distressed by the heat than other Bears, at any rate in England, and it is far more amusing and lively than any other species except the Malayan Bear. Captivity introduces it to many delicacies which it could not taste when at large, and it shows itself very handy in dealing with them; it peels an orange with its claws with great skill, and will make a current in its tank with its paw to bring a floating object to the margin. One clever female in the Bristol Zoo learnt to break cocoa-nuts by flinging them against the bars of the den; but the acme of Bear astuteness was reached by old "Sam," who died in the London Zoological Gardens after the very cold summer of 1903, thus giving rise to many jokes about our inclement climate. "Though born and bred upon an Arctic hummock, Autumn's excesses went against his stomach," said one rhymer of him. Sam, however, had often had his laugh at the public. It was his custom to put a piece of his rations on a low wall which skirted one side of the den, and then sit down with his back against the said wall. In this position he was invisible to visitors coming down a raised path outside it; these would, however, see the bit of food, and often charitably endeavour to push it through the bars to him with their sticks or umbrellas. But the ungrateful Sam, whirling round like a flash, would snatch these articles through, and they were of no particular value when he had done with them. This trick of his was well known at the time, and attracted much attention; I had the account from his own keeper.

The Polar Bear has produced hybrids in captivity with the Brown Bear ; in a small Zoological Garden in Germany several such specimens were bred, the Polar Bear being the father. Most remarkably, it proved to be the case that these hybrids were quite fertile, both when paired back 
to Polar or Brown Bears, and even between themselves. One hybrid and a three-parts Polar specimen were on view at the London Zoological Gardens when this book was written.

\section{THE PIED BEAR}

(Aluropus melanoleucus)

Although this animal is nowadays classed along with the Panda in the Raccoon and Coati family, and is often called the Great Panda, it is at any rate closely related to the Bears, and, being like a Bear in form and size, may be conveniently noticed here: no doubt, if the Raccoons and Coatis were not known, it would rank as merely an abnormal member of the Ursine family. It is a small animal for a Bear, and very curiously coloured, the main hue being white, with the limbs, ears, a band across the shoulders, and a ring round each eye, jet black. The tail is short as in the true Bears. This animal inhabits the high regions of the east of Tibet and the north-west of China, and little is known about it. It appears, however, to be chiefly a vegetable feeder like the ordinary Panda. As it has never been shown in captivity, it is one of the few of the world's remarkable beasts which are still desiderata in our Zoological Gardens.

\section{THE BLUE BEAR}

(Ursus pruinosus)

THERE is a little-known true Bear inhabiting much the same regions as the above animal, of which only one or two specimens have come to hand. This is known as the Blue Bear from the colour of its coat, which is of the colour known as "blue roan" in a Horse, an intimate mixture of black and white hairs. The coat is long and thick, and the ears are very furry; in size the animal is rather small, considerably less than the ordinary Brown Bear. 


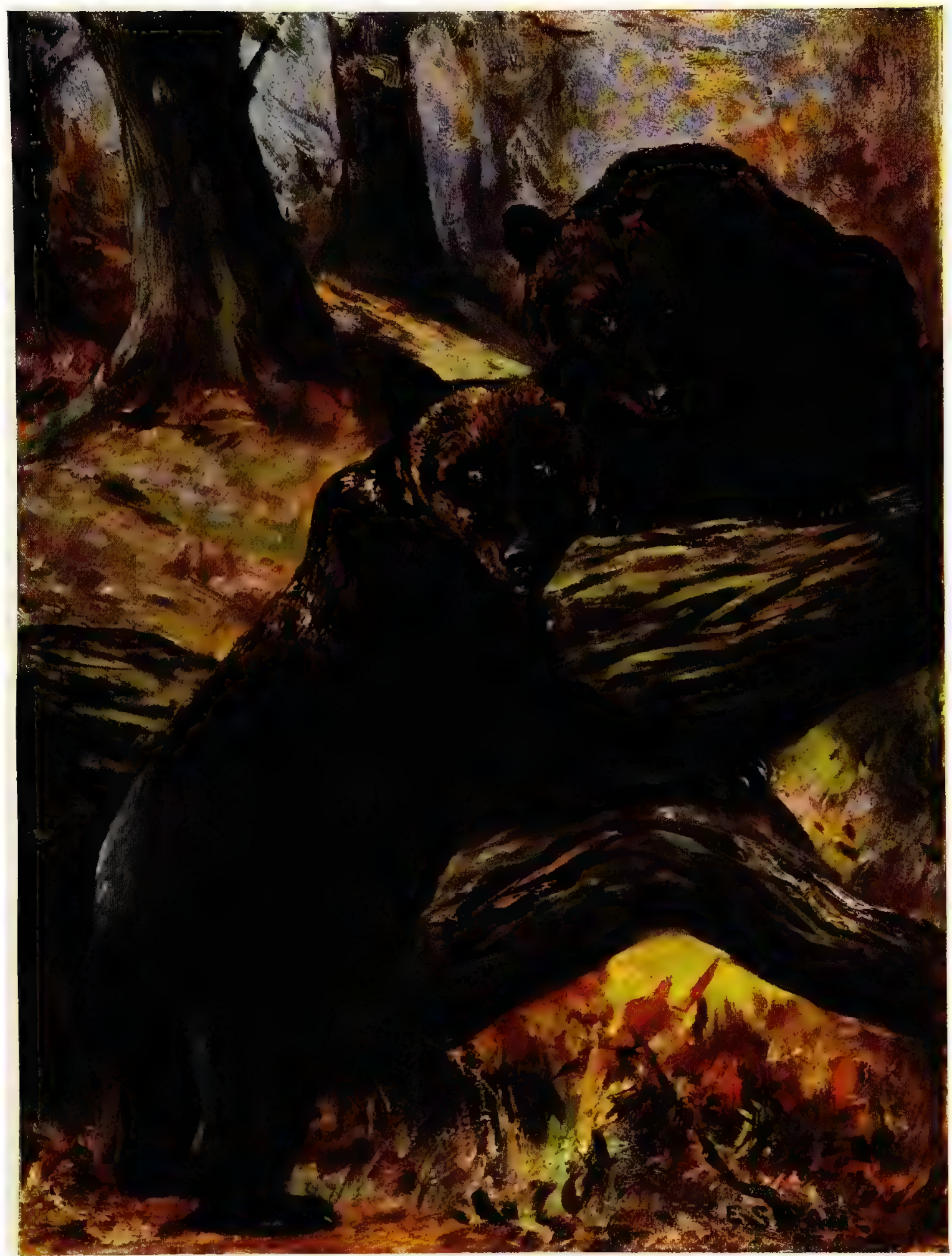

BROWN BEARS

By C. E. Swan 



\section{THE BROWN BEAR}

(Ursus arctos)

THE Brown Bear is the Bear par excellence with most people, and it certainly has the widest distribution of any of the family, being found all along the northern parts of the Old World, while it reappears in Alaska as a very large race, even superior in size to the famous Grizzly, which takes the Brown Bear's place in part of North America. In historic times the Brown Bear inhabited countries from which it has since been nearly or completely extirpated; thus, all students of Virgil remember his mention of the "Libyan she-bear," although the Bear is nearly extinct in North Africa, and other Roman writers remind us of the former existence of the Bear in Scotland. The Scotch Bears were of peculiar ferocity, for the Romans of the Empire took the trouble to send all the way to this remote country of Caledonia for Bears savage enough to act as executioners to Christian martyrs. In Africa south of the Sahara there are no Bears of any sort; nor are there any in the Australian region.

The Brown Bear displays a good deal of local variation in its wide range, besides much individual difference; the coat of some is nearly black, while others verge on silver-grey. The races inhabiting Syria and the Himalayas are of a light drab, with a white crescent on the chest, which, by the way, is commonly found in young individuals of the species in Europe. The Syrian Bearr is always comparatively small, but it can be formidable enough, and its encounters with mankind are well known to Bible students. This Bear, however, varies much in disposition in different parts of its range, and in the Himalayas, where it is called "Red Bear" or "Snow Bear," to distinguish it from the Himalayan Black Bear, it is not regarded as dangerous to man, and may even be seen feeding close by Sheep or Goats. Indeed, as a whole, the Brown Bear, like most of its family, is a vegetable-eater 
and hunter of small prey rather than a carnivorous animal, its feeding habits being much like those of the Pig. Roots, herbs, the leaves and twigs of certain trees, mushrooms, and all sorts of berries, form much of its usual diet; its fondness for honey is well known, and, in contrast to this sweet food, it readily devours Ants, presumably on account of their acid flavour. It is, however, not averse to animal food, and as it advances in years, in Europe at any rate, is inclined to kill large animals for food, and then becomes a scourge to stockowners, killing Horses, Cattle, Sheep, and especially Pigs; Bears in general seeming to have a strong liking for pork when they take to meat-eating at all. Although, however, people have often been killed by Bears, these animals seem not to take to man-eating. The Bear is fond of water, and likes, in hot weather, to bathe in it as well as drink. In Eastern Siberia and Alaska, and probably wherever fish swarm in the streams and are easily captured, he feeds largely upon them, so this gives him additional reason for haunting the water-sides. It is hardly necessary to say that so powerful a brute is a good swimmer when necessity arises, and, as everybody knows, he climbs trees readily. In descending these he comes down hind-first, unlike other climbing animals. His gait on the ground is rather heavy-looking, as, like Bears in general, he plants the whole sole of the feet on the ground, leaving a track much like a man's; but he can put on a very good pace, and no man could get away from him by fair running.

He stands, and even walks, on his hind-legs with ease, and has been known to carry off a heavy carcase in his arms when in this position, though more ordinarily he drags it with his mouth like a Wolf. In attack he also uses both paws and teeth, and can strike a most terrific blow, though the "hugging" that he is credited with seems not to be his custom.

One of the best-known of the Brown Bear's habits is his hibernation in winter; having fed fat on berries in the autumn, he chooses a snug den under a rock or in a hollow tree, and retires therein when the cold weather begins, to sleep the winter through. At this time 
he is not so completely comatose as a Dormouse or Bat, but may be waked up fairly easily; the stomach and bowels are empty, and the vent plugged up with the débris of the last meal. This "tappen," as the plug is called in Scandinavia, is excreted in spring, when the Bear comes forth, at first still fairly fat and not unduly hungry, as his fasting stomach has to become accustomed to food; soon, however, he becomes lean and ravenous, and is then particularly apt to make raids upon large animals. $\mathrm{He}$ is a clumsy killer, and mangles his victims horribly.

During all the summer he does not put on much flesh, and some unhappy individuals never accumulate enough adipose capital to be able to hibernate.

It is during the period of hibernation that the she-bear drops her cubs, at the beginning of the New Year. The little creatures are in number from one to four, and only about the size of Rats at first. Their mother guards them with the most devoted care, and her ferocity when robbed of them is proverbial. She knows, however, the value of wholesome correction, and uses it if they are disobedient, applying smacks and even bites to the refractory cubs. In this way she makes them climb trees if she sees danger approaching. They remain with her a long time, and older cubs, of a previous litter, are said to be told off as nurses for younger ones; a not improbable story, for the same thing may be seen with the older and younger broods of one of 'our commonest birds, the Moorhen (Gallinula chloropus).

The voice of the Bear is a hoarse roar or growl, but in the ordinary way it is not a noisy animal. Its destructiveness to man's possessions is to some extent compensated for by its own value when killed; its fur is much esteemed for rugs, and the virtues of "Bear's Grease" have long been well known, while the flesh is also appreciated as food in some places; within the last year or two it was even possible to procure it in Leadenhall Market, but more as an article of curiosity in diet than anything else. Bear hams are supposed to be especially good.

It is not necessary to do more than allude in passing to the keeping of Bears in captivity. They do well in confinement, and live for many 
years, but seldom breed; like Bears generally. A disposition to be surly: and treacherous is also very marked in the Bear family, which are, if anything, more dangerous than the large Cats in menageries. "Dancing." Bears are far less common in our streets than formerly, and of course the cruel sport of Bear-baiting has long been extinct, though, from the frequent allusions to it in Shakespeare and other authors, it must have been one of the most cherished recreations of our forefathers.

\section{THE GRIZZLY BEAR}

(Ursus horribilis)

Although it is scarcely more than a local race of the Brown Bear, the Grizzly Bear of the Western States of America has such a reputation that it deserves the dignity of a separate heading. It is larger than any of the Brown Bears except the Alaskan race, with a straighter profile and enormous claws on the fore-feet; its coat also is shorter, but not particularly grey, the name being properly "Grisly," and referring to the animal's reputation for peculiar ferocity. This used to be well deserved enough, but what with constant persecution and the improvement in fire-arms, the Grizzly is not the formidable foe he used to be, and generally avoids a conflict wherever possible. He has also ceased to frequent the prairies, and keeps to the mountains and woods where he has not been exterminated. This Bear differs from most others in not climbing trees-at any rate when adult-and it also has particularly carnivorous tastes. In spite, however, of its enormous power, which enables it to deal such blows with terrible fore-paws as to tear away several ribs from a Bullock's spine with a blow, it uses this very largely to turn over stones in search of Mice and such small prey, and has the usual bearish love of fruit. In some places it is found alongside of the smaller and commoner Black Bear of America, but the latter takes care to avoid encounters with this terrible enemy. The Puma, however, is said not to fear it, and even to attack and defeat it, relying on its own great agility. 


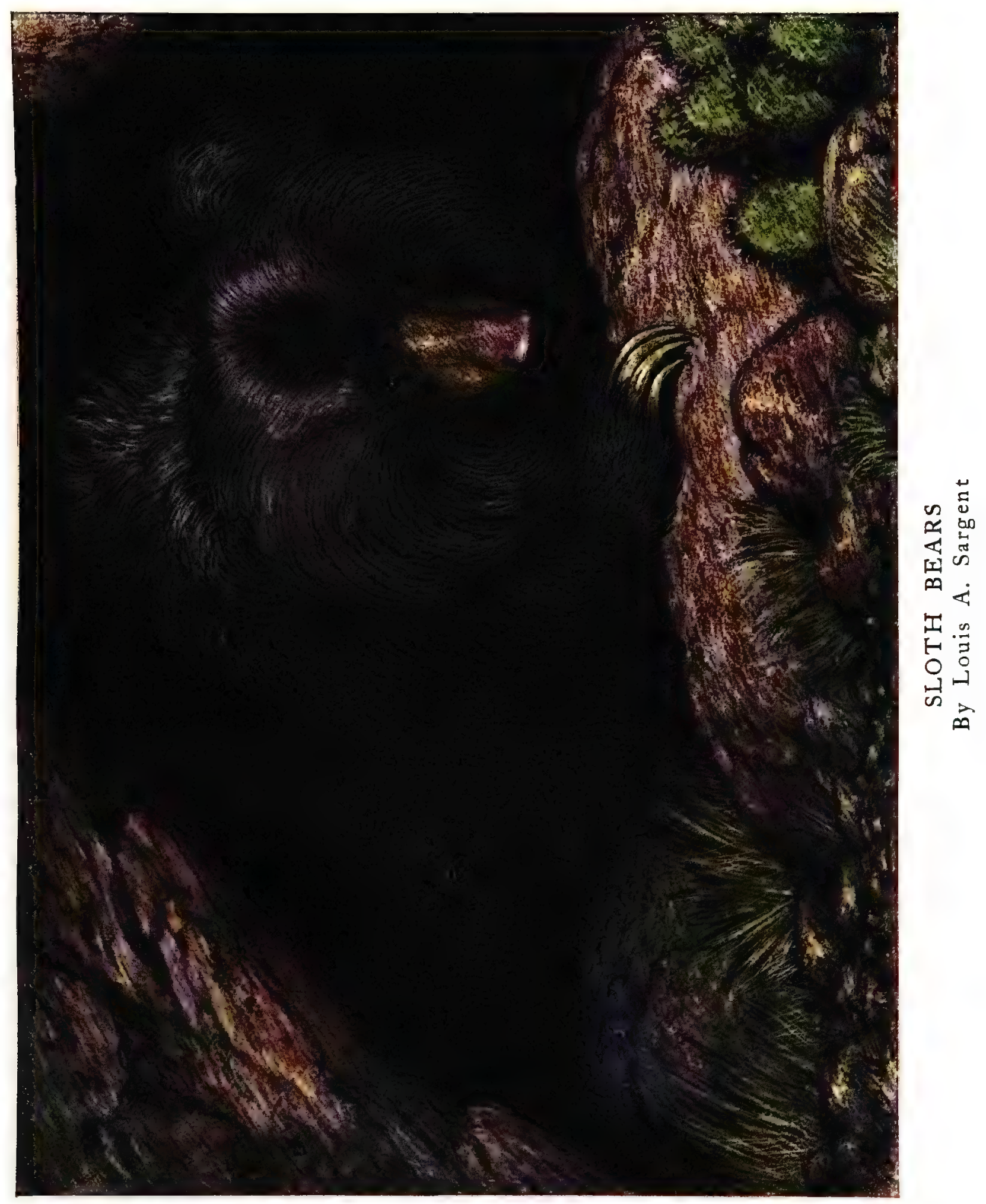





\section{THE SLOTH-BEAR}

\section{(Melursus ursinus)}

Although this most uncouth of Bears has often been denominated the "Five-toed Sloth" and "Ursine Sloth," it has no affinity with the true Sloths, which belong to a very different order, and will be treated of in due course in this book. Its resemblance to the Sloth lies in its very long coarse coat, in the long claws, and in the fact that it exhibits a certain deficiency in the teeth. Other Bears, like the carnivora in general, have six incisor teeth. in each jaw, but in the Sloth-Bear. the central pair of upper incisors are wanting; the grinders are also small and set far apart.

The black coat, with the white crescent on the chest, is a constant character of this Bear, but what especially distinguishes it from other black Bears is not only the coarse shaggy fur, but the long muzzle and loose lips, and the power it has of protruding these, making the most extraordinary grimaces. Its form is also an exaggeration of the usual bearish uncouthness, and its gait so awkward that when going at a gallop it looks as if some invisible person was unceremoniously bundling it along from behind. It cannot compare in size with the larger Bears, a male not measuring more than six feet from nose to rump.

In spite of its abundant hair, the Sloth-Bear inhabits the hot plains of India, and is the characteristic Bear of that region. It is found in Ceylon as well as on the mainland, but not in the Himalayas, and it has disappeared, owing to persecution by sportsmen, from some of its old haunts, notably in parts of the Deccan and Bengal. It is generally found alone, but sometimes a pair, or the female with her two cubs, are found together. Their usual haunts are in hilly or forest country, and they are particularly fond of making their dens in caves where such shelter is available. It is chiefly at night that these Bears prowl about in search of food, which is chiefly of vegetable substances and insects, this being one of the least carnivorous of all Bears. In search of fruit it will climb 
trees, and it actually sucks "white-ants" and beetle-grubs out of the ground, first blowing away as much of the dust as possible; this is, no doubt, the use of the great extensile lips. Although it is not positively averse to meat, it seems never to kill large animals for food, and its attacks on human beings, which are, unfortunately, not at all uncommon, seem to be due to the animal having been disturbed, or to sheer natural surliness. Although blessed with an excellent nose, the Indian Bear is not keen-sighted, nor is its hearing very good; thus it is liable to find itself suddenly confronted by a man, and in such cases strikes out savagely with its terrible claws, at the same time frequently biting its victim. Indeed, Blanford, in his admirable work on the Mammalia of British India, considers that there is more danger from the Bear than from the Tiger, which is normally inoffensive to man. As the Bear strikes at the face, the wounds inflicted are ghastly to a degree, and the victim, even if he recovers, is permanently disfigured.

She-bears with young are naturally most prone to attack, as they display the strong attachment to the cubs so usual in the family. There are only two cubs as a rule, usually born in the winter months, and, for some time after they come abroad with her, the female carries them on her back, clinging to the long hair. Naturally they are easy enough to tame when taken young, and they have a better reputation for temper in captivity than have Bears generally.

Their very uncouthness makes them an interesting exhibit, and the beast, known by its Mahratta name of Aswail, has long been one of the most familiar denizens of travelling menageries. Except for sport and on account of damage it may do, there is not much inducement to hunt this Bear, but it is pretty eagerly pursued by those who have not opportunities of going after nobler game. It is often captured in India and trained to perform, much as the Brown Bear is in Europe, being led about the streets to show off its acquirements to casual audiences.

As all the other known Bears are black, it will be convenient to mention them here, it being clearly understood that they do not possess any of the Sloth-Bear's peculiarities in form, coat, teeth, or habits, but rather agree in these points with the Brown Bear. 


\section{THE HIMALAYAN BEAR}

\section{(Ursus torquatus)}

THIs is the characteristic Bear of the wooded slopes of the Himalayas, the Brown Bear replacing it above the forest-belt, and the Sloth-Bear in the plains. In colour it resembles the latter, being black with a white crescent on the chest, which hue is very constant; but the size varies a great deal, for one may come across specimens seven feet from nose to rump, and others only half this length.

In general habits it resembles the Brown Bear of Europe more than the race of that animal which is its neighbour on the Himalayas, feeding not only on vegetable food, such as walnuts, corn, and wild rhubarb, and pilfering the pumpkins and honey of the villagers, but also attacking their live-stock, such as Cattle and Ponies. Cows attacked by it are horribly mutilated, being practically devoured alive. It is also dangerous to man, who is the more likely to encounter it as it resides within the zone of cultivation.

It bears captivity well, even in the unnatural climate of the plains of India, and it is very amusing when young, but becomes surly and dangerous later on in life.

\section{THE JAPANESE BEAR (Ursus japonicus)}

THE Japanese Bear is very similar to the Himalayan, quite a small animal, not being much larger than the biggest Dogs, but very stout and heavy; it is thick-coated, and sometimes entirely black, without any white on the chest. In Yezo, however, the northernmost island of the Japanese group, is found a race of the ordinary Brown Bear.

\section{THE AMERICAN BLACK BEAR}

(Ursus americanus)

IN its size, thick coat, and black colour, with often some white on the chest, this Bear strikingly resembles the Himalayan, but has a much 


\section{WILD BEASTS OF THE WORLD}

narrower head. It is also not constant in colour, being often brown, in which case it is known as the Cinnamon Bear; the brown form is, however, a mere variety, for a brown cub may even be brother to a black one.

It is the characteristic Bear of North America, being much less local than the formidable Grizzly, and maintaining itself even in long-settled districts much better than the Wolf, which animal long survives the Brown Bear in Europe. Like the Brown Bear and Himalayan Bear, it is omnivorous, and much resembles them in its habits; it is seldom dangerous to man.

\section{THE MALAYAN BEAR \\ (Ursus malayanis)}

THE Malayan Bear, which is not much larger than a Mastiff, is remarkable for having a short close coat, like a smooth-coated Dog, which shows off to the full its bearish awkwardness of form. Its head is particularly short. The colour is black, with a yellowish white patch of variable size and form on the chest. This Bear, which ranges from the Eastern Himalayas through Malacca to Borneo, is the most active climber of all Bears, and exceedingly amusing in captivity by its playful ways; it is often seen in menageries. It has very little of the carnivore in its tastes for food, being chiefly a vegetarian, with more than the usual love for sweets.

\section{THE SPECTACLED BEAR \\ (Ursis ornatus)}

South America is not the place in which one would expect to find a Bear, but the present species inhabits the Andes, where it is not very common, and little is known about it. It is a rather small animal for a Bear, and has a moderately thick black coat, enlivened by the white rings round the eyes which give it its name. It has been exhibited at the London Zoological Gardens, but not in recent years. 


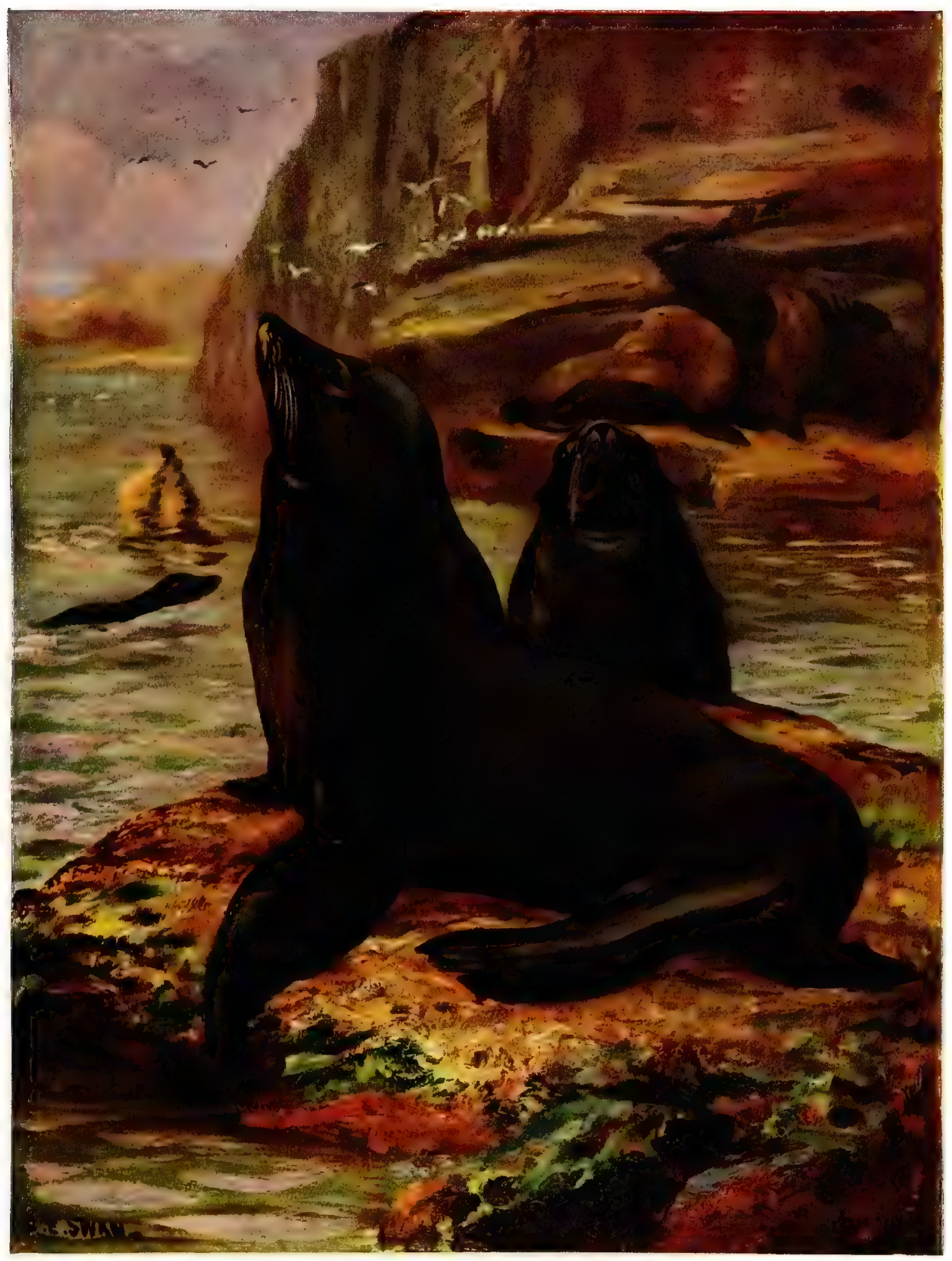

CALIFORNIAN SEA-LIONS

By C. E. Swan 



\section{THE CALIFORNIAN SEA-LION}

\section{(Otaria californiana)}

WiTH this animal we come to that remarkable group of water-carnivores known as the Pinnipedia (fin-footed), comprising the Sea-Lions, Walruses, and Seals proper, all of which are adapted more for swimming than for locomotion on land, their limbs having the basal part very short, while hardly more than the paws project from the trunk. These take the form of flippers or paddles, and in the Sea-Lion are very long and flat, and hairless on the ends and soles. The fore-paw has no claws, and the skin of the fingers' and toes projects far beyond their tips. The first toe in the fore-paw is the longest, the length of the other paw diminishing rapidly; while in the hind-paw the two outer toes are much longer and stronger than the three inside ones.

The tail, as in all the pinnipeds, is small and insignificant. Very obvious distinctions between the Sea-Lions and the true Seals are the comparatively long neck of the former and the presence of small external ears, which are wanting in the Seals proper.

The actions of the two groups are also different; in the water the Sea-Lion mainly uses its fore-paws in swimming, the hind-flippers seeming chiefly to come into play in steering; but on land they are turned forward like the hind-feet of an ordinary beast, and assist in supporting the body. The animal also has a true quadruped gait, a sort of awkward gallop, by which it can get along quite rapidly for a short distance, though soon becoming exhausted.

In spite of the awkwardness of its movernents, however, it is a good climber, and can get up almost any declivity which a man could ascend; the long rubbery flippers giving a good hold on the ground. But, of course, the creature's proper element is the sea, in which its motions are powierful $\underset{163}{\text { and }}$ graceful to a degree; it darts 
through the water with great speed, and can easily spring clean out of it, while it fearlessly takes "headers" from the rocks.

It is not easy to make sure of the colour of this animal, as its short stiff coat is so often seen in a wet state, but in any case there is a good deal of variation, several shades "of brown being found, while some specimens are distinctly grey; the female is rather lighter and browner than the male.

But the most remarkable sexual difference is in the size, the males exceeding the females in bulk in this family more than is the case with almost any other beasts; in the present species for instance, the male is seven or eight feet long, and the female less than six. The pups have a soft coat of dark slate-coloured fur; only one is born at a time, and it can see and move about at once, but does not take to the water for some time.

The food of the Sea-Lion consists mostly of fish and other sea animals; but it sometimes captures Gulls in a very cunning manner, by sinking under water and wriggling. its nose, which it leaves exposed, till it lures the greedy and inquisitive bird within reach of a spring.

The prey is bolted whole, the pointed grinders of these animals and Seals being unsuited for chewing, but only for keeping a good hold on a slippery morsel. They are extremely voracious, for it has been found that a pair would devour forty pounds of fish daily. Yet they have remarkable powers of fasting, and can go for months at a time without food, sustained by the thick coat of fat or blubber under the skin. They have the peculiar habit of swallowing stones as birds do, but the reason for this practice is not known; probably, as in the case of birds, which these creatures resemble in their habit of swallowing food whole, the stones serve to grind up the food in the stomach.

This Sea-Lion inhabits the western shores of the North Pacific, and is especially well known on the Californian coast, where in some places it is so tame, owing to protection, that it can be studied at close quarters like a tame animal, feeding on the refuse of the fisheries. It is a very noisy animal, uttering a harsh bark or yelp, and the din 
produced by the great assemblages which collect in the breeding-season is something appalling. It breeds on the Californian coast from May to August, and after breeding most of the animals disperse in search of food, until only a few remain about their haunts. The males fight previously for the females, and have so much trouble in securing places and keeping their harems together-for they each rejoice in securing as many wives as possible-that they have to dispense with feeding for a time, not being able to get to sea. Their courage is extraordinary, and so is their toughness and endurance-indeed, a herd has been driven over cliffs sixty feet high, and then escaped into the sea after the fall.

Many are destroyed for the sake of their oil, and the hide is also of value. This Sea-Lion, like the group generally, does well in captivity, and is the species usually seen in menageries, where they are a great attraction to visitors, and show much docility and intelligence. On some occasions they have bred. Those in the London Zoological Gardens live in peace with. Penguins, although sea-birds form part of their natural prey; but I have seen one amuse itself by teasing a Penguin, pulling it back by the tail whenever it tried to get out of the pond-a proceeding which the bird did not take in very ill part, for when the Sea-Lion tired of its fun, it was in no great hurry to land.

Altogether there are about nine species of the Sea-Lions (Otariida), and they are very widely distributed, being found in most seas except the North Atlantic and the warm waters of South-Eastern Asia, where no pinnipeds of any sort are found. They are all much alike in general appearance and habits, but differ somewhat in size, voice, and in the character of the coat, though this is not perceptible in the living animal, or indeed in the dead one, without close examination.

About half the species are what are called "Fur-Seals"-that is, they have under the coarse hair, which is all that can be seen externally, the beautifully soft under-fur which is the "sealskin" so familiar as a luxurious article of winter attire. To make the skins suitable for this, all the outer hair has to be removed. The southern species of 
Fur-Seals do not provide much of this nowadays, having been severely thinned down by reckless and wasteful destruction, and most of our sealskin comes from the Fur-Seal of the North Pacific (Otaria ursina) which breeds on the Pribyloff Islands, where it is carefully watched over and utilised with discretion. Only the "bachelor" Seals are killed for furs; these are the young males which are not old enough to fight for a home and family, for the males of these animals do not come to their full size and strength for several years, and meanwhile have to herd by themselves. These can therefore easily be driven off and knocked on the head; and, though this sounds a barbarous and coldblooded proceeding, it is kindness compared to what an unhappy. bachelor would have to endure if he trespassed upon the "married quarters"; for he would be assailed by each and every paterfamiliàs he encountered, and, as the Fur-Seal's idea of fighting is to bite and hold on till his teeth tear through, the victim's death would be slow and painful even for such an enduring animal as one of this hardy tribe. 


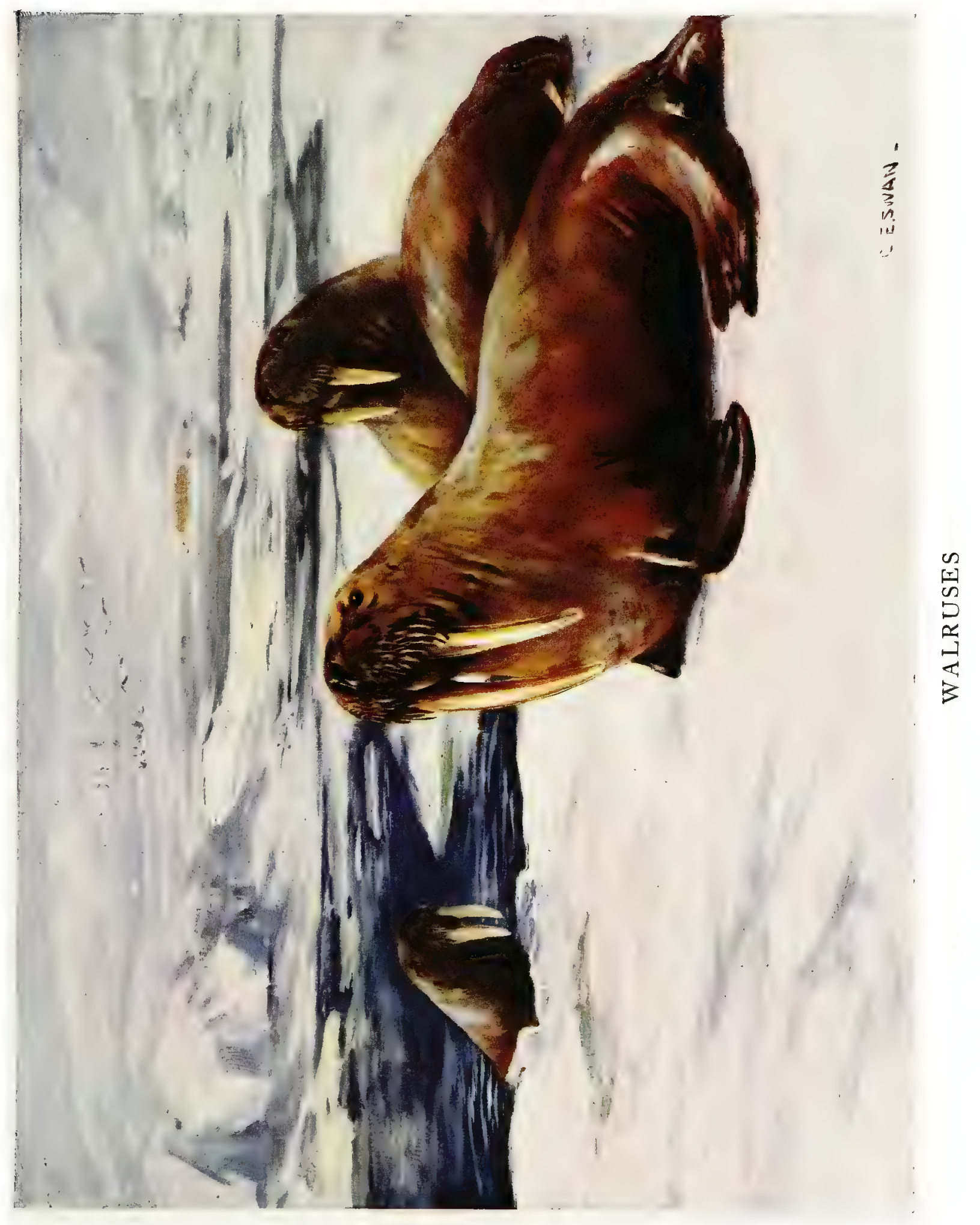





\section{THE WALRUS}

(Trichechus rosmarus)

THE huge unwieldy "Horse-Whale," as the old Norsemen called it, is the most remarkable of all the marine carnivores and constitutes by itself a family (Trichechida) which is to some extent intermediate between the Sea-Lions and the true Seals. The latter it resembles in having no external ears, but in general appearance, in spite of many representations in natural-history books; it is more like the former, especially in the forward disposition of the hind-limbs on land, and the consequent quadrupedal gait. The hind-limbs in the Walrus, however, present the peculiarity of being united at the heels by a web of skin, in which the small tail is enclosed. They resemble those of the true Seals in having the three middle toes shorter than the outside two.

The teeth are quite peculiar, and like those of no other beast. There are no incisors in the lower jaw in adults, and the grinders are small, wide-apart, and round-topped. In the upper jaw there are a pair of small incisors, and the huge canines which form the tusks so characteristic of the beast. The lower canines are small and not conspicuous; in fact, except for the great upper tusks, all the teeth look much alike. In the young there are two pairs of incisors in each jaw.

All the five toes on each foot bear nails, but these are small in the fore-foot, and the skin extends beyond them as in the Sea-Lions; on the hind-foot the three centre claws are larger. The soles of the feet are bare and rough, but with this exception, the "skin, which falls much into folds, especially on the shoulders, is covered with short light-brown hair; this, however, tends to disappear in old animals. Under the skin there is, as usual in the sea-beasts, a thick layer of 
fat or blubber. The moustaches are formed of very thick bristles as big as crow-quills.

The Walrus is a huge, bulky animal, heavily built, and reaching, in the bull, a length of twelve feet, or even more: an ordinary weight is two thousand pounds. There is not much difference in size between the sexes, and the cow's tusks may be as long as the bull's, but they are more slender, and tend to converge at the tip, whereas the male's are divergent. The length is about a foot, but some exceed this, and they are liable to be shortened by breakage and wear, for the Walrus keeps its tusks well in use; they serve not only as weaponsand the skill with which the beast uses them is remarkable, it being able to strike in almost any direction-but also as grapnels to help to secure a hold when the beast is landing, and as rakes for ploughing up the sea-bottom in search of food.

This food is varied in character, but commonly consists of bottomliving sea animals such as clams and other shellfish, sea-urchins, starfish, sandworms, and so forth. Flesh from the carcases of dead Whales is also devoured, and seaweed is found in the stomach, though there is some doubt as to whether this does not get swallowed accidentally. Possibly this is the case, as the shellfish eaten are often bolted whole, but the evidence on the whole would seem to show that: the Walrus is a sort of marine Pig, and will eat practically any organic substance that it can easily obtain.

The Walrus is naturally most at home in the water, and is very clumsy in its movements on shore; there, however, it spends a good deal of time in sleeping or basking. It has enormous strength, and can break holes in ice six inches thick with its tusks; and these are freely used on its fellows, for, although sociable, it is a pugrtacious. beast. When a herd of Walruses is lying for the most part asleep, on an ice-floe or rock, some are always kept on the alert by the practice each one has, when waking, of dealing his neighbour a dig with his tusks, the unfortunate recipient of course awaking, and passing. on the kind attention. They have, however, much real attachment: to each other, and are dangerous when hunted in the water, not only 
because the injured animal will turn and attack its persecutors, but also because its friends will make common cause with it. It may be easily imagined that the assault of a herd of these brutes is a serious thing for a party in a boat, which may easily be pulled over or stove in by the tusks of the furious animals.

The Walrus is credited with being, unlike the Sea-Lion, the husband of only one wife; but some cast doubts on his fidelity. It is universally agreed, however, that the female has great affection for her single cub; this is born in spring on the ice, and appears to be suckled up to two years old, at which age the tusks begin to appear. It is carried about a great deal on the back of the mother, who does her best to guard it against the attacks of the Grampus or Killer-whale. The only other natural enemy at all important for the Walrus is the Polar Bear, and even he would find a full-grown beast rather too much for him.

The note of the Walrus is a curious one, somewhat between a bark and a bellow; it also grunts and snorts. The Eskimo name, "Awuk," is supposed to give some idea of the cry.

The Walrus is a purely Northern animal, found all round the world, but chiefly in the high latitudes where ice is constantly present; it is one of the most characteristic forms of the Arctic regions, but seems to have ranged farther south in former times, and to have been driven away by constant persecution at the hands of man. The Walrus of the Pacific ( $T$. obesus) is considered distinct from the Atlantic species by some naturalists, but the distinctions between the two do not amount to much. As long ago as 890 A.D., when Ohthere the Norwegian described how he hunted the "Horse-Whales," and brought a tusk to our King Alfred, the Walrus was a valued object of pursuit; and it is a profitable quarry, as its products are various, its fat of course furnishing oil, while its hide is of use for harness-leather, and its tusks furnish good ivory for artificial teeth. Its flesh is also edible, and it furnishes a most important source of support for the Eskimos and other Arctic tribes. Civilised man has, however, pursued the poor animals with such brutal and greedy rapacity that Walrus- 
hunting is ceasing to pay as a pursuit. The havoc that has been wantonly wrought among them may be judged of by the fact that in I852 nine hundred were killed in Spitzbergen on one occasion, only half of which could be utilised. The extinction of this remarkable and useful animal-whose place in nature could not be filled by anything else-would be a standing disgrace to humanity; it would be a good thing, not only to regulate by international agreement its capture in its Northern haunts, but to transport it to the cold Southern seas, where it would probably thrive and become a source of great profit to future generations.

This, however, would be a task of some considerable difficulty, for the Walrus has been seldom brought even as far as Europe in captivity, although so curious an animal would be a great acquisition to any collection. Adults seem never to have been captured alive, but cubs have frequently been taken, and show great affection for their human associates, combined with considerable intelligencé. They require soft food, such as the bodies of shellfish, and the intestines of fishes, while they will also eat strips of fish or pork, and porridge or pea-soup.

They are certainly delicate animals, and require much care; the London Zoological Gardens have only exhibited two-one which arrived in 1867 , and did not live two months; and later another, which only remained at the Gardens for a few days.

There are few animals more worthy of the attention of such institutions than this, which would vie in attractiveness with the Hippopotamus and Elephant; and while this was passing through the press I was glad to hear that the chief animal-dealer of the world, Herr Hagenbeck of Hamburg, possessed several specimens. 


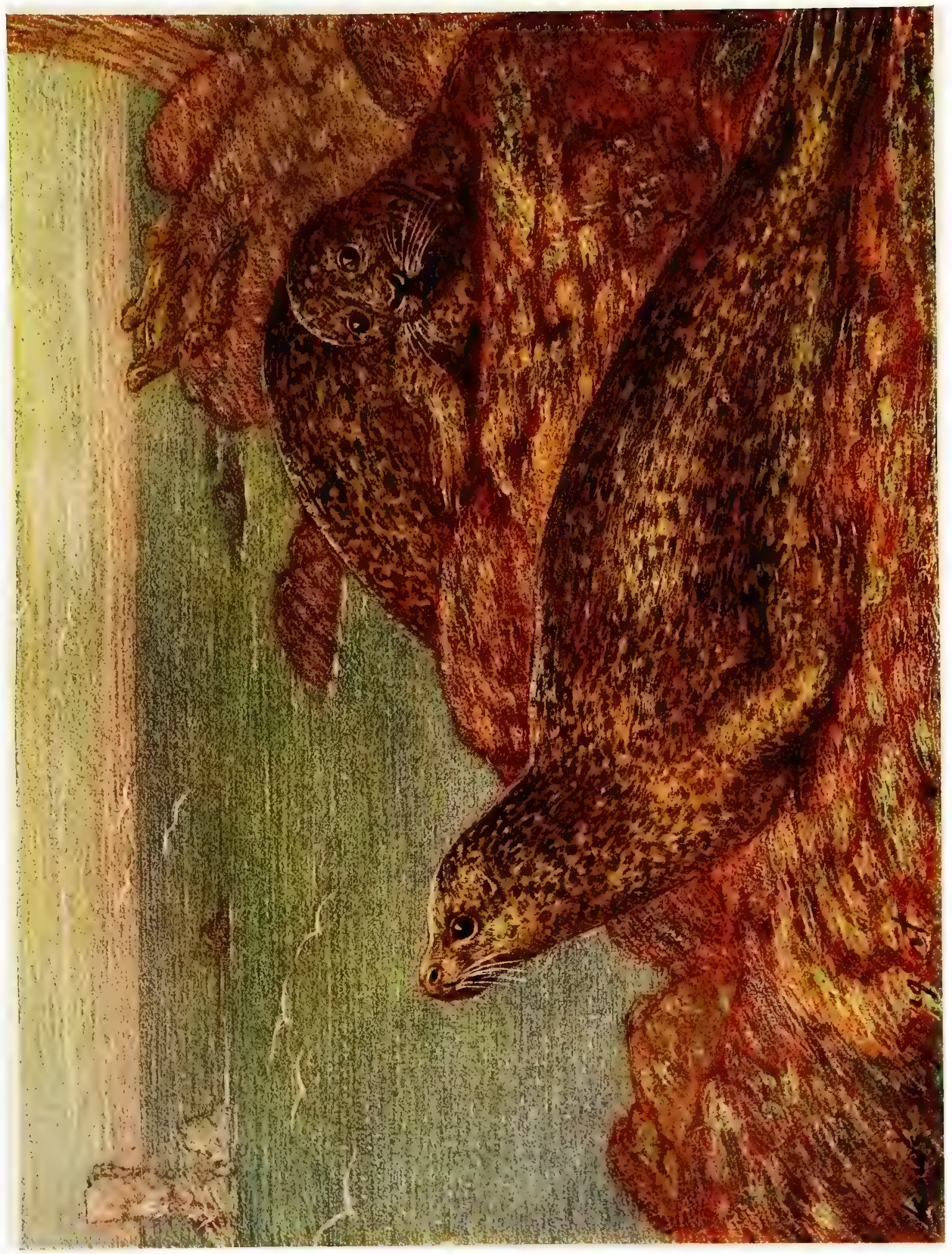

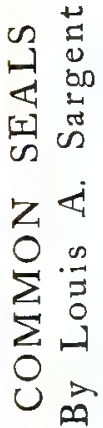





\section{THE COMMON SEAL}

\section{(Phoca vitulina)}

ThE true Seals are comparatively familiar animals to nature-lovers, the present species being a well-known frequenter of our coasts, while it is a good type of its family, the Phocide. The body, it will be noticed, is more fish-like than in the Sea-Lion, markedly tapering to the hinder end, while the neck is short. The hind-paws are permanently extended backwards, and have the two outside toes the longest; the short tail appears at their junction, and they are usually kept with the soles facing each other. Thus they work together as a sort of fish-tail, and are the chief propellers in swimming. The fore-paws are more like those of ordinary beasts than are those of the Sea-Lions, not having the skinny extensions of the finger-tips, but strong claws at the ends of all the five fingers. The hind-toes are also provided with claws; and the soles of all the paws are covered with hair.

The absence of the external ear in the Common Seal, though the ear-hole is noticeable, is a ready distinction between the heads of this animal and the Sea-Lion; the teeth of both are formed on much the same type.

The Seal is evidently much more perfectly adapted for marine life than the Sea-Lion; its fish-like body is adapted for giving the greatest effect to the paddling action of the fin-like hind-limbs, which are practically useless on land. When the beast comes ashore, it does indeed drag itself along to some extent by means of its fore-paws, but it chiefly progresses by jerking itself along with contractions of the body-muscles, wriggling on its belly like a huge maggot. It can get along quite rapidly by this very uncomfortable-looking method of progression, but naturally cannot go far without getting exhausted. Thus Seals are found to lie up very. near the water as a rule, so that 
a few jerks forward send them into it, while most of their life is spent at sea.

The pups, however, are born on land; but in the case of the Common Seal they take to the sea on the very day of birth. This is not the rule, however, with Seals, which generally stay on the land or ice, wherever they are born, for some days or even weeks. They are also usually born with a woolly white coat as baby-clothes.

The infant Common Seal, however, has the same spotted coat as its parents at birth, or very shortly after, but is without spots on the under-parts. As it gets older it becomes more spotted below, if a male, the females never being so much spotted; but, on the whole, there is little sex-difference in size or colour in this animal. A goodsized male will measure about six feet in length, and weigh up to sixteen stone; females run smaller, but not conspicuously so.

The Common Seal has a wide range, being found all round the world in the North, and occasionally entering the Mediterranean, though this sea is the proper domain of the unspotted Monk Seal (Monachus albiventer). In our Islands it is not common on the southern English coasts, being too liable to disturbance there, while the shores are unsuitable; but to the northward it becomes more abundant, and is much more familiar in Scotland, the western Islands and the Orkneys and Shetlands being its main haunts in the kingdom. In Ireland it is less common than in Scotland.

It is as sedentary as circumstances will allow, constantly frequenting the same haunts if it is undisturbed and finds the fishing good; but of course its movements are to a large extent governed by those of the fish on which it feeds. In pursuit of these it often ascends rivers to some distance.

The Seal does no harm to man except when it destroys Salmon and breaks the nets set for these fish; and it is of considerable utility in respect of its oil and hide. The latter, like that of all the true Seals, is not provided with the beautiful under-fur which makes "sealskin," but it has of late been much used for motoring-coats. Generally speaking, there is every reason to protect this harmless and interesting 
creature. It is often kept in captivity, in which condition it thrives well, and shows almost as much affection and intelligence as a dog; the exhibition of performing Seals and Sea-Lions at the Hippodrome must be fresh in the minds of many readers of this book.

\title{
THE GREY SEAL
}

\section{(Halichoerus grypus)}

THIs is the only other common British Seal, and, though less numerous on the whole, it replaces the ordinary animal in some places, as on the Scilly Islands and parts of the Irish coast. It is much bigger than the Common. Seal, reaching a length of eight, nine, or even ten feet, and a weight of over forty stone, in adult males; females grow little longer than Common Seals, but are much heavier. The muzzle in this Seal is longer than in the Common species, and its coat less spotted; in fact many specimens are uniform grey above, and a few males all black. The light grey crown of the head is very characteristic in almost all specimens.

This Seal is wilder and fiercer than the Common Seal, and frequents dangerous and wave-beaten localities; the pup is born with a white woolly coat, and does not change this or take to the water for some weeks. Although found in the northern regions of both worlds, the Grey Seal is not so widely distributed as the Common species.

\section{THE RINGED SEAL}

\author{
(Phoca hispida)
}

THE Ringed Seal, which is only a rare straggler to our coasts, is very similar in appearance to the Common Seal, but considerably smaller, being only about five feet long. It is a characteristically Arctic species, remaining in the high North all the winter, and furnishing an important part of the food of the Eskimos; indeed, it is believed to be the most northern animal inhabitant of the globe. In the winter it makes breathing-holes in the ice, and in spring brings forth its white-clad pup on the floes. The adult males are remarkable for their very strong, unpleasant smell.

\section{THE HARP SEAL}

\section{(Phoca groenlandica)}

The Harp Seal is another Arctic species which visits us occasionally; it is about the size of the Common Seal, and shows a very remarkable colour distinction between the sexes; the male is cream-coloured, with a black face and a broad black band down each side, while the female is grey; she is also considerably smaller than the male. 
True Seals of one sort or another are found in most seas, though chiefly in the North and South; there are none in Indian or South African seas, and the West Indian Seal (Monachus tropicalis) is all but extinct. The whole group, though differing much in detail, present a great resemblance, if not so alike as the Eared Seals, and here there is only space to mention two more species, each very remarkable in its way.

\section{THE BLADDERNOSE}

\section{(Cystophora cristata)}

REMARKanle for the inflatable skin on the nose of the male, the "Hood," as this Seal is often called, is the most noteworthy of the Arctic Seals. Its colour is a marbling of light and dark grey, and it grows larger than the Common Seal. The male is a very brave animal ; he not only fights savagely with his rivals in spring, like other Seals, but will turn on man when attacked, and even drag the corpses of his family into the water when they have been killed on the ice, so that, unlike most Seals, he was considered a dangerous animal by sealers until rifles were brought into use against him. Hood-Seals occasionally visit our coasts, but are very rare, and usually come as young specimens, while adults of the others arrive.

\section{THE SEA-ELEPHANT}

\section{(Macrorhinus leoninus)}

The Sea-Elephant is not only the largest of all true Seals, but exceeds all other carnivora, land or water, for it is considerably bigger than the Walrus-a male measuring fifteen feet, and being almost as much in girth; females do not exceed ten feet. The teeth of this huge brute are very small for its size, and it has no nails on the hind flippers; the male is likewise distinguished by a short proboscis, which varies in form, being either limp or dilated; it is about as long proportionately as a Tapir's. The colour of the coat is dark brown in adults, black in the young.

This great Seal used to have a wide range on the coasts and islands of the Southern Ocean, while a Northern race ( $M$. angustirostris) inhabited the Californian coasts. The last of the latter, however, seem to have been destroyed at the time of writing, and the typical Southern Sea-Elephants have been so thinned by relentless persecution, for their oil and skins, that they have been exterminated in many of their old haunts, notably the Falkland Islands. This animal, then, is evidently doomed to disappear unless protected in time; and this is the more unfortunate, as it is of high utility, and has never been seen in captivity in Europe. In the Zoological Gardens of Buenos Ayres, however, specimens have been kept. 


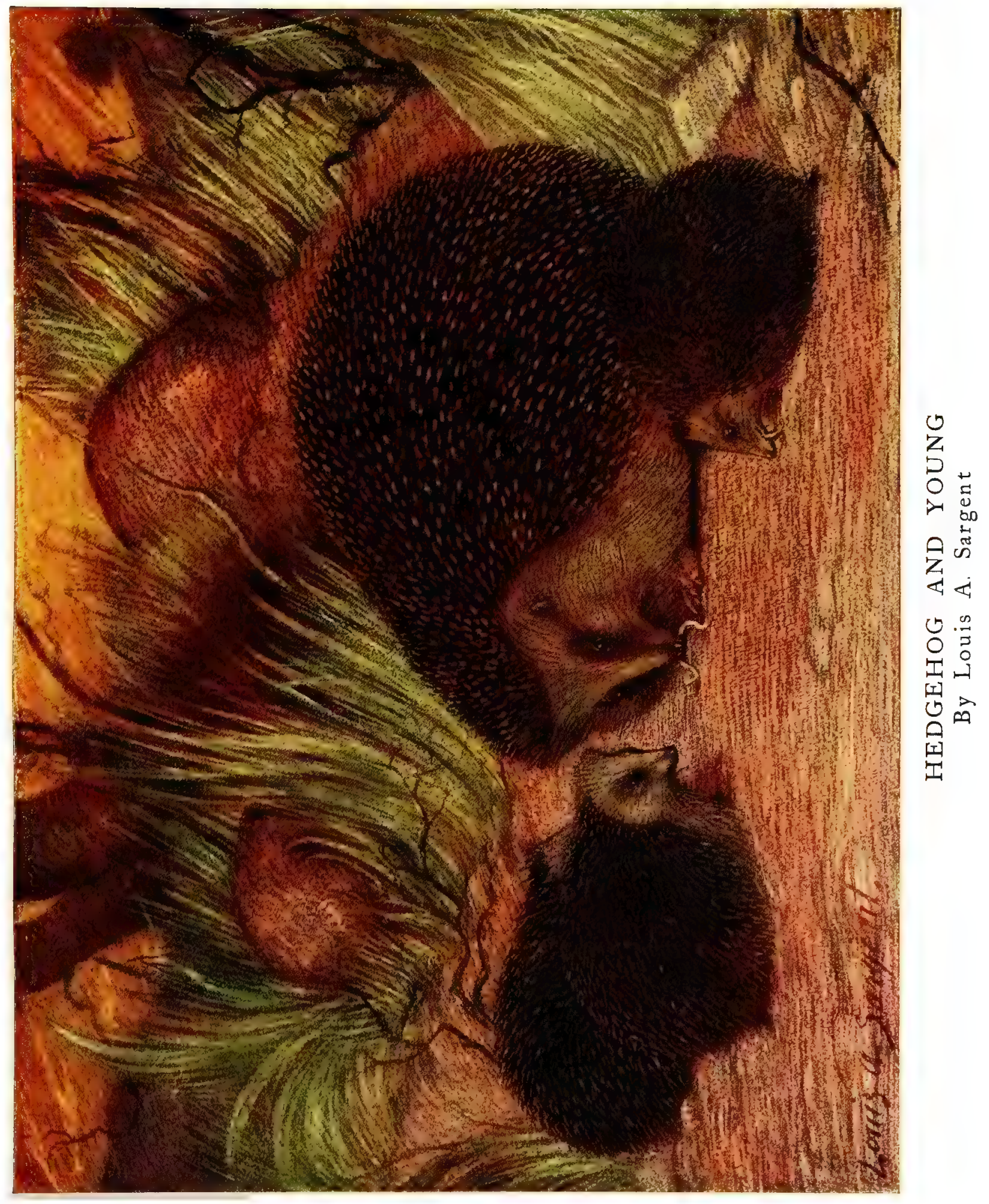





\section{THE HEDGEHOG}

(Erinaceus europaus)

THE Hedgehog, being so frequently kept in captivity, is perhaps the most familiar member, in Britain at any rate, of the order Insectivorasmall, insignificant, long-nosed beasts, never bigger than a Rabbit, which are nevertheless found almost all over the world except in the Australian region and most of South America. The general appearance of the Hedgehog is known to every one, but it is worth noting that he has five toes on each foot, and goes about flat-footed like the Bear; and that his teeth are a full set, comprising incisors, canines, and grinders; as usual in the order, the incisors are large and pointed, much like the canines of other animals.

The characteristic spines of the Hedgehog are set in his skin much like pins, the basal ends being thickened into "heads," which lie beneath the skin. Very young animals are nearly white in colour, and have the spines soft and flexible, but those illustrated are about halfgrown. The characteristic "rolling himself up" of the Hedgehog is done by the contraction of a powerful superficial muscle covering most of the body; it is that by which the Horse twitches his skin to jerk flies off, and a remnant of it in ourselves enables us to frown-thus, as the Hedgehog's contraction thus begins from the front, it is really "a frightful, fearful, frantic frown." It certainly renders the ordinary enemies of the little beast frantic enough, but some very plucky Terriers will worry him open, and the Fox is said to have dodges of his own for effecting that end.

Unless he meets with a mischance of this kind, the Hedgehog has few enemies except man, who, when he is a gamekeeper, persecutes the creature for its raids on Pheasant chicks, for, although the Hedgehog's usual food consists of snails, slugs, insects, and the like, it will

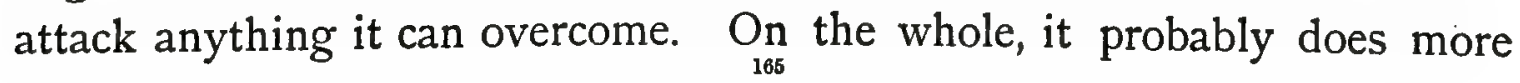


good than harm, for it is not very active, and generally makes its meals on creatures which are better out of the way. Fruit it will also eat, and it is accused of sucking the udders of Cows; this is no doubt a fable, but it has been well pointed out that the little animal would no doubt gladly lick up any drops of milk it might find oozing from the udder of a Cow lying down. Its raids on eggs seem to be confined to those of small birds, as it is apparently, unlike Mongooses, Stoats, and Rats, unable to negotiate large ones like fowl's eggs.

As a general rule, it goes about its business at night, but where unmolested gets on the move long before darkness sets in. In autumn it rolls itself up in a thick bed of leaves, and so sleeps away the winter in its hole, but in exceptional cases it has been found awake and on the move even in time of snow. The young, about half-adozen in number, are born in late spring, and there is another litter in early autumn.

The Hedgehog is usually a very quiet animal, but occasionally utters a squealing note, and is said to cry most pitifully when in the grip of some enemy. One used to hear a good deal of its being eaten, roasted in a ball of clay, by Gypsies, but it seems now to have disappeared from their bill of fare-or, at all events, not to be so widely appreciated as formerly.

It is one of the most frequently kept in captivity of all British animals, either simply as a pet, or in order that it may destroy Cockroaches in kitchens and cellars-a very congenial task. It readily eats bread-and-milk, meat, and other soft food, but is a dangerous companion for other animals, if defenceless. Miss W. Austen, whose beautiful work is well known to readers of this book, tells me that she had a Hedgehog which long lived in friendship with a Common Gull (Larus canus), but that when the animal died the Gull soon fell a victim to the Hedgehog that succeeded it.

Hedgehogs closely resembling our own species are found in Europe, Africa, and Asia, and to the same family are assigned the Rat-Shrew (Gymnura), which has the body, hairy coat, and long tail of a Rat, with a Hedgehog's head. This animal comes from the East 
Indies, from Malacca to Borneo, as does the Small Rat-Shrew (Hylomys suillus), which is hardly bigger than a Mouse, and has a short tail.

\section{THE MOLE}

(Talpa curopaa)

Although, by reason of his subterranean life, he is comparatively seldom seen, the Mole is a much more numerous animal than the Hedgehog, and most people recognise the little sausage-shaped, pig-snouted body, with the plush-like grey fur, at first sight. The eyes of the Mole are very small and hard to find, and there is some dispute as to how much he can see; but in any case sight cannot be of much importance to Moles, as some foreign species are undoubtedly blind. There is also no external ear in the Mole, but that need not affect his hearing much. Although his fore-legs are extraordinarily short, with broad paws carrying five well-developed fingers with long digging claws, his hind-feet are not noticeably peculiar in structure, though with the same number of toes; the tail is short and insignificant, and some foreign Moles have it even shorter.

The teeth of the Mole, having small incisors and large upper canines, rather remind one of those of the carnivora ; and, for his size, he is as fierce a carnivore as any, not by any means confining his repasts to his proper prey of the worms and grubs he hunts for underground, but ravenously devouring Mice, Birds, or Frogs, if he is lucky enough to capture such creatures. His own species is not exempt, if slain in a fight-a fairly likely occurrence, for Moles fight savagely when they meet. They are, in fact, strenuous livers in every way; they work as hard as they eat and fight, and they have need to do so, for a fast of a few hours is fatal to them.

The male Mole shows considerable affection for his mate, and the young are carefully looked after; they are born naked and helpless, and lie in an underground nest lined with dry grass. The elaborate galleries of the castle depicted in books as the Mole's fortress are, however, apparently simply the result of work on the mound and nest. Awkward as the Mole appears on the surface, he can travel at a fair pace, and is a bold and fearless swimmer on occasion; he works all the year round, merely going deeper when frost drives the worms down. One curious thing about the creature is its great variability in colour, which, after all, is probably simply the natural result of an underground life, this making it possible for offcoloured specimens to survive; at any rate, black, yellow, white, and more rarely pied varieties are recorded. 
Our Mole is not found in Ireland, but extends all across the Old World from England to Japan, and other species of the family are (Talpida) likewise found in the northern parts of the world.

\section{THE STAR-NOSED MOLE}

(Condylura cristata)

THIS is the most remarkable of the American Moles; it has a long, stout hairy tail, very unlike that of our species, and its snout is tipped by a curious star-shaped appendage, consisting of a ring of fleshy tentacles; these are almost imperceptible in the newly-born animal. The Star-nosed Mole is the most aquatic of the true Moles, burrowing habitually in wet soil by the water-side, and often below the water-level, while it takes to the water freely, and dives as well as swims. The common Mole of North America (Scalops aquaticus), although it has webbed hindfeet, does not care about water, and rather affects dry soils.

\section{THE DESMAN}

\section{(Myogale moschata)}

THIS creature, although referred to the same family as the Mole, and bearing some resemblance to it in the smallness of the eyes and ears and shortness of the limbs, is adapted to an aquatic life rather than to one beneath the soil. It is large for an insectivore, the body being about ten inches long, while the tail is about six inches more, stout, scaly, and flattened at the side. The fore-paws are of ordinary form, not adapted for digging as in Moles, and the hind-paws are specially suited for swimming, being long and webbed.

The nose of the animal projects far beyond the mouth, like a short trunk, and is very flexible. The coat resembles that of the Otter, having a soft under-fur and long outer hairs, and, as it is appreciated as a fur, the creature is a good deal persecuted in consequence.

The Desman lives in South-Eastern Russia, making burrows in the banks of lakes and streams, and hunting in the water for the insects and other aquatic creatures on which it lives. It has only one near relative, the Pyrenean Desman ( $M$. pyrenaica), a much smaller animal, with a proportionately longer nose, and the tail rounded instead of flattened. 


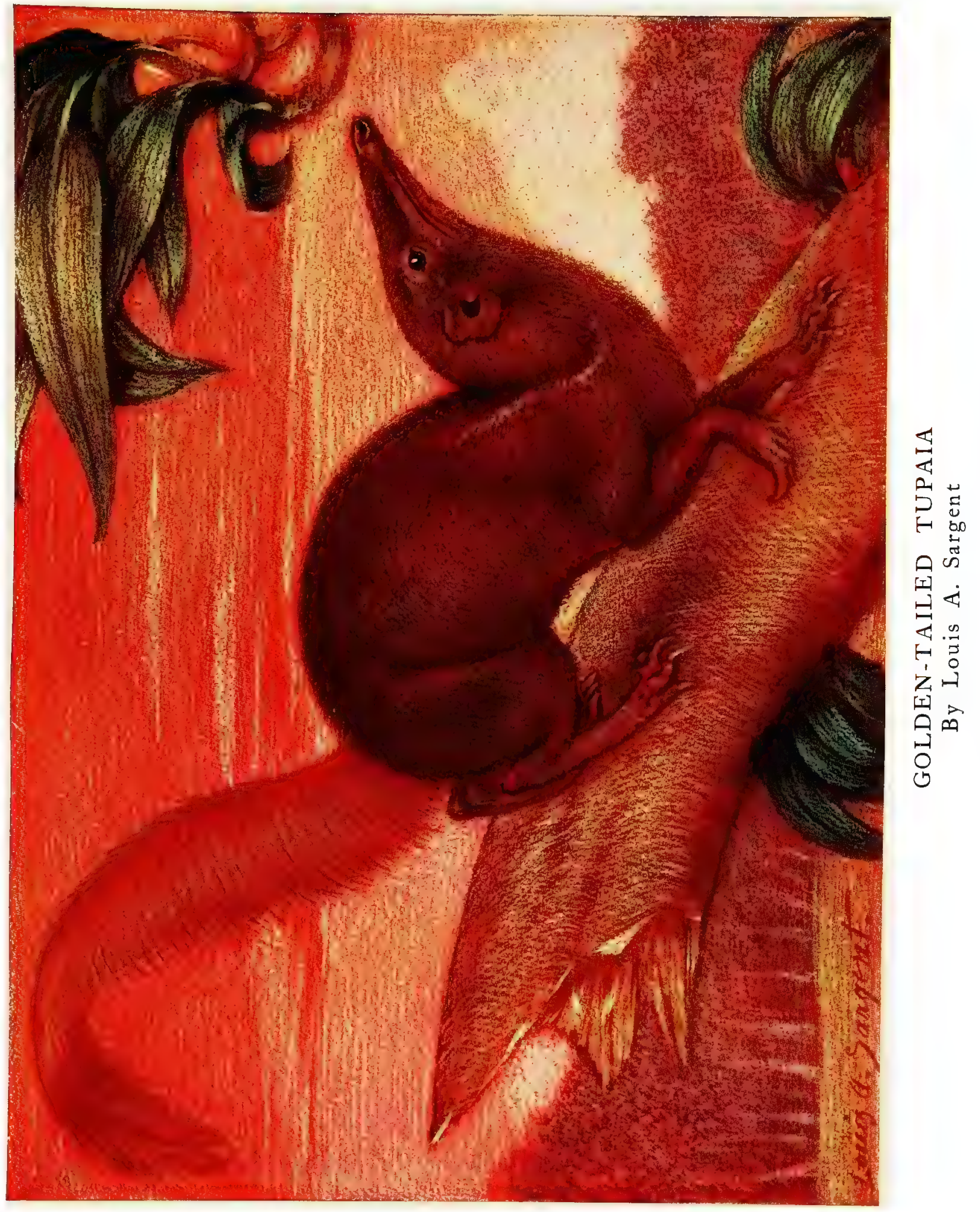





\section{THE GOLDEN-TAILED TUPAIA}

\section{(Tupaia chrysura)}

IN the warm climates of South-East Asia, from Southern India to the Philippines, are found a number of insectivores, the family Tupaiida, which present a remarkable resemblance to the Squirrels among the Rodents. Indeed the Malays have but one name for these two groups "Tupai," whence the scientific name of the typical genus is derived. The Golden-Tailed species is hardly more than a local race of the Tana (Tupaia tana), which ranges through Borneo and Sumatra. The more ordinary colour of the typical form is a plain dark brown on both body and tail. The Tana is the largest of the Tupaias, being about ten inches long without the tail.

These little animals, although so like Squirrels in general aspect, are distinguished by having the usual long snout of the insectivores; and if the teeth are examined, it will be seen that, unlike any rodents, they have canines, and more than one pair of incisors in each jaw. The eyes are large, as in Squirrels, not minute as in insectivores generally; but the ears are very small, and not unlike the human ear in shape.

In general habits they are very squirrel-like; they are creatures of the day, and very lively and nimble in their movements, both on the ground and on trees. They have the Squirrel's habit of holding their food in their fore-paws; but in the nature of that food they are true in great part to the traditions of their order, living mostly on insects, though they also readily eat fruit. The Malayan species $(T$. ferruginea) is a familiar little animal; when, in the rainy season, it finds things uncomfortably damp outside, it comes into houses, and makes itself at home. I once kept a specimen of the Madras Tree-Shrew ( $T$. ellioti) in Calcutta, and found it an interesting pet. It exhibited keen discrimination in the matter of the insects it ate, always refusing "warningly-coloured" 
butterflies; in this it showed itself more discriminating than most birds I experimented with, these usually eating the "warninglycoloured" kinds unless other butterflies were offered as well. As, however, the Tupaia always smelt the butterflies before eating them, it evidently was not impressed by the colour. This specimen lived peaceably with a tame Dove, but Tupaias are said to eat the young of birds in the wild state. Although they are such nice little animals, they are seldom seen in captivity; only two species have been exhibited at the London Zoological Gardens, and those a good many years ago.

\section{THE SHREWS}

THE Shrews (Soricida) are the most widely distributed and numerous family of the Insectivora; they are closely related to the Moles, but in appearance closely resemble the Mice among the rodents, just as the Tupaias do the Squirrels. In fact, they are often called Shrew-Mice, but a Shrew can always be distinguished from a Mouse by its long nose, minute eyes, which are hardly noticeable, and by the presence of canine teeth. Shrews live upon the ground, and feed on insects and such small prey; they are ravenous and ferocious little creatures, and will fight to the death at times. We have three species of them in Great Britain.

\section{THE COMMON SHREW}

(Sorex araneus)

THIs little creature resembles a Mouse in colour as well as in size, being brown; it is the best known of our species, and very widely distributed, being found all round the world in the North, in Europe, Asia, and North America. With us, however, it displays one curious limitation in its distribution-it is not found in Ireland. It is active both by day and night, and subject to some unknown cause of mortality in autumn, when many are found lying about dead.

\section{THE PIGMY SHREW}

(Sorex minutus)

The Pigmy Shrew is a pigmy indeed, being less than half the size of the Common Shrew, but very similar in colour. It is not found in the New World, but is as widely distributed as the Common Shrew in Europe and Asia, and is found in Ireland as well as in Great Britain, though it is not so common in the latter country as the Common Shrew. 


\section{THE WATER SHREW \\ (Neomys fodiens)}

THE Water Shrew is the largest of our Shrews, being considerably bigger than the Common Shrew; it is also more strikingly coloured, being jet-black above and usually pure white below, though some are grey there. Although it is amphibious in habits, it is not web-footed. It lives by the side of still clear water, and feeds on any insects, fish-spawn, and such like small articles of animal food it may procure. Its habits are exceedingly active and playful. It is not found in Ireland, but ranges from England east to the Altai Mountains.

\section{THE MUSK SHREW}

\section{(Crocidura corulescens)}

I SAID that the Hedgehog was the most familiar insectivore in the sense of being a common British animal often kept as a pet; but the most really familiar in its habits is the Musk Shrew, the well-known "Musk-Rat" of the East, for it is habitually found in and about houses. It is the biggest of the true Shrews, about equalling a Mole in size, and of a peculiar blue-grey colour. All Anglo-Indians are familiar with the chittering cry of the little beast as it prowls about at night along the walls in search of cockroaches; it is really a useful creature, and any attempt to disturb it makes it emit a most objectionable musky smell from certain glands on its sides. Our ordinary Shrews have these glands, and possibly their secretion is what prevents Dogs and Cats from eating Shrews, though they are consumed by Owls. The Musk Shrew is the only species which has been exhibited in the London Zoological Gardens.

\section{THE ELEPHANT SHREW}

THIS family (Macroscelidida) is confined to Africa, and contains a number of curious little animals, about the size of Rats, with peculiarly narrow snouts, large eyes and ears, and long hind-legs, on which they jump about; here, then, is another parallelism with rodents, the Jerboas being well-known jumpers in that order. Their food consists of insects; they have been kept in captivity, but I have never heard of any being brought to England.

\section{THE OTTER SHREW}

\section{(Potamogale velox)}

ThE Otter Shrew is a very curious beast discovered in West Africa by Du Chaillu, and having a family all to itself (Potamogalide). It is one of the largest of 
Insectivora, being nearly two feet long; but about half of this is taken up by the tail, which is flattened at the sides and very powerful; the body passes into it gradually as in a Lizard. The muzzle is broad as in the Otter, and the fur similar; the eyes are very small, the paws are small and not webbed, and the animal's very rapid swimming seems to be effected entirely by the tail. It feeds on fish, and has never been brought to Europe alive.

\section{THE TENREC}

\section{(Centetes ecaudatus)}

THE Common Tenrec, which is far the best known of its family (Centetida), is not unlike a Hedgehog, but with a longer muzzle, and coarse bristly light-brown hair instead of spines; it has no tail at all, though some members of the family have long ones. The male Common Tenrecs are remarkable for the large size of their canines, and the females for their great fertility, which exceeds that of all other beasts, as they may have more than twenty young in a litter. All the Tenrec family are confined naturally to Madagascar, but the Common species, being much esteemed as an article of food, has been introduced elsewhere. It feeds, itself, on small prey like the Hedgehog, and is easily kept; it has been exhibited in recent years at the London Zoological Gardens.

\section{THE ALMIQUI}

\section{(Solenodon cubanus)}

THE Almiqui of Cuba is the sole representative of its family (Solenodontida); and is remarkable for its occurrence in the West Indies, quite out of the range of the Insectivora in general. In appearance it is more like a gigantic Shrew than anything else; it is about as large as a small Rabbit, and is white on the head and shoulders and dark behind; the fore-claws are very large and powerful.

\section{THE GOLDEN MOLES}

The few species of Golden Moles (Chrysochlorida) are confined to South Africa, and, though resembling the true Moles in general form and habits, differ remarkably in some points, chiefly in the structure of the fore-feet, which, though as well adapted for burrowing as those of the Common Mole, are formed on a different plan; they have only four toes, the outer being absent, and all the toes are insignificant except the third, which bears an enormous claw, making up the most efficient part of the foot. Their fur is remarkable for its beautiful metallic lustre of green-bronze and copper, and furnishes a curious case of beauty which cannot be appreciated by its owners, as, in addition to having subterranean habits, the Golden Moles are quite blind. 


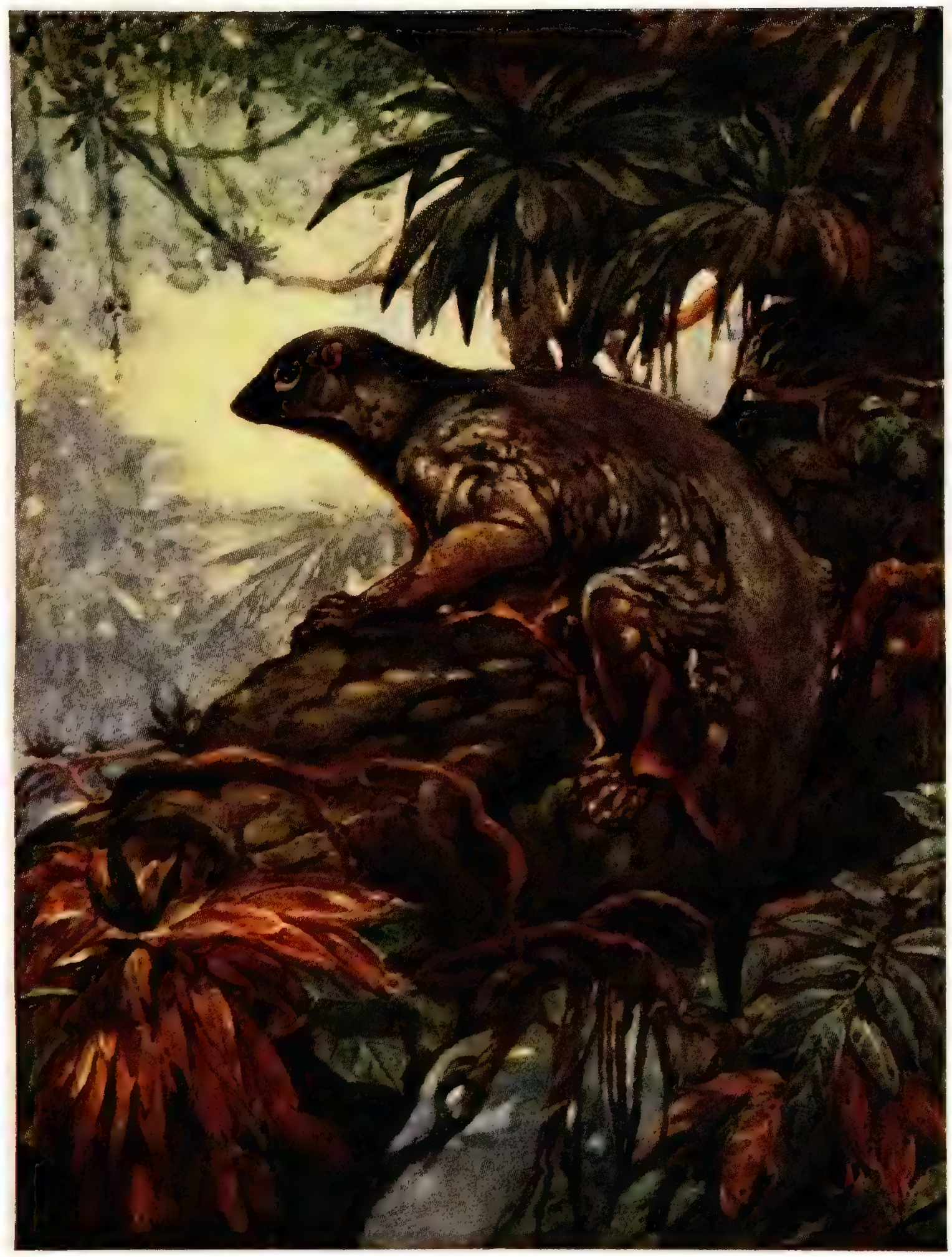

COBEGO

By Winifred Austen 



\section{THE COBEGO}

\section{(Galeopithecus volans)}

The Cobego, Colugo, Kubong, or Kaguan-for this nondescript creature rejoices in a variety of names as queer as its appearance-is usually classed with the Insectivora, mainly, to all appearances, because it will not fit in comfortably anywhere else in the natural system. The English and scientific names given to, it express this puzzle as to its attributes-it has been called a Flying Lemur, though it certainly is. not a Lemur, and does not fly in the proper sense of the word-and the scientific title (Galeopithecus) means Marten-Monkey, though, whatever it may be, it is neither Monkey nor Marten.

What it really is like in general appearance may be gathered from: the illustration ; in size it about equals a small Cat, and is a slim-bodied, long-limbed animal. The paws are five-toed on both fore- and hindfeet, with the length of the toes increasing from the inner to the outer, and all of them armed with sharp curved claws. All the toes are fully webbed - a quite unique character in a land animal.

Perhaps the most remarkable peculiarity about the animal's general form is the parachute, by which it executes its so-called flights. This is an extension of the skin, which reaches from the lower jaw, on each side, to the fore-paw, and runs on from the fore-paws to the hind-paws. From the hind-paws it is continued to the tip of the tail, which is thus entirely enclosed in it like the body; it is long, and has some prehensile power. Thus the creature's body, limbs, and tail form the centre framework of a skinny web, a sort of animated kite. The fur, which clothes uniformly both the body and the skin-extension, is beautifully soft, like that of the Chinchilla, and is variable in colour, but always of some sober shade, olive, brown, or drab, with a mottling of whitish spots; below, it is of a brownish-grey shade. 
But the peculiarities of the Cobego do not end with its general form; it has a most remarkable set of teeth, unlike those of any other creature whatever. The incisors are four in number in the upper jaw, the two inner widely separated, and notched on the crowns, the outer pair pointed. In the lower jaw there are six incisors with broad tops, notched in all of them; in the centre two pairs these notches are so deep and so numerous that these teeth look like little combs, and are utterly unlike the teeth of any other animal. Canines and grinders are present in both jaws, the latter being five on each side of each jaw.

Internally, the animal is remarkable for the small size of its brain and the large cæcum of the intestine, which equals the stomach in size, though this is not small. There are two pairs of teats in the female, situated near the armpits, and her breast is bare; the young animal, of which there is only one at a time, is very small at birth, and both naked and blind, spending its time clinging closely to the breast of its mother.

This animal is a characteristic denizen of the East Indies; it ranges from the Malay Peninsula through the islands to Borneo-and even to the Philippines, unless the form found there (G. philippinensis) is reckoned as distinct; the differences between the two are not very great however, and they are undoubtedly closely related. It is smaller and shorter-headed than the better-known Western form, and the teeth differ in some small particulars.

Cobegos are purely arboreal in their habits, and nocturnal; by day they remain clinging to the boughs-according to some observers, with the hind-feet only, like Bats, though it is more probable that all four feet are employed. They are not always easy to detect in the daytime, as their mottled fur gives much the effect of bark, and assimilates them to their surroundings-although it must be admitted that Moseley, in his "Naturalist on the "Challenger," says of an individual of the Philippine form that he met with, that it was easier to see than he had expected. When disturbed during the day, they hitch themselves up the trunks of the trees by a succession of short jumps. 
At the approach of nightfall the animal becomes active; it then exercises its peculiar power of making long leaps from one tree to another, supported by the skin-parachute with which it is provided. Dr. A. R. Wallace, in Sumatra, where he found the animal quite common, saw one clear a distance from one tree to another which he estimated at seventy yards. In this long distance the animal descended only about twelve yards or so, alighting near the foot of the tree aimed at. Dr. Wallace considers that the creature must be able to steer itself to some extent, otherwise in so long a flight it might very easily miss the goal it was making for.

According to Horsfield, if it does find itself forced to the ground, it travels by "slight awkward leaps," till it finds something up which it can climb. The same writer, who observed it in Java, mentions that it makes its presence known by a croaking, hoarse, disagreeable noise. He states that it is especially found on low hills abounding. with young luxuriant trees growing in a fertile soil; it lives entirely on young fruits and leaves, especially those of the cocoanut tree and of Bombax pentandrum; in this way it does a good deal of damage in plantations. Dr. Wallace also says the Cobego chiefly liveś on leaves, but it has also been said to feed on insects and small birds, in addition to the leaf and fruit diet. This is very likely, as few tree-haunting animals are pure vegetarians, from our poor relations the Monkeys. downwards.

This curious animal is remarkably tenacious of life, and hard to destroy by any ordinary means. It is said to be very gentle, and not to attempt defence when captured. Besides being appreciated as food in some parts of its habitat, the animal furnishes a fur which has some value-locally at any rate, since Moseley found skins of the Philippine form selling at Zebu, near the island of Bojol, north of Mindanao, on which these animals were very abundant, at five dollars a dozen.

One would have thought that so curious an animal as this, and, besides, no rarity in its own haunts, and to all appearances easily accommodated with food, would have been long ago brought alive to 
Europe and exhibited in our Zoological Gardens; but I have never seen it in any menagerie or in the possession of any dealer.

The great interest of the animal, of course, lies in the fact that it seems to give us some idea of the way in which the Bats were evolved, though it certainly is not in the direct line of descent of those animals, having too many peculiarities of its own, such as the webbed hindfeet and the remarkable teeth. It does, however, show the parachutemembrane in a more perfect form than any other creature of the kind, and parachutic animals occur in two or three other groups, not necessarily nearly allied, in two distinct families of Squirrels, and among the marsupials. None of these, however, have the webbed fore-paws and the tail completely included in the parachute-skin, which are the peculiarly bat-like points of the Cobego. 


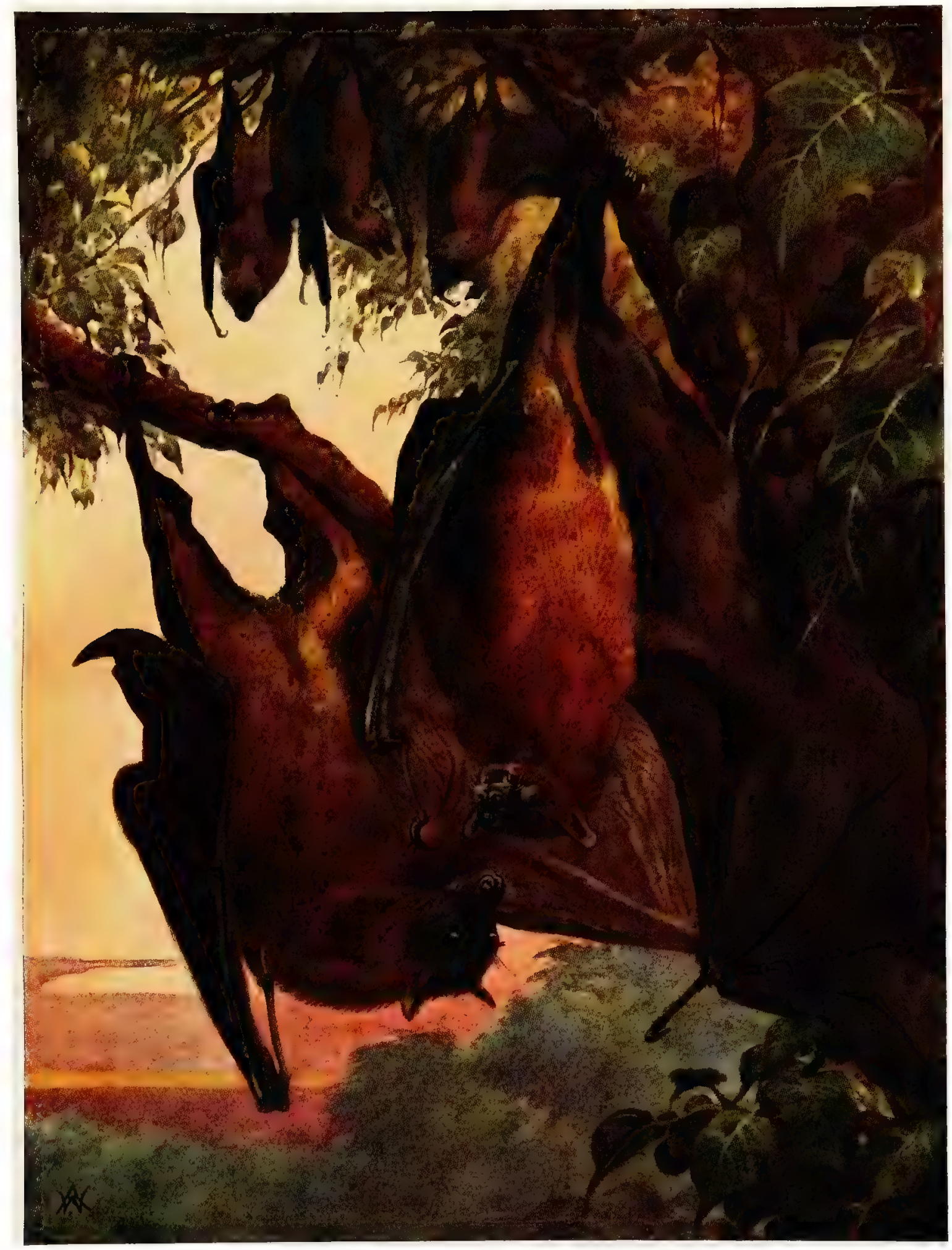

INDIAN FLYING FOXES

By Winifred Austen 



\section{THE INDIAN FLYING-FOX}

(Pteropus medius)

THE order of Bats, known scientifically as Chiroptera-hand-winged animals, their wings being simply the webbing between immensely- elongated fingers, continued along the sides of the body-is divided into the Megachiroptera or Big Bats, and the Microchiroptera or Little - Bats. To the latter division belong the Bats we are accustomed to see, and many other types found all over the world except in the Arctic and Antarctic regions, but the former only includes the family of Flying-Foxes (Pteropodida), fruit-eating Bats found in the warm regions of the Old World, from Egypt to Australia and the Pacific.

Of these the Indian Flying-Fox is a good example, and is the best known, being a very familiar creature in India, and often seen in menageries in other countries. It is one of the largest of Bats, measuring about four feet across the expanded wings, though the body is considerably less than a foot in length; there is no tail, and the skin which in ordinary Bats is found between the hind-legs, enclosing that member, is in the Flying-Fox confined to a flap along the inside of each leg. The toes are armed with powerful claws, and the thumb, which, as in all Bats, takes no part in the formation of the wing, and has to do duty for a whole paw, is also powerfully clawed. There is a minute claw also on the forefinger, and this little claw is one of the distinctive points of the Flying-Foxes, being found in nearly all of them, while in the other Bats it is absent. The ears, too, in the FlyingFox, although of very ordinary form, are notable for having the margin of each joined at the base, a peculiarity not found in the other Bat families, with all their eccentricities in the way of ears.

The head, as the illustration shows, is singularly like that of a Fox in miniature, and the small incisors and large canines add to the resemblance to a carnivore; but the grinders are noticeable for their grooved 
crowns, adapted for munching fruit. The eyes are distinctly large, and this is another point which separates the Flying-Foxes, which have good sight, from most other Bats, which have very small eyes, and rely for finding their way and their food more upon their sensitive wings, which can detect the smallest air-current or change of temperature, so that they really feel their way about.

In colour the Flying-Fox varies considerably, some being much blacker than those depicted, especially on the abdomen. The flight of the Flying-Fox is as different from the Bats one usually sees as is its general appearance; it travels slowly by steady uninterrupted sweeps of its great wings, like a large bird, from which it is hard to distinguish if seen "end on." When about to alight, it sails and wheels on motionless down-bent wings, and, on pitching in a tree, shows itself fairly active on foot, either walking along the boughs upside down with the thumbs and feet, or even by means of the feet alone, as in the ordinary resting-position represented. When in complete repose it hangs by one foot only, wrapped up in its wings, with the head tucked in on the breast.

It is a quarrelsome, ill-conditioned brute, biting savagely, and scratching its foe with the great claws of the thumbs; on such occasions it shrieks and cackles in a way which reminds one of an infuriated Monkey: Its claws come in handy in feeding as well as fighting ; sometimes it holds a fruit between the thumb and the adjacent part of the wing, or it may employ its toe-nails as a fork, bending the leg forward to hold the food against its body; the legs having remarkable freedom of action. The food thus secured, the Bat gluttonously gulps it down in great mouthfuls, for, like so many fruit-eating creatures, it is intensely greedy. This is presumably the result of its comparatively slight digestive power, for the fruit passes through the body of the beast in a very slightly altered condition, a peculiarity also notable in many fruit-eating birds.

Flying-Foxes begin to fly out for food at twilight, not in flocks, but one after another in a caśual way. They probably often traverse great distances, for their flight is very enduring, one having once been 
taken at sea 200 miles from land. Their ordinary food is wild fruit, almonds, and so forth, but when they get the chance they fall greedily upon orchards, devouring any sort of cultivated fruit except the orange tribe. They drink in captivity, so, no doubt, when in the wild state they are seen, as they often are, to sweep down and touch water, they are taking a sip on the wing.

At dawn they come back to the roosting-trees, for this species, like so many Fruit-Bats, only roosts in trees, and, as a great number roost together, their quarrelsome disposition leads to hours of skirmishing before they at last get sleepy and resign themselves to a day's rest.

Sometimes they drink the sap of the palms collected in the vessels hung up by the toddy-makers, and if this has fermented they get uproariously drunk, some being forced to rest at times helpless beneath the palms-lucky, no doubt, if some Jackal does not find them before they have recovered from the results of their intemperance. Considering the rowdy propensities of the Flying-Fox when sober, the arrival of an inebriated party at the "battery"-if one may coin such an expression for the roosting-tree-ought to be a sight worth seeing.

As is the general rule with Bats, the Flying-Fox has but one young one at a birth, which clings to the breast of its dam for a couple of months; it is usually born in the spring. In spite of this slow increase, the animal is very numerous in India, and their long trains crossing the sky at dusk are as familiar in Calcutta as the Rooks in England. The Flying-Fox is, however, a long-lived animal, having been known to reach twenty years of age in captivity, and seems to have no particular enemies, so that its abundance is not inexplicable. Owing to its ravages on fruit, it is one of the standing nuisances of the country, and certainly needs thinning down, though it would be a pity to exterminate so picturesque a creature. It has also some direct utility, being relished as food by the Goanese half-caste Portuguese, and by certain low Hindoo castes, in spite of its rank musky smell.

Numbers are caught alive for export as menagerie specimens, and, as might be inferred from what has been said above, they bear captivity well. They may often be obtained from our London dealers. 
This species cannot, however, compare in aptitude for cage-life with" the Collared Fruit-Bat of Africa (Cynonycteris collaris), a rather smaller species with a rudimentary tail, which bred freely, generation after generation, in the London Zoological Gardens, though the specimens were confined in cages so narrow that flight was impossible. This Bat is a cave-haunter, and does not roost in trees by day.

There are a considerable number of species of these Old World fruit-eating Bats, much alike in general habits, but varying considerably in size, from the Kalong (Pteropus edulis) of Malacca and the East Indies, which measures five feet across the wings, down to the little Long-tongued Fruit-Bat (Carponycteris minima), which is smaller than our Noctule or Great Bat, for the Megachiroptera, although they average considerably larger than the other section, are not always so. The Long-tongued Fruit-Bats have the tongue not only long and extensible, but furnished with a kind of brush at the tip, very suitable for licking out the soft pulp of fruit. Big or small, the Fruit-Bats are the bane of fruit-growers in the East, and the American Government is so afraid of these pests getting a footing in the Western world, that their importation into the United States is not allowed, and any one who comes ashore with a live Flying-Fox has the mortification of seeing his pet incontinently executed. 


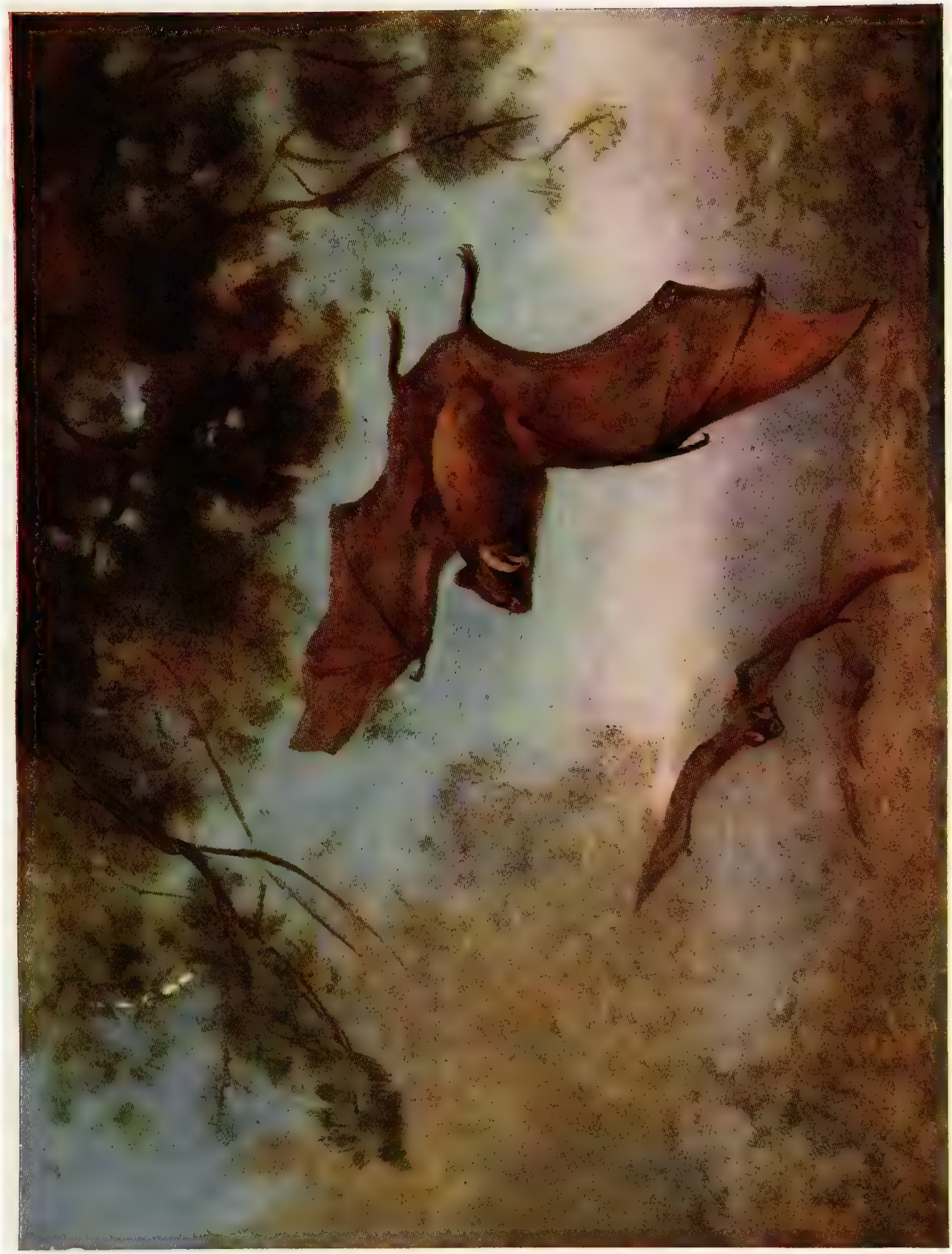

$\sum_{5}^{2}$ 



\section{THE VAMPIRE}

\section{(Desmodus rufus)}

OF all the numerous tribes of small Bats, mostly insectivorous in habits, the South American Vampire has the greatest notoriety, owing to its ghoulish habit of living on blood sucked from other animals. For many years, however, it was known that there were blood-sucking Bats in the warm regions of America before the habit was definitely brought home by Darwin to Desmodus rufus; and many innocent Bats had the injurious suspicion fixed upon them, notably Vampyrus spectrum, a big ugly Bat about two feet across the wings, which is now known to be a fruit-eater, like the Flying-Foxes of the Old World. The true Vampire is a quite ordinary-looking Bat as far as outward appearances go, as the illustration shows; all that is noticeable is that it agrees with the Oriental Fruit-Bats, and differs from most Microchiroptera. in having the membrane between the hind-legs little developed, and being almost tailless.

Its teeth, however, are very remarkable, and show its complete adaptation for a blood-sucking existence. The incisors, which are usually small in Bats, are in the Vampire very large and sharp, and the molars, which in insectivorous Bats are studded with sharp points for crushing their prey, are in the Vampire small and few, being practically of no importance to an animal whose food is liquid. Moreover, the stomach of the Vampire is much elongated, like a cæcum or blind-gut, so that it can contain a large quantity of blood to be digested. at leisure.

The sharpness of the incisors enables the Vampire to shave off, as it were, a small portion of the skin of its victim, and thus wound a number of capillary blood-vessels without giving pain, while causing a free flow of blood. Thus the victim, if asleep, is not awakened, and a case has even been reported in which a Vampire was found 
to be sucking blood from the toe of a man who was calmly engaged in conversation at the time.

The toes in man are usually the point attacked; Horses are bitten on the withers, and Fowls on the comb or the hocks. The attack is, of course, serious in the case of animals so small as poultry, nor is it without much inconvenience in the case of man and large domestic animals: a vampire-bitten big toe is apt to bleed for some time and give trouble when boots are worn, and bites on a Horse interfere with the saddling of the animal. Moreover, the loss of blood is not to be despised, especially in the case of individuals for whom the Bats show a special predilection, for, like blood-sucking insects, they have their preferences.

They are said to be afraid of light, so that a lamp kept burning in a stable is a good protection to Horses, and another preventive is found in thorny bushes hung up above the animals' backs, near which the Bats are afraid to venture for fear of tearing their wings. One would think that wire-netting in the windows and doors would be the simplest protection of all.

So far as structural evidence goes, there are only two other species of Bats, both also South American, which are blood-suckers by profession, so to speak; but it is not impossible that other species may attempt the practice in an amateur way, though it would be difficult for a Bat with the ordinary small incisors and long sharp canines to inflict a bite that would not wake the object of its attentions.

The whole of the Vampire family are confined to South America, most of them being fruit-eaters, and being peculiar in this habit among the "Small Bats"; some have the same long brush-tipped tongue that is found amiong. some Flying-Foxes, and even show a lengthened muzzle like them. Most Vampires, however, are shortfaced, like ordinary Bats, and have the curious flat fleshy appendage on the nose so often found in the Microchiroptera, and known as the "nose-leaf." 


\section{THE INDIAN VAMPIRE-THE RAT-TAILED BAT 183}

\section{THE INDIAN VAMPIRE \\ (Megaderma lyra)}

THis belongs to a different family from the true American Vampires, but is also a blood-sucker, though it goes about its business in a different way. It is a fairly large Bat, bigger than any British species, with a small nose-leaf, fairly large eyes, and enormous ears, joined to each other at the base. Its fur is of a peculiar bluegrey colour. This animal, which is common in India and Burma, preys on other Bats of smaller size than itself, on small birds, and on Frogs, sucking the blood of its victims, and eating up their flesh and even many of the bones, for it has great power of jaw and very strong teeth; it appears never to attack large animals. It has a gruesome habit of bringing its prey into houses to eat it-perhaps to escape being robbed of it by Owls-so that fragments of its victims, especially the hind-quarters, may often be found in bungalows near its haunts. I have kept this animal in captivity in India, and it has been brought to England, but never exhibited in the Zoological Gardens, any more than the true Vampire. There are other species of Megaderma found in Africa and Australia, all probably with similar carnivorous habits.

\section{THE FISHING BAT}

\section{(Noctilio leporinus)}

IT is hardly worth while here to detail the characteristics of the different families of insectivorous Bats, but some species, like the above, need mention on account of peculiarities in habit or form. That a Bat should catch fish is so remarkable a fact that it deserves notice, but the present animal habitually gets its food in this way, haunting either fresh water or the sea, and snatching up its prey with its feet, which are unusually large for a Bat and furnished with correspondingly large claws. The teeth have much the appearance of those of a rodent, there being two large incisors in the upper jaw, concealing a small pair behind them, and only one pair in the lower jaw. This is a large species for the group of Bats to which it belongs, being as big as some of the smaller Fruit-Bats.

\section{THE RAT-TAILED BAT}

\section{(Rhinopoma microphylum)}

IN most Bats, except the Fruit-Bats and blood-sucking Vampires, the tail is of considerable length, but not very noticeable, because it is usually included in the membrane stretching between the hind-legs. In one family (Emballonuridee), however, to which the present and the last species belong, it protrudes outside or beyond this skin. In the Rat-Tailed Bat, which is- a small delicately-formed species, the tail is as long in proportion as a Mouse's, and the membrane between the legs, being 
very short, is quite as conspicuous as the tail in most animals. The creature seems to have the ordinary habits of an insectivorous Bat; it is found from Egypt to Burma, and especially haunts tombs and ruins.

\section{THE PIPISTRELLE}

\section{(Vesperugo pipistrellus)}

Our common British Bats belong to a family (Vespertilionide) which is the most widely spread of all, and has no very striking peculiarities. The commonest in England is the above species, usually known as the "Flittermouse," and familiar to every one, as it is found even in towns, and flies low, and not unfrequently is abroad by day; while, though it hibernates, like all insectivorous Bats in Temperate countries, it retires late and comes out early, even appearing on fine days in winter. It is a small brown Bat, with no noticeable peculiarity about muzzle or ears. Its food is Gnats and such small insects, and it usually roosts by day in buildings. It is found all over Europe, North Africa, and east to Cashmere, but it is not the "Common Bat" of the Continent, that being Vespertilio murinus, a species rather bigger even than our Noctule Bat.

\section{THE NOCTULE}

\section{(Vesperugo noctula)}

ThE Noctule is the biggest Bat one is likely to see in England, and is nearly twice as big as the little Pipistrelle; it is also much brighter in colour, being of a light chestnut, but it has a rank unpleasant smell: This big Bat usually retires for the day into hollow trees, though sometimes found under eaves; it usually flies high, and feeds by preference on large insects like Cockchafers and other beetles. It is found over a large part of the Old World, Europe, North Africa, and Asia, and even Java and Sumatra, though not India proper.

\section{THE LONG-EARED BAT}

\section{(Plecotus auritus)}

THERE are a good many British Bats, but it is only possible here to allude to the three most conspicuous species, of which the present is certainly one, for, although a little creature like the Pipistrelle, it rejoices in the largest ears, for its size, of any known animal, except its near ally the American Long-Eared Bat ( $P$. macrotis). These ears, which are three-quarters the length of the body, can be both bent and folded, and are usually stowed away under the wings when the Bat hangs itself up to rest. The Long-Eared Bat is a widely-spread species in England-I have known one captured even in London-and also has a wide range abroad, from Europe and North Africa to the Himalayas. 


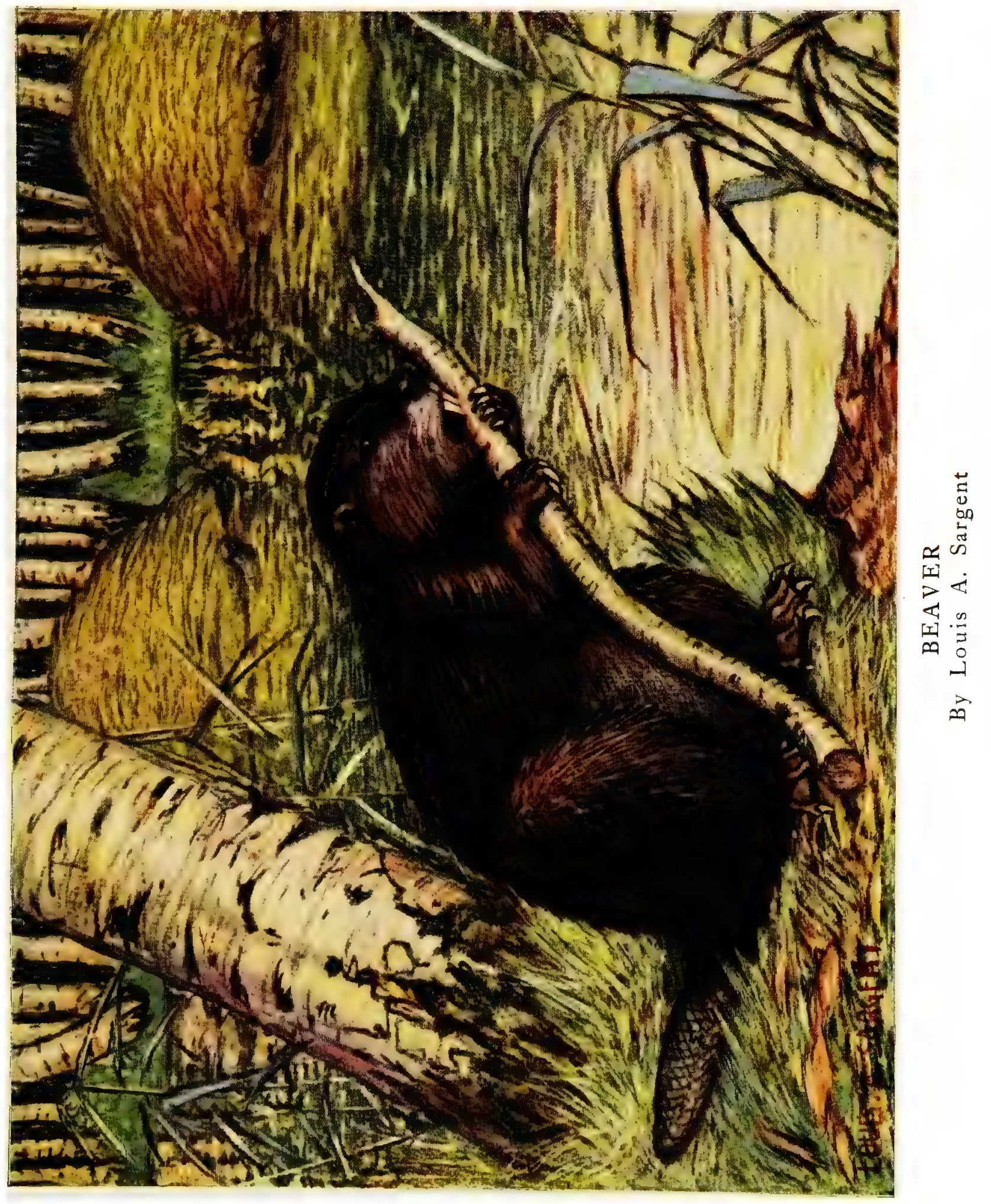





\section{THE BEAVER}

\section{(Castor fiber)}

WITH the exception of the Capybara of South America, presently to be noticed, the Beaver is the largest of the Rodents, and in some respects a good type of that order of beasts, notably in its short deep muzzle, in the large size of the hind-limbs as compared with the fore, and in the teeth, which, as in Rodents generally, are remarkable for the complete absence of canines and the presence in each jaw of two huge chiseltipped, continually-growing incisors, with which the gnawing is effected. These teeth are kept sharp by being faced with enamel only on the fronts, so that they wear away more from behind, keeping the anterior portion at an edge. The grinders are broad and flat, adapted for the chewing of vegetable food. The structure of the feet, in which the front pair are small and practically unwebbed, and the hind pair large and fully webbed, is similar to that found in several other aquatic rodents, and the number of toes, five on each foot, is usual in the Rodent order; but the Beaver has a remarkable peculiarity in possessing a double claw on the second toe of the hind-foot, which is used for scratching or combing the fur.

The tail is also quite a peculiarity of the Beavers, no other beast having a similar one. It is broad and flat, and oval in form, hairy only at the root, and covered for the rest of its surface with a scalylooking skin. It is of considerable use in swimming, especially in helping the animal to rise for air, and in sending him down for a dive, when the loud smack it makes warns all other Beavers for some distance. The ordinary agents in swimming are. however, the webbed hind-feet, the fore-feet being tucked up and not used at all in the water. As in the case of so many aquatic animals, the Beaver's fur is of two kinds, the long coarse hair which alone shows on the surface, and the soft close under-coat, which is the fur for which the animal is famous. The 
general colour of the Beaver is brown, as shown in the illustration, but, especially towards its Northern limit in America, black specimens occur, and, rarely, white or pied individuals are found. In size the Beaver equals a fair-sized Dog, weighing about thirty pounds, though specimens much heavier than this are met with.

It is found in the Northern Hemisphere all round the world, though the American race presents, as a rule, certain slight differences in the form of the skull, which have caused some authors to rank it as a distinct species. In Europe and Northern Asia the Beaver is a rare and very local animal, and comparatively little known, though the ancients were acquainted with it as the producer of the drug castoreum, which is contained in two pouches situated under the skin and muscles beneath the tail. They do not, however, seem to have been acquainted with the wonderful architectural and engineering instincts of the animal, and, indeed, these are seldom manifested in Europe, where the animals usually live in holes in the banks of streams like Water-rats, and have only been known in a few cases to build the dams and houses which have long been so familiar as the handiwork of the American race.

Beavers inhabited Britain in historical times, and lingered in the river Teify, in Wales, well into the Middle Ages, and they may still be found on the Rhone, the Elbe, and in Norway, to say nothing of remoter localities farther to the East. In America they used to range from the shores of Hudson's Bay to the Gulf of Mexico, but they were early exterminated from the more settled parts of the country, and have everywhere been much reduced in numbers. The country they affect is well-wooded land with plenty of water, and thus they have always had a stronghold in the great forests of the North. On the shores of large bodies of water they merely burrow in the banks, and it is chiefly in small streams that they display their remarkable instincts. Although most at home in the water, they obtain most of their food on land, as this consists very largely of the bark and soft wood of trees; and, though they are more active on land than their clumsy shape would lead one to expect, and can inflict very severe 
bites, they have little chance to survive among fierce and powerful carnivores like Lynxes, Bears, and especially Gluttons, unless they have deep water available to retire to. Thus it is that they are led to construct their wonderful dams and other works, when living away from deep water; they make, in fact, arrangements to insure constant water-accommodation. The dams they construct across streams cause the formation of ponds deep enough to insure the entrances of their burrows and houses being under water, and hence are of the most vital importance. They are constructed in the form of banks, with a foundation of brushwood, intermixed with mud, and poles; so much of the earth is sometimes used as to in time conceal the timber portion, but this is not usually the case. The woodwork is interlaced, but there is no planting of stakes such as the old accounts represent, and the whole construction has a very rough appearance. In dams mostly made of sticks, the surplus water naturally percolates through, but in an earth-bank dam openings are made at the top to allow for its discharge.

In addition to the dams, Beavers make canals leading from their ponds into the woods where they cut their wood, and if the banks are steep, they cut "slides" or runways in them. The celebrated "lodges" or houses are piles of sticks, mixed with mud, on the banks, with a small chamber inside, containing beds of leaves and chips, and having two neatly finished entrances opening under water. They are careful to plaster their houses with fresh mud as late in the autumn as possible, so that this mud, freezing, makes the whole structure as hard as stone, and impervious to their great enemy, the Glutton. Besides the houses, they have burrows, which they use as a last refuge in case of urgent danger.

In summer Beavers lead an easy life, wandering about and feeding on herbage, berries, \&c., as well as bark, but towards autumn they work hard at getting in their winter supply of wood. They gnaw through trees a foot in diameter, cut up the boughs into suitable-sized pieces, and sink these in piles in their ponds. Thus, when everything is frozen in winter, they can live at ease on their stores, eked out with 
water-lily roots and such food obtainable below water. The gnawed boughs are used to strengthen the dam and pile on top of the lodges, so that nothing is wasted. The upkeep of the dam is attended to with great care; the Beavers frequently survey it, and each one does such work on it as seems to him necessary. In working with mud, they carry it in their paws under their chins, but do not use their tails as trowels, as used to be supposed. The dam seems to be usually formed by a pair only, but if the pond formed is a large one, several families will take up residence on it, and help in maintaining it; they do not, however, live and work in large colonies. The young, which are born in May, are in number from one to six, begin to eat solid food at about a month, but are not full-grown till over two years old, at which age they leave the lodge of their parents to start in life for themselves. When small they cry exactly like a human infant, and they leave the nest when only as big as Rats.

The Beaver seems to be a long-lived animal for its size, reaching about twenty years-at any rate in captivity; but it is said that in the wild state the teeth of very old Beavers get so blunted that they cannot cut wood for themselves, and are ultimately killed by their neighbours for stealing the cut wood of others to satisfy their hunger-a sad end for so harmless and industrious a creature. Fortunately the persecution of man is less severe than it was, owing to other furs having come into competition with Beaver, and to the use of silk in making hats, but protection will probably be necessary if this wonderful animal is to maintain its existence indefinitely. Beavers do well in captivity, but their nocturnal habits make them often rather unsatisfactory exhibits in menageries. They have been established in a state of more or less freedom in at least one English park, and have often bred in the London Zoological Gardens. 


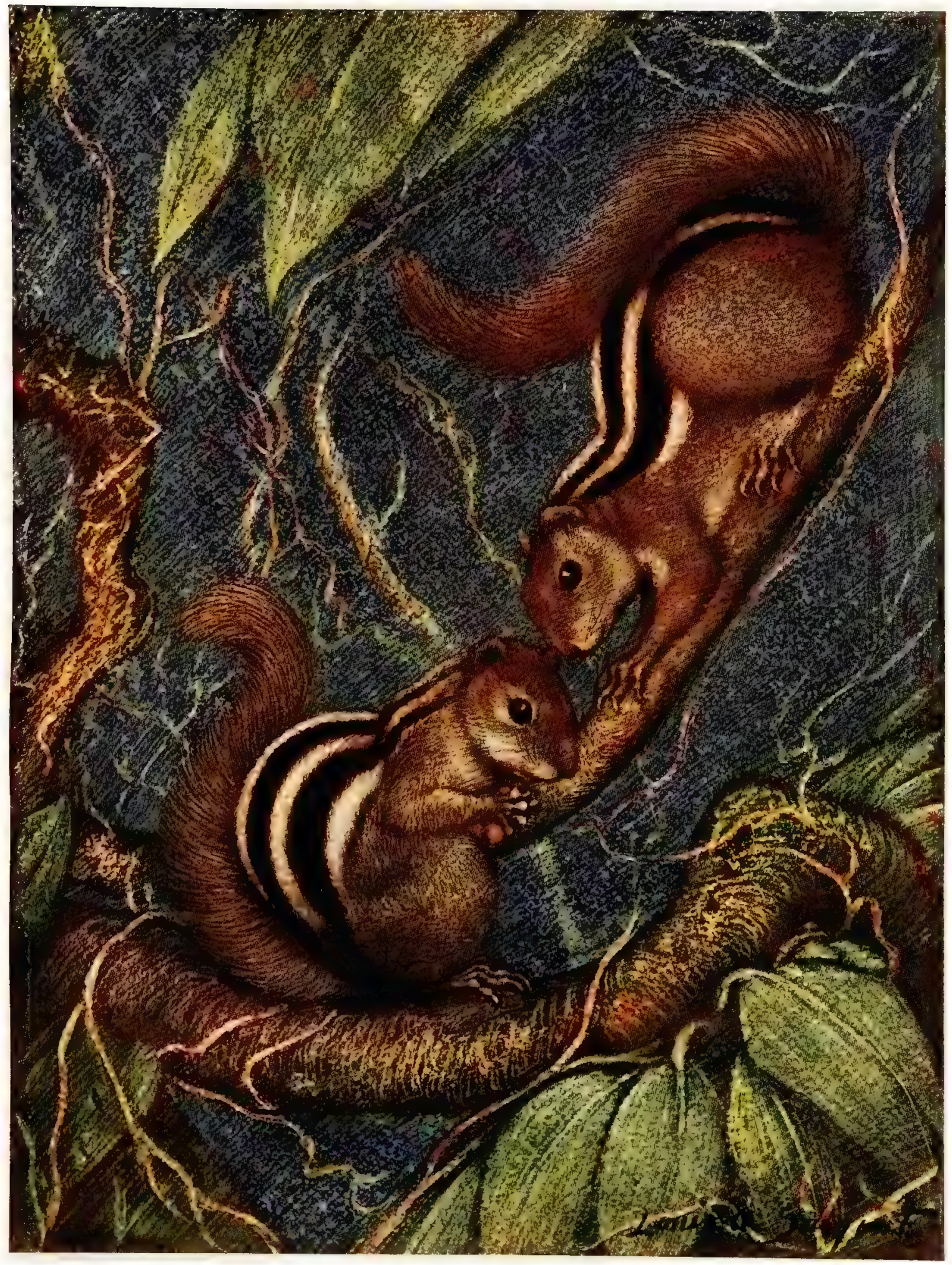

INDIAN STRIPED SQUIRRELS

By Louis A. Sargent 



\section{THE INDIAN STRIPED SQUIRREL \\ (Sciurus palmarum)}

WHEREVER they occur, and they are found almost everywhere except in the Australian region, the Squirrels are the most conspicuous of small beasts, from their liveliness and diurnal habits, while their pretty appearance and amusing ways give them a popularity denied to most of their rodent relatives. The most familiar of all of them, where it occurs, is the little Striped Squirrel of India, which lives the life of a semi-domesticated animal about human habitations. It is considerably smaller than our Squirrel, and, as the illustration shows, very differently coloured, and without the pretty ear-tufts which give such a striking expression to the Red Squirrel. The colour varies somewhat locally, some races being redder and less grey than the ordinary type, and both black and white varieties have been recorded. Indeed, it would be a remarkable thing if such were not the case, for the Squirrels are remarkable not only for the brightness of their colours, but also for the great tendency to variation they exhibit.

Although this species is often called the Palm Squirrel, it has no particular preference for palms, running up any tree that is handy. It feeds to a great extent on the ground, and is, like so many rodents, omnivorous, though chiefly a vegetable-feeder; shoots, seeds, and so forth, form its usual food, though it also eats some insects, and is reputed to plunder birds' nests, although it lives on excellent terms with the birds. Any scraps of human food, such as bread, which it can find or steal in its ramblings about houses, it will appropriate gladly, and it is difficult to keep it out of rooms when it has found some such inducement for coming inside; as for using harsh measures to it, one is averse to such a course with such a pretty little animal, so that, on the whole, it leads a privileged life.

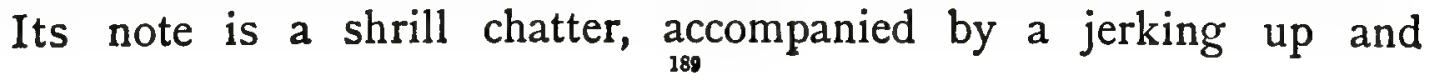


quivering of the tail, and heard to perfection when it has just escaped a Dog by running up a tree-with not an instant to spare, for it seems to enjoy the risk, and turns round at a safe distance to vituperate its enraged enemy.

It makes its nest in the branches of a tree or under a roof, and two to four young are produced in a litter; they are at first blind and helpless, as in most rodents. Many are reared by hand to be kept as pets-in Calcutta at any rate; but, for some reason or other, this species is quite scarce in the hands of English animal dealers, though they often have other foreign Squirrels, especially the beautiful Prevost's Squirrel (Sciurus prevosti) of the East Indies, which is brilliantly coloured with jet-black, bright chestnut, pure white, and iron-grey. There are many species of typical Squirrels, some as big as Cats, and others as small as Mice, but all presenting a strong family likeness. There is only room here to say a few words about our own species, which is, to my mind, about the prettiest of any.

\section{THE COMMON SQUIRREL}

(Sciurus vulgaris)

THE Common Squirrel is common not only in our islands, but all across the Northern portion of the Old World, even to Japan. The red colour so characteristic of it with us is not constant through all its range, Siberian specimens being mostly grey; it is these, having finer fur than our Squirrels, which furnish the Squirrel-skins so largely used for ladies' attire. Even in Britain the Squirrel is much less red in winter than in summer, and in the latter season the ornamental tufts on the ears are absent.

The active habits of the Squirrel are well known, and also his unfortunate destructiveness in woods, owing to his habit of eating the shoots and bark of trees. $\mathrm{He}$ is also an enemy to birds, whose nests he pillages of both eggs and young. On the whole, however, except when very numerous, he does so little harm that his many engaging qualities justify his preservation. The home of the Squirrel is a "drey," or domed nest, somewhat like that of a Magpie, and usually built high up in the small branches of a tree. In one of these abodes the young are born, usually early in spring-two or three is the common number. When taken and handreared they make, as is well known, most charming pets, and can be allowed to go 


\section{FLYING-SQUIRRELS-GROUND-SQUIRRELS}

about loose in a country place. In any case, if confined, they should not be put into the abominable wheel-cages so often used; a Squirrel needs a very large cage, at least two feet every way, with' a sleeping-box. Squirrels do not hibernate in winter, though they may keep at home in their nests in bad weather; but in autumn they make some attempt to provide against winter emergencies by burying nuts and acorns in the ground; many of these are not consumed, and so Squirrels unconsciously aid in the extension of the trees which bear their food.

It ought to be mentioned that the American Grey Squirrel (Sciurus cinereus), which is larger than our animal and without ear-tufts, has been introduced into Bedfordshire, and seems quite established there. A few may also be seen in the Zoological Gardens and other parts of Regent's Park; the species is a very familiar one in American parks, where it has domesticated itself.

\section{FLYING-SQUIRRELS}

THERE is a group of Squirrels which, though agreeing in general habits with ordinary Squirrels, differ in possessing a parachute-like expansion of the skin along the sides, like that found on the Cobego, but not so well developed, there being little, or not any, of this before or behind the legs. The use of this structure is, of course, the same as in the Cobego, to enable the animal to take long sailing jumps from one tree to another. Flying-Squirrels differ from typical Squirrels in being nocturnal; the larger kinds (Pteromys), some of which are the biggest Squirrels known, are purely Asiatic, and these have the parachute-skin best developed. The smaller ones (Sciuropterus) are not only found in Asia, but there is one in Europe, and one in America (Sciuropterus volucella), a very beautiful little grey animal, not so big as a Rat, which is sometimes imported here as a pet, and has bred in captivity. This is rather remarkable, for, as a rule, Squirrels very seldom reproduce in that condition, though they are easy enough to keep.

\section{GROUND-SQUIRRELS}

ONE usually associates Squirrels with trees, but a considerable number of species live on the ground, these being the Ground-Squirrels (Tamias), of which the pretty little American Chipmunk, something like the Indian Striped Squirrel, but smaller, is an example, and the animals of the genus Spermophilus, exemplified by the Souslik of the Old World and the so-called Striped Gophers of the New. There are also Ground-Squirrels (Xeris) in Africa. These terrestrial Squirrels live in holes, and resemble Rats in their habits. Some of them, with fair-sized ears and 
large bushy tails, resemble the ordinary Tree-Squirrels in their appearance so much, that it seems strange that they should live in such a different way; but from these there is a gradation to species with very small ears and short insignificant tails, and thus links are formed between the typical Squirrels and the group next to be noted.

\section{THE MARMOTS}

ThE Marmots are heavy, stout-bodied rodents, with the ears always, and the tail generally, quite short; they are burrowers, and at first sight look very different from the light, agile, bushy-tailed Squirrels, though really belonging to the same family (Sciuride). They are found in the northern parts of both worlds, two of the most familiar being the Alpine Marmot (Arctomys marmota), which used to be taken about for exhibition as Monkeys are now, and the Woodchuck ( $A$. monax) of North America, a familiar garden-pest in that country by its inroads on the vegetables. Both of these hibernate during the winter; they are about as large as Cats.

The well-known Prairie-Dog (Cynomys ludovicianus) is also a Marmot, but a much smaller animal, of the size of a Guinea-Pig, and sandy-coloured. It lives in communities or warrens-called "dog-towns"-in the open plains of North America, and the little Burrowing Owl (Speotyto cunicularia) lives in its company. Both bird and beast have lived together and bred in an enclosure in our Zoological Gardens, but though they did not hurt each other, their relations could not be called cordial.

\section{THE SCALY-TAILED SQUIRRELS}

IT is very doubtful if these animals are closely related to the true Squirrels, and in any case they belong to a separate family of rodents (Anomaturida). They are all West African, and present the very remarkable peculiarity of having a series of broad horny scales at the base of the under-surface of the tails, which are supposed to act as climbing-spurs, to hinder their slipping back when climbing. Most of the species belong to the genus Anomalurus, and have a parachute expansion of the skin of the sides, as in the Flying-Squirrels, but it is less wide than in those animals; and in one form (Zenkerella) it is absent. 


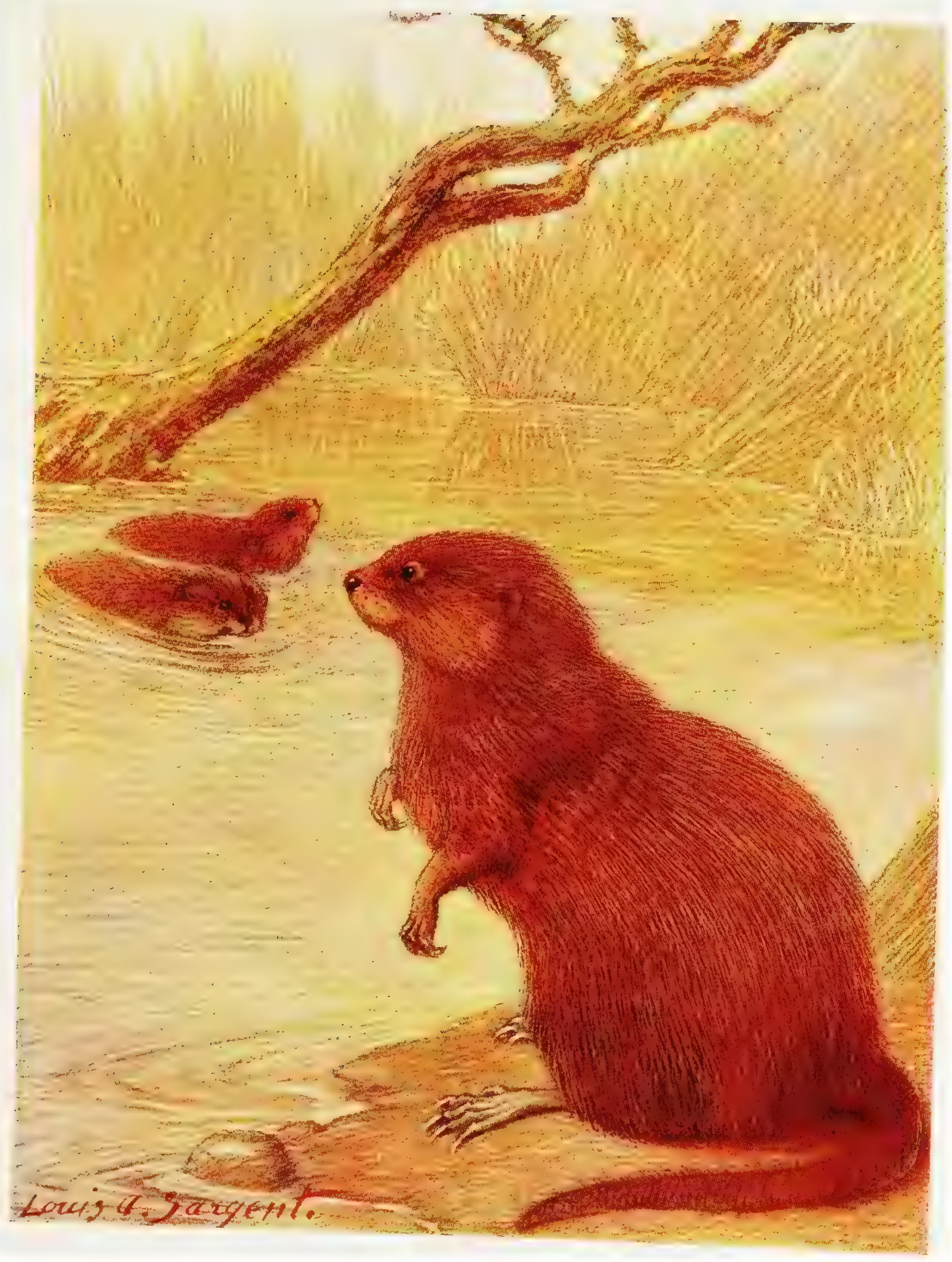

MUSQUASH
By Louis A. Sargent 



\section{THE MUSQUASH}

\section{(Fiber zibethicus)}

THE Rodents are far the most numerous order of beasts, comprising nearly a quarter of the known species, and among this host of gnawers more than a third belong to the family of Rats and Mice (Murida), so that this is the largest, and in some ways the most important, family of quadrupeds. They are not, however, animals of much distinction, so to speak, and few can boast of any name but "Rat" or "Mouse." The present animal, the Musk-Rat of North America, is one of the few exceptions, and is quite a notable creature in some ways. In size it is large for a Rat, measuring a foot in length without the tail, which member is naked, scaly looking, and flattened sideways-not vertically as in the Beaver, which in many ways the Musquash resembles.

The hind-feet are, however, not webbed fully like the Beaver's, but only at the bases of the toes. The fur is like that of the Beaver in character, consisting of a soft under-coat overlaid by long glistening hair, and, as in the Beaver, there are scent-pouches situated under the skin below the base of the tail, secreting the musky scent characteristic of this animal, as those of the Beaver do the "Castoreum."

The Musk-Rat is the common Water-Rat of North America generally, being an abundant animal, and widely distributed all over the Continent, from the "barren grounds" in the North to Mexico.

In general habits, as in appearance, it is very Beaver-like; living in small communities by the banks of streams and lakes, and making burrows with entrances under water, while for winter use it constructs domed houses or "lodges" made of grass, sedge, \&c., mixed with mud, very like miniature Beaver-houses. The materials of these, being edible from the Musquash's point of view, also serve for a winter supply of food; the ordinary diet consists of both land- and water-plants, but, unlike the Beaver, the Musquash has a decided carnivorous tendency, and devours fish, molluscs, and other items of animal food. One peculiar point in its habits deserves notice; it is active during the winter, and when it has to swim for some distance under ice, it will expel the

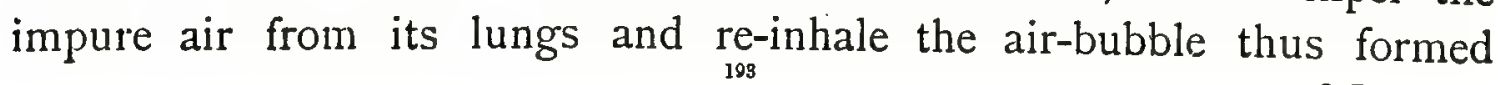


after it has been purified by contact with the ice and water. Musk-Rats have a habit of slapping the water with their tails like Beavers, and this serves as a warning of danger; their ordinary voice is a squeak, or a whimpering note when swimming happily about. The young ones, which are, as in Mice and Rats generally, naked and blind at first, are born in the burrows, and two or more litters, of five to nine each, are produced yearly. Being so prolific, Musk-Rats do a good deal of harm by boring holes in embankments, especially in the south, where the Alligator, one of their worst enemies, has been so much killed down of late; but they are in great demand for the fur trade, their skin being much used, especially when dyed, for the article called "electric seal." I need hardly remind my readers that such a thing as an Electric Seal does not exist; indeed, the only electric creatures are not beasts at all, but a few species of fish, like the Electric Eel of South America, and the Torpedo of the Mediterranean. Musquashes are seldom seen in captivity, but the species was exhibited at the London Zoological Gardens some years ago.

\section{THE LEMMING}

\section{(Mjodes lemmus)}

This quaint little creature, an inhabitant of the Scandinavian peninsula, has attained a great reputation on account of the tragic migrations it periodically performs. It is a very small animal, about twice the size of a common Mouse, stout and chubby in shape, with small eyes, ears, and tail, and thick fur-bright fawn above, with conspicuous patches of black on the head and shoulders, and white below. Altogether, it is not unlike a miniature Guinea-Pig. In the ordinary way, its life is uneventful enough; it is an Alpine animal, frequenting the high "fells" of the central mountain range, and feeding on the scanty vegetation of the heights. It is very hardy, not hibernating in winter, nor laying up a store of food, but burrowing under snow and turf to get at the means of subsistence. Lemmings are also about the most courageous beasts in existence-being more inclined to fight than fly when suddenly surprised, and sitting up on their haunches to defy man or Dog. Breeding twice a year, and having from three to eight in a litter, they multiply rapidly, and it is no doubt their great 
increase of numbers which occasions their wonderful exodus from the high plateaus and descent into the cultivated lands, which may happen at either short or long intervals; as few as five, and as many as twenty years, may elapse between "Lemming years." When once started on their pilgrimage, nothing stops the brave little creatures; they climb hills, enter towns, and fearlessly cross rivers and even lakes, for they can swim for miles, though, of course, in a long waterpassage many perish. Finding more to eat than they ever got at home, and not travelling continually, but often settling for a time, they breed more freely than before, but still move slowly on. All carnivorous creatures, furred and feathered, live luxuriously upon them, and disease makes havoc among the crowd, but still they slowly press onward, till at the end they reach the sea. Not knowing the extent of this new watery obstacle, the survivors boldly set out to swim across it, and with their death by exhaustion and drowning the expedition ends. One cannot help feeling touched at such a fate for the gallant little Vikings; but it comes as a relief to their human neighbours, for they are naturally almost as destructive as locusts in many places. Lemmings are not often to be met with in captivity, but I have seen a few both in the London Zoological Gardens and at Mr. Hamlyn's, and their habits would be well worth studying if they were kept as pets.

\section{THE ARCTIC LEMMING}

\section{(Cuniculus torquatus)}

ANother species of Lemming (Myodes obensis), closely allied to the Scandinavian one, is found in Northern Siberia and North America, but the characteristic Arctic Lemming is a very distinct species, even more chubby in form than the ordinary kinds, with no external ears, and hardly any tail. Moreover, the feet are different, the first toe of the fore-paws being quite rudimentary, while the third and fourth bear very large and strong claws, which receive an extra growth of horny matter in winter. At this season also, the coat, which is much greyer in summer than that of ordinary Lemmings, turns pure white. This little creature is active under the snow in the winter, and inhabits even Novaia Zembla, as well as Greenland. 


\section{THE FIELD-VOLE}

(Arvicola agrestis)

THE Musk-Rat and Lemmings form part of a well-defined group of the Mouse family known as Voles, containing numerous species of wide distribution, several of which are familiar in our own Islandsthe present one far too much so. The Field-Vole is about the size of the House-Mouse, but, like Voles in general, has smaller eyes and much shorter ears and tail; in fact, it is often called the Short-tailed Field-Mouse. It is of a dull-brown colour, and far less lively and active than the House-Mouse. Its favourite haunts are rough grassfields, and when it becomes numerous it does great harm by devouring stems and roots of grass, as in the well-known "Vole plague" in Scotland in 1892. Although widely distributed in Great Britain, and also all over Europe, this Vole is not found in Ireland. It is worth remembering that during the plague great service was done in the destruction of the vermin by Weasels, Rooks, Owls of several kinds, Kestrels, and Black-headed Gulls.

Field-Voles breed in burrows in the ground, and as they may have as many as six young in a litter, and up to four litters a year, their increase is naturally liable to become excessive if circumstances favour them.

\section{THE WATER-VOLE}

(Arvicola amphibius)

OUR familiar "Water-Rat" is our largest Vole, nearly equalling the ordinary Rat in size, but easily distinguishable by its blunt Vole-head and very short ears. Usually it is brown, but black specimens are common. Although not web-footed, it is a good swimmer and diver, and lives chiefly by the water-side, making its home in a burrow in the bank. Except when it attacks garden produce, such as potatoes, the Water-Rat is a harmless creature, living chiefly on marsh- and water-plants, and rarely touching animal food; while, from being . constantly on the move in the day, it is easy to watch, and thus becomes a favourite. Although, like the Field-Vole, unknown in Ireland, it is found across Europe and Northern Asia generally. 


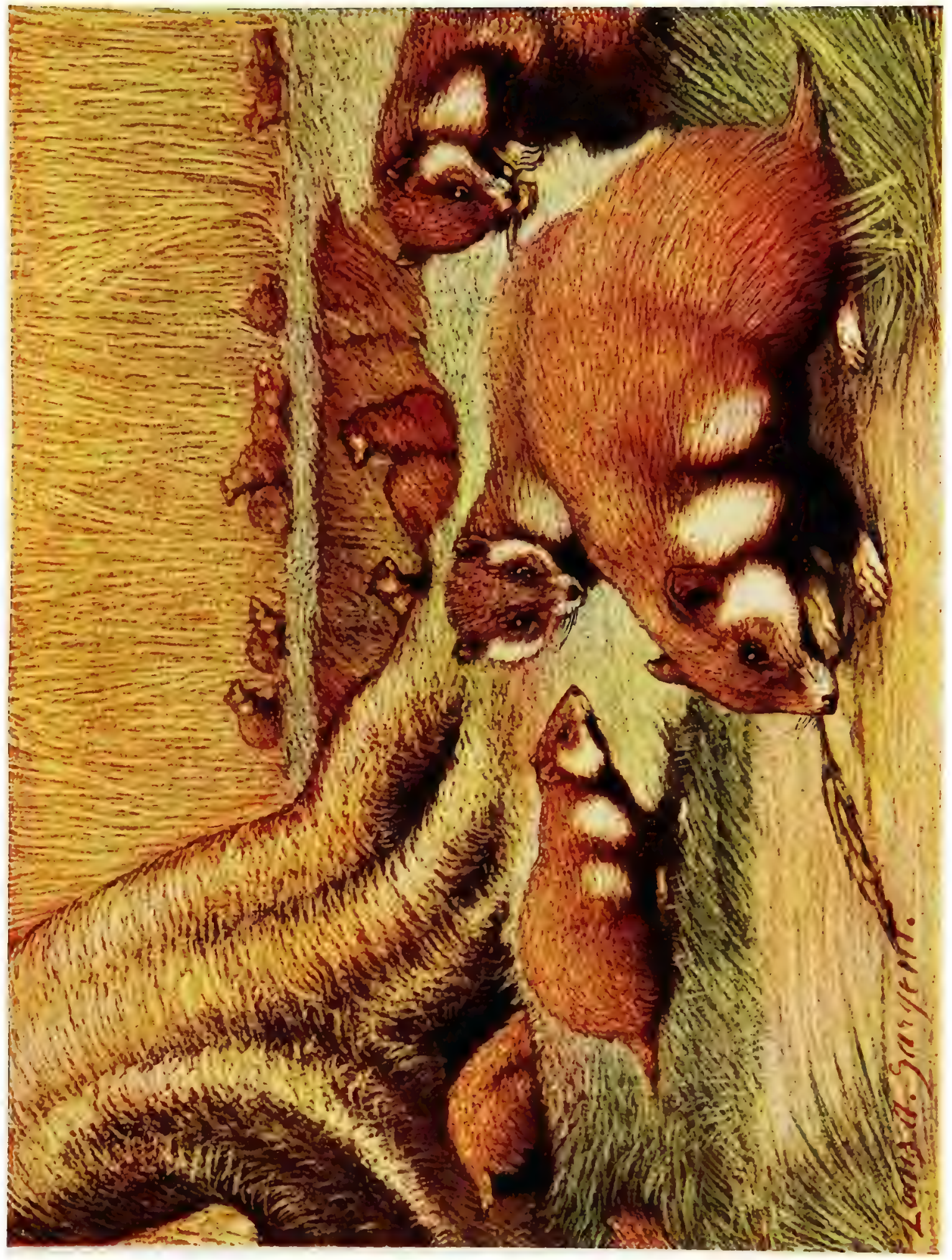

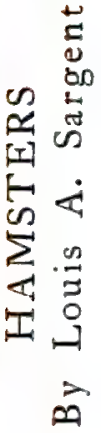





\section{THE HAMSTER}

(Cricetus frumentarius)

Fortunately for us, the Hamster is not included among British animals, although it is well known as near us as Germany, and ranges thence eastwards into Central Siberia. It is about the size of a Guinea-Pig, and not unlike one in form, except that it has a short tail, and also a smaller head and smarter appearance. The tortoiseshell colouration of the coat is somewhat variable, and pied specimens, or even pure black and white ones, are not uncommon. One notable peculiarity of the Hamster is the pair of cheek-pouches it possesses, which can be distended until the size of the head appears doubled. It blows its cheeks out like this when angry, which is pretty often, for the Hamster is one of the most touchy, illconditioned little animals in existence; but their more practical purpose is to serve, as in the case of other animals possessing these convenient face-pockets, as temporary receptacles for food.

When he has his mouth filled with provisions, he cannot bite; but he is not long in emptying his pouches and getting ready for the fray if he is not taken quite by surprise. $\mathrm{He}$ is really courageous as well as quarrelsome-will make a good fight with any Dog but an experienced ratter, and even attack a man without any provocation than that of passing near his hole. His relations with his fellow Hamsters are usually strained; even the male and female only agree during their short honeymoon in the spring, when they are quite strongly attached for the time being. But the feeling soon wanes, and when the young ones arrive, their mother turns them out-of-doors to seek their own living when they are a fortnight old. This is no hardship, for they have already begun to dig at that age; and, though born blind and naked, they have teeth from the first, and begin to eat corn at a week old, before they can see or have a full coat of fur, so that they can fairly be called a precocious litter. Their number is six to eight; and at least two litters appear in a year. 
The first burrows of the young pioneer Hamsters are not so deep and extensive as those of the older ones, the abode of the old male being the best of all. In this one finds a long vertical entrance shaft, sometimes more than two yards deep, from which a passage leads to a living-room, well lined with fine straw and other soft materials. Two run-ways lead out of this, a winding exit to the open air above, and a short passage to the store-room or rooms, for a wealthy old curmudgeon of a Hamster will have several, all, in the autumn, well stuffed with grain. The female's nesting-burrow has several entrances to the nest-chamber, and seldom has any storerooms, for she does not hoard up any food while nursing; when she is relieved of the care of her last litter, too, she has not as much time for her winter arrangements as the male has had, and hence they are not quite so perfect. In spite of the care it takes to avoid hunger in the winter, the Hamster has little need of food at that season, for it is a typical hibernating animal, and, blocking up the entrance of its burrow, sleeps as soundly as a Dormouse.

In its ordinary diet the Hamster is as omnivorous as the Common Rat; herbs, roots, and fruit, all contribute to its menu as well as the grain and seed it so carefully stores up, while it never spares birds, Mice, insects, or any small creatures that come into its power. And, as in spite of its heavy form, it springs nimbly enough, and climbs well, it is a formidable adversary. With such habits as it possesses, it is easy to see that the Hamster is a most noxious and destructive animal, and in some parts of Germany a reward is paid for its destruction, and there is, or was, a regular class of Hamstercatchers. Besides the reward, these find some profit in the little miser's hoards of grain, while the fur and even the flesh are utilised. From the account given, the Hamster does not seem an inviting animal as a pet; but hand-reared specimens are amiable enough, and some are occasionally imported here. The Hamster group of the Mouse family contains several more species in the Old World, of the same sturdy build as the common Hamster, but smaller, and a great many in America, including the ordinary wild or country Mice of that country, but many of these are shaped like ordinary Rats and Mice, not like typical Hamsters. 


\title{
THE HOUSE-MOUSE
}

(Mis musculus):

The typical Rats and Mice, relatives of our familiar pests, are a very large group, numbering over a hundred species, but, in nature, confined to the Old World, some being even found in Australia. Our House-Mouse is the most widely distributed of all, thanks to our involuntary assistance, being found practically everywhere, but usually about houses. It certainly did not inhabit the New World before Europeans got there, and no one knows the precise locality it originally inhabited in the Old; but it was probably near the seats of ancient civilisation, as it was so universally known in antiquity. The colour of the little animal is so well known as to be taken as a descriptive term; especially to be noted is the fact that it is grey underneath, not white. There is no need to say anything about its habits, for to most people it is more familiar than they could wish. It may be noted, however, that one peculiarity is its great activity, and another its characteristic and unpleasant smell, the chief drawback to the prettilycoloured "fancy" Mice, its descendants, as pets.

\section{THE WOOD-MOUSE OR LONG-TAILED FIELD-MOUSE}

\author{
(Mus sylvaticus)
}

THIs handsome Mouse ranges widely across the northern parts of the Old World, and is widely spread and abundant with us, occurring even in the London parks; but it is essentially a country Mouse, and seldom enters buildings except sometimes in winter. It is decidedly larger than the House-Mouse, and more prettily coloured, being brown above and white below and on the hind-feet. Although destructive in gardens and fields, and an enemy to small birds, it is a charming little creature, and makes a nice pet.

\section{THE HARVEST-MOUSE}

\section{(Mus minutus)}

THE tiny Harvest-Mouse is much smaller than the Common Mouse, not being more than three inches long; it is handsomely coloured, being red-brown above and white below. It does very little harm, and, as it is fond of insects, is probably of considerable use. The beautiful nest it makes for its young has long attracted attention; it is built on a tall weed or among stalks of corn, fashioned 
of split grass blades, and round in shape. This little Mouse is a famous climber, and its tail is to a considerable extent prehensile; a cornfield is its forest, where it disports itself like a miniature - Monkey. Although not an abundant species, it is found all across the northern parts of the Old World.

\section{THE HOUSE-RAT}

(Mus rattus)

I THINk it desirable to avoid the name "Black Rat" or "Old English Rat" for this species; for it is believed to be a ship-borne immigrant into Britain, although a far older one than the Grey or Sewer-Rat, and in India, where it is undoubtedly a native, it is usually brown. It is a smaller animal than the Sewer-Rat, with a more delicate form, larger ears, and longer tail; and in habits it is less fierce and carnivorous, and much more of a climber, affecting the upper parts of houses, and in some cases, as in the Laccadive Islands, living in trees. This is one of the Rats which has been mainly instrumental in propagating the terrible "Plague," which is a Rat-disease, and conveyed to man by the agency of the Rat-fleas, which often bite human beings. Naturally, a Rat which is found about rooms is particularly apt to communicate the disease to man, so that the almost complete extirpation of this Rat in Britain by the other common species, more objectionable in itself as this is, has been a great benefit.

\section{THE SEWER-RAT}

(MIus decumanus)

THIS is the ordinary Rat found in our country nowadays, and widely distributed over the world wherever ships and wheeled vehicles give it an opportunity to travel as a stowaway. Although its natural colour is greyish-brown, it is often black, so that, judging by colour, it is easily confused with the true rattus. It is much more of a burrowing and aquatic animal than that species, and takes to a waterside life quite readily, being a faster swimmer than the Water-Vole, if not, perhaps, so enduring. Its original home appears to be Western China; at any rate we know it was an immigrant from the East, and its progress is pretty well known; hordes of these Rats swam the Volga in 1727 , on their westward journey, and a few years afterwards they first appeared in England. It is a most destructive and dangerous creature, not only damaging human property by its gnawing and burrowing, by eating corn and other provisions, and killing young game and poultry, but occasionally attacking children and even adults, who have been killed by swarms of these vermin. Yet it appears to be the ancestor of the tame Rats so often kept as pets, and its intelligence and courage compel admiration, although its extermination, like that of its rival, would be a benefit to the world at large. 


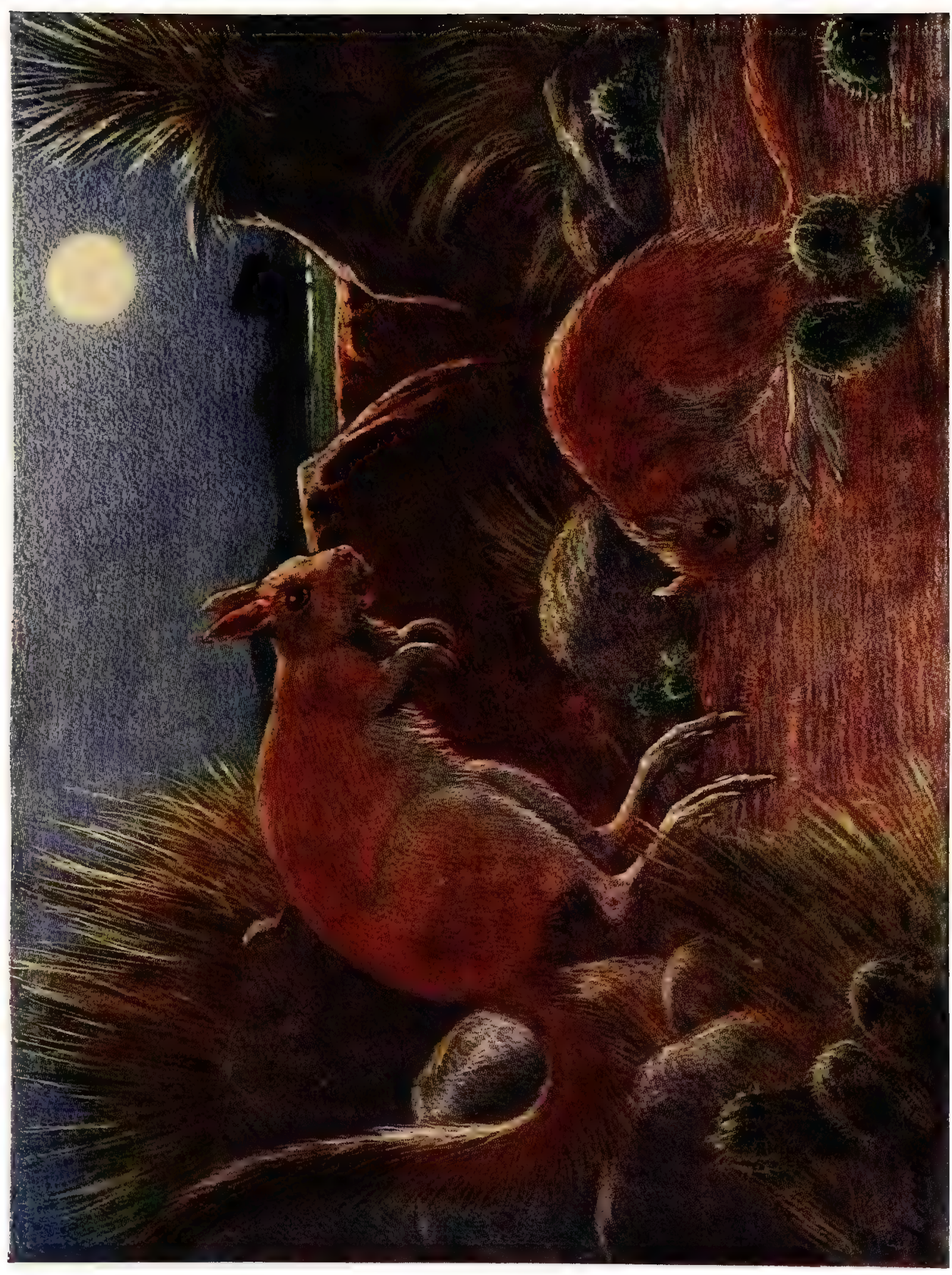

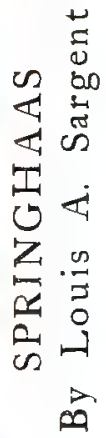





\section{THE SPRING-HAAS \\ (Pedetes caffer)}

THERE are many rodents which are specially adapted for jumping on their hind-legs like Kangaroos, but the present animal is very much larger than any of the rest, about equalling the Common Hare in size; in fact, its name, in Dutch, means the Jumping Hare. The real affinities of the animal are, of course, with the rodents, among which it stands rather alone, so as to form a family by itself (Pedetida), though formerly classed with the Jerboas.

The toes are five on the fore-foot, provided with strong curved claws: on the hind-foot there are only four, the first being absent; the third is the strongest, and they are armed with stout straight nails almost like pointed hoofs.

This is a well-known animal in South Africa, and it extends north to Angola and to East Africa; it affects high and dry country, whether level or hilly, and during the day conceals itself in burrows, which it digs; these are complicated in form, and serve as an abode for more than one family of the animals.

In the night the Spring-Haas is abroad in search of food, which is vegetable, consisting of herbage and roots: its movements, as might be expected from its shape, are in bounds like those of Kangaroos, sometimes for a distance of several yards, but, according to some, it is not so enduring as these marsupials, and is easily hunted down. There are two motives for persecuting it; it is very destructive to crops in all stages, and in the second place, it is very good eating, and hence in demand for food. When captured, it makes some resistance by scratching with its powerful hind claws, but it is not a savage animal, and becomes gentle in captivity. It is said to breed in summer, and to have three or four young ones, which remain for some time in the burrow. Moisture is very objectionable to the Spring-Haas; it sleeps a great deal in rainy weather, without becoming actually torpid, and a favourite method of capturing the animal is to pour water into its burrow. Some years ago a specimen lived in the London Zoological Gardens for some time; but this was the only one the Society had ever received. 


\section{THE JERBOAS}

The true Jerboas (Dipodida) are even more specialised for jumping than the Spring-Haas. They are small animals, about the size of Rats, with very big heads, round plump bodies, and long thin tails, tufted only at the tip. Their fore-feet are exceedingly small, and held up close under the chin as a rule, so as not to be noticeable. The hind limbs have the instep portion, between hock and toes, very long and thin, and as the animals walk on the centre three toes only-the first and fifth being very short or absent altogether-they have a curiously bird-like look. Although, when going fast, they progress by successive very rapid and extensive bounds, in the ordinary way they toddle about on their spindly legs with alternate steps, which gives them a very quaint appearance.

They are essentially desert-animals, with soft fur of a sandy colour, matching the soil of their home, and they live by day in burrows, often in communities, coming out at night to feed on seeds, herbage, and, in the case of some of the larger species, on the eggs or young of the desert birds. Their range is from Eastern Europe to Northern Africa and Central Asia, and there are a good many species. One of these, the Egyptian Jerboa (Dipus agyptius) is frequently imported into England, and, being a very clean and gentle little animal, makes an ideal pet. The great point in keeping it is to give it a good run, and plenty of dry sand to scratch and roll in.

\section{THE GOPHERS}

ThE Gophers (Geomyida) are an American family of rodents, living on the ground and usually burrowing. They are provided with cheekpouches, lined with hair and opening outside the mouth, and some of them, like the Pocket-Gopher (Geomys bursarius) of the Mississippi plains, are well-known animals. The Pocket-Gopher is like a shorttailed heavily-built Rat, with soft brown fur and enormous teeth and front claws. It is a great burrower, and lays up stores of seeds and. roots, especially potatoes when it can get them. 


\section{THE KANGAROO-RATS}

Closely allied to the Gophers, and having the same external cheekpouches, is a family of little American desert rodents (Heteromyida), of which some species are remarkably like the Jerboas of the Old World, in general shape, colour, and jumping habits; the resemblance extends even to the peculiar tufted tail, but the hind-legs are not so long, or their toes so much reduced, as in the true Jerboas.

\section{THE MOLE-RATS}

Two families of rodents, the Spalacida and the Bathyergida, are very like Moles in form and habits, especially the latter one. They have small or rudimentary eyes and ears, and sausage-shaped bodies like Moles, but the characteristic rodent incisors are particularly well developed, and they feed on vegetable food, chiefly roots, for which they explore the earth and drive tunnels, as the true Moles do after worms and grubs. One of the Spalacide, the Blind Mole-Rat (Spalax typhlus) is found in Eastern Europe, Western Asia, and North Africa. It has no visible ears or eyes-the latter being indeed covered with skin-and a curious broad flat head; in spite of its blindness, however, it is a far-seeing animal in one sense of the word, for it lays up a store of bulbs in a chamber in its burrow. The Bamboo-Rats (Rhizomys) of Eastern Asia and Africa belong to this family, but are less completely mole-like than most of these burrowing Rats, having small external ears and visible eyes.

The Bathyergidae are confined to Africa, and the best-known is the Coast-Rat or Sand-Mole (Bathyergus maritimus) of the Cape, which burrows on the sea-shore. It is almost blind, and rather a large animal, being nearly a foot long; in fact, most of these "rodent Moles" are bigger than our Mole. In Somaliland there are some extraordinary little creatures (Georychus) belonging to this family; they have small eyes and no ears, but their tail is fairly long. The remarkable thing about them, however, is that instead of the thick soft fur of most burrowers, they have practically no hair at all, and are nearly naked. 


\section{THE DORMICE}

THE family of Dormice (Myoxida), which in appearance and habits are intermediate between Mice and Squirrels, though more nearly allied to the former, is familiar to us by our own pretty little species (Muscardinus avellanarius), a beautiful little chestnut animal with a hairy tail, and rather larger than a House-Mouse. It is a harmless little thing, living in woods and hedges, and feeding on nuts, seeds, and wild fruit. It prudently lays up a winter store, but, as everybody knows, spends most of the winter-indeed, half the year-in sleep, for it is the best-known of our hibernating animals, and its sleepiness is proverbial. Besides the Common Dormouse, there are on the Continent two large species, nearly as big as Rats, and grey in colour instead of red. The Garden Dormouse (Myoxus quercinus) is a very pretty animal, with black patches round the eyes, and the tail grey at the root, black in the centre, and white at the tip. The Fat Dormouse (M. glis), esteemed such a delicacy by the Romans, is bigger, with a tail nearly as bushy as a Squirrel's. The rest of the Dormice are African.

\section{THE COYPU}

\section{(Myopotamus Coypus)}

THE Coypu is the only generally well-known member of the family Octodontida, which are African and American only. Most of them are ground or tree animals, but the Coypu is a gigantic Water-Rat, bigger than a Cat, with webbed hind-feet. It is a common animal in South America, and well known over here in two capacities-it produces the so-called "nutria" fur, having a soft under-coat like so many aquatic animals, and it is exhibited by travelling showmen as a huge and terrible Sewer-Rat I Thus it usually appears under a false name-the word "nutria" being Spanish for Otter. In Zoological Gardens it does well, and frequently breeds; the young are born active and wellfurred, with open eyes. They are fond of riding on the back of their mother in the water, and it might at first be supposed that the peculiar position of the nipples in this animal-along the sides instead of on the under part of the body-was specially adapted to suckling them in this position; but as a matter of fact this curious location of the teats is found in the land Octodonts also. 

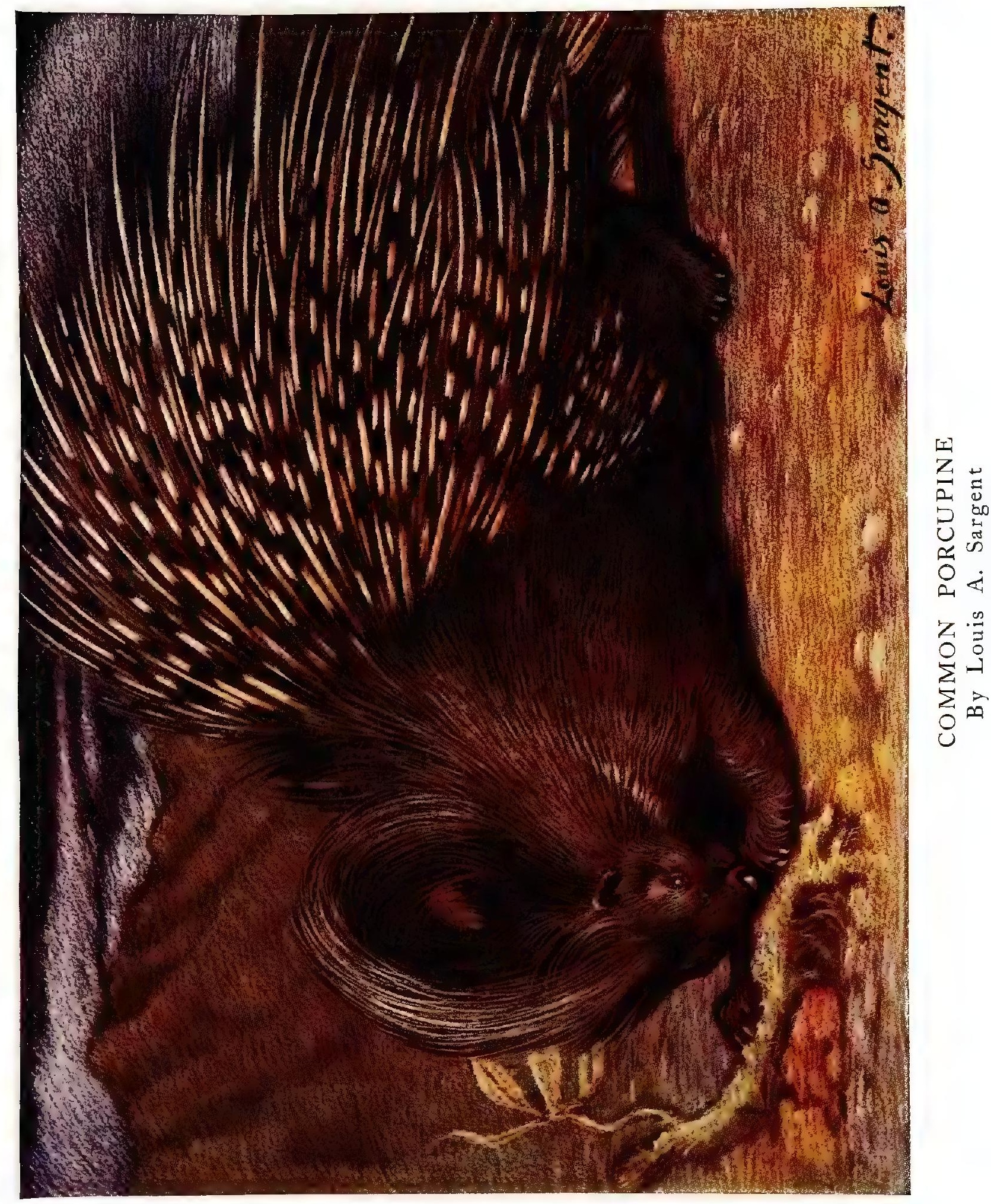



\section{THE COMMON PORCUPINE}

(Hystrix cristata)

IT is not surprising that this Porcupine has always been one of the bestknown of rodents, for it inhabits an anciently civilised portion of the world-the countries bordering the Mediterranean, both European and African-and its curious defensive armature of spines is calculated to impress any observer in a very literal sense. It is one of the giants of the rodent order, measuring about two feet six inches in length, and being heavily built. The characteristic "quills" are confined to the hinder-part of the body, the fore-part being covered with ordinary hair, with a crest of long stiff bristles; but the quills themselves are simply exaggerated hairs, and all gradations of thickness may be found on the animal. The long quills of the body are ringed with black and white; the short ones growing on the tail are themselves short, white throughout, and open at their tips; when shaken they produce a rattling sound, which is supposed to be a warning to the Porcupine's enemies. For, though a slow-moving creature, and not gifted, as old legends asserted, with the power of darting its quills like arrows, the animal is not to be attacked with impunity. When it tucks in its head and bristles up its quills, no one can do anything with it, and it may even assume the offensive and charge backwards on the foe. In any case, some of the quills are certain to be loose, and to fly out in these warlike manœuvres; this fact furnishing the foundation for the story of the Porcupine's exploits in archery. The puncture of one of the quills is a serious matter, if it be not extracted immediately, as it works more deeply into the flesh; for this reason, carnivorous animals often pay with their lives for a rash attack on a Porcupine, the spines becoming fixed in their mouths and throats. Nevertheless, they seem to be unable to resist the temptation, no doubt hoping to catch the animal unawares; the Leopard, at all events, is said to be in the habit of killing the Porcupine by a blow on its undefended 
head. When fighting each other, Porcupines make use of their curious retrograde charge, and if one finds himself pierced by a quill from the enemy, he is careful to extract it as soon as possible. They are unsocial animals, living in burrows excavated by themselves, and are seldom seen abroad in the day; their food is purely vegetable, and consists of roots, herbs, and fruit, which is sometimes pilfered from gardens. Their note is a grunt, and from this, and the bristly nature of their coat, no doubt, comes their popular association with Pigs, a group with which they have no relationship at all, as an examination of their typically rodent teeth, to say nothing of their paws, at once makes clear.

Young Porcupines are more advanced at birth than most young rodents, having their eyes open, and possessing a coat of spines, which are, however, short and flexible and lie close to the skin. They grow, however, very rapidly. Two or four young ones form the litter, and they are born in spring. The flesh of the Porcupine is very good, and is said often to appear on the dinner-table at Rome, the Campagna being a well-known haunt of the animal; while everyone is familiar with the use of the quills as penholders and toothpicks. In captivity Porcupines live well, and become tame; they also breed freely, and will stand the English winter in an ordinary sty. All fittings, however, must be made of brick and iron-rods, or the animals will soon make their escape by gnawing.

The Common Porcupine is replaced in South Africa and India respectively by two very similar species, both large, and with crests of long hair (Hystrix africa-australis and H. leucura); there are also in Eastern Asia two or three more species, not so large or wellcrested; but the habits of all seem to be very much alike.

\section{THE BRUSH-TAILED PORCUPINES}

THESE are very different-looking animals from the ordinary large Porcupines, being much more like big Rats; they have spines, but these are comparatively short, and do not do much to break the 
outline of the body, while the tail is long and very Rat-like, but terminated by a tuft of flattened and twisted bristles. There are two species, one African (Atherura africana) and one East Indian ( $A$. macrura), the latter being the larger of the two.

\section{THE CANADIAN PORCUPINE}

\section{(Erethizon dorsatus)}

Ir is a curious fact that, while the Old World Porcupines are all burrowing ground-animals, those of the New World should all be climbers, though the present species is less of a tree-animal than the others. It is also the only northern one, ranging from Alaska and Canada to Virginia and Mexico, though it seems best known in the northern parts of its range. Although much the largest of the American Porcupines, it is considerably smaller than the big Porcupines of the Old World, being about two feet long. It is heavily built, with long powerful claws, and a tail which, though short, has some power of grip, and so aids in climbing. The spines are short, and much hidden in the long sooty-brown hair with which they are plentifully intermixed; they are as sharp and serviceable for weapons on the tail as elsewhere, and, in fact, the sudden sharp blows of that member which the animal gives are a very efficient mode of defence, in addition to the protective value of the spines generally. As they come out freely, the spines are liable to be unwillingly taken away from the conflict by the adversary, with the same result as noted in the case of the Old World Porcupine. The animal which seems to ibe most successful in its attacks is the Pekan or Fisher Marten (Mustela pennanti), which craftily burrows under the snow and attacks the creature's under-parts, these not being defended by spines in any Porcupines. But, as a rule, this Porcupine seems to be fairly safe; it is certainly a very slow mover on the ground, and not an active animal in the trees,. whence it gets its chief food, devouring both the bark and the leaves. Indeed, when a Porcupine has finished 
with a tree, this is not of much use to any one coming after. In spite of the damage thus done to forests, however,-for the Porcupine is active and feeds all through the terrible northern winter-it is protected by law in some districts, as being the only creature suitable for food that a lost traveller in extremities could capture without a gun; in fact, a species of emergency-game. Away from its native country, the Canadian Porcupine is very little known, but a fair number have been brought to England of late years.

\section{THE COUENDOU}

(Synetheres prehensilis)

THIs Brazilian animal may be taken as a type of the prehensile-tailed Porcupines of the hot parts of America. It is about the size of a Cat, with a curious snub nose and a long prehensile tail, and the feet very well adapted for grasping boughs, there being a fleshy pad opposite the toes on the hinder pair. The spines are very different from those of other Porcupines, being short all over the body, and uniformly distributed over head, back, and sides, intermixed with a coat of short fur.

The Couendou is a sluggish, harmless creature, spending most of its time in the trees on whose leaves and bark it feeds, and sleeping in the forks of the branches. This species has often been exhibited in the London Zoological Gardens, as have other species, for the group includes several kinds. Some of these have the fur so long that the short spines are concealed, such as the Mexican Tree-Porcupine (S. nova hispanice) which approaches the southern territory of the big northern animal last mentioned. 


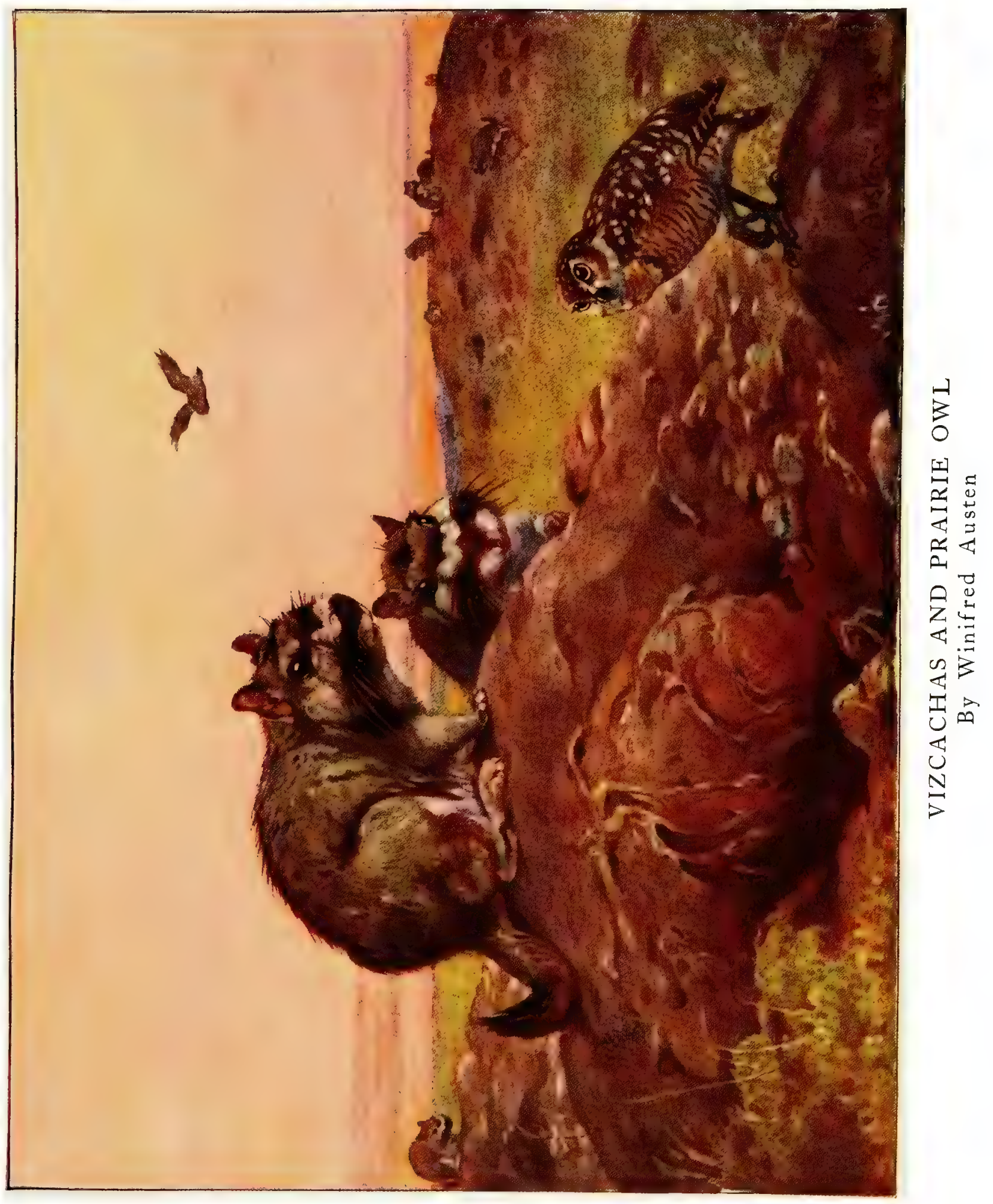





\section{THE VIZCACHA}

\section{(Lagostomus trichodactylus)}

THE Vizcácha is one of the most characteristic animals of the Pampas region of South America, where its habits have been closely studied by many obsérvers, especially by Mr. W. H. Hudson in Argentina. It is about the size of a Hare, the male being considerably larger than the female, which is also lighter in colour; the young closely resemble the adults in miniature. The tail is bushy, and the feet have four toes on the front paws, but only three on the hind.; In its movements the Vizcacha is clumsy; when going about slowly it rests its hind-limbs on the hocks. in an awkward-looking: way, and its' speed is so small that no Dog can fail to overtake it. Thus it relies for defence on its power of burrowing, and on the social habits which make the "Vizcachera" a little selfsupporting community, somewhat like that of the Beavers in the North.

A Vizcacha colony is usually stàrted by some old male, who digs but his subterranean dwelling in some favourable spot; ultimately he is joined by others, and a warren is formed. The earth thrown up out of the burrows, which are very wide at the mouth; makes ámound, securing the inmates against the danger of floods, atid their continual cropping of the herbage creates a smooth close turf for 'some distance round their homes, on which they can play and feed in security, béing able to see an enemy. from some distance, and so escape in timé.

Vizcachas are nocturnal animals, and it is not till nightfall that they come forth, at first siting on their haunches at the entrance of their holes, the lady members of the party conspicuous by their alert and lively: behaviour: They have considerable valriety of notes, and the squeaks, squeals, grunts, and "groans that they are able to produce have quite the effect of an animated conversation. Like rodents generally, they have a passion for exercising their teeth, a $\underset{200}{ }$ are particularly fond of $\underset{2 \mathrm{D}}{\mathrm{g} \text { awing }}$ 
down the giant thistles of the pampas in order to feed on the seeds; the dead stalks, and any bones or other rubbish they may come across, are dragged on to the mound, and help to elevate it. They are not very prolific animals, only breeding once a year, and then bringing forth only two or three young ones. Yet they manage to hold their own in spite of several dangerous enemies, especially the Puma, which hunts them untiringly, and appears to be their worst foe. Another is the common Pampas Fox (Canis azara), a grey animal, rather a small Wolf than a Fox, which, having by force possessed himself of one of the burrows in the village, is all too apt to depopulate it by devouring the young Vizcachas sooner or later, though the old ones appear to be a match for him, and even regard his presence in their midst with indifference, until he embarks upon his evil courses.

Like so many of their order, too, they come into conflict with man by their destructiveness to vegetation, to say nothing of the danger to riders caused by their burrows, and are hence hunted to extermination by their human neighbours. The most effectual method of getting rid of them appears to be the shockingly cruel one of earthing up their burrows and leaving them to die of hunger. Men make a special business of this, for the doomed colony must be watched for days lest its inhabitants should dig themselves out, or be rescued by their neighbours. For, to their credit be it said, animals from neighbouring Vizcacheras will come at night and try to release their friends; indeed, in time of peace, if I may use the expression, there is a good deal of friendly intercourse between neighbouring colonies, visits being paid and returned. The Vizcacha, however, considers his house to be his castle, and will not carry hospitality so far as to ask a friend inside; indeed, it takes very severe pressure of peril to induce a hunted Vizcacha to trust himself inside a neigh= bour's front door.

The Vizcachas have other friends, or at least harmless associates, besides each other. The best known of these is the little long-legged Burrowing Owl (Speotyto cunicularia), shown in the picture, which shares the burrows of the Vizcacha in South America, as it does those 
of the Prairie Marmot (Cynomys Iudovicianus) in the prairies of the north of that continent.

Two other hole-building birds also are commonly found about Vizcacheras, making their little burrows in the sides of the entrances of those of the Vizcachas, the Minera (Geositta cunicularia), a bird resembling our Wheatear in appearance and habits, and a Sivallow (Atticora melanoleuca), very similar to our House-Martin, except that it has no white patch on the back. Certain insects also affect the Vizcachas' mounds especially, so that the Vizcachera is quite a little world in itself.

The flesh of the Vizcacha is edible, though apparently but little used; but the fur appears to have no special value. It does well in confinement, and is generally to be seen in our Zoological Gardens, where young have been produced on several occasions.

\section{THE CHINCHILLA}

(Chinchilla lanigeri)

THE family to which the Vizcacha belongs (Chinchillide) is not a numerous one, but includes another animal, which, though of no such remarkable interest in its habits, is particularly well known by reason of the value justly set upon its extremely beautiful fur. The Chinchilla resembles the Vizcacha in general form, but has five toes on the fore- and four on the hind-feet, and is very much smaller, being considerably less in size than a wild Rabbit; it is also a very much prettier animal, with a smaller and neater head and large rounded naked ears. The coat of the living animal is just like the exquisitely soft, marbled silver-grey fur so familiar in ladies' costumes, for, unlike so many other furs, it needs to undergo no preparation in the way of plucking or dyeing. The tail, however, is curiously out of keeping with the rest of the skin, being covered with long coarse wiry hair. The claws are small and insignificant.

Chinchillas are Alpine animals, found in the Andes of Chili and 
Bolivia, where they live in barren stony places, running up and down high rocks, however steep, with the greatest agility.' They are social, and live in burrows, to which they retire on the slightest alarm, so that the hunters are obliged to avail themselves of the services of tame Peruvian Weasels to dislodge them, much as we do with Ferrets in the case of Rabbits; the South American Weasel, however, appears to be sufficiently accommodating to retrieve the Chinchilla it has killed. 'Living in a wild state on herbage, roots, and moss, the Chinchilla is easy to keep in captivity, and makes a charming little pet, though not remarkable for intelligence. . It : has often bred in the Icondon Zoological Gardens; the young appear to be "few in number, and to be born in a precocious condition, like: young Hares rather than Rabbits: So useful and charming a little animal ought certainly to be domesticated, if only, as a fur-producer, as it gives no more trouble to keep than a Rabbit. In Peru there is a slightly different species of Chinchilla, the Short-tailed (C. brevicaudata).

\section{THE LONG-TAILED CHINCHILLA}

\section{(Lagidium cuvieri)}

WrTH a general resemblance to the Common Chinchilla, this species differs by its smaller ears and long well-clad tail, as well as by having only four toes on the fore-feet. It is also a much largèr animal, being as big as a good-sized Rabbit, and its fur, which cannot be compared in quality with that of the true Chinchilla, is not'of so pure a grey: It inhabits the same districts as ithat animal, and has much the same habits; it is rarely seen in captivity. 


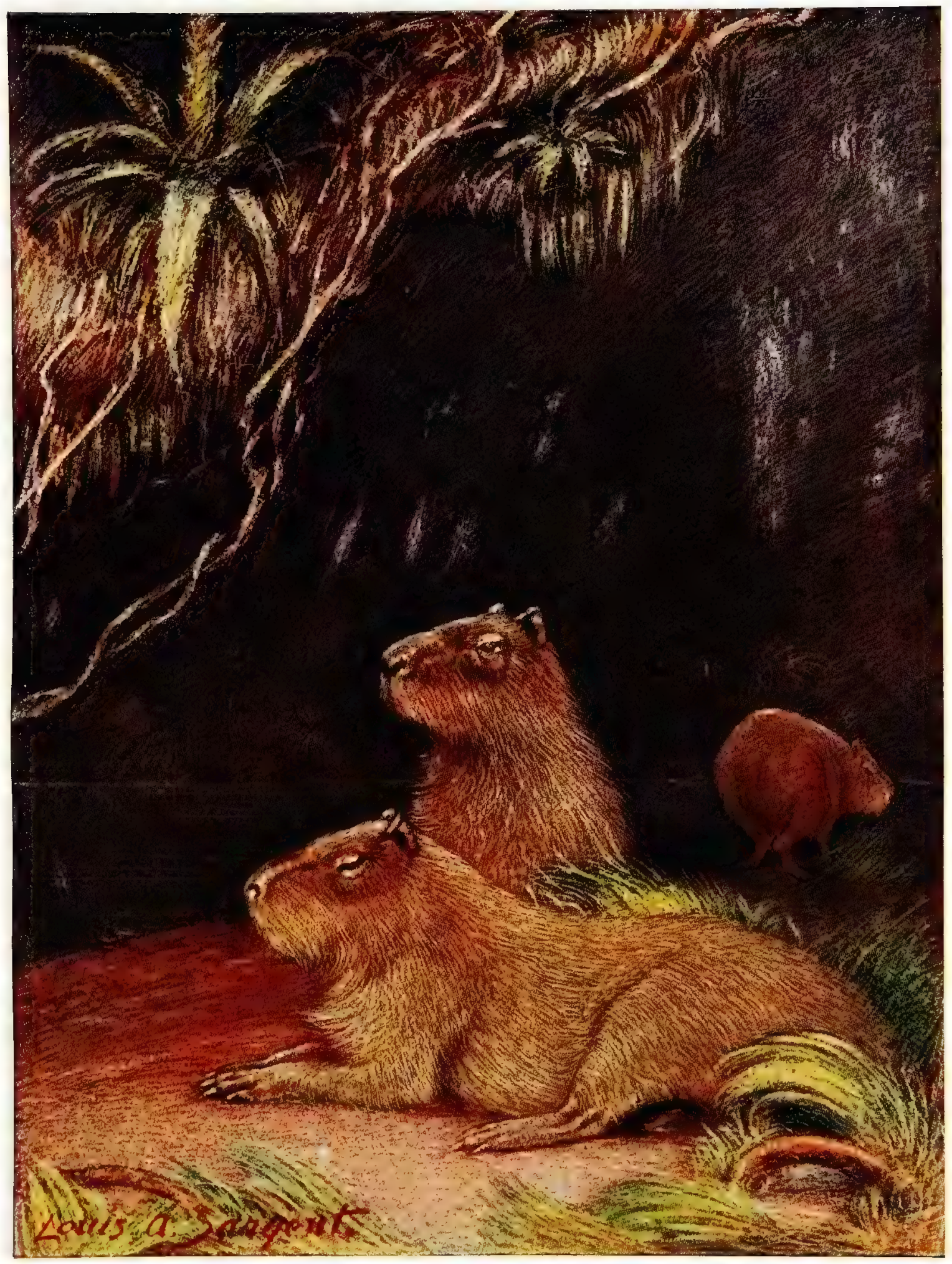

CAPYBARAS

By Louis A. Sargent 



\section{THE CAPYBARA}

(Hydrochorus capjbara)

The Capybara may be called a gigantic water Guinea-Pig, for it belongs to the same family of the rodents (Caviida) as our familiar pet, and bears a general resemblance to it in form. Like the Guinea-Pig, it has four toes on the fore-feet, and three on the hind, and is without a tail; but it stands decidedly high on its legs for a rodent, and its feet are rather peculiar. They are all webbed, and have nails so broad and blunt that they practically amount to hoofs. "The Capybara is much the largest of the rodents, being about four feet long-in fact, as big as a moderate-sized Pig. Its coat shows no difference according to age, sex, or season, and is coarse and scanty, not completely concealing the skin in places.

The home of the Capybara, which is also known as Carpincho and Cabiai, is South America, from Brazil to Northern Argentina; it is essentially a water-side animal, taking refuge whenever disturbed in the water, where it swims and dives with grace and ease." Although feeding to a considerable extent on water plants, however, it grazes on land a good deal, and is found ashore quite as much as afloat. On land it walks easily, and when frightened rushes off with a heavy gallop, emitting a hoarse bark at the same time. When resting, it often sits upon its haunches like a Dog, but, like the Cavy family generally, does not use its fore-feet to lift its food. Capybaras are sociable animals, always found in herds. They are prolific, considering their size, since from five to eight young ones are born annually.

Their worst natural enemy is the Jaguar, whose principal prey they are in many places; some also fall victims to Alligators, and they are also persecuted by man in places, as their flesh, though no great delicacy, is edible. The skin is of little value. When not molested, they become remarkably tame, and can be approached within a few yards; it is said that Horses are very much afraid of them, possibly on account of the headlong rush for the water the uncouth creatures make when disturbed. In its own country. the Capybara is a byword for ugliness and laziness, though it seems hard that so harmless a creature should be maligned. In 
captivity it is well known, and thrives admirably, frequently producing young; and, although coming from so warm a climate, will bear the English winter well out-of-doors, and take to water in any weather.

\section{THE PATAGONIAN CAVY}

\section{(Dolichotis patachonica)}

The Patagonian Cavy, or Mara, is a large animal for one of its family, though not to be compared with the Capybara for size; still, it is a good deal larger than the common Hare. It is high on the legs, with small feet; the ears are rather large, and the tail a mere tubercle. The coat is thick, except upon the slender legs, and of a grizzly brown colour, the short close fur on the limbs being light chestnut.

The Mara is a characteristic animal of the dry open lands of Patagonia and La Plata, where it takes the place of such animals as the Hare, and is seen abroad by day. Usually two or three are seen together; although they sit up like Hares at times, they walk along in the ordinary way, not hopping. They are swift runners, and also adepts at burrowing, a combination not often found; but they are said to be willing to save themselves the trouble of making their own burrows by using those of the Vizcacha, wherever possible.

Maras have two young at a birth; they do well in captivity, and breed in that condition, being established in one or two English parks, There is another species of Mara (Dolichotis salinicola) which frequents saline plains, and in size and colour bears much the same relation to the Patagonian kind that the Rabbit does to the Hare, being much smaller and of a dull grey colour.

\section{THE GUINEA-PIG}

\section{(Cavia porcellus)}

The Guinea-Pig is a typical example of the ordinary Cavies, which are all small, timid, insignificant little creatures, tailless and short-legged, living among rocks or herbage. All of them are South American, as indeed are all the present family. The Common Guinea-Pig was found already in a domesticated state, used as an article of food, and 
showing much variation of colour, when the Spaniards invaded South America; the natural wild colour is the uniform grizzly brown, called "Agouti" by our fanciers. There is no need to say very much about this well-known little animal, which always attracts attention by its greediness and noisy squeaking, almost as much as by its variegated colours; but it is worth while to mention its remarkable precocity. Young Guinea-Pigs are not only born fully furred and with their eyes open, but also soon begin to run, and are provided with teeth; they will sometimes start eating solid food on the very day of their birth. As they really are good eating-as good as Rabbits in any case-and are even easier to keep than those animals, it is a pity they are not more utilised for table purposes. When cooked, they should be scalded, scraped, and fried.

\section{THE AGOUTIS}

THE Agoutis (Dasyprocta) are a group of rodents belonging to a family (Dasyproctida) closely allied to the Cavies, and, like them, especially South American, but also found in the West Indies.

They are about as big as small Hares, with Rat-like heads and rather long legs, so that they walk and run freely. The tail is very short and hardly noticeable, except in the Acouchy (D. acouchy), but even in this species it is small and insignificant. Agoutis have a close hard coat of grizzled yellow and black, producing a brown effect; they are forest animals, living in small parties on the ground, where they feed on fallen fruit and nuts, roots, \&c., sitting up and holding their food in their fore-paws, like most rodents. In captivity they do very well, and sometimes display an instinct for hiding superfluous food. Their flesh is eaten and appreciated in their own country, where they are accordingly much valued as game animals.

\section{THE PACA}

\section{(Coclogenys paca)}

THE Paca, or Labba, belongs to the same family as the Agoutis, but in form resembles a Guinea-Pig, being heavy and thick-set; it is a good-sized animal, being about two feet long. Its cheeks are peculiarly 
swollen, the bony cheek-arches of the skull being hollowed out into great capsules, communicating by holes with the interior of the mouth; the use of this curious structure is quite unknown. The toes are five on each foot. The coat of the Paca is short and "coarse, of a dark sooty brown, marked with lines of white spots, very: unlike that of the Agoutis.

In general habits, however, it is much like these animals, but is a burrower, and also takes freely to the water, diving as well as swimming, while the Agoutis only do the latter. The Paca is more esteemed as game than those animals, being much fatter and more like pork in the quality of its flesh. It has a wide natural range, from Guatemala to Paraguay, and is not uncommon in captivity, though a surly and rather uninteresting beast.

\section{THE TAILED PACA}

(Dinomys branicki)

THE present animal, though allied to the Cavies and Agoutis, is sufficiently distinct from them to be given a family of its own. Externally, it is much like the Paca, but has only four toes and a welldeveloped and conspicuous hairy tail, several inches long:

The history, of the creature is most curious. In 1873 a Peruvian one morning found a specimen of this animal, till then unknown, walking about his courtyard. He killed it, and the specimen was duly recorded and named scientifically. Nothing more was heard of the animal till 1904, when Dr. Emil Goeldi, of the Museum of Para, received two live specimens, a female and young, which he was able to study in the Zoological Garden of that institution. They proved to be harmless, lazy, good-tempered creatures, and had the habit of sitting up and holding their food in their fore-paws, when eating, as the Agouitis do, but not the Paca. 


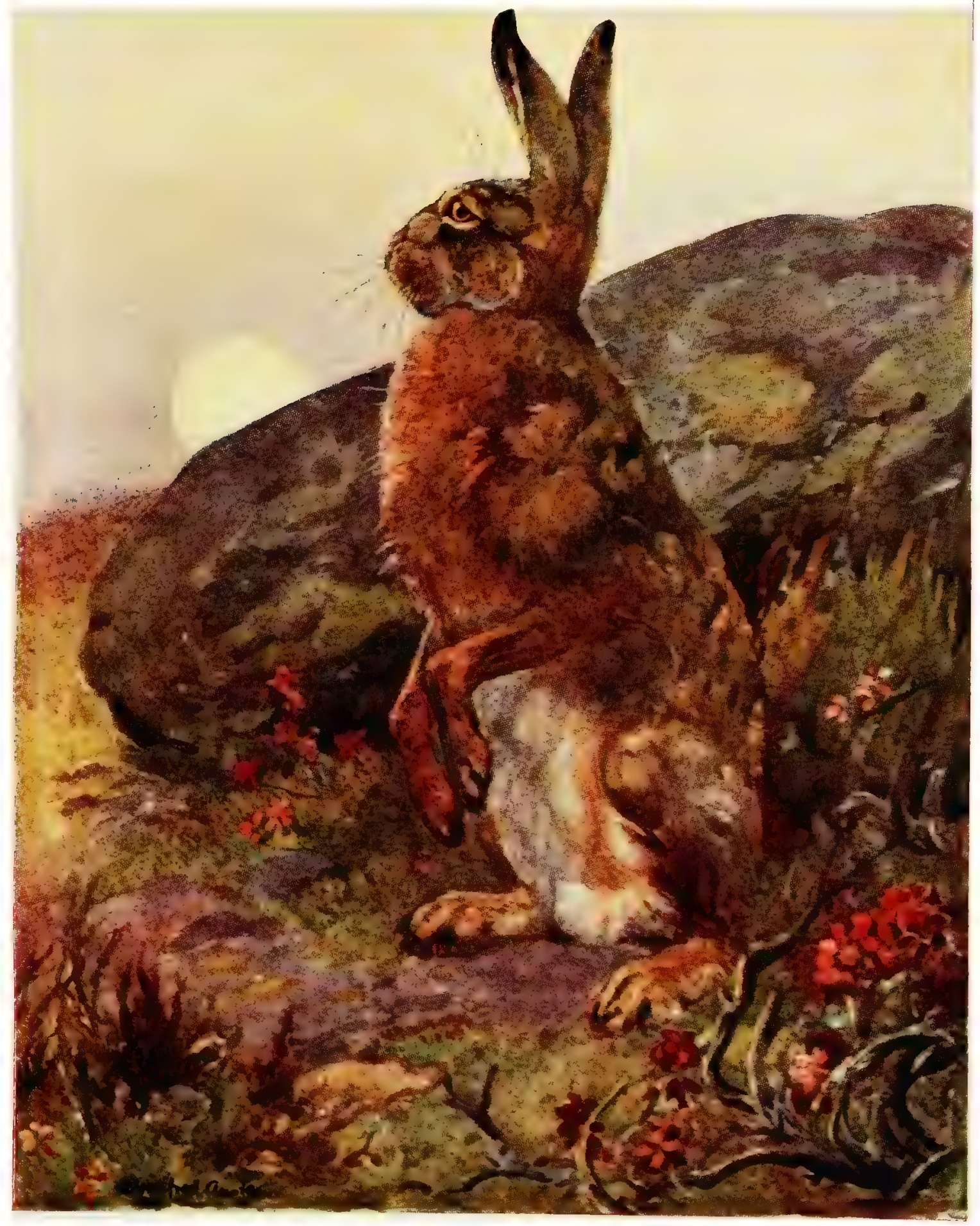

HARE

By Winifred Austen 



\section{THE COMMON HARE}

\section{(Lepus europaus)}

THE Common Hare has for ages attracted the attention of man more than almost any other of the smaller animals of Europe, its excellence as a sporting beast of the chase and a delicacy for the table having particularly commended it to the Greeks and Romans, who thought even more of it in these capacities than we do. For a rodent it is a large animal, weighing from seven to twelve pounds, and its peculiar form, with long ears and short tail, is very distinctive, not only among rodents, but among beasts in general. The slender but powerful limbs, of which the hind pair are much the stronger, bear five toes on the fore and four on the hind feet, and have the pads covered with hair. The teeth differ from those of most rodents, in that there are two pairs of incisors in the upper jaw instead of one; but the second pair are very small, and are set behind the great centre pair, so that they are neither noticeable nor useful.

The coat of the Hare does not vary much in colour, though occasional black and white specimens have been recorded, and a very pretty silver-gréy variety sometimes occurs, in which the tawnyyellow ground of the fur is replaced by white, the black "ticking" remaining. In the northern part of its range the Hare shows some tendency to turn white in winter.

It is essentially a European animal, being generally distributed over Europe, and not found outside it; in certain European countries, also, it is absent-in North Russia, Scandinavia, and Ireland, though in the last-named it has been artificially introduced in a few places. Artificial introduction, also, has established it in New Zealand, where 
it thrives well and attains a great size; it does not become a pest like the Rabbit, being less prolific and not a burrower.

Its life of constant exposure on the surface of the ground is made up for by its great speed and agility; its long hind-legs enable it to gallop very rapidly, especially up hill; but the same peculiarity of form is against it in descending a slope, and makes it apt to overbalance. It cannot see ahead very well when running, and hence is apt to run into danger. In addition to being a good runner, the Hare can leap to a vertical height of five feet, and clear as much as five yards' width at a spring; it also swims well and strongly, and readily takes to the water, crossing rivers and even arms of the sea.

By choice it lives in open country, squatting by day in its "form," a depression it makes among the herbage, and coming out at evening to seek its food of grass and other plants; it often ravages gardens and crops, and indeed prefers cultivated land. Hares are not, however, so destructive or omnivorous as Rabbits. They are usually solitary, but in early spring, when they pair, several may be seen playing about together, even by day-the proverbial madness of the "March Hare." The bucks fight savagely together, striking heavy blows with their fore-feet, so as even to kill each other at times; indeed, the Hare, though proverbially so timid, is only so with man and the numerous carnivorous enemies which seek its life. With its own kind, and harmless animals like Cattle and Sheep, it is bold enough. The doe usually produces about five young, which are born furry and open-eyed, not helpless and blind like young Rabbits; these leverets she soon disperses in separate forms, going regularly to each one to suckle it. In this way they run less chance of being lost than if collected all together; and the precaution is needful, for Hares have many enemies, from the Wolf, Lynx, and Eagle, down to the Weasel and Crow, to say nothing of the depredations of man. When being killed the Hare utters a loud painful scream, but its usual note is only an inward grunt, or a low call to its mate and young.

As every one knows, Hares, besides being shot, are hunted in two ways, being "coursed," or run by sight, by a couple of Greyhounds, 
or hunted by scent by a pack of Harriers, Beagles, or the curious shortlegged Basset-hounds. Its great power of doubling often saves it from swift Dogs, but its habit of running more or less in a circle is fatal to it when pursued by those which run by scent and gradually tire it out. Hares are not often kept as pets, but, when once their great natural shyness is overcome, have been known to become very affectionate, though often strangely spiteful for creatures with such a reputation for harmlessness.

\section{THE MOUNTAIN HARE}

\section{(Lepus variabilis)}

ThE Mountain Hare is somewhat intermediate in size and form between the Common Hare and the Rabbit, though closer to the former; it weighs about six pounds, and has shorter feet and limbs than our other species. Its coat is of a drabbrown in summer, becoming bluish-grey in autumn, whence the name Blue Hare, often given to it to distinguish it from the Brown or Common Hare of the lowland country. In winter it becomes pure white, except the tips of the ears, which remain black; but this change, like the similar one in the Stoat, is not constant except in the colder localities inhabited by the animal, and in the south of Scotland and in Ireland seldom occurs, especially in the latter country. This is an animal of high elevations and cold climates; with us it inhabits the Scotch mountains, but is, curiously enough, the only Hare native to Ireland. Outside our islands, it is found practically all round the northern parts of the world, a large local form of it being the so-called Polar Hare of Arctic America.

In Ireland it often produces a buff-coloured variety; and where it meets the Common Hare, the two species sometimes interbreed.

\section{THE RABBIT}

\section{(Lepus cuniculus)}

Originally the familiar Rabbit must have been an animal of more limited distribution than any of the Hare family, for its really natural home seems to be only Western, and especially South-Western, Europe, particularly the Spanish peninsula, extending to the other European countries bordering the Mediterranean. Now, however, what with its domestication by man and his introduction of it into various countries as a wild animal, it is certainly by far the most numerous of its. kind. The wild Rabbit is a small animal compared to most of its tame descendants, 
and, as every one knows, is naturally of a greyish-brown colour, though black, sandy, silver-grey, and other varieties occur even among wild ones, Its ears and tail are much shorter than those of the Hare, and the former have no black patch at the tip. The weight of a wild specimen is two to three pounds.

The social and burrowing habits of the Rabbit are well known, and also the fact that the young, which are kept by the doe in a warm nest in the burrow lined with her own fur, are helpless and naked at first, very different from the young of Hares. There is little need also to dwell on the excellence of Rabbits as food, and their destructiveness when too numerous, especially in our Australasian colonies, where the climate is more favourable to them than it is here. It is important, however, to point out that the animals called "Rabbits" in America are various species of Hares, solitary, non-burrowing animals, with active young; the breeding habits of the true Rabbit being quite exceptional among the Hare kind.

Hares of one sort or another are, indeed, found almost all over the world, except in the Australian region and in Madagascar and southern South America; they are all sufficiently like our species in general appearance to be recognised as members of the Hare and Rabbit family, though they differ much in detail both in form and habits. There are Desert-Hares, Rock-Hares, and even swamp-loving species.

In hot countries Hares are often very foul feeders, and in India, at any rate, are for this reason not often eaten by Europeans, which makes it easier to understand Moses' prohibition of Hares to the Jews, though they do not chew the cud as he imagined when mentioning them as cud-chewing animals without divided hoofs.

\section{THE PIKAS}

Pikas (Lagomyida), also known as Mouse-Hares or Calling-Hares, are a small family of little animals inhabiting Asia, and in one case North America. In general character they are much like the Hare family, and like them have two pairs of upper incisors, but they have quite short limbs and ears, and no tail at all.

In fact, except for their soft, Rabbit-like fur, they at first sight remind one much more of Guinea-Pigs than anything else. They hide among rocks in mountainous districts as a rule, though in Central Asia they are found burrowing on the steppes in communities. Several of them are also remarkable for their loud whistling calls. Like true Hares, they remain active in winter, but have the foresight to lay up in summer a large store of the grass and other plants which form their food, for consumption at that time. The young are said to be naked at birth. Pikas are seldom seen in captivity, but of late years the London Zoological Gardens have had examples of one or two kinds. 


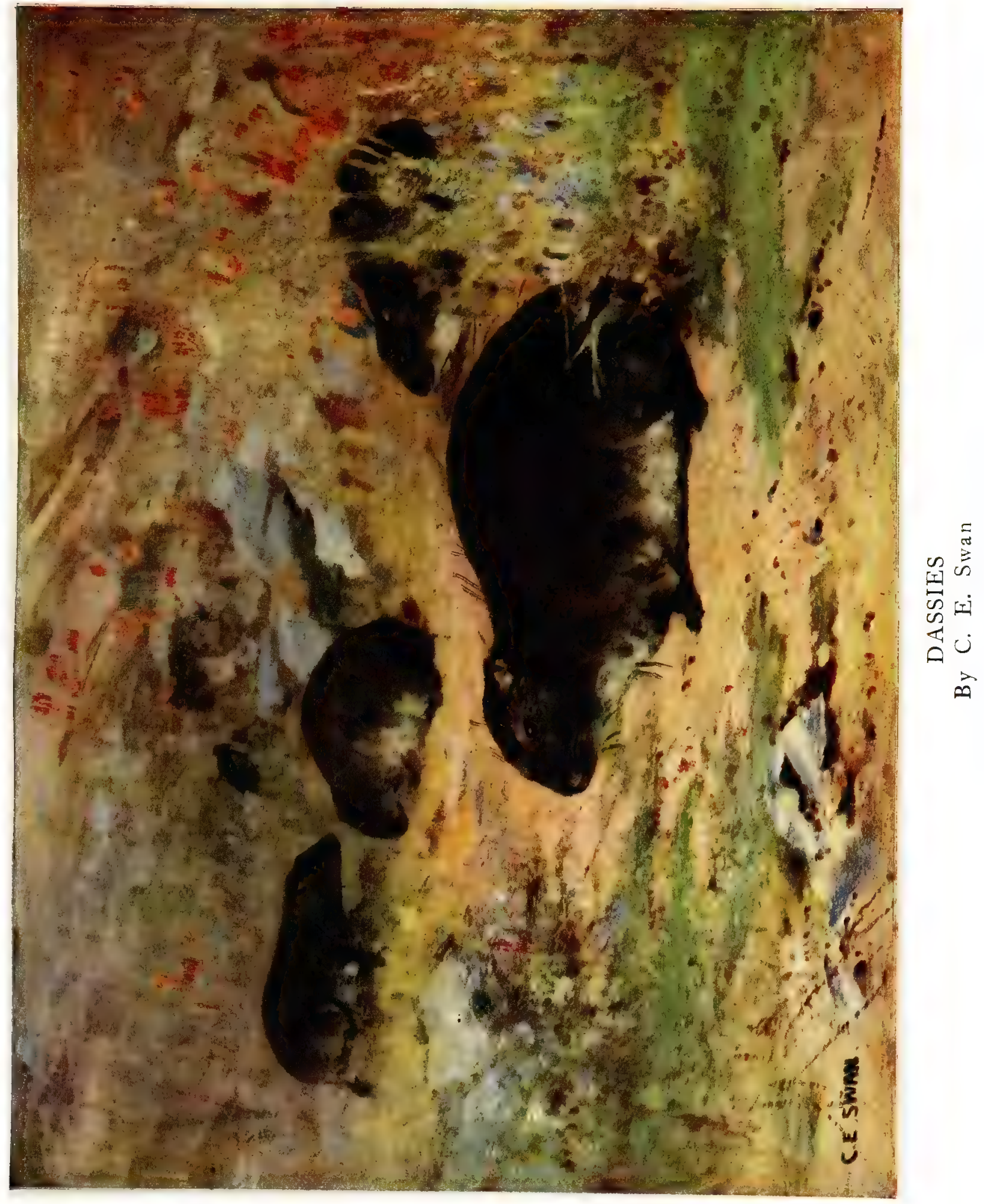





\section{THE DASSIE}

\section{(Hyrax capensis)}

As a whole, the animals of the hoofed order (Ungulata) are so distinct in appearance that their relationships are at once apparent even to an untrained eye; but the little animals of the family Hyracida at first sight look much more like rodents, and, indeed, were at one time classed with that order of animals.

The Dassie, or Rock-Rabbit, of the Cape, is a very good type of the family, all of which bear a strong general resemblance to each other. In size it about equals a Cat, and is heavily built, with the tail quite rudimentary and not noticeable. The legs are short, with four toes on the front feet and three on the hind. These are provided with flat nails, except the inner toe on the hind-foot, which has an ordinary curved claw, no doubt used for scratching. In walking, the animal goes on its toes, not on the flat of the foot like so many rodents.

The coat is thick and soft, quite unlike the usual covering of a hoofed animal; and there are whiskers at the sides of the muzzle, and a small tuft of similar long hairs under the chin.

The teeth are very peculiar; the grinders, indeed, almost exactly resemble those of a Rhinoceros in miniature, forming a curious contrast to the general appearance of the creature, but the front teeth are especially characteristic. As in rodents, there are no canines at all, and two large, continually-growing incisors in the front of the upper jaw. These, however, instead of being flat-fronted and square-tipped -chisel-shaped, in fact-come to an edge down the front, and terminate in points, while they are set somewhat apart, not close together like a rodent's incisors. In the lower jaw there are two pairs of incisors, rounded in shape and projecting straight forwards.

The internal structure of this animal, such as that of the brain and stomach, allies it to the hoofed order, and not to rodents. The 
habits, however, are, on the whole, more like those of some of that order than any other beasts. The food is entirely vegetable, chiefly the shoots of shrubs, and this is sought by the Dassies in the morning and evening. They inhabit cliffs and stony hills, taking shelter when alarmed in holes and crevices in the rocks, for they do not make burrows, their soft feet and blunt nails being quite unsuitable for digging. In the day-time they may often be found basking in the sun, and sometimes sitting up on their hind-legs to look round. On these occasions, the cry of the animal may be heard if it is alarmed -a shrill prolonged note,- variously described as a whistle and a hiss.

The Dassie is a very active animal, climbing over rocks and clinging to them, even when almost perpendicular, in a very remarkable manner. This it can do by virtue of certain peculiarities of its feet; the soles of these are naked, and very copiously supplied with sweat-glands, producing a soft clammy surface eminently suited for adhesion, while the muscles are so arranged that the soles can be contracted and cause the foot to adhere like a sucker without any effort, even dead animals remaining thus clinging.

The young Dassies are born about the end of the year, in the early summer of the Southern Hemisphere; three was the number in two litters observed by Moseley, who says they were very playful, chasing each other about the rocks. These were of the size of very large Rats. The Dassies are sociable animals, and live in family parties; although timid, they are inquisitive, and, after being startled, will after a time come out to take another look at the disturber. Their great enemies are Leopards and some of the large birds of prey, especially the splendid Black Eagle of the Cape (Aquila vulturina), which is locally called the "Dassie-vanger" (catcher) by the Boers.

The worthy Boers who colonised South Africa, by the way, seem to have had a perfect genius for misnaming animals. "Dassie" is a corruption for "dasje," a Dutch diminutive of the name of the Badger, to which animal the present one certainly bears but the 
faintest resemblance, either in form or habits, but nevertheless the name, being in popular use at the Cape, and not confusing to English people, may well be allowed to stand. "Rock-Rabbit," also a Cape term, is not correct either, and much more likely to make people run away with a false idea of the Dassie's affinities.

The flesh of this animal is sometimes used for food, but is dry and tasteless. It is tenacious of life, requiring a large charge of shot, and bites fiercely if not killed outright. In captivity it lives well, but does not like being shut up in close quarters, becoming irritable and biting readily. Many specimens have been exhibited in the London Zoological Society's Gardens, and it has bred there, though not of late years.

There are about twenty species of Dassies altogether, all so much alike that any one could at once recognise their relationship, and all are purely African animals except one, the Syrian Dassie (Hyrax syriacus) which ranges into Arabia and Palestine. This animal is well known by name as the "Coney" of Scripture, its habit of sheltering its feebleness by lodging among rocks being noted there, while it was forbidden to the Jews as food as being one of the cudchewers which had not cloven hoofs. It does not, as a matter of fact, chew the cud, but, like the Hare, has a habit of champing its jaws in a way that suggests its doing so. "Coney," of course, simply means "Rabbit" in old English, and every one is familiar with the retention of the word in legal phraseology, "trespassing in search of Conies" being such a common rural offence. It is rather curious to find English colonists at the Cape making, the same mistake, and calling their Dassies Rock "Rabbits."

\section{TREE-DASSIES}

Although there is such a general similarity among the members of this small family as far as appearance goes, there is a curious difference in point of habits in some cases, several of the species, forming 
the group Dendrohyrax, being tree-animals. These live in holes of trees, climbing about the branches and trunks, in the same way as their rock-loving relatives traverse the rocks, their peculiar power of clinging with the feet being just as well suited for an arboreal life as for climbing precipices. At the same time, it is curious to find any animal of the. hoofed order climbing trees at all, although one or two of the small African Antelopes, and even the common Goat, will jump up on to accessible branches at times. One of these Tree-Dassies has, at the time of writing, been living for some time along with the Squirrels in their open enclosure at the London Zoological Gardens, and has passed the winter outdoors. 


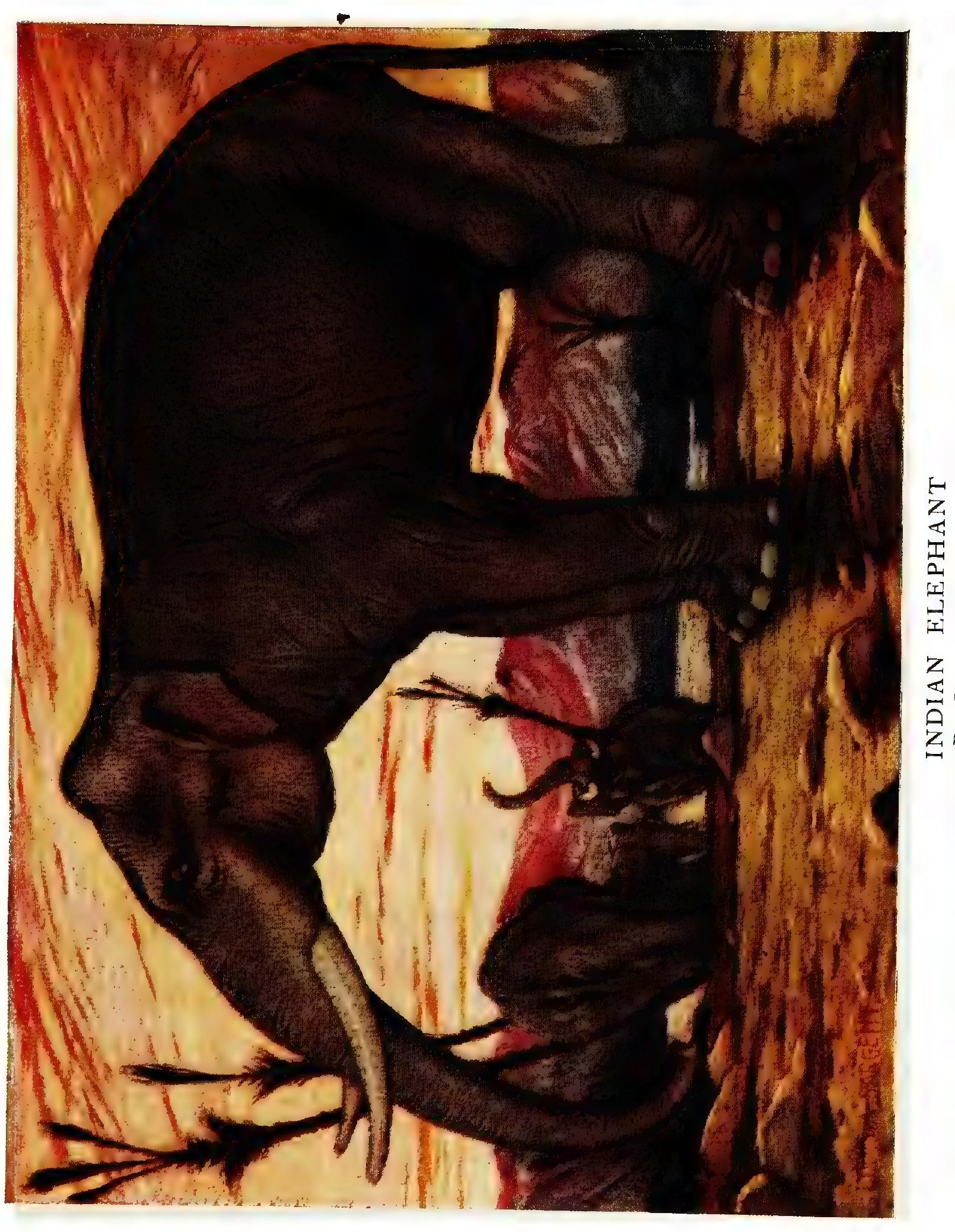





\section{THE INDIAN ELEPHANT}

\section{(Elephas indicus)}

OF the two known living Elephants the Indian species is much the more familiar, being that commonly seen in captivity both in its native country of South-Eastern Asia, where it ranges from India to Sumatra, and in menageries away from it. Although not quite so large as the African species, the Indian Elephant is, as every one knows, a huge animal, the male occasionally reaching a height of eleven feet at the shoulder, though it is usually two feet or more less. The female is considerably smaller. It is a curious fact that twice the circumference of the Elephant's fore-foot gives practically the height. The Elephant is even more remarkable for its structure than its size; the long prehensile nose or trunk is a peculiarity which has appealed to humanity ever since the Romans called the Elephant the "snakehanded" beast, and its general shape is very unlike that of the hoofed animals in general, with which it is usually classed. It will be noticed that the joints of the limbs, which are nearly straight, are situated nearly as in ourselves, the wrists and heels being down quite near the toes, and the true knee plainly visible, whereas in most hoofed animals the wrist forms the so-called "knee" of the fore-leg, and the heel the "hock" of the hind-leg, the true knee being tucked up to the body and constituting the stifle-joint. There are five nails on the fore, and four on the hind feet, the toes being five in both.

The huge size of the Elephant's head always attracts attention, but the expanse of brow, which gives the appearance of intellect, is really due to the development of air-cells in the skull, to give surface without weight, the brain of the animal being remarkably small. The teeth are not the least wonderful parts of the creature's organisation. There are no canines, and no incisors except the great tusks in the upper jaw, which grow continuously; in the Indian Elephant, how ever, they are confined to the male-that is, in their full development, those of females being so short as not to be noticeable. The grinders are equally remarkable in their way; they are very large and longi- 
tudinally oval, and when worn show alternating layers of enamel, ivory, and bony cement. They keep gradually working forward in the jaw, the rear teeth coming through from behind as the fore ones are worn away, till at last the remnants of the latter are shed. Thus the Elephant is cutting its teeth all its life, and never has more than one, or one and a half, in use at one time on each side of each jaw; the total number produced is twenty-four, six for each side of either jaw. This number must last the animal's lifetime-at any rate if it wears them all out it must die of indigestion-but the danger of this cannot be great, as there seems good reason to suppose the beast lives a hundred years.

The existing Elephants are among the few land animals which are practically naked, there being hardly any hair on the body, although the end of the long thin tail is tasselled with stout bristles. Young Elephants, however, are more hairy than adults; at birth they are about the size of an ordinary Pig, with the trunk shorter and the forehead less prominent than in the old animal. Only one is produced at a time, and for some time it is carefully kept by the mother beneath her body, under which it can of course walk quite comfortably; as, otherwise, the adventurous sallies of the little creature, which is as playful as other, young animals, would expose it to the risk of capture by the Tiger, which willingly preys on young Elephants if he can get them. The little Elephant sucks with the mouth, not the trunk; the old one's teats are situated close up to the armpits.

Elephants become adult at about twenty-five years of age; the members of a herd keep close together, and often show such similarity in appearance that they are evidently related. Of course it takes, an Elephant expert to notice this, but there are individual differences conspicuous to a trained eye, besides others more noticeable. Thus, many Elephants have the trunk and face blotched with flesh-colour, and presumably the extension of this hue all over the body constitutes the rare White Elephant. In some cases there are five instead of only four nails on the hind-foot; and some males are devoid ot tusks, these being known in India as ".mucknas." "In Ceylon almost all male Elephants are tuskless. The Elephant is a remarkably active animal for its size, although it can neither gallop nor jump, its only pace being a walk, either slow or fast, and it can stride a ditch of 
six and a half feet. It climbs up or down hills with great facility, negotiating slopes which would puzzle a Horse, as, when ascending, it goes down on its wrists, and when descending, on its knees, the situation of its joints making these postures convenient. It is also a strong swimmer, and when in the water has the great advantage of being able to breathe through its trunk held above the surface. With the trunk is collected the food, which consists of grass, and the leaves, twigs, and fruit of various trees; and water is drawn up by it and squirted into the mouth or over the body when bathing.

The Indian. Elephant frequents forest country, and is timid and social; it is almost always in herds, and stray females and young animals can gain entrance to these; adult males, no doubt, would have to face the opposition of the leading "tusker," or adult male, in the herd, and such are often found solitary, and sometimes become the well-known "rogues." These individuals have thrown off the natural timidity which is so strong a feature in Elephants, and attack man ferociously; but a "rogue" is not necessarily permanently solitary, since some herd-bulls develop these vicious propensities. The actual leader of a herd is, curiously enough, always a female, and the animals in their travels display a remarkable aptitude for picking out the safest and most convenient routes across a country.

The best-known note of the Elephant is the shrill "trumpeting" sound, but it also roars when in fear or pain. It attacks enemies with its tusks and feet, not with the trunk, and female animals often bite each other's tails off, not having tusks to gore with; mucknas have to put up with much ill-usage from tuskers.

Except when a known rogue, the Elephant is protected in India on account of its utility when domesticated; its capture is usually effected by driving a herd into a stockade or "kheddah," where the captured animals are roped, and afterwards removed, by the aid of tame Elephants. Elephants seldom breed in menageries in India or in Europe and elsewhere, but frequently do so in Burma and Siam. Captive-bred animals are no great acquisition, as they. are long in growing to a useful size, and are apt to be wanting in due respect for man-a serious matter in the case of such a gigantic animal. $\therefore$ In the ordinary way, the docility of the Elephant is its most remarkable quality, but, as is well known, the adult male is subject 
to periodical fits of blind fury, when he is said to be "must"; fortunately a discharge from an orifice in the temple precedes and gives warning of this dangerous period.

\section{THE AFRICAN ELEPHANT (Elephas africanus)}

WITH close general correspondence in appearance and habits with the Indian Elephant, the African differs in several details. Its forehead is low and receding, and its ears twice the size of those of the other species, almost touching over the neck. Its trunk terminates in two equal lips, instead of the upper finger-like process and short lower margin found in the end of the Indian Elephant's trunk; and there are only three nails on the hind-foot. Moreover, in this species, most of the females develop tusks as well as the males.

The African Elephant is taller and more leggy in build than the Indian species, and the male at any rate attains a greater size. It is more of an open-country animal than the Indian species, and is faster in its movements. As every one knows, it is the animal from which most of the ivory of commerce is derived, and for that insignificant product a noble creature like this is being exterminated, although it is known to be capable of domestication and trainingthough said to be less amenable to this than the other species. The late celebrated "Jumbo," of the London Zoological Gardens, was an African Elephant, and a few specimens are always to be seen in captivity somewhere or other. In classical times the Elephant inhabited North Africa, but became extinct there during the Roman Empire. It seems to have been used in warfare by the ancients, but, judging from the fact that the old writers speak of Elephantdrivers as "Indians," it is evident that the practice of taming Elephants, and the supply of animals to some extent, came from the East. Before leaving the subject of Elephants, it may be mentioned that the celebrated Mammoth (Elephas primigenius), the extinct Elephant of the northern parts of the world, was nearly related to the Indian species, differing chiefly in its heavy coat of hair and its huge upcurled tusks. 


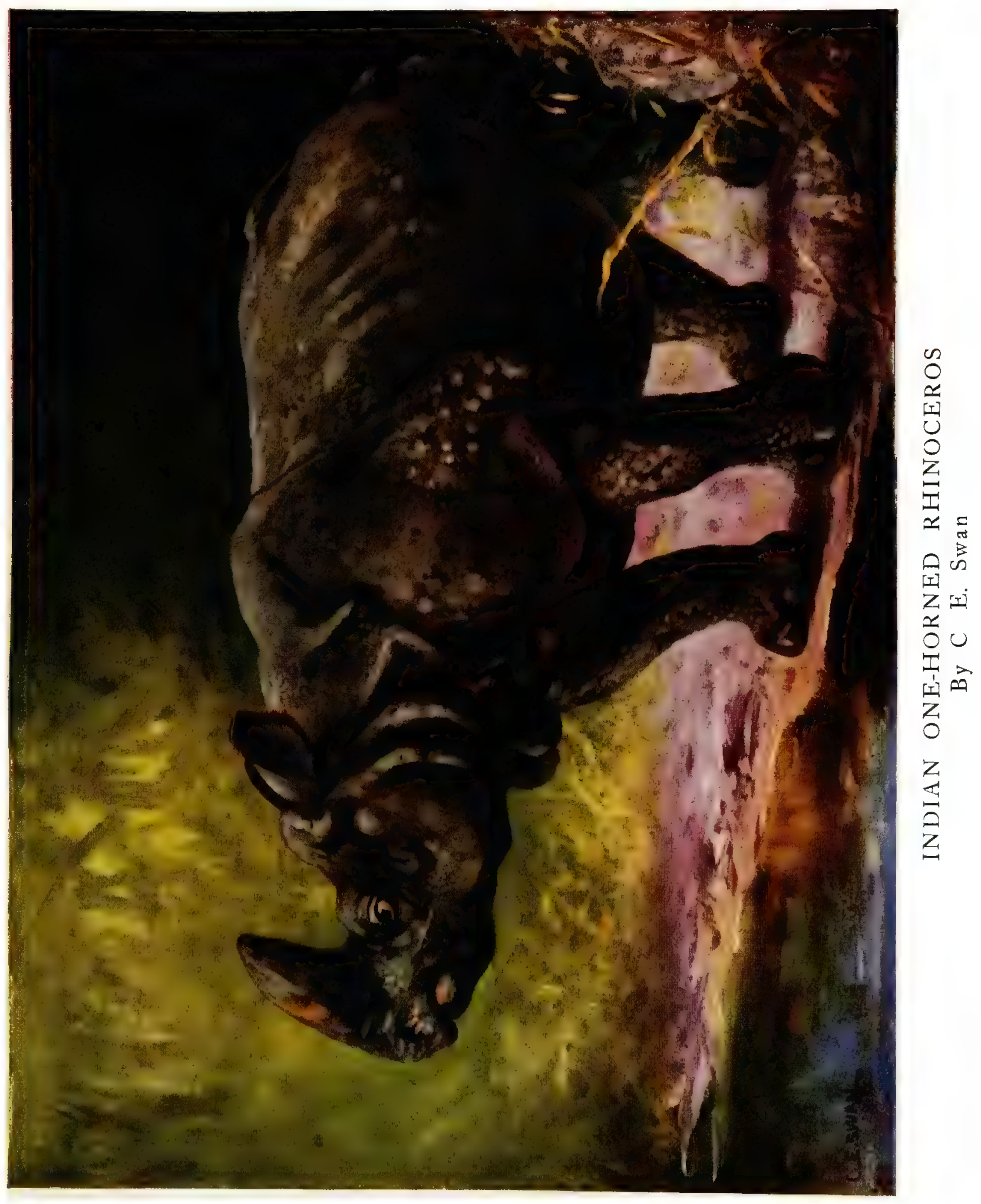





\section{THE INDIAN RHINOCEROS}

(Rhinoceros indicus)

Owing to its inhabiting a country of ancient civilisation like India, the great Indian Rhinoceros has always been the most familiar of the small family of large hoofed animals of which it is a member; while, though not absolutely the largest, it can challenge comparison with any of them in peculiarity of aspect, owing to the curious armourplate-like arrangement of its heavy and folded hide, which is studded with tubercles simulating the rivets of real armour.

The horn on the nose is solid throughout, and composed of a mass of horny fibres like agglutinated hair; it is merely seated on the skull, having no bony core, and a captive individual in the London Zoological Gardens once accidentally wrenched his off, to his exceeding pain and dismay. The hoofs are three in number on each foot, but the animal is not supported entirely on them, like a Horse or Cow, but treads also on a pad covering the bases of the toes. The skin is naked and very thick, but in the fresh state is not impenetrable to bullets as used to be supposed.

The mouth is provided with a good set of flat-crowned grinders, but the front teeth are very scantily represented, there being no canines in the upper jaw and usually only one pair of incisors, while the lower jaw has only a pair of small incisors and an outer pair of rather large sharp-edged teeth, which some regard as canines and some as incisors. Whatever they are, the animal knows how to make use of them, ripping an adversary with them as a Boar does with his canine tusks.

This Rhinoceros is one of the largest living land animals, measuring from five to nearly six feet at the shoulder, and exceeding at times ten feet from nose to root of tail ; the said appendage is puny and rather short, not reaching a yard. The horn in this species is not very long, seldom reaching more than a foot; it is found in both sexes, as in most Rhinoceroses. When newly born, the Rhinoceros is about as 
large as a Pig; it has no horn at birth, but otherwise is a very perfect miniature of its parents. It grows rapidly-at first, at any rate-but is a long-lived animal, believed to live for a hundred years.

The Rhinoceros is a much more active creature than would be supposed from its ponderous build; it has a rapid if heavy trot, and can even gallop. In the ordinary way, however, it is not very energetic; it easily finds food and shelter in the great grass-jungles it frequents, and it much enjoys' wallowing in the mud, like so many tropical animals. Its range in India has greatly diminished in historical times; in the time of the Emperor Baber, in the sixteenth century, it extended to Peshawur, and it used comparatively recently to be found along the base of the Himalayas. Its last stronghold is in the plains of Assam, and it is to be hoped that the Indian Government will be able to secure its protection there indefinitely. It is a harmless animal, rarely attacking man even when provoked, and, though it is greatly feared by Elephants, these beasts are so nervous in disposition that their dread of any animal must not be taken as proof that it is a natural enemy, as the Rhinoceros has been credited with being.

There is also a certain amount of positive utility in the Rhinoceros, from the fact that its flesh is considered good food even by Europeans, while its heavy skin can be turned to a variety of uses when cured. It thrives well in captivity, and lives for many years, but, like all Rhinoceroses, is scarce in the animal trade, and very expensive accordingly. During all the time I was in Calcutta-seven years-our dealers were trying to get hold of a live Rhinoceros of any sort, but not a single specimen came to hand.

\section{THE SONDAIC RHINOCEROS}

(Rhinoceros sondaicus)

THis is the only other kind of Rhinoceros with one horn; like the last, it is found in India, but has a much wider range altogether, extending from. Eastern...Bengal through Burma and the isles to Bornea. Though as tall as the other species, it is not so heavy, and his a smaller head; moreover, the skin, although falling in folds, as 
in the great Indian species, differs slightly in the arrangement of these creases-the fold in front of the shoulder runs right across from side to side of the neck, like that behind the shoulder and over the hips. In the Sondaic Rhinoceros, also, the skin is not tubercled, and the nose-horn is confined to the males-at any rate as a rule.

This species usually frequents hilly districts, though it also occurs in the marshy alluvial soil of the Sunderbunds. It frequents tree rather than grass jungle, and is said to be more harmless than the great Indian Rhinoceros. It has once been exhibited in the London Zoological Gardens.

\section{THE ASIATIC TWO-HORNED RHINOCEROS}

(Rhinoceros sumatrensis)

THE Hairy Rhinoceros, as this species might well be called, for its body is thinly covered with hair and its ears fringed therewith, is the smallest of all known kinds, not reaching five feet at the shoulder, and being sometimes less than four. Its skin shows fewer folds than those of the large Asiatic kinds, and only the fold behind the shoulder crosses the back.

In addition to the horn on the nose, there is another over the eyes; the front one grows to a considerable length, well over two feet. This species much resembles the last in range and habits, being a forest animal, found from Assam to Borneo. It has been exhibited in the Zoological Gardens of London and Calcutta, and young ones have been born in the latter place, while in the London Docks a young one was produced aboard ship by a female which had just been imported from Singapore.

\section{THE COMMON AFRICAN RHINOCEROS}

(Rhinoceros bicornis)

THE "Black Rhinoceros," as this species is often rather absurdly called-for it is grey, like Rhinoceroses generally-is the commonest 
species now living, ranging all over Africa from Abyssinia to the Cape. It is about as big as the great Indian Rhinoceros, and, like it, has a pointed prehensile upper-lip, but a smooth skin without creases; it is also provided with two horns, the front one, on the nose, sometimes exceeding a yard in length, while that over the eyes is seldom much more than half the length of its fellow; but the proportions vary greatly.

This Rhinoceros is for the most part a bush-haunter, and lives almost entirely by browsing, eating twigs, leaves, and fruit. Opinions differ as to its character, but the general opinion is that it is an irritable, vicious animal, being unusually inclined to attack men unprovoked, and thus very different in disposition from most of the family. Indeed, some years ago, the expedition of Mr. A. Chanler and Lieutenant von Höhnel into East Africa was broken up through the repeated attacks of these animals, who ultimately disabled the latter gentleman. Although so common in the wild state, this animal is rarely captured, and only two have been exhibited in the London Zoological Gardens.

\section{THE GREAT AFRICAN RHINOCEROS}

(Rhinoceros simus)

THE Square-mouthed Rhinoceros of South Africa, so called from its upper lip not terminating in a prehensile point, is also sometimes called "White"-a term as absurd as "Black" for the other, and for the same reason, the animal being also grey. It is the largest land animal after the Elephants, a big male standing six and a half feet at the shoulder, and being about twelve feet long. Like the common kind, it is smooth-skinned, and has two horns, which vary much in length, the front one sometimes exceeding four feet in length. The Square-mouthed Rhinoceros lives in the open, and is a grass-feeder, and generally harmless in disposition. It has never been brought to Europe alive, and is now, by the persecution of hunters, reduced to about a dozen individuals-if even these still exist-in South Africa, though now also found to inhabit Central Equatorial Africa. 


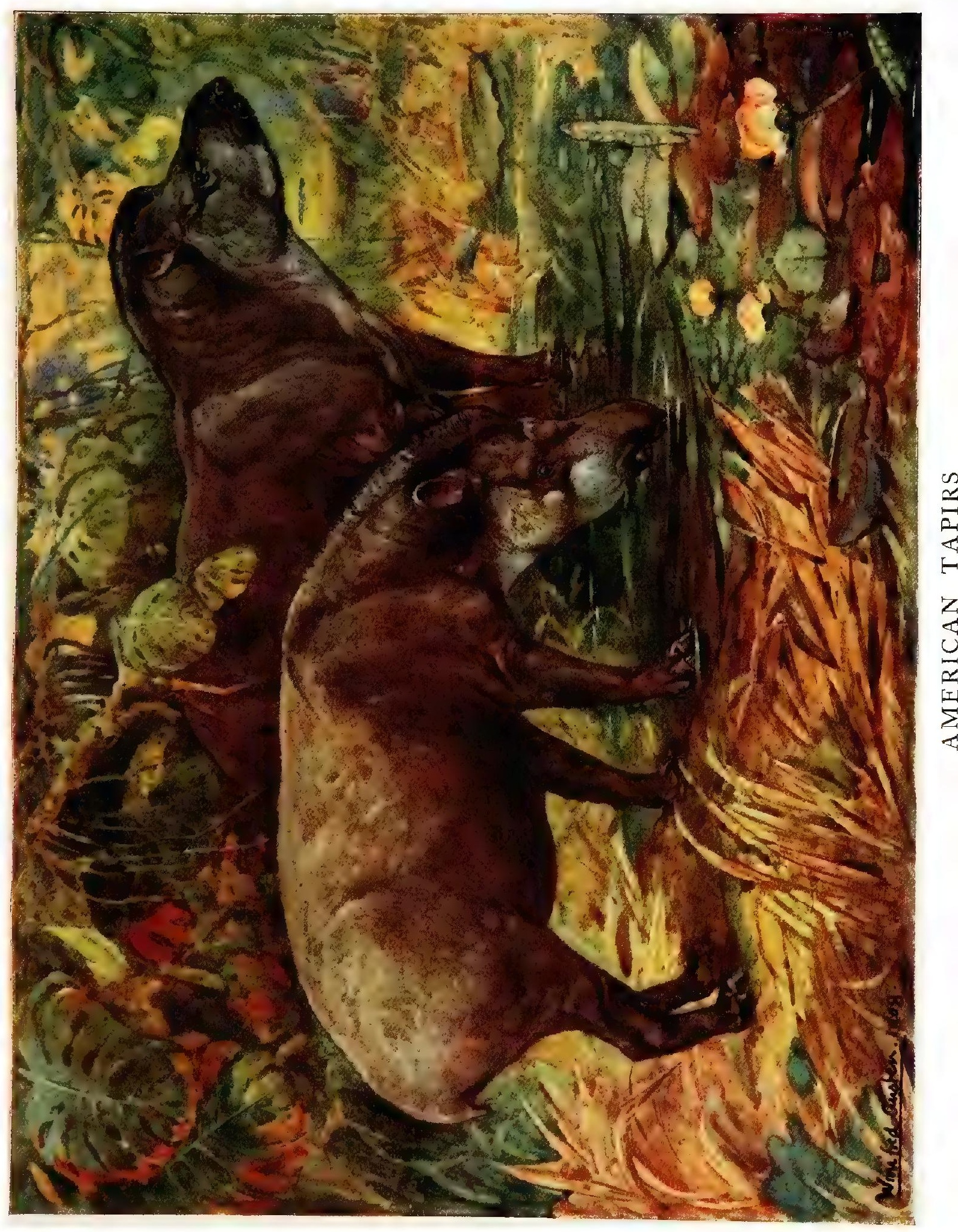





\section{THE AMERICAN TAPIR}

\section{(Tapirus americanus)}

The Common Tapir of South America is the best known of the small family of hoofed animals it represents, and, as all are very uniform in general appearance and habits, may be taken as a type of Tapirs in general. There is something curiously old-world and unfinished about the appearance of the creature, as if it had failed to complete its evolution-something recalling both a Pig and a Pony, while the short trunk suggests an abortive attempt at an Elephant. This little trunk is freely movable, and is used to grasp the herbage on which the creature feeds; when turned up it gives a most comical sneering expression to its owner. In size the Tapir about equals a stout Pony.

The teeth show incisors, canines, and grinders all well developed, and the limbs have four hoofs on the fore feet and three on the hind; the animal, however, like the Rhinoceros, does not rest entirely on these hoofs, but also on a pad under the base of the toes. The tail is almost as short and insignificant as a Bear's.

The coat, which is short, is so scanty that it allows the skin to be seen; but on the neck it forms a standing mane. The colour of the young animal is very different from the uniform brown of its parents; it is very dark, and gaily variegated with cream-coloured longitudinal stripes, alternating with rows of spots of the same tint, and as the fur is very close, the little creature looks for all the world like some painted toy animal. At this stage it is only about as big as a Terrier. Only one young one is born at a time, and it is lively and active, according to the universal rule among hoofed animals.

The Tapir is essentially a forest animal, confined to the wooded parts of South America.

It is usually found solitary or in pairs, and frequents the waterside, for, though not exactly aquatic, it is very fond of water, and 
frequently goes into it; it swims well, and has a habit of walking along the bottom. One of its peculiarities is that it always takes to water to deposit excreta. As may be conjectured from its stout build, it is rather a strong than a swift animal ; it rushes through the forest with great force when alarmed, and in this way often escapes when seized by its chief foe, the Jaguar, forcing its feline enemy to let go its hold by rushing under boughs. It also bites severely when brought to bay.

Its food is vegetable, consisting of grass, leaves, and fruit, and it is itself esteemed as food by the natives, the flesh being somewhat like beef in quality; insignificant as it is compared to the mighty animals inhabiting corresponding latitudes in the Old World, it is the biggest game animal in South America.

The Tapir is a harmless animal, and not difficult to tame, and is sometimes kept in a state of liberty in its own home, while it is also a familiar exhibit in Zoological Gardens, and has produced young there. It needs a quantity of water sufficient to bathe in, and has to be kept indoors in a warmed house in winter, like the Elephant and Rhinoceros.

\section{BAIRD'S TAPIR:}

\section{(Tapirus bairdi)}

BaIRD's Tapir, which much resembles the ordinary South American Tapir in appearance, save that its cheeks are noticeably, pale-coloured, is a Central American animal ranging from Southern Mexico, to Panama; in general habits it seems to resemble the Common Tapir, but is addicted to frequenting mountainous districts. It has been known ever since the time of the celebrated traveller Dampier, who wrote of it in 1676 as the "Mountain Cow," though mentioning that personally he had never seen it. It presents a remarkable difference from the ordinary Tapirs, in having the partition of the nostrils bony, but this does not affect its outward appearance. The same peculiarity 


\section{THE PINCHAQUE TAPIR-THE MALAYAN TAPIR 235}

is found in another Central American Tapir ( $T$. dowi ); also not remarkable-looking externally, and chiefly notable for peculiarities in the skull. It is strange that these two distinct Tapirs should both occur, apparently together, in a comparatively small area like Central America; but very little is known about them, though both have been exhibited in the London Gardens, 'which have possessed all the five known Tapirs except the next species.

\section{THE PINCHAQUE TAPIR}

(Tapirus roulini)

OF all the Tapirs this is the most nearly related to the common South American species, having no special peculiarity of the nasal division and a plain brown coat. This is, however, much thicker and closer than in the ordinary Tapir, and the chin is white. The thick furry nature of the coat is to be accounted for by the habits of the species, this being strictly a mountain animal, inhabiting a temperate climate, for it is confined to the Andes of Colombia and Ecuador, where it ranges up to eight thousand feet, and appears not to descend into the plains.

\section{THE MALAYAN TAPIR}

\section{(Tapirus indicus)}

THE Tapirs afford an interesting example of what naturalists call "discontinuous distribution," four out of the five species, as we have seen, being American, while the other inhabits so remote a region as the Malay peninsula and its adjacent islands, ranging as far east as the island of Borneo. The explanation of this is that Tapirs had formerly a wider range, since extinct species are found fossil in Tertiary strata in Europe and China as well as in North America; for some reason or other they have failed to maintain their existence in the North.

The Malay Tapir is the most remarkable in appearance of all; it 
is rather larger than the Brazilian species, and has an exceedingly close coat and no mane. Its colour is very peculiar, being black and white very sharply contrasted; the head, neck, and fore-quarters generally are black, and also the hind-limbs, while the body is white, so that the general effect is of a black animal round whose body a white sheet has been tightly sewn. As so often happens, however, it resembles its relations much more closely when young, the infant Malayan Tapir having the same curious display of whitish spots and stripes on a dark ground which are found on the young of the American kinds, so that no one would know that they would grow up so different in colour. No doubt this spotted coat was the livery of the original ancestor of the family.

The Malayan Tapir has the same habits as the Brazilian, being a forest-dweller and fond of water; it occasionally falls a prey to the Tiger, as its relation does to the Jaguar, and it seems strange that creatures of this primitive type, with no special facilities either for escape or defence, should have been able to maintain their existence through long ages in the same countries as two of the most terrible of the carnivores.

This Tapir is not nearly so common in captivity as the Brazilian species; it does well enough in India, though not better than American Tapirs, but in Europe it has the reputation of being a delicate animal, and has comparatively seldom been exhibited in the London Zoological Gardens. 


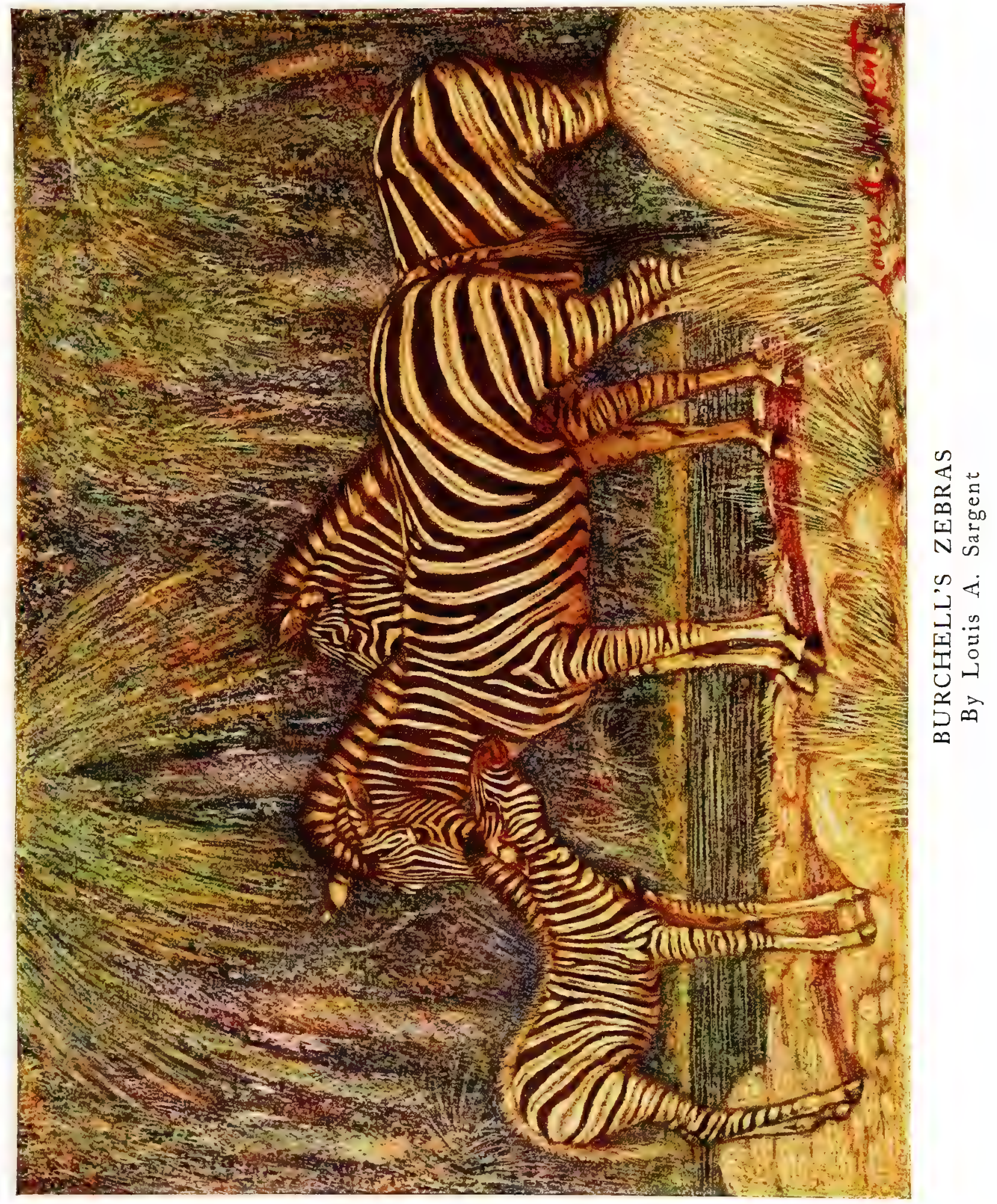





\section{BURCHELL'S ZEBRA}

(Equus burchelli)

BURChELl's Zebra, nowadays, is the best known of all the Zebras, as it is the commonest and most widely spread, inhabiting open, dry country in Africa generally, south of the Sahara. In form and size this Zebra is intermediate between the Horse and Ass, though inclining more to the latter, especially in having the root of the tail covered with close, short hair, and in being without the bare, hard patches called "chestnuts" on the hind-legs, though they are present and of large size upon the front pair.

In certain details of its beautiful markings, it varies a great deal; the "shadow-stripes" between the main black stripes are absent in some local races, in some of which the legs may be striped right down to the hoofs, while in others they are plain. Hence many sub-species have been named; but there is considerable variation even among individuals of the same herd. It has even been suggested that the Quagga of South Africa (Equus quagga), now unfortunately extinct, was merely an extreme form of this Zebra, which is still known to the Boers as "Bonte (variegated) Quagga." The true Quagga was striped with brown, and this only on the fore-quarters, the legs and hindquarters being plain.

The gaily-striped pattern of the Zebra looks very striking in a menagerie, but those who have seen the animal wild say that at a little distance the dark and light stripes combine to produce a grey effect, so that the creature is not conspicuous at all, by colour, though its lively movements and loud shrieking bray make it a noticeable animal.

Zebras, like all the wild members of the Horse tribe, live in herds, under the control of the master stallion; their food is grass, and they avoid bushy localities, their great enemy being the Lion, who prefers the Zebra to anything else he can get in the way of game. Except, 
however, when it goes to drink, he does not get many chances to secure this delicacy, which seems to commend itself to him by its abundance of oily fat. The same peculiarity of Zebra meat makes it much esteemed by African natives; Europeans seldom shoot the animal, except to provide meat for their negro followers.

The Zebra foal has the handsome markings of its parents at birth, and very soon acquires swiftness enough to keep up with the herd. It is easily tamed if captured young, and even old individuals can be broken to harness; some time ago the Honourable Walter Rothschild used to drive three of them in England, along with a Pony, "four-inhand." They have also been tried for coaching work in South Africa, and, though they were rather ready to bite at first, they pulled willingly enough. It was found, however, that they had not sufficient strength to bear continuous heavy work. Of course their great recommendation was their natural immunity from the diseases to which Horses are so liable in Africa, especially that communicated by the Tsetse-fly (Glossina morsitans). Hopes were entertained that mules between this Zebra and the Horse might share this desirable quality, but on experiment it was found that this was not the case. These Zebra-Horse hybrids, by the way, favour the Horse in colour, but show indistinct stripes, which in pattern more resemble those of Grévy's Zebra than those of the present species.

Burchell's Zebra is the only species commonly seen in menageries nowadays; it lives and breeds well in captivity, and it is to be hoped that more attempts to domesticate and work it in its native country will be made, for complete success can hardly be expected at first, and the ultimate utility of the animal would be very great, the provision of transport animals being one of the greatest difficulties in the opening-up of Africa.

\section{THE' MOUNTAIN ZEBRA}

(Equus zebra)

THIS is the animal which used to be called the Common Zebra, as it was at first the best known in Europe; but it is now nearly extinct, being reduced to one or two herds in the mountains of the Cape, and also occurring in Angola. It is smaller than Burchell's Zebra, and more closely resembles the Ass, especi- 
ally in its long ears. Its stripes are bold, on a cream-coloured ground, with no shadow-stripes, and run down to the hoof; on the quarters; above the base of the tail, they form a characteristic "gridiron pattern" of short cross-bars meeting a central band. A small dewlap on the middle of the neck is also a characteristic of this animal.

\section{GRÉVY'S ZEBRA}

\section{(Equus grevyi)}

THrs beautiful animal, the largest and finest of all wild animals of the Horse family, was only made known to modern science in 1882 , although from the fact that it inhabits countries near the seats of ancient civilisation, being found in Abyssinia and Somaliland, it was no doubt the animal known to the ancients as "Tiger-Horse" (hippotigris). In size it equals a rather small Horse, with a particularly large but beautifully-formed head and ears. The stripes are very narrow, numerous, and closely placed, black on a pure white ground, and the barrel-stripes do not curve backwards across the quarters as in the other Zebras, both body and hind-quarters being covered with stripes running upwards almost directly. This splendid animal has of late years been represented in the London Zoological Gardens, and while the present work was being written a foal was born there.

\section{THE ASS}

\section{(Equus asinus)}

THE wild ancestor of our humble coster's drudge still exists in North-East Africa, and the typical race exactly. resembles in colour a common grey Donkey, with the same characteristic cross on the withers, caused by the back-stripe intersecting with a shoulder-stripe. In Somaliland, however, there is a race on which these stripes are absent, while the bars on the legs, which may often be seen in tame Donkeys, are very well developed and distinct.

The wild Ass is bigger than the ordinary Donkeys one sees, though not larger than the fine breeds kept for riding in parts of the East and for Mule-breeding in Europe, and it has the beauty, sleekness, and agility of the Zebra, though the characteristic length of ears is always noticeable. The degeneracy of the Ass in captivity is simply due to neglect, the existence of fine large domestic breeds showing that fine Asses may be had if due attention is paid to their treatment and selection. But neither the Ass itself, nor its hybrid offspring with the Horse, the Mule, is much thought of in England, where there is ample facility 
for maintaining Horses, the chief advantages of the Ass and Mule being their ability to work hard with poor food and little attention.

\section{THE KIANG}

(Equus hemionus)

THE Kiang of Tibet is the most Horse-like of the relatives of the true Horse. It equals a small Horse in size, and has a more Horse-like head and shorter ears than any of the other Ass-like species, while the tail is not so closely haired at the base. Indeed, some writers speak of the animal as a wild Horse. It has not, however, the "chestnuts" on the hind-legs, and on the whole is more Ass than Horse. In colour it is chestnut, with the muzzle, legs, and under-parts white; and a dark streak down the back continuous with the chocolate-coloured mane. Inhabiting the cold Tibetan plateau, it grows a thick woolly coat in winter. Sportsmen rather dislike this beast, as they do not want to shoot Donkeys, and the inquisitive Kiang will insist on interfering with their stalking by galloping noisily about and disturbing the game.

The Chigetai of Mongolia is apparently only a local race, allied to this animal, but the Onager ( $E$. hemionus onager), which ranges from Arabia to NorthWest India, where it is called the Ghorhkur, is by some naturalists regarded as distinct: at any rate, it is more Donkey-like than the Kiang, being smaller, with longer ears, and lighter in colour. All these Asiatic wild Asses are very swift, and have never been domesticated, though specimens of all have been exhibited in Europe at our Zoological Gardens.

\section{THE WILD HORSE \\ (Equus caballus prezevalskii)}

IT is now pretty generally agreed that the wild form of our Horses is the so-called Prezevalsky's Horse of Mongolia, which is a wild Pony, heavy-headed, hog-maned, and switch-tailed, with a colour often seen in heavy working Horses here, a yellowish or reddish brown on the body, with the muzzle, backs of the legs, and belly shading to white, and the mane, long hair of the tail, and fronts of the legs black. Specimens of this animal have been brought to England of recent years, and the Duke of Bedford has a herd at Woburn Abbey. The wild Horses found in America and Australia are not natives of those countries, but are the descendants of tame Horses which have gained their liberty since the days of European colonisation. 


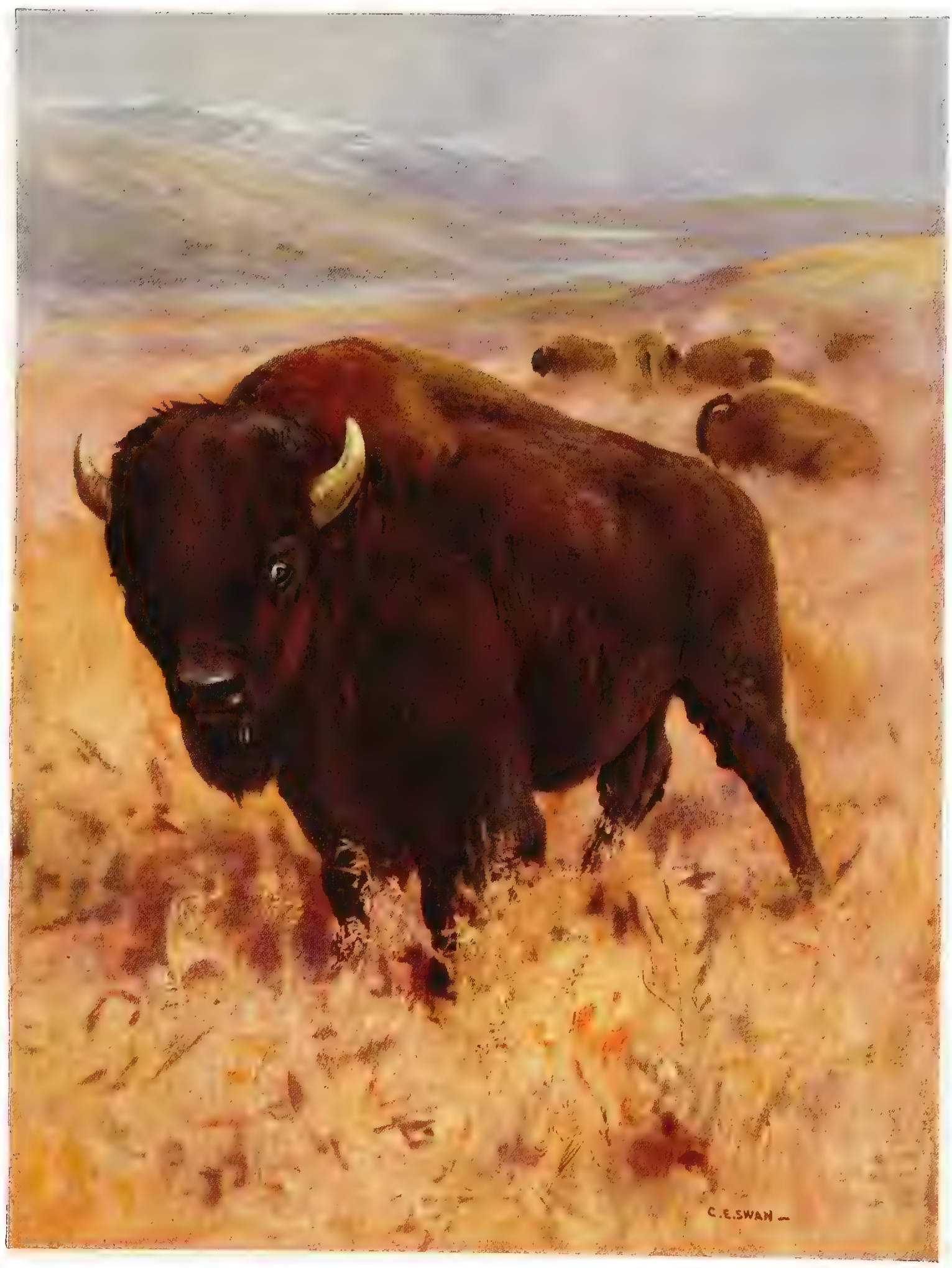

AMERICAN BISON

By C. E. Swan 



\section{THE AMERICAN BISON}

(Bison americanus)

Whether we consider its extraordinary appearance, or the tragic contrast of its former excessive abundance and its so very recent and almost complete extermination at the hands of man, the "Buffalo" of schoolboy stories of adventure is one of the most interesting of the wild animals of the $\mathrm{Ox}$ tribe.

In build it is distinct from any of them, being so heavy and shaggy before, with the hind-quarters comparatively weak, and the tail decidedly short, while the head owes its imposing appearance to the heavy crop of hair and beard, the horns being proportionately shorter than in any of the other Oxen. A large bull will stand nearly six feet at the peculiarly high withers; the cow is of course smaller and not so heavily formed. The young calf is bright red-brown in colour, very different from the dark coats of its parents, and, being straight-backed, with no sign of the heavy mane, would not easily be recognised as a young Bison at all by any one unacquainted with it.

In summer the Bison sheds its long winter coat, and for some time is almost bare, and presents a most disreputable appearance.

This animal was formerly one of the characteristic features of the landscape over a large portion of North America, and existed in larger numbers than any other beast of equal size anywhere, ranging from the Great Slave Lake to Mexico. It was, however, in the great plains of the West that it was especially at home, and it is usually spoken of as a prairie animal, although there was also a woodland race, to which most of the survivors belong.

Bison are essentially gregarious, and were also to a certain extent migratory, as such large numbers of animals of their size naturally exhausted the pasture in one locality. They were noted for their extreme stupidity and persistency in following any particular course, and in this way many members of a great herd, or even whole herds, 
used to perish at times in boggy places, or in crosising rivers on thin ice, as those behind would push on to destruction their unfortunate predecessors.

Like so many large animals, they like wallowing, and in default of ponds or rivers, would make mud-holes in soft ground, which hollows have remained as some of the signs of the animal's previous occupation of land where they have long since vanished.

For such heavy animals they are remarkably active; and were of course dangerous to hunters when hard pressed, though not nearly as much so as the true Buffaloes of India and Africa. Their natural enemies were chiefly the Wolves, which attacked calves and weakly adults, and sometimes the Grizzly Bear. The Red Indians regularly hunted them for the flesh and skin, and indeed chiefly subsisted on them in many places; but it is to white men that the almost complete extermination of this fine animal is due. The completion of the Union Pacific Railway in 1869 seems to have given the deathblow to the Bison, splitting the great central herd of millions of animals, which still remained after all the encroachments of civilisation, into two parts, of which both the northern and southern sections had practically ceased to exist by 1890 . The cause of the persecution was chiefly the demand for the hides, or " robes," but the beasts were actually shot down merely for their tongues in some cases.

In various places in North America, and especially in British territory, a few hundred Bison are still preserved, which, if carefully guarded, ought to be sufficient to perpetuate the race, while they are well represented in European Zoological Gardens, in which they breed freely enough. In captivity Bison are formidable from their great strength, and, though they have been trained to the yoke, and, by this quality, are good draught animals, they are very difficult to control if excited. Thus, if they are thirsty and come to water, it is impossible to keep them from rushing headlong to it. As they have so good a coat, and are very hardy, bearing the terrible blizzards of the plains, and scraping away the snow to find food, they have been crossed with domestic cattle to improve the latter in these respects. These "Cataloes," as the hybrids are called, can only be bred from the Bison bull and tame Cow, not vice versâ, and, in spite of the great distinctness of the parent stocks, they are fertile. 


\section{THE EUROPEAN BISON-THE GAUR}

\section{THE EUROPEAN BISON}

(Bison bonasus)

THE European Bison, although a slightly larger animal, is less remarkable in appearance than the American species, although its close relationship is obvious at a glance. It is, however, less heavy in front, and has a less copious growth of mane there, and, in fact, approximates more to the ordinary $\mathrm{Ox}$ in appearance.

It is a forest animal, and has long existed only in small numbers in two localities, the forest of Bielowicza in Lithuania, and in the Caucasus, though in ancient times widely distributed in Europe. The few hundreds in existence are protected by the Russian Government. This Bison is much rarer in captivity than the American species, and seems to be a less free breeder in that condition. It is often called the Aurochs, but incorrectly, this being the German name of the Urus, or wild ancestor of our domestic cattle, an animal now entirely extinct.

\section{THE YAK}

(Poephagus grunniens)

THE Yak is a large but short-legged wild $O x$, with large spreading horns much like those of many domestic cattle, and a heavy fringe or flounce of long hair covering the flanks and bases of the limbs; the tail also is bushy, like a Horse's. The colour is a brownish black in the wild race, which is only found in the Tibetan highlands and the countries adjoining. In these regions, however, tame Yaks are largely kept, and are, indeed, the chief cattle employed by the natives. They are smaller than the wild ones, and often white or pied, and sometimes hornless; and it is these that are seen in European Zoological Gardens. Yaks are hardy animals and good climbers; they can bear any amount of cold, but are very sensitive to heat. Their voice is a grunt, very unlike the bellow of most of the $\mathrm{Ox}$ kind.

\section{THE GAUR}

\section{(Bibos gaurus)}

THE Gaur is the characteristic wild $O x$ of India, and also extends east to Malacca; it is often miscalled Bison by sportsmen in India. It is smooth-coated, unlike the true Bison, but also very high in the withers, with good-sized, well-curved horns. The coat is black, with the legs white, in adults; but calves are chestnut. The bull is a huge animal, being usually six feet at the withers, and has even been known to reach eight. $\mathrm{He}$ is, however, far less savage than wild Oxen generally, 
and, though a delicate animal in captivity, seems to be the ancestor of the semidomesticated cattle called Gayals kept by the native hill-tribes in Assam and Tenasserim. These, like most domestic animals, are often more or less pied, and are not rare in menageries.

\section{THE BANTENG}

\section{(Bibos sondaicus)}

THE Banteng is more like some domestic cattle than any of the preceding, being nearly straight-backed; it is short-coated and white-stockinged like the Gaur, but also has a white patch on the stern, and the cows as well as the calves are chestnut, as are the bulls in Burma, where the animal is known as Tsine. In the typical race of the Banteng, however, from Malacca east to Borneo, the old bulls are black, contrasting beautifully with their mates. This is an animal of the grass-plains, while the Gaur frequents hill-forests; it is domesticated in Java and Bali. Notwithstanding this, it is a rare animal in zoological collections, and even in museums, though at the time of writing there is a male of a tame strain in the London Zoological Gardens.

\section{THE WILD OX}

(Bos taurus)

As this animal, the Urus of Roman writers, still survives in the persons of its numerous tame descendants, it needs mention here, though it has been extinct since the seventeenth century, having formerly shared the European forests with the Bison. It seems to have been black or brown in colour, and to have resembled in form the white "wild" cattle still preserved in some British parks-which, by the way, still sometimes produce black calves. Its size, however, was much larger than that of any modern breed, and it is believed to have reached a couple of yards at the shoulder. Julius Cæsar says it was little smaller than an Elephant.

Cattle which have run wild in modern times from undoubtedly tame stock are found in many parts of the world, notably in America and Australasia, and are fierce and dangerous to a degree.

The humped tame cattle of India and most of Africa-the so-called Zebus (Bos indicus) have apparently descended from a perfectly distinct animal than the Urus, but one which became extinct so long ago as to leave no record in history. They differ from our breeds in their shorter body and higher legs, differently shaped and set horns, their rarely heard grunting voice, and their gentle disposition, and usually in their different colouration, most usually irongrey. Some have run wild in India. 


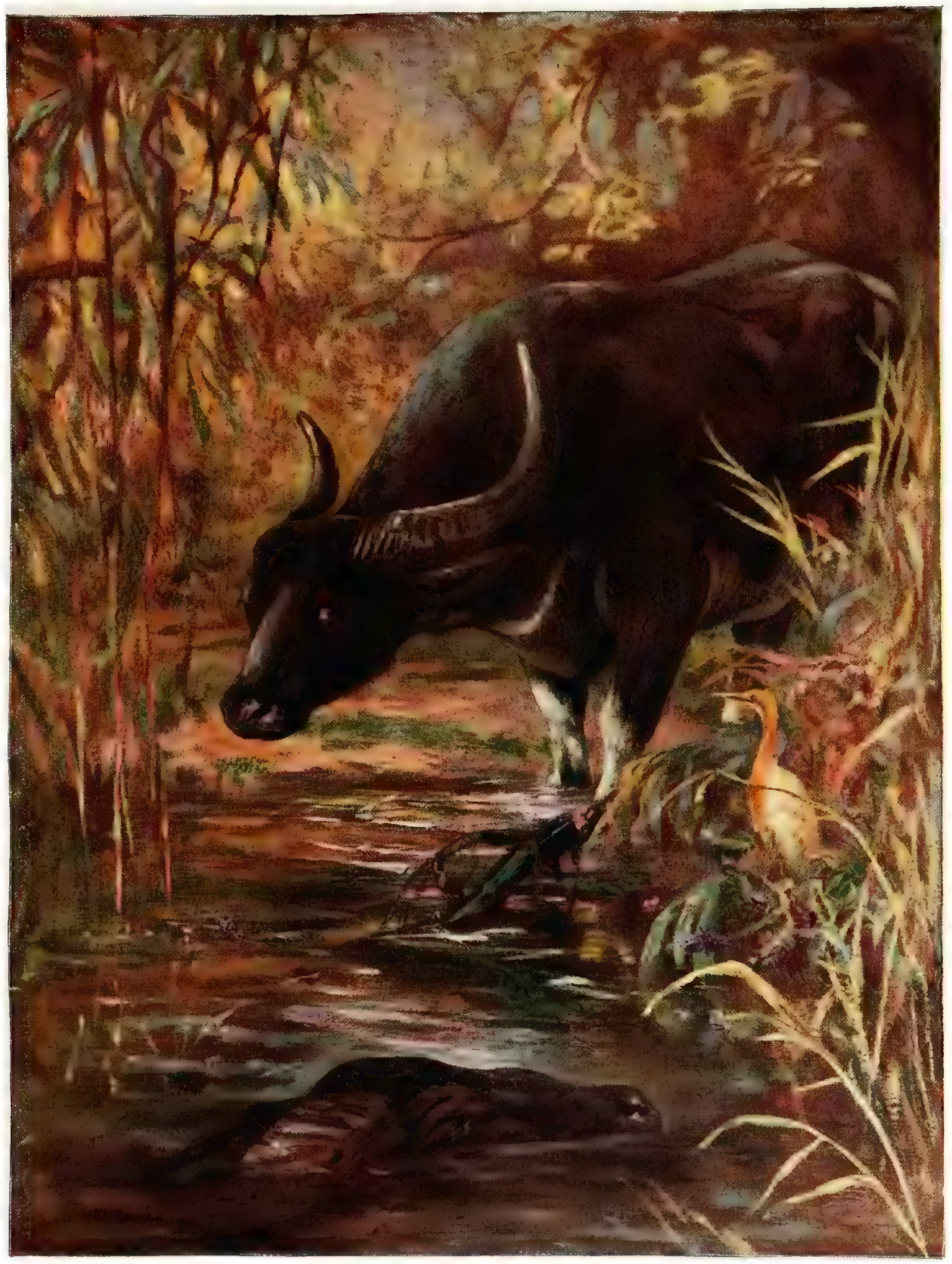

INDIAN BUFFALOES

By C. E. Swan 



\section{THE INDIAN BUFFALO}

(Bos bubalus)

THE Water-Buffalo, as this animal is often called-and very appropriately, for it is nearly as aquatic as the Hippopotamus-is equal to any of the Ox tribe in size, though it does not stand very high at the shoulder, owing to its comparatively short legs; as the illustration shows, it is a very different animal in every way from the well-known American one which so often usurps its name.

The feet of the Water-Buffalo have large broad hoofs, adapted for progress in marshy localities; its hide is very thinly covered with hair, the dark skin being visible through the scanty black crop, but the ears have a slight fringe, and the tail the usual bovine tassel at the tip. Many Buffaloes have white "stockings," but this is not universal; in Assam there is, or used to be, a dun-coloured local race. These Buffaloes also differ much in the length, and to a certain extent in the form, of their horns; though these always agree in being set well apart on the forehead, in inclining backward, and being triangular in section. Some, however, are much longer and less curved than others, and those of the cow are longer and slenderer than those of the bull; good horns may be as much as six feet each, or even more, in length.

In its movements the Indian Buffalo is usually slow, like most marsh-loving animals, but is capable of being violently energetic on occásion; it is naturally, however, an ease-loving creature, delighting to wallow in water or mud, in which it immerses itself to the eyes and ears. It swims well, and when walking, as when swimming, carries the nose high, so that it is on a level with the back. Its food is the coarse vegetation of the marshes it frequents, so that its wants are simple, and it needs fear no enemies except the Tiger, which, however, is hardly a match for the old bull. Perhaps because of being 
so immune from attack, however, the Indian Buffalo is an aggressive and dangerous animal-the old solitary bulls, which will attack man unprovoked, being almost, if not quite, the most savage of all wild things. A herd, however, is far less ready to act on the "offensive. The attack of an old "Urna," as the wild Buffalo is called in India, is all the more dangerous because the beast has cunning as well as courage, and chooses a favourable moment to make his attack, while the rush-jungles he frequents are most unfavourable ground for his human adversary.

The natural home of the Water-Buffalo is India and Ceylon, but, as it has long been domesticated, it has been carried to many other parts of the world, and is kept in warm climates throughout Asia, in Egypt, and even in Italy and Hungary. In Northern Australia it has been introduced, but allowed to run wild again, and is now hunted for its hide. Tame Buffaloes are useful for their great strength, especially in soft marshy country, and for their power of thriving on coarse food; the cows also are good milkers, but the beef is not esteemed. They retain all their hatred for the Tiger when in a tame condition, and a well-known plan among Indian sportsmen, when a wounded Tiger has taken cover, is to drive in a herd of Buffaloes, who will to a certainty expel or kill him. Although dangerous to strangers, tame Buffaloes are very gentle with their owners, and may be seen controlled by tiny naked native children. In colour the tame Buffalo varies little more than the wild one-it is all black, white-stockinged, or dun; but sometimes it is white-haired, with a flesh-coloured skin, like a white domestic Pig.

Curiously enough, although constantly kept alongside of the humped Indian cattle, it appears never to interbreed with these animals. That it should do so with its wild relatives, when near the marshy haunts of these, is natural; and many tame Buffaloes have wild blood in their veins, for a wild bull will often come out of the marsh and assume the leadership of a herd of tame cows, whose services the unfortunate owner has to dispense with until the bull has tired of their company. Tame Buffaloes, as a general rule, are 


\section{THE AFRICAN BUFFALO}

smaller and scraggier than wild ones; they do best in low wet districts, where they can wallow freely, but are also kept even in the mountains. In Calcutta they are commonly seen working in the streets, being put to pull heavy carts, such as dray-horses-unknown in the East-would be used for here.

\section{THE AFRICAN BUFFALO}

\section{(Bubalus caffer)}

THE Buffalo of Africa differs strikingly from the Indian one in several particulars; with the same general form and black colour, it is higher on the legs, and has very hairy ears and different horns, shorter than those of the Indian species, and immensely expanded at their bases, which in old bulls actually meet on the forehead, producing an impenetrable horny shield. At least, this is the case with the large South African form, the typical Cape Buffalo; but the species ranges over Africa generally, south of the Sahara, and several of its local races depart somewhat from the type. Those of Eastern Africa are brown instead of black, and show some transition to the Dwarf Buffalo or Bush-Cow of West Africa (Bubalus nanus), which is a short-horned tawny animal, only about as big as a Jersey Cow, and is often ranked as a distinct species.

These African Buffaloes are gregarious, like the Indian species, but are not so fond of water. They are all very dangerous when attacked, and many accidents have happened to hunters engaged in their pursuit. Their chief wild enemy is the Lion, but even he has to use discretion in his attacks.

Worse, however, than any natural enemy, and even than the wasteful destructiveness of man, have been the ravages of rinderpest among these animals, which in certain parts of East Africa have become almost extinct, owing to contracting this disease from the tame cattle of the natives. The African Buffalo itself has never been domesticated, but is sometimes to be seen in Zoological Gardens. 


\section{THE TAMARAO}

(Bubalus mindorensis)

The Tamarao is the wild Buffalo of the Philippines, and is an ugly, thick-set, short-horned animal, black in colour, and of about the size of a little Kerry bull. It is, however, a dangerous creature, and is dreaded both by the natives, and also by tame Buffaloes which have run wild in its territory, these animals being widely kept in the East Indies, and readily reverting to the wild state.

\section{THE A NOA}

(Anoa depressicornis)

Although Buffaloes and Antelopes both belong to the same family of hollow-horned ruminants, they present a very great contrast in appearance as a rule; yet, just as there are Ox-like Antelopes, such as the Eland and Gnu, so in the Anoa we have a Buffalo which makes a decided approach to the Antelopes. The animal, which is only found in Celebes, is very small for a Buffalo, being indeed the smallest of the wild Oxen, and not as large as our smallest domestic cattle.

In general form it resembles the Indian Buffalo, but its limbs, head, and neck have a delicate and refined appearance, much like those of Antelopes, and its horns, which are about a foot long in the bull, are perfectly straight and smooth; they are directed straight backwards, and in the cow are very small.

The coat is scanty as in the large Buffaloes; in adults the colour is black, but the calves, which have a thick, almost furry coat, are light brown in colour. Adults are sometimes marked with white on the face, eyes, and back, somewhat as in certain Antelopes. This is a scarce animal in captivity, but has been occasionally exhibited here. 


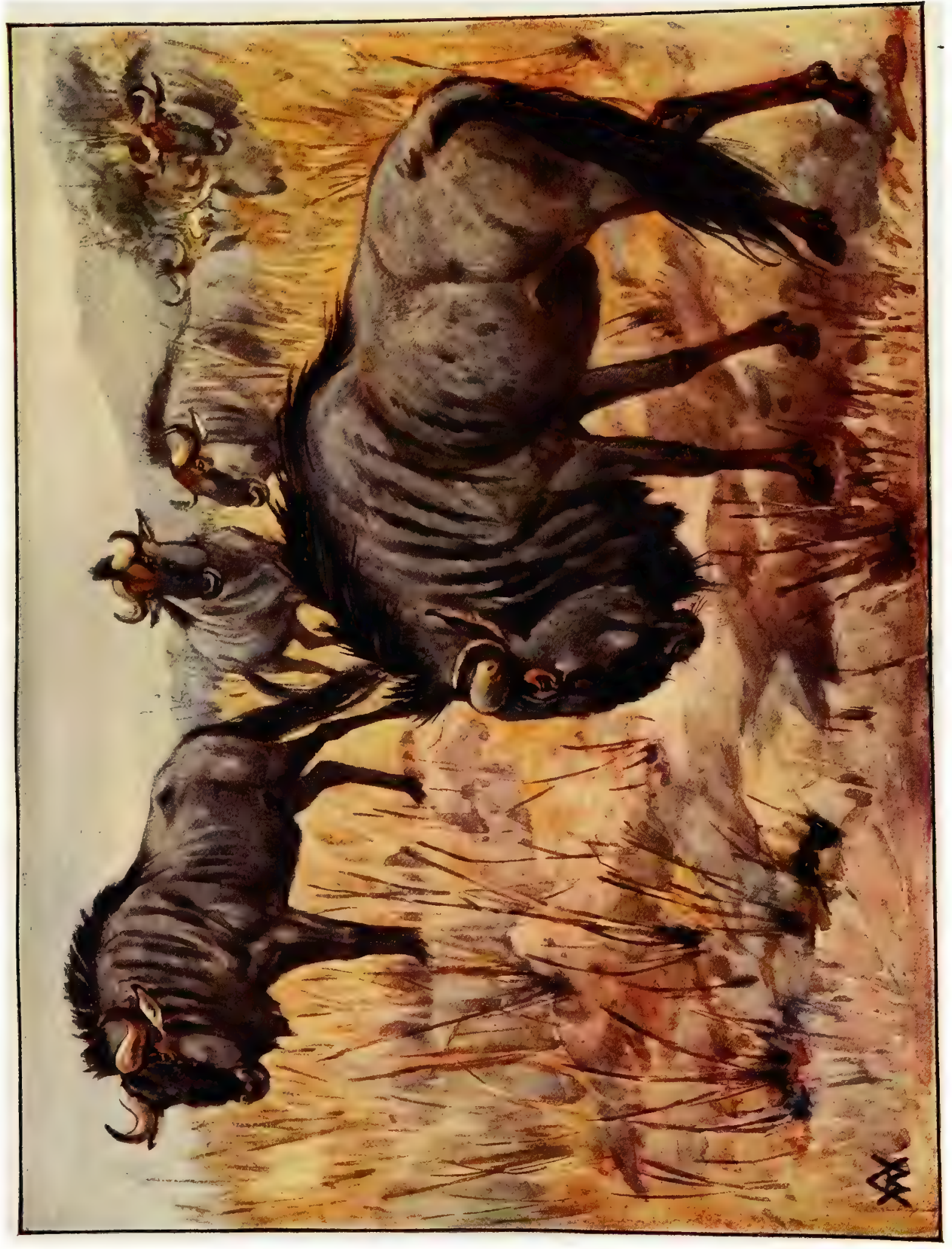





\section{THE BLACK-TAILED GNU}

(Connochates taurinus)

THE family of Oxen (Bovida) contains not only those animals, but all other ruminants with the same type of horns-hollow ones, permanently seated on bony cores, also permanently affixed to the skull. Such are the Sheep and Goats, and the numerous tribe of Antelopes, which make up most of the family, but are confined to the Old World, and chiefly to Africa

"Antelope" is used as the proverbial simile for light and elegant gracefulness; but there are Antelopes of many different shapes, and our present subject, one of the best known of African Antelopes, cannot be called elegant by any stretch of imagination, and does not at all accord with the popular notion of an Antelope, while it does suggest such incongruous animals as a Bull and a Pony, the latter of which it about equals in size.

The usual colour of the coat is, as the illustration shows, a bluish grey, slightly brindled with black, whence the name Brindled Gnu, often used; but there is a certain amount of local variation, and two races of the species are distinguished besides the typical South African one-the White-bearded Gnu from East Africa, in which the long hair under the chin is white instead of black, and the Nyasaland race, in which the beard is black as in the typical form, but there is a white crescent across the face, which is much smoother and less shaggy than in the other races.

The sexes are much alike in general appearance, and both are horned, though the bull is heavier. The calf's horns at their first appearance are straight spikes set some distance apart, and only acquire their peculiar and characteristic curvature as they grow.

The Black-tailed Gnu, commonly known to hunters as the Blue Wildebeest, is a widely ranging animal in Africa, the typical form reaching Benguela on the West Coast, and Lake Nyasa in Central Africa, while it is particularly common in the south-east part of the 
Continent. It frequents dry open plains and thin bush, but not absolutely waterless districts, as, unlike so many Antelopes, it likes an occasional drink.

It is very gregarious, being usually found in herds containing one to several score; at some seasons the bulls associate apart from the cows and young. A lone bull will often be found associating with other Antelopes, and the herds are often in company with Burchell's Zebras.

Black-tailed Gnus are quarrelsome and excitable animals, and their antics, prancing and whisking their long black tails, are very characteristic. They are wary and hard to approach, and, if wounded, are remarkable for their extraordinary tenacity of life and power of travelling under injuries-even a broken limb will not disable them. It may be truly said of Antelopes that "they run in all shapes"; for the heavy-headed, awkward-looking Gnu is really one of the swiftest and most enduring animals in existence, and even when severely wounded is often too much for a horseman.

When brought to bay he is dangerous, and will charge savagely. Except for a trophy, he is not much good when brought to book, the venison he furnishes being of very inferior quality from a European point of view.

These Gnus do well in captivity, and may generally be seen at the London Zoological Gardens, where they have bred; they are, however, dangerous animals to deal with.

\section{THE WHITE-TAILED GNU \\ (Connochates gnu)}

THIS is the real original Gnu-the name being a Hottentot one-but it is very rare nowadays-almost extinct, in fact. It shows an exaggeration of the peculiarities of the Brindled species; its horns are more sharply bent down and abruptly turned up, showing a very decided "pot-hook" shape; its neck is arched, and decorated by a stiff erect mane, and its tail is particularly bushy and horse-like. As the name of the species implies, the tail is white, the mane is also white at the roots, though dark at the tips. The general colour of 
the coat is brown, so dark that the animal is commonly known in Africa as the Black Wildebeest. The muzzle is sprinkled with long white hairs, and a few of these surround the eyes.

In disposition and habits, as in appearance, this animal exaggerates the peculiarities of the Brindled Gnu, being much fiercer, and more excitable and given to cutting capers than that animal. It was formerly -about half-a-century ago-a very abundant animal in South Africa, ranging to the southward of the habitat of the Blue Wildebeest, and frequenting the "Karroo" districts. It frequently associated with the Quagga, just as its relative still does with Burchell's Zebra, but the same fate of extinction by man's persecution that has befallen its equine companion, has nearly overtaken the White-tailed Gnu also, and now two or three herds, preserved on Boer farms, are all that represent this remarkable creature in a wild condition nowadays.

Fortunately the White-tailed Gnu does well in captivity out of its native land, and has long been well known in menageries; it has bred freely in our Zoological Gardens, and specimens of both this and the other species were on view there at the time of writing.

\section{THE HARTEBEESTS}

Allied to the Gnus or Wildebeests are the Hartebeests (Bubalis), a group of Antelopes also of very peculiar form, though less odd in aspect than the former, having none of the heavy Buffalo-like appearance about the head, nor the Horse-like tail, although that appendage is of fair length and well-haired. Their chief peculiarities, indeed, are the very marked slope of the back towards the hind-quarters, and the long miserable-looking face, with the eyes set near the top of the head, which is crowned by a pair of strongly-ringed horns of only moderate length, but with a more or less well-marked double curve, very angular in some species. Both sexes are horned, and look much alike.

Hartebeests are about as big as a Donkey, and range from fawn to bay in colour, sometimes varied with black on the face and legs. Except for details in the shape of the horns, they are much alike and easily recognisable. There are eight species, all purely African, except one ( $B$. boselaphus) which ranges into Arabia and even the borders 
of Palestine, and they frequent dry open country in herds, and have great speed. Their venison is usually very good.

\section{THE SASSABY}

(Damaliscus lunatus)

THE Sassaby represents a group known as Bastard Hartebeests, which show the peculiarities of those animals in a slightly less marked form, the face being shorter and the horns less angulated. In colour it resembles some of the typical Hartebeests, being a rich red-brown, with a purple gloss; its horns are rather over a foot long, and present in both sexes, as in all this group. It is a South African species, and celebrated for its speed and endurance, although it is doubtful if in these respects it much exceeds the Blue Wildebeest and one or two of the true Hartebeests; but it is at any rate so fast that hunters do not like to risk injuring their Horses by hunting it to no purpose. It has never been exhibited at our Zoological Gardens.

\section{THE BLESBOK AND BONTEBOK}

(Damaliscus albifrons and D. pygargus)

THESe Antelopes, also close allies of the Hartebeests, are both South African, and, being much alike, have even sometimes been confused together. Both are rather above a yard at the shoulder, of a brown colour, with a beautiful lilac or violet gloss in life, and with a white face and more or less white legs. The Bontebok is the gayer of the two, having a white patch on the stern and the legs all white; its horns also are black, those of the Blesbok being pale.

They are both South African species, but did not occur together, the Bontebok having been confined to the south of the Orange River. It is now nearly extinct, being only found in a protected state on one or two farms, while the Blesbok, which used to be excessively abundant, is now fast approaching the condition in which it will be absolutely dependent on protection for its existence as a species, having been recklessly shot down by hide-hunters. Both species have been exhibited in the Zoological Society's Gardens. 


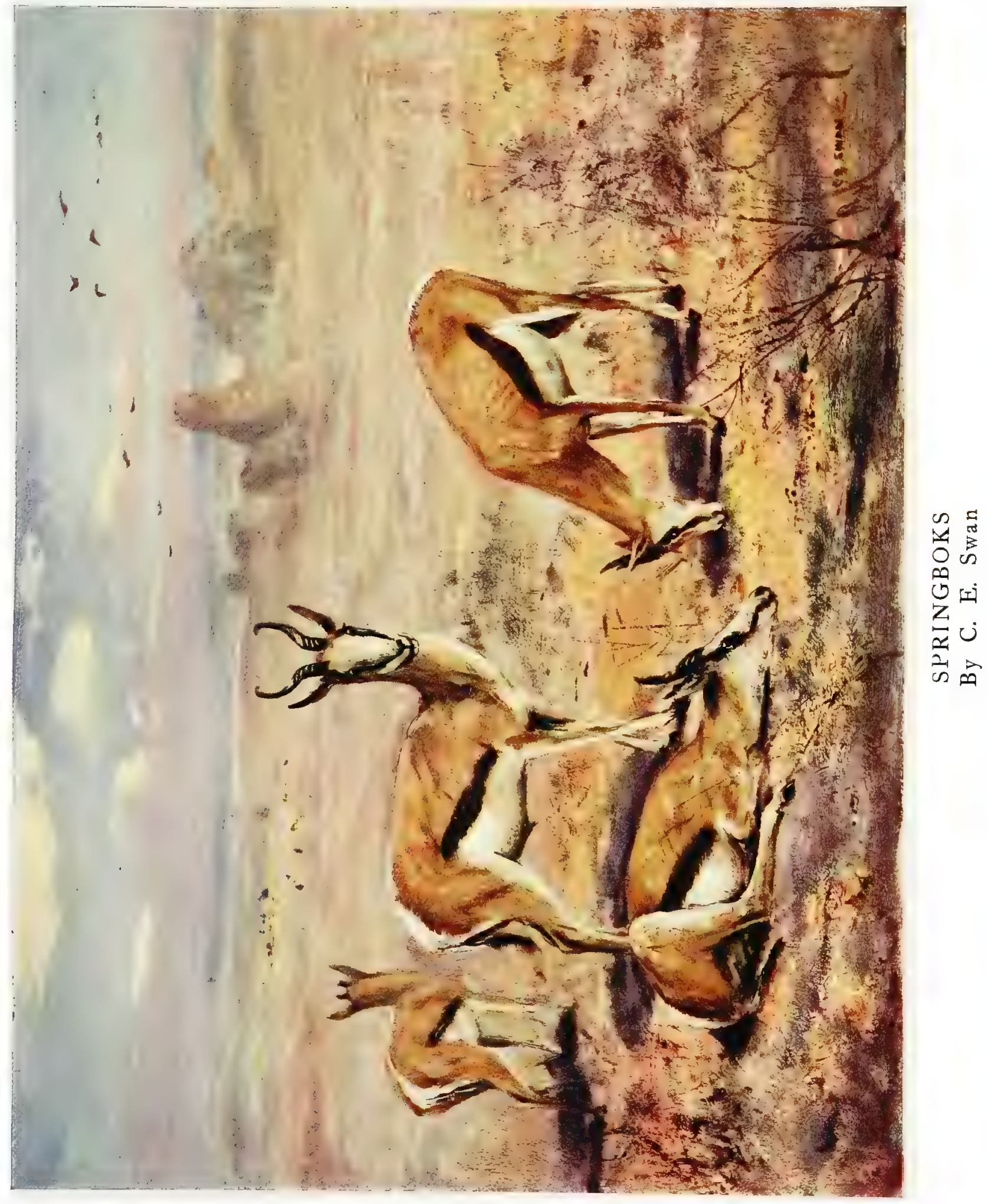





\section{THE SPRINGBOK}

\section{(Gazella euchore)}

THE Gazelles and their allies form a numerous group of Antelopes in which, as a rule, the delicacy and grace which one usually associates with these animals reach their most typical development; and the Springbok of South Africa is the most notable of all for its rich colouration and peculiar habits, to say nothing of its familiarity as the commonest of South African Antelopes, which has led to its name being a household word as the title of the well-known Colonial football team.

The most noteworthy point about the Springbok is the peculiar fold of skin along the hinder part of the back, lined with white hairs five or six inches long. In the ordinary way one only notices a white streak along the hind-quarters, but when excited the animal expands this fold, making a startling display of a great white fan of fur; at the same time it springs perpendicularly into the air for a height of three or four yards, an action it repeats again and again. This is called "pronking" by the Boers, and such a striking habit has of course always called attention to this pretty creature. Like most Gazelles, the Springbok is not a large animal, being of the size of an ordinary Goat-about two and a half feet at the shoulder. The buck's horns are usually about fifteen. inches measured along the curves, but may occasionally be more; the doe's are not so large. Young ones are at first of a duller colour than the parents, being yellowish grey with the side stripes indistinct.

The home of the Springbok is Africa south of the Zambesi, but it ranges up to Mossamedes on the West Coast. It frequents, like Gazelles in general, dry open country, and is very gregarious and migratory, "trekking" at times in large herds, though the enormous masses which were the wonder of travellers half-a-century ago are hardly any longer to be seen. These hosts of Springbok, deserting in their countless thousands the barren haunts where subsistence had failed them, used to swarm down into the cultivated lands, devouring 
all vegetation before them like locusts. So huge were their numbers that the rear-guard of the great herd were always in a famishing state; while tales are told of the Lion himself being carried away in the midst of the troop, unable to do more than keep a clear space among his unwilling escort, and of Sheep and shepherds, caught by the "trek-bokken" in narrow passes where there was no escape, and trampled to death. It is doubtful if any animal of the size has ever been so abundant; now matters are so changed that the creature, once so serious a pest, receives protection, for in moderation it is a very desirable animal. In addition to its great activity, it is very swift, being usually too much for a Greyhound; and it also has sufficient courage to turn and fight the Dog when by chance it is overtaken. A great many are, of course, shot, though not without careful stalking, and the venison, which is very good, is regularly on sale at Cape Town when in season, and has even been offered on the London markets, having been brought over in cold storage.

The Springbok is not unfamiliar in captivity, and has bred in the Cologne Zoological Gardens, but it is not a very hardy animal, and probably requires more space for exercise than it usually gets.

Except that none of them have the peculiar "fan" of the Springbok, and that their colours are generally less rich, the rest of the Gazelles, which number about two dozen species, are fairly well typified by that animal. Their range is very wide, including all of the open parts of Africa-though there are no others but the Springbok south of the Zambesi-and extending into Asia as far as India and even Tibet. The animal known in the Authorised Version of the Bible as "Roe" is really one of the Gazelles (Gazella dorcas). In a few Gazelles, it should be noted, the does are hornless, but usually they have small horns. Two or three abnormal types of Gazelle deserve notice here on account of their peculiarities.

\section{THE DIBATAG}

(Ammodorcas clarkei)

THIS is a very slender, long-necked, graceful Gazelle, confined to East Central Somaliland. The tail is long and slender, and there are no horns in the female. When on the move this animal endeavours to make both ends meet by carrying 
the head back and the tail curved forward, giving a very curious effect. It is chiefly a browser, and seems independent of water.

\section{THE GERENOOK}

(Lithocranius walleri)

THE Gerenook, although it has a rather short tail, like other Gazelles, exaggerates the peculiarities of the Dibatag; indeed, its neck and legs are so long that it can justly be called a Gazelle modelled on the lines of a Giraffe. It inhabits Somaliland, but is also found outside it, ranging to the Kilimanjaro district. Like the Dibatag, it browses much, as one would expect from its form. In height the male is more than a yard at the shoulder; the female is hornless.

\section{THE BEIR A}

\section{(Dorcotragus megalotis)}

THE Beira is a curious little Antelope, mostly grey in colour, and compact in shape, with very large ears, and, in the buck, short straight horns four or five inches long. The animal stands considerably less than two feet at the shoulder. It is only found in Northern Somaliland, where it frequents rocky hills. Neither this Antelope nor the last two have been brought to England alive, apparently.

\section{THE CHIRU}

\section{(Pantholops hodgsoni)}

THIS is an Asiatic Antelope of the Gazelle group, with very long ringed horns in the male, nearly straight and erect; they measure about two feet long, the animal itself being about as big as the Springbok. The female is hornless. The Chiru, which inhabits the bleak Tibetan plateau, has a very thick, close coat, of a fawn colour, the face of the male being black. Its tail is short, as are those of the typical Gazelles inhabiting cold climates. This Antelope is a very fast trotter, and lives in large herds, the bucks fighting savagely for the does. It seems never to have been brought to Europe alive.

\section{THE SAIGA \\ (Saiga tatarica)}

The Saiga is an ugly Sheep-like Antelope, with rather short ringed horns of a curious pale yellowish colour. They are confined to the male, which also has an 
enormous Roman nose, which he wrinkles up to keep it out of the way when he is grazing. The coat is pale sandy, and very close and thick; the size about that of a Sheep. The Saiga is a steppe animal, living in Southern Russia and SouthEast Siberia : it lives in large herds, and is rare in captivity, though our Zoological Society and the Duke of Bedford have possessed specimens.

\section{THE PALLAH \\ (Apyceros melampus)}

ThE Pallah is rather a large Antelope for one of this group, standing about a yard at the shoulder; the doe is hornless, but the buck has very beautiful horns, with a lyre-shaped curve, backwards, outwards, and upwards. They measure about twenty inches in length. The general colour of the coat is bright redbrown. The Pallah is found in south of East Africa, being replaced on the west side by a very nearly allied form, the Angolan Pallah ( $\mathscr{E}$. petersi), which has a black face-streak. The Pallah is a gregarious Antelope, frequenting forest country, and is remarkable for its powers of leaping.

\section{THE BLACKBUCK}

\section{(Antilope cervicapra)}

Although not to be compared in size with many African Antelopes, since it only stands about as high as the Springbok, the Blackbuck, which is confined to India, can vie in beauty with almost any of them. The buck's horns are strongly ringed, and twisted in a close spiral. They are very long for the animal's size, measuring two feet or even more. The doe is usually hornless, but in rare cases bears small smooth curved horns, very unlike those of the buck. Her colour, and that of the young, is a light fawn, white on the underparts ; but the adult buck is, with the exception of the white belly and insides of the legs, nearly all black, giving a striking contrast. In some cases old bucks assume the fawn coat for a time at any rate; this happens in captivity with some individuals, and an old fawn-coloured buck has been observed in the wild state. The Blackbuck is a gregarious animal, and very polygamous, only one old black male being seen with a herd of does and young. It frequents open plains, and sometimes does much harm to crops: its speed is very great-too much for a Greyhound as a rule, though the Cheetah, as remarked in the article on that animal, can surpass it for a short distance. The Blackbuck does well and breeds freely in captivity. 


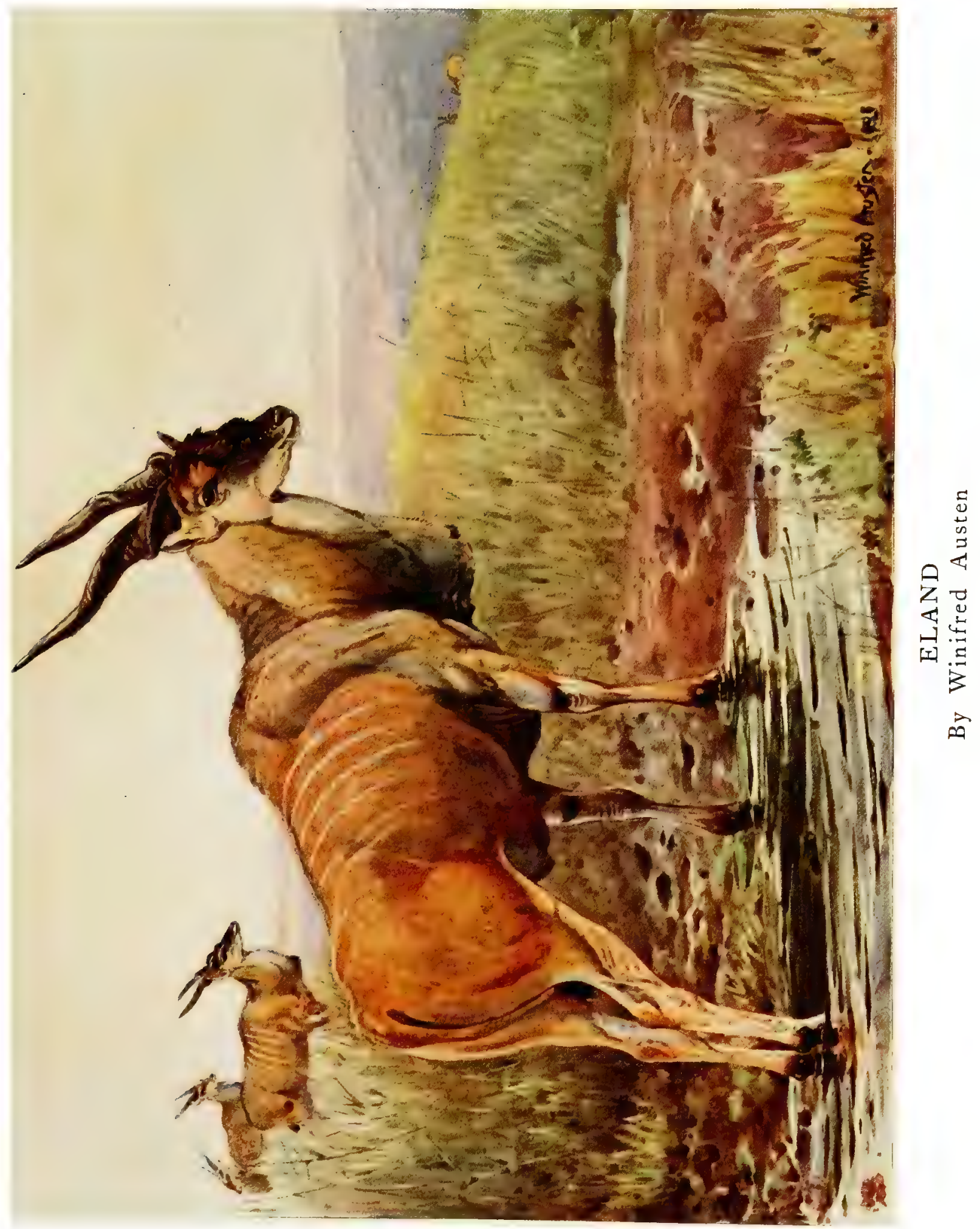





\section{THE BEISA ORYX}

(Oryx beisa)

THIs fine Antelope is one of a small group of large species which have somewhat of the Horse in their proportions and general appearance; indeed, it has been suggested that the legendary Unicorn originated in stories of a one-horned Oryx of some kind, such specimens sometimes occurring. The Beisa is about the size of a small Donkey, and both sexes bear the long lance-like horns, ringed at the base and smooth at the tip. The horns of the female are, however, longer and slenderer than those of the male, and may even exceed a yard in length; those of males seldom much exceeding two and a half feet. Probably as a protection against these terrible weapons in their combats with each other, the skin on the shoulders of the male Beisa is very thick; he is also slightly stouter-necked and taller than the female, but the sexes are not easy to distinguish when a herd is sighted.

Blanford has drawn attention to the pointed triangular shape of the hoof in this Antelope, and says that this form of foot is particularly characteristic of desert-haunting species like these Oryxes and the Gazelles, the more forest-haunting species having rounder feet, like Deer or Cattle.

The Beisa Oryx is a characteristic animal of North-Eastern Africa, from Suakin southward to the Tana River, and is very well known in Somaliland. It frequents dry open country, feeding mostly on grass, though occasionally browsing on acacia shoots; and, though in some localities it drinks regularly, it is often found quite away from any water, and evidently living entirely without it.

It is very elegant in its movements, which are much like those of a Horse; it usually walks or trots, but will gallop if greatly alarmed. When charging, it puts down the head between the fore-legs, so as to bring forward the points of the long horns; it is a fierce animal, and decidedly dangerous when brought to bay.

Though often found solitary, especially in the case of males, the Beisa is usually seen in herds, numbering from half-a-dozen up to forty or more; indeed, there is at least one record of a herd numbering 
as many as five hundred being seen in Somaliland, where this animal is still common, especially in the desert Haud plateau. In a herd, as might be expected, the proportion of males to females is very small.

The chief foes of the Beisa are the Lion, which lives largely on these Antelopes, and man, for they are keenly hunted by the outcast tribe of Somalis called Midgans, to say nothing of European sportsmen.

The Midgans use bows and poisoned arrows, and employ packs of dogs, described as savage yellow pariahs, no doubt similar to the common tan-coloured pariah of Indian towns in appearance, though of higher courage. They need this to be able to attack so strong and fierce an animal as this Antelope, and some of the pack are often injured or killed.

The thick skin of the male Beisa's shoulders is of value to the warlike Somalis for making shields, as it is sometimes about threequarters of an inch thick, and will make a shield stout enough to turn either arrow or spear. The horns are also employed for weapons, and many are brought for sale at Aden. The venison is very good, if the animal is in good case when killed. The Beisa is not an uncommon Antelope in captivity; indeed, it is the only one of the Oryxes which is often met with, and may usually be seen in the London Zoological Gardens, where it has bred on more than one occasion. Of the true Oryxes there are but few species, so all of them may be noticed here in detail.

\section{THE TUFTED ORYX}

(Oryx callotis)

This species is very similar to the Beisa, but the conspicuous tuft at the end of the ears at once distinguishes it from all other Oryxes; it also differs from the Beisa in a few details of colouring, being redder in general tint, with no black patch down the front of the fore-leg below the knee, but with the black cheek-stripe running down from the eye usually much better developed. This species replaces the true Beisa in British East Africa south of the Tana River, and is also found in German East Africa; its general habits seem to be very similar to those of that species, but it frequents open bushy country rather than bare desert plains. 


\section{THE GEMSBOK}

(Oryx gazella)

THE Gemsbok of South Africa, although also very like the Beisa at first sight, is more distinct from that animal than the last species. It has very much more black in its colouration, the streaks down from the eyes and the patch across the muzzle being better developed, while the bases of all the limbs are nearly solid black, and there is a black patch on the hind-quarters just before the tail. Moreover, there is a fringe of long hair on the throat, forming in the male a conspicuous tuft on the middle of the neck. In size this Antelope is rather larger than the Beisa, and its horns, which are similar in form, may reach nearly four feet in length-they are longer in females than in males.

This Oryx is found in the dry regions of South-West Africa, and has been known since Buffon's time; its Boer name supposes a resemblance to the "Gems," or Chamois of Europe, and is as inappropriate as several other titles of comparison bestowed by these Dutch pioneers on the new animals they met with in South Africa. It is now nearly, if not quite, extinct in the Cape Colony itself, although its effigy, along with that of the White-tailed Gnu, figures in the arms of that State.

The Gemsbok is a true desert-animal, being able to exist where there is no water, although it drinks at times, and digs up the bulbs of desert plants with its hoofs, thus obtaining a certain amount of moisture. It is not very gregarious, only a pair or a small family being usually found in company; its speed appears to be only moderate, but it is possessed of great courage-even the Lion, apparently, sometimes falling a victim when he attacks it. Although so long known, it seems never to have been brought to Europe alive.

\section{THE BEATRIX ANTELOPE}

(Oryx beatrix)

IN general form this Antelope, which inhabits Southern Arabia, resembles the Beisa, but is a much smaller animal, measuring less than a yard at the shoulder. Its colour is also very different, being chiefly white, 
with the legs and some patches on the muzzle and cheeks very dark brown, and the tip of the tail black. Several specimens have been exhibited in the London Zoological Gardens.

\section{THE LEUCORYX}

(Oryx leucoryx)

The Leucoryx, which is rather smaller than the Beisa Oryx, is the most distinct of all the Oryxes, owing to its horns having a strong backward crescentic curve, instead of being straight as in the rest; they may exceed a yard in length. The general hue of the animal is cream-colour, darkening into brown on the neck and shoulders; the face-markings-nose-patch and eye-stripes-are brown instead of black. This species is found from Dongola to Senegal, inhabiting deserts in herds; it gets much of its food by browsing on acacia twigs, and the Arabs hunt it on horseback for its flesh, which they esteem highly, and its hide. It is not a very common animal in collections, but has lived and bred in the London Zoological Gardens.

\section{THE ADDAX}

(Addax naso-maculatus)

THE Addax is closely allied to the Oryxes, and similar in general form, but its horns are very different, having a decided spiral twist much like those of the Koodoo, though they are ringed like those of the Oryxes. In the female they are much thinner than in the male, and have the spiral twist less pronounced. A male's horns may measure a yard along the curve. The Addax is rather less than a yard in height at the shoulder; in colour it is a light brown, greyer in winter and redder in summer, with the haunches and all the limbs white, a black patch of long hair on the forehead just below the horns, and below this two white patches, meeting each other across the nose. The Addax has the same range as the Leucoryx, and is also a scarce animal in collections, though our Zoological Society has exhibited it. 


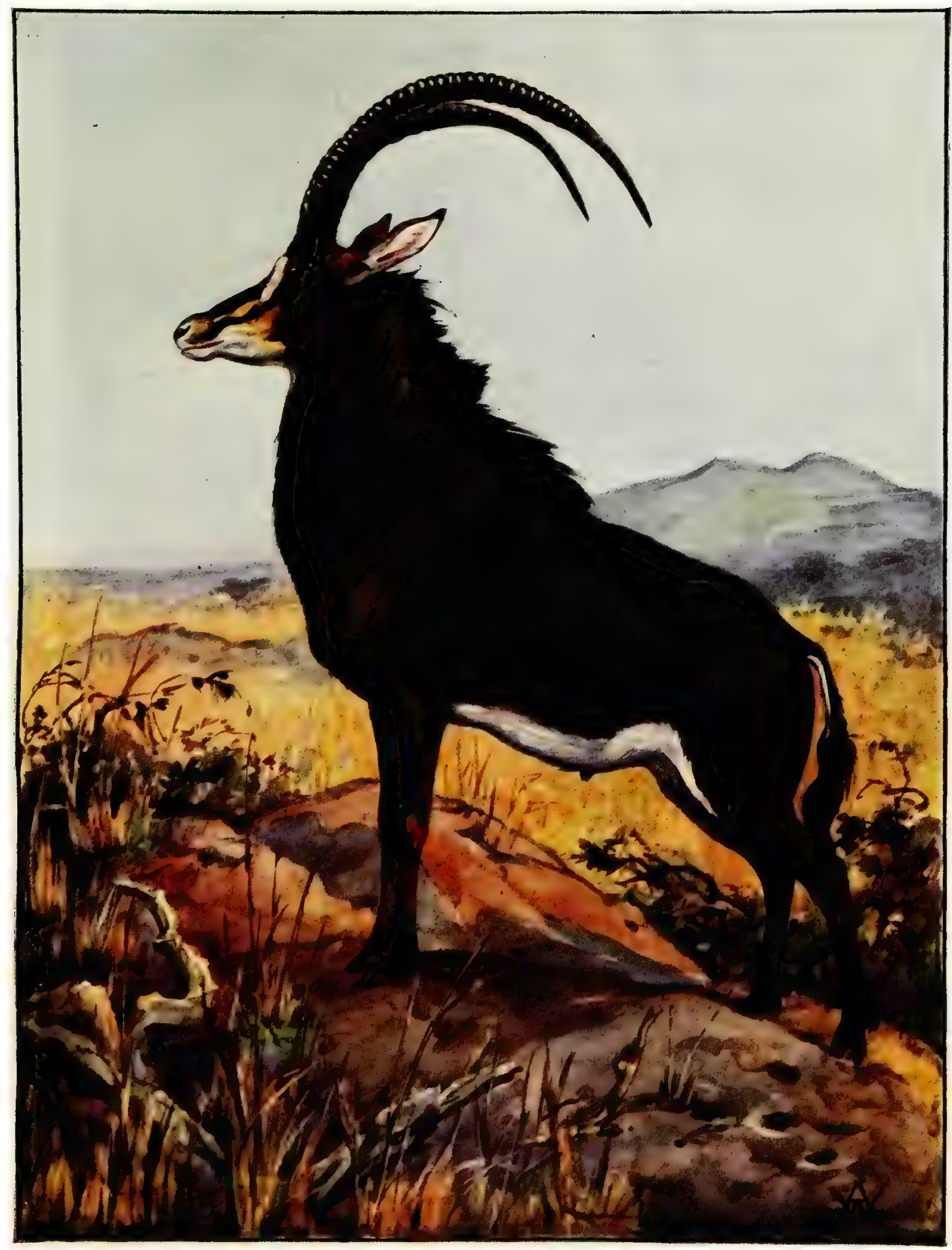

SABLE ANTELOPE

By Winifred Austen 



\section{THE SABLE ANTELOPE}

\section{(Hippotragus niger)}

Although belonging to the same group of Antelopes as the Oryxes, the Sable is a very distinct type, and certainly excels all its relatives in beauty-if indeed it is not the finest of all. Antelopes, as many would maintain. It is large enough to be imposing, being as big as a full-sized Pony, and its carriage is as gallant and showy as its colours and form are striking and beautiful.

The cow is not much inferior in beauty to the bull; but she is rather dark brown than black, especially in the southern portion of the Sable's range, the females of northern herds being very dark. They may, however, always be distinguished from the bulls by their horns, which are decidedly shorter and not so strongly curved, besides being slenderer. The horns of a good bull are over a yard long.

The young Sable is of a light brown, without the face-markings of the old animal at first.

Like all the finest Antelopes, the Sable is an African animal, being especially characteristic of South Africa, though it ranges up to German East Africa and Angola. It was first discovered by the well-known sportsman, Harris, in the Transvaal, but is now extinct there, though English people still sometimes call it the "Harrisbuck"; the Boers know it as "Zwart-wit-pens". (black-white-belly).

The kind of country it prefers is high; open, and rather bushy, and it is fairly sociable, a number of cows and calves being found in herds together. With these, however, there will be only one old bull, for the Sable is a fierce animal, and brooks no rivals. It may even be aggressive to other Antelopes, as it has an unscrupulous habit of turning out Lichtenstein's Hartebeest from beds or lairs which this animal is fond of making for itself. The attitudes of the Sable Antelope are very picturesque, as it carries its neck gracefully arched; its pace is good, but it has not the extreme speed of some much less handsome and symmetrical Antelopes. When driven to bay it is very 
dangerous, being not only high-couraged, but marvellously quick with its horns; like the Gemsbok, it fights lying down, and is very dangerous to hounds. The venison it affords is not of very high quality, but of course the beautiful head is valued as a trophy.

Although not what one might call a common or cheap animal in the wild-beast trade, the Sable Antelope does well in captivity, and is well known in Zoological Gardens.

\section{THE ROAN ANTELOPE}

\section{(Hippotragus equinus)}

THE Sable Antelope's only existing near relative, the Roan or Equine Antelope, is a sort of inferior edition of the noble "Harrisbuck." It is considerably larger, it is true, but its horns, though massive, are considerably shorter-about two and a half feet in the bull, and two in the cow. The colour also is not nearly so beautiful; the face, indeed, is marked with black and white much as in the Sable, but with more black, this colour covering the jaw and meeting the black on the muzzle; the body-colour, however, is some shade of light brown, sometimes really a roan, but varying from quite a dark brown to nearly white. The ears are long and Donkey-like, and are carried drooping. The calf is very like the Sable calf, but may be distinguished by the difference in the face-marking, though this is indistinct at first.

The Roan ranges more widely than the Sable, being found over Africa generally south of the Sahara, and it shows a good deal of local variation. In its general haunts and habits, it is much like the Sable, but goes in smaller herds, and has a louder voice, this being described as a bellow, while the other species only snorts. It is not remarkably fast, although its habit of running with its mouth open often gives a delusive idea of its powers, but its courage is unrivalled" among Antelopes, and it will turn and charge, not only when wounded, but even when galloped too hard.

Like the Sable, the Roan does well in captivity, and has been exhibited at our Zoological Gardens, though not so frequently.

The only other Antelope closely allied to the Roan and Sable 


\section{THE KOB ANTELOPES-THE WATERBUCK}

Antelopes was the Blaauwbok (Hippotragus leucophaus), which was smaller than either of them, and bluish-grey in colour, without distinct face-markings, but this animal has been extinct for more than a hundred years; when it existed, it was only known to inhabit the southwestern corner of Cape Colony. There are only five stuffed specimens of it in Museums-none of them at South Kensington, unfortunately, though there is one in Paris, the others being at Leyden, Vienna, Stockholm, and Upsala respectively.

The Cervicaprine group of Antelopes is typified by the Reedbucks (Cervicapra), which are animals of moderate size, with rather short horns with a forward curve. To the same group belong the various species of Kobs and Waterbucks.

\section{THE KOB ANTELOPES}

THE Kob Antelopes (Kobus) are a group of about a dozen species, equalling or exceeding the common Fallow Deer in size, with no very striking characteristics, their shape being Deer-like, and their horns, which are only found in the males, somewhat lyre-shaped, and ringed except at the points. Several of them are very handsome animals, such as the White-eared Kob (Cobus leucotis), which is nearly black, with the ears, muzzle, throat, and parts of the limbs white. Most of these Antelopes are, however, of some shade of brown. They are widely distributed over Africa south of the Sahara. Among them the Waterbuck and Lechwe deserve special mention here.

\section{THE WATERBUCK}

(Cobus Mipsiprymnus)

THE Waterbuck and its immediate ally the Sing-Sing (Cobus unctuosus) are the largest of the Kobs, and have a longer coat than is usual in the group, which are generally very sleek. The Waterbuck itself, indeed, has very coarse hair, much more like that of a Deer than an Antelope, and might readily be mistaken for one of the Deer family 
were it not for the different horns of the buck. In size it about equals a Pony, and is heavily built, not light and elegant like the Kobs in general; its strong horns are about two and a half feet long. The general colour is light brown, with a curious elliptical ring of white on the hind-quarters, quite unlike any marking found on any other animal.

This Antelope, which has a peculiarly noble appearance, in spite of its somewhat coarse build and pelage, is not an aquatic species, as its name would imply, but merely haunts the neighbourhood of water, and sometimes takes to it to stand at bay when pursued. At such times it is dangerous, as it defends itself fiercely. It frequents bushy country, but feeds chiefly on grass, and it is a good climber, ascending rocky ground with great agility. Usually it goes in small herds, consisting of a buck and a few does. Its meat is very poor indeed, being so rank that nothing but sheer hunger is likely to recommend it to a European palate. The Waterbuck is widely distributed over Africa, from Somaliland to the Limpopo River in the south; but in the west and in parts of East Africa it is represented by the abovementioned Sing-Sing, which has not the white ring on the stern, but is otherwise very similar.

\section{THE LECHWE}

(Cobus lechr)

THE Lechwe is rather smaller than the Waterbuck, not being much over a yard at the shoulder; its colour is very handsome, being a rich bay, with black down the front of the limbs and white belly. The backs of the pastern-joints are naked, as in the swamp-frequenting Tragelaphine Antelopes like the Situtunga, although the hoofs are not lengthened as in those animals. The Lechwe is, indeed, also an aquatic Antelope, but does not frequent marshy soft-bottomed swamps, rather affecting flooded plains, on which it wades about in large herds, browsing on such plants as project above the water. It swims well, as might be expected, but does not do so as long as it can get a "take-off" from the bottom, preferring to splash along by a succession of bounds. 


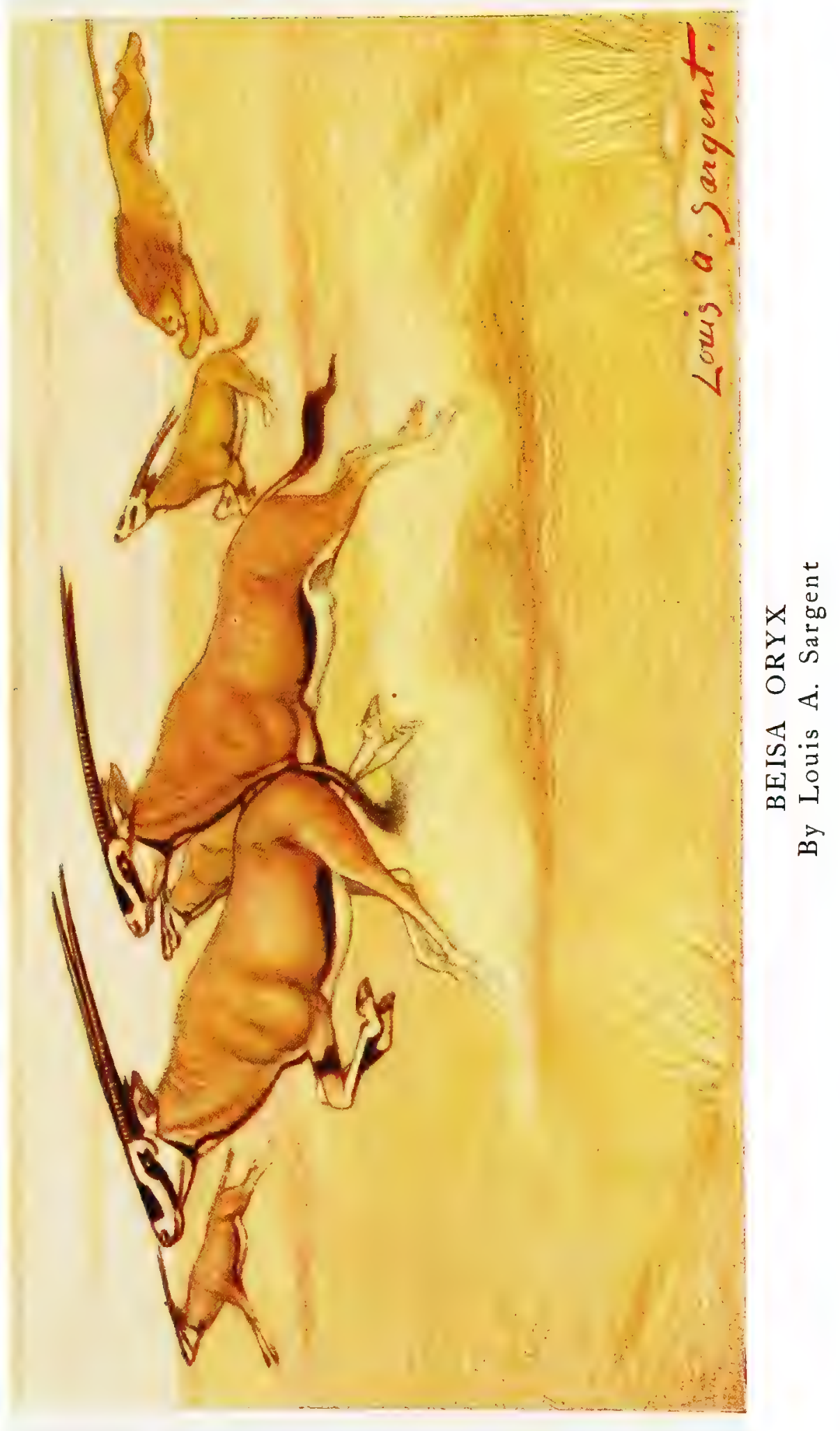





\section{THE ELAND}

\section{(Oreas canna)}

THE Eland is one of a very distinct group of Antelopes known as the Tragelaphine section, characterised as a rule by twisted horns, angular in section, which are smooth or nearly so, and by the presence in most cases of distinct white markings on some part or other of the coat. None of them are very small, and the Eland itself is by far the largest of all Antelopes, a large bull reaching six feet at the shoulder, or even more at times, and making a Buffalo seem small by comparison.

The cow is considerably smaller and lighter in make, and the bull does not attain his full bulk and characteristic peculiarities for some years, since he may attain his mature height before he assumes the mat of long hair on the face and the immense fatty thickening of the upper part of the neck, which mark the perfectly adult bull, and are never found in the cows and young males. Old animals, especially bulls, lose so much of their coats that the dark skin shows through and gives them a grey appearance.

The horns are not of great length, those of the bull being about two and a half feet long, while the cow's, which are slenderer, will be about a couple of inches longer.

The Eland has a wide range over South Africa, and shows a good deal of local variation. The southern or Cape Eland is a plain lightbrown animal, without any white marking; but as one proceeds northwards this race gradually passes into the striped variety, which is known as Livingstone's Eland, having been first discovered and characterised by the great missionary explorer. In this the sides are noticeably marked with several thin white stripes, most distinct in the females and calves, and there is a well-defined black patch on the inner side of the fore-leg above the knee. Females and young 
animals also have a black stripe down the back in this variety, which is far the most handsome, and nowadays the best known, the Eland of the south being extinct in Cape Colony.

Such a large animal as the Eland has, of course, attracted attention from the earliest times of African colonisation, and the Boer settlers of the Cape bestowed on it its present name, which really means "Elk." Except that both Eland and Elk are ruminants, and that each is remarkable for its large size, the two beasts have absolutely nothing in common; but, as previously observed in these pages, the Boer pioneer appears to have had the most delightfully happy-go-lucky methods of nomenclature when he came across a new animal.

The manners and movements of the Eland are what might be expected from his ponderous Ox-like carcase, so strangely combined with a small harmless-looking head. $\mathrm{He}$ is a good walker, and can trot at a pace which will force a Horse to go beyond a trot to keep up with him. When allowed to "go his own gait" he is sufficiently enduring, but if forced into a gallop he soon becomes blown and exhausted, for he cannot keep up this pace more than a mile or so. Yet he is able to bound or spring in a remarkable way for so heavy an animal, and can easily get away from a horseman on broken or wooded ground. When cornered he will charge at times, but his attack is not very difficult to avoid, for he has none of the quickness and determined ferocity of such animals as the Gnu and Sable Antelope. Bull Elands, also, often get so fat that they can be driven by a horseman almost like cattle; but the cow, as is so often the case with ruminants, is much more active, and some specimens of this sex may give a mounted hunter a long chase.

The Eland is undoubtedly an easy-going, peaceful animal by nature; although sometimes it may be found singly or in small family parties, it is often met with in large herds, in which case several bulls will be found living in apparent friendship along with their female associates. Its food consists, according to circumstances, either of grass or leaves, for it is addicted to browsing as well as grazing, and, in fact, prefers country which is more or less wooded, if not actual forest. It is 
found on low rocky hills as well as on grass plains. Like so many Antelopes, it can, although not abstaining from water when this is available, go for long periods without it, for it is found constantly in the Kalahari Desert, where there is water only for a few months of the year, and even attains a particularly heavy weight in this arid region. The Eland is, indeed, a very "good doer," and is particularly apt to lay on fat, a characteristic which seems to have greatly endeared it to hunters; at any rate, they are generally loud in their commendations of its flesh, which is said to be much like beef, but of a superior quality. It must be remembered that the need of fat is keenly felt in a life in the wilds, and any animal which supplies plenty of this-which most game beasts do not-naturally commends itself to the hunter's proverbially keen appetite. Mr. F. C. Selous, indeed, thinks that Eland meat has been over-rated, in comparison with that of some other Antelopes, though he admits that it is excellent if the beast really is fat, which, of course, is determined by the quality of the food it has been living on.

Eland calves, which are somewhat like those of our Jersey cattle, are usually born in July, and are easily tamed. Indeed, the animal is one well suited for domestication, though its mildness of disposition is, it must be remembered, only comparative-the male, like almost all horned animals, being liable to become dangerous in captivity. I know of a case in which one, in a fit of anger, fatally gored a Burchell's Zebra which had long lived in the same paddock with it.

Hopes used to be entertained that the Eland would be added to our list of European domestic animals as a producer of choice meat; but, though it has constantly lived and bred well in our Zoological Gardens-and even, with but little protection from the weather, in various private parks-it still remains a mere menagerie animal. This is probably because, in Europe, it cannot hope to compete in utility with our ordinary domestic stock; but the recent idea of introducing it into Australia is a very good one, as its powers of doing without water would make it a most invaluable animal for that country-or any other where droughts work havoc with ordinary cattle. So far, 
however, only a very few live specimens have reached Australia. It is quite possible that Elands, properly trained, could be used as saddle and draught animals ; but, of course, they would have to be trained when young, and would require perseverance and caution in breaking-in.

\section{THE DERBIAN ELAND}

(Oreas derbianus)

THE Derbian Eland is very closely related to the common species, but is an even finer animal, with more massive horns, and a much handsomer coat, this being of a rich reddish fawn, striped with white much as in the striped form of the Common Eland, but set off by a black neck, separated from the chestnut body by a white band across the shoulder. This Eland inhabits Senegal and the Gambia; it is a forest animal, and feeds by browsing on the trees, the bulls, according to native accounts, pulling down boughs for their mates and young. Little, however, is known about this splendid Antelope, and few skins even have reached Europe, to say nothing of living specimens, which would be a great addition to any Zoological Garden. 


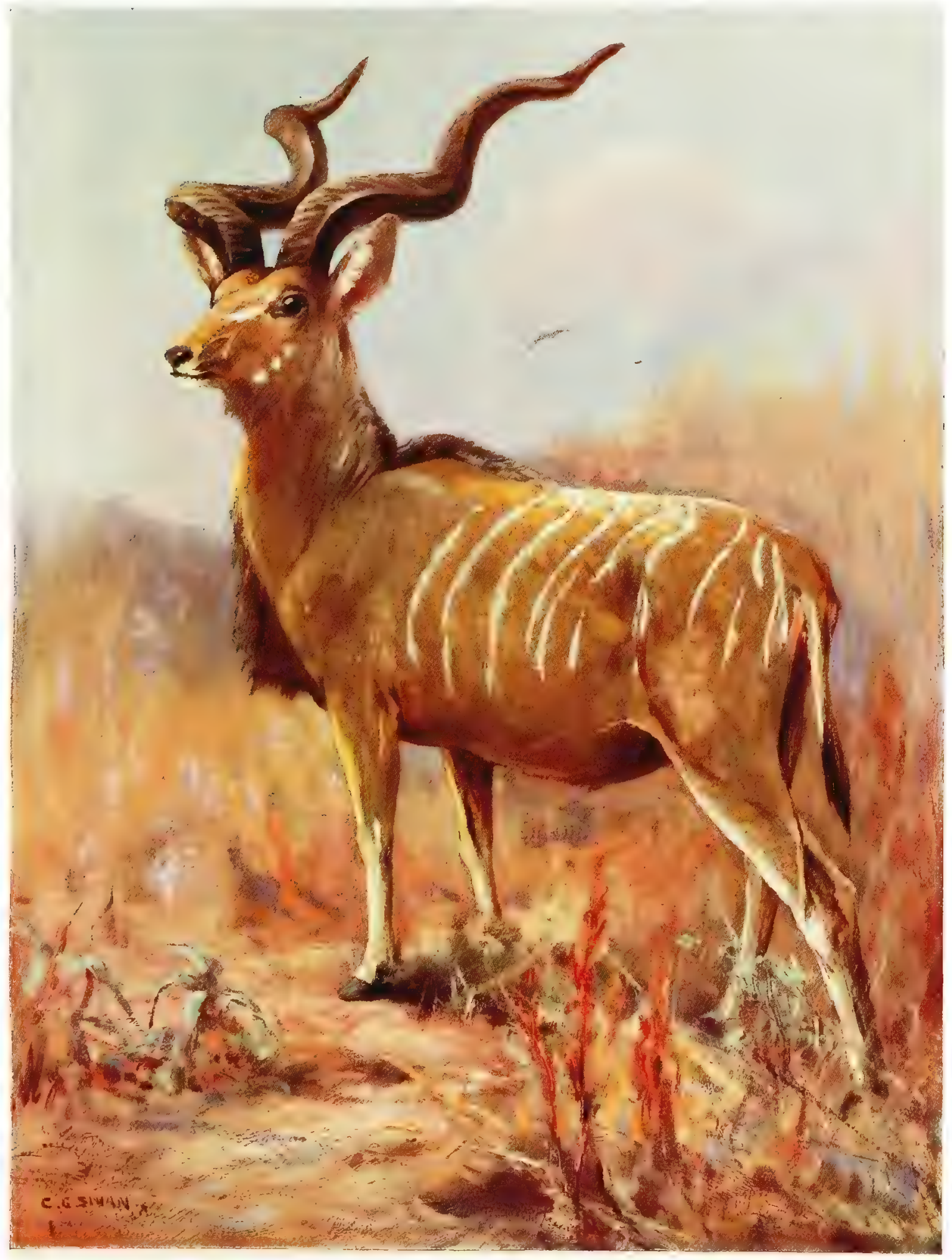

KOODOO

By C. E. Swan 



\section{THE KOODOO}

(Strepsiceros kudu)

IT is a question whether the Koodoo or the Sable Antelope is the most beautiful of all Antelopes, and our illustrations give at any rate a fair opportunity for comparison of these two magnificent beasts. The Koodoo, which is, like the Eland, one of the Tragelaphine group of Antelopes, is also a large animal, but not to be compared in dimensions with that giant species, though about equal to a Horse in size.

The horns in the bull grow to a great size, sometimes four feet measured in a straight line, which, of course, means that over a foot must be added for the measurement taken along their spiral curves; but such specimens of these are rare, though a good horn should be more than a yard, measured straight. In the cow there are, as a rule, no horns; but in very rare cases females with under-sized and malformed horns have been recorded. In colour the female is browner than the male, which gets grey with age.

The Koodoo has a wide range in Africa, from Abyssinia and Somaliland to Cape Colony, but has, unfortunately, been exterminated in some places, not only owing to human persecution, but owing to rinderpest, which has proved a deadly scourge not only to domestic cattle in Africa, but also to several of the wild ruminants, which are unfortunately susceptible to its ravages. Specimens from the northern part of Africa have fewer white stripes than the southern ones. The favourite ground of the Koodoo is hilly country clothed with bush, and not too far from water, as it usually drinks regularly. In such ground, of its own choosing, it can easily evade a horseman; but the bull, at any rate, is a heavy animal in the open, and can be galloped down, though the cow is fleeter.

These Antelopes are usually found in small herds, and even the old males sometimes form little bands of their own. In spite of their imposing appearance and fine horns, they have remarkably little spirit, and show, when at bay, according to Mr. F. C. Selous, less idea of self-defence than any other Antelope-a remarkable contrast to their rival, the plucky and gallant Sable. The note of the Koodoo is a bark, which it utters when alarmed; opinions vary about the quality of 
its flesh. In captivity it is not common, though it has several times been exhibited in the Zoological Gardens, and one specimen lived there for seven years; unlike its relative the Eland, it appears to be a delicate animal, and probably requires more exercise and a more varied and natural diet than usually falls to the lot of menagerie animals.

\section{THE LESSER KOODOO \\ (Strepsiceros imberbis)}

THE Lesser Koodoo was first described by that most excellent but greatly neglected naturalist Edward Blyth, and is confined to Somaliland and the coast of British East Africa. In most respects it is a beautiful miniature of the ordinary Koodoo, but is more slenderly built, and has no fringe of hair down the front of the neck. It measures little more than a yard at the shoulder, and the buck's horns are only about two feet in a straight line, with a less open spiral than those of the large species.

In general habits the Koodoo is not unlike its big relative; it frequents thick forest near water, and is only found in small parties. It has great powers of leaping, and is very wary and hard to shoot -more so than the large kind. A curious point about it is that the meat, according to Mr. F. J. Jackson, disagrees with many East African natives in a most peculiar way, causing great pain in the mouth and gums when eaten. A few specimens have been kept in the London Zoological Gardens, but have not thriven, and it is rare in a living state on the Continent, even if known there at all.

\section{THE BONGO}

(Boocercus euryceros)

The Bongo is a very fine example of the Tragelaphine Antelopes, being about as big as a Donkey, and very richly coloured-a bright chestnut with very distinct white stripes down the sides. There is the white crescent across the face so common in the Antelopes of this group, and another across the chest, while the legs are marked with black and white. The tail is much like that of an Ox, and the twisted horns are massive, but not very long, proportionately, being 
about two and a half feet round the curve. They are frequent also in the female, which is, however, less richly coloured than the male, besides being smaller.

The Bongo is a forest Antelope, found in West and Central Africa, from Liberia and Gaboon to East Africa. As in the case of so many animals from this unhealthy and little explored region, little is known about it, and living specimens are still desiderata for European menageries; there is, however, a fine stuffed one in the South Kensington Museum.

\section{THE INYALA}

(Tragelaphus angasi)

THE Inyala is a good-sized Antelope, standing about three and a half feet at the shoulder. Its shape is graceful, but presents nothing remarkable; the development of its coat, however, is peculiar, this forming a fringe, not only down the front and back of the neck, as in the Koodoo, but also along the flanks, where it is especially long, and the hips. The twisted horns are about two feet long in the male; in the female they are absent. The tail is of fair length, and bushy throughout.

The colour of this Antelope is remarkably beautiful, and differs very much in the two sexes, the male being of a purplish slate, with indistinct pale lines down the flanks, and a few white markings on the face and lower parts of the sides, while the legs below the knees and hocks are tan-coloured; the female is bright tan throughout, with the flank stripes conspicuously pure white.

This Antelope is found in South-East Africa; it is purely a forest animal, and goes in small troops, consisting of a buck and a few does and young. It is not a common animal, and specimens of it are scarce even in Museums, though a fine pair may be seen at South Kensington. So far, it seems not to have been brought to Europe alive.

\section{THE BUSHBUCKS}

ALL over Africa south of the Sahara are to be found species or races of the genus Tragelaphus, graceful animals, with no striking peculiarity 
of form or coat, rather short bushy tails, and, in the bucks, moderatesized twisted horns. They are all smaller than the Inyala; not exceeding about two and a half feet at the shoulder; and the straight twisted horns, which are only present in the bucks, are about a foot long.

The colour varies a great deal, some forms being strongly spotted and striped with white, and others plain, or nearly so; but they are all of some shade of brown in the ground-colour.

All are forest-dwellers, and they do not go in large herds, but only in small parties. The two best-known forms are the beautifully variegated Harnessed Antelope (Tragelaphus scriptus), from West Africa, which is fairly well known in captivity, and thrives well, having bred in the Earl of Derby's menagerie many years ago; and the Bushbuck of South Africa ( $T$. sylvaticus), which is nearly self-coloured on the body, though marked with white on the throat and limbs. This is a well-known game animal at the Cape, and has been represented in our Zoological Gardens.

\section{THE SITATUNGAS}

The Sitatungas (Limnotragus), or Marshbucks, are a small African group of three species, closely allied to the Bushbucks, but differing in their very long hoofs and in the fact of the back of the pasterns being bare and horny, this structure of the foot adapting them for living in marshes, a very unusual habitat for Antelopes. They are larger than the true Bushbucks (except the Inyala), standing a yard or more at the shoulder, and the horns of the males are longer and with a more open twist, presenting some approach to those of the Koodoo on a small scale. Their coats are shaggy and self-coloured, though there are white marks about the head and neck. The females are of a redder brown than the males, and show more tendency to white markings on the body-at any rate when young. These are truly aquatic Antelopes, living in swamps and spending their time more or less immersed in water, though they are rather waders than swimmers. They live well enough in captivity; but, of course, must have a soft litter, not a hard even floor; two of the three species have been represented in the London Zoological Gardens. 


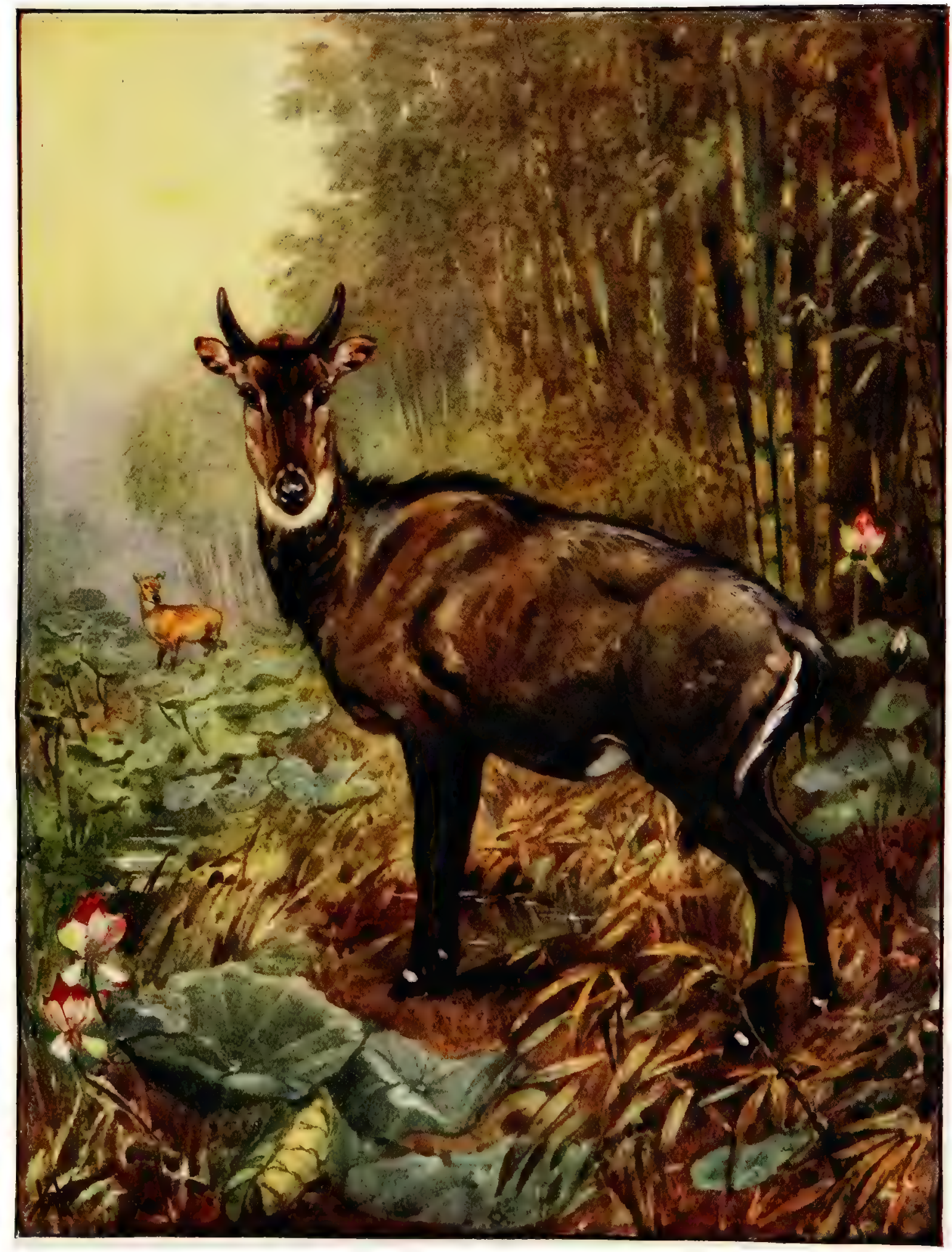

NILGHA I

By Winifred Austen 



\section{THE NILGHAI}

(Boselaphus tragocamelus).

THE Nilghai owes whatever distinction it possesses to the fact that it is the largest of the few Antelopes of Asia; for in itself it is not a particularly striking or interesting animal, and in Africa would not be of much account. It is a member of the Tragelaphine group, but differs from all of them in the shortness of the horns, which are also without any twist; they never reach even a foot in length, and in the female are absent altogether. The cow Nilghai also differs much in colour from the bull, being of a light fawn or yellow colour, but with the same white markings as her mate. The calves are also fawncoloured, and the male illustrated was not quite in full colour, the fully mature bull being of a pure iron-grey, much the same colour as a "blue roan" Horse. In size the Nilghai about equals a Pony, and there is something very Horse-like about its general appearance, although the kind of Horse it suggests is a very badly-shaped one.

The Nilghai is a purely Indian animal, and does not reach Burma or Ceylon, nor does it ascend the Himalayas. It is usually found in small herds, generally frequenting country where there is more or less cover, though not affecting really thick forest. It feeds both on grass and on leaves, wild fruit, \&c., and is often very destructive to the crops of the natives. With the Hindoo section of these it is a sacred animal, simply because its name means "Blue Cow," so that the sanctity of the bovine race has been absurdly transferred to it. Mohammedans, of course, will eat its flesh readily enough, but it is not much hunted by European sportsmen, because no one cares much about possessing a head with such insignificant horns. It thus comes about that the Nilghai is probably less hunted than any other animal of the size; but, of course, it has natural enemies to reckon with in the shape of Tigers, Dholes, and other carnivores.

The bull Nilghai is not a very fast animal-at any rate, he can be ridden down if he is pressed hard at first; but the cow is swifter, and will gallop straight away from a horseman.

This Antelope has long been a familiar animal in menageries; it 
thrives and breeds well in captivity, and might have become a common park animal here, had it possessed better qualifications for such a position; but as it is only moderately ornamental, and the bulls are decicledly dangerous, there has been no great inducement to take it up. When preparing to attack, the Nilghai goes down on its knees, and then springs up suddenly.

In Calcutta I heard that Nilghais could be, and had been, broken to harness, and would go well in a trap; but my informant added that if they did bolt there was no stopping them I

With the Nilghai we come to the end of most of the larger and more remarkable Antelopes, the others being nearly all small, and not striking in appearance.

\section{THE FOUR-HORNED ANTELOPE}

(Tetraceros quadricornis)

This is also a purely Indian Antelope, and it is at once distinguished from all others of the family-and, indeed, from all other living wild animals-by the possession of two pairs of horns. Not that these are very much to boast of, the hinder pair, which are situated in the usual place for horns-at the top of the head-being little conical black spikes only about four inches long, while the front pair, placed on the forehead, are considerably shorter, and in some individuals, in the south of India, never appear at all. In any case they develop later than the hinder ones; in the female there are no horns. Except for its number of horns, there is nothing very remarkable about this Antelope; it is a small animal, with a narrow muzzle and rounded back. The colour of the coat is a light brown.

The Four-horned Antelope is a forest animal, and solitary in its habits; it drinks daily, and so is usually found near water. It thrives well in captivity, and is usually to be seen in the London Zoological Gardens, where young have been produced on more than one occasion.

\section{THE DUIKERS}

WERE it not for its possession of a second pair of horns, the Fourhorned Antelope would be a very typical representative of the 
Cephalophine group of Antelopes, the other members of which are the widely-distributed Duikers of Africa, forming the genus Cephalophus. The Duikers are all short-legged, pointed-headed animals, with rounded backs and short conical horns, which are sometimes present in the males only, and sometimes in the females also. They are nearly all very small, often under two feet at the shoulder, though the Yellow-backed Duiker (Cephalophus sylvicultor) of West Africa stands nearly a yard at the shoulder, and there are two or three other species nearly as large in that part of Africa. A very characteristic point of Duikers is the tuft of hair which grows between the horns, and often conceals them when they are especially short. They also have the face-gland situated below the eyes, and present in so many ruminants, very well developed.

In general colour Duikers are brown or grey, and seldom possess any conspicuous markings, though the large Jentink's Duiker (Cephalophus jentinki), which is the second largest, has a black head and neck and a light grey body, and the Banded Duiker ( $C$. doria) has the back with conspicuous transverse black stripes on a chestnut ground.

Duikers are bush-h lunting Antelopes, found either singly or in pairs, not in herds, and are very active, their Boer name of Duiker (diver) being derived from the way in which they plunge, as it were, into the cover. About three dozen species are known, chiefly, as might be supposed from their habits, located in the forest regions of the West of Africa. The most widely distributed and best known is the Common Duiker (C. grimmi), which is found from the Cape Colony to Somaliland and Angola; it stands rather over two feet at the shoulder, and varies much in colour, from red-brown to silver-grey. This species is often on view at the Zoological Gardens, and about half-a-dozen others have been represented there.

The Neotragine Antelopes form another group composed of species mostly of small size, though not so uniform in type as the Cephalophine group. Only the males have horns, and these are short and straight. To this group belong the Rhebok (Pelea capreolus), a grey Antelope frequenting hill-tops, the Grysbok and Steinboks (Raphiceros), the Oribis (Ourebia), and some other types requiring more particular mention. All the group are African. 


\section{THE KLIPSPRINGER}

(Oreotragus sallator)

THE Klipspringer is, of all African Antelopes, the best adapted for a mountain life; its feet are peculiarly formed, there being no bend at the pasterns, and the hoofs being long in a vertical direction, so that the feet look like so many pegs, the animal standing on the very tips. The hair is very coarse and thick, and the horns very small and erect.

The Klipspringer is a small animal, standing about two feet at the shoulder, and is extremely active, skipping about from rock to rock, and finding a foothold in the most inaccessible places; it is only found in small parties, and ranges from Somaliland to the Cape, wherever there is rocky ground.

\section{THE ROYAL ANTELOPE}

(Nanotragus pygmaus)

IN spite of its imposing title, this is the smallest Antelope known, being only about as big as a wild Rabbit, with long and very slender legs. Its horns are very minute, not an inch long; and the coat is bright fawn above and white below. This tiny creature lives in the forests of the West Coast of Africa, being found singly or in pairs, and is extraordinarily active, being said to make bounds of three yards at a time. It is rare even in Museums, and has never been brought to Europe alive.

\section{THE DIKDIKS}

THE Dikdiks (Madoqua) are little creatures not bigger than Hares, with long noses which in some cases almost approach the trunk of the Tapirs in form. Like the Duikers, they have a tuft of hair on the crown, and their tails are very short. They are bush-haunting animals, and not more than two or three are found together. There are about half-a-dozen species of these little Antelopes, widely distributed over East and North-East Africa. They are rare, however, in captivity, and up to date only one species has been exhibited at our Zoological Gardens. 


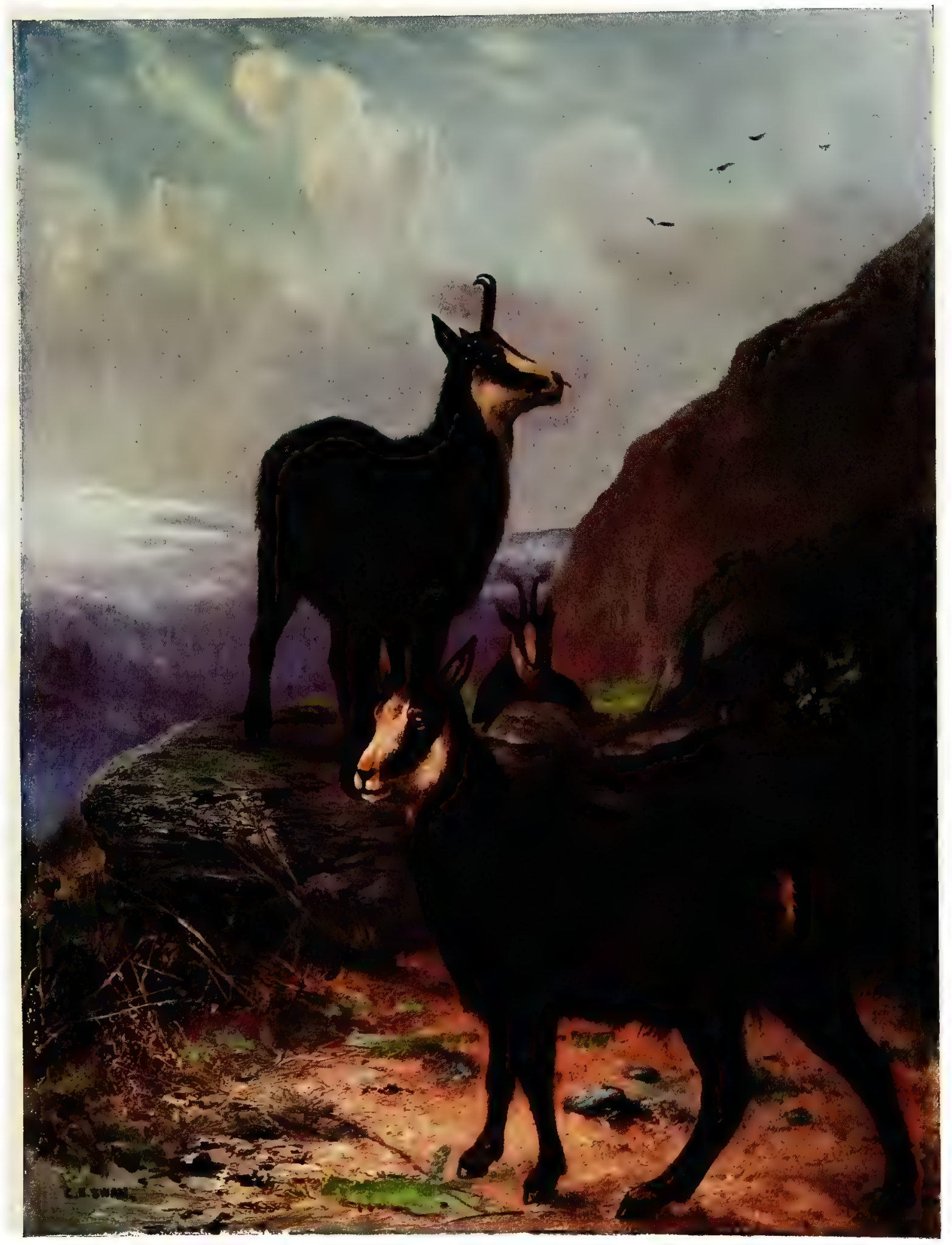

CHAMOIS

By C. E. Swan 



\section{THE CHAMOIS}

(Rupicapra tragus)

THE Chamois is of interest in various ways, especially as the type of a group of non-African mountain Antelopes, which in general appearance and habits closely approach the Goats-indeed, they are often called Goat-Antelopes-and as being, with the exception of the Saiga of the Russian steppes, the only Antelope found in Europe. To Europe, indeed, the Chamois is naturally confined, inhabiting the mountains, in which it is widely distributed, from the Pyrenees, where it is known as the Izard, the Alps, where it is also called Gems, to the Caucasus.

In size the Chamois is about equal to an ordinary Goat, standing about two feet at the shoulder; its coat varies according to the seasons, being longer and nearly black in winter, while short and brown in summer. There is an under-coat of thick wool, and the animal feels cold but little, though it has a strong objection to heat.

The sexes, as in all this group, are remarkably alike, both possessing horns of very similar appearance. The feet of the Chamois are especially adapted for mountain-climbing, the sole being hollow by reason of the outer edge of each hoof being higher than the inner, and the animal is celebrated for its remarkable sure-footedness, being always found high up in the mountains, and commonly on ground very dangerous for the hunter.

It is usually in herds of a score or less (though old bucks are usually solitary), and keeps as near the snows as practicable; but in winter it is naturally forced to lower levels in search of its food, which consists of the various Alpine plants. The pairing season is in autumn, and then the bucks fight savagely; the kids are born in spring, being sometimes single and sometimes twins, and follow the doe almost immediately.

Chamois, as is well known, are keenly hunted by the inhabitants of the mountains they frequent, and the "Gems-bart" (Chamois-beard) is one of the most highly-prized trophies of the Alpine hunter. As the animal, of course, has no beard, it is made of a tuft of the long hair which grows along the back. The enthusiasm with which the Chamois 
is pursued is no doubt due to the fact that there is nowadays so little big game in Europe, and to the danger incurred in the pursuit of an animal living in such inaccessible places, as it certainly does not afford any imposing trophy, while the flesh is only moderately good, and the so-called "Chamois" leather, though it gets its name from this animal, is mostly made from the skins of Sheep, Deer, Goats, and subjected to a peculiar process of preparation, consisting chiefly in impregnating the skins with oil.

The Chamois is not one of the easiest of animals to keep in captivity, and so is not a very familiar exhibit in menageries; but specimens are at the time of writing thriving in the London Zoological Gardens. The animal has also been introduced into the mountains of New Zealand, the Emperor of Austria having presented six specimens in 1907 to the Government of that Colony; all of these reached the country safely, and were liberated under the care of Mr. A. E. L. Bertling, formerly head keeper at the London Zoological Gardens, and now Game Ranger to the New Zealand Government; and, as they have already bred, the species will probably be established in the Southern Hemisphere, to the great edification of sportsmen.

\section{THE GORAL \\ (Nemorhadus goral)}

THE Goral is the Himalayan representative of the European Chamois, but differs rather widely in appearance, being smaller and more thickset, with much shorter horns, not hook-shaped, but evenly curved backwards. The coat is brown in colour, with a white patch on the throat, but there is also a grey form, lately distinguished as $N$. bedfordianus. The Goral frequents either grassy slopes or rocky forests; it does not range very high, not going above eight thousand feet, and has but little fear of man, though cautious enough when persecuted; there is less temptation for the sportsman to molest it than exists in the case of the Chamois, nobler game being available in the Himalayas. In Formosa there exists a long-tailed species of Goral ( $N$. caudatus), in which the tail, which is usually short in these Goat-like Antelopes, is quite long and bushy. This, as well as the common species, has been exhibited at the London Zoological Gardens. 


\section{THE SEROWS}

THE Serows, like the Gorals, are stoutly-built, thick-coated animals, with short backwardly-curved horns. They are of good size for this group, about equalling a Donkey, and rather resembling one owing to their long ears. There are several species or races, ranging from the Himalayas to Sumatra and Tibet, and these differ much in colour. The typical Himalayan Serow (Nemorhadus bubalinus), however, is mostly black, with tan on the flanks, and the belly and legs white. This is a scarce animal, generally solitary, and frequenting forestclad slopes; awkward and uncouth as it looks, it is very active, especially in going down hill, and is a beast of the highest courage, being even able to make a good fight against the dreaded Dholes, and having been known to charge to avenge its wounded mate. It has only recently been exhibited at Regent's Park.

\section{THE ROCKY-MOUNTAIN GOAT}

\section{(Haploceros montanus)}

THIS is one of the most extraordinary-looking of all ruminants; in form it is very stout and thickset, with short legs, and carries the head low; and, as it has a pure white coat, very long and thick in winter, there is something about it which strongly suggests the Polar Bear. Its horns are short, black, curved backwards, and sharply pointed, with a swollen gland behind them; the ears are quite short. In size this animal may be compared to a large Goat, though the thick fur makes it look larger than it is. It is one of the few members of the hollow-horned ruminants found in America, where it lives at the upper limits of forest growth in the Rocky Mountains.

It is a wonderful climber, though its mountaineering feats are performed more by sheer muscular power and flexibility of limb than by bounding and springing like most mountain animals. It is very rare in captivity, and a male that has thriven well there for years is one of the greatest treasures of our Zoological Gardens, being the only living specimen in Europe. 


\section{THE TAKIN}

(Budorcas taxicolor)

ONE of the least known of the ruminants is this awkward-looking animal, which is about as big as a Donkey, with very short thick legs, a large clumsy head, and a long shaggy coat. The buck's horns are rather like those of the Brindled $\mathrm{Gnu}$, but the points are directed backwards, those of the female not having the angular bend downwards at the base.

The Takin was first known from the little-explored Mishmi Hills on the Assam frontier, where it is of a brown colour; but there is a race ranging from Eastern Tibet to North China, in which the male has a bright straw-yellow mane. Little is known about this animal, and it has never been exhibited alive in Europe.

\section{THE MUSK-OX}

(Ovibos moschatus)

AN animal called an "Ox" seems out of place among the GoatAntelopes, but it is agreed by naturalists that it is not a true $\mathrm{Ox}$, and Mr. Lydekker suggests that its place should be here-it certainly does not "fit in" anywhere else.

In size it resembles a small Kerry bull, and is stoutly built and very low on the leg, these peculiarities of form being enhanced by the very long and heavy coat, which hides the short ears and tail. The horns are broad at the base and turn sharply down, following the outline of the face as far as the eyes, when they turn up like hooks and end in sharp points. The colour of the beast is dark brown, and a thick under-coat of wool helps to keep the animal warm in winter; it needs some such protection, as it is a thoroughly Arctic animal, being confined to the barren grounds of the high northern parts of America and North Greenland. Here it lives in herds, feeding on the scanty Arctic vegetation, and displaying, when hunted, much more activity than could be expected from its very clumsy appearance. Although it does at times possess a musky odour and flavour, this is not constant, but very little is known about the animal, which has only once been brought to England. 


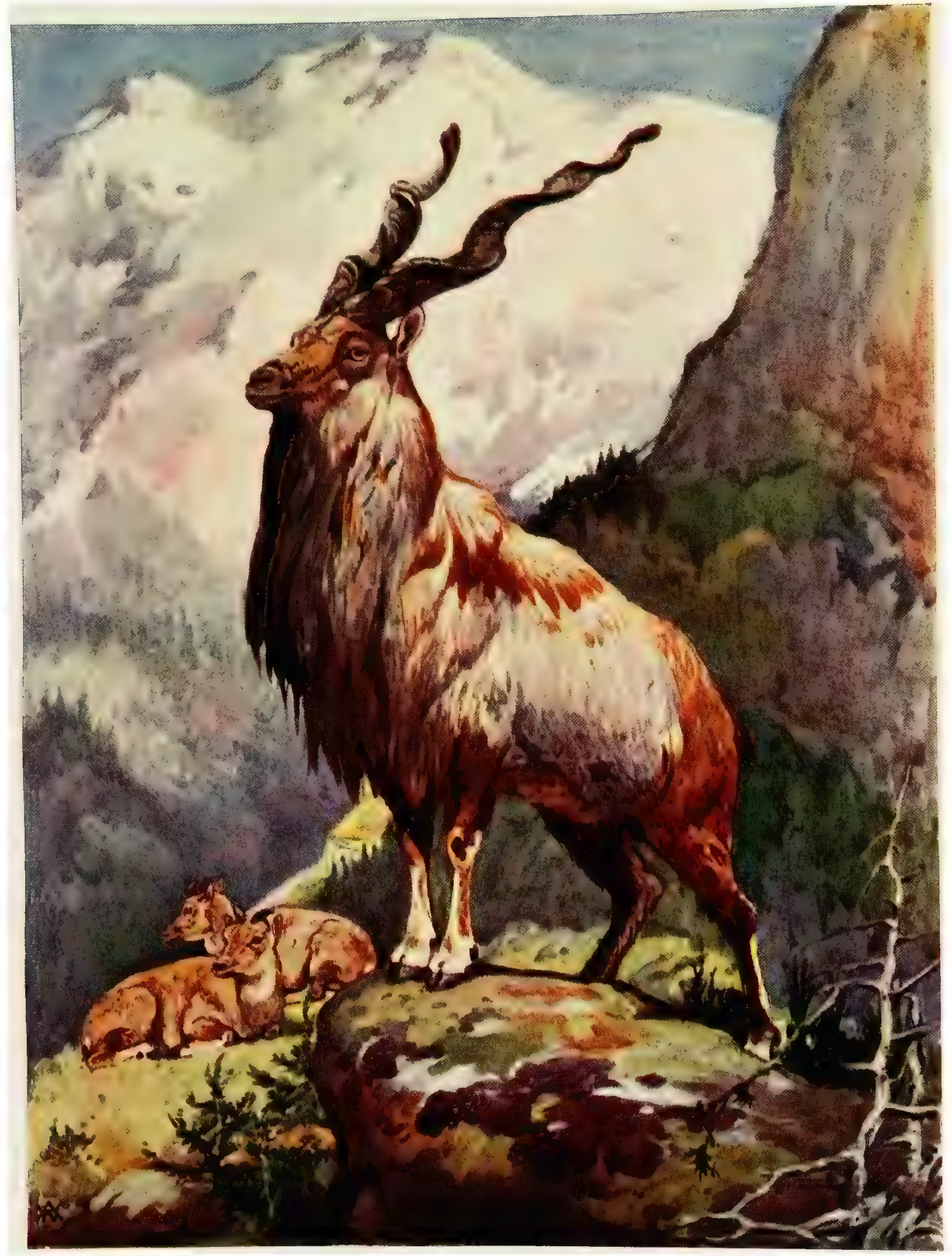

MARKHOR

By Winifred Austen 



\section{THE MARKHOR}

(Capra falconeri)

Although belonging to the prosaic group of Goats, the Markhor is one of the finest of game animals, with "the tumbling cataract of his beard" and the grand free sweep of his great spiral horns. He is also a good-sized animal, standing over a yard at the shoulder, and sturdily built.

The horns vary much in development according to locality, there being a great difference between the wide-spreading corkscrew type, which is most admired, and the straight horns with a tightly-twisted screw-like spiral, which are accompanied by smaller size and inferior development of beard, while intermediate forms exist connecting the two extremes.

Horns of the open spiral type will measure four feet or more along the curves, though in a straight line they may not be much more than a yard, which is about the length of the straight closespiral form. In the female the horns are quite short and insignificant, though they show the characteristic twist.

The Markhor wears his long beard both summer and winter, but changes the rest of his coat to some extent, the summer dress being short and whitish, while in winter it is long and grey; he has, however, no under-garment of wool like some other Wild Goats, and hence is rather more sensitive to cold than these. The female is brown in summer, and never has any beard; while the kids are light drab, with a black stripe down the back.

This noble Wild Goat is found in the mountain ranges of the Indian North-West, the Pir Panjál to the south of Kashmir, and the Baltistan, Astor, and Gilgit ranges to the north, as well as in many of the Afghanistan hills, including the Sulaiman range, where the poorest specimens, of comparatively small size, with straight screw horns, are found, the splendid open-spiralled specimens attaining their fullest development in the Astor and Baltistan ranges. 
The Markhor, like Goats in general, is a gregarious animal, and a splendid climber, being found in places where its pursuit entails crossing the most dangerous ground. Its favourite haunts in many cases are among the forested heights, though in Afghanistan it has to dispense with cover and make the best of stony hillsides. Its attachment to cover is no doubt largely due to its comparative sensitiveness to cold-not to any deficiency in climbing power, for it is admitted to be the equal of any Goat in this respect; and some of the steep slopes covered with short smooth grass or fallen pine-needles are as bad to negotiate safely as any ground could be-at least to human feet.

One curious fact about the animal is that it is credited by the natives with being a snake-eater-a trait which certainly requires confirmation; but the same story is told about the tame Goat.

It is not common in captivity, though it thrives well enough in that condition, and a young one has recently been born at the London Zoological Gardens. Its father is a most savage and dangerous animal, so that the front of his yard has had to be doubly barred, and he possesses to the full the "personal atmosphere" which has made hegoats so notorious. It is doubtful, however, whether the Markhor has anything to do with our tame Goats, though it will breed with these, and though they often strikingly resemble it in form of horns; it will be noticed, however, that the spiral in a tame Goat's horns generally runs inwards at first, instead of turning outwards as in the Markhor.

\section{THE WILD GOAT}

(Capra hircus)

There seems to be no reasonable doubt that the real original ancestor of our Goats is the animal known as the Persian Ibex (Capra hivcus agagrus), which is still a well-known animal in South-Western Asia, extending east to Sind. This beast is practically indistinguishable from many tame Goats; the colour is a light brown in summer, getting greyer in winter. There is a small chin-beard as in the tame Goat, and this is black, as is the face, a stripe all down the neck and back, and another along the lower part of each flank, a broad collar at the shoulder, and the tail and fronts of the legs, with the exception of the 
knees. The horns bend backwards in a semicircular curve, and in front are keeled and jagged. In the females the horns are much smaller, and curve back only slightly, and there is no beard or collar.

The height of the male is about a yard at the shoulder. The natural haunt of the Wild Goat is among crags, and it goes in herds; it is prolific, often producing two kids at a birth, as it so frequently does in domestication. Near Quetta, where it reaches the domain of the Markhor, hybrids between the two animals have been obtained. No animals run wild more readily than Goats, which have always retained much of their original agility and intelligence, and so it comes to pass that in many places far removed from the haunts of the original animal there are Wild Goats which originally came there as the dependants of man, since the Goat can thrive under a greater range of climate and conditions than any other domestic animal, and hence has been carried almost everywhere.

\section{THE IBEXES}

What may be called the typical Ibexes, as distinguished from the Wild Goat, have similar backwardly curving horns, but the front edge of these is flat and more or less broad, not a knife-edge as in the "Persian Ibex." It is broken up by knots or lumps at regular intervals. The best known nowadays is the Asiatic Ibex (Capra sibirica), which ranges through the mountains from the Altai to the Himalayas; it is a magnificent animal, as big as the Markhor, and bears horns which may be four feet long. The coat is of a uniform pale brown, with dark streaks down the back and legs, becoming nearly white in winter, and with a dark chin-beard in the male. There is a thick under-coat, and this hardy animal cares little about cold, keeping. at high levels close up to the snow at all times of the year.

It is much hunted by Dholes and the Snow Leopard, and also persecuted by man, both by the local natives and by European sportsmen. Such persecution in time past has now almost exterminated the European Ibex (Capra ibex) or Steinbock of the Alps, an almost identical but smaller horned species, now only to be found in a few valleys in the Italian Alps. Another Ibex (Capra vali) is also found 
in the mountains of Abyssinia; and there is one in Arabia (C. nubiana); somewhat intermediate between the Asiatic Ibex and the Wild Goat in colour and style of horns.

\section{THE TURS}

THE Turs form a group of three species, two of them found in the Caucasus and one in the Pyrenees. The Caucasian Turs are of a nearly uniform brown, and they have very different horns, those of the East Caucasian species (Capra cylindricornis) being strongly curved and diverging sideways, while in the West Caucasian animal (C. caucasica) they turn backwards as in the Ibexes. The Spanish Tur (C. pyrenaica) has the horns ridged and twisted, and in its colour more resembles the Wild Goat.

\section{THE TAHR}

\section{(Hemitragus jemlaicus)}

THIS well-known Himalayan Croat is an animal of a type very distinct from any of the above. There is no beard in either sex, and the horns, which curve backwards, are quite short, being hardly more than a foot long even in the buck, although he is as big as the Markhor. As, however, he possesses a fine dark brown coat, with a long palecoloured mane covering the neck, he is a sufficiently imposing animal. Females and young animals are much paler. All stages of growth can commonly be seen in our Zoological Gardens, where Tahr have long lived and bred remarkably well. In the wild state, like Markhor, they frequent very steep ground, often covered with forests, and the two species may at times be found together.

There are two other species of Tahr, the Arabian (H. jayakari), which is the smallest Wild Goat known, being only about two feet at the shoulder, and the Nilgiri Tahr of South India, often erroneously called Ibex by sportsmen there. This species (H. hylocrius) is larger than the northern Tahr, but has not the long mane, though old bucks are ornamented by a large whitish "saddle," contrasting with the dark brown coat. 


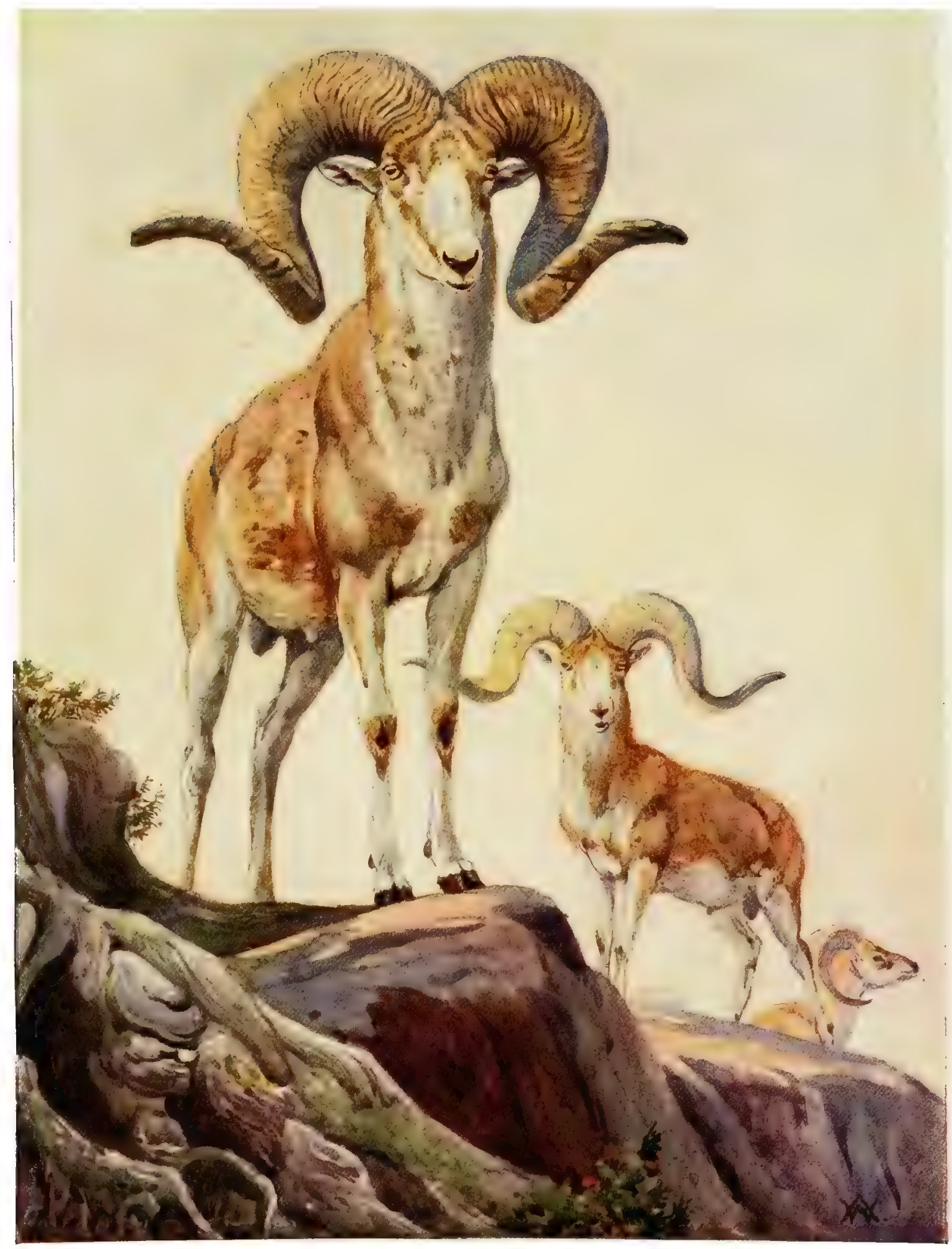

MARCO POLO'S SHEEP

By Winifred Austen 



\section{MARCO POLO'S SHEEP}

(Ovis poli)

A SheEp as big as a Donkey, with horns measuring a couple of yards along their splendid spiral curves, is an animal that cannot very well escape notice, and so it is not surprising that it was described by the great Venetian traveller Marco Polo, who met with it when, in the thirteenth century, he traversed its home on the bleak Pamir steppes, "the roof of the world," though it was not until seventy years ago that actual specimens of the animal, in the form of skulls, were brought to England and the species duly named. Of recent years this grand animal has been a good deal hunted, and is now fairly well known, though it has never been exhibited in our Zoological Gardens as yet. The ewe is a much less imposing animal than the ram, being not only smaller, but, as is usual with wild Sheep, having quite short, slightly curved, insignificant-looking horns.

The coat is short, close, and very thick; as in all wild Sheep-and in most tame ones in some parts of the world-it is composed of hair, not wool, the latter type of coat being the result of human selection. The long tail found in many breeds of tame Sheep has also no counterpart in this or most other wild species, which are usually short-tailed.

The coat of the great Sheep varies to a certain extent according to season, being longer in winter, when also the male develops a ruff of especially long white hair on the front of the neck, while the ewe's throat becomes brown.

Marco Polo's Sheep ranges from the Thian Shan Mountains to the Oxus valley, and shows a certain amount of local variation, the Thian Shan race not having such fine horns as the typical Pamir form. Like wild Sheep generally, it does not so much frequent rocks as open undulating ground; for these animals, like their domestic 
relatives, though they climb well and like to live high up, care more about good grazing than for skipping from rock to rock and nibbling stray tufts of herbage or browsing on bushes, as Goats are so fond of doing. The pasture of the Pamir in summer is of a very good and nourishing character, but in winter there is a great scarcity of food in this elevated and wind-swept region, and many of the giant Sheep die of sheer hunger in the early spring, while others fall victims to Wolves. Sometimes, too, whole flocks perish by getting snowed-up and smothered in valleys through not moving out into the open in time to avoid the coming storm. In spite of all these destructive agencies, however, the Sheep held their own very well till ter years ago, when an epidemic of rinderpest thinned them out as severely as it has done other game animals in Africa.

The gait of this Sheep when well on the move is a vigorous and rapid gallop; it is usually seen in herds, like all of its kind, but the adult rams, the special objects of the sportsman's pursuit, keep together in small parties. Now and then, of course, they fight, using the same head-to-head butting tactics so familiar with our tame rams. The flesh of this animal is more like beef than mutton, as might indeed be expected from its size.

None of the other wild Sheep have horns that can compare with Marco Polo's, as they are much shorter, and have no second twist or but a slight indication of one, merely curling round once or less. There are, however, two other species which also deserve to be called giant Sheep. The first of these is the Argali (Ovis ammon), found in East Central Asia and Tibet, where it is known to sportsmen by its native name of Nyan. This is, if anything, an even bigger animal than Polo's Sheep; with horns, although much shorter, very much more massive, being about eighteen inches in circumference at the base. This is the only giant Sheep which has been exhibited at our Zoological Gardens. The other is the Bighorn (Ovis canadensis), of the mountains of the Pacific coast of North America; the great Sheep of Kamtchatka is also considered to be a race of this species. The Bighorn is usually a darker-coloured animal than the other two species, 
especially on the legs, and it has smoother horns; but it varies much locally both in size and colour. In Alaska there is a race of it (Dall's Sheep) which is nearly or quite white; and there is also a nearly black variety. Bighorns are especially remarkable for their great climbing powers.

\section{THE MOUFLON}

(Ovis musimon)

THE Mouflon of Corsica and Sardinia is so very similar to tame Sheep in size, voice, and-allowing for the unfamiliar hairy and coloured coat-general appearance, that it is in all probability the ancestor of these. The colour is a bright brown, becoming darker and duller in winter, with the legs and abdomen white, and black streaks dividing this colour from the brown of the flanks and running down the legs. The rams have a well-marked white saddle-mark, which is wanting in the ewes, these being also usually hornless, or with very small horns.

More or less black varieties of Mouflons are not uncommon; several have been bred in the London Zoological Gardens, but the parent ram is himself partly black. He is a very brave animal, and, desiring to get at the buck Markhor next door-a much bigger animal than himself-he broke the padlock on the door of separation with his head, and then went in and made the vicious Goat acknowledge his supremacy. Another race or species of Mouflon (Ovis orientalis) inhabits the mountains of Western Asia, and is also found in Cyprus; this is less variegated in coat than the European animal, and is generally larger, though the Cyprian race is smaller than the Corsican and Sardinian animal.

\section{THE URIAL}

(Ovis vigner)

THE Urial, which is about the size of a tame Sheep, but more leggy, is of a sandy colour, with a black or black-and-white ruff in the ram; the ewe in this species is horned, though the horns are small. It is found from Bokhara through Persia to the Punjab, where, unlike 
other wild Sheep, it has to endure a really hot climate. It is possible that this species has been a part ancestor of tame Sheep, as it will breed with them; it has also crossed in the wild state with the Argali.

\section{THE BURRHEL}

(Ovis nahura)

THE Burrhel forms in some respects a link between the Sheep and the Goats, but on the whole it is certainly a Sheep, and no one used to wild Sheep would call it anything else. Its size is that of a tame Sheep, and its colour very distinctive, being a stone-grey-rather browner in summer-with, in the rams, strong black bands along the sides and down the fronts of the legs, while the face and chest are also black. The ewes have only the black on the legs; but they have short horns. Those of the male turn out considerably sideways. This Sheep inhabits Tibet and the adjacent parts of the Himalayas; it frequents either rolling or craggy ground, and fights like a Goat, rearing up to butt. It thrives remarkably well in captivity, and breeds freely.

\section{THE AOUDAD}

(Ovis tragelaphus)

THE Aoudad or Arui, which is the only wild Sheep found in Africa, where it inhabits the mountains north of the Sahara, is the most distinct-looking of all Sheep in general appearance, and was, indeed, originally described as an Antelope.

It is a tall, leggy animal, sloping-backed, and standing about a yard at the shoulder. The colour is uniform sandy-red or chestnut, without markings. Its horns turn well outwards, and are almost as big in the ewe as in the ram. The tail is quite long for a wild Sheep's, reaching nearly to the hocks, and a growth of long hair fringes the front of the neck and chest, and covers the fore-legs down to the knees; this is most developed in the ram, and especially, like the Lion's mane, \&c., in captive specimens.

In captivity, indeed, this species thrives marvellously, and, though coming from such a hot climate, will endure even so severe a winter as that of New York in the open. 


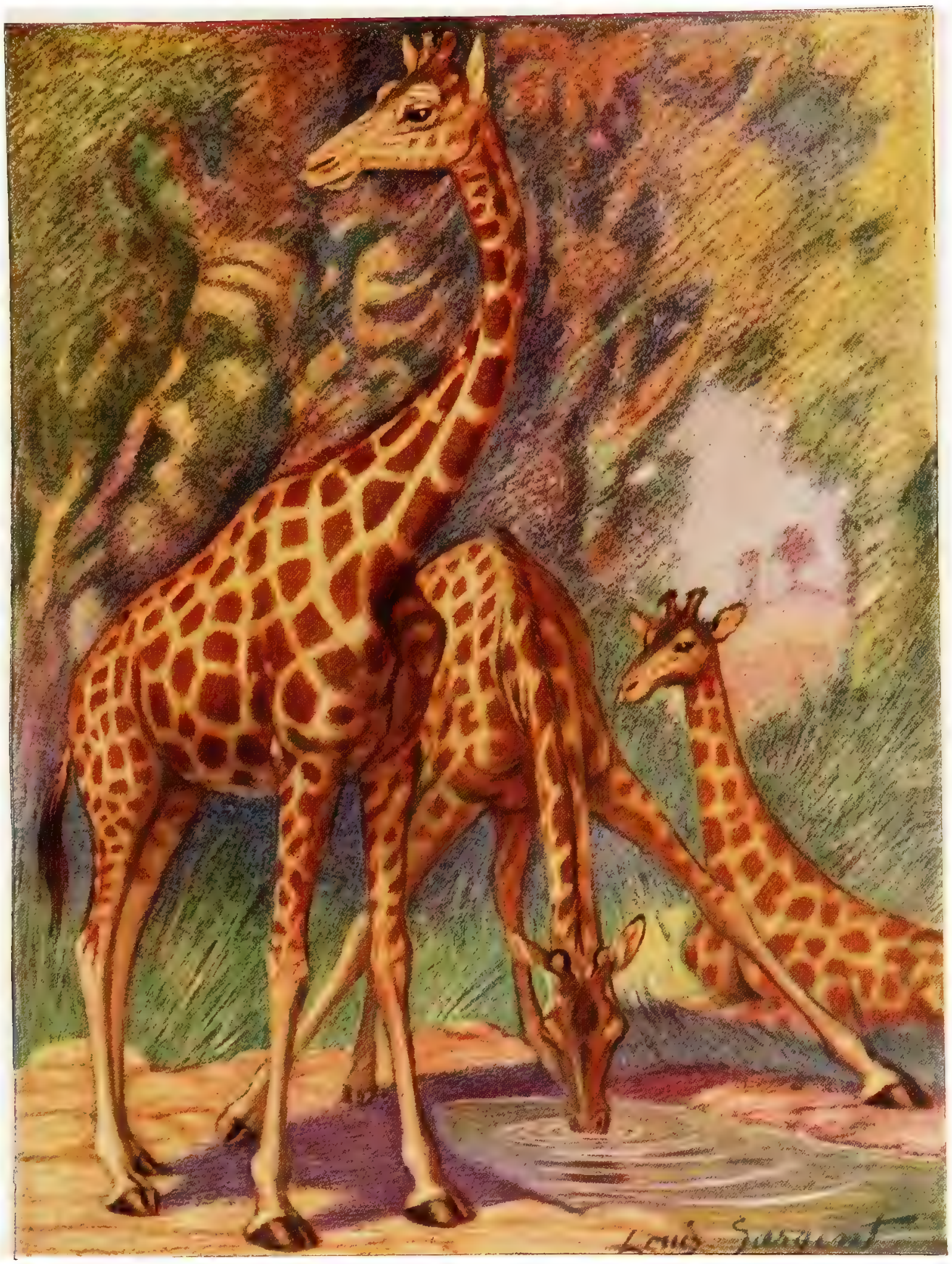

GIRAFFES

By Louis A. Sargent 



\section{THE GIRAFFE}

\section{(Camelopardals giraffa)}

IT was well said by the late Mr. Phil Robinson in his charmingly amusing book "Noah's Ark," that the Giraffe is about the best instalment of the impossible that has been vouchsafed to us; for one could hardly reasonably expect an animal to grow to the height of six yards, which is what the bull Giraffe commonly does, though a twentyfoot specimen is apparently still a desideratum. The cow stands two or three feet shorter.

It is not only the extreme height, due to the extreme elongation of neck and legs, that makes the Giraffe so remarkable an animal. One curious fact about it is that the neck, long as it is, has only the seven vertebræ almost universal in beasts-no more, in fact, than the almost neckless Hippopotamus possesses. This seems a case of carrying the "economy of Nature" rather too far, and accounts for the comparatively stiff appearance of the Giraffe's otherwise graceful neck.

The feet are noticeable for the fact that they entirely lack the small "false hoofs" so usually found in ruminants, to which group of hoofed animals the Giraffe belongs, only the two large toes-third and fourth-forming the cloven hoof, being present.

The head presents several points of interest: the nostrils can be closed at will, as in some aquatic animals, and the tongue, which is well developed and more or less prehensile in ruminants generally, possesses these qualities in perfection in the Giraffe, in which it is unusually long and movable; in colour it is nearly black. The horns are bony prominences covered with the hairy skin: they are common to both sexes, and are found in the new-born calf, in which, however, the bony core seems to be undeveloped, as the horns lie flat back on the head. They also have larger tufts at the tip than in the adult animal. 
On the whole, the young Giraffe resembles its parents more closely than any other animal, the proportions being perfect at birth, so that, with the exception of the recumbent horns, it might be mistaken for a miniature model of the old ones. It is more swift and active than these are, however. Most people know that Giraffes are purely African animals; they have a wide range in Africa, but are only found south of the Sahara, and in open, dry, thinly-forested country.

They are sociable animals, and usually found in herds; their food consists of the leaves and twigs of various trees, their great height adapting them better for browsing than any other animal. When they wish to reach down to the ground, on the other hand, they straddle in a very awkward way. They will drink water when it is available, but can do quite well without any, so that they may be found many miles away from any supply, a peculiarity which has stood them in good stead in face of human persecution. Among other animals their only enemy seems to be the Lion, which occasionally pulls one down, especially when he has friends to assist him in the feat, and catches the Giraffe alone.

A herd of Giraffes are most difficult for any enemy to approach; their sight and scent are both good, and their great height gives them an advantage in perceiving danger by either of these means which other animals do not possess. Moreover, they are not by any means easy to see in their natural surroundings, their mottled colouration being inconspicuous among the trees on which they feed; unless, as not infrequently happens, they are browsing on scrub a good deal lower than themselves.

This colouration, it should be mentioned, varies a great deal locally, so that several local races have been described; it is sufficient to say here that the Giraffe of the south of Africa has a yellowish groundcolour with rather ill-defined brown spots, while in the northern part of the animal's range it tends to become a dark-brown netted over with a mesh-work of white lines; while at the same time the bony lump on the forehead, which is always present, develops into what may be called a third horn. 
Generally speaking, the bull Giraffe is much darker than the cow, and old females are considerably darker than young ones.

The gait of Giraffes when walking quietly is most graceful; it will be observed on watching it that both legs on the same side are moved together. When pressed, however, they break into a very awkward gallop, with their long necks rocking to and fro, and their brush-tipped tails raised erect over their backs, while they straddle their hind-legs so much that it is dangerous to ride close alongside for fear of receiving an involuntary kick. The Giraffe also can and does kick deliberately, but no one seems to have observed the wild animal do what tame ones undoubtedly practise-deliver a swinging blow with the horns, which, blunt as they are, are formidable weapons with the leverage of the long heavy neck. Owing to the Giraffe's long stride, it travels at a pace which gives a horseman much trouble to get on terms with it, and in spite of its height it manages to get through a wood in a most remarkable manner.

The meat of a young cow in good condition is very good indeed, and keeps for a long time, but the old bull smells so terribly strong that it is difficult to remain in his vicinity, let alone eat any of him, though opinions vary as to the precise description of odour he emits. The hide, which is extremely thick, is of value for making whips; but, taking it on the whole, there is very little reason for destroying this uniquely beautiful and absolutely harmless animal. One point to be noted about it is that it is one of the few beasts which are absolutely mute, for no one seems to have heard a Giraffe utter a sound under any circumstances.

The Giraffe has been known in captivity for a very long period, as the Romans used to exhibit it in the brutal shows wherein whole Zoological Gardens were massacred in the arena. In post-classical times it became almost forgotten, and it was not till 1836 that the first specimen reached our Zoological Society's Gardens. Here Giraffes have done remarkably well, and bred quite freely, though they cannot be called very hardy animals. Their transport is also naturally rather difficult, but I have seen one in good condition in Barnum's travelling show. 
They are, of course, to be seen in every leading Zoological Garden, which institutions could not be considered complete without one; but during the outbreak of Mahdism in the Soudan, they became very difficult to procure, and the prices asked were very exorbitant.

It may be worth mentioning that in the menagerie of the King of Oude, who was deposed after the Indian Mutiny, there was a Giraffe which was accustomed to be saddled and ridden daily. This idea might well be adopted elsewhere, and a properly broken Giraffe would not only earn its keep by carrying riders, but might be allowed to do a little tree-pruning in a public garden, to its own benefit and the saving of labour to the gardeners.

Captive Giraffes are said not to attain anything like the richness of colour and commanding height which they exhibit in the wild state-indeed, Mr. H. A. Bryden thinks that they compare more unfavourably in these respects with their wild relatives than any other animals commonly exhibited in captivity. 


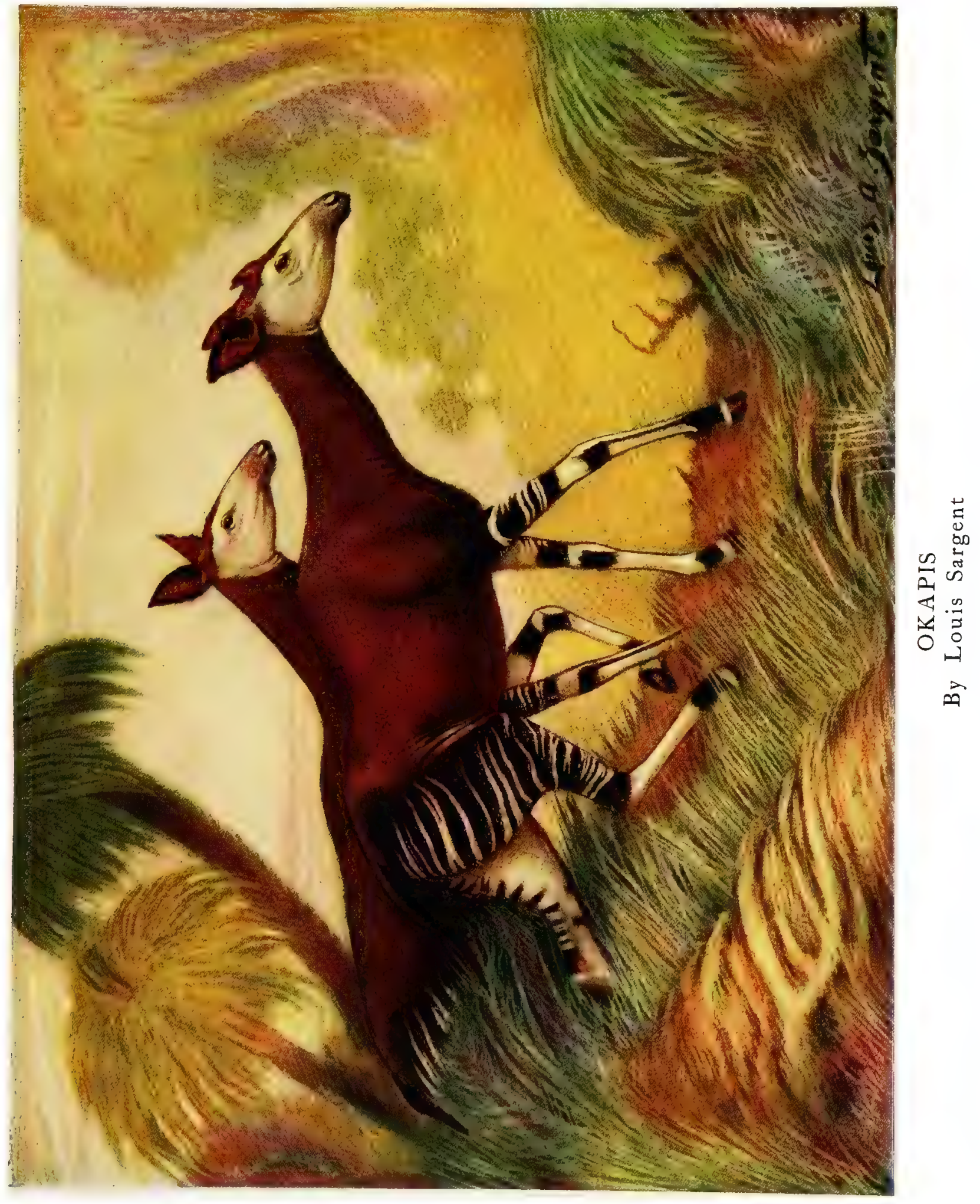





\section{THE OKAPI}

(Okapia johnstoni)

THE Okapi is the only other living member of the family Giraffide besides the true Giraffe, and, as many of my readers no doubt know, has only been made known to science during the last decade, its discoverer being Sir Harry Johnston.

As far as its general form goes, it gives us a good idea of what the Giraffe's ancestors were probably like, foreshadowing, as it were, that animal's peculiarities, for its neck and legs are rather long, and its shoulders high, while its head distinctly recalls the Giraffe shape. As in the Giraffe, the back hoofs are wanting, the front ones forming the usual cloven hoof of a ruminant. The Giraffe is noteworthy for having its canine teeth-present only in the lower jaw, and, as in ruminants generally, lying close to the incisors-divided by a deep notch, and this small peculiarity is repeated in the Okapi.

Its horns, however, differ somewhat from the Giraffe's; for one thing, they are confined to the male, and, though short and covered with hairy skin, are tipped, not with a tuft of hair, but with a bare cap of bone, like a very rudimentary Deer's antler. The two horns are generally not quite like each other.

In the colour and pattern of its gay and strikingly-marked coat, the Okapi is very different from the Giraffe, and, indeed, from any other beast whatever, though the banding of the bases of the limbs and the hind-quarters are somewhat like those of a Zebra. In fact, when the first definite proofs of the existence of the animal, in the shape of pieces of the striped part of the skin, came to hand, it was thought to be a new kind of Zebra, and named as such.

The sexes are practically alike in colour, and the same may be said of the young, though these have a more furry coat, the hair of the adult animals being very close-lying and sleek. 
In size the animal may be compared to a large Donkey or a Mule, and it was first vaguely heard of by reports obtained by $\mathrm{Mr}$. H. Stanley from the Pigmies of the Central African forests, that they knew of an animal something like a Donkey, which they caught in pitfalls. That anything of the Horse kind should live in a dense forest seemed so strange to Sir Harry Johnston that he resolved thoroughly to investigate the question, and in 1899 he had the opportunity of himself questioning some Pigmies whom he had rescued from the clutches of a showman; and they told him that the beast was like a Mule with Zebra's stripes. That the description gives some idea of the animal, no one who looks at the illustration will deny, but nothing was said about the cloven hoofs, a detail which the Pigmy mind was evidently not scientific enough to take cognisance of.

Thus, when next year Sir Harry obtained further information about the beast from the Belgian officers at Fort M'Beni in the Congo Free State, and even the strips of skin above mentioned, there was nothing to dissipate the Zebra idea, and when he went Okapihunting in the forest and saw the marks of cloven hoofs, he was still off the scent.

However, in I90I, Sir Harry, then Governor of Uganda, received from Eriksson, a Swedish officer in the Belgian service, a skin and a couple of skulls of the Okapi, and at once perceived its relationship to the Giraffe. Since then quite a number of specimens-more than two dozen-have come to hand, and a good deal of information about the animal has been acquired, notably with regard to the horns of the male. There are now three stuffed specimens to be seen at the South Kensington Museum, and skeletons have also been sent to Europe. Moreover, two or three specimens have been captured alive, including a baby one about a week old, which was photographed, apparently . from life, though it only survived a month. Before long, therefore, we may expect some enterprising individual to bring a live Okapi to Europe.

All the specimens have so far been obtained in the Semliki Forest, and the Belgian Government, in whose jurisdiction the haunts of the 
animal lie, have wisely forbidden any one to hunt it without special permission. It appears to be purely a forest animal, and very wary and quick of hearing, as might be expected from its large ears. It is not usually gregarious, only a pair, and sometimes their young one, being found together; and they travel in single file, the male strictly observing the rule of "ladies first," a piece of gallant behaviour which is apt to lead to his receiving the bullet of the hunter when the pair are in retreat. He also is credited with keeping watch while his mate grazes, whereas in many, if not most ruminants, it is the female which does sentinel duty; but a monogamous animal might naturally be expected to show more devotion to his female than the usual polygamous members of this group.

The Okapi is said to be gentle and harmless, with a soft gazellelike expression in its dark eyes; it appears to low like a Cow. Its food consists of leaves and grass, in search of which latter it frequents open places in the forests traversed by little brooks which enable the grass to grow; these places it only visits at night, and it has very seldom been seen alive by Europeans as yet. The savages procure it not only by means of pitfalls, but also by lying in wait for it and spearing it. Their word Okapi, applied to it, really means "Donkey," and the more usual name is Dumba.

\section{THE PRONG-BUCK}

(Antilocapra americana)

ThE Giraffe family find their nearest allies in the Deer, while the Prong-buck, although it has a distinct family (Antilocaprida) all to itself, is undoubtedly very near the hollow-horned ruminants, and therefore rather out of place here; but it demands notice, and the true Antelopes are so numerous that it could not be dealt with after them. It is often known in North America, where alone it is found, simply as "the Antelope," and, were it not for its peculiar horns, would pass as one of that group. It is about as big as a Fallow-deer, and 
slenderly built, with large eyes, long ears, delicate limbs, and short tail. Its colour is pale sandy brown, white on the stern and underparts, while the front of the neck is white crossed by a band of the body-colour.

The horns, which are only found in the buck, are situated far forward-above the eyes, in fact; they are not a foot in length, and stand nearly upright, but with a slight curve backwards at the tip. Their great peculiarity is that they have a tine or prong about the middle of the front, and also that, although composed of horn, covering a bony core, they are shed yearly. Only the outer horny part comes off, a new horn forming on the core underneath it. This curious change, which is the most distinctive point of the animal, was first observed by A. D. Bartlett, in the London Zoological Gardens, where this animal has several times been exhibited, though it is delicate, and not very easily kept even in its own country.

It is essentially a prairie animal, and is possessed of great speed, though it is no jumper, and would appear not to be so fast as some of the true Antelopes of the Old World. Its flesh is esteemed as good venison, and it is persecuted by Wolves as well as by man, so that its numbers have been greatly reduced, and it is one of the animals whose extinction is to be feared if it cannot be efficiently preserved. 


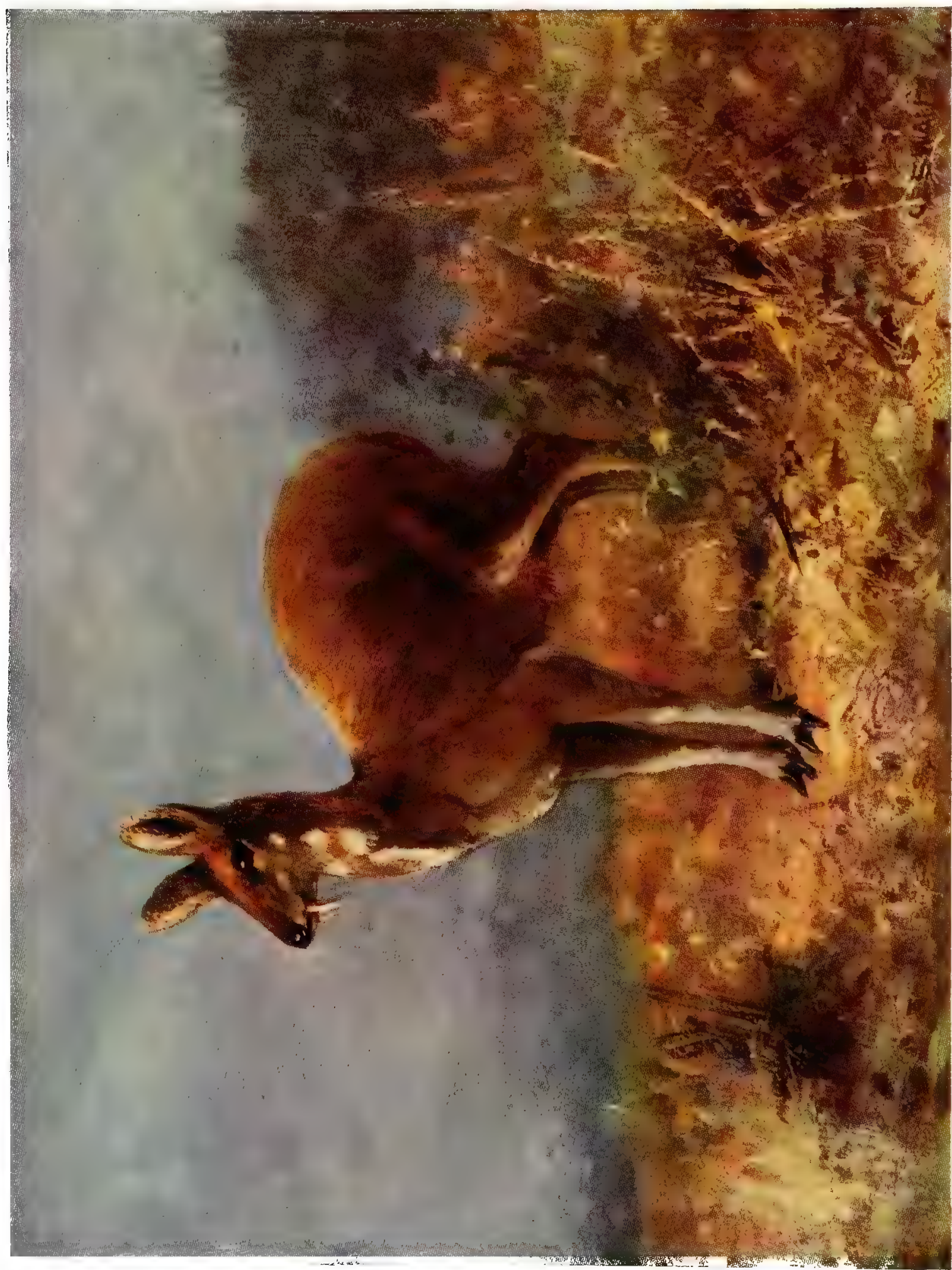

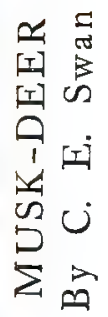





\section{THE MUSK-DEER}

\section{(Moschus moschiferus)}

THE Musk-Deer has for many centuries been a familiar animal on account of its valuable scented secretion, though little known in its own person, which is indeed insignificant enough, for it is a small creature, not so large as an ordinary Goat, and measuring less than two feet at the shoulder. It is also one of the very few Deer which never possess horns, these weapons being replaced by the long upper canines in the males; the female's canines are quite short, and of no service as weapons.

In build the Musk-Deer is also very different from other Deer, having particularly long hind-legs; its hoofs are particularly characteristic, being very pointed, and with the small hinder pairs, or "false hoofs," much better developed than in any other ruminant-so much so, in fact, that they are of use in helping the animal to get a grip on rocky ground, being movable. The coat is very characteristic, being composed of long and extraordinarily coarse hair, almost like small quills; it is extremely close and thick, and the hairs are very brittle.

The colour varies a good deal, some specimens being much redder than others, while pale and dark varieties occur, and some have white on the under-parts. The young animals have white spots, like Deer fawns generally.

The Musk, which has given the animal its reputation and commercial importance, is to be found in a pouch about the size of a hen's egg, situated under the skin of the abdomen; it is a darkcoloured substance of a pasty consistency. This "musk-pod" is absent in the female, which also differs from the male not only in not possessing tusks, but in having the tail, which is very short in both sexes, covered with hair in the ordinary way, while in the male it is naked except at the tip. 
Unlike other Deer, the Musk-Deer has a gall-bladder like most animals. The Musk-Deer is purely a mountain animal, but it has a wide range, being found from the Western Himalayas to Western China. It frequents forest-covered places, and ranges very high up, being indifferent to cold, from which its remarkable coat well protects it. In its movements it is very active, and it is remarkable for its agility and surefootedness, travelling in great bounds. The food of the Musk-Deer consists of leaves, flowers, lichens, and grass; it is evidently, like the Goat, an animal that enjoys a change of diet.

It is solitary in its habits, and never seen in flocks, at the most a pair consorting together; and it is also a very silent animal, except for an alarm hiss, and the loud screams which it will utter when captured.

Few animals are more relentlessly persecuted by man than this, and the persecution has been a long-continued one, for musk used formerly to be even more esteemed than it is at the present day, being used freely in cookery and medicine as well as in perfumery. The great value of musk in the last-mentioned art lies in the extraordinary power of the scent, which, almost intolerably strong in the crude article, gives a needed "body" and persistence to the various delicate manufactured perfumes. It might naturally be supposed that so highly flavoured an animal would be unpalatable-at any rate to Europeans, but Mr. Lydekker states that even the buck's meat is free from muskiness if the scent pouch is removed at once; the doe, of course, is not musky at all, and the venison is very good.

The skin of the Musk-Deer does not seem to be commonly utilised, but if properly cured it makes a most excellent bedroom mat, on account of its warm nature. These Deer are secured either by shooting or snaring, the latter poaching method being especially favoured by natives.

Although it is not a very common animal in captivity, the MuskDeer does well in our climate, and is sometimes on view in our Zoological Gardens; it also thrives in those few parks in which it has been introduced. It would be a very desirable proceeding to acclimatise this valuable and harmless animal, not only in some of our mountain 
districts in Great Britain, but also in such parts of our Empire as New Zealand, where conditions suitable to its existence occur; but few things are more remarkable than the extreme indifference of humanity to the naturalisation of unimpeachably useful animals, though we have distributed pests widely enough.

There seems to be only another species of Musk-Deer known beside the common one-the Kansu Musk (Moschus sifanicus), which is said to have longer and darker ears. The Musk-Deer is so very different from other Deer that it has even been doubted whether it does not deserve a family to itself; but it is generally treated merely as an outlying member of the typical Deer (Cervida).

\section{TYPICAL DEER}

THESE, as every one knows, usually have horns, confined-except in the case of the Reindeer, and of individual "freak" does in one or two other species-to the males, and shed and renewed at more or less regular intervals. The growth of these horns, which are composed of true bone, and have no real horn in them, is one of the most wonderful things in nature. They begin as soft knobs, covered with the "velvet," a skin coated with plush-like fur, and gradually assume their full size and form, hardening meanwhile. Then the knotted ring at the base (the "burr") forms, and the blood circulation dies away almost completely. The velvet dies and dries, and is rubbed off by the stag against trees, \&c., and he is as anxious to use his new weapons for combat as he was previously to save his tender growing antlers from contact with the boughs, \&c. In Deer with the usual branching horns, the young stag's first set have only one spike, and the prongs increase in number yearly till the maximum is reached; but when the stag has passed his prime, the antlers diminish in size and beauty yearly as he advances in age. Deer are found everywhere except in the Australian region and in Africa south of Sahara; but they are not nearly so numerous or so varied a family as the hollowhorned Ruminants, or even as the Antelope section of that family. 


\section{THE MUNTJAC}

(Cervulus muntjac)

This is a curious-looking little Oriental Deer, with short legs and small two-pronged horns seated on long bony pedestals, the bases of which are continued down as ridges on the skull, and show prominently under the skin of the face. The buck has the upper canine teeth in the form of short strong tusks.

The coat is very sleek and of a foxy red, but dark brown and greyish black varieties occur, and sometimes albinos. I once saw a skull of a buck which had an extra little antler growing out of the sides of the horn-pedestals of bone.

The doe, except for the absence of long tusks, and of the horns and their supports, is very like the buck, and has the same ridges on the face. A marked peculiarity of this animal is its strong garny scent, and also its note, which is a bark like that of a Fox. Inde d it is often known in India as the "Barking Deer." Another peculiarity of this animal is the length of its tongue, which can be put out of the mouth far enough for it to lick its face all over with it. It is a forest animal, usually solitary, and very clever at getting quickly through thick cover. When at bay, it relies more on its tusks than on its little horns, and will make a stout defence with them. Its meat is very good venison indeed, which is sufficiently remarkable, seeing that the animal is, in captivity, almost as omnivorous as a Pig, eating cooked meat readily; I have also read of a case in which a buck, which was allowed his liberty, searched for and ate hens' eggs.

This Deer is found all over India, both in mountains and plains, and ranges east to Borneo; it does well in captivity in England, and would be an excellent subject for acclimatisation anywhere, being very easy to keep and transport. There are only about half-a-dozen other species of Muntjacs, all from Eastern Asia, and all sufficiently like the common species for their relationship to it to be obvious at sight. 


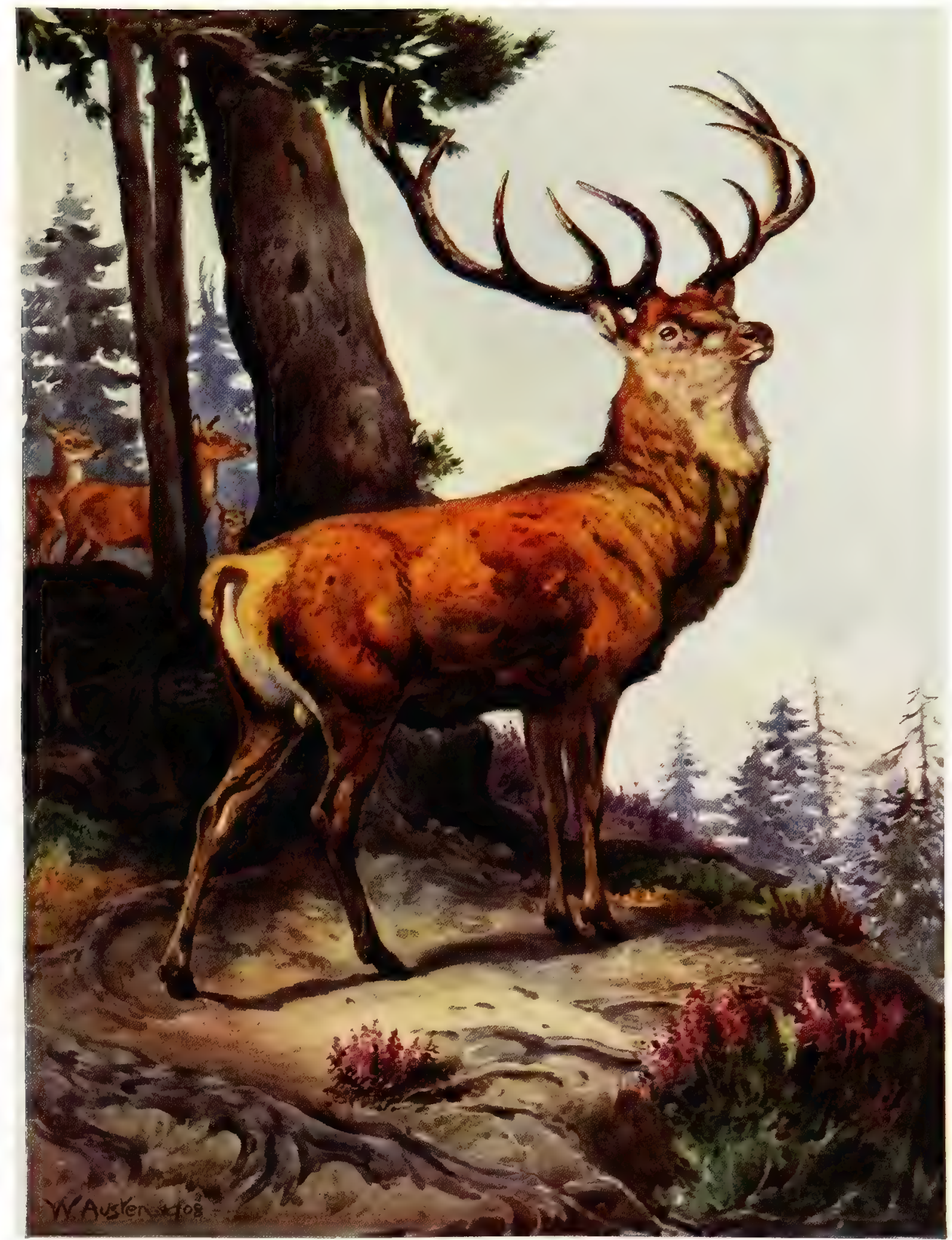

RED DEER

By Winifred Austen 



\section{THE RED-DEER}

\section{(Cerous elaphus)}

THE Red-Deer may be taken as the type of the Deer family, and, though not so large as some of them, it is unrivalled among living species in majesty of appearance and in the beauty of its finelybranched horns. These have, besides the "brow-tines" at the base, a "bez" or second, and a "tres" or third tine, while the three points at the end of the horns is known as the "crown." The words bez and tres, by the way, are pronounced "bay" and "tray." When the stag has the three lower tines, he is said to be a "royal," although his horns are as yet not nearly perfect; many specimens even have more than three of the terminal points, for this Deer is very variable as to the form and branching of its antlers.

Antlers a yard long may be considered good, but much larger specimens are preserved in some Continental collections; the evidence available goes to show that the Red-Deer of to-day are distinctly degenerate compared to their ancestors. Some stags never have horns at all, but may yet become owners of a harem.

The Red stag measures about four feet at the shoulder; his coat is redder and shorter in summer than in winter, and is variable according to individuals; there is even a breed of white animals of this species preserved in some parks. The hind is coloured like the stag, but the fawns are spotted with white.

This Deer is a typically European animal, being found over most of Europe and in North Africa; eastwards it ranges into Persia, the "Maral" of that country being a race of the Red-Deer. It is the largest of our living British land animals existing in a truly wild state, and its great stronghold is in the Scottish Highlands and Islands, though it is also found in the free condition in Devon and Somerset, and in Kerry in Ireland. As a park animal it is much more widely distributed with us, and park specimens are larger and finer than those from the bleak northern mountains, rather inappro- 
priately called "forests," for the Red-Deer, like most of its family, is properly a forest animal, and only attains its full development when it has the shelter and the variety of food afforded in a forest country. Thus, in New Zealand, where this Deer was introduced from Scotland, it is now a far finer animal than its ancestors were, although the stock is very much inbred, the original animals introduced having been only about a dozen all told. It may be gathered from this that the Red-Deer is a browser as well as a grazer; the development of the antlers depends very much upon the feeding the animal gets in the winter and spring, as, of course, their production involves a great drain on the system. Red-Deer's horns are perfect in autumn, and at this time the stags, which usually live apart from the hinds, often in small bachelor parties, fight savagely, and roar defiant challenges to each other; and at this time, especially if at all tame, they are apt to be very dangerous to man. Red-Deer are in any case most destructive animals to crops, devouring corn, apples, and roots, and the stag is worse, being more wasteful, than the hinds; in the hunting country on Exmoor, a "Deer Damage Fund" is maintained to compensate for the loss thus occasioned to the farmers. Their depredations are made at night. On the other hand, Deer-stalking is one of the great attractions of the Highlands, and has done much for the prosperity of that part of our country.

On the Continent the Deer has not only to contend with man, but with his hereditary enemy the Wolf, and even with us he is liable to be attacked, especially when young, by the Golden Eagle.

The venison is esteemed, but not so much so as that of the FallowDeer, and the great recommendation of the animal is its picturesque appearance and its value to the sportsman. Like Deer generally, the Red species does well and breeds freely even in close confinement; it had among the ancients a reputation for long life, but in point of fact a stag seems to be past his prime long before he reaches twenty years.

Closely allied to the Red-Deer are several Asiatic species, such as the Hangul of Cashmere (Cervus cashmirianus); but in Central Asia begins the range of the Wapitis, of which the North American species (Cervus canadensis) is the type. These are animals of much greater size than the Red-Deer and most of its allies, but otherwise very similar. They have, however, shorter tails, and squeal instead of 
roaring in the breeding season. Horns of the American Wapiti may measure over five feet in length. These great Deer do well in our parks, but are very dangerous animals at the rutting-time.

\section{THE SAMBUR}

\section{(Cervus unicolor)}

THE Sambur and its allied races take in South-East Asia the place occupied by the Red-Deer and Wapitis in the northern parts of the world. The typical and finest form of Sambur is found in India, where it inhabits both the mountains and the plains, being known as the Jerrow in the Himalayas. It is about the size of the Red-Deer, but far less elegant in build, and its tail is much more bushy. The old stag is of a very dark brown, while the hinds are redder, and the calves, which are usually unspotted, quite foxy red in many cases. But it is the antlers which make the greatest distinction between the two types. Those of the Sambur have no bez or tres tines-only the brow tine and two points at the crown. The beam of the antler is, however, very thick and rugged, and, as it may attain a yard in length, the head is imposing enough.

Sambur are forest-haunting animals, usually less gregarious than Red-Deer, as they never collect in large herds, and are often found singly. The shedding of the horns is very irregular in this species, and sometimes stags do not drop them for years together. The Eastern races of Sambur, which range to the Philippines, are usually smaller than the Indian variety, some of them not being so big as FallowDeer. Of recent years Sambur have been introduced into New Zealand.

\section{THE SPOTTED DEER}

(Cervus axis)

THIs very beautiful Deer is widely spread in the plains of India, inhabiting groves near water. In size it is about equal to our Fallow-Deer, and is very like that animal in summer coat, but even more richly coloured, the chestnut ground of the white-spotted hide 
being very bright. The horns of the buck are, however, very different, having, like those of the Sambur, three tines only on each, a brow-tine and two end points. They are long and slender, but vary a good deal, some diverging much more than others; a yard is not an uncommon length. This Deer is gregarious, and suffers a good deal from the persecution of various carnivora, as well as the assaults of man; but it holds its own well, and is a common animal. The fawns may be born and the horns shed at any time of year. In European parks this Deer does well, though the fawns are apt to die when dropped in the winter.

\section{THE FALLOW-DEER}

(Dama vulgaris)

No hoofed animal exceeds this familiar ornament of our parks in grace and beauty, though its white-spotted coat is less brilliant than that of the last species, and varies a good deal in depth of tint. In winter the spots disappear, and there is a sooty variety which never has any. White specimens are also found. The horns of the Fallow-Deer are very different from those of other typical Deer, being palmated or flattened at the ends; both brow and bez tines are present.

This Deer's natural home seems to be the countries bordering the Mediterranean; but it is far better known in semi-captivity as a park -animal, for which position it is eminently fitted, not only by its great beauty and utility as a provider of excellent venison, but by its gentleness, for it is the only Deer in which the bucks are usually not dangerous. It must be admitted, however, that vicious individuals occasionally are found. When it is found living free and is hunted, the Fallow-Deer exhibits much more cunning than the Red-Deer, in spite of its long domestication. 


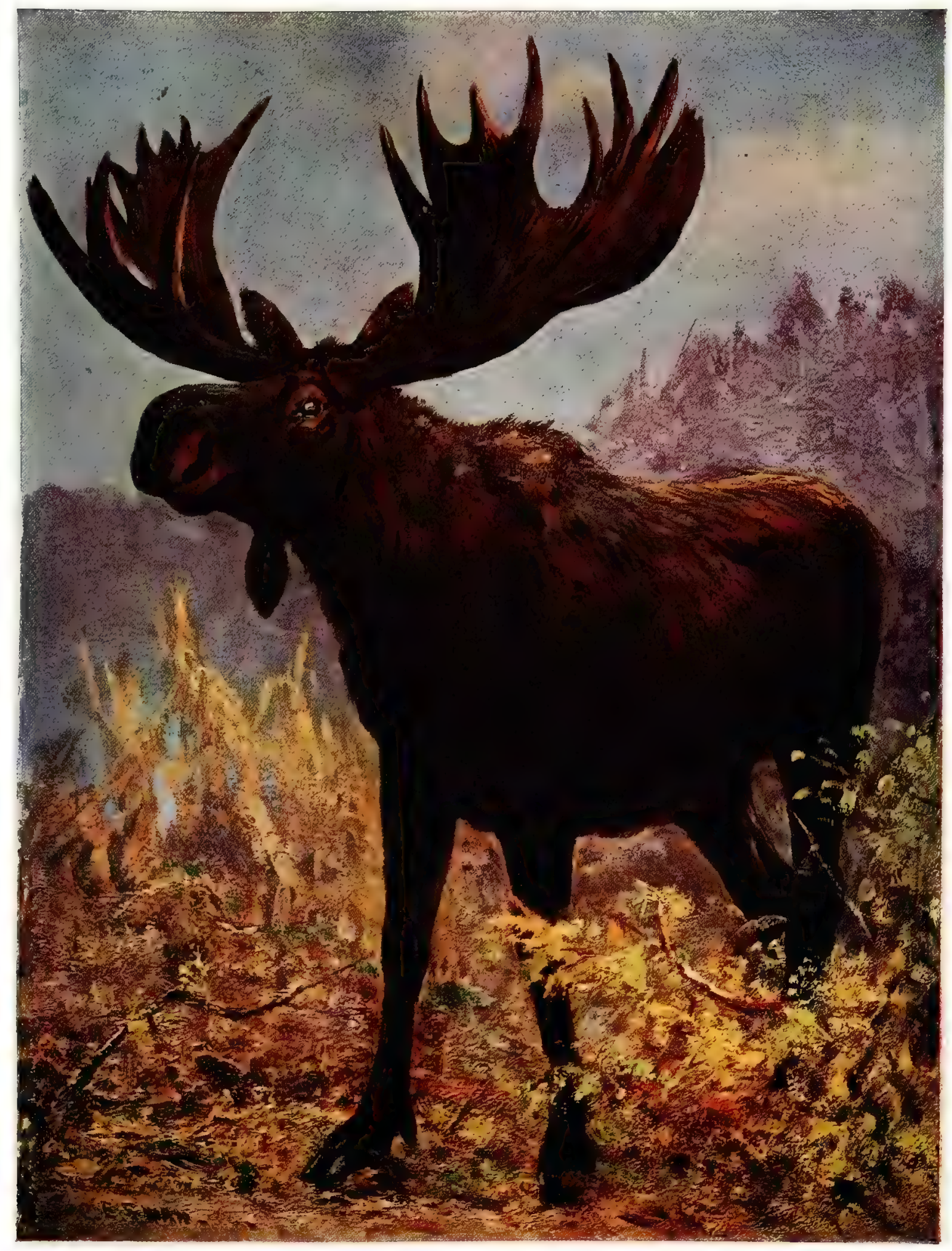

ELK

By C. E. Swan 



\section{THE ELK OR MOOSE}

(Alces machlis)

The Moose of America is the same animal as the Elk of the Old World, for its range extends all round the globe, in the great northern forests; indeed, it is a pity that the name Elk cannot be entirely dropped in favour of the American title, as it has been so extensively misapplied.

In America, for instance, "Elk" always means the Wapiti, and in Ceylon it is applied to the Sambur; moreover, the long extinct giant Fallow-Deer of Europe (Cervns hibernicus), of which such wellpreserved horns are dug up from the Irish peat-bogs, used to be called the "Irish Elk."

However called, the true Elk is a very distinct animal from all other Deer, presenting as it does so many remarkable points. Its short neck is unique among Deer, and in fact no other creature presents the combination of a short neck and long legs. The antlers of the male are also characteristic, with their broad palmated form, and lateral direction on each side of the head, to say nothing of the absence of the brow-tine.

In young animals the antlers are not palmated at first, and show more resemblance to those of ordinary Deer. Another peculiarity of the bull Moose is the "bell," or hair-covered pouch, which hangs from his throat, its use being quite unknown.

The great muzzle, short tail, and characteristic form of body and limbs are common to both sexes. The calves are much lighter in colour than adults, but are not spotted. The Moose easily excels all living Deer in size, measuring about six feet at the shoulder, while its antlers may.span five feet in width. It attains its greatest size in America, and especially in Alaska; the illustration was taken from a splendid Alaskan bull mounted in the South Kensington Museum: 
this animal, by the way, is darker on the legs than usual, Elk usually having the limbs much lighter than the body-nearly white, in fact. But, as with so many animals, there is much variation in depth of colour in this species. The Elk, wherever found, is essentially a forest animal, and, its structure rendering it unsuited for grazing, it feeds on the foliage and twigs of trees; it is a very destructive animal in the forest, rearing :up on its hind-legs to eat off twigs growing high up, and "riding down" young trees by straddling the stem and pressing then down till it can reach the crown. The; mountain-ash is a great favourite with it, and where Elk are at all common this tree gets fairly eaten out of the forest.

In summer time it varies its diet with water-plants, wading in to feed on the leaves of water-lilies, and plunging its head under to pull up their roots. Owing to its broad spreading hoofs, it is at home on marshy ground, and is particularly fond of water, this taste being not at all uncommon among the Deer family. It swims with great power, and higher out of the water than other land animals.

Its ordinary gait is a walk, and it moves through the forest very skilfully, avoiding touching the twigs in a most marvellous way, considering its huge antlers; it trots well and swiftly, and is very enduring at this pace, but, like the Eland, cannot gallop for long at a time.

This is not a gregarious animal, though at times a single family may be found together. The bull has no ambition to own a harem, but he mates more than once in a season, the attachment of the pair being short-lived. A most keen-scented and quick-eared animal, he is difficult to approach at other times, but in the breeding season in autumn he loses his caution to a great degree, and becomes fearless. and even aggressive.

He not only uses his horns in attack, but, like many Deer, is a skilful boxer, and his terrible chopping blows with the fore-feet are greatly dreaded: the cow, when with a calf, is almost equally dangerous, as she practises the same tactics. The bull is often lured to his doom at the breeding season by imitations of the roar of his mate; for at this time of the year the females call as well as the males. 
The cow Elk drops her young in spring; she is more prolific than any other equally large animal, frequently having twins.

In winter, Moose are exposed to great danger from the attacks of man and Wolves, as they cannot travel well on "crusted" or surfacefrozen snow, owing to their great weight, which causes them to break through. To avoid as much as possible the necessity of travelling about at this time, they "yard," as it is called; this means that one or more animals select a sheltered piece of forest with plenty of their favourite trees, and keep to it, their constant travelling over the same ground beating down the snow and giving them a safe range-safe, that is to say, against the Wolf, which dares not face the great Deer in a fair fight; but, of course, once a hunter finds the "yard," the unfortunate inmates are more or less at his mercy. If wounded, they do not die unavenged if they can help it, for an infuriated Moose is one of the most dangerous of animals. At the beginning of the new year the bull drops his antlers, and these are renewed by autumn.

So large a beast as this has, of course, always been greatly subject to human persecution; which has exterminated it over much of its range. In Europe it is now confined to Scandinavia, Northern Russia, and East "Prussia: in classical times"it was widely spread in Europe, and even inhabited Britain. Its equally large and far more beautiful rival, the Giant Fallow-Deer, became extinct long before the dawn of history, unless the unknown beast called the "Schelch" in the "Nibelungen Lied," and mentioned as distinct from the other ancient European big game, Aurochs, Bison, and Elk, was this animal.

In America it still exists as far south as the northern parts of New York, and is well known in Canada. It is, of course, greatly esteemed both there and in Europe as a sporting animal, and its meat is not to be despised. In former times it was trained as a sledge animal in Scandinavia, and showed such speed that its use was prohibited as facilitating the escape of criminals-a measure which does not say much for the police efficiency of the government of the period: it might very well be tried again for use in the countries it 
naturally inhabits, where transport in winter is always a matter of more or less difficulty. There seems to be plenty of evidence that this formidable creature is really one of the most easily tamed of the Deer tribe when taken young enough, and the experiment has been tried on both sides of the Atlantic.

Notwithstanding this, the Elk is not a common animal in captivity, and at the time of writing there has been no representative of the species in our Zoological Gardens for some years, though several have in times past been on view there. A praiseworthy attempt is being made to introduce this grand beast into New Zealand, where it certainly would greatly add to the attractions already offered to sportsmen by that enterprising colony.

\section{THE MILOU DEER}

(Cervus davidianus)

THis curious Deer is not closely related to the Moose or to any other species. It is about as big as the Red-Deer, but clumsily formed, with a Donkey-like appearance, especially about the tail, which is longer than any other Deer's, reaching down to the hocks and ending in a tuft. It carries its head low, and, according to Mr. Lydekker, trots like a Mule, with an action quite unlike that of its family generally. Its antlers are very ugly, and of an altogether peculiar type. There is no brow-tine, but a long straight beam merely forked at the tips, and sending out a long branch from the back near the base.

This Deer is fond of water, and feeds on water-plants when it can; it has a braying call. The coat is plain brown in the adults, and spotted with white in the fawns. Its native home is unknown, as it has only been seen in the Imperial hunting park at Pekin, and I believe it is not to be found there since the recent troubles in China, so that the only known specimens of the race now living are the small herd in the Duke of Bedford's park at Woburn; specimens have also been exhibited at our Zoological Gardens. Of course there is a possibility that some traveller will rediscover it in a truly wild state, so that it is worth while to draw attention to it here. 


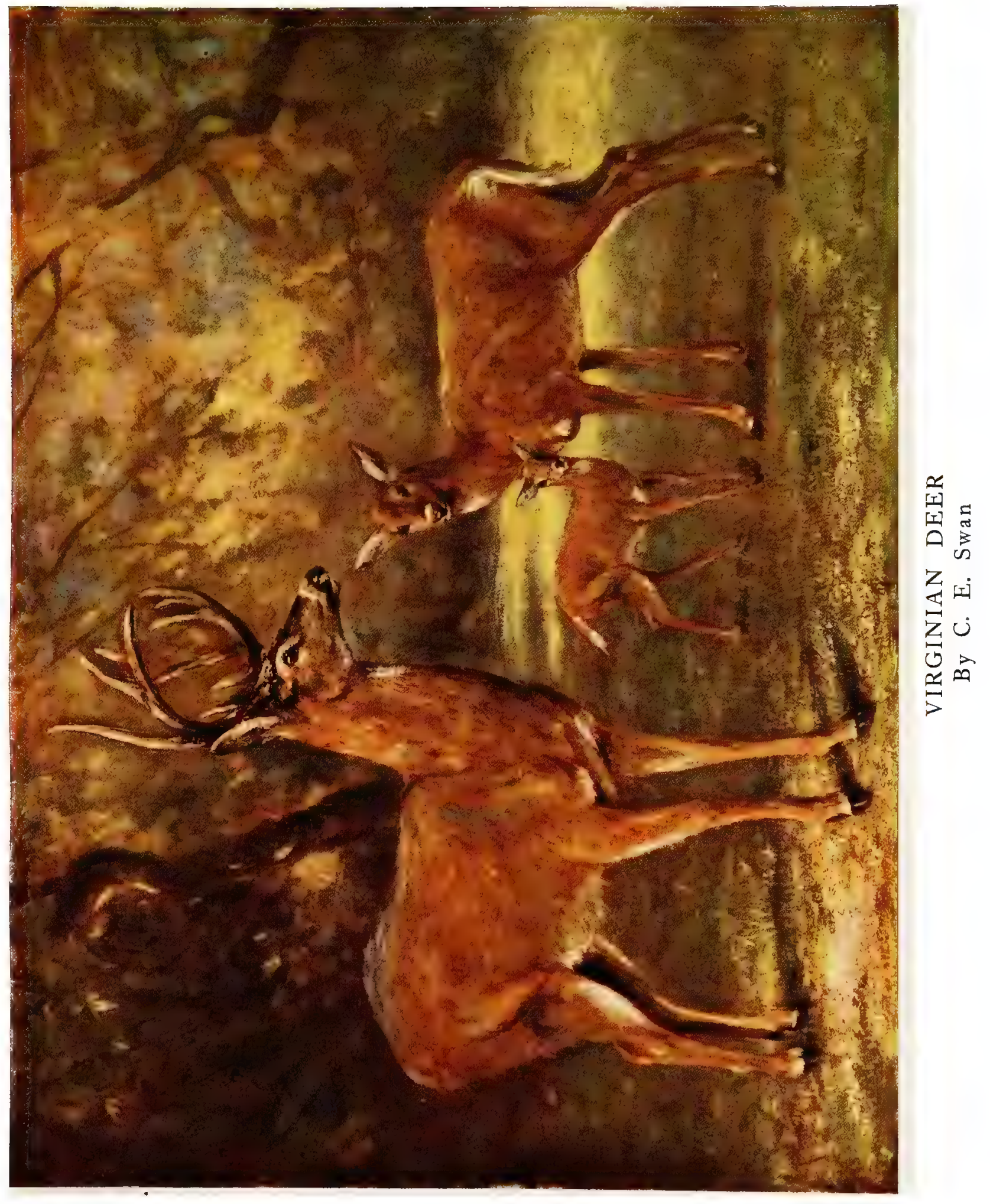





\section{THE VIRGINIAN DEER}

(Cariacus virginianus)

THE Virginian or White-tailed Deer, as it is called in its own country, is far the most abundant and widely-spread Deer in North America, and continues to exist even in long-settled districts where any woodland remains.

It is about the size of our own Fallow-Deer, and equally graceful in form, but differs very much in colour of coat and style of antlers. The general hue is reddish brown in summer and grey in winter, the difference being usually very marked, though there is much individual variation. The fawns are usually white-spotted in the orthodox Deer fashion, but self-coloured ones, like that in the illustration, a British Museum specimen, are not uncommon; and $\mathrm{Mr}$. Lydekker records a case in which a doe in captivity bore a spotted one and a plain one together-the normal number at a birth in this species being two.

The antlers of the buck, like those of all purely American Deer, are of a very different type from those of the Old World species. It will be noticed, for instance, that there is no brow-tine, while the style of branching is quite different, and the beam bends abruptly forward in a peculiar way. The length of the horn is about two feet. The typical race of this Deer inhabits the eastern side of North America, from Maine southwards, but different races or local varieties of it range through the Western States, down through Mexico and Central America, even into Peru and Bolivia in the southern half of the continent. As so often happens, the southern races are much smaller than the northern or typical form of the species.

This Deer is a woodland species as a rule, and is very shy and wary ; indeed, it is owing to its cunning that it is enabled to maintain itself so well in the neighbourhood of man, though it is nowadays also protected as a sporting animal. When rushing off, its tail, which is rather long for a Deer's, and conspicuously white for the most part, 
is strikingly displayed, while the head is carried low. Like so many Deer, it is very fond of water, and will often wade in after waterlilies, like the Moose. In the ordinary way, like most other Deer, it both grazes and browses on tywigs and leaves, and is very fond of beech-mast.

This is the Deer ordinarily hunted by American sportsmen, Deershooting in the Adirondack ranges of New York State being one of the recognised pastimes in the States.! It does well and breeds freely as a park animal; over here as well as in its native country; but is not often kept in :England. No. Deer becomes so tame and confiding as this species does in many instances, but it is also capable of showing itself extremely vicious, so that it evidently cannot be implicitly trusted.

\section{THE MULE-DEER}

(Cariacus macrotis)

THE Mule-Deer is one of the most distinct and handsome of American Deer; it is rather larger than the Virginian at its best, and has particularly big ears, whence its: name. As its tail is tipped with black, it is often called the Black-tailed Deer, though this name more properly belongs to another American species (Cariacus columbianus). The antlers of the Mule-Deer are very handsome, and branch in a characteristic and peculiar way; : a little distance above the head the beam forks into two like a letter $Y$, and each of these branches similarly forks again, producing a very symmetrical "head." The whole antler is usually over two feet long. The colour of the coat is brown in summer and grey in winter, with white on the face, underparts, and base of the tail.

The Mule-Deer is widely distributed over western North America; it keeps in small herds, and in habits is more like an Antelope than a Deer, frequenting dry open country more than woods, and feeding chiefly on grass. It is a fine hill-climber, and also appears to be the swiftest of the Deer, which are not, as a rule, very fast animals compared with the average Antelope; at any rate, it appears to be able to escape, from both Wolves and Greyhounds. It has thriven well and bred remarkably freely in our Zoological Gardens. 


\section{THE PAMPAS DEER}

(Cariacus campestris)

THE Pampas Deer is a small species, light brown in colour, and with three-pointed antlers in the back. This is one of the few open-country Deer, inhabiting the grassy plains found in some parts of Brazil and ranging south over the Argentine Pampas to Patagonia. It is chiefly remarkable for the extremely strong nauseating smell emitted by the buck, which is said to be perceptible a mile off, so that he would appear to be worse than the Skunk as a scent-diffuser.

\section{THE HUEMUL}

\section{(Xenelaphus bisulcus)}

THE Huemul is a smaller and stouter-built animal than the FallowDeer, brown in colour, with the buck's horns showing two nearly equal spikes only; it ranges along the mountains of South America from Chili to Patagonia, and sometimes comes out on the plains. Where it has not met with men, it is extraordinarily tame; Mr. Hesketh Prichard, in his book on Patagonia, mentions a case in which a doe came up and smelt him, and her mate made as if to turn him over with his horns.

\section{THE BROCKETS}

THE Brockets are a number of small species of Deer from Central and South America, in which the horns are reduced to short single spikes; their tails are very short also. The best known is the Red Brocket of Brazil (Cariacus rufus), which has been often exhibited at the London Zoological Gardens; this is also the largest, but is not much over two feet at the shoulder. It is a solitary animal, frequenting either forest or grassy plains, and very destructive to crops.

\section{THE PUDUS}

The Pudus (Pudua) are very like the Brockets, but still smaller and with shorter horns. They inhabit Western South America, and the Chilian Pudu is the smallest Deer known, being little more than a foot at the shoulder. The only other kind, found in Ecuador (Pudua 
mephistopheles) is not much bigger, and is noteworthy as being the only ruminant which has no tail at all.

\section{THE ROE}

\section{(Capreolus caprea)}

Although an Old-World Deer, ranging from Great Britain to the Caucasus, this species is more nearly allied to the American types just described. It is a small animal, little over two feet at the shoulder, with long ears and a very short tail; the legs are long and the build very graceful. The buck's horns are seldom a foot long, rough in the beam, and carry three points, but have no brow-tine. The coat is red in summer, grey with a white patch on the stern in winter; the fawns, of which there are two at a birth, are spotted as usual.

The Roe is found solitary and in pairs or families, and is a woodland animal; it is a most graceful creature, and is often kept as a pet on the Continent. The buck, however, in spite of his small size, is a very dangerous animal. It is only nowadays found in the northern parts of Great Britain, and does not thrive so well in parks as our other Deer. In Siberia its place is taken by a much larger Roe (Capreolus pygargus), which may be as big as a Fallow-Deer, and often migrates in large herds.

\section{THE WATER-DEER}

(Hydrelaphus inermis)

This curious Deer, which agrees with the Musk-Deer in having long upper canine tusks in the buck instead of horns, seems to be allied to the Roes. It is a small animal, less than two feet at the shoulder, and light brown in colour. The fawns are spotted, but not very distinctly; a great peculiarity of the animal is the number of them it produces at a birth-from three to six-thus showing a prolificacy unrivalled among ruminants.

The Water-Deer is found in Eastern China, where it lives in the long reeds by the water-side, and on river islands; it swims readily, and has a bounding action when on land. Its venison is only moderately good, or it might be a good subject for acclimatisation, especially as it does well in our climate, though seldom imported. 


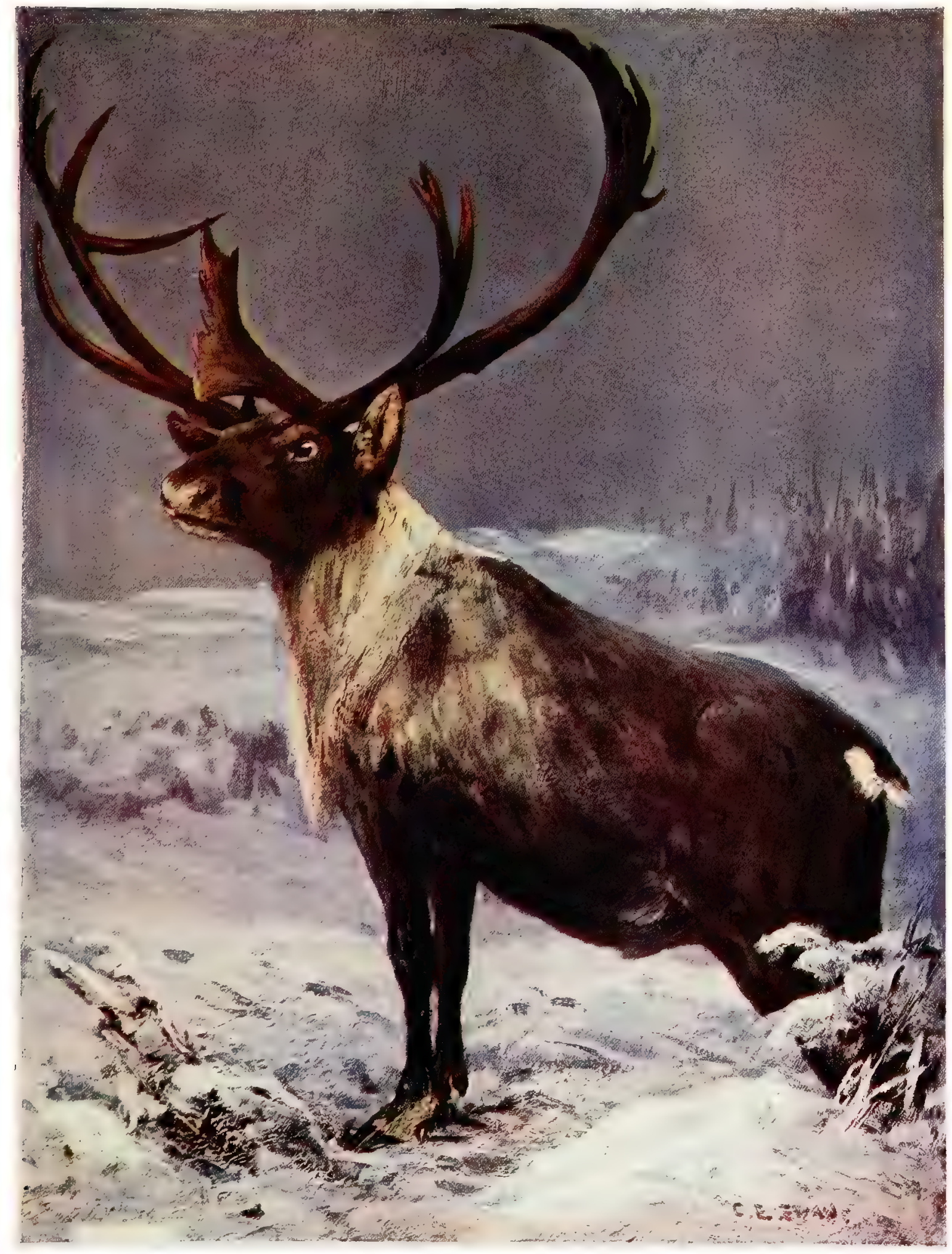

REINDEER

By C. E. Swan 



\section{THE REINDEER OR CARIBOU \\ (Rangifer tarandus)}

LIKE the Elk, the Reindeer is an example of an animal inhabiting both worlds, but known by a different name in each; for the Caribou of America is not regarded as a different species from the Reindeer of the Old World, though presenting some slight differences, not important in an animal so variable locally as this is.

It is very strikingly different from all other Deer, and, with the exception of the misshapen Moose, is the least elegant of the family, its large head, usually carried low, short thick neck and legs, and sturdy build more suggesting an Ox than one of the graceful and elegant Deer family. It is a large animal, often considerably exceeding our Red-Deer in size. The ears and tail are both short, and the feet broad, with great power of expansion, so that they readily support the beast on a yielding surface like snow or mud. The back or false hoofs are larger than in any other species except the MuskDeer.

The coat is very thick and close, and varies a good deal in colour, some specimens being much whiter than others. The white neck is a very marked character in some American races, from one of which the illustration is taken; the females show less white than the males, and the winter coat is whiter than the summer one. The young fawns are not spotted, like those of most other Deer.

The antlers of the Reindeer are altogether peculiar, and can be distinguished at once from those of any other Deer, though in no other species are they more variable, both individually and locally. Especially to be noted is the fact that the brow and bez tines are forked or flattened, while the tres tine is absent altogether; the beam is strongly bent, and is often flattened at the end.

Often, especially in the American Caribou, one brow-tine is very 
large and branched, while the other is of the ordinary prong-like shape, and other instances of asymmetry occur. The antlers often attain a very great size, sometimes measuring over five feet along the curves of the beam; the horns of the American forest race, known as Woodland Caribou, are peculiarly short, but well-branched, while some races have very straggly-looking horns.

This is the only: Deer in which the does usually have horns as well as the bucks, though individual cases of horned does havevery rarely-been recorded in other species. The horns of the females, however, are much smaller and less branching than those of the males, and in Kazan the female Reindeer are said to be hornless. The two sexes shed their horns at different times, the does dropping them much later than the bucks, and not forgetting to remind their partners of their defenceless condition while they have the chance to assert themselves.

The antlers are developed very early in the life of the animalbefore it is two months old, in fact, whichever the sex, whereas those of other Deer do not make their first appearance till it is nearly a year old or even : more.

The Reindeer is one of the characteristic animals throughout the Arctic regions, being found as far north as Nova Zembla and Spitzbergen, but also ranging south as far as the Kirghiz steppes and Lower Canada. It is migratory wherever the character of the country permits it, and in classical times seems to have been found as far south as Germany. In spite of its awkward appearance, it is an active animal, being able to travel for long distances with great speed, and to negotiate the most difficult ground; it is a good hill-climber, and in Scandinavia affects the high "fells," while at the same time, unlike most mountain animals, it can traverșe soft ground easily, and can, in fact, get along over swampy country where any other animal would inevitably succumb; a tame individual has been seen to be bogged up to the horns, and then extricate itself without assistance. It will also manage to get along through soft snow, travelling by bounds like a gigantic Rabbit: generally, however, it does not bound or leap like 
other Deer, and will crawl under an obstacle rather than jump over it. It is the fastest and most powerful swimmer of all Deer, and swims higher out of the water than any other beast, buoyed up by the air entangled by its thick coat.

With the exception of the Woodland Caribou of America, which keeps to cover and is found only in small numbers together, the Reindeer affects open country and is found in large herds; the Barrenground American race, which lives north of the forest limit, is said not to interbreed with its forest relatives, even when they meet.

The staple food of the Reindeer is the celebrated Reindeer "moss" -a lichen which grows abundantly in the north; it also feeds on any other available vegetation-grass, shoots of trees (where available) and bushes, and even seaweed. When its food is concealed under the snow, it reaches it by pawing with its fore-feet, the idea that the expanded brow-tine is a "snow-shovel" being apparently a mistake. It has, like so many Arctic animals, a great power of elaborating fat, and lays on more of this than any of the Deer when food is obtainable; but, of course, it often has to suffer much privation during the long winters, when the surface of the snow is liable to freeze hard.

The Wolf is a deadly enemy to it in winter, and it is also much subject to the attacks of insects, such as gadflies, in summer. It is a wary and restless animal, always ready to shift its ground if hunted.

Its meat is, of course, a very important article of food to the natives of the countries it frequents, and the skin is also of value, and many are sent to England, while the antlers are extensively exported also.

Most important of all, however, is the utility of the Reindeer as a domestic animal, in which capacity it has been known from very ancient times, both in Europe and in Asia; the Caribou of America has never been domesticated, but Lapland Reindeer have been exported to Alaska.

The value of this creature to the northern tribes who use it is invaluable, as no other animal could supply its place; since it furnishes meat, milk, hides, and is also used as a working animal. In this 
capacity it is generally yoked to a sledge, either singly, as in Lapland, or several abreast, as in Northern Asia. Some tribes in Asia also ride their Reindeer, which are larger than the European breed; but, generally speaking, tame Reindeer are not so large and fine as wild ones, and they are also more variable in colour.

Reindeer will live in our climate, but do not thrive very certainly, though they have often been exhibited in our Zoological Gardens; they certainly ought to be introduced into the cold regions of the southern hemisphere, where there is at present a complete absence of land mammals, so that they would be of great service to those forced to spend any length of time in the inhospitable islands of these southern seas. 


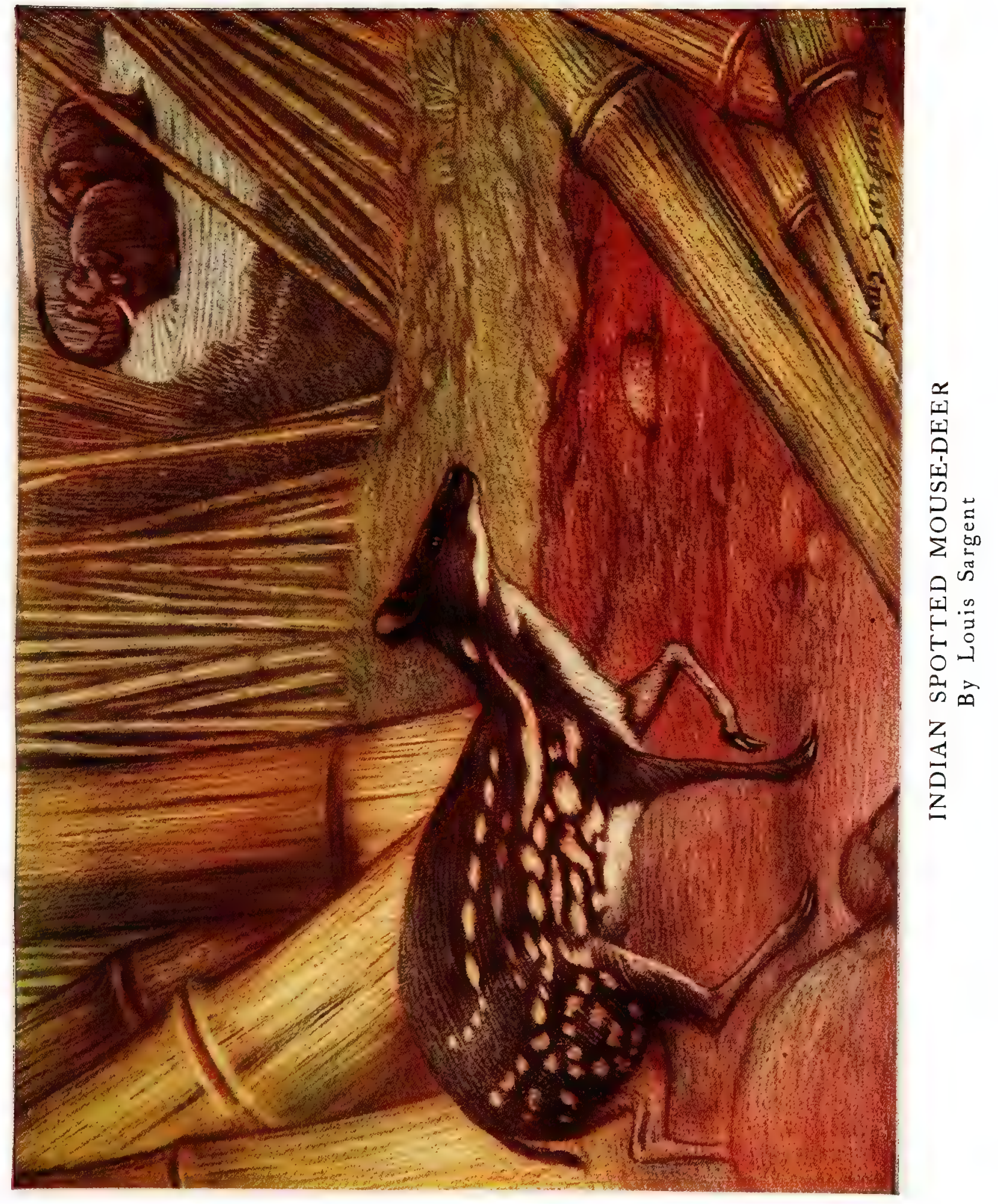





\section{THE INDIAN MOUSE-DEER}

\section{(Tragulus meminna)}

THIs insignificant-looking little animal is one of the small family of Chevrotains (Tragulida), as they are often called in books, which represent a very primitive type of ruminant, and give us some idea of what the ancestors of Deer and Antelopes were like before they developed horns.

Even the typical ruminant stomach is not fully developed in the Mouse-Deer, although it chews the cud. This organ should consist of four compartments-the paunch, honeycomb bag, manyplies (a chamber with longitudinally pleated walls, and the rumen or true stomach-but in the present animal the manyplies is not developed.

The slender limbs also show a primitive feature unknown in the higher ruminants; the small back hoofs, which represent the second and fourth toes, are really the terminations of complete toes, the bones of which are hidden under the skin, whereas in other ruminants this is never the case, only the lower ends of these toes remaining, even when they are present at all.

The teeth of the Mouse-Deer also show a primitive feature in the front grinders being narrow-topped and pointed, not broad and suited for crushing, as all the grinders of ruminants usually are. The long tusk-like upper canines of the male, though much less developed, of course recall those of the Musk-Deer, and there has been much confusion between the two groups, the Chevrotains having long been regarded as allies of that animal, although they have no special relationship to it any more than to other Deer, except in so far that it is also a primitive type, though not nearly so much so as the MouseDeer are.

As in the Musk-Deer, the canines of the female Mouse-Deer are short; indeed. in none of the ruminants with long tusks in the males 
are these organs well developed in the female, and, as they never occur along with large horns, they appear to be primitive weapons which the more highly organised ruminants have been able to dispense with as their horns became more efficient.

The Indian Mouse-Deer does not measure more than a foot at the shoulder, and is not so big and heavy as a Hare; its curious olivebrown coat with white spots will, distinguish it from any other animal.

The colouration, however, recalls that of many young Deer fawns, and no doubt is another primitive peculiarity, since the coat or plumage of young beasts and birds often appears to "hark back" to their ancestors. The young Chevrotains, however, are apparently always like their parents, even when these are self-coloured.

In its habits the Mouse-Deer is singularly unobtrusive; it is usually solitary and chiefly nocturnal in its habits, so that, although widely spread over Southern India in forest tracts, and also found in Ceylon, it is comparatively very little known. In the daytime it hides. among rocks, and here the doe drops her young, which are usually twins. The gait of the little animal is peculiarly stealthy; it carries its head low, and steps daintily along on the very tips of its tiny hoofs. Some of the poses of Chevrotains show their primitive character very well; unlike other ruminants, they sometimes sit up on their haunches like a Cat or a Dog, and when lying down do not incline to one side, like hoofed animals generally, but rest on a level as it were, with the fore-feet tucked under them.

This little creature is not very common in captivity, but it has bred in that condition, and has often been exhibited at the London Zoological Gardens, where all the species of the family have been on view at one time or another. Mouse-Deer should be fed and treated much like Rabbits, appreciating such food as salad, sliced carrots and fruit, bran, \&c. It is important not to keep them constantly on a hard floor, as they are subject in that case to enlargement and soreness of the hocks, while damp is also injurious to them-at any rate, in the case of the Asiatic species. Except that the males will, as 
might be expected, maltreat each other, they are harmless little things; and in one case, when one of the present species was kept in the Calcutta Zoo in the aviary along with some birds, I noticed a hen Gold Pheasant had struck up a friendship with the little Deer, and always kept near it.

\section{THE KANCHIL}

(Tragulus javanicus)

THE Kanchil, or Little Malay Chevrotain, is the smallest of the family, and thus the smallest of ruminants except the little Royal Antelope of West Africa. It is, in fact, about as big as an ordinary Rabbit; its coat is of a rich red-brown, with the under-parts white, and the throat streaked brown and white. The tail is longer than in the spotted Indian Mouse-Deer. The Kanchil ranges from Malacca to Java, and, like all the family, is a forest animal. Its name, in Malay, means "little," and in the folk-tales of the Malays it stands for the small, weak, but cunning creature which outwits stronger ones by dint of brain-power and resource, just as the Rabbit does in Negro. stories, and the Wren in European fairy tales. In the case of the: Kanchil, at any rate, there is probably some foundation for this view of its character; for, unless these little primitive creatures are very cunning, it is difficult to see how they have existed for so many ages, since they have neither great speed nor defensive weapons, and are not highly prolific.

\section{THE NAPU \\ (Tragulus napu)}

THE Napu is the largest of the Asiatic Mouse-Deer, rather exceeding the Indian spotted species in size. In colour, however, it is very similar to the Kanchil, and, like that species, has a longer tail than the Indian one. It has much the same range as the Kanchil, but is not nearly so abundant an animal. Apart from the great difference in size (the Kanchil being only about eighteen inches long from nose 
to tail, and the Napu nearly a foot more), the two species can be distinguished by the difference in the brown-and-white streaking on the front of the neck, the Napu having five white streaks here, while in the Kanchil there are only three.

\section{THE WATER CHEVROTAIN}

(Hyomoschus aquaticus)

This animal is the only other species of Mouse-Deer known, and is the only one found away from Asia, its home being in West Africa. It is the largest of the known species of the family, being considerably bigger than the Napu, and more heavily built in proportion to its size, the legs being less slender and delicate.

In the structure of the limbs also, it is more primitive even than the other Mouse-Deer, for the supporting bones of the large third and fourth toes which form the "cloven hoof" are not fused inte a "cannonbone" as in all other ruminants, even the other Mouse-Deer, but remain separate beneath the skin; thus, as in the Pig, all four toes of the foot are distinct in the skeleton.

In colour the African Mouse-Deer combines the peculiarities of the Asiatic species; it is spotted and striped as in the Indian kind, but the spotting, which is pure white, is on a red ground like the coat of the Eastern or Malayan species. This creature is found along the sides of rivers and streams, and, though specimens kept in captivity during the last century did not display any of the aquatic proclivities with which this animal is credited in the wild state, the last individual the London Zoological Gardens possessed frequently entered the water to which it was allowed access.

That this creature is really a very ancient form is shown by the discovery of fossil remains of a very closely allied species in Greece, which was named Dorcatherium, before the present animal was known to exist at all; a fact which, with the discovery of the Okapi, encourages us to hope for yet more novelties - if the discovery of a supposed extinct type can be reckoned as such-in the wilds of the West African bush. 


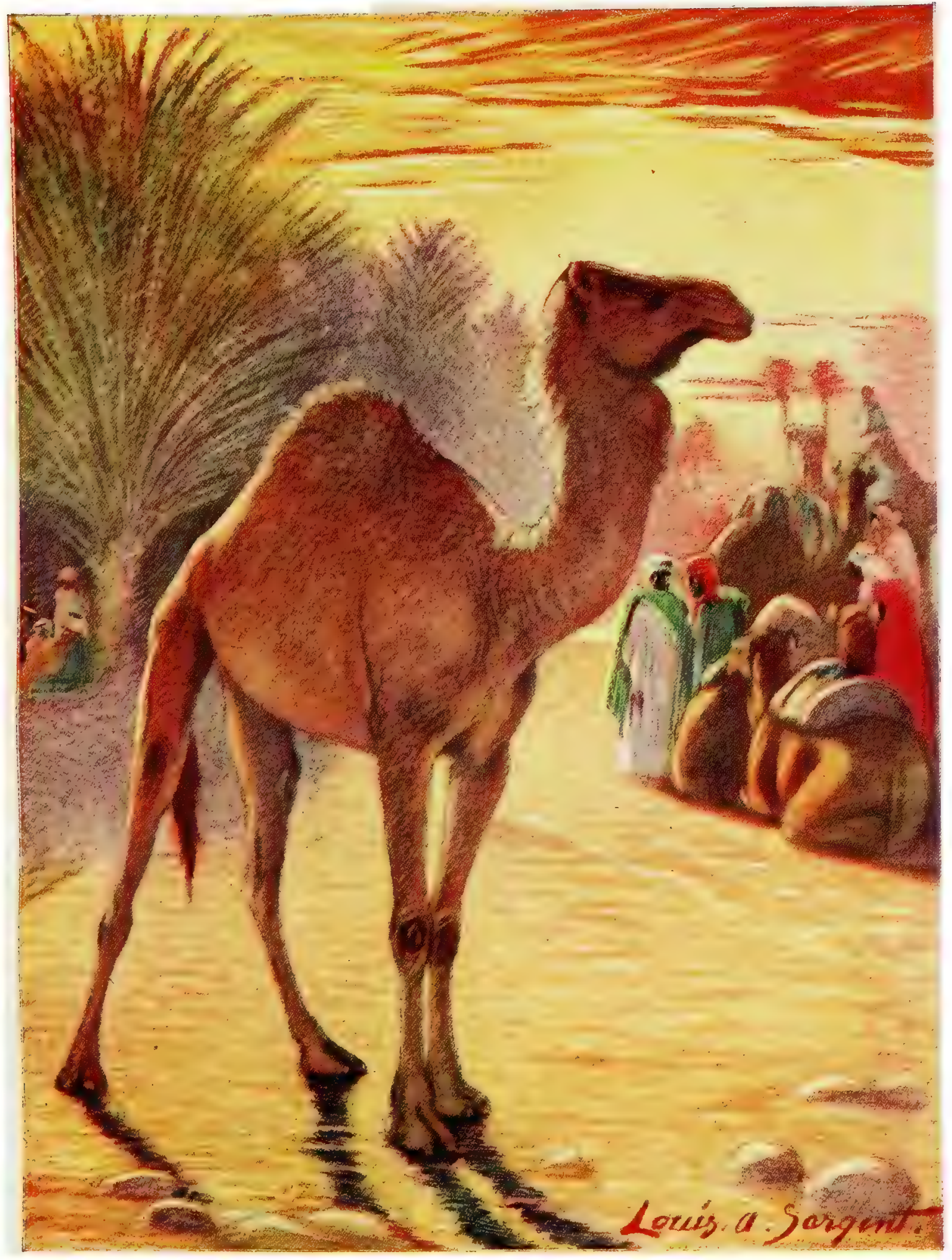

ONE-HUMPED CAMEL

By Louis A. Sargent 



\section{THE CAMEL}

(Camelus dromedarius)

Some apology is necessary for the introduction of so thoroughly domesticated an animal as the ordinary One-humped Camel into a book on Wild Beasts; for this animal has been so long and so thoroughly domesticated, that it is not known to exist anywhere in a primitively wild state. On the other hand, it is far too important a type to be left out, and it may be urged that no "wild beast show," stationary and scientific, or migratory and mercenary, is complete without Camels, while they have at any rate reverted to a wild state in parts of Spain.

The Camel is the representative of a small group of ruminant animals known as Tylopoda (pad-footed); they cannot be called hoofed in the ordinary sense of the word, as the two toes, third and fourth, which alone are present-there being no back toes-merely bear large blunt claws at their extremities, and the animals do not walk on the very tips of the toes as ruminants usually do, but the whole undersurface of the toes is applied to the ground. In the Camels, these toes, though distinct above, are confined below in a single broad horny pad or sole.

The Camel is also peculiar with regard to its teeth. In other ruminants there are no upper incisors whatever, and the lower canines are like incisors in shape, and lie close alongside of these teeth; but the Camel has a full set of upper incisors in its youth, and the outer pair are always present, though they are pointed canine-like teeth. Then the canines, present in both jaws, are typical in form, not incisor-like in the lower jaw, and the first grinders in the upper jaw are canine-like teeth; thus the Camel is well provided with teeth for biting, and, it may be added, has the will to use them on occasion; and in this it is greatly aided by the flexibility of its neck. 
The typical ruminant stomach is not quite fully developed in the Camel, which, like the Mouse-Deer, has not the third compartment or "manyplies"; it has long been known as remarkable, however, for the water-pouches, which are found in the walls of the first and second compartments, and by their muscular rims can be shut off from the rest of these cavities. This structure has reference to the Camel's famous power of abstaining from water, which, however, has been somewhat exaggerated; as a matter of fact, it can, generally speaking, go without water only about twice as long as the Horse, and cannot compare in powers of abstinence from fluid with the Giraffe and several of the Antelopes, which can live on a dry régime for months, though without any special arrangement for water storage in their interiors.

The characteristic hump of the Camel is not so important a feature as those above mentioned; it is chiefly composed of fat, which is gradually absorbed into the system in case of scarcity of food or other organic need. Hence a hard-worked and underfed Camel has a flabby hump, and a plump firm one is an unfailing sign of high condition.

The ordinary colour of the Camel is the sandy-dun represented in the illustration, and this is no doubt the primitive tint, as it is what might be expected in a desert animal; but black and white Camels are also found, though pied and spotted ones seem to be unknown.

There is much difference, also, in the various breeds of Camels, the ordinary slow-paced pack-Camel comparing with the swift and slender "Dromedary," which is a sort of Camel-thoroughbred, much as a cart-horse does with a racer.

The ordinary gait of the Camel is deliberate, and he moves the two legs on the same side together in a very characteristic way; but he is very enduring, and in this, as well as in his powers of bearing thirst and subsisting on the coarsest and driest herbage-and very little of that-his value as a beast of burden consists. When lying down, the Camel, like the Mouse-Deer, does not lean to one side like most hoofed animals, but lies down squarely, with the limbs bent under him, and the bare horny pads on the chest, knees, and stifle- 
joints are adapted to this position: This Camel is kept throughout the hot, dry, and barren districts of Africa and Asia; and he is especially fitted for such countries; in fertile districts, where the Horse and $\mathrm{Ox}$ can be employed for the same work, he is of comparatively little use; and he is extremely destructive to trees and shrubs, devouring branches as thick as a man's little finger. His docility and patience have been rather over-rated; he is really a rather ill-conditioned animal, given to biting very severely and to grumbling, gurgling, and growling, not only at the proverbial "last straw," but at the first. In the breeding season the bull Camel is positively dangerous, and at this time he blows out a red bladder from his throat, to the accompaniment of a bubbling noise.

The female produces one calf at a time, which is able to follow her immediately, but is suckled for the whole of its first year.

Camels are, as is well known, chiefly employed as pack-animals, and will carry a load up to five hundred pounds, but they are also employed to a limited extent for purposes of draught. They are never bitted, but controlled by a ring through the nose. For many years past they have been much employed in Australia, a country for which they are peculiarly well suited. They are very surefooted on almost any sort of ground, being as good at hill-climbing as in marching over the level desert, though they do not like really loose sand more than any other creatures. They are very awkward swimmers, being, apt to overbalance in the water, and their long loose limbs are apt to slip laterally, and get dislocated in marshy groundso much so that if they have to be taken over such country, it is usual to tie their hocks together. Yet Camels brought up in marshy land will be accomplished "bog-trotters," and it is a curious fact that these desert creatures have run wild in the Spanish marshes, where they wade about like so many quadruped Flamingoes.

Both the meat and milk of Camels are utilised by the Arabs, and their woolly hair is used for the manufacture of cloth, while their bones are valuable for inlaying work, being nearly as dense as ivory. 


\section{THE BACTRIAN CAMEL}

(Camelus bactrianus)

ThE Bactrian or Two-humped Camel is in all essential points of structure very similar to the one-humped or Arabian species; but is more stoutly and heavily built, and has a much heavier coat, to say nothing of the characteristic two humps instead of one. It presents much the same colour variations as the ordinary Camel, with which it is sometimes crossed, and produces a hybrid which has but a single hump. These mule Camels are in some respects better working animals than pure-bred ones; they are capable of reproduction, but the second cross animals are not good for much.

The Bactrian Camel is the characteristic Camel of temperate and cold climates, being kept from Southern Russia through Central Asia to China; it can endure intense cold, and some tribes possess both this animal and the Reindeer. Like the ordinary Camel, it is chiefly used for burden, but sometimes for draught, and is exceedingly frugal and hardy. In the Gobi Desert it is found in an apparently truly

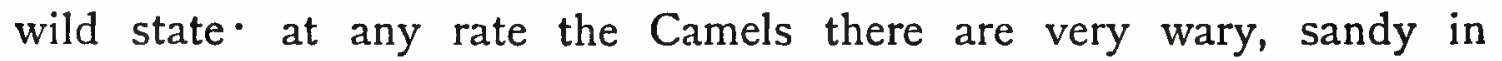
colour, and with comparatively small humps; a specimen can be inspected in the South Kensington Museum.

In European menageries this Camel thrives admirably, as it finds nothing uncongenial in our climate; the pair at present in the Zoological Gardens breed regularly, and it may be observed that the baby Camel has the humps in the form of mere flaps of skin at first, filling out and standing up as the little animal grows. 


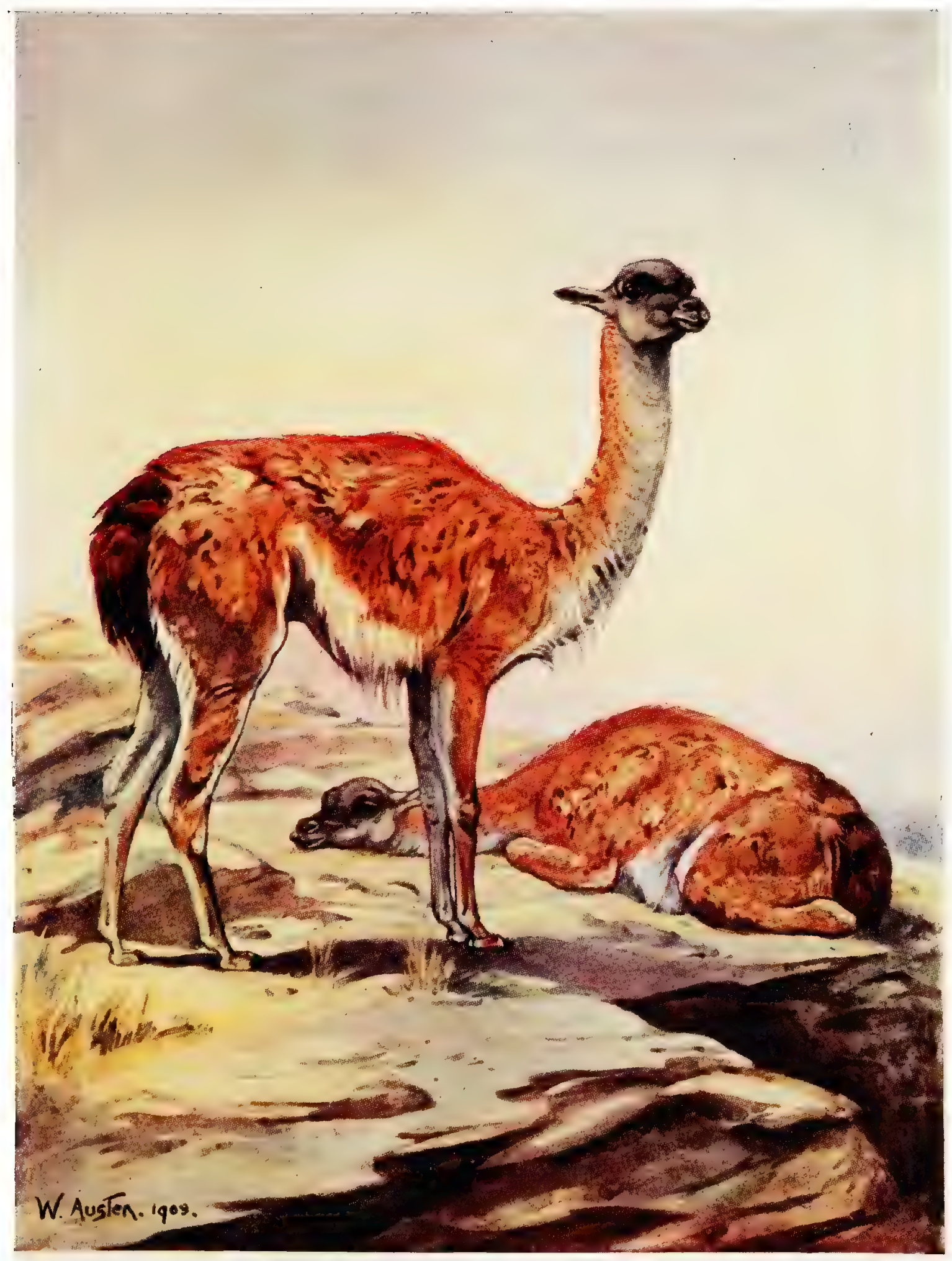

GUANACOS

By Winifred Austen 



\section{THE GUANACO OR WILD LLAMA}

(Auchenia huanacus)

THE Guanaco and its ally the Vicugna are the American representatives of the Old-World Camels, and the only other members of the family Camelida. The resemblance of the Guanaco to the Camel is obvious at once, although it has a very straight back instead of the familiar hump, a much shorter and bushier tail and longer ears, and the toes almost completely divided, instead of being united below into a single pad, so that the foot is very like that of a two-toed bird.

The resemblance extends to points less easily observable; the Guanaco has essentially the same structure of stomach as the Camel, with its characteristic water-pouches, and also possesses, like that animal, the canine-like outer incisors and pointed canines, though it has not the canine-like premolars.

In size the Guanaco is about equal to our Red-Deer, and in appearance, as the illustration shows, a very elegant creature; a characteristic point of its appearance is the way in which the body is "tucked up" at the loins, as in a Greyhound. The coat is of a woolly nature in the body, and very soft and fine. There is not much variation in colour, but some specimens have the face blacker than others, and white and pied varieties may occasionally occur.

The range of the Guanaco is very wide, extending over the temperate parts of South America generally, from the Andes of Ecuador to Tierra del Fuego. It is a very active beast, being equally at home on rocky slopes, in ascending and descending, while it shows itself remarkably sure-footed, and showing great speed when on the open plains. It is a particularly common and characteristic animal in Patagonia. Its food consists of such herbage as may be found about its haunts, and it seems to be able to live on very little, as it is sometimes found in the most barren localities, and, in some cases, appears to drink either 
salt water or none at all. For all their hardiness, however, the severe winters of Patagonia are often too much for the Guanacoes, and in many places there may be found large deposits of the bones of the unfortunatè animals, generally in some sheltered locality near water, whereto they have resorted in the vain hope of picking up some nourishment.

Guanacoes are essentially gregarious, and are usually seen in large herds; one buck will accumulate a harem sometimes numbering as many as a hundred does; but this he does not manage without a struggle; for, in spite of their harmless and innocent appearance, these creatures are savage and quarrelsome to a degree, and any old veteran is pretty certain to be well marked with scratches from the teeth of former rivals, especially about the neck, which is the main point of attack. As, however, the skin here is very thick, the combatants cannot hurt each other very seriously. The Guanaco also attacks by rearing and striking its adversary with its knees; besides which it spits freely, though one would think that this method of offence would not much impress a serious enemy, though disconcerting enough to a visitor to a menagerie. The note of the animal is a laugh or neigh, and the buck will often thus challenge intruders on his domain, for, though wary when it has been at all hunted, the Guanaco is very inquisitive, and has some idea of resenting the intrusion of strangers.

Its natural enemy is the Puma, which, where they occur together, makes it a principal object of pursuit, springing on it and breaking its neck; sometimes the Guanaco will make a brave resistance to its foe, but very seldom with success. The young are also attacked, by the Colpeo (Canis magellanicus), a large, Wolf-like Fox; but this animal does not range far out on the plains. The Patagonian Indians-now, alas! sadly reduced in number-also hunt the Guanaco keenly, as it forms their principal means of subsistence. It is true that its flesh, which is like lean mutton, is not so much esteemed by them as that of the "Ostrich" of Patagonia-really Darwin's Rhea (Rhea darwinii), which is more palatable and nourishing; but as the bird is much more wary, it is often a case of Guanaco venison or nothing; and 
besides, they need the skins of the old animal for making their "toldos" or tents, and, those of the young for their own clothing. The Guanacoes are hunted with the bolas-balls connected by thongs and thrown at the animals; and the aid of Hounds is requisitioned, the Guanaco Hound being apparently yery similar to a smooth Lurcher or the Kangaroo Hound of Australia.

It may be mentioned that Guanacoes take to the water readily and swim well, unlike their relative the Camel. The Guanaco is the wild ancestor of the Llama, the only large domestic animal possessed by the American aborigines at the time of the Spanish conquest of the New World-in fact, the only other domestic animals found there at all were the Dog, Guinea-Pig, Turkey, and Muscovy Duck.

The Llama has a heavier coat than the wild Guanaco, and is most often white in colour, though, like most domestic animals, it varies a good deal; thus, of the pair at present in the London Zoological Gardens, the buck is black, with a white "blaze" on the face, and the doe white, with the head marked with fawn-colour. Llamas breed well in Europe, and are to be found in most menageries. Their original use was as pack animals, and they can be ridden, but their habit of spitting is highly objectionable. Apropos of this, I may mention that, though this nasty trick was noticed in the earliest account of the Llama, written in the middle of the sixteenth century, and though I have often heard from eye-witnesses of the animal's expectoratory performances, I have never seen the feat performed myself, though a constant frequenter of Zoological Gardens; and I mention this to show how cautious one ought to be in disbelieving accounts of unusual habits in animals, merely because one has not had personal experience in any particular case.

Another domestic breed of the Guanaco is the Alpaca, which is smaller than the Llama, and usually black, or nearly so. Its fleece is very long, reaching nearly to the ground, and hanging all over the face. It is solely on account of this wool that the animal is bred, being kept in large flocks on the mountain pastures and regularly shorn. The name of the animal is, indeed, more familiar than that of 
any other of this group, owing to the large use of Alpaca wool in making various fabrics. This animal would be a good subject for introduction into some of our colonies where suitable conditions exist, and, indeed, it was tried in Australia, but the herd imported did not thrive, possibly on account of the heat of the climate, unsuitable for mountain animals; New Zealand would probably have been better.

\section{THE VIC̣UGNA}

(Auchenia vicuna)

The Vicugna is a considerably smaller animal than the Guanaco, and has a shorter head even in proportion to its size-indeed, it might very easily be mistaken for a young specimen of the larger species, as its colour is very similar. It may, however, always be distinguished by the absence of the bare patches found on the stifle-joint of the hindlegs in the Guanaco, which agrees in this respect with the Camel. The Vicugna is found high up in the mountains of South America from Peru to Central Bolivia. In general habits it much resembles the Guanaco, but is, unlike that species, purely alpine, and never occurs in the plains.

Its wool is peculiarly fine and soft, and the animal would be well worth domesticating, as, of course, this product can at present only be obtained by hunting the wild animals. A worthy priest in Peru, the Curé Caprera, once succeeded in producing hybrids between the Vicugna and Alpaca, which bore fine fleeces and were fertile, but poverty fell upon him, and the valuable breed was lost. There would be no difficulty, however, in repeating the experiment, for the Vicugna thrives in captivity as well as the Guanaco, though both are naturally not as often met with as the domesticated Llama. 


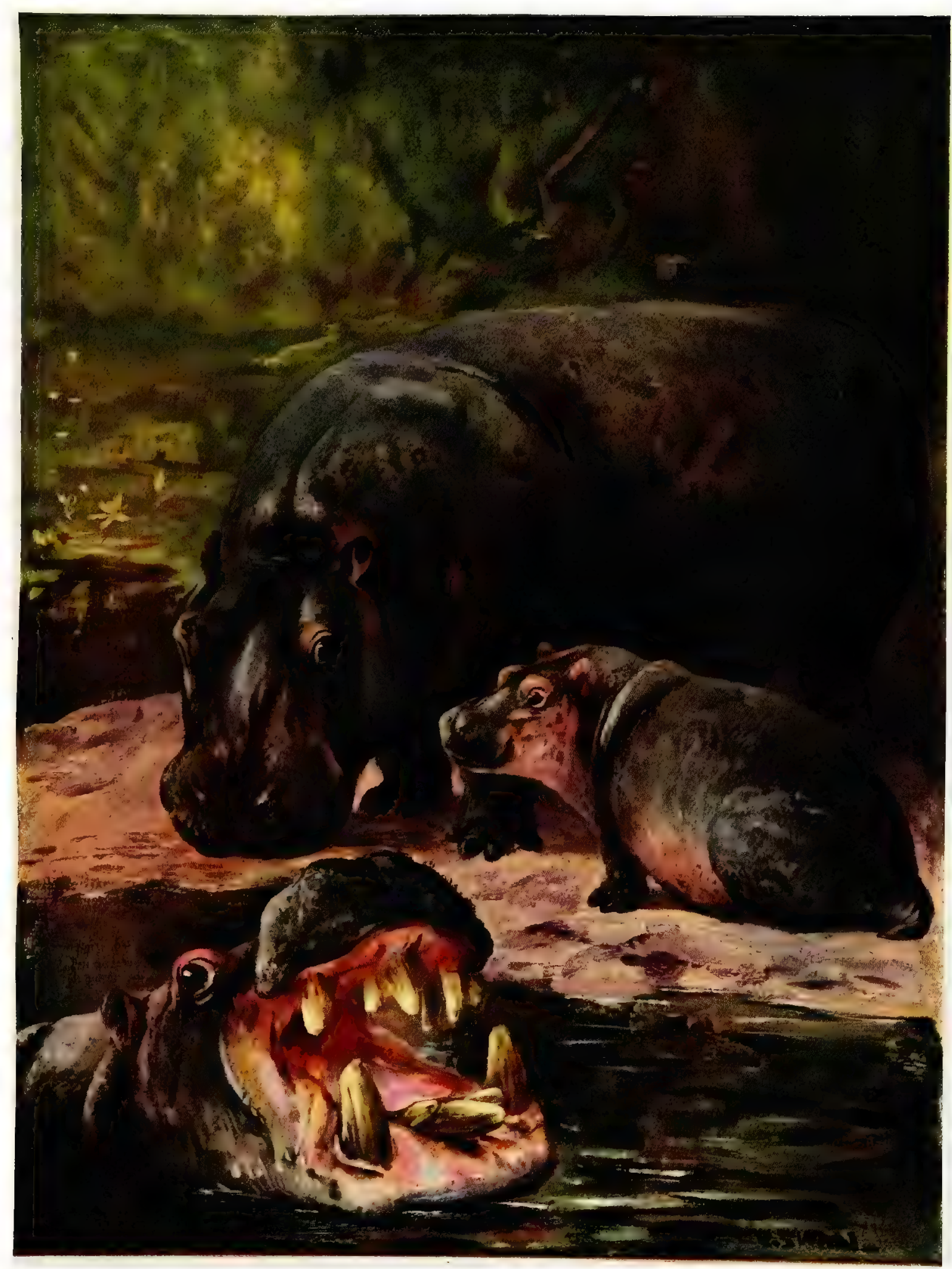

HIPPOPOTAMI

By C. E. Swan 



\section{THE HIPPOPOTAMUS}

(Hippopotamus amphibius)

THE very ugliness and unwieldiness of the "River-Horse"-the Greek name of the beast, which has been adopted as its English one-has always attracted attention to it, and indeed it is one of the most remarkable of hoofed animals, as well as the largest after the Elephants and the great Rhinoceroses. Its relationships are not at all with the Horse, the family to which it belongs being nearer to the Pigs than to any other existing animals. It resembles Pigs in having four hoofs on each foot, but all these touch the ground, and the weight is likewise borne, as in the Tapir and Rhinoceros, by pads beneath the base of the toes. The huge broad swollen muzzle is very unlike that of a Pig, and the teeth are very characteristic of the animal. There are a pair of huge canines in each jaw, which grow continuously, and, meeting at the tips, wear each other flat, the upper pair being slantingly bevelled off behind, and the lower in front. There are two pairs of incisors in each jaw, of which those in the upper jaw curve outwards, while the lower incisors project straight forwards in a very curious way, and look like thick sticks of ivory. These also have continuous growth.

The small eyes have a bulging appearance, and the features, if the expression may be permitted, are so arranged that the animal can have its nostrils, eyes, and ears all above water, while the rest of its body is submerged. The body generally is devoid of hair; but there are a few bristles on the muzzle and on the short tail. Not the least remarkable peculiarity of the Hippopotamus is that its sweat is red, and has much the appearance of blood. The young animal, as the illustration shows, is not so uniformly grey as its parents, and has a much more reasonably-sized face; there is only one at a birth, and when quite small it has the habit of riding on the back of its mother when in the water. 
The bull Hippopotamus reaches a length of twelve feet, but only stands about five in height; the female is smaller. The young Hippo takes five years to grow up, and the animal's whole length of life is about thirty years, judging from the ages attained by animals bred in captivity.

The Hippopotamus is one of the characteristic beasts of Africa, having been originally distributed almost all over the river-systems of that continent south of the Sahara. It has long, however, disappeared from Lower Egypt, and has given way in other places to human persecution. In habits it is essentially aquatic, though its requirements are not exacting, as it is in many cases found on quite small streams, so long as they contain pools sufficiently large for it to shelter in. Although it can swim well, enough, it is not, as the small size of its feet show, especially a swimming animal; its special accomplishment is sinking below the surface and walking along the bottom. It can remain under for more than five minutes, but cows carrying a young calf rise more frequently than others, for the benefit of the little one.

On land the Hippopotamus is much more active than its awkward shape would lead one to expect, and can gallop at a rate which would give a man small chance of escape. It also climbs steep places readily, and on occasions travels long distances overland from one pool or stream to another; often so many animals have followed the same path for such unnumbered generations that regular roads are formed. The food of the animal consists of marsh vegetation and grass; this it generally seeks by night, but is more ready to come abroad by day where it has not been perșecuted. Its depredations on the crops of the natives are naturally very severe; for an animal whose stomach is eleven feet long needs a great deal of material to replenish it, while to the damage done by its appetite must be added the trampling down of much more by the creature's movements. At the same time, the great bulk and large food-requirements of the Hippopotamus must make it useful in clearing away the rank growth of aquatic plants which are constantly blocking up water-courses in Africa. 
Hippopotami are 'gregarious animals, and almost always live in herds; but furious fights take place between rival males, whose wide mouths and terrible array of teeth enable them to bite with great power. Some individuals are extremely savage, and will attack any man or cattle they may find swimming in their haunts, and bite through canoes, and even larger craft such as river-steamers. In fact, the ferocity of the Hippopotamus, in addition to its raids on the crops, is a justification for its destruction when it comes into too close contact with humanity, though no excuse for its complete and wasteful extermination. When much hunted, it becomes very wary, and is difficult to shoot, so small a part of the head being exposed when it rises to breathe as to offer but a very small target for the rifle.

Natives capture it in various ways-by pitfalls, by harpoons, by weighted spears suspended in trees in connection with a cord which will be struck by the animal passing underneath, and by the cruel method of keeping herds in isolated pools till they are starved to death. The great value of the Hippopotamus to natives is its flesh, which is considered good even by Europeans, and the abundant supply of fat it gives, fat being always at a premium with the African negro, who has to subsist chiefly on vegetable food and the dry meat of wild game. The layer of fat immediately under the skin is especially prized, being very pure, and when salted is known at the Cape as "Zee-Koe speck,"-"Zee-Koe," or Lake-Cow, being the Boer name of the animal. The tusks of the Hippopotamus also yield ivory of good quality, and its skin, which is very thick-as much as two inches in places-makes the sjamboks, or hide whips, about which one hears so much. Walking canes can also be made of the hide; after the long quadrangular strips have been rounded down, they are soaked in oil, and then polished, so as to look rather like amber; they are quite as stiff as real cane of the same thickness.

Although the Romans exhibited the Hippopotamus in their shows in the arena, it was not for many centuries after the fall of their empire that the beast was again seen alive in Europe. At last, in I850, the celebrated Obaysch, obtained as a quite young calf on the 
Nile, was brought to the London Zoological Gardens, and, when a mate was obtained for him, bred there. Since then Hippopotami have been better known in menageries, and have bred elsewhere. They thrive well enough, but must be kept warm in winter, and either have constant access to a bath or be bathed by hand, or their skin will soon become disordered. It may be mentioned, in conclusion, that the Hippopotamus is supposed to be the "Behemoth" of Scripture, and that an extinct species, found fossil in India, was probably the "Water Elephant" of Sanscrit writers. At any rate, this semimythical beast, though represented on ancient Indian sculptures with an Elephant's head and fore-feet and Dolphin's hinder-parts, is there given teeth which are somewhat like those of a Hippopotamus, but utterly different from the Elephant's.

\section{THE PIGMY HIPPOPOTAMUS}

\section{(Hippopotamus liberiensis)}

THERE is only one other living species of Hippopotamus-the much smaller kind confined to the tropical parts of Western Africa. This is not bigger than a large Pig, and in its general form is like the young of the ordinary species, as it has not the huge muzzle of the large Hippopotamus. In colour also it is different, being of a greenish cast, shading into yellowish below, and it has only one pair of incisors in the lower jaw. The accounts, however, which represent it as being not so fully aquatic as the large kind, but more like a Pig in.habits, seem not to be correct, for Sir Harry Johnston has recently stated, in his book on Liberia, that the small Hippopotamus is also a wateranimal. But it is a little-known creature, and only one short-lived specimen has reached England. 


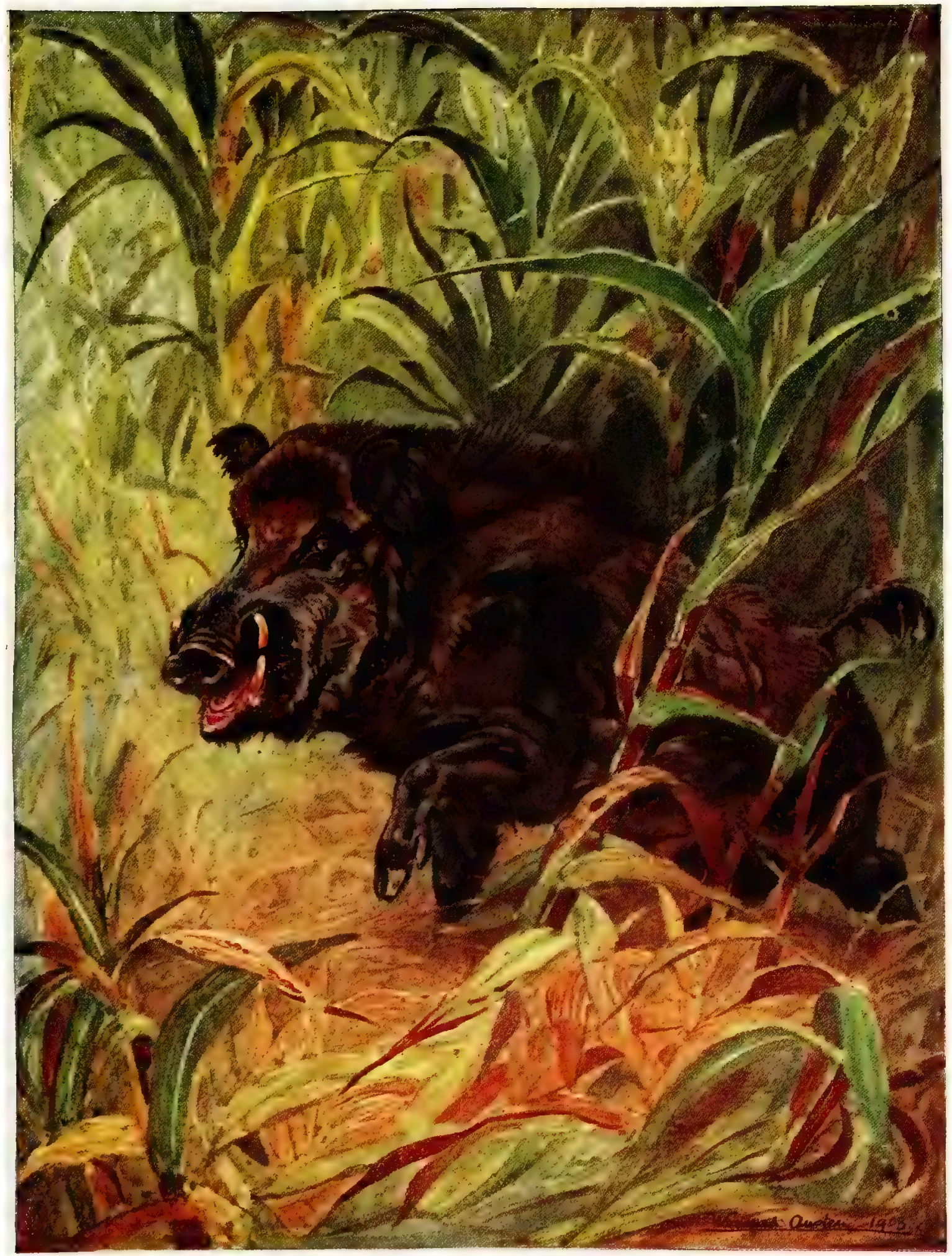

INDIAN WILD BOAR

By Winifred Austen 



\section{THE INDIAN WILD BOAR}

(Sus cristatus)

THERE is practically very little difference between the Wild Boar of India and that of Europe and Western Asia (Sus scrofa), but the Eastern animal deserves the honour of heading and illustrating this article, as the noblest representative of the porcine race, since he is unequalled in courage.

In size a large Indian Boar will reach or even exceed a yard at the shoulder, and the lower tusks will be about nine inches long, including the portion embedded in the jaw. The Boar's tusks are very curious as well as very formidable weapons; they are simply enlarged. canine teeth, but have the peculiarity of growing continuously, and the upper pair turn outwards and upwards instead of growing downwards as upper canines usually do. The two pairs meet and work against each other in such a way that they wear each other to an edge, which much increases their efficacy as rippers. A Boar's tusks are most formidable when he is in his prime; as he becomes older, the lower pair get so long and curved that he cannot rip much with them; and though the increased length of the upper pair brings these into use, they are not so effective. So, though the old Boar is more crusty in his temper, he has less ability to gratify it. The skin of the beast's neck is very thick, which is a great protection against the tusks of his rivals.

In the Sow, which is smaller than the Boar, the tusks are quite short, so that she does not rip, but bites, which she can do to some purpose, for the typical Pigs have a very full and complete set of teeth.

The Indian Boar, although its coat is not so long and thick as that of the European species, is well covered with hair, which is of a brownish or grizzled black in adult animals, becoming greyer with age. The young Pigs are marked with longitudinal stripes of brown and buff, this being the usual pattern in the young of this family, just as 
the white spots are in the coats of Deer fawns. In some.localities brown Wild Swine have been observed, and there is a good deal of variation in size and form, the Boar of the rich lands of Bengal, where the feeding is good, being heavier in build than the Punjab Pig, which has to travel farther for his meals.

Wild Swine are widely spread through India, Ceylon, and Burma, in the hills and plains alike; they are fond of cover, and often make shelters for themselves by cutting quantities of grass, and then burrowing under the pile. Such shelters are used especially by Sows with litters, but also sometimes by old Boars, which generally live by themselves, while the Sows and young animals go in "sounders" or herds.

Wild Swine generally feed at night, and are practically omnivorous ; they root like tame Pigs for their food, but much more energetically, and are terribly destructive to crops. They like frequenting marshy land, where they can dig up roots in the soft soil, and they will also root for those fish which in India bury themselves in mud when the water dries up in the hot season. Carrion occasionally forms part of their food, but they are not usually ranked as foul feeders. They gladly devour, of course, any wild fruit they can get.

Like their tame relatives, they are prolific animals, having several young in a litter, and breeding more than once a year. Many are killed by Tigers, Leopards, and no doubt other carnivora; but the Sow fiercely defends her litter, and the "grim grey Boar" is an adversary that even the Tiger prefers to leave alone as a rule. Should he venture on an attack, he stands an excellent chance of being fatally ripped before he can kill his victim,

The great courage of the Boar makes "Pig-sticking," as the pursuit of him is styled, with humorous modesty, in India, the finest and most manly of field sports. Several riders engage in it together, and for about a mile the pace is very great, for the Boar has a great turn of speed for a short burst, and is also an active jumper, easily clearing obstacles in awkward places where a Horse cannot get a good "take-off" owing to his size. If, however, he finds his pursuers are 
overhauling him, he turns, with a savage grunt, and charges desperately. Then is the time to hold one's lance steady and not try to prod at him; but, with all precautions, the shaft will often be snapped or the spear wrenched from the rider's grasp, and the half-impaled Boar makes good his charge at a second foe; and this goes on till the gallant brute at length bites the dust. Horses often get cut, sometimes very badly, in these encounters, but the riders are seldom hurt by the Boar, as, if one happens to be thrown, there is generally some one else handy to divert the beast's attention, since all ride close up in the hope of getting "first spear." The chief danger lies in the very bad ground over which the chase has often to be pursued. The Arab Horse is found to be the safest mount, from his cleverness in getting over dangerous places at a high speed, and in dodging the Boar's attack, while his high courage makes him less afraid of the alarming brute than other Horses.

The Boar is more respected by his adversaries than any other beast of chase; as in the case of the Fox, he is not shot, except on ground where riding after him is impossible, and, moreover, his female relatives are allowed to go unscathed. Indian Wild Swine have done well in captivity in England, and bred for many years in the Royal Park at Windsor.

\section{THE EUROPEAN WILD BOAR}

(Sus scrofa)

IN addition to his thicker coat, the European Boar has a less leggy build than the Indian variety, and has the last grinder in the lower jaw of smaller size and less complex structure, but the differences are barely of specific importance. This Swine is the Wild Boar so well known in literature; it occupies the region west of India, ranging over Europe generally and into North Africa: it inhabited Britain down to the time of the Civil Wars. It is still an esteemed beast of chase on the Continent, but is usually shot, not hunted; and its flesh is much 
esteemed, especially for making the celebrated Westphalian hams. In general habits it is like the Indian Boar.

Our tame Pigs, which descended from one or both of these species, have run wild in Australia and New Zealand, and are as hairy and tusky, and nearly as savage, as true Wild Swine; but they still show marks of servitude in the concave profile, as they do not seem to revert to the straight face-line of the wild type.

\section{THE PIGMY HOG}

(Sus salvanius)

The Pigmy Hog, which is a little brown animal hardly larger than a Hare, and with a very short tail, inhabits the grass-jungle of the Terai or foot-hills of the Himalayas. Here it lives in herds, both sexes associating; but little is known of its habits, for it is seldom seen. The only specimen I ever saw alive was one recently exhibited at the London Zoological Gardens, but many years ago it bred there. This would be a very good animal for acclimatisation, as it is too small to be seriously destructive or dangerous, though fierce enough when in herds, and it provides the most delicious pork; moreover, it would probably give much sport when hunted with hounds.

\section{THE RED RIVER-HOG}

(Sus porcus)

This West African Pig deserves notice as the dandy of its family, for it has a sleek, bright chestnut coat, set off by black markings on the face, and its pointed ears are tufted like those of Lynxes. The young ones are striped like most other wild Pigs. It is a fierce animal when brought to bay, and seems to have a strong carnivorous tendency, as a tame specimen kept in West Africa made itself a nuisance by devouring fowls. It is usually to be seen in our Zoological Gardens. 


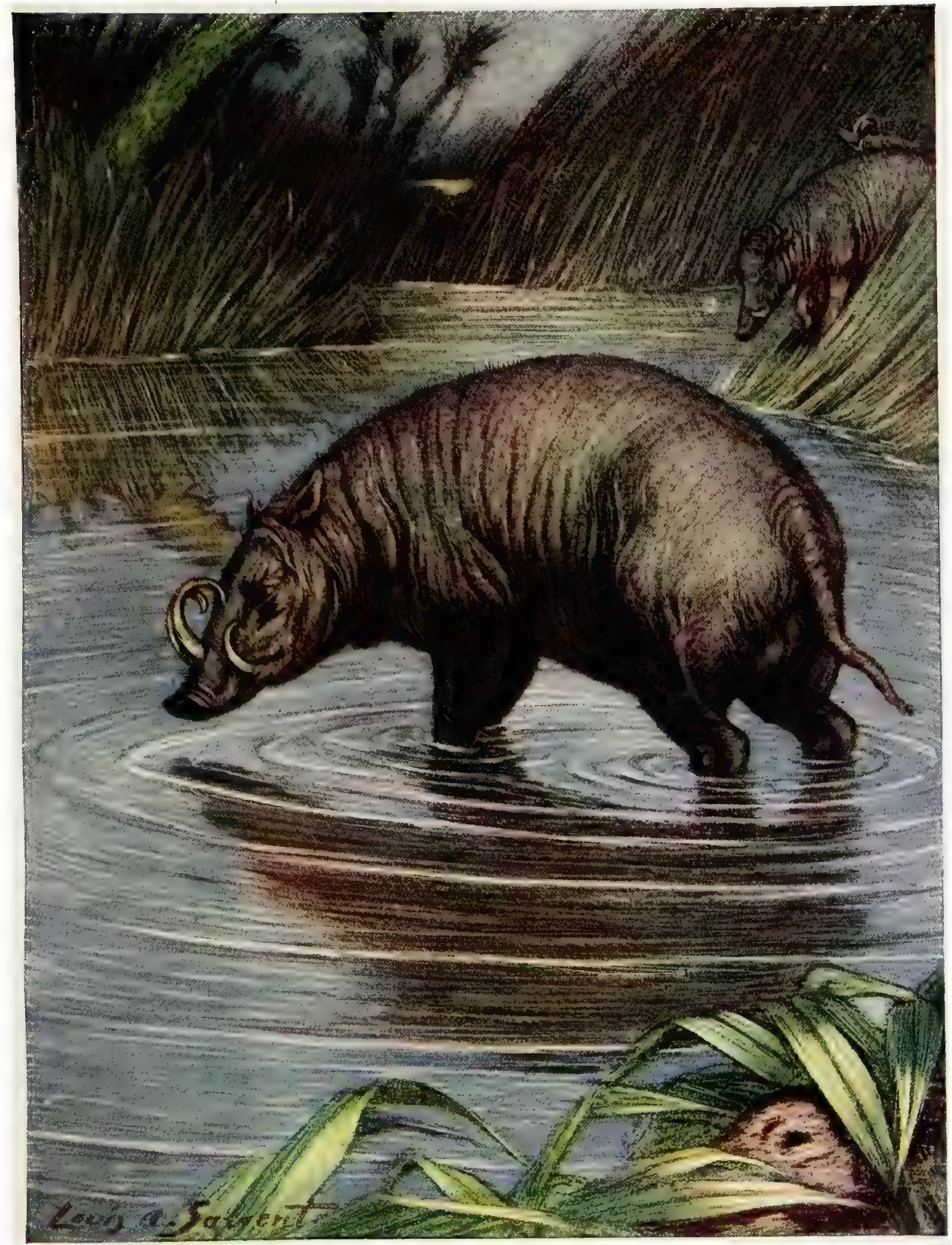

BABIRUSA

By Louis A. Sargent 



\section{THE BABIRUSA}

\section{(Babirusa alfurus)}

Even classical naturalists in ancient times had heard of a "Fourhorned Hog," which was to be found in the far East, so that the reputation of this most remarkable of wild Swine was early widely diffused, though the animal itself has but a limited range, being confined to the islands of Celebes and Bouru in the East Indies.

The so-called horns were, of course, the tusks, which are certainly remarkable enough to give any animal a reputation. The lower canines are chiefly notable for their great length and curvature, being, indeed, when fully developed, too long and curved for the proper use of such teeth. The upper ones, however, as the illustration shows, grow directly upwards, and actually pierce the skin of the face, presenting an exaggeration of the condition found in the Wild Boar. Their development varies considerably, and in some cases they not only approach, but again pierce the skin of the head in curling downwards and forwards. These huge tusks are of pure ivory, having no enamel coating at all; they are confined to the Boar, the Sow having the canines quite small.

They certainly are not well designed for fighting, though the fact that in old animals they are usually found to be broken, shows that they are used in that way; and probably the suggestion of Dr. A. R. Wallace, that they are degenerate, over-developed organs, comparable to the overgrown teeth sometimes seen in Rabbits and Rats that have had the misfortune to lose one incisor, is the correct one. The other teeth of the Babirusa present the peculiarity of being less numerous than in the Wild Boar and its immediate allies, there being two upper incisors and four grinders wanting from the full Pig complement.

The Babirusa is one of the very few land animals which is prac- 


\section{8}

\section{WILD BEASTS OF THE WORLD}

tically naked. Its coarse, rough, wrinkled skin is only very thinly covered with small brown hairs, which are only noticeable on close inspection; there is, however, a scanty tuft on the end of the tail. The young, however, have rather more hair, which is black in hue.

The eyes are peculiar, as Dr. Graham Renshaw has pointed out, in having the iris nearly white, which gives the animal a very characteristic expression. It will be noticed that the general form is quite slender and elegant for a Pig, and the head unusually small, so that, taking the horn-like upper tusks also into consideration, it is not so surprising that the name of the animal means in the Malay language "Pig-Deer."

The Babirusa is found in forests, usually singly, for it is not a very sociable animal. Like so many naked beasts, it is very fond of a bath, though wallowing is a taste common to many of the Pig family. It is a fierce brute, and fights bravely when brought to bay. Guillemard, in "The Cruise of the Marchesa," mentions an instance in which an infuriated Babirusa actually started to run up a sloping tree-trunk in pursuit of a native who had climbed the tree to get out of his way, thus confirming a rather incredible-sounding native story that this Pig would ascend suitable trees. Tree-climbing is certainly a very abnormal performance for a cloven-hoofed animal; but among the Goats the Markhor has been known to climb, and so will even the common Goat -always, of course, if the tree is suitably sloped and branched. It is just possible that it is in this way that the old story arose which credited the Babirusa with hanging himself up at night by his curved tusks : possibly some unfortunate specimen had involuntarily committed suicide by getting up on a branch, and, falling, hitching his tusks on another, and the assumption was thence made that the position was voluntarily selected.

For a Pig, the Babirusa is not at all prolific; it has only two young at a time, and these remain for a day or two in a hole lined with leaves, wherein they are deposited at birth. They soon, however, follow the mother about.

This curious Pig thrives well in captivity, but is not a very common animal in menageries; it has produced young in our Zoological 
Gardens, and bears our winters in an outdoor sty, in spite of its lack of a hairy coat:

\section{THE WART-HOG}

\section{(Phacochorus athiopicus)}

ThE Wart-Hog, or Vlack-Vark, has long been known as a menagerie exhibit under the unflattering title of "the ugliest animal in creation"; and it must be admitted that there is considerable justification for the description. About the size of a Wild Boar, the Wart-Hog is remarkable for the great breadth of its head and muzzle, which are further disfigured by the characteristic warts-a pair of small ones just below the eyes, and two much larger protuberances on the snout. The body is nearly naked, except for the tuft at the tip of the tail and a mane of long, laxly-drooping bristles down the neck and back. The tusks are very characteristic: the upper and lower canines both follow the same outward curve, and the former, unlike what obtains in the Wild Boar, are much the larger and more conspicuous. They may attain even to a length of a foot outside the gum in a fine Boar, and even in a Sow may be four or more inches, for the female Wart-Hog, unlike the female of other wild Swine, has quite large and conspicuous weapons. The young are not striped like those of the more typical wild Pigs; there are only four at a litter, and the mother has but four teats accordingly. The Wart-Hog has a wide range through Africa south of the Sahara, and at least two local races are recognised, the Wart-Hog of the north-east being considered by some a distinct species from the southern type; but the differences are hardly of specific importance.

Wart-Hogs go in small parties as a rule; they do not care so much for soft ground and forest country as most Pigs, but rather affect dry country and scrub. They are not, however, averse to wallowing. Their usual food consists of roots, for which they seek at night. One of their most marked habits is their tendency to "go to ground," for they much appreciate the shelter of the large earths constructed by the 
Aard-Varks (Orycteropus). These they prudently enter backwards, so as to get out easily and present the front to an invading foe. When galloping they have a very grotesque appearance, not oniy on account of their general ugliness, but because of the finishing touch given by the erection of the tail, whose tasselled tip droops forward. When driven to bay they fight fiercely, but are not so savage and dangerous as the true Wild Boars and Bush-Pigs. The pork is very good and tender when the animal is in good condition.

\section{THE FOREST-HOG}

(Hylochorus meinerzhageni)

THis Pig, the giant of the family, has only been recently discovered, which is not surprising, as it inhabits the little-known forest region of Equatorial Africa. It is of large size-even the sow, judging from the mounted specimen in the South Kensington Museum, being as big as an ordinary Wild Boar, and provided with almost equally formidable tusks, so that her mate would be a monster indeed, worthy to personate the Calydonian and Erymanthian Boars of the classical Greek legends.

In structure this Pig comes between the typical Pigs and the WartHogs; its coat is black, and very thin, so that the skin appears through it as in most of our tame Pigs. 


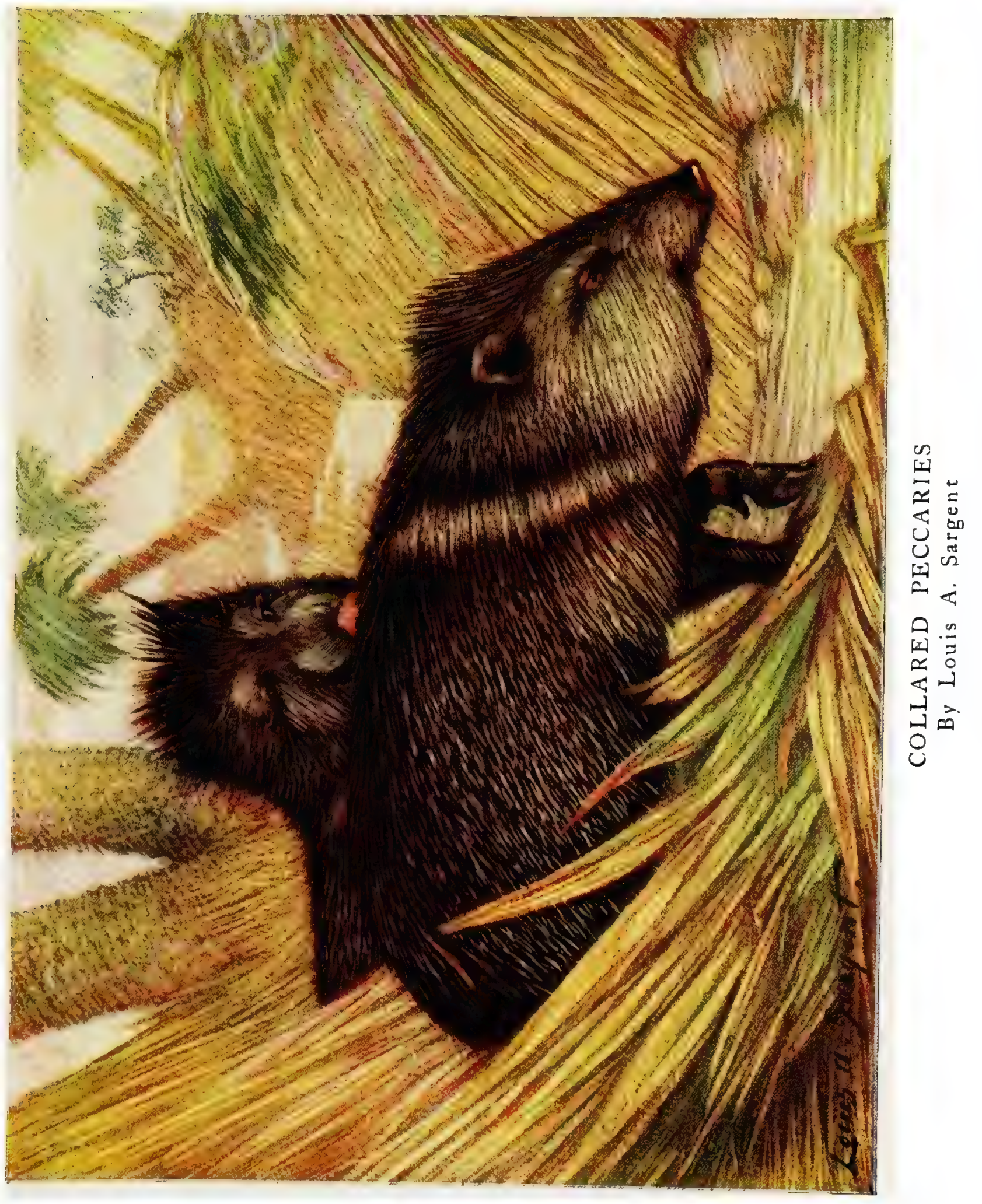





\section{THE COLLARED PECCARY}

(Dicotyles tajacu)

The true Pigs (Suida) are purely Old-World animals except where man has introduced his domestic Swine artificially; but America has Pigs of her own in the shape of the two species of Peccary, which are sufficiently distinct to be classed in a separate family (Dicotylida). Of these the Collared Peccary is the better known, and is the only one found in North America, where it ranges as far north as Arkansas, being really a southern animal, as it is chiefly found in the northern part of South America.

It is a rather small animal for one of the Pig tribe, not reaching quite a yard in length, and it presents some remarkable differences from the true Pigs in the matter of its teeth and toes. The upper canines point downwards as in most animals, and the lower ones do not project outwards; thus those teeth have a quite ordinary appearance, not appearing outside the lips, and cannot be used in ripping. They are, however, large for the size of the animal, which can give a most severe bite. In the upper jaw there are only four incisors, whereas the Wild Boar has six in each jaw.

In the feet it will be noticed that the outer back toe of the hindfoot is missing, so that the fore-feet are even-toed, having the usual two large hoofs and two small ones of the Pigs, and the hind-feet asymmetrical. The stomach is different from that of the Old-World Pigs, not consisting of a single cavity only, but of three, thus approaching to the ruminant type. The tail is remarkably short-a mere rudiment, in fact. The coat of the Collared Peccary is very full, forming a mane or crest down the head and back, and is composed of bristles so coarse that they look like miniature Porcupine-quills, especially as they are similarly ringed with alternate black and white bands. 
On the hinder part of the back is a gland secreting a very evilsmelling fluid; gentle titillation of the gland appears to please the Peccary, and the pair at the Zoological Gardens may be occasionally seen standing head to tail and rubbing each other's back with their cheeks, no doubt to procure this gratifying sensation.

The female. Peccary, which closely resembles the male, has only two teats, not a large number like the common sow, and in accordance with this she only brings forth one or at most two little Peccaries at a birth. These young Peccaries are not striped like the young of most typical Pigs, nor do they possess the cream-coloured neck-stripes or "collar" of the adults. In fact, their colour is altogether different, being a plain light-brown with a black stripe down the centre of the back.

The Peccary is a sociable, active, and very courageous animal. Like the Swine tribe generally, it lives in cover, and will eat practically anything; but it is not so fond of water as most of them, being able to do without a drink when it can get access to such succulent food as the prickly pear, and seldom resorting to it to bathe. Being a small-footed animal, too, it cannot swim so fast as Pigs generally do. It is also not very fast on foot for more than a short distance, and after a run of a few hundred yards it will turn and face Dog, Horse, or man, bristling its long hair and champing its teeth with the greatest fury, and will then fight to the death. Occasionally it will attack man unprovoked, but naturally such instances are the less likely to occur where the animals have been a good deal hunted and have learnt caution, as in the United States, where the animals have never been found but quite in the south-west corner, and are now nearly extinct. The danger in a conflict with Peccaries lies especially in the fact that there are generally a number to contend with, as the animal usually goes in herds, sometimes numbering as many as thirty animals, and from such a mob there is little chance of escape, unless a tree be at hand which can be climbed.

Even the Jaguar, one of the chief natural enemies of these plucky little Pigs, has to be very careful how he picks off a straggler, for if 
he has not a line of retreat planned out, he is likely to be torn in pieces by the infuriated friends of his victim. The Harpy Eagle also attacks these animals, but presumably only the young, as he could certainly not carry off an adult.

One peculiarity about the habits of the Peccary is its fondness for a sheltered home, in which it agrees with the Wart-Hog of the Old World. What a band of Peccaries particularly like is a hollow fallen tree, in which they ensconce themselves one by one, going in stern first. The one nearest the entrance of course keeps guard, and the whole number may thus be killed off with little risk, each, as his comrade in front is shot, coming forward to take his place.

Peccaries are hunted by men for their flesh, which is of good flavour, more gamy than, and not so fat and cloying as, ordinary pork; but it is important to cut out the scent-gland on the back as soon as possible after the beast has been killed, or the flesh will be so tainted as to be unfit for food. The hides are also of some value, and it is to obtain these that the animal has been so largely killed down in Texas.

In captivity these Peccaries thrive as well as other Pigs, and, as any one can see at the London Zoological Gardens, where they have bred, will bear our climate well with ordinary pig-sty accommodation.

\section{THE WHITE-LIPPED PECCARY \\ (Dicotyles labiatus)}

The White-lipped Peccary, or Warree, is similar to its better-known relatives in all essential respects, but is a slightly larger animal, with the tail a little longer. There is also a considerable difference in colouration, the Warree not having any collar, while, as implied by its English name, its lips are white, as are also the throat and chest.

This species of Peccary is found, like the common kind, in northern South America, and it extends into Central America, but not farther north. 
In general habits and attributes it closely resembles its relative, as might be expected, but it is very much more fierce and aggressive. It has, indeed, been suggested that this is due to the fact that it usually associates in much larger herds, so that it is more conscious of strong support, but it is probable that there really is some difference of disposition in any case. At any rate, there was once a specimen of the White-Lipped Peccary in the Calcutta Zoological Garden which had a very adventurous career and showed a very unpleasant character. It at first lived in friendship with a Malayan Tapir, but ultimately seriously injured its large companion; it was then associated with a Rhinoceros, but was soon apparently bored by the monster's company and jumped over a three-foot wall into the next paddock. Here its companions were a pair of Spotted Deer (Cervus axis), which were quite ready to be civil, but were often annoyed by their uninvited guest. This state of things went on for nearly two years, when a nip on the nose so provoked the buck that he fatally gored the peccant Peccary and terminated its variegated career. This species, although not so common in captivity as the other, has yet been exhibited at the London Zoological Gardens, and has produced hybrids with it. Peccaries, however, will not interbreed with ordinary Pigs. 


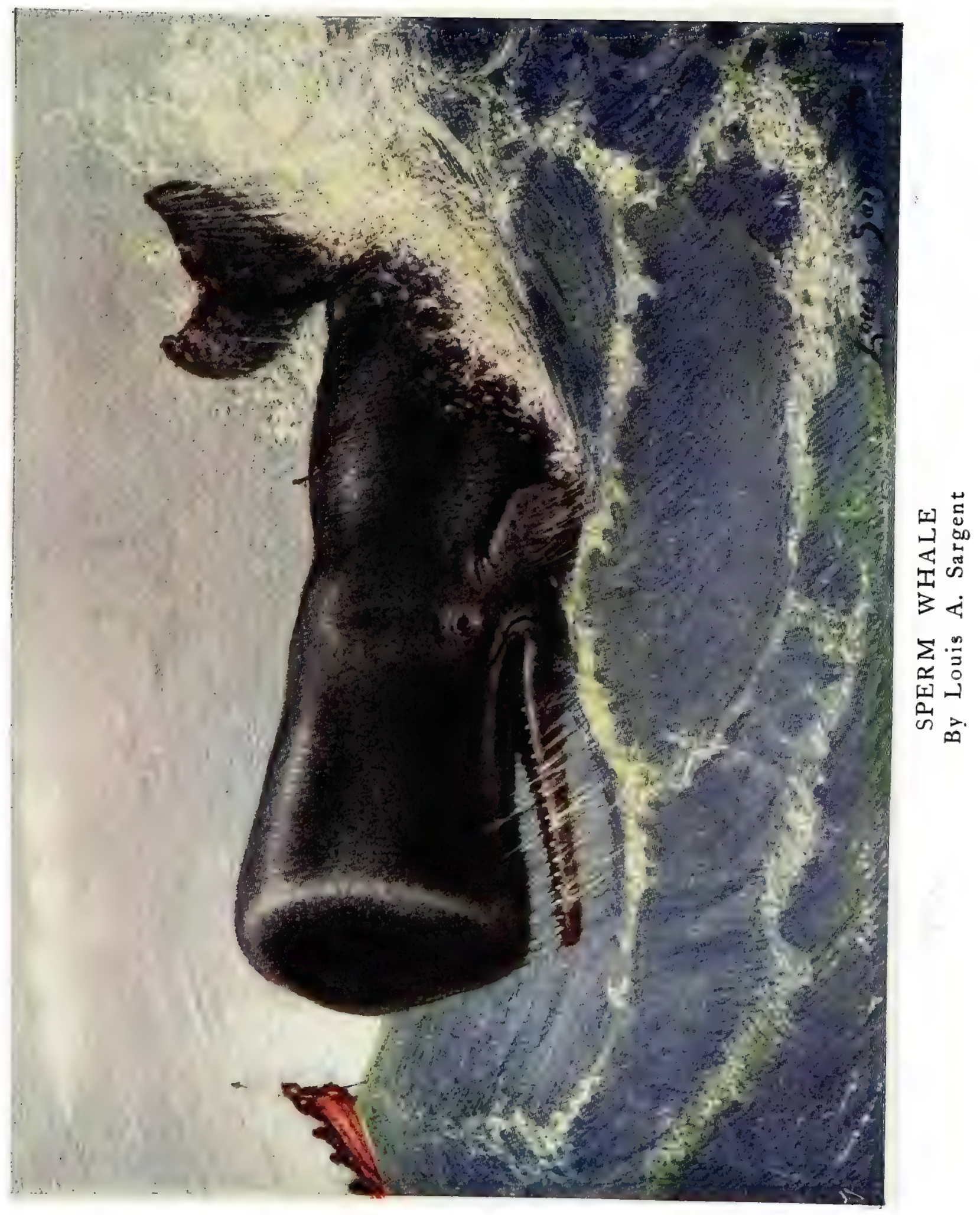





\section{THE SPERM-WHALE}

\section{(Physeter macrocephalus)}

BoTH on account of the value of its products, and of the terrible revenge it sometimes takes on its assailants, the Sperm-Whale, if not absolutely the largest, is the most noteworthy of the beasts of the sea. In these days of popular education, it is hardly necessary to remind readers of this book that the Sperm-Whale is a beast, and not a fish, though the latter term is commonly applied to the members of the order Cetacea, to which all the Whales and other similar animals belong.

Under the skin of its fins are the bones of a beast's fore-paw, and it breathes the air just like a land animal; hence the tail-fin is horizontal, to aid rising in the water. The "blow-hole," however, is not situated on the top of the head, as in other Cetaceans, but at the end of the huge muzzle, in a position more in accordance with that of the nostrils of other beasts, to which it corresponds. It is, however, but a single orifice, as in other toothed Whales, whereas the "blow-hole" in the Whalebone Whales is a double orifice, like the nostrils of beasts in general.

In the form of its massive head the Sperm-Whale differs from all other Cetaceans. Seen "end on," the muzzle is widest in the middle, and tapers above, and much more below; its great bulk is mostly made up of a collection of cells containing oil laden with the characteristic product of spermaceti, and underneath this a mass of fat, the outline of the actual skull being quite different, as it is beaked much like that of an ordinary Porpoise. The lower jaw is also peculiar, being very long and narrow; it is well provided with large conical teeth, set well apart, and without enamel covering. Their number varies remarkably, from twenty to twenty-five on each side; while it is quite common for the two sides of the jaw not to match in this respect. In old males 
they are particularly massive, but short. These teeth are received into holes in the upper jaw, which is only provided with about eight teeth barely appearing above the gum.

The eyes are small, and there are no external ears, while the ear orifice, about a foot behind the eye, is only big enough to admit the tip of a finger.

The tongue is very short and small for the size of the animal, and cannot be protruded: the inside of the mouth is conspicuously white, contrasting with the general black colour of the hide. This is occasionally, however, marked with white, especially about the hinderparts. As is usual in Cetaceans, it is hairless; but this species differs from the Whalebone Whales in the cleanness of its skin, which in many of the others is apt to be encrusted with barnacles or other parasites.

The adult bull Sperm-Whale is an enormous brute, at least twenty yards long, but the "cows" are not more than half his size. They go in herds or "schools," which may number as many as fifty, and are commonly accompanied by one old bull; younger bulls go in smaller schools by themselves. Sometimes several schools will unite into one great herd; and single individuals may be found, which are usually old bulls.

The Sperm-Whale, or Cachalot, as it is sometimes called, is remarkable for its wide distribution, even among the ocean animals, which, naturally enough, often range more widely than any of the beasts of the land. Except in the Arctic and Antarctic waters, it is to be found practically everywhere, though most especially in the southern seas; and, unlike most Whales, is generally met with in warm waters. Now and then individuals occur on the British coasts, either alive or as stranded carcases, and these are always old bulls, which no doubt have been driven from the herd and were leading a wandering life. As a general rule, however, this is an animal of the deep sea, and avoids even the neighbourhood of land, so that it is not to be expected in our narrow waters. It can be recognised at sea by its "spout," which is discharged in a single jet diagonally forward, not in 
a double upright jet as in the Whalebone Whales; this spout is composed of steam or vapour from the exhaled breath. A large bull Whale will remain below water an hour without rising to breathe, but when up "he will "blow" many times in succession, at intervals of ten seconds or so, before diving again. Smaller specimens do not stay below so long.

When travelling quietly, the Sperm-Whale only shows the top of its head and back above water, but when going at speed, it travels "head out," as the Whalers say, its huge head appearing at each vigorous stroke of the tail-flukes, and then disappearing again. In spite of its unwieldy shape and huge size, it can spring clear of the water like a Salmon, descending with a tremendous splash. Its food consists of Cuttle-fish or Octopuses, often of enormous size; in fact, the earliest proof of the existence of gigantic species of this class of animals was afforded by the vomiting of huge fragments of their tentacles by Sperm-Whales when wounded and dying. It will also feed on true fish, though it is a puzzle how so clumsy a creature catches these; it is thought that the white lining of its mouth, when displayed below water, acts as an attraction to smaller marine creatures.

The baby Cachalot is about five yards long; usually there is but a single one, as is generally the case with the Cetacea, but twins are occasionally produced. It is active at once, and is suckled by the cow when lying on her side, taking the teat in the corner of its mouth. It may be born at any time of the year. Unlike some of the Whalebone Whales, the cow Cachalot shows but little maternal devotion, and will often desert her young when hunted. Generally speaking, indeed, this huge animal is harmless and timid, but there are many exceptions, and no creature is so terrible in its fury as the fighting Cachalot. Such an animal will not only crush a boat with powerful blows of its tail, but will ram it with its head, or even bite it in two, to accomplish which feat it rolls over on its back, so as to bring the formidably-armed under-jaw uppermost. Savage bulls will even charge a ship, and as several have actually been sunk by such animals, their 
crews escaping in the boats, there is reason to believe that many a vessel whose fate is unknown may have come to this end.

This also accounts for the belief in the ferocity of Whales which is expressed by classical writers; no doubt in ancient times Cachalots were more common and dangerous. Nowadays, this animal has been so much hunted for its valuable oil and spermaceti, that it has been much reduced in numbers, and the fishery has declined. In addition to the above products, the Sperm-Whale is the source of ambergris, a soapy substance with a powerful scent, which is used in perfumery, and is very valuable. It is a concretion formed in the intestines of sickly individuals, and is sometimes found floating in the sea.

\section{THE PIGMY SPERM-WHALE}

(Cogia breviceps)

THIs Cachalot bears somewhat the same relation to the large species as the Pigmy Hippopotamus does to the ordinary kind; it looks more like a large Porpoise than anything else, having a back-fin and an ordinary-looking Porpoise-like head-except that the mouth is situated some distance below the end of the snout-and being only about ten feet long. It is confined to the Southern Seas.

\section{THE BEAKED WHALES}

These Whales belong to the same family (Physeterida) as the two Sperm-Whales, and are characterised by their pointed muzzles, and by only having a single pair of teeth, situated in the lower jaw. Unlike the large Cachalots, they have a small back-fin. Some species or other of this group is to be found in all seas, but several of them are exceedingly rare. The best known is the Bottle-nose (Hyperoodon rostratis) of the North Atlantic, which is hunted for its oil and spermaceti. It is about thirty feet long, black when young, and light brown when old. 


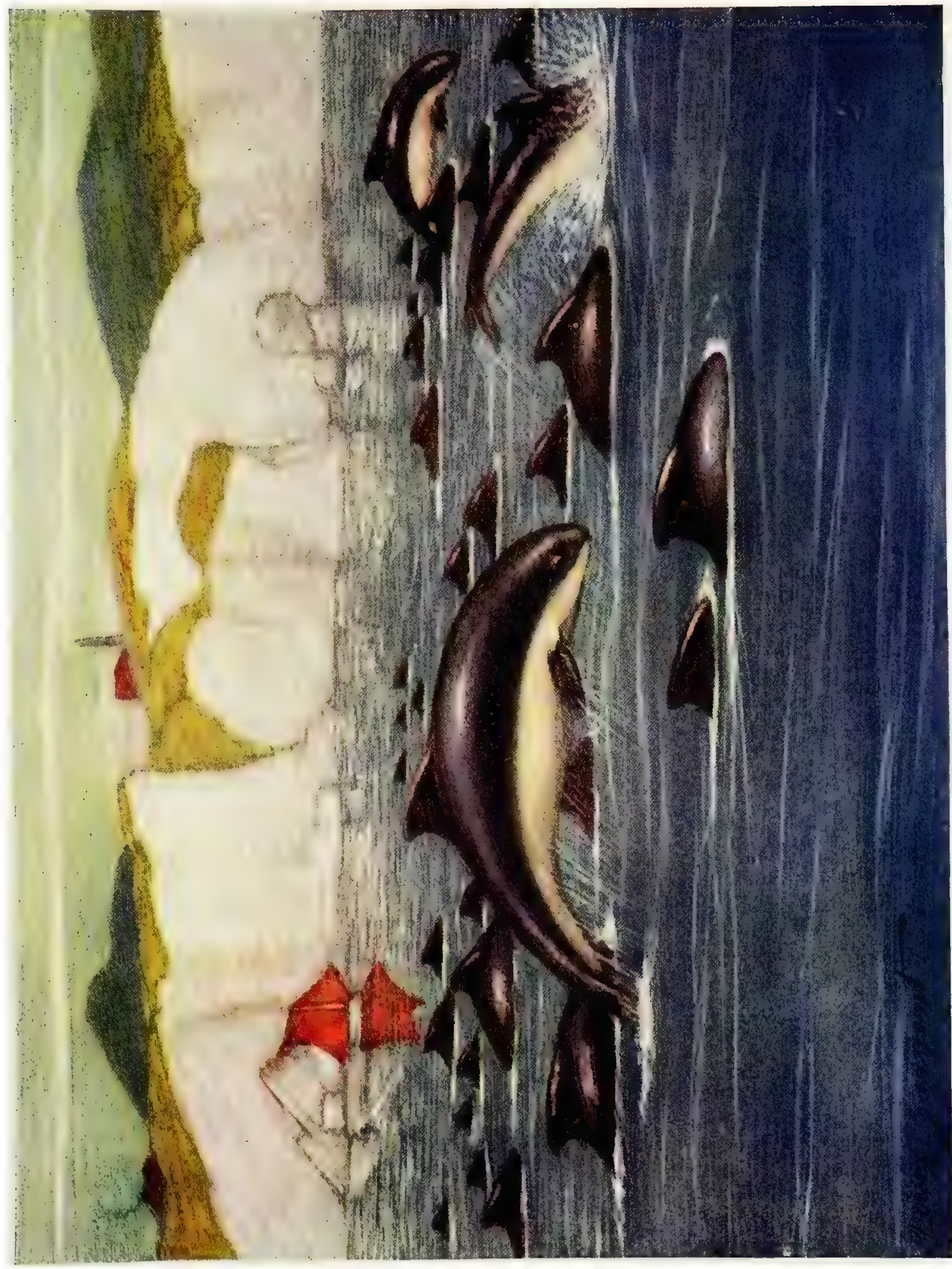

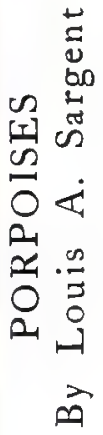





\section{THE PORPOISE}

(Phocana communis)

The Porpoise is far the most familiar Cetacean to British eyes, as it is a common animal round our coasts; it is also a fair average sample of the Dolphin family (Delphinida) to which it belongs-which family includes about half of the whole Cetacean order, numbering some three dozen species.

The most noteworthy peculiarity differentiating the Porpoise from its allies is the form of the teeth, which are heart- or spade-shaped rather than conical and pointed, as in most Dolphins. They are very small, and, as in this group generally, exceedingly numerous, and at the same time variable in number, twenty-five or twenty-six on each side of each jaw. As in all existing Cetaceans, they show no distinction into incisors, canines, and grinders. Their only use is to hold the fish on which the creature feeds, which are bolted whole; the stomach is complicated, consisting of three compartments, of which the first is much the largest, as in the stomach of the ruminants. This kind of stomach is characteristic of the Cetacea, and it has even been suggested that they chew the cud; but no one has ever seen them do so, and their teeth and jaws are never suitable for such an action.

It will be noticed that the Porpoise has a back-fin, which, it may be mentioned, is different in structure from that of a fish, not being supported by rays or spines, and the same applies to the tail-fin. Porpoises vary a good deal in size, measuring from four to a little over six feet; their colour also shows some variation in the extent of the black and white, and a creamy-white Porpoise, with the fins on the back and tail edged with black, has been seen upon one occasion.

The Porpoise is essentially a coast animal, often coming close inshore, and not found in the open ocean; often, indeed, it ascends rivers, 
and has been seen as high up the Thames as Chiswick. It has a wide distribution, being found both in the Atlantic and the Pacific, but only frequents their northern portions, and is rare in the Mediterranean.

The fish it selects as food are those of moderate size, such as Mackerel and Herrings, whence the name "Herring-Hog," sometimes applied to it ; its name "Porpoise," by the way, is supposed to mean "Hog-fish." It is a sociable creature, usually seen in parties, and is lively in its actions, frequently jumping out of the water as depicted in the illustration. A very common belief credits these gambols with being an indication of bad weather. The female produces a single young one.

The Porpoise does no harm to man except when it gets caught in a fishing-net, which it damages by its powerful struggles for freedom; nor is it nowadays much utilised, for most of the "Porpoise-hide" boot-laces are really made from the skin of the Beluga or White Whale. Our ancestors, however, thought highly of the Porpoise as a table delicacy; it had the great advantage of being legitimate food for Fridays, being reckoned canonically as a fish, and was served up roasted, with a sauce made of white bread-crumbs, sugar, and vinegar. It must have been the Porpoise that Tom Hood was thinking of in "Miss Kilmansegg" when he said of Queen Elizabeth that she

$$
\begin{aligned}
& \text { "Broke her fast upon ale and beef } \\
& \text { Instead of toast and the Chinese leaf, } \\
& \text { And, in place of Anchovy, Grampus." }
\end{aligned}
$$

Porpoises have been successfully kept in captivity at the Brighton Aquarium, and one short-lived individual was exhibited at the London Zoological Gardens, the only Cetacean which has ever graced the collection. There are only about three species of true Porpoises, the others being the Prickly-finned Porpoise (Phocana spinipinnis) of South American waters, which is black all over, with fewer teeth than our species, and short spines on the short back-fin and the back itself, and the little Eastern Porpoise ( $P$. phocanoides), ranging from the Cape east to Japan, which is only about four feet long, and has no back-fin at 


\section{THE COMMON DOLPHIN}

all. The name "Porpoise" is, however, commonly given by sailors to all Cetaceans which are too small to be dignified with the title of "Whales," such as the various Dolphins.

\section{THE COMMON DOLPHIN}

(Delphinus delphis)

This celebrated animal is nearly related to the Porpoise, but is much larger, measuring from five to eight feet; it is also more elegantly formed, being a perfect model of symmetry, with the jaws prolonged into a narrow beak-like muzzle clearly marked off from the forehead. The sharp conical teeth are very numerous, being from forty-six tofifty on a side. In colour the Dolphin is lighter than the Porpoise, and has a grey or buff shading between the dark hue of the back. and the white of the belly. It is the common Cetacean of theMediterranean, and also inhabits the Atlantic, though it is a more southerly animal than the Porpoise, seldom occurring as far north as Scotland, though sometimes to be found in the Channel. It appears possible that it ranges even into the southern oceans, but there is some doubt as to the exact species in this case. The Dolphin is not a coast-loving animal like the Porpoise, but keeps more to the open sea, where it is found in schools. Like the Porpoise, it feeds on fish.

Lively as the Porpoise is, it cannot be compared with the Dolphin, which is perhaps the jolliest beast alive. When the school catch sight of a ship, they hasten towards it in single file, jumping out of the water in sheer exuberance of spirits; coming alongside, they range up to the bows, and there play all sorts of antics, seeming delighted to find something with which they can have a race. So wonderful are their swimming powers, that they have no trouble, not only in keeping up with a great liner, but in indulging in the most beautiful feats of fancy swimming in the meantime. Thus, I have seen them jump out of the water, and turn on their backs in the air right in front of the ship's stem, heedless of the risk they were running. The stroke of 
the tail must give them an enormous impetus, or be given so rapidly that it escapes the sight; for, watch as I might, I could never catch sight of it. The beautiful creatures slid through the water apparently motionless, for all the world as if they were moved by will-power alone, like Hiawatha's canoe.

It seems a shame to countenance the taking of such happy lives; but as the supply of fresh meat is sometimes a matter of importance at sea, it must be mentioned here that the flesh of the Dolphin is quite good eating, even to a landsman, according to Mr. Frank Bullen. Here it should also be said that the "Dolphin" of sailors is really a fish (Coryphana hippurus), and it is this creature which changes its colours while dying.

Being so well known in the Mediterranean, the Common Dolphin was, of course, familiar to the ancients, who told wonderful stories of its intelligence and its friendliness to man; it was even credited with the philanthropic habit of rescuing drowning people by carrying them ashore on its back. At any rate, in the present day, some species of Dolphin helps the Moreton Bay natives in their fishing by driving the fish inshore to them.

Dolphins more or less nearly allied to this species are found in all seas, and even in some great rivers, and three kinds visit our coasts-the White-beaked Dolphin (Lagenorhynchus albirostris), distinguished by its white muzzle; the White-sided Dolphin (L. acutus), with a white and buff stripe along its flanks; and the Bottle-nosed Dolphin (Tursiops tursio), with a peculiarly swollen muzzle, which last kind reaches ten feet in total length. 


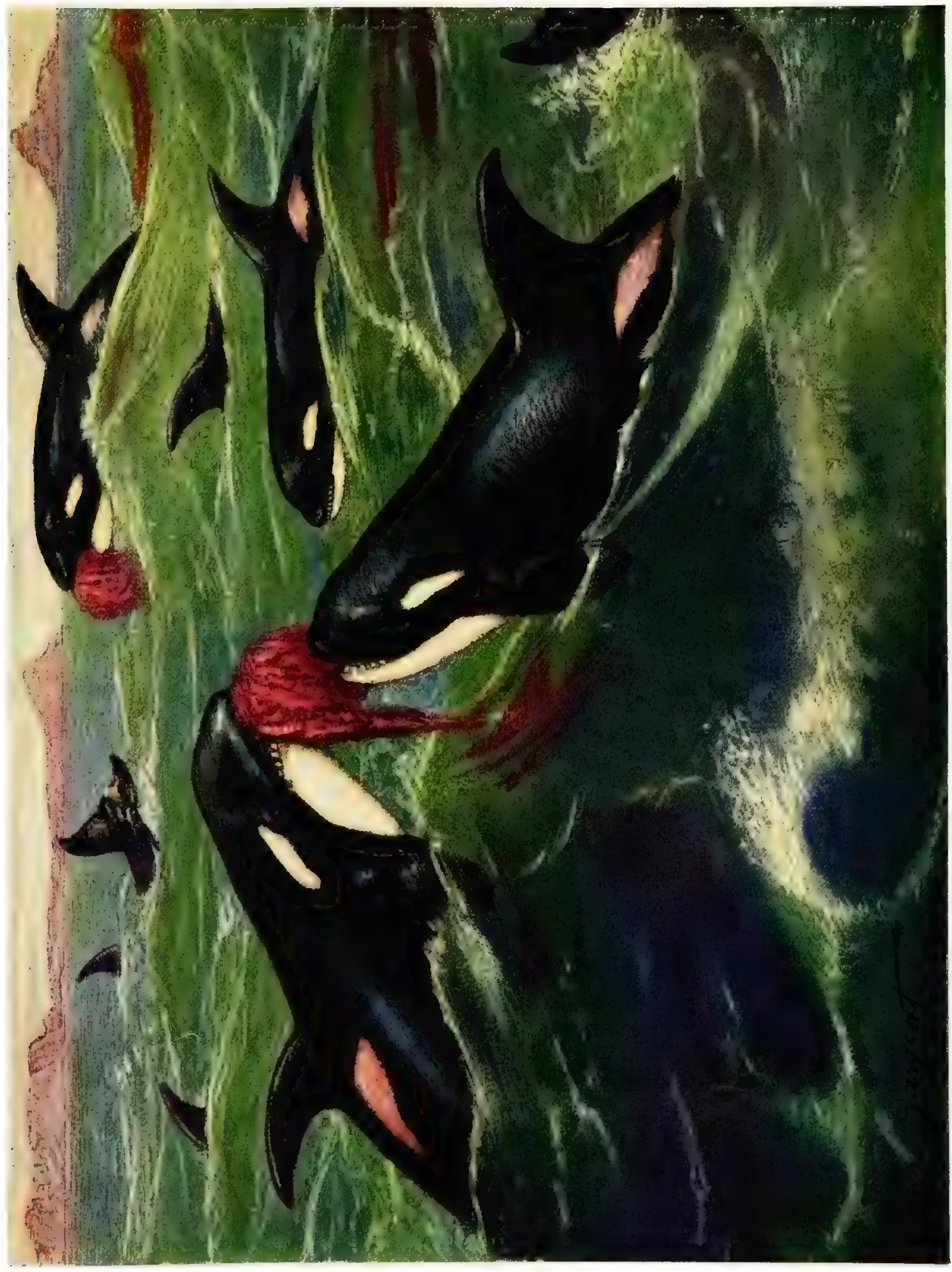

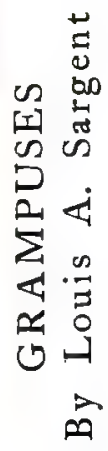





\section{THE GRAMPUS \\ (Orca gladiator)}

THIs fierce member of the Dolphin family, the deadly foe of the rest of its kin, is in form very like a huge Porpoise; it is the largest of the Bolphin group, and is often alluded to as " "Whale," for it reaches ten yards in length. Its teeth are large and powerful, but not very numerous for an animal of this family, numbering from ten to thirteen on each side of the jaws. The high back-fin is a characteristic point of this creature; it is sometimes so tall and thin that it droops over at the tip. The Killer; as the Grampus is perhaps more usually called, varies not only in the length of this fin, but also in colour, the light markings differing much in tint and extent. If all the varieties can be regarded as forms of one species, the Killer may be said to be found in all seas; it often visits our coasts, and sometimes comes up the rivers-on one occasion a party of three ventured up the Thames nearly to Battersea Bridge; and: apparently had the luck to get back safely to sea again.

In the ordinary way, however, the Grampus haunts the open sea, over which it ranges: in packs, 'seeking what it may devour. It is, indeed, a sort of Sea-Wolf, though to liken it to the Wolf gives no idea of its courage: and ferocity-it is rather to be compared to the Bhole or Red" Dog. Like; that animal, it disđains carrion, preferring. fresh meati and that usually of its own killing. It is the only: Cetacean which habitually feeds on other beasts, and it is the worst foe of Porpoises, Dolphins, and Seals, which it bolts whole after shaking and crunching their luckless carcases. So much do the Seal tribe fear it that they will rush on the ice, even close to a man; to escape its attacks. Often they fall victims even when they have taken shelter on a floe, for the relentless Killer. bears down the piece of ice till the victim is tilted into the water and his ready jaws. 
The ferocity of the Grampus is equalled by its storage capacity; one has been found to have devoured no less than thirteen Porpoises and fourteen Seals. Even the great powerful males of the Sea-Lions, for all their courage, dare not face this terror of the sea, but hastily make for the shore and "haul up" when his pointed backfin appears in their vicinity; and, though he dares not attack the old Walrus, he hankers after its cub, and sometimes obtains the little animal by his cunning. In vain the mother carries it on her back, for the foe butts her so violently from below that it is shaken off; but the Killer, in attempting this manœuvre, sometimes loses his life at the tusks of the infuriated parent.

The ferocity of the Grampus is best shown, however, in his attacks on Whales-that is to say, on the Whalebone Whales, for the Sperm-Whale is too much even for him.

The wretched Leviathan, when attacked by these Sea-Hounds, vainly lashes the water with his huge tail flukes and flippers; the savage pack bound into the air and descend with resounding smacks upon his back; they fasten like Bull-Dogs on his huge lips and drag his mouth open, tearing at and devouring his tongue. Ultimately the poor baited giant succumbs to exhaustion and loss of blood, and the ravenous pack glut themselves on his flesh. Although they cannot kill the Sperm-Whale for themselves, they will gladly feed on his carcase when he has been killed by the Whalers, and they also vary or make up their diet with fish.

With all their ferocity, they do not attack man, although displaying practically no fear of him-another curious analogy with the Dhole and the African Hunting-Dog. It would seem that human flesh is distasteful to these boldest of the carnivorous beasts.

Indeed, off the Australian coast the Killers are actually in partnership with the Whalers, helping in the attack on the Whales, and taking their fill of flesh as payment.

In the ordinary way, however, these creatures are naturally regarded as a great nuisance and hindrance to the Whaling industry, as they frighten away the game. 


\section{RISSO'S DOLPHIN}

(Grampus griseus)

THIS peculiar Dolphin reaches thirteen feet in length, and in form is much like a large Porpoise, with a swollen forehead and long pointed curved flippers. Its teeth are confined to the lower jaw, and are only few in number, three to seven on each side. Its colour is very peculiar-grey, with the belly white and the fins black; but it varies a great deal, being sometimes black above. A characteristic point is the number of pale streaks and spots scattered all over the body. Risso's Grampus, as the creature is sometimes called, is very different in habits from the true Grampus, being harmless in disposition and depending on Cuttle-fish for its food. It is a gregarious animal, and found nearly in all seas, though rarely taken. In a few cases it has been found on our coasts.

\section{THE BLACKFISH}

(Globicephalus melas)

THE Blackfish, well known in our northern islands as the "Ca'ing Whale," is a Porpoise-like creature, with a bulging forehead surmounting a short snout; it is black nearly all over, but has a white patch on the throat continued downwards as a long streak. It is a large animal for a Dolphin, reaching twenty feet in length, and has ten teeth on each side of the jaws.

This Whale is found in all seas, and is, as above remarked, well known in the north of our islands, though rare in the south. "Blackfish" is the Whalers' name for it in Australasian waters. It is the species called "Ca'ing" (driving) Whale in the Shetlands, and "Grindhval" in the Faroes; and the inhabitants of these groups find it a most convenient creature. This is because it goes in very large herds, which follow their leader as blindly as Sheep, and it is also inclined 
to enter the "voes" or inlets of the sea. When a shoal is seen about such a place, every one who can turns out, and boats put out and try to get behind the Whales and drive the whole school up the voe into shallow water. This they can easily do unless the leader breaks away; and if they succeed, there follows a massacre of the unfortunate Blackfish with any available weapon, women as well as men taking their share in the work. Such a capture is a windfall indeed to the islanders, for each Whale is reckoned to be worth more than three pounds, yielding a barrel of oil and a good supply of meat.

\section{THE BELUGA}

(Delphinapterus Leucas)

ThE Beluga, or White Whale, which is the only close ally of the Narhwal, next to be noticed, much resembles the female of that animal in form, having no back-fin and a comparatively small head. It has not the Narhwal's tusk, however, but possesses a set of ordinary teeth; but these are not large, and there are only eight or ten on each side of the jaws. In length this animal reaches four yards or more. The colour is pure white in fully aduft individuals, but younger ones are mottled, and the youngest specimens are grey.' The White 'Whate feeds on fish and Cuttles; it is one of the characteristic Arctic'animals found everywhere in the high North, but it sometimes strays southwards, and several individuals have occurred on our own coasts. This is one of the very few Cetaceans which have been kept in captivity; a pair were once exhibited for a short time at the Brighton Aquarium, and one which was kept in America got so tame that it would come up to be harnessed, and carry people round its tank on its back. 


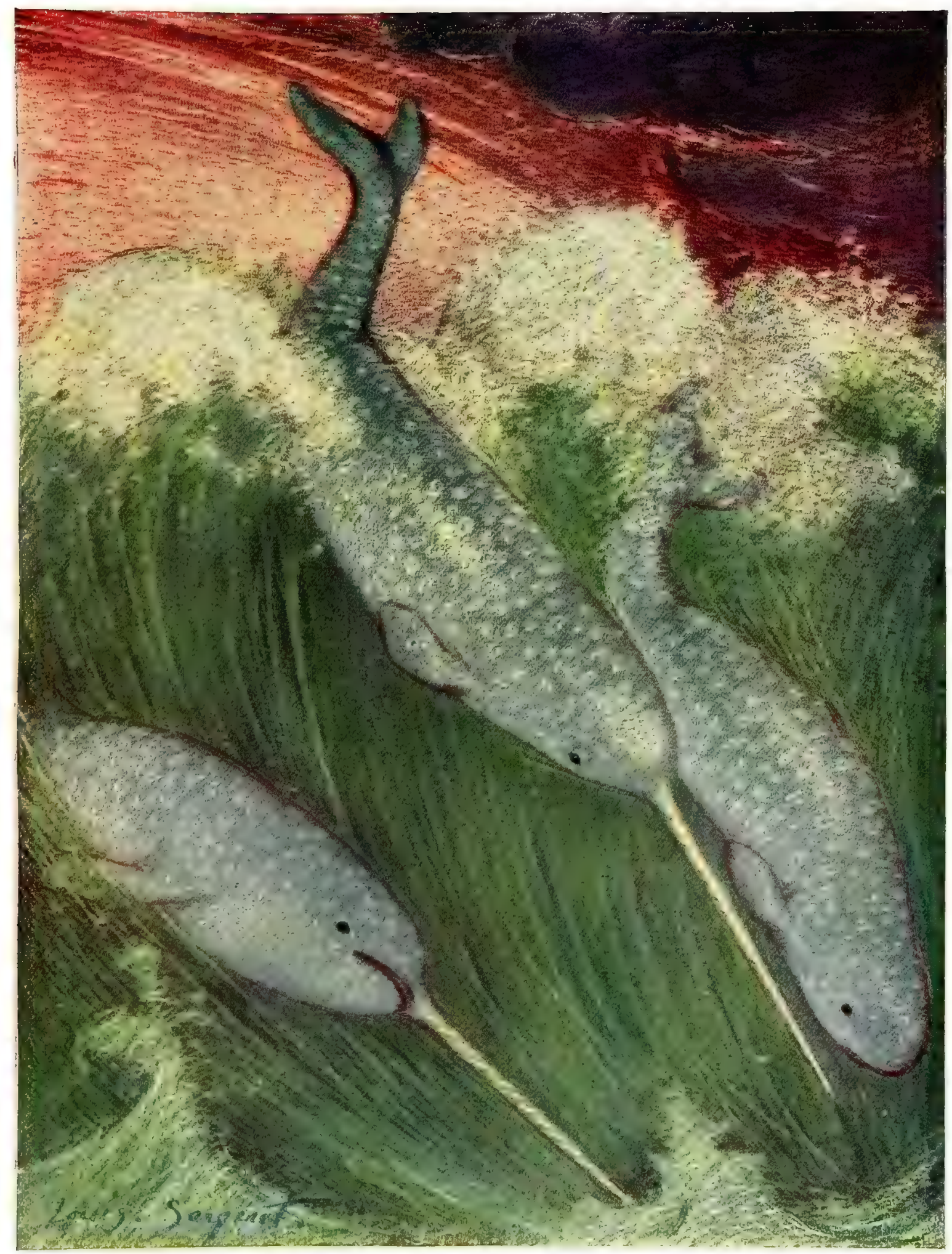

NARWHALS

By Louis A. Sargent 



\section{THE NARHWAL}

\section{(Monodon monoceros).}

THE Sea-Unicorn, as the Narhwal is often appropriately called, is one of the most remarkable beasts in the world; and quite unique in its dental arrangements. . It has only two teeth in its head, and in the case of the female neither is of any use, as they, remain "short and embedded in the gum. In the male the left tooth grows into the long tusk-often miscalled a horn-which in length about equals half that of the animal's body. The right tooth generally remains aborted, as in the female, but in very rare cases both grow into long tusks, as may be seen by a skull in the South Kensington Museum. In one case also a female with a "well-developed tusk, though not so long as in a male, has been recordèd, no doubt an analogous case to the occasional development of horns in female Deer.

The tusk is hollow for a great part of its length, and the spiral grooving of the surface is purely superficial, and does not indicate a twisted structure. 'In length this huge tooth may measure ${ }_{n}$ as much as seven feet, the beast itself being about fourteen. The newly-born Narhwal has' a few irregular rudimentary teeth, which soon disappear; in colour it is much darker than the adult, for this creature gradually whitens with age, and old ones are more white than grey.

The Narhwal is a purely and characteristically-Arctic animal, found all round the world in the vicinity of the eternal ice; it very rarely leaves the Polar regions, and only three specimens have ever reached our coasts. In its native haunts it has been observed to be a swift swimmer, and of a sociable and playful disposition, males often indulging in fencing-bouts with their tusks; no doubt they also engage in serious combats for the females, since the most obvious purpose of the tusk is to serve as a weapon. It certainly appears not to be used to procure the food, which consists mostly of Cuttle-fish and, among 
true fish, of the various flat-fishes. The animal's mouth is not only practically toothless, but small, and it is a puzzle when it is found to have swallowed, in sections, a Skate larger than the diameter of the mouth, unless it had picked this up in fragments, some other animal having done the biting. That the tusk is put to some use appears from the fact that the point is always clean, the base being encrusted with a greasy substance.

Little, however, is known about the habits of this strange creature, though its "horn" has been a familiar curiosity for many centuries, and was that assigned to the Unicorn of fable; it still has some value.

\section{THE WHALEBONE WHALES}

The Narhwal is the most nearly toothless of the Dolphins, though not so quite short of teeth as the Beaked Whales; but there is an important section of the Cetaceans which have no teeth at all-the Mystacoceti, or Whalebone Whales. The Whalebone, or "baleen," which takes the place of teeth, hangs from the sides of the upper jaw in long parallel slips, whose inside edges fray out like hairs; it is, in spite of its name, a horny, not a bony substance. The use of the ranges of baleen plates is to strain off the water when these Whales feed; they all have very large mouths, though their throats are narrow, and feed on sea-animals which swim in shoals, gulping in great mouthfuls of the life-laden brine, and then letting the water drain off at the sides of the mouth, leaving the hapless victims stranded on the great tongue. A humble miniature repetition of this performance may be seen in the Common Duck's way of feeding, and in the wild Shoveller Duck (Spatula clypeata), the straining plates of the bill are, as Darwin has pointed out in one of the most interesting sections of his great work, a very fair reproduction of whalebone on a small scale, various other Ducks showing graduating approaches to the Shoveller's perfected arrangement. 


\section{THE RIGHT WHALES}

THE great Right Whales (Balanida), which have no back-fin and possess the longest whalebone, are those which have been most ardently pursued by Whalers, especially as they are neither swift nor fierce, and so not so very hard to kill. There are only two species, the celebrated Greenland Whale (Balana mysticetus), a purely Arctic animal, which is white on the lower jaw and at the base of the tail, and has the longest whalebone of any; and the Biscay Right Whale (B. australis), widely spread over the world's seas, which is all black, with smaller head and shorter "bone." Both of these, beginning with the last, have been so mercilessly hunted that it hardly pays to trouble about going after them nowadays. The Biscay Whale has occasionally been found on our coasts, but the other apparently never, though it is much more familiar by name, owing to the extensive use formerly made of its whalebone.

Both of these Whales measure about twenty yards; but there is also a Dwarf Right Whale (Neobalana marginata), which only measures about as many feet; it has long whalebone, but also a small back-fin, and is a rare animal, only known from Australasian waters.

\section{THE RORQUALS}

MOST of the Whalebone Whales belong to the family Balanopterida, and of these the Rorquals or Finners (Balanoptera) are by far the best known, all of the four kinds, which seem to be spread over all seas, occurring more or less frequently on our own coasts.

Finners, as their name implies, have a back-fin, which is small and set far back, much nearer to the tail than to the snout. Their shape is long and narrow, and their throats are pleated or thrown into many folds, and will expand like a Pelican's pouch. Their whalebone is short and coarse, and, from their great speed and the fierce temper they sometimes display, they used to be thought too dangerous and unprofitable to be worth hunting; now, however, what with the scarcity of better Whales, and the facilities afforded by steamwhalers and harpoon-guns, \&c., they are successfully attacked and made to contribute their quota to the world's needs. 
The commonest, with us at any rate, is the Common Rorqual ( $B$. musculus), which measures about twenty yards, and is slate above and white below, with black whalebone. Then there are the Blue Whale ( $B$. sibbaldi2), the hugest animal in existence, which grows to thirty yards, and is blue-slate all over, also with black whalebone, and Rudolphi's Rorqual (B. borealis), which is slaty-black spotted with white above, and white below, with white tips to the black whalebone: This is about fifteen yards long, but is not so small as the fourth species, the Pike-Whale ( $B$. rostrata), black above and white below, with a white band across the llipper, and pale-coloured whalebone. This is only about ten yards long, but is a great fish-eater, like the Common Rorqual, the idea that all Whalebone Whales feed on minute creatures not being quite correct.

\section{THE HUMPBACK}

(Megaptera longimana)

THE. Humpback, which is found in all seas, is a clumsy-looking Whale, with a pleated throat and short hump-like back-fin. It is variably marked with black, white, and grey, but its great characteristic is the length of the flippers; which are also white in colour. They measure about four yards, the whole length of the beast being about fifteen. The whalebone, is short and black. This is a rather tame and playful Whale, being particularly given to smacking its friends with its flippers, producing a naise which may be heard miles off in calm weather.

\section{THE CALIFORNIAN GREY WHALE}

\section{(Rhachianeates glaucus).}

This Whale, which is confined to the Pacific coast of North America, up and down which it ranges according to season, is of a mottled grey colour, with light-coloured whatebone. It has no back-fin, and only two pleats on the throat. It measures about fourteen yards only, but is considered one of the most dangerous of all Whales, owing to its fierce temper and its habit of frequentingi: very shallow water, where it is difficult to see what it is doing owing to the stirred-up sand; hence it is often called "Devil-fish.". 


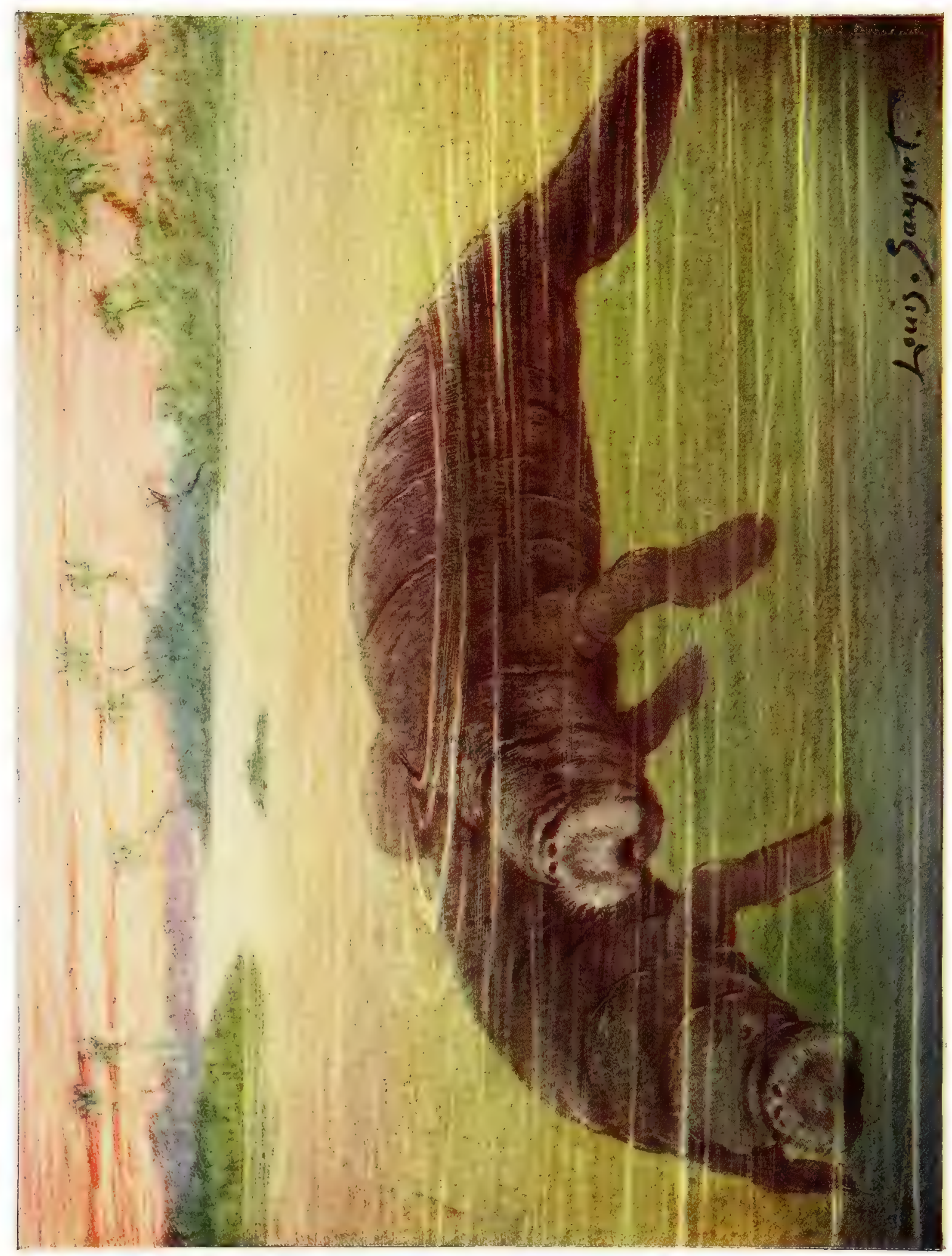

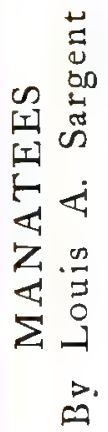





\section{THE MANATEE}

(Manatus americanus)

THE Cetaceans are not the only beasts which in their form and their exclusively aquatic habits resemble the fish; there is another perfectly distinct order of which the same may be said, though in the Sireniar as these animals are called, the resemblance to fish is not carried so far. The Manatee, which we take as a type of this group-a very small one, by the way-has no hind-limbs, any more than a Whale or Porpoise, ${ }_{r}$ and the general form of its body is fish-like, though not so much so as in those animals. Nor are the fore-limbs, though they are more like fins than paws, so completely fin-like as in the Cetaceans. They have some power of movement at the elbow and wrist-joints, as well as at the shoulder, and, indeed, the very name Manatee is derived from the Latin manzs, a hand, through the Spanish, owing to the habit the animal has of employing these flexible flippers more or less as hands in managing its food and its young.

The nostrils are at the end of the muzzle, not on the top of the head, as in most Cetaceans, and the lips, which are very bristly, show a cleft in the upper one, whose halves open and close, so as to grip the leaves on which the creature feeds; for, unlike the Cetaceans, the Sirenians are essentially vegetarians. The eyes are small, as in the Whale tribe; and the Manatee resembles these also in having: a mere pin-hole for an: ear.

The body is practically naked, what hairs there are being very minute, and ends in a broad, rounded shovel-shaped tail, set horizontally like a Porpoise's, and no doubt for the same reason, the Manatee being of course an air-breather, and needing to "blow" frequently. There are no teeth in the front of the jaws, but a good set of grinders, broad-crowned and ridged like those of hoofed animals, and utterly unlike what are seen in Cetaceans. There are eleven on $\underset{361}{2}$ side in 
both jaws, but as these work forward as in the case of the Elephant's grinders, and are shed when worn out as fresh ones cut through behind, in practice only about half that number are in view and in use at once.

The Manatee grows to about eight feet in length; its home is the coasts and estuaries of the warm parts of the eastern coasts of America. On the opposite side of the Atlantic, on the West Coast of Africa, is found another species (Manatus senegalensis), and confined to the fresh waters of the Amazon and Orinoco is a third (Minatus inunguis), but all are very much alike.

The Manatee is a slow, sluggish creature, very different from the lively, active Porpoises and Dolphins. Its food consists of aquatic plants, on which it browses by the aid of its bristly cleft upper lip as above stated. It will feed on land herbage also when this is conveniently accessible from the water, but there seems no reason to believe that it ever comes ashore to graze, as has sometimes been stated. The probabilities are very much against such a performance, since, from observations made on a specimen at our Zoological Gardens years ago, the Manatee is very helpless and excessively uncomfortable out of water. When lying on its chest it is especially ill at ease, but obtains some relief by rolling over on its back, the fact being that its weight compresses its chest and makes breathing difficult.

It may here be mentioned that it is for this reason that stranded Cetaceans cannot live very long, although air-breathers, the unfortunate brutes, whose chests are built for expansion, being slowly choked by their own weight.

Owing to the sluggish mode of life and vegetarian habits of feeding of the Manatee, it prefers quiet, shallow water; when not browsing it rests under the surface, only coming up to blow every two or three minutes; but it can also float when the water is too deep for this to be convenient. It has but one young one at a time, and this the mother is said to hold under her fore-flipper, the teats being situated just behind the arm-pits.

The young animal has a couple of incisors in the upper jaw, but 
these are mere rudiments, and are concealed beneath the horny plates which cover the front part of the mouth and even the tongue, which is small and not movable. Manatees live in pairs, and the male is said to exhibit much affection for the female, so that if his mate is harpooned there is considerable chance of securing him also.

There is considerable inducement for hunting these creatures, the flesh being very good eating, while the abundant fat supplies an oil of excellent quality; and the animal is all the more valuable as the forest region of South America, so prolific in vegetation and in small forms of animal life, is singularly deficient in large beasts, especially those of edible kinds. Thus the Manatees, under the names of "Peixe-boi" (Ox-fish) and "Vacca Marina" (Sea-Cow), are important animals to the water-side population of their native haunts.

The Manatee is not a difficult animal to keep in captivity in its own country, and several specimens have been exhibited elsewhere-for instance, in Philadelphia, at the Brighton Aquarium, and in our own Zoological Gardens.

\section{THE DUGONGS}

THE Dugongs (Halicore) are so like the Manatees in general appearance that any one would at once see that they are near relatives of those animals, which they resemble in size and in general form. They can, however, be immediately distinguished by the tail, which in the Dugongs is forked like that of a Porpoise.

There are also some noteworthy differences in the teeth, the male Dugong having two large incisor tusks, which grow continuously, though only the tips show outside the mouth; while in the female they never project beyond the gum, remaining undeveloped in their sockets.

The young animal has several more small front teeth, which are never seen, being hidden under the horny gums. Moreover, the grinders differ somewhat in structure from those of the Manatees, and 
are less numerous, not exceeding half-a-dozen in all. There are three species of Dugongs, so much alike that they are hard to distinguishthe Indian (Halicore australis), the Australian (H. australis), and that of the Red Sea (H.tabernacul ). They are sea animals, though keeping near the coasts, and feed upon sea-weed; and one or other of them is found from the Red Sea to Australia. As, like the Manatees, they are good for food and yield excellent oil, they have been much persecuted; and there is reason to fear that, as the Manatees themselves have been much reduced by man's attacks, the whole of this harmless, interesting, and useful order of animals will be exterminated unless reasonable protection be given in time. 


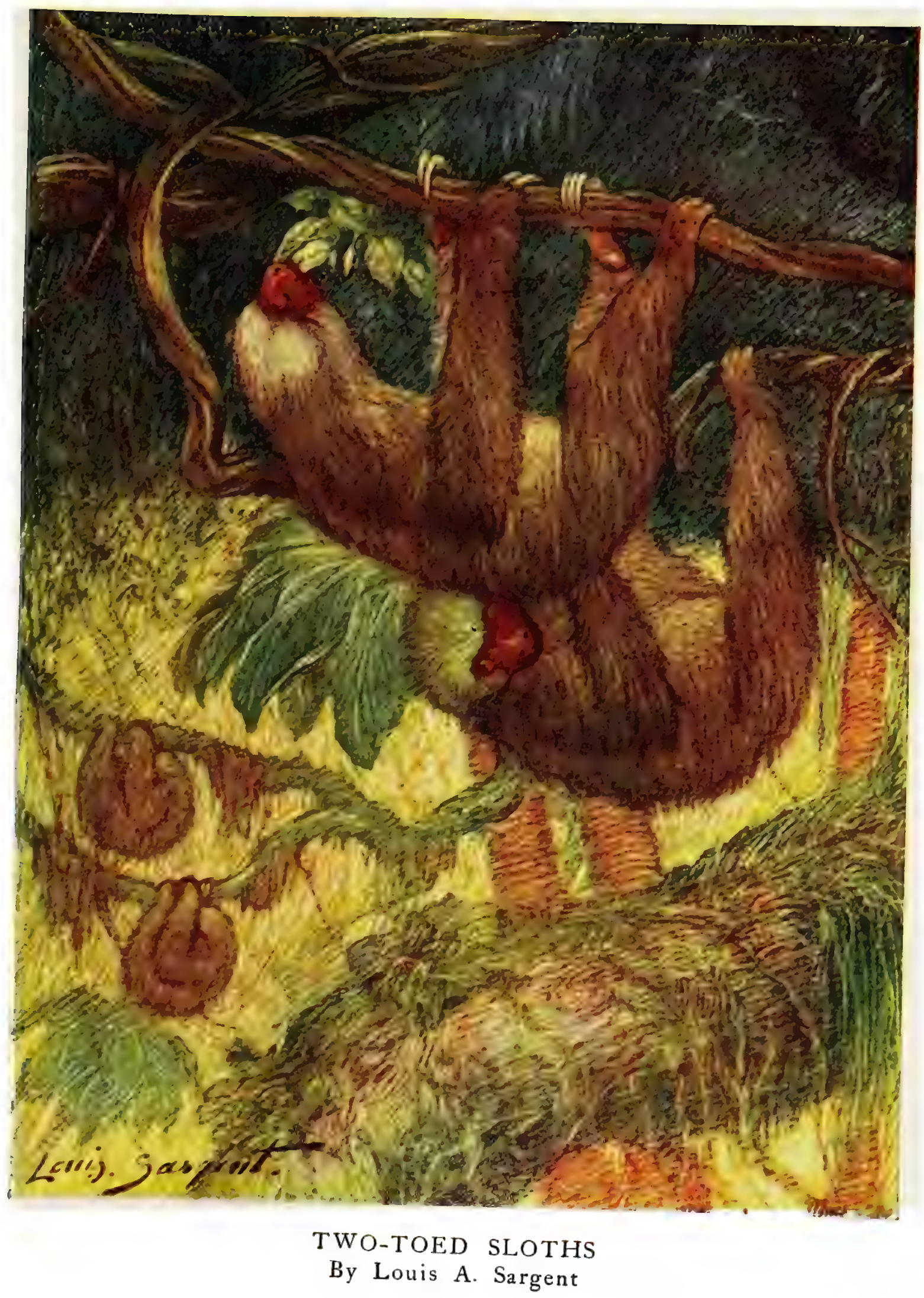





\section{THE TWO-TOED SLOTH}

\section{(Choloepus didactylus)}

THE Sloth has achieved the somewhat paradoxical feat of acquiring an extended reputation merely by not exerting himself, although his sluggishness has been somewhat overrated by people who have not had the opportunity of observing him under the only conditions for which he is fitted by nature.

The Sloth is, indeed, one of the most perfect examples of an animal specialised exclusively for one way of living -in his case, that of treeclimbing, and climbing upside-down at that. His long limbs are terminated by two toes only on the fore-feet, and three on the hind, and these are joined in a common skin, and provided with powerful hooklike claws, so that he remains suspended without the slightest muscular exertion. His tail, which would be of no importance to a creature in his position, is a mere rudiment, and, like his ears, not noticeable, especially as his coat is so long and shaggy, except on the face.

His muzzle is short, and but poorly provided with teeth; indeed, he belongs: to the order of beasts known as Edentata or toothless animals, in all of which the teeth, though usually not completely absent, are deficient in the front of the mouth, and of very simple shape elsewhere. Thus the Two-toed Sloth has no incisors, and, indeed, only ten teeth at all in the upper jaw, and eight in the lower, which are peg-like in shape; the first pairs in each jaw are bigger than the others, however.

In size the Sloth may be compared to a Terrier; and in colour it is very variable; generally, however, in a wild state it exhibits a decided greenish tinge, which is not due to the colour of the hair itself, but to the growth of minute vegetable organisms on it, this being rendered more possible by the fact that each hair is minutely grooved. The Sloth therefore may almost be said to gather moss, unlike the 
proverbial rolling stone; but in dead and captive specimens this curious microscopic growth naturally disappears from the hair.

The Sloth was one of the earliest American animals to acquire a reputation, but it was some time before naturalists understood how to put him right side up, as it were. In his proper upside-down position he is able to move about among the boughs with considerable speed; this he does entirely by clawing himself along hand over hand, never jumping like so many other arboreal animals. In the thick forests he frequents he can travel a long distance without ever coming to the ground, by simply passing from one tree to the boughs of another touching it, or by means of the many trailing creepers. His best time to be on the move is in windy weather, for then, even if the trees are not close enough for him in the ordinary way, the swaying of their boughs brings them into contact, and he is not slow to avail himself of the opportunity of changing his quarters if he desires to do so.

The chances are, however, that he does not so desire, for he is really a very lazy, sluggish animal, and does not need to move about much for his food, which is all about him, consisting as it does of leaves, shoots, and fruit. To bring a coveted morsel within his reach, he will hook a bough towards him with his fore-legs, which are much longer than the hinder ones. In the very exceptional cases when the Sloth is absolutely forced to come to the ground to get to a distant tree, he is seen at great disadvantage. He cannot walk at all in the proper sense of the word, as he rests sprawling on the outer edges of his hook-like feet, and so is reduced to hauling himself along by grasping at any roughness of the ground; on a smooth surface he is almost helpless. It was from seeing him in this unhappy position that the old writers formed such erroneous ideas of his miserable incompetence.

One old book says, for instance: "Its legs are thick, and awkwardly placed; so that it can only move one of them at a time, and requires an hour to advance three yards. When it has, by the most laborious exertions, ascended a tree, it remains there till it has stripped it of everything that can be eaten, when it rolls itself into a ball, and, to 


\section{THE THREE-TOED SLOTHS}

save the trouble of a gradual descent, falls to the ground with a horrid scream."

Even yet the Sloth does not seem to be fully understood by everybody, for a modern scientific writer, some years ago, actually went to the other extreme, and stated that it could walk, trot, and gallop, and this although Sloths of one species or other have been constantly on view at the Zoo, for, as might be expected in the case of such sluggish creatures, they thrive quite well in captivity.

They cannot, however, be called very interesting animals in a menagerie, as, being nocturnal, they are really slothful all day, coiling themselves up into a ball, with their head tucked in and the long forearms grasping a perch. The Sloth's one instinct, indeed, is to "hold on," and his only idea of defence is to grapple and hug his enemy with his powerful limbs and claws.

He holds on to his sluggish life with the same pertinacity, and is one of the very hardest beasts to kill, surviving some time even a puncture of the brain or spinal cord, and being remarkably resistant to poison. The female Sloth has but one cub at a time, and this is carried on her breast as she climbs about the trees.

All the Sloths are inhabitants of the warm forest-clad regions of America, the Old-World animals sometimes confused with them being sluggish, short-tailed Lemurs-the African Pottos and Asiatic Loriseswhich are quite brilliant and vivacious creatures by comparison. The ordinary Two-toed Sloth is an inhabitant of Brazil, and there is another two-toed species (Choloepus hoffmanni) in Central America.

\section{THE THREE-TOED SLOTHS}

THE Three-toed Sloths (Bradypus) very closely resemble their twotoed relatives in most respects, but differ from them in certain details. Most noticeable of these is, as the name implies, the presence of three toes on the fore-feet as well as the hind; but there is also a difference in the teeth, the four foremost teeth in the Three-toed Sloths not being 
larger than the rest; indeed, those in the upper jaw are considerably smaller. One very curious point about these Three-toed Sloths is that they are the only beasts which have more than the regulation number of seven vertebræ in the neck-for they have nine. This would seem to be an admirable adaptation to allow the beast to twist its head about as it hangs upside-down; but then we are confronted with the awkward fact that among the Two-toed Sloths the Brazilian species has the ordinary seven neck-vertebræ, and Hoffmann's Sloth of Central America only six-the only exception to the rule of seven on the side of deficiency. Cases like this show that anatomical characters are not necessarily in themselves important, and are thus worthy of careful note.

There are several species of Three-toed Sloths, ranging, like the Two-toed kinds, through tropical America; they are often called by the name of "Ai" - said to be derived from their cry; the Brazilian Two-toed species being known by the title of "Unau." In any case, the note is not to be described as a "horrid scream," being rather a bleat or a snort; but they are not noisy animals. 


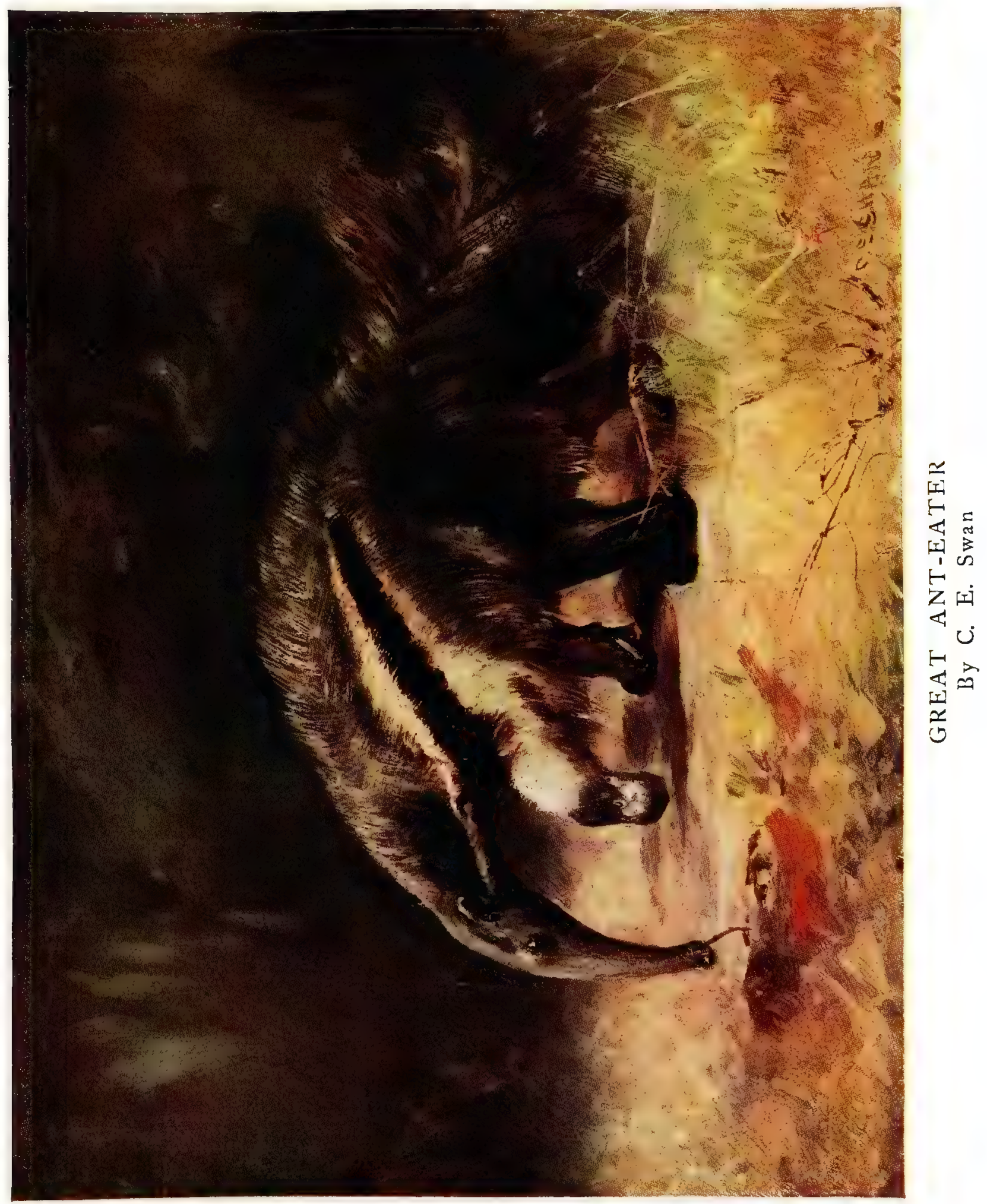





\section{THE GREAT ANT-EATER}

(Myrmecophaga jubata)

THE Ant-Bear, as this creature is sometimes called in its own country, easily stands first among the curious beasts of the New World. It is a truly typical member of the Edentata, having no teeth at all, and but a very small mouth, the long jaws being bound up in the skin almost to their ends. The tongue is very long and extensile, and looks much like a big worm. The fore-paws are also extraordinary: there are five toes, but these are very unequally developed, the middle one forming the main part of the foot, and carrying a huge claw; the other toes are all small, and the fifth has no claw, but is covered at the tip with a hard skin-for on it, and on the backs of the next two toes, the beast rests on walking, the tips of the toes being turned in, to keep the claws sharp for digging. This is what gives the peculiar clubbed appearance to the fore-foot, so well shown in the illustration. The hind-feet are much like those of a Bear, with five ordinary-looking toes and elaws, and the beast treads flat-footed like that animal, behind, though walking on its knuckles before.

In size this Ant-eater is far the largest of the living Edentates, being about six feet from snout to tip of tail; with a height of a couple of feet at the shoulder; it is, 'in fact, as big as a small Bear, but narrow. and slab-sided in form. Its coat is coarse, but close, except on the great bushy tail, which is laid over the animal as a blanket when it goes to bed. Internally, the Ant-eater is remarkable for having the hinder part of the stomach very strong and muscular, like the gizzard of a bird, no doubt to facilitate the grinding of the food, which is necessarily swallowed whole, there being no facilities for chewing it.

The Great Ant-eater is a characteristic animal of tropical America, but is not common; its favourite haunts are on low moist ground, either in forests or in the swampy plains. It is purely a ground animal; and neither climbs nor burrows, nor can it travel fast; a man can easily 
overtake and even drive it along; but it is not a creature to take liberties with, nevertheless, for when roused to desperation it will turn and hug its enemy, its huge fore-claws penetrating with deadly effect. It is even said that the Jaguar himself has succumbed to the fatal talons, and Dogs are liable to fare badly in such an encounter.

The ordinary use of these formidable claws is to tear open Anthills, or those of the Termites-the so-called "White-Ants" so numerous everywhere in the tropics, for on such small creatures the Ant-eater feeds, licking them up with its long slimy-tongue.

The Ant-eater seems usually to be a solitary animal, but the female displays considerable affection for her single cub, which when quite small is already a miniature of the parents; there is a case on record in which an Indian, who had captured a young Ant-eater, was pursued by the infuriated mother, and perished in her relentless grip, as he unhappily tripped over his blow-gun in trying to escape her attack. The creature is sometimes killed for food, and its flesh is said by Bates, who found it a great stand-by when on one occasion he found it difficult to get anything to eat but fish and vegetables, to be very good, something between pork and goose in flavour.

A creature of this kind does not seem at first sight to be at all a promising subject for captivity; but in point of fact it thrives well, and is usually to be seen in the large Zoological Gardens, including our own. It has even bred in one of these institutions on the Continent. Minced raw horse-flesh mixed with milk has been found by experience to be a good substitute for its natural insect food, but this diet would probably be much improved by the admixture of a quantity of the various kinds of dried insects now so much in favour for feeding insectivorous birds, as well as of that invaluable insect, the Mealworm. It will also eat such small animals as Cockroaches and young hairless Mice. Although, of all land animals, hardly any can be less suited to aquatic habits, in captivity at any rate it shows a decided inclination to take to water, and those kept in our Zoological Gardens are always provided with facilities for having a bath, of which they are not slow to avail themselves. 


\section{THE TAMANDUA ANT-EATER}

(Tamandua tetradactyla)

"TAMANDUA" appears to be a native name for the Ant-eaters generally, but here it is usually appropriated to a rather small species, which also inhabits tropical America, but does not encroach on the domain of the large one, as it is a climber, and keeps mostly to the trees.

The Tamandua, which is about as big as an ordinary Cat, is sufficiently like the Great Ant-eater to be recognisable at a glance as a near relative of that most eccentric-looking beast, and its feet are similarly formed: Its muzzle, however, is of only moderate length, and its tail very different, being devoid of long hair, and indeed bare towards the end; besides which, it is prehensile.

The limbs are shorter than in the big ground Ant-eater, and though the beast walks on its front knuckles in the same way, its gait is awkward and straddling, for it is only really at home in the branches. The method of defence is much the same as in the large species-a clutching inward stroke with the well-armed fore-paws. In colour this species is very different from the large kind; it presents much variation, but, broadly speaking, the general hue is straw-colour, with the flanks covered by a broad black patch along each side. The coat is short and close throughout. This Ant-eater feeds on those Ants and Termites which make their nests in trees; it will live in captivity, but is not so common in that condition as its larger and more sensationallooking relative.

\section{THE LITTLE ANT-EATER}

\section{(Cycloturus didactylus)}

THIs, the only other species of the Ant-eater family, is more different from the other two even than these are from each other, and is the most thoroughly adapted for a life in the trees. It is quite a small creature, only about as large as a Rat, and is covered with soft strawyellow fur. The tail is very long and naked below, and is strongly prehensile. The muzzle is quite short, but bent downwards in a way almost unique among animals. The feet differ greatly from those of 
the other Ant-eaters; the hind ones have practically only four toes, the first being rudimentary; the other four are strongly clawed and curved, being opposed to a pad on the heel, so as to grip boughs in climbing. The fore-paw is even more peculiar, there being practically, only two toes, the very large and strongly-clawed third toe, and the second, which is much slenderer; the others are rudimentary.

This little creature has much the same range as the other two Ant-eaters, but none of the three interfere with each other, the Great Ant-eater being terrestrial, the Tamandua chiefly a tree-dweller, while the Little Ant-eater is entirely so. It feeds to a great extent on the grubs of tree-building wasps, which it extracts from their cells by means of the pincers formed by the two-toed fore-limbs. It is not an easy animal to keep alive in captivity, and so far has not been exhibited in our Zoological Gardens.

\section{THE PANGOLINS}

THE Pangolins (Manida) of tropical Africa and Asia resemble the Ant-eaters of the New World in their toothless jaws and long tongues adapted to a diet of Ants, and even in their habit of walking on the fore-knuckles to protect the huge digging claws, but they are not closely related to them, although belonging to the same order of Edentates. In their general appearance they differ from any other beasts, being covered with broad horny scales above, and on the tail and outsides of the limbs. The long tail is very broad and thick where it joins the body, and there are no external ears. In fact, were it not for the scanty hairs that are found on the under-surface, these creatures might reasonably be taken for some curious sort of Lizard rather than for beasts of any kind. When disturbed, these creatures roll themselves into a ball, and are then practically invulnerable owing to the hard sharp-edged scales. They are slow-paced, nocturnal animals, some species living entirely on the ground and in burrows, and others climbing trees. One young one is born at a time, and this, in the Burmese species at any rate, rides on the base of the mother's tail, clinging with its powerful claws.

These animals are very rare in captivity, but one species, the West African (Manis tricuspis), has been exhibited in our Zoological Gardens. 


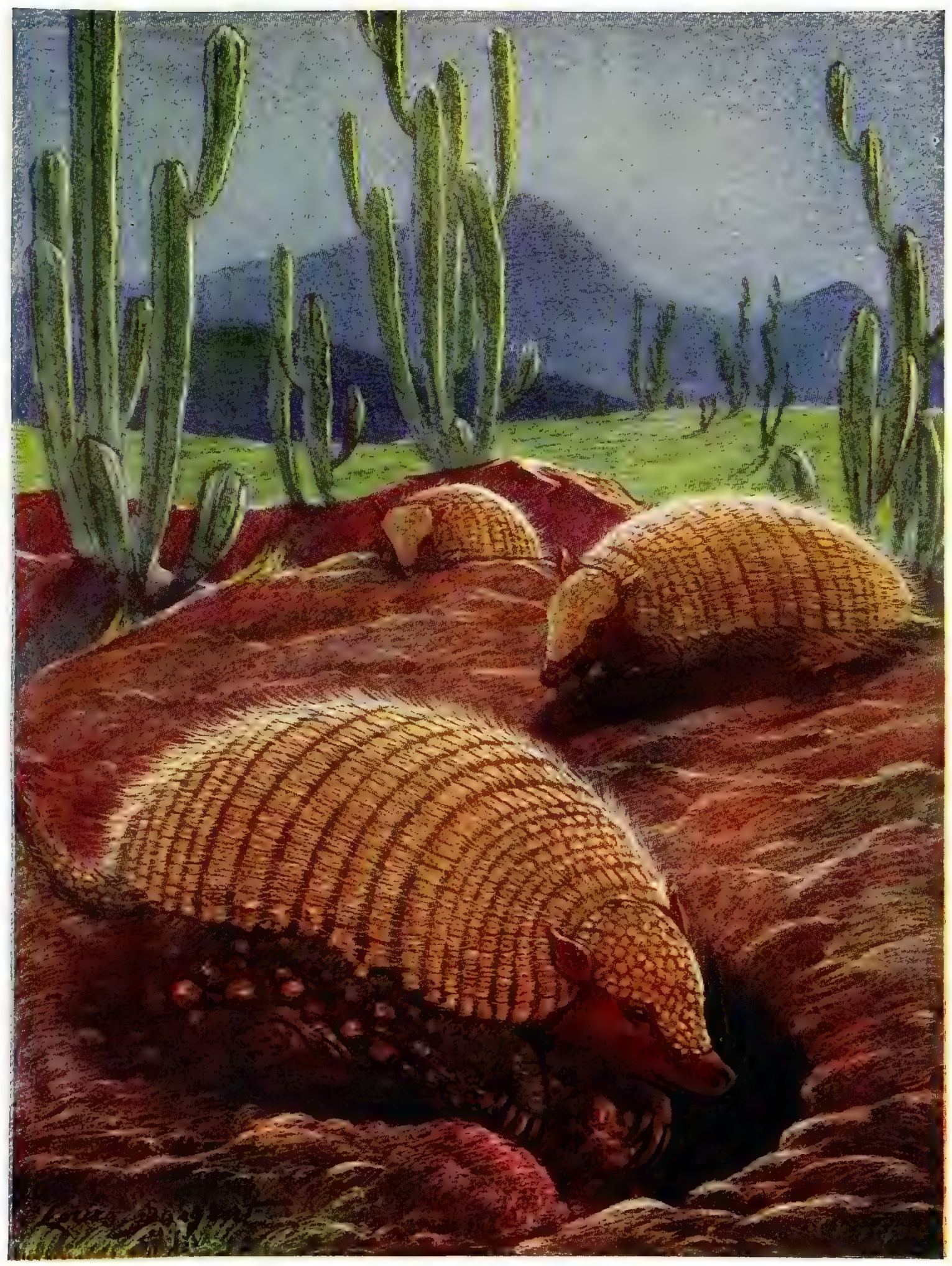

HAIRY ARMADILLOS

By Louis A. Sargent 



\section{THE HAIRY ARMADILLO \\ (Dasypus villosus)}

BEING frequently brought to Europe in captivity, the Hairy Armadillo is the best known of its family (Dasypodida), which are distinguished, not only from all other Edentates, but all beasts of any sort, by their peculiar jointed cuirass of bony plates, formed by the deposition of bone in the skin of the upper parts.

This forms two great shields on the fore-parts and hind-quarters respectively, with several bands filling up the intervening space, and allowing of the necessary flexibility of the body; the tail is covered by rings of plates, at any rate at the base. In the present species many hairs appear at the joints of the plates, and the under-surface of the body also shows a good many, although they are so scanty that the general effect is much like that of the sparsely-bristled skin of an old fowl when plucked, leaving the hair-like feathers known as "filoplumes." The body of the Armadillo is peculiarly broad and flat, and as the legs are very short, with their basal joints not projecting from the body, the whole effect is rather tortoise-like. There are five toes on all the feet, all clawed, the claws on the three outer front toes being particularly strong.

The teeth are about three dozen in all, and very simple and uniform in structure, like pegs: there are none in the front of the mouth, as in Edentates generally. The tongue is long and narrow, and can be protruded some distance out of the mouth, showing a slight tendency to the worm-like type of tongue so characteristic of the Ant-eaters. In length the beast measures about two feet, but is surprisingly heavy and solidly built for its size.

The Hairy Armadillo, which is very closely related to the Sixhanded Armadillo of Brazil, also a well-known species, is found in Argentina, and its habits on the Pampas have been admirably described by Mr. W. H. Hudson. He points out how curious it is that this comparatively slow and lowly organised creature is able to maintain its existence in the face of the encroachments of civilisation, to

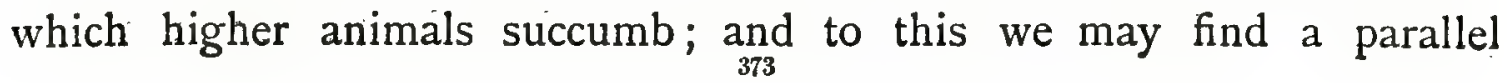


in the successful survival of the humble Hedgehog with us, while we have nearly exterminated the Wild Cat, and only allow the Fox to survive that he may make sport for us. The Armadillo is diurnal or nocturnal according to circumstances and the risks he runs from mankind; he is easily satisfied in the matter of food, devouring worms, grubs, mice, snakes, the eggs and young of ground-breeding birds, and any carrion he can come across. Should he scent out the carcase of a Horse, he is in luck's way, for he will drive a shaft under it and live in luxury, eating away at the carcase from beneath. If his more natural animal food should fail, he will make shift with herbage, and even maize has been found in its stomach.

Clumsy as it is, the creature can move nimbly enough, and it displays some strategy in capturing its prey. When it scents a mouse, for instance, according to Mr. Hudson, it will creep cautiously up and fling itself bodily on the unfortunate little rodent; while snakes it circumvents by sawing them into helplessness with the notched edges of its armoured overcoat.

The said coat of mail also protects it to a considerable extent from the attacks of beasts of prey, and it is further secured by its great strength and powers of rapid burrowing. When seized it does not bite, but uses its claws to some purpose.

Man himself relishes the flesh of this creature, as in the case of several others of the family; it is said to eat better than roast pig, and is very fat-almost too rich, in fact. Of all animals, certainly, none looks so much as if it were made to be eaten; there is so little to be done to make it ready, as its few sparse hairs are easily singed off, and the shell makes a capital dish to roast it in.

In captivity the Hairy Armadillo is a very hardy animal, but its cage or sty must be strongly constructed, or the beast, which is very restless and constantly on the look-out for a weak point, will fairly force itself out. It bears cold well, and will endure our winters in an outdoor habitation-a sufficiently remarkable thing in the case of an animal practically devoid of fur. The Armadillo, however, appreciates the value of a warm bed, and, if provided with straw, will bite it up into chaff, and then bury itself in the heap thus formed. Armadillos are long-lived animals for their size; at any rate, a species allied to the present lived in the Calcutta Zoological Gardens for twenty years. 
Most of the Armadillos are much like the Hairy species in general appearance, and few are any larger, but some especially remarkable species deserve notice.

\section{THE GIANT ARMADILLO \\ (Priodon gigas)}

The Giant Armadillo, as its name implies, is much larger than any other Armadillo, for it éven exceeds a yard in length. In general structure it resembles the common Hairy Armadillo, but the armour bands across the back, between the shoulder- and hip-shields, are more numerous, about a dozen in all, and the feet are somewhat different, the hind toes being very short, with short nails, while the middle toe of the fore-foot is enlarged at the expense of the other four, and bears an enormous claw. Strangely enough in an "Edentate" animal, the teeth are very numerous indeed, being about two dozen on either side of each jaw, a number unequalled in any beast except some of the Cetaceans. This Armadillo inhabits the Brazilian forests, feeding on insects and carrion; it bears a bad name as a violator of graves, and probably deserves it-its great claws are quite equal to any feat of the kind, and its appetite sufficiently accommodating.

\section{THE BALL ARMADILLOS}

THESE curious little animals (Tolypeutes) have the shoulder- and hipshields very well developed, but only three cross-bands between them; they can roll themselves up like Hedgehogs, and when thus contracted form perfect balls, the head and short tail fitting neatly into crevices. They are not less remarkable when running about, for the fore-feet have a huge middle claw on the tip alone of which they tread, while on the hind-feet the three middle claws are enlarged, and support that part of the body, though not absolutely on their tips. Three species of these Armadillos are known, and two of these have been exhibited at our Zoological Gardens.

\section{THE PICHICIAGO}

\section{(Chlamydophorus truncatus)}

THIs quaint little creature, which differs much more from the other Armadillos than these do amongst themselves, is a sort of armour-plated 
Mole, for it spends most of its time in burrowing. It is the smallest Armadillo known, being hardly six inches long, and has a rather pretty appearance, its armour-plating being pink, and the hair on its underparts, which is silky and abundant, and conceals the small eyes and ears, pure white. There are no solid shoulder-and hip-shields, but the body is covered from head to hinder end, which is, as it were, cut off flat, with a series of transverse bands. The flat hind end has a solid shield, notched below for the short tail, which is permanently turned downwards. The limbs are very short and the claws well adapted for burrowing, the centre fore-claws being especially enlarged. The home of this curious animal, which is not common, is the sandy districts of Western Argentina; it has but one relative, from Bolivia (Chlamydophorus retusus), which is not quite so small in size.

\section{THE AARD-VARKS}

ThE Aard-Varks or Ant-Bears (Orycteropodida) of Africa are placed with the Edentates on much the same principle as the Cobego is associated with the Insectivores, because they will not "fit in " anywhere else, their relationship to the other families of this order being very questionable.

They are most extraordinary-looking animals, about the size of small Pigs, and something like a caricature of a Pig in appearance. The snout is long, with the end broad, but the mouth small; the ears long like a Hare's, the tail very thick at the root and rapidly tapering, and the limbs short and with four toes on the front and five on the hind paws, all with strong straight claws. The mouth is well provided, except at the front, with peg-like teeth, and the tongue is long, though not so much so as in the Ant-eaters. In captivity, at any rate, the animal often feeds in a different way, for one I watched sucked up its breadand-milk just like a Pig, and did not lick its food like an Ant-eater. Yet in the wild state they appear to feed on Ants in the same way as those animals. They are great burrowers, making huge earths, but, as they come out at night, are rarely seen. There are two species or races; the Ethiopian (Orycteropus athiopicus) from North-East Africa, which is nearly naked, and the Cape Ant-Bear (O. capensis), which is covered with hair; and both have been on view at the London Zoological Gardens. 


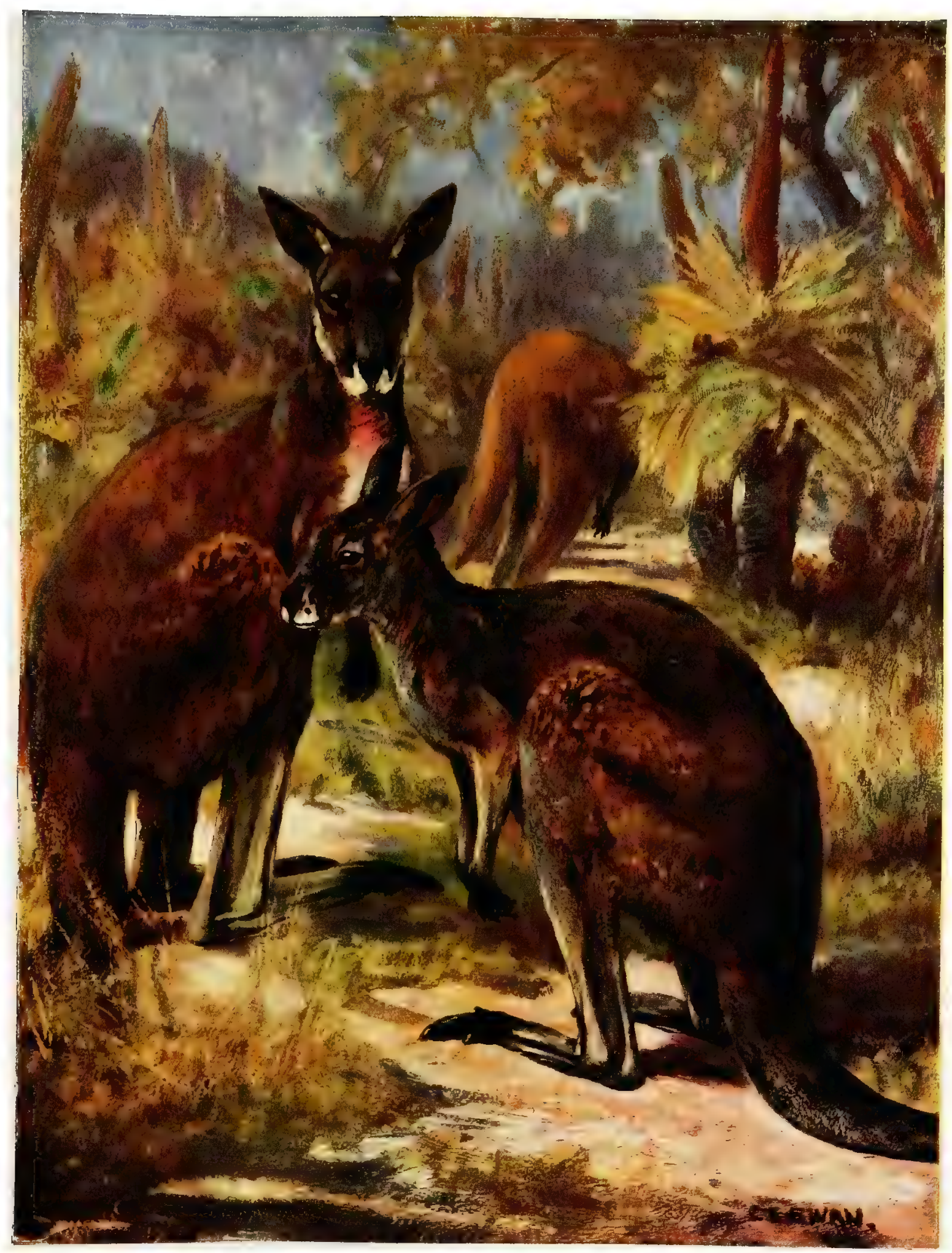

\section{RED KANGAROOS \\ By C. E. Swan}





\section{THE RED KANGAROO}

(Macropus rufus)

THE Red Kangaroo is the most beautifully-coloured of the large species of the Kangaroo family (Macropodida), a group which are so much alike that when one has been seen any of them can easily be referred to its proper position. As every one knows, Kangaroos belong to the order of Marsupials, or pouched animals, whose females are typically characterised by a pouch on the abdomen in which the young-born extremely tiny and imperfect-are placed by the mother immediately on birth, and thereafter remain hanging to the teats for a considerable period.

In addition to their characteristic bodily shape, with small fore-legs and long hind ones, the Kangaroos are noticeable for their peculiar hind-feet, which are chiefly made up of the huge fourth toe, which is armed with a powerful claw; the fifth toe is of only about half the length of this, and the second and third toes not only equally short, but exceedingly slender, and bound up together in the skin, so that only their two claws, which the animal uses for scratching itself, are visible externally. The first or great toe is absent altogether.

The fore-feet have five ordinary-looking toes, and the animal uses them as hands, in lifting its food to its mouth, \&c. The teeth of the Kangaroo are decidedly peculiar; there are no canines in the lower jaw, and the upper pair are insignificant and early shed. The upper incisors are six in number, the lower only two; the grinders are suited for crushing and chewing the food of these creatures, which, like the hoofed animals, feed on herbage, and similar products of the vegetable kingdom,

The leaping gait of the Kangaroo is well known to every one, and, when going fast or far, is the only means of locomotion it has; the fore-feet are only used when the creature is moving along slowly, when it places these paws on the ground, and swings its hind-limbs forward with the action of a person walking on crutches. In the ordinary way, its leaps are not more than a yard or so, but when pressed it bounds 
along in leaps of three or four yards, and can keep up this exertion for an hour or two, clearing in its course obstacles which are serious to pursuers, such as Dogs, which employ the ordinary -quadruped way of going about. When thus travelling, it alights only on the toes of the hind-feet, and it can also stand upright on these, with the aid of the powerful tail, when it wishes to take a look round. On a slope the Kangaroo is awkward and liable to overbalance itself, and so avoids such ground when pursued. It swims well and powerfully, and will often take to water when brought to bay. In this case, however, it stands up on its hocks, and seeks to grapple its antagonist and force him under water. On land, it takes up a similar position, and strikes terrible blows with the powerful claws of the hind-feet, which are quite capable of disembowelling an antagonist in the case of large species like this. The Red Kangaroo is, indeed, the largest of the family-a male measuring over eight feet in total length, of which a yard is tail. The great difference between the sexes in this species is rare among Marsupials; the male only being red, while the female is grey-often much more so than the specimen figured,

The rose-pink colour on the male's throat looks unnatural in a beast, and indeed it is not in the fur itself, but is due to staining by a pollen-like substance-a sort of natural rouge which is secreted by the skin in that part. Kangaroos have but one young one at a time, and these are born not only blind and naked, but with the limbs of nearly equal length; the young are excessively small, being in a large species like this only about as big as one's thumb at birth. The mother places them in her pouch with her lips, holding it open with her paws. When they cease to cling on to the teat, from which they can at first be only removed by force, they put out their little heads and begin to browse on the grass like their mother; then they venture out to hop about and play, but in case of alarm rush hastily back to the old one and tumble head first into the pouch. A hunted doe Kangaroo, if carrying a big young one, and hard pressed, will fling the "Joey," as it is called in Australia, aside to lighten herself, returning to look for it afterwards if she escapes with her life. So swift is the female of the Red species, when unencumbered, that she is called the "Flying Doe," and can hardly be caught by a Dog except on soft ground; the male is slower. 
Kangaroos are hunted in Australia not only for sport, but on account of the harm they do to the not too abundant pasturage, as their peculiar teeth, of which the lower incisors project forward and can be slightly separated and brought together, having besides sharp inner edges, fairly cut the grass out by the roots.

The Hound used in hunting them is very similar to a Greyhound, but rather more powerful, and, though derived from crosses in the first place, is now a distinct breed. They used to be imported into India in my time, and no doubt are so still, as they are excellent Dogs for swift game.

The present species of Kangaroo is, however, not so much hunted as the commoner Great Kangaroo (Macropus giganteus), as it inhabits chiefly the eastern and southern hilly districts, whereas the other is found almost all over Australia; it has, like all these large Kangaroos, plenty of courage, and the male specimen mentioned in Gould's magnificent work on the Mammals of Australia as being procured by him for the British Museum was not captured, he says, without making a fierce and desperate resistance. This beast weighed two hundred pounds, and his meat supported Gould and his party, who were making a forced march, for four days. The best part of a Kangaroo, it may be mentioned, is the thick powerful tail, which is much esteemed for making soup.

Though not nearly so common in captivity as the Great Kangaroon the Red species is not rare in collections, and, like Kangaroos generally, thrives well even in close confinement, and breeds freely.

The typical Kangaroos are all Australian, with the exception of at few in New Guinea, New Britain, and the Aru Islands, one of which (Macropus bruni) was the first Kangaroo to be brought to the notice of science. They vary a good deal in size, from large species like the Red, the Common, and the Wallaroo (Macropus robustus), through the smaller species called Wallabies, to some not bigger than Hares. Their habits also present some differences in detail, some being beasts. of the plains, while others never leave the hills, where they hop about from rock to rock.

The Rock Wallabies have the tail less thick at the base than the more typical kinds. 


\section{THE TREE KANGAROOS}

$F_{\text {ROM }}$ the Rock Wallabies the transition is easy to the Tree Kangaroos (Den drolagus), of which there are a few kinds inhabiting Australia and New Guinea: In these animals the fore- and hind-limbs are proportioned as in ordinary animals, and the tail is not thickened at the base; yet they sit upright and jump on their hind-feet, and are unmistakable Kangaroos, in spite of these climbing and perching habits. They spend most of their time in trees, feeding on the leaves as they climb and jump among the boughs. They are moderate-sized animals for Kangaroos, not being bigger than an ordinary Dog, and are seldom seen in confinement, though our Zoological Gardens have exhibited two of the species.

\section{THE RAT KANGAROOS}

The Rat Kangaroos (Aepyprymnus, Bettongia, Potorous) are small creatures, only about as big as Rabbits, with pointed ratty-looking heads, short ears, and thin tails; their form is also rather Rat-like, the hind-limbs being shorter than in the larger Kangaroos: There are sevenal kinds, found in Australia and Tasmania. They are very different in habits from the large Kangaroos, being more like some rodents. They have but little speed, and are solitary and nocturnal, taking refuge in holes when disturbed, and making concealed nests of grass in cavities scratched out under a bush. Their tails are prehensile, though never used in climbing, as these are ground animals, but employed for bringing home the grass for the nest, which is grasped in a bundle by the tail. In addition to herbage, they live on roots, which they scratch up with their long fore-claws.

\section{THE MUSK KANGAROO}

\section{(Hypsiprymodon moschatus)}

THis curious little beast is the smallest of the Kangaroos-being only as big as a Rat, and resembling this animal in its naked scaly tail. Its most remarkable peculiarity, however, is the fact, that, unlike other Kangaroos, it has a great toe on the hind-foot; this is nailless, and set far up, not far from the heel, but is opposable, and thus this animal forms a link between the Kangaroos and the Phalangers. It is found in Queensland, where it lives in the forests, hiding by day in a nest lined with leaves, and feeding on roots, berries, and also-a remarkable diet for a Kangaroo-insects and worms. It has two young at a birth. Though it seems not to be rare, it has never been brought to England. 


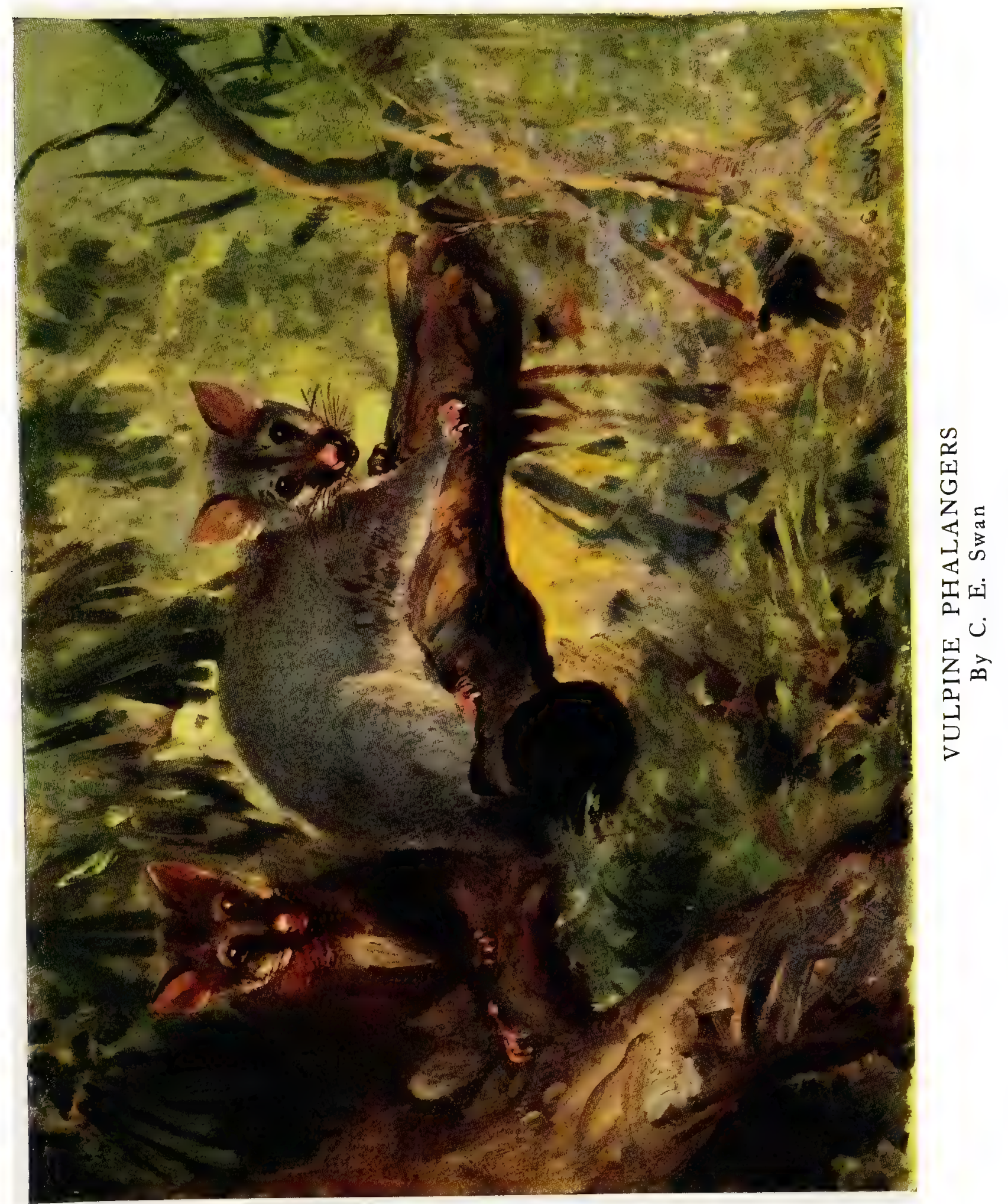





\section{THE VULPINE PHALANGER}

\section{(Trichosurus vulpecula)}

The Vulpine Phalanger is the animal commonly known in Australia as the Opossum, although it is a very different animal in many ways: from the true Opossums of America; and belongs to a family (Phalangexida) closely allied to the Kangaroos; although the general shape of the creature is very different, and quite of the ordinary quadruped type. The limbs of this Australian Opossum are short, and all the paws have five toes; those on the fore-foot present nothing peculiar in appearance, but in the hind-foot the second and third toes are joined in a common skin up to the claws, and the first, which is opposable to the others like: a thumb, has no nail. The tail is bare on the under-surface at the end, and it is prehensile.

The teeth of the Phalanger are a fairly complete set, there being six. incisors in the upper jaw and four in the lower, while canines are present in the upper only, and are not large. The grinders are well represented, and the centre pair of lower incisors are large, as in Kangaroos. In size this pretty animal rather exceeds an ordinary Cat; its coat is thick and soft, and in colour generally corresponds with the specimens shown in the illustration, over most of Australia. In Tasmania, however, the creature grows to a greater size, and is sootybrown all over. A pretty white specimen was once shown at our Zoological Gardens; its eyes were dark brown, not pink as is so often the case in albinistic animals.

This beast is presumably the proverbial "'Possum" which lives up gum-trees, those trees being so important an element in the Australian. flora; it is a true climbing animal, seldom coming to the ground, and moving slowly when there. Even on a tree it is not very active, and can be caught by a good climber. It is quite nocturnal, and spends the day sleeping in a hole in a tree, whence it is sometimes rudely extracted by the Australian blacks, who jerk the poor 'Possum out by the tail, and dash its head against the trunk before it has time to bite and scratch in self-defence. It is relished by these people as fool, but their liking for eating it would not be much recommendation to a 
European, as they are some of the most omnivorous of savages. The Australian Opossum's meat, however, is quite passable, being much like Rabbit. This is not surprising, as it is chiefly a vegetable feeder, devouring shoots and fruit, though, as it likes an occasional small bird in captivity, it is evidently not a pure vegetarian. In the breeding season it utters loud cries; the young are one or two only in number, and remain a long time in the pouch of the mother.

The fur of this animal is esteemed for the manufacture of rugs, and it is presumably on account of its utility for this purpose that the beast has been introduced into New Zealand, although it is destructive in orchards, as might be expected from its feeding-habits. I have heard that the fur in New Zealand examples is finer, following the usual rule, that furred creatures grow better fur in a cool than a warm climate. In captivity the Vulpine Phalanger thrives well and breeds freely; it will live in an outdoor hutch, and so far abandons its nocturnal habits as to take food by day. It is always well represented in our Zoological Gardens.

The Phalangers are the most numerous family of Marsupials, and vary considerably in size and to some extent in form, though all are short-legged climbing animals. Only a few of the more remarkable can be noticed here.

\section{THE CUSCUSES}

THE Cuscuses (Phalanger) are noticeable for the fact that their prehensile tails are naked for the end half; they have shorter ears and muzzles than the Vulpine Phalanger, which they resemble in size and generally in habits, though less vegetarian in their tastes. They are the most westerly in range of all the Marsupials of the Old World, as only one is found in Australia, and they extend from New Guinea to: Amboyna. There are about half-a-dozen species in all, and some of them are extremely variable in colour, being pied and spotted, as is so commonly the case in domestic animals, and so rarely in wild ones.

\section{THE FLYING PHALANGERS}

THE Flying Phalangers are provided with an extension of skin along: the flanks, similar to what is found in the Cobego and the Flying. 
Squirrels, and they perform sailing "flights" from tree to tree in the same way; indeed the smaller Flying Phalangers are commonly called Squirrels in Australia, there being no true Squirrels there, though true native Rats and Mice of various kinds occur. These Flying Phalangers vary a great deal in size more than the Flying Squirrels, the biggest (Petaurista taguanoides) being as big as a Cat, while the smallest (Acrobates pygmaus) is not larger than a Mouse, and is indeed known locally as the "Opossum Mouse."

One of the Flying Phalangers (Petaurus breviceps), a lovely little animal about as big as our Squirrel, with exquisitely soft grey chinchilla-like fur, is constantly to be seen at our Zoological Gardens, and has bred freely there.

\section{THE KOALA}

(Phascolomys ursinus)

WHEN watching the quaint appearance and antics of Bears in menageries, many people may have regretted that Nature has not been kind enough to provide a Bear small enough to be a safe and convenient pet; but such an animal practically exists in the Koala, this Marsupial being popularly called "Native Bear" in Australia. It is really a member of the Phalanger family, but differs from all these in the absence of a tail, and it is larger than any of them, though not exceeding a Terrier in size. In general appearance it is extremely Bear-like, and its ears are tufted like those of the Indian Sloth-Bear; its teeth, however, are not at all of the Bear pattern, but resemble those of the Vulpine Phalanger in type, and its fore-paws are quite unlike those of any other beast, the thumb and forefinger being opposed to the other fingers, as the thumb alone is in Monkeys; the hind-paws are like those of the Vulpine Phalanger. The coat of the Koala is of soft thick grey fur, the nose having a large naked pad. The creature lives almost entirely in the trees, and is very slow in its movements on the ground; it has but one cub at a time, and when this is big enough to leave the pouch, it rides on its mother's backanother resemblance to the Sloth-Bear. The food of this creature consists practically entirely of the shoots of the gum-trees, and it is not easy to keep in captivity unless this food can be supplied. It has, however, been exhibited in our Zoological Gardens, and I should suggest that any one trying to bring it home should get a quantity 
of gum-leaves dried, and make tea of them, mixing this and the leaves with artificial food; when once in England gum-leaves could sometimes be obtained for the animal, so that it need not be entirely deprived of its natural diet.

\section{THE NOOLBENGER}

\section{(Tarsipes rostratus)}

THIs extraordinary little Australian animal, which is of about the size of a Mouse, is very different from all other Phalangers. It has very short claws and a nearly naked prehensile tail; its jaws are long and slender, and poorly provided with tiny, pointed teeth, though there are two long lower incisors. The mouth is small, and the tongue long and pointed; it is used to lick honey from the flowers, this being the only beast which lives on honey, though the little Flying Phalangers also partake of it. In captivity the Noolbenger readily eats insects, and no doubt does so at large. It is, of course, an excellent climber. Although it would make a nice pet, it seems never to have been brought to Europe.

\section{THE WOMBATS}

THE Wombats (Phascolomyida), of which there are three species found in Australia and Tasmania, are very like giant Guinea-Pigs in appearance, and even have rodent-like teeth, the canines being absent, and the incisors two only in each jaw, enamel-faced and continually growing. They are, however, true Marsupials, of rather large size, being about two or three feet long and very bulky. There are five welldeveloped toes on the fore-feet, but on the hind the first toe is very short and nailless, and the three middle ones joined at the base. These creatures are nocturnal burrowing animals, living on the ground, and feeding, like rodents, on roots and herbage. They are singularly harmless, sluggish, and inoffensive; one has even been known to allow itself to be picked up and carried, though on an attempt being made to tie its legs it at length lost its temper, made a whizzing noise, and snapped sharply enough. As might be expected in the case of such philosophical animals, they bear captivity well, and one or other kind may constantly be seen in our Zoological Gardens. 


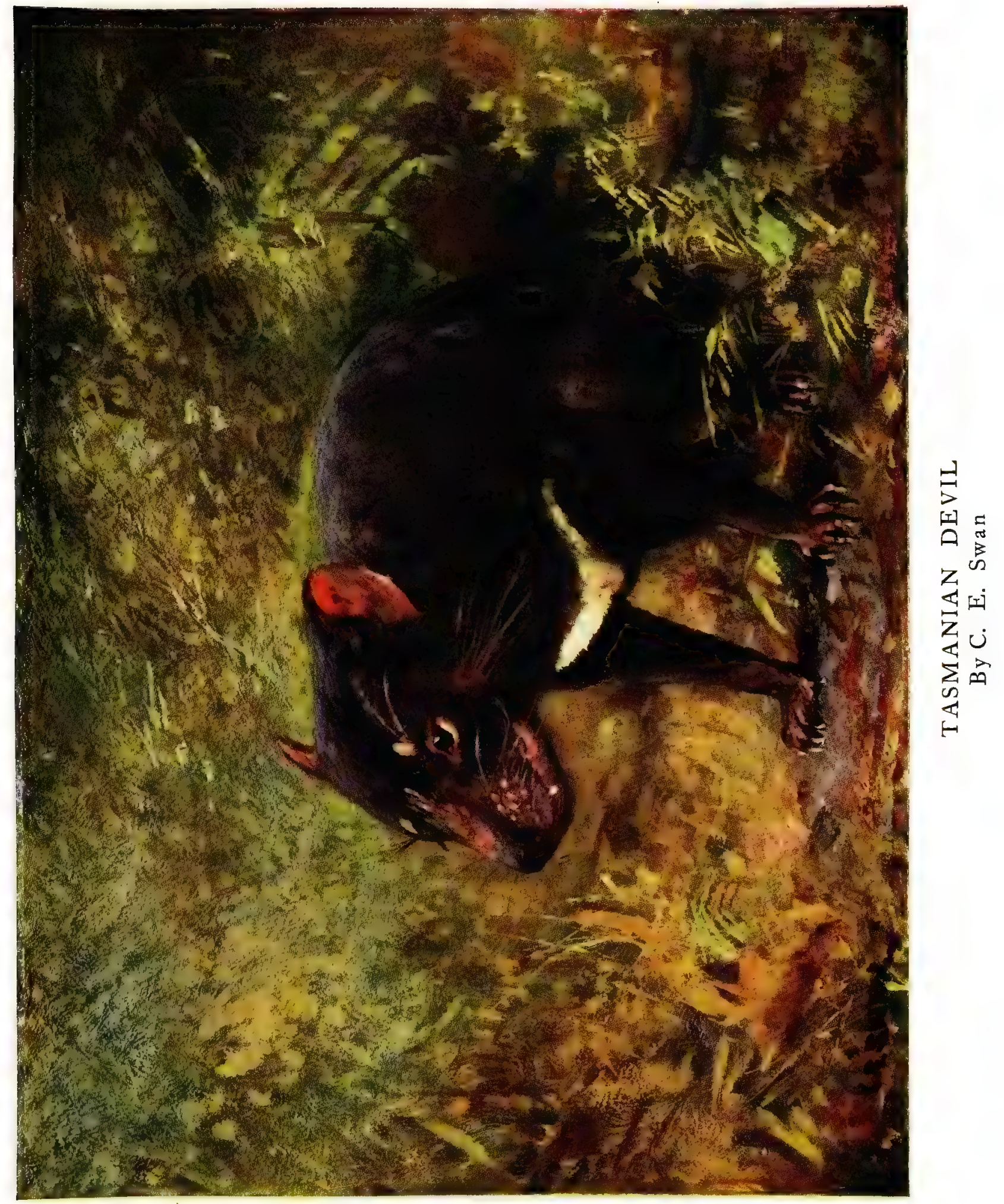





\section{THE TASMANIAN DEVIL}

(Sarcophilus ursinus)

So varied are the types of Marsupials that the order is almost an epitome of the whole class of beasts, putting on one side the fish-like Cetaceans and Sirenians and the flying Bats; in addition to the vegetable-feeding types we have been considering, we have Marsupial carnivores of various grades, of which the Australasian group of Dasyures (Dasyurida) are the chief. Among these the Tasmanian Devil has attained special notoriety on account of its ferocity, and, with one exception, it is the biggest carnivorous Marsupial, though not larger than a Badger. There are five toes on the fore-feet, and four on the hind, the first being absent; the beast goes on the soles of the feet like a Bear, and much resembles a small one, except for having a tail of ordinary length. The teeth are singularly like those of the true Carnivora, with large canines and small incisors; the latter, however, are eight instead of six in the upper jaw. The grinders are very large and powerful, and in strength and bone-cracking power may be compared to those of the Hyænas. In fact, no animal of the size can boast of such a set of teeth.

The Tasmanian Devil is confined to the island whence it takes its name; "remote, unfriended, solitary, slow," it prowls about at night in search of food, which consists of the flesh of any creature it can catch and overpower, and, although not a large animal, it is a serious enemy to Sheep as well as to poultry. It will also feed on carrion, and is believed to search the beach for stranded fish. When eating, it will use its fore-paws to hold up its food, unlike most of the true Carnivora. It is a really fierce animal; resents interference by savage snorts and growls, when disturbed in its lair among the rocks, and is credited with snarling with its dying breath, according to Herbert Spencer, who tauntingly alludes to the admiration it gains thereby; but surely so "game" a Marsupial need not fear the comments of a peevish philosopher!

The number of young is three to five; thus it might easily increase and be a serious pest, but it is easily trapped with any meat bait. 
In captivity it acts up to its character; furiously resents interference, greedily devours its rations, and quarrels with its companions. It may generally be seen in our Zoological Gardens, and sometimes even in a travelling menagerie, for which it forms a nice sensational exhibit. It is worth mentioning that the Devil's flesh has been eaten and found to taste like veal, because it does not look like the sort of animal one would care to eat ; but in the early days of Australasian colonisation people were not disposed to be particular, so long as they got some fresh meat.

\section{THE THYLACINE}

(Thylacinus cynocephalus)

The Thylacine is the largest carnivorous Marsupial at present living, and bears a remarkable resemblance to one of the Dog family, especially in its head, muzzle, and limbs. The coat, however, is close and flat, like that of so many tame Dogs, not furry like a Wolf's or Fox's, and the tail is not of the "brush" type, being very long, straight, and covered with close, short hair; it is also very thick at the root.

The colour of the animal is light brown, banded across the hinder part of the back with bold black stripes, whence the names of "Tiger" and "Zebra-Wolf" often applied to the beast. This colouration only recurs in the Banded Duiker among the Antelopes, and, if the two animals lived in the same country, would certainly be set down to " mimicry." In size the Thylacine is rather smaller than a Wolf, and is long-bodied and low on the leg; its teeth differ from those of the true Dogs in being more numerous; as in the "Devil," there are eight upper incisors, and the grinders are also more numerous than in the true Carnivora. This animal is nocturnal, and hides by day in the clefts of rocks; it used to be a pest to Sheep-owners, and has consequently been so much persecuted that it is very near extinction, being, like the Tasmanian Devil, confined to Tasmania. Indeed, it would now pay to preserve the few survivors in the mountains, as, although the beast has been exhibited in our Zoological Gardens, it is rare in the animal trade, and would be worth twenty pounds a specimen alive.

\section{THE TYPICAL DASYURES}

These animals (Dasyurus), which are known in Australia as Native Cats, somewhat resemble the Mongooses among the true Carnivora in 
general form, but have larger heads; in size they are considerably smaller than an ordinary Cat. Their fur is very peculiarly coloured, being light-brown with white spots; black varieties are quite common, and, as these retain the white spots, they have a very striking appearance. In habits these creatures resemble the Martens; they are good climbers, and prowl about the trees at night in search of birds and other prey; in the day they retire into hollow boughs to sleep. They have about six young ones at a time. From their carnivorous tastes, these animals are a great pest to poultry-keepers, and are persecuted in consequence. They are easily kept in captivity, and the commonest (Dasyurus viverrinus) is usually to be seen in our Zoological Gardens. There is a species in New Guinea, as well as four in Australia.

\section{THE TAPOA-TAFA}

\section{(Phascologale penicillata)}

The Tapoa-Tafa is Rat-like in size, form, and general colour, but has a very characteristic tail, covered for the last two-thirds with long black hairs. This animal is similar in its general habits to the Dasyures, and is equally bloodthirsty; it is generally distributed over Australia, except in the north.

Allied to it are a whole series of smaller carnivorous Marsupials, of a Rat- or Mouse-like type, some of them climbers and some groundlivers, which take the place in Australia of the Shrews and other Insectivora, which do not exist in that continent. One of them (Antechinomys lanigera) is a jumping species, and thus curiously recalls the Elephant-Shrews of Africa.

\section{THE BANDED ANT-EATER \\ (Myrmecobius fasciatus)}

THIS peculiar little creature is much the most distinct of this varied family of Marsupial carnivores. In size it is insignificant enough, being no larger than a Squirrel, and, as it has a long bushy tail, it is at first sight not unlike one until the long slender muzzle is noticed. The colouration is very remarkable and pretty, being chestnut, with the back covered with transverse bands of black and white alternately. Like the two Ant-eaters of America and the African Pangolins, it has a long worm-like tongue; but, unlike these crea- 
tures, it retains a very full set of teeth, numbering from fifty to fiftyfour; all, however, are very small, and set apart from each other, except the last four lower grinders. These teeth are remarkably like those of some of the earliest fossil beasts known, so that this little insignificant creature is perhaps the oldest beast now living. It is a ground animal, feeding on Ants and other insects, and has no pouch; the young, however, hang on to the mother's nipples as in other Marsupials, and are concealed by her long fur.

\section{THE BANDICOOTS}

THE name Bandicoot properly applies to a large Indian species of Rat (Nesokia bandicota), but it has been transferred to a curious family of Marsupials (Peramelida), which agree with the Kangaroos in the structure of the hind-feet, having the second and third toes thin and united, and the fourth very large and strongly clawed; the fifth is of fair size, but the first rudimentary. In their teeth, however, the Bandicoots show undoubted resemblance to the carnivorous Marsupials of the last family, the canines being well developed and the lower incisors six in number. In spite of the Kangaroo-like structure of the hind-foot, this member is not prolonged, and the general form of the creature is like that of a large, long-snouted, short-tailed Rat, and they resemble Rats in their movements. The fore-feet have the middle toes large and strongly clawed, and the outside ones rudimentary; the foot is, in fact, adapted for digging, and the animals are ground-livers and feed largely on roots, though they also freely partake of such animal food as they can get, in the shape of insects, \&c.; they are, in fact, omnivorous. There are a good many species, found not only in Australia, but in the islands adjacent. Two Australian Bandicoots differ so much from the ordinary kinds, however, as to demand special notice; these are the Rabbit Bandicoot (Peragale lagotis); which has Rabbit-like ears and a fully-haired tail, and is bigger than the others, being as large as a real Wild Rabbit; and the very remarkable Pigfooted Bandicoot (Choropus castanotis), which is hardly as large as a Rat, with long ears and most peculiar feet. The limbs are long and slender, and there are only two toes in the fore-foot, with small claws; while on the hind-foot all the toes are exceedingly small and useless except the fourth, which is large, with a short claw; the creature is thus almost in the position of a hoofed animal, and it goes about on tiptoe in a very similar way. 


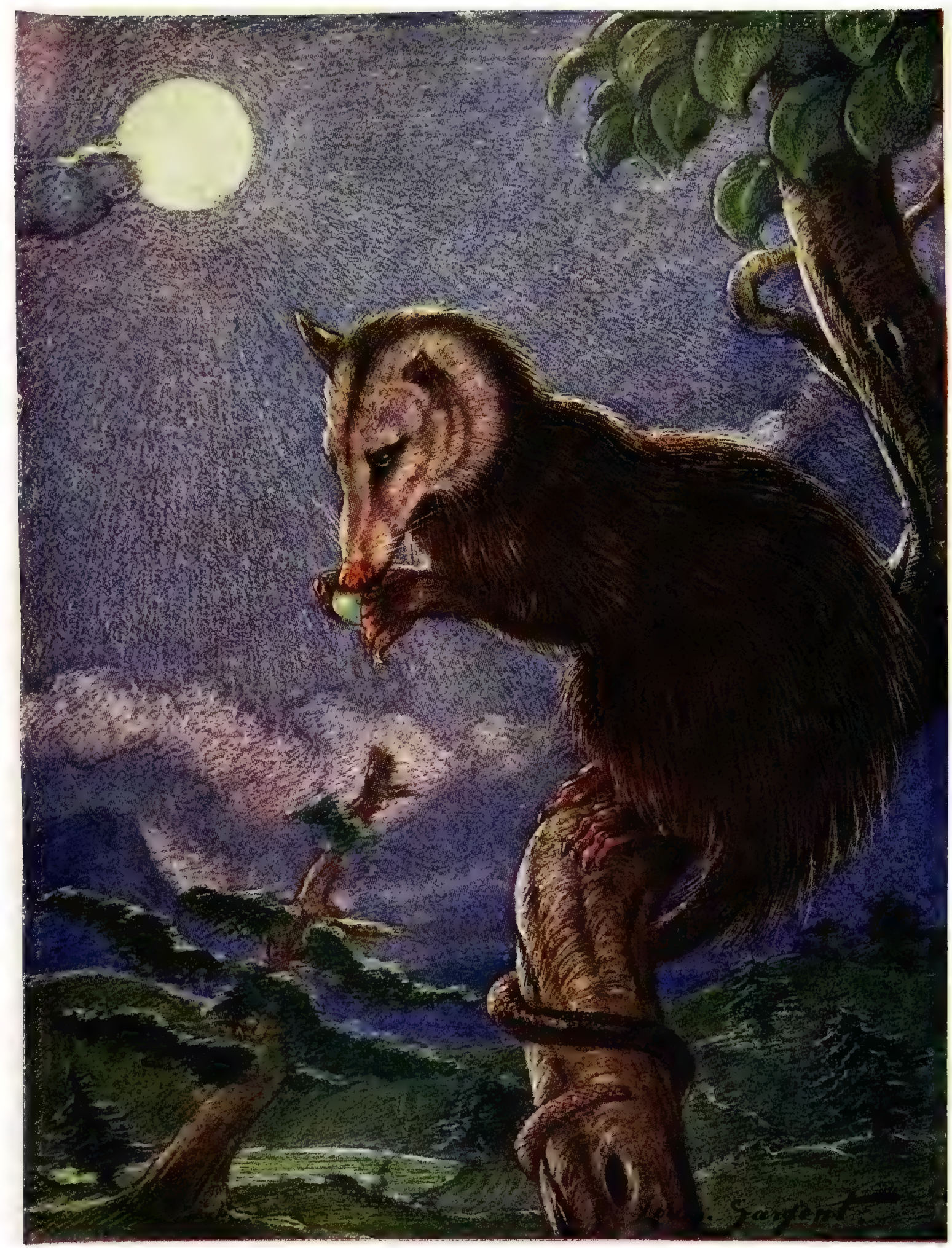

COMMON AMERICAN OPOSSUM

By Louis A. Sargent 



\section{THE COMMON AMERICAN OPOSSUM \\ (Didelphys virginianus)}

The familiar 'Possum of American natural history and folk-lore enjoys the distinction of being the only Marsupial found in the northern part of the world, and thus it was the first of these pouched beasts to come under the notice of naturalists.

Although considerably the largest of its family (Didelphyida), it is not a very big animal, hardly equalling an ordinary Cat in size; and in general structure it is a good type of the American Opossums, which are a very uniform group in most respects.

Its short legs have five toes on each foot, all clawed with the exception of the great toe of the hind-feet, which can be opposed to the others like a thumb, so as to aid in climbing. The teeth much resemble those of the true Carnivora in general appearance, the canines being large, the molars sharp, and the incisors insignificantly small. The incisors, however, are more numerous than in the Carnivora proper, which never have more than six in each jaw, whereas the Opossum's incisors are ten in number in the upper and eight in the lower jaw; their size is, however, so small that they cannot be of very much use to the animal.

The tail is only hairy at the root, being bare and scaly like a Rat's for the rest of its length, and it is strongly prehensile, so that the animal can suspend itself by it when it wishes to lower itself down to reach something from a higher bough when foraging for food in a tree.

The ragged-looking coat varies a good deal in colour, not only locally, but individually and as a matter of age; in the mixture of black and white hairs it presents the darker colour predominates in the younger specimens, and the light in the older ones.

This Opossum has much the widest range of its family, being, in fact, a member of a tropical group which has intruded, or succeeded in maintaining itself, in a temperate region, much like the Kingfisher among our British birds; for it is not confined to North America, but ranges through Central America down through Brazil, the so-called Crabeating Opossum of South America not being a really distinct species. 
It is a slow-moving, rather stupid animal, largely arboreal in its habits, and very omnivorous in its food; it devours birds and their eggs, Squirrels and any other small animals which fall in its way in its nocturnal prowlings, for it is a creature of the night. Fruit also forms part of its food, nor does it disdain the tender shoots of plants which show themselves in the spring, when it is pinched with hunger after the hard times of winter. Sometimes, it is said, it even lives in towns and acts as a street-scavenger by night, retiring into drains or climbing up to the roofs to escape observation by day. It not unfrequently gets into trouble by robbing hen-roosts, but in compensation for the harm thus done, it itself furnishes a valued article of food, though its meat is most especially appreciated by the " nigger" element of the American population, who take the keenest possible delight in a 'Possum hunt by torchlight, and consider 'Possum stew as one of the greatest delicacies they can obtain. With this idea in mind, they do their best to capture the Opossum alive after he has been "treed" by their Dogs, and carry him home in triumph to be fattened up for the table on bread, potatoes, and so forth, of which he consumes a most unprofitable quantity. One very characteristic trait of the Opossum is that when brought to bay it proceeds to feign death, a trick so familiar that "playing 'Possum" has become a proverbial expression for deception. This death-feigning instinct is found in many other animals of very diverse kinds-the Fox, for example-but the Opossum is considered to be a particularly skilful artist in this line. It is as well, however, to handle him with caution when apparently defunct, or a severe bite may remind his incautious captor that he is not so dead as he looks. When provoked in captivity, the Opossum snarls in a peculiar way, opening his mouth, which is remarkably wide, and showing his fine set of teeth, without making any noise.

The young Opossums are brought forth in a very helpless state and very minute, as in Marsupials generally; they are only half-an-inch long, and have no claws on the hind-toes at first; about a dozen form a litter. During the first fortnight after they are born the old Opossum keeps her pouch very tightly closed, and the young ones are not as big as Mice till nearly a month old. As in the case of the Kangaroos, they do not leave the pouch entirely for some time. This Opossum has long been well known in menageries, but is not very commonly kept, as it does not make at all an attractive pet. 
Taken as a group, all these American Opossums are much alike, so that any species of them can be readily referred to its family. All the other species are much smaller than this common North American one, some being hardly bigger than Mice; and most of them have but a rudimentary pouch or even none at all. The young of several, when they cease to cling on to the nipples of the old ones, ride on her back, holding on not only with their paws, but also by twining their tails round that of their mother. One beautiful little species of this group is the Murine Opossum (Didelphys murina), a pretty chestnut-coloured animal hardly bigger than a Dormouse, but with its tiny head a perfect miniature of the big Opossum's, and the same habit of noiseless snarling. The last specimen of this little creature exhibited in our Zoological Gardens was imported accidentally along with bananas.

Some of the small Opossums are very like Shrews, having comparatively short and non-prehensile tails; and, indeed, these little Opossums seem to be the natural representatives of these Insectivores in South America.

\section{THE WATER-OPOSSUM}

(Chironectes yapock)

The Water-Opossum enjoys the distinction of being the only truly aquatic Marsupial, and, in adaptation to this habit, has large webbed hind-feet. Like an Otter-by which name it is called in Demerarathe Water-Opossum lives in holes in the banks, and feeds on fish and other aquatic creatures. Its cheeks are pouched to hold its food, and it has the marsupial brood-pouch fully developed. The litter are about six in number. This Opossum is about as large as a Rat, and peculiarly coloured, being light grey, with some large transverse dark-brown patches on the upper parts. It is found in Brazil as well as in Guiana, but has never been exhibited at our Zoological Gardens.

\section{THE MARSUPIAL MOLE}

\section{(Notoryctes typhlops)}

THIs curious little animal, which is the sole representative of its family (Notoryctida) is of peculiar interest as exemplifying the great variety among these pouched animals; it is a quite recent discovery, 
having only been described in 1891 . In general form it is quite Mole-like, with very short limbs, in which the second and third toes in the fore-foot are greatly developed at the expense of the other three, and bear enormous claws. The muzzle is shorter than in the true Moles, and has a callous pad at the tip; the eyes are covered by the skin.

The teeth are very peculiar, though on the whole conforming to the general type of the carnivorous Marsupials. The canines, however, are small, and the teeth vary remarkably in number, being sometimes different on the two sides of the jaw. This creature lives in the dry and arid districts of Central Australia; it is essentially a burrower, and very few specimens have ever been captured.

\section{THE RATON RUNCHO}

(Canolestes obscurus)

THE "Opossum Rat," to give this animal an English name, is, except its relative Canolestes fuliginosus, the only living representative of the family Epanorthide, though these are well known as fossil animals. Only one specimen of each of the living species has ever been taken, and C. fuliginosus was described fifty years ago, from Ecuador. The "Raton Runcho" was captured at Bogota; and is about the size of a small Rat, and resembles one in shape and is of a dark colour. On the fore-paws it has five toes, the first and fifth bearing nails instead of claws; the hind-feet have practically only four toes, the first being rudimentary.

The teeth are very remarkable; in the upper jaw are several incisors and well-developed canines, as in the carnivorous Marsupials; but in the lower jaw we find the two great projecting incisors of the vegetarian Phalangers and Kangaroos, the canines are very small, and the grinders also are like those of Phalangers. There is, however, no union between the second and third toes of the hind-foot, which are free, as in carnivorous Marsupials. Moreover, the creature, which is a climber, is said to live on small birds and their eggs, so that to a certain extent it unites two great Marsupial divisions, though it must be referred rather to the herbivorous section as far as structure goes. 


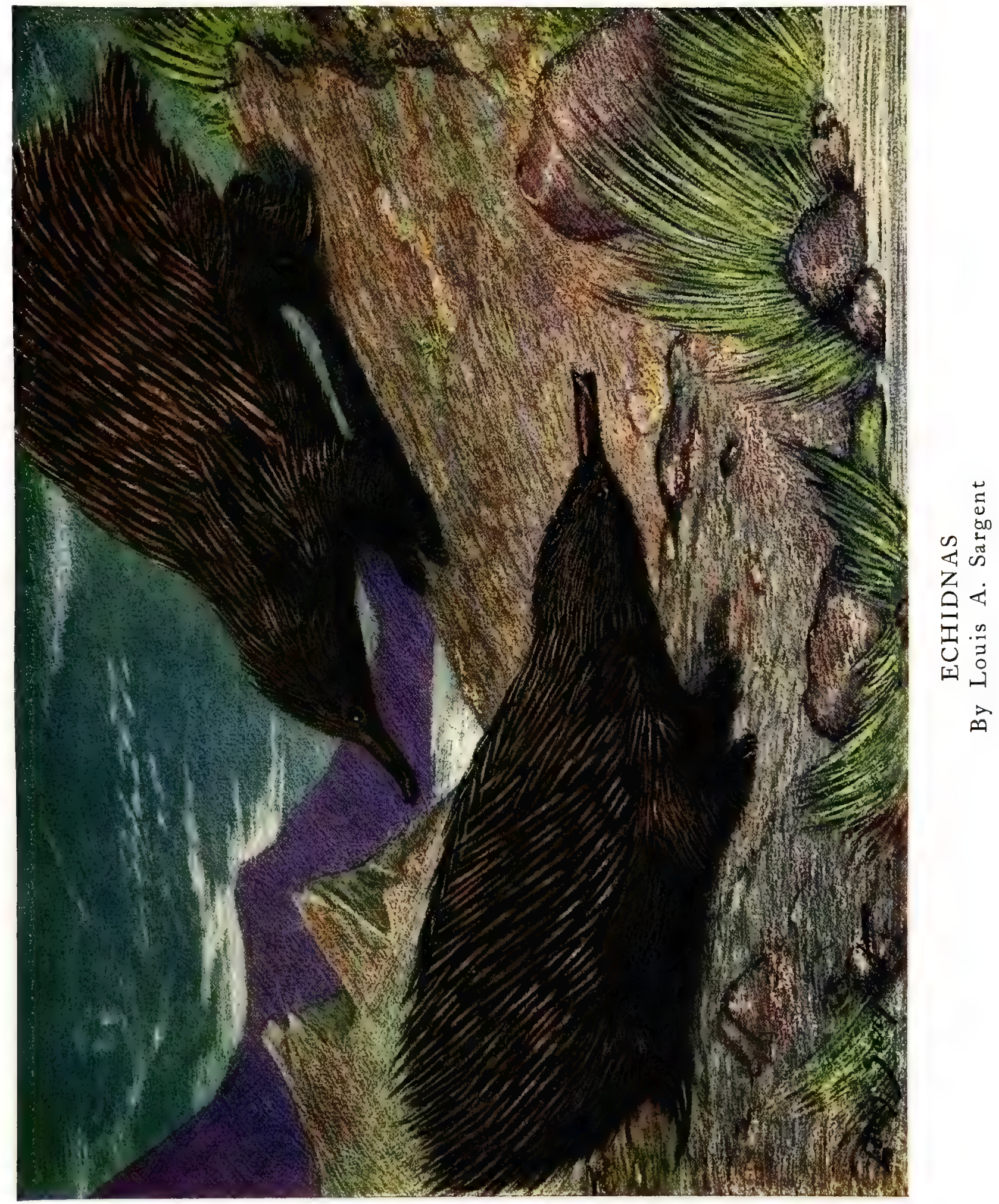





\section{THE ECHIDNA}

\section{(Echidna hystrix)}

BEING a frequent exhibit at the Zoological Gardens, the Common Echidna is the best known-though not the most remarkable-of the extraordinary order of beasts known as Monotremata, the lowest of milkgiving creatures, for, unlike all others which suckle their young, they lay eggs like birds. It must not be supposed that on this account they form in any way a link between birds and beasts, although in some particulars of their anatomy also they are bird-like. But in these points they are reptilian also, and it will be remembered that most reptiles are egg-layers. The fact appears to be that both beasts and birds arose from reptilian types, so that they form as it were the two branches of a letter $\mathrm{Y}$, the reptiles being the stem; and our living monotremes are the sole survivors of a race which branched off from the beast stem very soon after the departure from reptiles, when all these great classes were more alike than they are now.

The Echidna has, it must be admitted, a very bird-like head, with its narrow toothless beak and want of external ears; the jaws, however, are united nearly to the tips, where there is a small mouth, and the nostrils are also at the end, as in a beast's muzzle. The tongue is long and worm-like, as in the Ant-eaters.

The short, stumpy, awkward-looking limbs bear each five huge claws, those on the fore-feet particularly strong and broad; on the hind-foot the toes are turned out and back in a very peculiar way, unlike what is seen in other beasts. The tail is very short, and concealed by a cluster of the spines which cover the upper parts of the broad squat body, the lower, as is always the case in spiny beasts, being hairy. On the middle of the back the spines of the opposite sides overlap each other.

In length the creature $\underset{393}{\operatorname{measures}}$ about a foot from muzzle to 
tail; it may be compared to a small Rabbit. The sexes are alike in general appearance, but the male is provided with a spur on the heel, horny like a Cock's, but perforated by the duct of a gland on the leg.

The Echidna inhabits Australia and New Guinea; it shows a considerable amount of local variation, three races being distinguished, of which the most distinct is the Tasmanian Echidna, in which a thick coat of fur grows between the spines and almost conceals them from view. A similar difference, it will be remembered, exists between the species of American Porcupines. The food of the Echidna consists of Ants, which, like an Ant-eater or Pangolin, it licks up with its long worm-like tongue. Along with these it swallows a great deal of sand, and sometimes nothing but this is found in its interior, for it has the power of living a long time without food, being able to exist thus for weeks together. This is, of course, a reptilian peculiarity, and another is the creature's low temperature, which is only about $78^{\circ}$.

The Echidna is a nocturnal animal, frequenting sandy and rocky districts, where it hides in holes in the daytime; when on the move, it shuffles about actively enough, though with a very awkward gait, with the fore-toes turned inwards and the hind ones outwards. It has no means of active defence, but is a "passive resister" of the first order; it not only can roll itself up like a Hedgehog, but is so strong and struggles so vigorously that the only way to handle it without getting hurt is to catch hold of it by one hind-leg while it is unrolled. When disturbed, it also tucks in its head, and clings to the ground so tenaciously that the only way of moving it is to fairly scrape it off the surface with a spade. This is on a hard surface like boards; on the ground it will soon get out of reach, for it is, as might be expected from its structure, a remarkably powerful and rapid burrower. When asleep, it generally rolls itself up; in performing its toilet, it shows considerable power of change of position, as the work is done entirely with the hind claws. Unlike its relative the Platypus, it seems to have no voice.

The Australian natives call this creature in some places Nickobejan, 
and in others Jannocumbine and Cogera. They eat it-as they do most things-their method of cooking being to roast it in the skin, and fifty years ago, at any rate, it was considered good eating by our colonial countrymen also.

It is, however, the reproduction of this animal that has the greatest scientific interest. About the beginning of August-which is, of course, winter in Australia-the female lays her one egg, which is about as big as a Sparrow's, but rounder in shape, and of a yellowish colour without markings; a specimen of it can be seen in the South Kensington Museum in the case devoted to this group of animals. The egg, when laid, is placed by the animal in her pouch, which is a special temporary development, having been formed, a short time before the egg is laid, by an overgrowth of a fold of the skin. The temperature of this pouch is higher than that of the body generally, and thus aids in the incubation of the egg. The young one has a hard pimple on its snout, like the "egg-tooth" which can be seen on the bill of a newlyhatched chicken, its purpose being similarly the breaking of the shell, which is then removed from the pouch by the mother.

She has no teats, but the milk oozes from the surface of the skin and collects on tufts of hairs, which are sucked by the young one. This, at birth, is very small, weak, and quite naked; it remains in the pouch till it is as big as one's fist, but the spines do not appear till after the fur has grown. When caught at this age, it can be reared on milk.

As soon as it becomes prickly, the mother, probably finding it an uncomfortable object to keep in her pocket, digs a burrow and puts it there while she roams abroad. When at length she abandons it as able to shift for itself, her pouch gradually shrinks away, not to reappear till the next breeding season.

During the driest part of the year the creature falls into the state of "æstivation," or summer sleep, which in some animals living in hot dry countries, answers to the hibernation of some of those inhabiting climates with a severe winter. The only enemy which seems to attack the Echidna, other than man, is the Thylacine or Marsupial Wolf of 
Tasmania, which appears to be able to overcome it as the Fox and Badger with us do the Hedgehog:

The Echidna is not difficult to keep in captivity, feeding on minced raw meat, chopped hard-boiled egg, and milk; probably a mixture of dried "Ants' eggs" and dried "Flies," as used for insectivorous birds, would be a beneficial addition to this diet. Only the typical Australian race has been exhibited in this country at the time of writing.

\section{THE THREE-TOED ECHIDNA}

(Proechidna bruijni)

Besides a local race of the ordinary Echidna, there exists in New Guinea a very distinct species. In this animal the muzzle is much longer than in the common kind, and is curved downwards. The body is much more furry than in the Australian Echidna, and is less spiny, thus recalling the Tasmanian race. But the most notable distinction is the fact that there are only three toes on each foot--though this is not invariable, for sometimes others are developed on a small scale, and a specimen has been found with five toes on the fore-feet and four on the hinder pair. In size this creature is larger than the Common Echidna. 


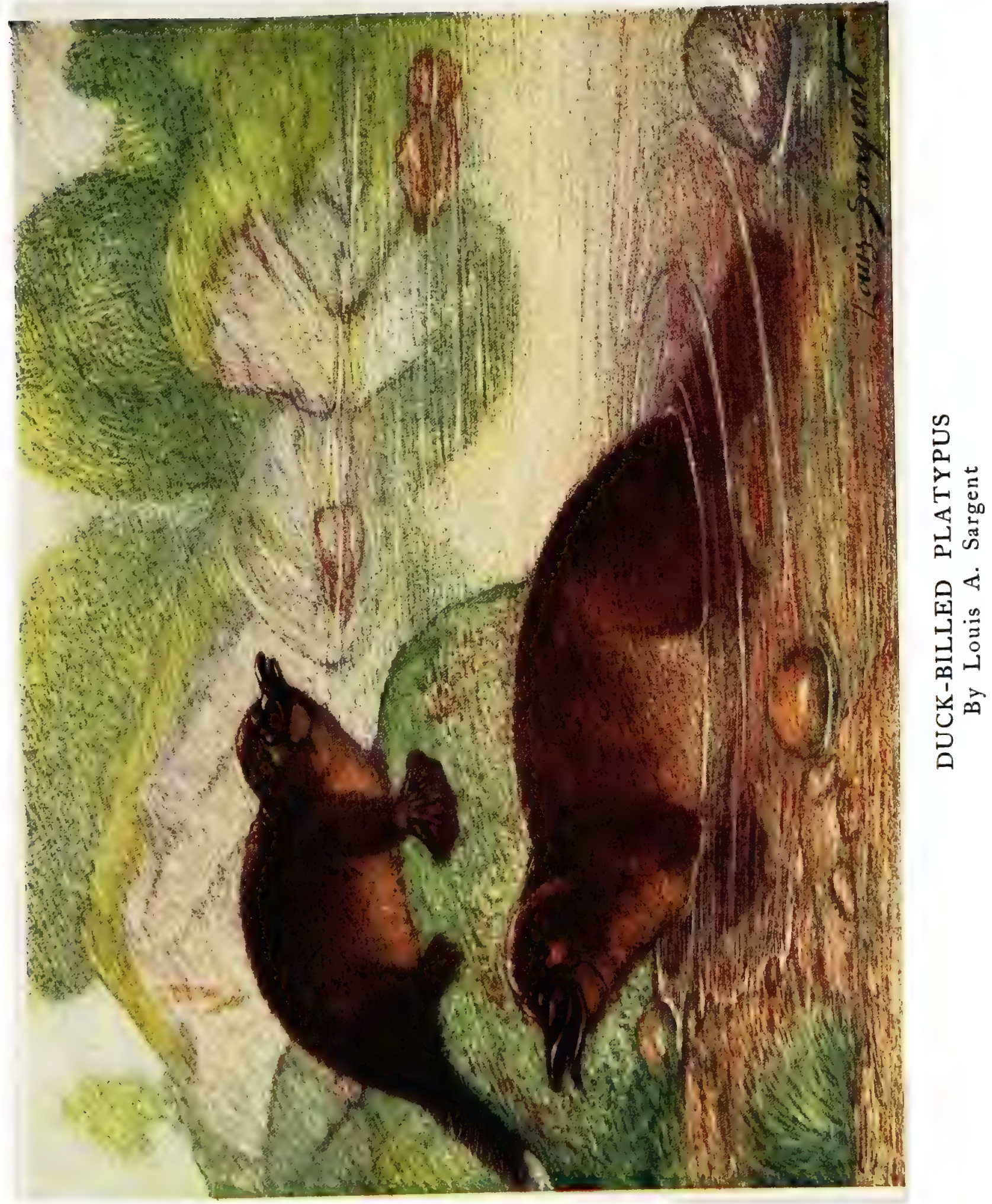





\section{THE PLATYPUS}

(Ornithorhynchus anatinus)

IT is not astonishing that the first specimens of this creature which reached Europe should have been suspected of being "faked"; for no one could reasonably be expected to believe in the genuineness of a skin which seemed to have come from a web-footed Mole as big as a small Rabbit, provided with a Duck's bill! The bill of the creature has, indeed, a peculiarly artificial look, as the skin of it is continued as a sort of flap at the base, giving it the appearance of being fastened on; it is much softer in life than would appear from the examination of stuffed specimens, and the nostrils are situated towards the tip, not at the base as in most real Ducks, though in one of our British species, the Golden-eye Duck (Clangula glaucion) they occupy much the same position. The inside of these Duck-like jaws is provided in the Platypus with flat horny plates, which serve as teeth in chewing the food; but in young specimens there are true teeth, two pairs of broad flat grinders with very complicated crowns, and a minute pair in front of these. Like the Echidna, the Platypus has no external ears.

The legs of the creature are excessively short and furnished on each foot with five toes, strongly clawed and fully webbed; on the fore-feet, indeed, the web extends well beyond the tips of the claws, but it is folded back when the animal is walking or engaged in digging. On the hind feet there is in the male a horny spur on the heel, perforated to discharge the secretion of a gland in the leg, as in the case of the male Echidna. There has been considerable discussion as to this structure, so analogous to the poison-fangs and glands of venomous Snakes; and it seems that the secretion is poisonous, though very faintly so, while the animal is not in the ordinary way at all inclined to use its spurs in self-defence. It is, however, not the easiest creature to handle, as its $\underset{397}{\operatorname{skin}}$ is so loose that it feels as if 
enclosed in a fur bag, while its appearance, as it shuffles along, is so quaint and unnatural that Dogs prefer barking at it to biting it, and Cats fairly run away from it. The fur of the Platypus is thick and soft, and composed of two sorts of hair, the under-fur being shorter, while the end portions of the longer hairs are stouter. On the upper part of the flattened tail, which, by the way, ends off squarely, not tapering as tails usually do, the hair is coarser and stronger than elsewhere, and the under-side of the tail is nearly naked in adult specimens, though covered with fine silvery-white fur in the young. Young animals also have the under-jaw white, this becoming mottled in the old ones; the under-part of the upper jaw, which is quite soft, is of a flesh colour. As happens to some extent in the case of some of the softer-billed Ducks, the beak loses considerably in appearance in the dried specimens, becoming hard and leathery-looking. The bill is much used by the beast in dressing its fur, and it also combs itself with the claws of the hind-feet.

Any one, on looking at this creature, could see at once that it was aquatic in its habits, and, indeed, it is usually seen in the water, where it swims well, propelling itself with the fore-paws, and with the head only above the surface, the body being level with it. The high position of the eyes in the head is an advantage to the animal when swimming, but renders it liable to run against objects when travelling on land, where it runs awkwardly, but rapidly enough. It is, of course, a good diver, and seldom remains for long together on the surface, while it is very shy, diving at once when alarmed, after which it is hard to see it again. It is most active in the early morning and the evening, and especially affects weedy places in the rivers. In suitable localities the Platypus is widely distributed over Australia, and it is found in Tasmania also. Its method of feeding is, as might be expected, very similar to that of a Duck, and its food is the same as that especially sought by those birds-water-snails and other shellfish, and small aquatic life generally. The cheeks are provided with pouches, and these the animal fills with food before rising to the surface to chew it with its teeth. The true teeth of young specimens 
are gradually worn away by this, and the permanent horny teeth gradually grow up round and replace them. Much sand is taken in as well as food, after the manner of birds.

The home of the Platypus is a burrow, dug by the beast itself, for it is an excellent burrower as well as a good swimmer; the tunnel may be as much as twenty feet long, and has two entrances, one under the water, and one a foot or more from it. At the end of the hole is to be found an enlarged chamber which is lined with dry weed. It is here that the young ones are deposited when old enough to be left by the mother for a time, and it is believed that the eggs, which are two in number, yellowish, and flexible-shelled like a Snake's, are deposited also in the burrow, for the female Platypus does not develop a nursing-pouch like the Echidna. She resembles that animal, however, in having no teats, the milk exuding upon the surface of the skin. The young have short bills, adapted for sucking it up; and when first born they are blind and naked.

The Platypus is known to the Australian blacks by the names of Mullingong and Tambreet; they eat it, especially esteeming the young ones, the sight of a plump young Platypus fairly making a "blackfellow's" mouth water, The colonists, by whom the beast is known as "Duckbill" and "Water-Mole," used to use the fur for rugs, and I am sorry to say sometimes do so still, although this most interesting and harmless animal is very properly protected by law. Such an animal as this would be a most desirable exhibit in any Zoological Garden, but so far it has not been brought to Europe alive. Even the Australian Zoological Gardens do not exhibit it; but this is not surprising, as there seems to be at present but little knowledge of the management of delicate animals at the Antipodes.

Delicate the Platypus certainly is, compared to its relative the Echidna; but it has been successfully kept in captivity in Australia for some weeks, and even taken some distance on the homeward journey.

Dr. Bennett, in his Wanderings of a Naturalist, gives a very interesting account of a couple of young specimens which he kept for 
some time; they appeared to have been very nice little pets, much resembling Puppies in many of their ways, as they constantly played with each other. and would nibble at his fingers sportively with their bills. They enjoyed bathing and rolling about in shallow water, but did not like a deep bath, nor did they stay in for more than a quarter of an hour at a time. This indicates the sort of accommodation such creatures should have when closely confined for a voyage to Europe; it would be best to keep them in a cage, and let them out for a bath two or three times a day. They slept a great deal, curled up into balls; and usually together; when disturbed they growled, a habit also common to old specimens. The food given them-soaked bread, chopped egg, and finely minced meat-does not seem to have agreed with them; but on such a diet many of the more delicate insectivorous birds, such as Nightingales, would not long survive; yet these are kept for long periods by our fanciers on more suitable diet, including plenty of live food, and there seems no reason why this very bird-like beast should not be treated in the same way, using "dried flies" and "dried Ants' eggs"-well soaked, of course-with the addition of Mealworms. Earthworms and Water-Snails could easily be taken in sufficient quantity to last the whole voyage if only a few of the Platypus were shipped; it would surely be worth while to go to considerable trouble and expense to import an animal of such surpassing scientific and popular interest, the only Monotreme besides the Echidnas. 


\section{N D E X}

AARD-WOLF, tOO

Aard-Varks, 376

, Cape, 376

, Ethiopian, 376

Acouchy, 215

Addax, 260

African Buffalo, 247

$\begin{array}{ll}\text { " } & \text { Civet, 90 } \\ \text { Elephant, 228 } & \text { Mouse-Deer, } 320 \\ \text { " } & \text { Ratel, 128 } \\ \text { " } & \text { Rhinoceros, 231-232 } \\ \text { " } & \text { Wild"Cat, } 80\end{array}$

Agoutis, 215

Aguarâ-guazu, I08

Almiqui, I72

Alpaca, 327

Alpine Marmot, 192

American Badger, 127

, Bison, 241-242

" Black Bear, I5I152

" Caribou, 313

" Chipmunk, 191

" Marten, II7

" Mink, I I9

" Opossum, 389-39I

" Raccoon, i16

" Tapir, 233-234

Angolan Guereza, 22

" Pallah, 256

Anoa, 248

Ant-Bear, 369-370

" Cape, 376

"Ethiopian, 376

Ant-"Eaters, Banded, $387-388$

Great, 369-370

" Little, $371-372$

, Tamandua, 37 I

Antelopes, Four-horned, 274

, Harnessed, 272

" Kob, 263

"Roan, 262-263

", Royal, 276

", Sable, 261-262

Aoud'ad, 288

Ape, Barbary, 27

Arabian Tahr, 284

Arctic Fox, II I

Lemming, 195

Argali, 280

Arimau-dahan, 77

Armadillos, Ball, 375

$$
\begin{array}{ll}
, & \text { Giant, 375 } \\
, & \text { Hairy, 373-375 }
\end{array}
$$

Arui, 288

Hairy, 373-375 Biscay Right Whale, 359

A siatic Ibex, 283

" Two-horned Rhinoceros,

Ass, $230-23 \mathrm{I}$

Aswail, 150

Aurochs, 243

Avahi, 55

Awantibo, 56

Aye-aye, 56
BABAKOTO, 55

Babirusa, $337-33^{8}$

Baboons, Black, 36

," Gelada, 36

Sacred, 36

Bactrian Camel, 324

Badger, 125-127

Bagdas, 90

Baird's Tapir, 234-235

Bald Chimpanzee, 2

" Ouakari, 47

Ball Armadillos, 375

Bamboo-Rats, 203

Banded Ant-Eater, 387-388

" Duiker, 275

Bandicoots, 388

$$
\text { ") } \quad \text { Pabbit, } 388
$$

Banteng, 244

Barbary Ape, 27

Barking Deer, 84

Barrigudos, 39-40

"Humboldt's, 40

Bassaricyon, I 39

Bats, Fishing, I 83

" Long-eared, 184

Rat-tailed, I 83-184

" South American White,

I4I, I4

Beaked Whales, 348

Bear, American Black, I5 152

" Blue, 144

" Brown, I45-148

" Cat, 92

, Grizzly, I48

" Mimalayan, I 5 I

", Japanese, I 5 I

" Malayan, I 52

Pied, 144

Polar, I4I-144

,, Spectacled, 152

Bear-Pig, I 28

Beatrix, 259-260

Beaver, $185-188$

Beech-Marten, I 18

Beira, 255

Beisa Oryx, 257-258

Beluga, 356

Bhaloo-soor, 128

Bharal-hay, 73

Bighorn, 286

Binturong, 92

Bison, American, 24 I-242

Black European, 24.3

Black Baboon, 36

" Bear, American, I51I 52

"Cat, I I9

"Fox, II9

" Guereza, 23

" Howler, 46

" Lemur, 54
Black Leopard, 65-67

" Tamarin, 5I

", Wildebeest, 25

Black-backed Jackal, 105-106

Blackbuck, 256

Black-eared Marmoset, 5

Blackfish, 355-356

Blackheaded Ouakari, 47

Black Rat, 200

Black-tailed Deer, 3 ro " Gnu, 249-250

,3 Marmoset, 52

Bladdernose, 164

Bleauwbok, 263

Blesbok, 252

Blind Mole-Rat, 203

Blue Bear, I44

"Whale, 360

" Wildebeest, 249

Boar, European Wild, 335336

, Indian Wild, 333-335

Bongo, 270-27 I

Bonnet Monkey, 25

Bontebok, 252

Bottle-nose, 348

Bottle-nosed Dolphin, 352

Brazilian Otter, I35

, White-eared Marmoset, 5 I

Brindled Gnu, 249

Brockets, 3I I

" Red, 3II

Brown Bear, 145-148

") Capuchin, 41-44

"Hare, 219

" Howler, 46

", Hyæna, 98-99

", Monkey, 25

Brush-tailed Porcupine, 206207

Burchell's Zebra, 237-238

Buffalo, 24I

" African, 247

" Dwarf, 247

"Indian, 245-247

Bunder, 25-28

Bun manus, II

Burmese Civet, 90

Burrhel, 288

Burrhel-Tiger, 73

Bushbucks, $271-272$

Bush-Cow, 247

CACHALOT, 345-348

Cacomistle, 140

Ca'ing Whale, 35 5-356

Californian Grey Whale, 360

allin" Sea-Lion, I53-I 56

Hares, 220

Camel, 32I-323

" Bactrian, 324

, One-humped, 321

" Two-humped, 324

Canadian Lynx, 8I

" Porcupine, 206-207
Cape Eland, 265

Capuchin, Brown, 4I-44

" Horned, 4I

" Smooth-headed, 4I

White-throated, 4 I

Capybara, 2I3-2I4

Caracal, 83-84

Carcajou, I 21

Caribou, 3 I 3-3 I 6

" American, 313

11 Woodland, 3I4, 315

Cat, African Wild, 80

" Bear-, 92

" Black, I I9

"Servaline, 79

"Wild, 79-80

Caucasian Turs, 284

Cavy, Patagonian, 2r 4

Central American Tapir, 235

Chacma, 36

Chamois, 277-278

Cheetah, 85-88

Cherry-crown Monkey, 32

Chevrotain, Little Malay, 319

Chigetia, 240

Chilian Pudu, 3 II

Chimpanzee, I-4

Bald, 2

Chinchilla, 2 I I-2 I 2

" Long-tailed, 212

" Short-tailed, 212

Chipmunk, American, I9I

Chiru, 255

Civet, $89-90$

"African, 90

" Burmese, 90

" Large Indian, 90

"Small Indian, 90

Clawless Otter, 135

Clouded Leopard, 77-78

Coast-Rat, 203

Coati, Ring-tailed, I 37

White-nosed, I 37-I 38

Coatimondis, $137-138$

Cobego, $174-176$

Collared Fruit-Bat, I 80

"' Peccary, 341-343

Colobus Monkey, 2 I

Colugo, 173

Coney, 223

Couendou, 208

Cougar, 69

Cow, Mountain, 234

Coyote, IO4

Coypu, 204

Crab-eating Macaque, 27

" Raccoon, I 38

Cuscuses, 382

DALL's Sheep, 287

Dassie, 221-223

$$
\text { Syrian, } 223
$$

Dasyures, Typical, $3^{86-387}$

Deer, Barking, 300

" Blacked-tailed, 3 ro 
Deer, Milou, 308

" Pampas, 3I I

" Spotted, 303-304

" Typical, 299

" Virginian, 309-310

"White-tailed, 309

Derbian Eland, 268

Desert-Hares, 220

Desman, I68

Devil-fish, 360 Pyrenean, 168

Devil, Indian, 122

"Tasmanian, 385-387

hole, I13-II 5

"Malay, 113

Diademed Sifaka, 55

Diana Monkey, 29-32

Dibatag, 254-255

Dikdiks, 276

Dingo, $107-108$

Dog, Red Wild, II3-II 5

Dolphin, Bottle-nosed, 352

" Common, 351-352

" Risso's, 355

"White-beaked, $35^{2}$

"'. White

Douroucoulis, 48

Duckbill, 399

Duikers, 274-275

" Banded, 275

" Common, 275

" Jentink's, 275

"Yellow-backed, 275

Dumba, 295

Dwarf Buffalo, 247

" Lemurs, 55

" Right Whale, 359

Eastern Porpoise, 350

Echidna, 393-396

," Three-toed, 396

Egyptian Jerboas, 202

Eland, Mongoose, 95-96

Eland, 265-268

" Derbian, 268

" Livingstone's, 265

Elephant, African, 228

"Indian, 225-228

White, 226

Elephant-Shrew, I 7 I

Elk, 305-308

Emperor Marmoset, 52

Endrina, 55

Enjocko, 8

Ermine, 120

European Bison, 243

$$
\begin{aligned}
& \text { " Ibex, } 283 \\
& \text { Mink, I I9 } \\
& \quad \text { Wild Boar, 335- } \\
& 336
\end{aligned}
$$

Fallow-Deer, 304

" Giant, 305

Fat-tailed Lem

Fennec, II2

Field-Mouse, Long-tailed, 199

Field-Vole, I96

Fisher, 118

Fishing Bat, 183

Five-toed Sloth, I49

Flittermouse, 184

Flying-Fox, Indian, 177- 180

Flying Phalangers, $3^{82-383}$
Flying-Squirrels, I9I

Forest-Hog, 340

Fossa, 92

Four-horned Antelope, 274

Fox, IO9-I I Hog, 337

"Arctic, II I

" Black, 119

" Red, Iog

", Silver, 109

Fruit-Bat, Collared, I 80

"Long-tongued, 180

Fur-Seals, $155^{-1} 56$

GALAGOS, 55

Garden Dormouse, 204

Gaur, 243-244

Gelada Baboons, 36

Gemsbok, 259

Genets, 90-9I

" Common, 91

Geoffroy's Marmoset, 52

Gerenook, 255

Ghorpkur, 240

Giant Armadillo, 375

, Fallow-Deer, 305

Gibbon, Hainan, 16

" Javanese, I5

Silvery, 14

Giraffe, 289-292

Glutton, 121-123

Gnu, Black-tailed, 249-250

, Brindled, 249

"White-bearded, 249

"White-tailed, $250-251$

Goat, Rocky-Mountain, 279. wild, $282-283$

Gölden-headed Marmoset, 5 I

Golden Moles, 172

Golden-tailed Tupaia, I69-I 7o

Gophers, 202

Goral, 278

Gorilla, 5-8

Grampus, 353-354

Risso's, 355

Great Ant-Eater, 369-370

Kangaroo, 379

Green Monkey, 31

Greenland Whale, 359

Grévy's Zebra, 239

Grey Indian Mongoose, 93-94

Seal, 163

"Whale, Californian, 360

Grison, $123-124$

Grizzly Bear, 148

Ground-Squirrels, 191-192

Grysbok, 275

Guanaco, 325-328

Guatemalan, Howler, 46

Guereza, 2I-24

, Angolan, 22

" Black, 23

Kirk's, 23

Guinea-Pig, 214-215

Hainan Gibbon, 16

Hairy Armadillo, 373-375

Rhinoceros, 231

Saki, 47

Hamster, $197-198$

Hangul, 302

Hare, Brown, 219

, Common, 217-219

,. Jumping, 2OI

, Mountain, 219
Hare, Polar, 219

Harnessed Antelope, 272

Harp Seal, 163-164

Harrisbuck, 26I

Hartebeests, 251-252

Bastard, 252

Harvest-Mouse, 199-200

Hedgehog, 165-167

Himalayan Bear, $15 \mathrm{I}$

$$
\begin{array}{ll}
" & \text { Lungoor, I9 } \\
" & \text { Lynx, 81 } \\
\text { Serow, 279 }
\end{array}
$$

Hippopotamus, 329-332

Hog, Pïmy, Pigmy, 332

Four-horned,

Hog-Badger, 127-I 28

Hoolock, 13-16

Horned Capuchin, 4I

Horse, Prezevalsky's, 240

"Wild, 240

Horse-Whale, 157

House-Mouse, 199

" Rat, 200

Howler, Black, 46

" Brown, 46

, Guatemalan, 46

" Red, 200

Huemul, $31 \mathrm{I}$

Humboldt's Barrigudo, 40

Humpback, 360

Hunting-Dog, I 1 5-1 16

"Leopard, 85

Hyæna, Brown, 98-99

" Spotted, 99-100

" Striped, 97-98

IBEXES, 283-284

" Asiatic, 283

" European, 283

, Persian, $\mathbf{2 8 2}$

Ichneumons, 93

Indian Buffalo, 245-247

" Civet, Large, 90

". Civet, Small, 90

" Devil, I22

", Elephant, 225-228

" Flying-Fox, 177-180

" Jackal, 106-107

" Marten, I I8

" Mongoose, Grey, 93 94

" Mouse-Deer, 317-3I9

" Ratel, I 28

" Rhinoceros, 229-230

". Striped Squirrel, 189-

Igo

"Vampire, 183

, Wild Boar, 333-335

Inyala, 271

JACKAL, Black - backed, I05106

" Indian, 106-107

" Maanhaar, 100

"' Maned

Jagua

Jamrach's Mangabey, 32

Japanese Bear, 151

1. Monkey, 28

Javanese Gibbon, 15

Jentink's Duiker, 275

Jerboas, 202

" Egyptian, 202

Jerrow, 303

Jumping Hare, 202
KagUAN, 173

Kalong, I80

Kanchil, 319

Kangaroos, 57

$\begin{array}{ll}\text { " } & \text { Common, } 379 \\ \text { " } & \text { Gree, 380 } \\ \text { " } & \text { Musk, 379 } \\ \text {. } & \text { Red, 377-379 }\end{array}$

Kansu Musk-Deer, 299

Kiang, 240

Killer, 353-354

Kinkajou, 139-140

Kirk's Guereza, 23

Klipspringer, 276

Koala, 383-384

Kob Antelopes, 263

,White-eared, 263

Koodoo, 269-270

Lesser, 270

Kulong, I73

LABBA, 21 5-216

Lake-Cow, 33I

Large Indian Civet, 90

Lechwe, 264

Lemming, 194-195 ." Arctic, I95

Lemurs, Black, 54

n Dwarf, 55

. Fat-tailed, 55

. Mouse, 55

, Ring-tailed, 54

, Ruffed, 53-54

." Slow, 56

Leopard, $65-68$

, Black, 65-67

" Clouded, 77-78

"Hunting, 85

Lesser Koodoo, 270

Leucoryx, 260

Linsangs, 90-91

Lion, $57-6 \circ$

i) Marmoset, 49-52

Little Ant-Eater, 371-372

, Malay Cherrotain, 319

Livingstone's Eland, 265

Llama, 327

Wild, 325-328

Long-eared Bat, 184

Long-tailed Chinchilla, 212

" Field-Mouse, 199

Monkey, 28

Long-tongued Fruit-Bat, 180

Loris, Slender, 56

Lucivee, 8

Lungoor, 17-20

, Himalayan. 19

" Madras, I9

" Malabar, 19

"yñ, 8I-8

"Bay, 8

, Canadian, 8r

Himalayan, 8

, Northern, 8I

", Spotted, 8I

MAANHAAR Jackal, IOO Macaque, 26-27

, Crab-eating, 27

Madras Lungoor, 19

Tree-Shrew, 169

Malabar Lungoor. 19

Malay Chevrotain, Little, 3 I9 
Malay Dhole, II3

Malayan Bear, 152 Tapir, 235-236

Mammoth, 228

Mandrill, $33-36$

Maned Jackal, 100

," Wolf, 108

Mangabeys, 32

$$
\begin{array}{ll}
" & \text { Jamrach's, } 32 \\
" & \text { Sooty, 32 } \\
\text { White-collared, 32 }
\end{array}
$$

Mara, 2I4

Marco Polo's Sheep, 285-287

Markhor, 28I-282

Marmoset, Black-eared, 5I

1) Black-tailed, 52

" Brazilian Whiteeared, $5 \mathrm{I}$

Emperor, 52

" Geoffroy's, 52

" Golden-headed, 51

" Lion, 49-52

" Pigmy, 50, 51

, Silky, 52

Marmots, 192 Alpine, 192

" Prairie, 96

Marshbucks, 272

Marsupial Mole, 39I-392

Marten, American, II7

" Beach, 118

"Indian, 118

" Pine, 117

". Stone, I 8

Meerkat, 96

South African, 71

Mexican Tree-Porcupine, 208

Mias, II

Milou Deer, 308

Mink, I 19

" American, 119

European, II9

Moles, 167-168

" Golden, 172

," Marsupial, 39I-392

"North American, 168

, Star-nosed, 168

Mole-Rats, 203

Mongoose, Egyptian, 95-96

$$
\text { " Grey Indian, 93-94 }
$$
White-tailed, 22

Monkey, Bonnet, 25, 27

Brown, 17-25

" Cherry-crown, 32

", Colobus, 21

," Diana, 29-32

" Green, 31

Japanese, 28

" Long-tailed, 28

" Negro, 40

" Proboscis, 19

" Red-faced spider, 3739

Rhesus, 52

" Snub-nosed, 20

" Squirrel, 48

Tchelli, 26

White-whiskered Spi-

der, 37, 39 Woolly Spider, 39

Moose, 305-308

Mouflon, 28

Mountain Cow, 234 Hare, 219

Zebra, 238-239

Mouse-Deer, African, 320
Mouse-Deer, Indian, 31 7-3I9

Mouse-Hares, 220

Mouse Lemurs, 55

Mouse, Opossum, 383

Moustached Tamarin, 52

M'pungu, 8

Mule-Deer, 3 IO

Mullingong, 399

Muntjac, 300

Murine Opossum, 39I

Musk-Deer, 297-299

"Kansu, 299

Musk Kangaroo, 380

Musk-Ox, 280

Musk-Rat, I7 I, 193

Musk Shrew, I7 I

Musquash, 193-194

NAPU, 319-320

Narhwal, $357-35^{8}$

Negro Monkey, 40

Nilghai, 273-274

Nilgiri Tahr, 284

Nisnas, 30

Noctule, I 84

Noolbenger, 384

North American Mole, I68

" Otter, 135

Northern Lynx, 81

, Raccoon, $13^{8}$

Ntschego, 8

Nyam, 286

OCELOT, 78-79

Okapi, 293-295

Old English Rat, 200

Onager, 240

One-humped Camel, 32 I

Opossum, 381-382

$$
\text { " Common American, }
$$
389

" Mouse, 383

" Murine, 391

Opossum Rat, 392

Orang, 9-I2

Orang-utan, 9-12

Oribis, 275

Oryx, Beisa, 257-258

"Tufted, $25^{8}$

Otter, 133-135

" Brazilian, I35

" Clawless, 135

" North American, 135

"Small-clawed, 135

, Spotted-necked, I35

Otter Shrew, I 7 I-I 72

Ouakari, Bald, 47

" Black-headed, 47

, Red, 47

Ounce, 73-74

Ox, Wild, 244

PACA, 21 5-216

,' Tailed, 216

Painter, 69

Pallah, 256

" Angolan, 256

Pampas Deer, 31 I

Panda, I40

Pangolins, 372

Panther, 65, 66

Paradoxures, 91

Patagonian Cavy, 214

Patas, 30

Peccary, Collared, 34I-343

") White - lipped, 343-
Pekan, II 8

Persian Ibex, 282

Phalangers, Flying, 38z-383

$\therefore \quad$ Vulpine, $3^{81}$ - 382

Pichiciago, 375-376

Pied Bear, 144

Pig-footed Bandicoot, 388

Pigmy Hippopotamus, 332

, Hog, 336

" Marmoset, 50, 5I

" Shrew, I7o

"Sperm-Whale, 360

Pikas, 220

Pike-Whale, 360

Pinchaque Tapir, 235

Pinché, 51,52

Pine Marten, I 17

Pipistrelle, 184

Platypus, 397-400

Pocket-Gopher, 202

Polar Bear, I4I-144

, Hare, 219

Polecat, I I9

Pongo, 8

Porcupines, Brush-tailed, 206207

', Canadian, 205-206

".

Common, 207-208

Porpoise, 349-35I .

" Eastern, $35^{\circ}$

, Prickly-fiuned, 350

Potto, 56

Prairie-dog, 192

, Marmot, 96

Prevost's Squirrel, 190

Prezevalsky's Horse, 240

Prickly-finned Porpoise, $35^{\circ}$

Proboscis Monkey, 19

Prong-Buck, 295-296

Pudas, 3II-3I2

" Chilian, $3 \mathbf{I I}$

Puma, 69-72

Pyrenean Desman, 168

QUAGgA, 237

$$
\text { .. Bonte, } 237
$$

RABBIT, 219-220

" Bandicoot, 388

Raccoon, 138-139

$$
\text { " American, I } 16
$$

Crab-eating, 138

" Northern, 138

Raccoon-Dog, I 16

Rasse, 90

Rat Kangaroos, 380 ". $\quad$ Old English, 200

"Rat-Shrew, I66 Small, 166

Rat-tailed Bat, $188_{3}-18_{4}$

Ratel, African, 128

, Indian, 128

Raton Runcho, 392

Red Brocket, 3I I

Cat, 84

"Deer, 30I-303

" Fox, IO9

Howler, 45-47

" Kangaroo, 377-379

Ouakari, 47

River-Hog, 336

Wild Dog, I I 3-I I 5

Red-backed Saki, 47

Red-faced Spider Monkey, 37-

Red-handed Tamarin, 51

Reedbucks, 263

Reindeer, 3 I 3-316

Rhebok, 275

Rhesus, Common, 25

" Monkey, 52

Rhinoceros, Asiatic Two-horned, $23 \mathrm{I}$

" Black, 23I-232

" Common African. 231-232

Great African, 232

Hairy, 23 I

Indian, 229-230

Sondaic, $23 \mathrm{I}-232$

Square - mouthed, 232

White, 232

Righ" Whales, 359

"' "' Biscay, 359

"' $\quad$ Biscay, 359
Ring-tailed Coati, $\mathbf{1 3 7}$

Ringed Seal, I 63

Risso's Dolphin, 355

" Grampus, 355

River-Hog, Red, 336

River-Horse, 329

Roan Antelope, 262-263

Rock-Hares, 220

Rock-Rabbit, 22 I-223

Rock Wallabies, 379

Rocky-Mountain Goat, 279, 357

Roe, 254

Roes, 3 I 2

Roloway, 29

Rooi-Kat, 84

Rorquals, $359-360$

$$
\text { " Common, } 360
$$

" Rudolphi's, 360

Royal Antelope, 276

Rudolphi's Rorqual, 360

Ruffed Lemur, 53-54

Runcho, Raton, 392

SABLE, II 7-II9

" American, II 7

"Antelope, 26I-262

Sacred Baboon, 36

Saiga, 255-256

Saki, Hairy, 47

, Red-backed, 47

Sambur, $3 \circ 3$

Sand-Mole, 203

Sassaby, 252

Scaly-tailed Squirrels, I92

Sea-Elephant, 164

Sea-Lion, Californian, I 53I 56

Sea-Otter, 136

Sea-Unicorn, 357-358

Seal, Common, I6I-163 
Shrews, Elephant, I7I

" Musk, I 7I

"Otter, I7I

" Pigmy, 170

", Water, 171

Siamang, I6

Siberian Tiger, 92

Sifaka, Diademed, 55

Silky Marmoset, 52 Tamarin, 49

Silver Fox, 109

Silvery Gibbon, I4

Sing-Sing, 263

Sitatunga, 264, 272

Skunk, 129-1 30 " Small, 131-1 32 Southern, I3I

Slender Loris, 56

Sloth, Five-toed, 149 Ursine, 149

Sloth-Bear, 149-1 50

Slow Lemurs, 56

" Loris, 56

Small-clawed Otter, 135

Small-headed Capuchin, 4I

Small Indian Civet, 90 Rat-Shrew, I66

, Skunk, 13I-132

Snow-Leopard, 73

Snub-nosed Monkey, 20

Sondaic Rhinoceros, 230-23I

Sooty Mangabey, 32

South African Meerkat, 7 I

South American White Bat, I4I, I44

Southern Skunk, I3I

Spanish Tur, 284

Spectacled Bear, 152

Sperm-Whale, $345-348$

"̈ Pigmy, 348

Monkey, 37-38

. . Red-faced, 37-

White - whisk.

" $\quad$ ered, $3^{8}, 39$ Spotted Deer, 253-254 39

Hyæna, 99-100

, Lynx, 8I

Spotted-necked Otter, 135

Springbuck, 253-254

Spring-Haas, 20

Square-mouthed Rhinoceros 232

Squirrel, Common, 190-19I
Squirrel, Indian Striped, 189, I90 Prevost's, 190 Scaly-tailed, 192

Squirrel Monkey, 48

Star-nosed Mole, 168

Steinbok, 275, 283

Stoat, 120

Stone Marten, I I8

Striped Hyæna, 97-98

Suricate, 96

Syrian Dassie, 223

TAHR, 284

" Arabian, 284

Nilgiri, 284

Tailed Paca, 216

Takin, 280

Talapoin, 3 I

Tamandua Ant-Eater, $37 \mathrm{I}$

Tamarao, 248

Tamarin, Black, 51, 52 " Moustached, 52

,. Red-handed, 5 I Silky, 49

Tambreet, 399

Tana, 169

Tangalung, 90

Tapir, American, 233-234

" Baird's, 234-235

" Central American, 235

" Malayan, 235-236

, Pinchaque, 235

Tapoa-Tafa, 387

Tarsier, 56

Tasmanian Devil, 385-386

Tayra, 123

Tcheli Monkey, 26

Teetees, 48

Teledu, I23

Tenrec, I 72

Three-toed Echidna, 396

Thylacine, 386

Tiger, 6I-64

1" Siberian, 62

Tiger-HIorse, 239

Timber Wolf, 103

Toddy-Cat, 9 I

Tree-Civets, 9 I

Tree-Dassies, 223-224

Tree Kangaroo, 380

Tree-Porcupine, Mexican, 208

Tree-Shrew, Madras, I69

Tsine, 244

Tufted Oryx, $25^{8}$
Tupaia, Golden-tailed, I69-170 Turs, 284

" Caucasian, 284

". Spanish, 284

Two-horned Rhinoceros, Asiatic, 231

Two-humped Camel, 324

Typical Dasyures, $386-387$

.. Deer, 299

URIAL, 287-288

Ursine Sloth, I49

Urus, 243-244

VAMPIRE, $18 \mathrm{r}-182$

Vervet, 3 I Indian, 183

Vicugna, 325, 328

Virginian Deer, 309-3 Io

Vizcacha, 209-2I I

Vlack-Vark, 339-340

Vulpine Phalanger, $381-382$

WALLABIES, 57

Walläroo, 379

Walrus, $157-160$

Wanderoo, 19, 28

Wapitis, 302

Waree, 343-344

Waterbuck, 263-264

Water-Buffalo, 245-246

Water Chevrotain, 400

Water-Civet, 92

Water-Deer, 31 2

Water-Hog, 339-340

Water-Mole, 399

Water-Opossum, 391

Water-Rat, 196

Water Shrew, I 71

Water-Tiger, I 35

Water-Vole, 196

Weasel, I 20

West Indian Seal, I 64

Whaiapu-Sais, 48

Whalebone Whales, $357-358$

Whales, Beaked, $34^{8}$

, Biscay Right, 359

" Blue, 360

, Ca'ing, 35 5-356

" Californian Grey, 360

" Dwarf Right, 359

" Greenland, 359

, Right, 359

"Whalebone, 357-358
Whales, White, 356-357

White-beaked Dolphin, 352

White-bearded Gnu, 249

White-collared Mangabey, 32

White-eared Kob, zó3

$$
\text { " Marmoset, Brazi- }
$$
lian, 51

White Elephant, 226

White-lipped Peccary, 343344

White Lungoor, 32

White-nosed Coati, $137^{-1} 3^{8}$

White Rhinoceros, 232

White-sided Dolphin, 352

White-tailed Deer, 309

$$
\text { " } \quad \text { Gnu, 250-251 }
$$

White-throated Capuchin, 41

White Whale, 356-357

White-whiskered Spider Mon-

key, 38-39

Wild Boar, European, 335$33^{6}$

" Cat, 79-80 ndian, 333-335

" "African, 8o

" Dog, Red, I I3-II5

Goat, 282-283

. Horse, 240

" Llama, 325-328

, Ox, 244

Wildebeest, Black, 25 I

Wolf, Ior-IO4 Blue, 249

" Maned, Io8

, Timber, 103

Wolverine, I2 I

Wombats, 384

Woodchuck, I92

Woodland Caribou, 3 I 4

Wood-Mouse, I99

Woolly Spider Monkey, 39

YAK, 243

Yellow-backed Duiker, 275

ZEBRA, Burchell's, 237-238

, Grévy's, 239

,$\quad$ Mountain, 238-239

Zebra-Wolf, 386

Zebus, 244

Zee-Koe, 331

Zorillas, I 32

African, 132

Zwart-wit-pens, 26I

THE END 

